\title{
ELEMENTS \\ OF
}

HIGHWAY ENGINEERING

ARTHUR H,BLANCHARD 


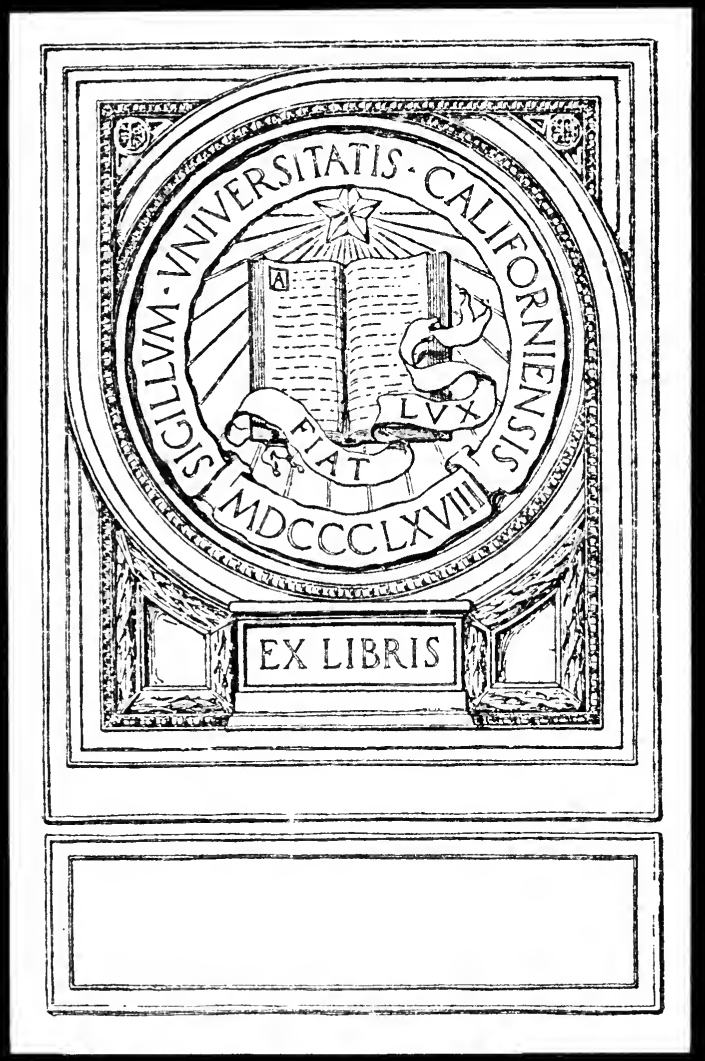




$$
\text { . }
$$




\section{WORKS OF}

ARTHUR H. BLANCHARD, C.E., A.M.

Published by

JOHN WILEY \& SONS, Inc.

Elements of Highway Engineering. A Short TextBook Designed for Students in Civil Engineering Courses. 8 vo, xiii +497 pages, 202 figures. Cloth, $\$ 3.00$ net.

Section 15, Highways and Streets, in American Civil Engineers' Pocket Book.

By ARTHUR H. BLANCHARD, C.E., A.M. AND

HENRY B. DROWNE, C.E.

Text-Book on Highway Engineering. A Comprehensive Text-Book for Students and a Reference Work for Engineers.

8 vo, xiii +762 pages, 234 figures. Cloth, $\$ 4 \cdot 50$ net.

Highway Engineering, as Presented at the Second International Road Congress, Brussels, 1910. 8 vo, v +299 pages. Cloth, $\$ 2.00$ net. 


\title{
ELEMENTS
}

\author{
$\mathrm{OF}$
}

\section{HIGHWAY ENGINEERING}

BY

ARTHUR H. BLANCHARD, C.E., A.M.

Professor in charge of the Graduate Course in Highway Engineering in Columbia University in the City of New York; Consulting Highway Engineer; Member, American Society

of Civil Engineers, Société des Ingénieurs Civils de France, Canadian

Society of Civil Engineers, Association Internationale Permanente des Congres de la Route, Association Internationale pour l'Essai des Materiaux.

FIRST EDITION

FIRST THOUSAND

NEW YORK

JOHN WILEY \& SONS, INC.

London: CHAPMAN \& HALL, Limited

1915 


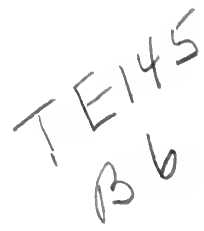

Copyright, 1915, by

ARTHUR H. BLANCHARD

Publishers Printing Company

207-217 West Twenty-fifth Street, New York 


\section{PREFACE}

THis book has been written at the suggestion of several professors of civil engineering who desire to use a didactic text, covering the principles of highway engineering, of such length as to be suitable for one-semester courses included in civil engineering curricula. The text of this work is made up of original manuscript, and also of material from the "Text-book on Highway Engineering," by Blanchard and Drowne, which has been revised and remodelled to meet the requirements of a book suitable for use by engineering students who take courses in highway engineering aggregating from one to three hours a week for one-half of the collegiate year. It should be noted that the "Text-book on Highway Engineering" was designed to be a comprehensive text for highway engineering students and a reference book for engineers.

Each chapter of the "Elements of Highway Engineering" has been written with a view to emphasizing the fundamental principles which have been evolved from past experience as well as from the modern practice of highway engineering which, as a science and an art, is rapidly developing in the fields of economics, administration, legislation, materials, and methods. Specifications, per se, examples of construction, and detailed cost data have been omitted, as such material is not considered essential to a broad general knowledge of the science of highway engineering. The text of the chapters, occupying $45^{\circ}$ pages, has been profusely illustrated with 202 figures, equivalent in space to 85 pages.

As the nomenclature of materials and methods of construction and maintenarce may be confusing to the student, a glossary, constituting Appendix I, has been included. Appendices II and 
III, containing, in detail, methods for determining physical and chemical properties of bituminous and non-bituminous highway materials, will be found of value to professors who wish to elaborate upon the subject of essential properties of materials and their determination.

For a course constituting one hour a week for a half year, it is suggested that the subject matter might be reduced in amount by the omission of the text covering examples of state legislation, pages $3 \mathrm{I}$ to 36 ; surveying and mapping, pages 64 to 75 ; mining and manufacture of bituminous materials, pages 196 to $2 \mathrm{ro}$; interpretation of tests of bituminous materials, pages $2 \mathrm{I} 4$ to 222 ; descriptions of machines, pages 98 to III, $24 \mathrm{I}$ to 247 , and 288 to 293 ; sidewalks, curbs, and gutters, pages 406 to 420 ; and highway structures, pages $42 \mathrm{I}$ to 450 . The total number of pages thus eliminated amounts to about I Io.

The author gratefully acknowledges his indebtedness to the engineers and chemists whose writings he has quoted, to technical periodicals for certain tables and cuts, and to numerous manufacturers for furnishing photographs to illustrate the text.

The author requests that users of this work as a text-book submit suggestions pertaining to elaboration or reduction of the several sections of the book to meet individual requirements. It is also requested that readers call the attention of the author to errors which may occur in the text. Coöperation along the above lines will be appreciated.

Columbia University,

A. H. B.

New York City,

September I, I9I5. 


\section{TABLE OF CONTENTS}

\section{CHAPTER I}

Historical REviEW

Ancient Highways of the Eastern Hemisphere-Early Grecian Highways-Early Roman Highways-Early French HighwaysEarly British Highways--Early American Highways.

\section{CHAPTER II}

Economics, Administration, Legislation, and Organization · .

Economics-Benefits of Improved Highways-Financing Highways-Labor Tax-Convict Labor-Direct Taxation-Direct Appropriation-Bond Issues-Private Subscription-Administration and Legislation-France-Germany-Great Britain-United States -Municipalities-Organization-State and County DepartmentsUrban District Departments.

\section{CHAPTER III}

Preliminary Investigations .

Location-Foundations-Drainage-Width-Local MaterialsClimatic Conditions-Maintenance-Local Environments-Æsthetics-Traffic-Traffic Classification-Effect of Different Classes of Traffic-Loads and Tire Widths-Methods of Taking Traffic Census.

\section{CHAPTER IV}

Surveying, Mapping, And Design.

Surveys for Roads - The Transit Line-Levels-Final SurveysStaking Grades-Mapping Road Surveys-Plan-Profile-CrossSections-Surveys for City Streets-Traverse-Levels-Mapping Street Surveys-Design of State Highway Systems, City Highway Systems, and Park Highway Systems-Scope of Highway Design - Location-Widths of Roads, Streets, and Park HighwaysGrades-Street Intersections-Curves-Cross-Sections of Roads and Streets-Crown Formulas-Drainage and FoundationsSelection of Type of Wearing Course. 


\section{CHAPTER V}

Grading, Drainage, and Foundations

Grading-Excavation-Embankment-Classification of Materials-Shrinkage of Materials-Machines-Road Drags, Scrapers, Elevating Graders, Rollers, and Scarifiers-Drainage-Subdrainage - Pipe Drains-Surface Drainage-Side Ditches and GuttersFoundations-Classification-Natural Foundations-Soil Classification-Loads on the Foundation-Artificial Foundations-Stone Foundations-Telford Foundations-V-Drain Foundations-Broken Stone Foundations-Cement-Concrete Foundations-Foundations Over Marshes-Old Pavements as Foundations-Bituminous Concrete Foundations.

\section{CHAPTER VI}

EARTh AND SAND-Clay Roads

Occurrence-Soils-Sand, Clay, and Sand-Clay ConstructionDrainage-Wearing Course of Earth Roads-Wearing Course of Top Soil Roads-Roads with Sandy Subsoil-Roads with Clayey Subsoil-Burnt Clay Roads-Straw Roads-Petrolithic RoadsMaintenance-Drags vs. Scrapers-Road Drag Regulations.

\section{CHAPTER VII}

\section{GRAVEL RoADS}

Development-The Gravel-Formation and Occurrence-Requisites of Gravel-The Binder-Testing Gravel-Mechanical Analysis - Construction-Preparation of Subgrade-Construction of the Wearing Course-Sizes of Gravel-Thicknesses of Courses-Spreading and Compacting the Gravel-Cost Data-Maintenance.

\section{CHAPTER VIII}

\section{Broken Stone RoAdS}

Rock Classification-Essential Properties of Rock-Testing the Rock-Abrasion, Cementing Value, Toughness, Hardness, Absorption, and Specific Gravity-Quarrying and Crushing-DrillingBlasting-Crushing Plants-Voids and Weights of Crushed Stone -Construction-Tresaguet's and McAdam's Methods-Sizes of Broken Stone-Foundation and Subgrade-Construction of the Courses-Miscellaneous Roads-Slag Roads-Shell Roads-Cost Data-Maintenance-Causes of Wear-Ordinary Repairs-Resurfacing-Characteristics.

\section{CHAPTER IX}

Bituminous Materials

Definitions of Bituminous Materials and Methods of UseSources, Mining, and Manufacture-Rock Asphalts-AsphaltsTrinidad and Bermudez Asphalts-Alcatraz Asphalt-Gilsonite 
Bituminous Materials-Continued

Asphalt-Petroleums-Tars-Gas-House Coal Tar-Coke Oven Tar-Water Gas Tar-Tests and Specifications for Physical and Chemical Properties-Lists of Tests-Brief Descriptions of TestsInterpretation of Results of Tests-Utilization of Tests in Specifications.

\section{CHAPTER $\mathrm{X}$}

Dust Prevention and Bituminous Surfaces

Dust Prevention-Classification of Surface Treatment Methods -Development-Formation of Dust-Pathogenic and Other Effects of Dust-Use of Palliatives-Classification of Palliatives-Watering - Calcium Chloride-Emulsions-Light Oils and Light TarsBituminous Surfaces-Bituminous Materials-Construction Methods-Maintenance-Mechanical Appliances-Gravity and Pressure Distributors-Characteristics-Advantages-Disadvantages -Causes of Failure.

\section{CHAPTER XI}

Bituminous Macadam Pavements

Development-Bituminous Materials-Construction-Methods of Construction Using Broken Stone-Methods of Construction Using Gravel-Cost Data-Maintenance-Characteristics.

\section{CHAPTER XII}

\section{Bituminous Concrete Pavements}

Development-Mineral Aggregates-One Product of a Crushing Plant - Combinations of Broken Stone and Fine Material-Mechanically Graded Aggregates-Topeka, Asphalt Block, and Bitulithic Pavements-Patents-Bituminous Materials-Bitumen ContentWearing Course Mixtures-Construction-Subgrade and Foundation-Wearing Course-Manufacture and Laying of Asphalt Blocks -Mechanical Appliances-Cement-Concrete Mixers-Mixers with Heating Attachments-Dryers, Storage Bins, and Mixers-Cost Data-Maintenance-Characteristics.

\section{CHAPTER XIII}

Sheet Asphalt and Rock Asphalt Pavements

Development-Materials for Sheet Asphalt Pavements-Asphalt Cement-Binder Stone-Sand and Filler for Wearing CourseConstruction of Sheet Asphalt Pavements-Subgrade and Foundation-Binder Course-Wearing Course-Asphalt Plants-Rock Asphalt Pavements-European Practice-American PracticeCost Data-Maintenance of Sheet Asphalt Pavements-Repairs and Conditions of Guarantee-Characteristics. 


\section{CHAPTER XIV}

Cement-Concrete Pavements

Development-Cement-Concrete-Construction-Subgrade and

Foundation-Methods of Construction-Mixing Methods-OneCourse Pavement-Two-Course Pavement-Reinforced Pavements -Oil Cement-Concrete-Expansion Joints-Grouting MethodBituminous Surfaces on Concrete-Cost Data-MaintenanceCharacteristics.

\section{CHAPTER XV}

Wood Block Pavements

Development-The Wood-Wood Preservation-Manufacture of Blocks-Construction-Subgrade and Foundations-Cushion Layers-Construction of Wearing Course-Fillers-Cost DataMaintenance-Characteristics.

\section{CHAPTER XVI}

Brick Pavements

Development-The Brick-Brick Clays and Shales-Size of Brick-Testing the Brick-Construction-Subgrade and Foundation-Cushion Courses-Methods of Laying the Brick-Joint Fillers and Expansion Joints-Cost Data-Maintenance-Characteristics.

\section{CHAPTER XVII}

\section{Stone Block Pavements}

Development-Stone Blocks-The Stone-Manufacture of Blocks-Size of Blocks-Tests for Stone Blocks-ConstructionSubgrade and Foundation-Cushion Layers-Construction of Wearing Course-Joint Fillers-Durax and Kleinpflaster Pavements-Stone Trackways-Cobble Stone Pavements-Clinker and Slag Block Pavements-Cost Data-Maintenance-Characteristics.

\section{CHAPTER XVIII}

Street Cleaning and Snow Removal

Street Cleaning-Hand Cleaning-Machine Sweeping-Hose Flushing-Machine Scraping and Flushing-Methods Applicable to Various Types of Roads and Pavements in Urban DistrictsNew York-Philadelphia-Boston-Washington, D. C.-Great Britain-France-Germany-Snow Removal-Removal by Machines-Removal by Use of Salt-Removal by Flushing. 


\section{CHAPTER XIX}

Comparison of Roads and Pavements . $\cdot{ }^{*} \cdot \cdot \cdot \cdot \cdot \cdot \cdot \cdot$
Development-Essentials of An Ideal Road or PavementDurability-Sanitary Qualities-Noiselessness-Slipperiness-Resistance to Traffic-Annual Cost-Methods of ComparisonRecords and Cost Data Forms.

\section{CHAPTER XX}

Sidewalks, Curbs, and Gutters .

Sidewalks-Essential Qualities - Width and Slope of SidewalksMaterials-Construction Methods-Cost Data-Asphaltic Mastic -Brick and Tile-Cinders-Cement-Concrete-Gravel-Small Stone Setts-Stone Flagging-Curbs-Stone and Cement-Concrete Curbs-Gutters-Methods of Construction-Cost Data.

\section{CHAPTER XXI}

\section{Highway Structures}

Bridges and Culverts-Determination of Waterway-CulvertsDesign, Location, and Construction-Vitrified Pipes-Cast-Iron Pipes-Corrugated Metal Pipes-Stone Box-Reinforced Concrete Box-Drop Inlets-Catch-Basins-Bridges-Design, Location, and Construction-Steel, I-Beam, Pony Truss, Plate Girder, Concrete, and Reinforced Concrete Bridges-Guard Rails-Wood, Pipe, and Concrete Rails-Highway Signs-Road Signs-Direction, Distance, and Danger Signs-Highway Department Signs-Street SignsCar Tracks-Location-Track Construction-Rails-Surfacing Adjacent to Rails-Pipe Systems-Design and Location-Repaving Trenches.

\section{APPENDIX I}

Glossary of Terms Applicable to Highway Engineering

\section{APPENDIX II}

Tests for Bituminous Materials

Specific Gravity-Flash-Point-Solubiiity in Carbon Disulphide - Solubility in Carbon Tetrachloride-Consistency-Viscosity Test -Float Test-Penetration Test-Melting Point-Loss on Evaporation-Distillation-Ductility-Solubility in Petroleum Naphtha and Character of Residue on Glass-Fixed Carbon-Paraffin. 


\section{APPENDIX III}

Tests of Non-Bituminous Materials ?

Apparent Specific Gravity of Rock-Apparent Specific Gravity of Sand, Stone Screenings, or Other Fine Highway MaterialAbsorption of Water per Cubic Foot of Rock-Abrasion Test for Broken Stone or Broken Slag-Abrasion Test for Gravel-Toughness Test for Rock or Slag-Hardness Test for Rock or SlagCementation Test for Rock, Slag, or Gravel Powder-Mechanical Analysis of Broken Stone, Broken Slag, or Gravel-Mechanical Analysis of Sand or Other Fine Highway Material-Mechanical Analysis of Mixtures of Sand or Other Fine Highway Material and Broken Stone, Broken Slag, or Gravel-Voids in Mineral Aggregates - Rattler Test for Paving Brick. 


\section{ELEMENTS OF \\ HIGHWAY ENGINEERING}

\section{CHAPTER I \\ HISTORICAL REVIEW*}

IT Is the purpose of this chapter to give a broad general review of the development of the art and science of highway building to about A.D. I840. Many of the various forms of modern pavements were not introduced until after this date. Since the later developments are intimately connected with the details of construction of roads and pavements, the historical review relative to each type will be of greater value if included in the chapter to which it specifically refers.

Ancient Highways of the Eastern Hemisphere. The economic value of highways in its broadest sense was not appreciated as much by the ancient races as it is to-day. The primary object of the roads built by them was to facilitate the movements of troops rather than for the development of commercial, industrial, agricultural, and social interests. History previous to r 900 B.C. is rather vague concerning the subject of highways. Herodotus tells of a road which was constructed about 4000 B.C. and over which materials of construction used in building the pyramids were supposed to have been hauled. Although Biblical history mentions in several instances that there were public highways, the first roads of which there is any authentic record are those in the Assyrian Empire built about I900 B.c. These roads radiated from Babylon, and the remains of one can still be seen to-day between Bagdad and Ispahan. This road, as well as the oldest bridge on record of

* Prepared by Mr. Henry B. Drowne, Instructor in Highway Engineering in the Graduate Course in Highway Engineering, Columbia University, and Engineer, Lane Construction Corporation. 
any importance, which is that over the River Euphrates near Babylon, was built during the reign of Queen Semiramis.

Early Grecian Highways. History is not very definite as to the methods of construction of the roads of ancient Greece. Many of these roads were built as approaches to religious temples. One of the principal roads led from Athens to Eleusis, and served as a means of communication with Peloponnesus, Thebes, and Phocis, and the greater part of the North. The Greeks, according to some authorities, were not as attentive to drainage, in connection with the construction of their roads, as were the Romans. They paved their roads with large square blocks of stone. The royal roads of Greece were under the authority of the Athenian Senate, which levied taxes for the maintenance of the roads. In some of the largest cities, such as Thebes, the care of the streets was intrusted to a person of high rank.

EARLy Roman Highways. According to Isadore de Seville, who lived in A.D. 700, the Carthaginians were the first to build paved roads. Their methods were later copied by the Romans. Carthage flourished from about 600 B.c. to I46 B.C., at which time this empire was destroyed by the Romans. The Romans built roads on a more extensive scale than any of the other nations. Road building was a state policy in the Roman Empire. Gautier says that the Romans divided their roads into the following classes: royal roads, vicinal roads, and private roads. The royal roads included the main military roads which traversed all of Europe and the northern part of Africa. The vicinal roads connected the royal roads with the towns or cities. The private roads connected the royal roads or vicinal roads with some particular locality other than a town or city. By means of this system of roads the whole of the Roman Empire could be readily traversed. Soldiers were able to travel as much as twenty miles a day over these roads.

During the reign of the kings, the Roman roads were doubtless constructed of the natural soil. In the year 3II B.c. the censor Appius Claudius commenced the construction of the first paved road, which led from Rome to Capua. This road was named Via Appia (Appian Way), and was later extended and 


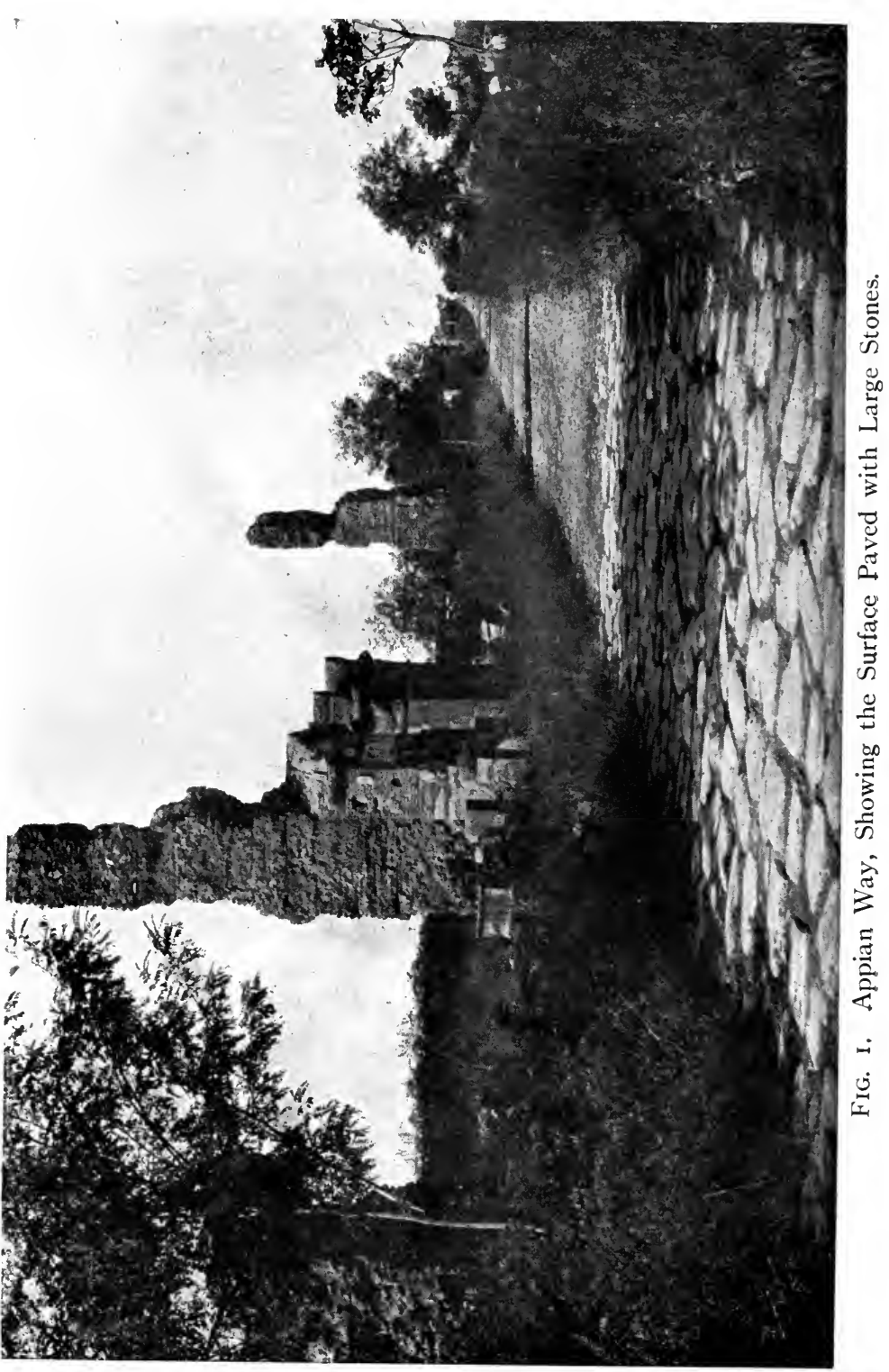


improved by Trajan. This marked the beginning of the construction of Rome's remarkable system of highways. During the next century Rome continued to flourish, and since the roads were an absolute necessity for the movements of troops to the various provinces, the construction of roads increased to such an extent that at the end of 200 B.c. the total system comprised about 48,500 miles. Many of the main roads were built under the auspices of different rulers and bear their names. Among these roads may be mentioned the Appian, Aurelian, Flaminian, and Domitian ways. Twenty-nine of these roads led to the capital. During the reign of Trajan, the Roman Empire reached its greatest magnitude, comprising Italy, Rritain, Gaul, Spain, Western Germany, part of Asia Minor and Arabia, the northern part of Africa, and the islands in the Mediterranean.

It is evident in examining the old Roman roads, very clear traces of which appear in many of the European countries, that directness of line between two points was a prime object. A straight line was attained many times in spite of the natural difficulties which had to be overcome. Tunnels, bridges, and retaining walls remain as monuments to the skill of the Roman engineers. The Flaminian Way, in crossing the Apennines, passes through a tunnel about one thousand feet long; the Appian Way near Ariccia, for a length of about seven hundred and fifty feet, is constructed on a viaruct, the retaining walls of which have a mean height of 43 feet, while the viaduct contains three arch spans which serve as a waterway. In low and level land the roads were elevated to a considerable height above the adjoining ground.

Some of the great military Roman roads were from 36 to 40 feet wide. The middle part, I 2 to 16 feet in width, was generally paved or surfaced with some suitable material. This part of the road is supposed to have been used by the infantry. On each side of the middle portion was built a raised path, about two feet wide, which may have been used by the officers. Beyond these paths on either side was a width of about eight feet, which was supposed to have been used by the cavalry. 


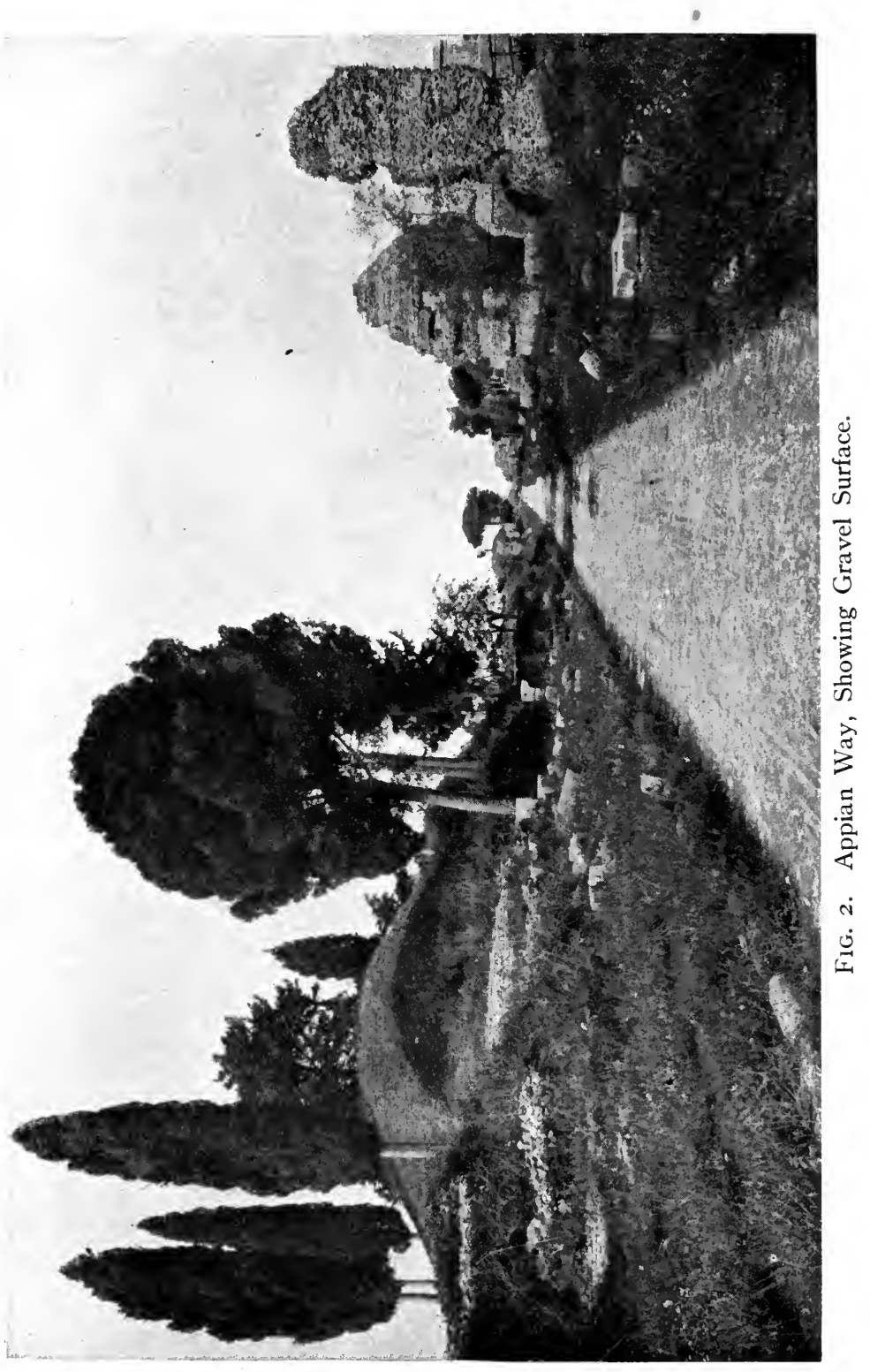


The breadth of the vicinal roads was fixed by the law of the "Twelve Tables" at 8 feet.

In constructing these roads two parallel furrows, defining the width of the road, were made, and the soil between these furrows was removed to such a depth that a firm and solid foundation was obtained. Sometimes when the soil was soft, it was made more compact by driving small piles into it. This trench was then filled up to a certain height with sand, which was firmly compacted. Upon this sand-bed four successive layers of masonry were built as follows:

I. The Statumen, Io to 20 inches thick, formed of large stones laid flat in courses and bonded together with mortaror clay.

2. The Rudus, about eight inches thick, composed of rubble masonry.

3. The Nucleus, having a thickness of ro inches, built of masonry similar to concrete and often composed of fragments of pottery and brickbats.

4. The Summa Crusta, formed of very hard materials bonded together with a lime mortar. On many of the military roads large stones, bedded in the Nucleus, were used for this layer, while on other roads small stones mixed with mortar were employed.

The total thickness of the four courses was about four feet. All of the roads, however, were not constructed according to this standard. Some of the roads that were originally built of sand or gravel were later surfaced with stones of variable dimensions. The Appian Way between Rome and Brindisi for a length of about five hundred miles was surfaced with large stones, cut into irregular shapes, bedded very carefully in mortar, and laid, in some cases, with very close joints. These stones, 3,4 , and 5 feet square, were, according to some authorities, transported more than one hundred miles for use in this road. In many places on the Domitian Way the surface was paved with square blocks of marble. 'In others, the stones were brought from the fields and laid in mortar. Between Nîmes and Beaucaire, where the Roman road has been found to be intact in places, it was paved with dressed stones about seven inches thick. Excavations have shown in some cases that the 
Statumen was replaced by broken stones of "variable size. In other places the Statumen was replaced by a layer of compacted earth, the Rudus consisted of a bed of lime mortar, and a layer of broken stone replaced the Nucleus. Archæologists have found that old Roman streets within the cities of Pompeii and Herculaneum were paved with large blocks of lava. They have also unearthed some paved streets in which the blocks of a similar size to those used to-day were laid on a mortar bed.

The reasons which led to the adoption of the different types of massive construction have not been given by historians. Without doubt, the availability of the materials influenced the use of different sized stones and the arrangement of courses. It is not difficult to imagine that the desire of the rulers to leave behind some substantial monument of their reign led to the use of some of the methods adopted. The traffic certainly was not such as to warrant the construction of roads four feet thick. Chariots and carts on two or four wheels, having a width of about five feet, were the principal types of vehicles used. First cost was probably of secondary importance, since a large part of the work was done by captives or by the armies.

The care of the roads was intrusted to a person of high rank. The office of Superintendent of Highways, or Curator Viarum, as it was then called, was one of great dignity and honor. Julius Cæsar was the first of high rank to occupy this office, and after his occupancy the office was rarely conferred upon any but men of consular dignity. Due to the fact that the roads played such an important part in the development of the Roman Empire, it is not surprising that the memories of Cæsar Augustus, Vespasian, Trajan, and Domitian were honored, at the order of the Roman Senate, by the erection of triumphal arches.

Early French Highways. During the year A.D. 300 the wonderful system of roads, built up by the Romans in Gaul, was abandoned due to the Barbarian invasion. In 395 the Roman Empire was divided into two parts, the Eastern and 
the Western Empires. The Western Empire was finally destroyed in 476 and at its downfall road building practically ceased. Since the small amount of commercial traffic was accomplished with pack-animals, the highways outside the large cities became in time no better than bridle-paths. No care was taken of them, and the borders, as well as the roadway itself, became covered with small trees and bushes.

During the reign of King Charlemagne, from $77 \mathrm{I}$ to 8I4, some activity was again shown in building highways, necessitated by his various military expeditions. The work was done by the armies or by the people whom he vanquished. It was about 950 that the streets of Cordova, Spain, were supposed to have been paved. After the reign of Charlemagne, and up to A.D. IIoo, conditions grew worse. In France the feudal régime was inaugurated and kingly rights were assumed by the dukes, counts, and other titled personages, who set themselves up as leaders of their districts. The whole nation was disturbed by the internal wars resulting from the disputes of these feudal chiefs. It was during this period of petty wars that the roads perhaps suffered the most, since at times they were torn up and destroyed as a matter of defence. The social state in the Middle Ages was such that the use of a road as a means of communication was practically abandoned. It was not safe for any one to travel, since both life and property were at stake. Where travel was possible the head of each fief demanded toll of the persons using the road, the money being used for his own private enterprises. Since the head of the fief had absolute and final authority in his particular district, the tolls were heavy and an extreme hardship to those who had to pay them. From I IOO to I 200 the only road construction undertaken comprised the opening of some of the old roads incidental to the movements of troops in the Wars of the Crusades. The deplorable conditions, as outlined above, continued in France until the middle of the thirteenth century, at which time a few of the roads leading from Paris to the feudal provinces in the near vicinity were improved. This work was generally done under the direction of the provincial chiefs, and the paving was ac- 
complished in a very primitive manner. The strêets in the City of Paris were filthy early in the thirteenth century. On good authority it is stated that King Philip Augustus was so disturbed at the stench, when he opened a window in his palace one day, that he ordered all of the streets of the city to be paved with stone. This improvement was not demanded by the character of the traffic, as it was not until about I300 that carriages, the use of which had almost entirely disappeared, again came into vogue. In spite of various edicts issued by royal proclamation from 1465 to 1600 , the feudal system and the administrative organization of the government were such that the revenues, which should have been spent in maintaining the roads, were diverted to other channels. Roads of secondary importance were not improved at all, and the main highways, except in the vicinity of large cities, were not practicable for use as carriageways.

In I66I, Colbert, who was Minister of Finance of France at that time, did much to try and bring about a change in conditions. In spite of his far-sighted policies with regard to the construction and maintenance of highways, no material progress was made in developing the French system up to I700, with the exception of the construction of a few roads near Paris, among which were those of Orleans and Versailles. The construction and maintenance of the French roads for a long time had been generally carried out by means of the "corvée," which was a system of compulsory labor. M. Turgot, a minister of France, recognized the injustice of this system and suggested several reforms both as to the "corvée" and the feudal systems. Although Turgot was bitterly opposed, he succeeded in bringing about the general abolishment of the "corvée," in I776. He was supported and defended by King Louis XVI until Marie Antoinette took part against her spouse. Turgot was forced to resign in $\mathrm{I} 777$, and would have been imbrisoned in the Bastille if the King had not interfered.

Due to the fact that Turgot had accomplished the abandonment of the "corvée," it became necessary to find some method of constructing the highways at a greatly reduced cost. This 
problem was successfully overcome by Pierre Marie Jérôme Tresaguet, who at this time was chief engineer of the District of Limoges, France. It was due to his efforts and skill as an engineer that the first steps toward modern and scientific roadbuilding were taken. Tresaguet's mode of constructing roads, as described by himself in 1764 , and adopted generally in France in 1775 , was as follows:

"The bottom of the foundation is to be made parallel to the surface of the road. The first bed (of stones) on the foundation is to be placed on edge, and not on the flat, in the form of a rough pavement, and consolidated by beating with a large hammer, but it is unnecessary that the stones should be even one with another. The second bed is to be likewise arranged by hand, layer by layer, and beaten and broken coarsely with a large hammer, so that the stones may wedge together and no empty space may remain. The last bed, three inches in thickness, is to be broken to about the size of a walnut with a small hammer, on one side on a sort of anvil, and thrown upon the road with a shovel to form the curved surface. Great attention must be given to choose the hardest stone for the last bed, even if one is obliged to go to more distant quarries than those which furnish stone for the body of the road; the solidity of the road depending on this latter bed, one cannot be too scrupulous as to the quality of materials which are used for it." $\mathrm{He}$ is also credited with being the first to propose a system of maintenance.

The Revolution naturally retarded the development of the national road system of France. During the period from 1804 to I8I4, while Napoleon Bonaparte was Emperor of France, road-building gained a new stimulus. One result was the establishment of the remarkable system of national roads. It is very probable that Napoleon's various military expeditions into the surrounding countries furnished the motive for the construction of these roads. About this time was created the renowned Department of Roads and Bridges, which was given control of road construction in France.

EARLY British Highways. Conditions in Great Britain after the fall of Rome and during the Dark Ages were similar 
to those in France. The roads were allowed to fall into a most deplorable state. An act passed in England in $\mathrm{I}_{2} 85$ directed that all bushes and trees should be cut down for a distance of 200 feet on either side of the highway. The undergrowth had become so thick along the highways that it afforded an excellent hiding-place for robbers, which led to the improvement sought by the above act.

The first act for paving the streets of London was passed in I532, and apparently for a somewhat similar reason as was the case in Paris. In the statute, the streets were described as "very foul, and full of pits and sloughs, so as to be mighty perilous and noxious, as well for all the king's subjects on horseback, as on foot with carriages." Laige irregular boulders, 6 to 9 inches deep, were first used. Due to the wide joints between the stones, the irregular shapes, and the unstable foundations, the surface soon became very rough.

In I555 a law was passed providing that surveyors should be elected to take charge of the roads in their parishes and empowering them each year to exact four days' work on the roads from every parishioner. In 1562 , these supervisors were empowered to turn any watercourses or springs from the highways to ditches on the adjoining ground, and were further empowered to repair a road with material taken from any source with or without the owner's permission. The first turnpike act was passed in 1663 , but little was done to the roads. Although passable, they were in a very poor condition. Ruts and mud-holes 4 , feet in depth were of frequent occurrence. By I809, due to the fact that the turnpike system had been extended, there were over one thousand turnpike trusts to keep the roads in repair. This supervision, however, was partially restricted to small communities. It was not until McAdam took charge of the roads that any systematic improvement of the roads was accomplished.

John Loudon McAdam returned from America to Scotland in 1783 , and was commissioner and trustee of roads in Scotland from this time until $\mathrm{I} 798$. Minutes of evidence given by him in I823 said: "In I798 I began to make it a sort of business. 
Without saying to any one what my object was, I travelled all over the country in different parts-as often as I had leisure and convenience down to the time I took charge of the Bristol Roads, or about the latter end of $\mathrm{I}_{\mathrm{S}} \mathrm{I}$. I found that the roads were extremely bad in all parts of Great Britain as far back as $\mathbf{I} 798$, and that very little improvement took place in them between then and the year I8I5, which I attributed to the ignorance of the persons who had charge of them, the ignorance of the surveyors, the total want of science. I found the materials so applied that the roads were all loose, and carriages, instead of passing over the roads, plowed them; that was the general fault of the roads; and the loose state of the roads, I apprehend, was owing to the bad selection of materials, the bad preparation, and the unskilful laying of them." McAdam was the first to recommend the construction of a broken-stone surface of small-sized broken stone without any foundation other than that furnished by the earth road-bed. Associated with the period in which McAdam demonstrated the success of his method of construction are the names of several other engineers, namely, Telford, Walker, and Edgeworth, all of whom helped further to perfect the principles laid down by McAdam and Tresaguet.

The boulder pavements first used in London were later succeeded by a crude type of block pavement composed of blocks measuring 6 or 8 inches across the surface. The blocks were very irregular in shape, and as no stable foundation was provided, these pavements were no improvement on those first constructed. It was not until 1824 that the deficiencies of this system were pointed out by Telford. He recommended using paving stones of granite, cut square on all sides, so as to furnish a close joint and having a base the same dimension as the top surface. The dimensions of the stones were to be as follows:

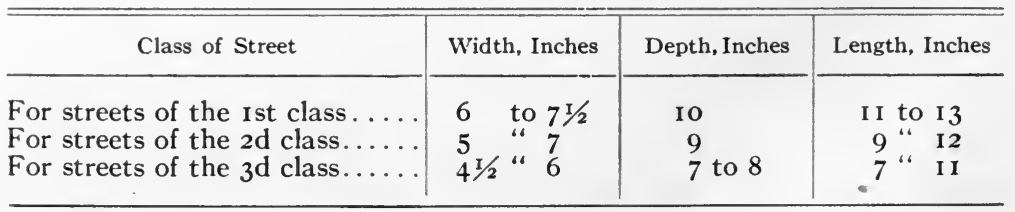


He also recommended constructing the pavement on a brokenstone foundation 12 inches deep.

In other parts of Europe, from the time of Rome's downfall to about the beginning of the eighteenth century, the history of road-building is practically a repetition of the developments during the same period in France and England. It was not until after the influential work of Tresaguet, McAdam, Telford, and others had been accomplished that any marked progress in the development and construction of roads throughout Europe took place.

EARly American Highways. According to existing records, the first highways constructed in America were those supposed to have been built by the ancient Incas of Peru. Gautier, in describing one of these roads which led from Quito to Cuzco, said the road had a width of 25 feet, and was paved in some places, where it was necessary, with large stones ro feet square. The roadsides were bordered with trees and supported in places by retaining walls.

The development of highways in North America was much slower than in other countries. As the United States was settled by many colonists from England, at a time when the road situation in England was particularly bad, the value of improved highways was not appreciated. The colonies were established along the eastern coast at widely separated points. Most of the communication between the different settlements was carried on by water. Because the colonists were occupied in protecting themselves from the Indians, and on account of lack of money, they did very little in the way of laying out roads outside of the settlements, except to clear out rough trails. It is known that some paving was attempted within the settlements at a very early date. The streets of Boston were paved, probably with cobble-stones, as early as I663.

Records show that a similar form of pavement was introduced in New York at about the same time. The following rules were adopted by the Government of New York in I664: "The highways to be cleared as followeth, viz., the way to be made clear of standing and lying trees, at least ten feet broad; 
all stumps and shrubs to be cut close by the ground. The trees to be marked yearly on both sides; sufficient bridges to be made and kept over all marshy, swampy, and difficult dirty places, and whatever else shall be thought more necessary about the highways aforesaid."

The French, who first settled in Canada, took advantage of the various great rivers and lakes on the northern border of the United States and the Mississippi River and its tributaries in establishing a line of settlements west of the Allegheny Mountains. It was evidently the intention of the French to form a cordon of settlements west of those of the English.

The only connections between the French and English settlements over land were the various trails made by big game animals or by the Indians. The buffalo seemed to have had a peculiar instinct in picking out the easiest trails. In many instances these trails were followed by the Indians, and with the progress of civilization they became highways.

The old York road which ran between New York City and Philadelphia was the first important highway in the colonies. It was laid out in I7II. In forcing the French from the Ohio Valley about the middle of the eighteenth century, several military expeditions were sent out from Virginia across the Allegheny Mountains. George Washington was one of the first to lay out a military road over this route in $\mathrm{I} 754$, for the purpose of moving Colonel Fry's army. In I 755, General Braddock, of the English Army, in making a similar expedition against the French, followed somewhat the same route as laid out by Washington. There was very little real progress in road-making until the last quarter of the eighteenth century, when the necessity for more and better roads was met in many cases by the construction of toll roads in various parts of the country. These roads were built and owned by private corporations which exacted payment from those using them.

The old Lancaster Turnpike, which ran from Philadelphia to Lancaster, Pennsylvania, was the first broken-stone road built in the United States. As originally constructed in I792, the surface was composed of stones of all sizes thrown together 
and covered with earth. The roadway became very unsatisfactory, and at a later date it was reconstructed with a brokenstone surface, no stones being used in the surface that would not go through a 2-inch ring. The success of this type of construction was quickly appreciated, and many of the toll roads constructed up to I8I I were built by this method. By I8I I there were about 4,500 miles of highways comprising 3I 7 turnpikes that had been chartered in New York and the New England States. Many of the roads built by private corporations were not a financial success, and whenever abandoned they usually came under the control of the State in which they were located. During the time that toll roads were being built to a large extent, the forced labor system was practically abandoned. It gradually returned with the decline of the toll roads and is still in operation in many of the States.

The construction of the Cumberland or National Road by the Government led to some further activity in road-building. This road extended from Washington westward to St. Louis, and was built with a 20-foot width of broken stone, 18 inches deep at the middle and 12 inches deep at the sides. It was started in 1806, and various appropriations were made for its construction by Congress during a period of over forty years. In certain localities the Cumberland Road was built upon the bed of the road as laid out previously by Washington and Braddock.

Up to 1840 the principal paving material used in American cities was cobble-stone. The improvement of highways outside of the cities was retarded, for a period of several years beginning with 1837 , due to a money stringency. The rapid development of the railroads in this country also served to establish communication between points which otherwise would have been connected by improved highways. 


\section{ECONOMICS, ADMINISTRATION, LEGISLATION, AND ORGANIZATION}

Since the middle of the nineteenth century financial problems pertaining to the construction of streets have been given consideration by American municipal engineers. It was not until about I890, however, that active interest in the finances of the improvement of highways outside of built-up districts developed in the United States. The rapid development of the building of highways is shown by the remarkable increase in the appropriations by states, counties, townships, and districts in the period from I9O4 to I9I4. The total appropriations in I9O4 were $\$ 79,000,000$, while in I9I4 they reached the sum of $\$ 225$,$\infty 0^{\circ}, \infty 00$. Since 1890 marked progress has been made in the methods of construction, but the economic problems of highway engineering have not been given the consideration by state and county highway departments which the importance of the subject demands.

The construction and maintenance of highways involve the expenditure of large sums of money which must eventually be paid by the people. In business, unless the capital invested is protected by available assets and unless it has an earning capacity, the investment is not considered a desirable one. To apply this criterion to the expenditure of money for highway construction is difficult, but the same underlying principle should be kept in mind. It is impracticable to state the value of good roads in dollars, although statisticians have frequently attempted to show the saving that would result in the cost of hauling various products over improved surfaces. Such figures may be very misleading, since they are based frequently on data of a meager nature. The return for the capital invested will there- 
fore have to be summed up from the standpoint of thę advantages resulting from the improvement of highways.

Benefits of Improved Highways. The benefits which result from the construction of a given highway naturally depend upon its local environments. The improvement of highways outside urban districts may or may not result in identical benefits to the communities in which they are respectively located. In the enumeration of the advantages resulting from the development of good roads and streets, it is, therefore, evident that in general only a group of the benefits mentioned will result from the improvement of a specific highway. The advantages and benefits of good highways are set forth in the following list, but not in relational order based on their value, since such rating will vary with individual highways.

I. Development of commerce.

2. Development of industries.

3. Development of agriculture.

4. Development of natural resources.

5. Development of intellectual and social life.

6. Improved appearance of roads and streets.

7. Permanency of alignment and grade of highways.

8. Decrease in cost of transportation.

9. Development of methods of transportation.

Io. Facilitation of travel.

II. Development of tourist travel.

I2. Improvement of sanitary conditions.

I3. Increase in land values.

I4. Increase in fire protection.

15. Increase in rural population.

I6. Development of rural free delivery.

It is apparent that many of these advantages cannot be estimated on a money basis. Although the surfacing will wear out in time, many of the advantages resulting from the original improvement are permanent, and under proper methods of financing, the cost would not be considered out of proportion to the benefits derived.

Financing Highways. The systems of financing the con- 
struction and maintenance of highways in the United States will be considered under the following heads:

I. Labor tax.

2. Convict labor.

3. Direct taxation.

4. Direct appropriation.

5. Bond issues.

6. Private subscriptions.

Labor Tax System. The labor tax system permits the payment of highway taxes in labor instead of cash. This system was extensively used in the United States in the development of highways outside of built-up districts until 1890 . Although it is being rapidly abolished in many sections, nevertheless statistics show that in I9I4 the system was in use in twenty-one states. Little good can be expected from such a system, since interest and earnestness of effect are generally lacking. The work is usually done at times which suit the convenience of those that perform it rather than at times which would be advantageous from the standpoint of the improvement of the highways. Of course work done by this method is generally better than none at all, but it is realized that the expenditure of an equivalent sum of money under intelligent administration will produce better and more far-reaching results. There are instances where results accomplished by this method have been very satisfactory, as, for example, the excellent work done with road drags on the highways in different parts of the country, particularly in connection with the maintenance of earth roads.

Convict Labor. Since Igro the utilization of convicts in connection with the construction of roads has received considerable attention in many parts of the United States. The use of convicts for this purpose is not, however, of recent origin, as they were used in the construction of the ancient highways of Rome and, throughout the Middle Ages, on highways in other parts of Europe. The sociological and economic problems involved are many. It has been affirmed by various authorities that convict work on highways must comply with the following conditions: "(I) It must not compete with outside 
free labor; (2) it must be a benefit to the convict himself; (3) it must be a benefit to the state; (4) it must provide the means to rehabilitate the convict in society after his release or at least partially to sustain his family and dependents during his imprisonment.

"The evidence available indicates the advisability of following the honor system for the good of both the convict and the state. The privileges given should be such as to make road work the goal of the prisoners' endeavors. These privileges should be: (I) absence of guns and chains; (2) substitution of plain uniform for stripes; (3) commutation of sentence; (4) better food; (5) a wage; (6) freedom after work hours."*

The following conclusions have been derived from an exhaustive study of the use of convict labor on highways in northern parts of the United States: "(I) The system can be successfully applied under varying conditions of climate, location, and class of prisoners; (2) as far as possible the honor system should be used and commutation of sentence allowed; (3) the choice of convicts for honor road work should be based upon temperamental fitness rather than upon nature of crime and length of term, but acceptance should be voluntary on the part of the prisoner and dependent on his satisfactory physical condition; (4) of all kinds of convict employment, that on the highways should be most attractive in wages and privileges; (5) a wage should be paid not to exceed the net earnings of the prisoner; (6) accurate data should be kept to show all unit costs, together with the engineer's estimates of the amount and value of the work done; (7) the prisoners should be under the prison representatives acting as foremen, and construction work should be under the highway department representatives acting as engineers; (8) concrete bridge work, grading, and drainage present a very useful form of work and should be generally employed."*

Direct Taxation. In many communities a certain part of the general tax is assessed as a highway tax to be used both

* Sydney Wilmot, in I913 Thesis, Graduate Course in Highway Engineering at Columbia University, Proceedings of the Academy of Political Science, January, I9I4. 
for the construction and maintenance of the highways. It is generally, however, of such small amount in rural districts that very little new construction can be accomplished. In order to further the construction of new highways, several states levy a tax for this purpose on the abutting property, which pays in part for the cost of new construction. Such a system is thought to be an equitable one in some localities. In districts where there are large areas between the highways the amount of $\operatorname{tax}$ is varied, depending upon the distance of the property from the highway. One advantage of the direct tax is that future indebtedness is obviated. The highway work in many of the cities of the United States is carried on by some form of special assessment. While in some cases the entire cost of grading is paid by the city, there are a few instances where the city pays a certain per cent of this cost. The same general scheme is also carried out in the original construction of pavements and in repaving work. An examination of Table* No. I will show the practice as followed in several American cities. The amount of assessment is based on the frontage of the property on the street, the total area, or a combination of the frontage and the area. The frontage rule is more commonly used than either of the others. In some cases the amount assessed is due on completion of the work. In others, however, the amount is paid in several equal annual installments, deferred payments bearing interest. The charter of New York City was amended in I9Io, with reference to the paving and repaving of streets and the method of payment therefor, to read as follows:

"Street pavements shall be divided into two classes, namely: Class 'A,' or permanent pavements, and Class 'B,' or preliminary pavements. Class 'A' shall include all pavements of sheet asphalt, asphalt block, wood block, granite block, or other materials that shall; from time to time, be designated for this class by the Board of Estimate and Apportionment. Class ' $\mathrm{B}$ ' shall include all pavements of bituminous macadam and such other pavements that shall from time to time be designated for this class

* See Transactions, Am. Soc. C. E., Vol. XXXVIII, pages 336-342. 
TABLE No. 1

Apportionment of Cost of Pavements in Fifty Cities

\begin{tabular}{|c|c|c|c|c|c|c|c|}
\hline \multicolumn{2}{|c|}{ LOCALITY } & \multicolumn{2}{|c|}{$\begin{array}{l}\text { Grading } \\
\text { Percent } \\
\text { Paid by }\end{array}$} & \multicolumn{2}{|c|}{$\begin{array}{c}\text { Original } \\
\text { Paving Percent } \\
\text { Paid by } \\
\end{array}$} & \multicolumn{2}{|c|}{$\begin{array}{c}\text { Repaving } \\
\text { Percent } \\
\text { Paid by } \\
\end{array}$} \\
\hline $\begin{array}{l}\text { Ref. } \\
\text { No. }\end{array}$ & City & $\begin{array}{l}\text { Prop- } \\
\text { erty }\end{array}$ & City & $\begin{array}{l}\text { Prop- } \\
\text { erty }\end{array}$ & City & $\begin{array}{l}\text { Prop- } \\
\text { erty }\end{array}$ & City \\
\hline I. Alabama. & Montgomery. & 50 & 50 & 50 & 50 & $5^{0}$ & 50 \\
\hline 2. Arkansas.. & Little Roc & IOO & $\ldots$ & IOO & $\ldots$ & IOO & \\
\hline 3. California.. & San Francisco & IOO & $\cdots$ & 100 & $\cdots$ & $\cdots$ & IOO \\
\hline 4. Connecticut. & Hartford.... & $\cdots$ & IOO & 67 & 33 & & 100 \\
\hline 5. & New Haven. & $\cdots$ & IOO & $a$ & & $b$ & \\
\hline 6. Dist. of Colum. & Washington. & $\cdots$ & IOO & $\cdots$ & IOO & $\cdots$ & 100 \\
\hline 7. Delaware.... & Wilmington. & $\cdots$ & Ioo & $\cdots$ & 100 & $\cdots$ & IOO \\
\hline 8. Florida. . & Jacksonville. & 50 & 50 & 50 & 50 & 50 & 50 \\
\hline 9. Georgia. & Atlanta... & $\therefore$ & IOO & 67 & 33 & 67 & 33 \\
\hline I0. “. & Augusta. & 50 & 50 & $5^{\circ}$ & 50 & 50 & 50 \\
\hline I I. Illinois... & Peoria....... & IOO & & 100 & & IOO & \\
\hline 12. Indiana.. & India & 100 & $d$ & 100 & $d$ & 100 & $d$ \\
\hline I3. Iowa & Burlingto & $\cdots$ & 100 & IOO & $c$ & $\cdots$ & 100 \\
\hline I4. Kansas... & Tope & $\cdots$ & IOO & IOO & $\cdots$ & 100 & \\
\hline I5. Kent & Lou & 100 & $\ldots$ & 100 & $\ldots$ & $\ldots$ & 100 \\
\hline 16. Louisiana. & $\mathrm{Ne}$ & 75 & 25 & 75 & 25 & 75 & 25 \\
\hline I7. Maine.... & Portland... & & 100 & $\ldots$ & IOO & $\cdots$ & 100 \\
\hline I8. Maryland.... & Balt & 100 & $\cdots$ & 100 & $\therefore$ & $\cdots$ & 100 \\
\hline I9. Massachusetts & Low & 100 & .. & $\ldots$ & 100 & $\ldots$ & 100 \\
\hline 20. & Springfield & $\ldots$ & 100 & $\ldots$ & 100 & $\ldots$ & 100 \\
\hline 21 & Wor & 100 & $\ldots$ & $\ldots$ & 100 & $\ldots$ & I 00 \\
\hline 22. Michigan..... & Det & 100 & $c$ & 100 & $c$ & IOO & $c$ \\
\hline 23. Minnesota.... & Minr & $\cdots$ & 100 & 100 & $c$ & IOO & $c$ \\
\hline 24. & St. Paul..... & 100 & $\ldots$ & 100 & $\ldots$ & 100 & $\cdots$ \\
\hline 25. Missouri. & Kansas City.. & 100 & & Ioo & $\cdots$ & IOO & $\cdots$ \\
\hline 26. & & $\cdots$ & IOO & IOO & $\cdots$ & IOO & $\cdots$ \\
\hline 27. Nebraska.... & Omal & $5^{0}$ & 50 & 100 & $c$ & 100 & $c$ \\
\hline 28. New Hmpshre & & & 100 & $\cdots$ & IOO & $\cdots$ & IOO \\
\hline 29. New Jersey... & Newark. . & 100 & $\cdots$ & IOO & $\cdots$ & IOO & $\ldots$ \\
\hline 30. & Pate & IOO & & IOO & & $\cdots$ & 100 \\
\hline 3I. New York.... & Albany & 100 & $d$ & 100 & $d$ & IOO & $d$ \\
\hline 32. " " & Bro & 100 & $\cdots$ & 100 & $\cdots$ & $5^{\circ}$ & $5^{\circ}$ \\
\hline 33. & Buffa & IOO & . & IOO & $\cdots$ & IOO & $\cdots$ \\
\hline 34. & $N$ & IOO & $\cdots$ & 100 & $\cdots$ & $\cdots$ & 100 \\
\hline 35. & chester. . & IOO & $\cdots$ & IOO & $\cdots$ & IOO & $\cdots$ \\
\hline 36. & & 100 & $\ldots$ & 100 & $\cdots$ & IOO & $\cdots$ \\
\hline 37. Ohio... & Cinc & 98 & $2 c$ & 98 & $2 c$ & 98 & $2 c$ \\
\hline $3^{8 .} " \quad \ldots$ & Day & 100 & $c$ & 100 & $c$ & 100 & $c$ \\
\hline 39. Oregon....... & Port & 100 & $\cdots$ & 100 & $\cdots$ & 100 & $\cdots$ \\
\hline 40. Pennsylvania. & Harr & IOO & & IOO & $\cdots$ & 100 & $\cdots$ \\
\hline & & $\cdots$ & 100 & 100 & $\cdots$ & $\cdots$ & 100 \\
\hline 42. " " & & 100 & $\cdots$ & 100 & $\cdots$ & $5^{\circ}$ & $5^{\circ}$ \\
\hline 43. Rhode Island. & Providen & 100 & & $\ldots$ & IOO & $\cdots$ & IOO \\
\hline 44. South Carolina & Charlest & $\cdots$ & 100 & $\cdots$ & 100 & $\cdots$ & 100 \\
\hline 45. South Dakota. & & 100 & $c$ & 100 & $c$ & 100 & $c$ \\
\hline 46. Tenr & Nashville. & $\ldots$ & IOO & $\cdots$ & 100 & $\cdots$ & 100 \\
\hline 47. Utah. . . . & Salt Lake. & 50 & $50 c$ & IOO & $c$ & 100 & $c$ \\
\hline 48. V & & $\cdots$ & 100 & $\cdots$ & 100 & $\cdots$ & IOO \\
\hline 49. Washin & & 100 & $\cdots$ & 100 & $\ldots$ & 100 & $\cdots$ \\
\hline 50. Wisconsin.... & Milwaukee. . & 100 & $c$ & 100 & $c$ & $\ldots$ & 100 \\
\hline
\end{tabular}

$a$ I sq. yd. for each front foot; city remainder. $\quad b \quad 3 \mathrm{~T} / 2$ sq. ft. for each front foot; city remainder. $c$ City pays for street intersections. $d$ City does not pay for street intersections. 
by the Board of Estimate and Apportionment. No street, or portion thereof, that shall have been paved with class 'A' pavement shall be repaved at the expense of the adjoining propertyowners, unless a majority of the owners of the property on the line of the proposed improvement shall petition for such repaving at their expense by assessment.

"Whenever a street paved with class ' $B$ ' pavement shall be repaved, the repaving shall be done with class 'A' pavement, unless owners of property on the line of the proposed improvement petition the local board having jurisdiction for a second class ' $\mathrm{B}$ ' pavement, to be laid at the expense, by assessment, of the adjoining property-owners, and in such event second-class ' $B$ ' pavement shall be laid if said local board so orders, and the Board of Estimate and Apportionment consents. Whenever a class. ' $A$ ' pavement shall be laid to replace a class ' $B$ ' pavement that has been laid at the expense of the propertyowners by assessment there shall be deducted from the cost of such improvement the cost of the class ' $\mathrm{B}$ ' pavement, and the difference shall be paid by assessment upon the adjoining property, and the amount equal to the cost of said class ' $\mathrm{B}$ ' pavement shall be borne and paid by the city. But in no case shall the cost of a second or additional class ' $\mathrm{B}$ ' pavement be so deducted from the amount to be assessed for the laying of a permanent or class ' $A$ ' pavement.

"The class of the original pavement of any street shall in all cases be determined by the local board having jurisdiction and the Board of Estimate and Apportionment."

Another form of direct taxation is the licensing of motor vehicles. The money received in license fees for both vehicles and operators and the money received from penalties and fines imposed for non-observance of the laws as a rule are usually paid into the state treasuries to be used for the maintenance of highways. In I9I4 the revenue collected in New York State from this source amounted to $\$ 1,530,000$, and in the State of California to $\$ \mathrm{I}, 340,000$.

Direct Appropriation. When payment for highway improvement is made from the general taxes of a community, the ex- 
pense is borne by all the people residing therein. A large amount of the state highway work is paid for on this basis. In many municipalities and towns an amount sufficient to cover the cost of the highway improvement is made an item of the annual budget.

Bond Issues. Due to the large sums of money required where extensive construction is contemplated, the revenue available from the general taxes will not usually meet the expense of the improvement. In such cases it has become common procedure to issue bonds, bearing interest from $2 \frac{1}{2}$ to 6 per cent, which are redeemable at different periods. The amount of bonds issued should never be out of proportion to the taxable wealth of the corporate body issuing them. The yearly cost of the bonds will be the sum of the amount which will have to be paid out in interest and the amount which will have to be set aside as a sinking fund to redeem the bonds. The issuance of bonds renders a large sum of money available for immediate use and extends the repayment over a long period of years. If the term of the bonds is made so long that the highways are worn out before the bonds are redeemed and no provision made either for the maintenance of the highways or for the redemption of the bonds, a very unfortunate financial situation arises. To illustrate this point the following case was cited by Clifford Richardson, M. Am. Soc. C. E.:

"It appears from the Report of the Register of Deeds of the County of . . . that in I870 it issued bonds for $\$ 300,000$ to run for twenty years bearing 6 per cent interest. For twenty years the community paid annually $\$ 18,000$ interest on this loan. When the bonds became due in $1890, \$ 360,000$ interest had been paid, but no provision had been made for retiring the principal. It was therefore necessary to issue $\$ 300,000$ in bonds payable after another thirty years, and at a like rate of interest, to take up the first series. By I920, when these bonds become due, $\$ 900,000$ in interest will have been paid thereon, and the county will still owe the amount borrowed." Richardson further states that "as the life of a well-constructed road may be looked upon as being between ten and fifteen years a community which 
issues bonds of this type (to run for ten to fifteen years), with the proper provision for sinking fund, cannot be considered to have done anything unreasonable, especially in view of the fact that the improvement in the value of adjacent property by the construction of good roads and the consequent increase in its taxable value, may more than meet the demands of the sinking fund and interest. The bonds would be paid for and the debt wiped out during the life of the road, and the cost of the latter would be the amount paid. There would be no further responsibility incurred.

"It would be very different, however, if bonds were issued for forty-one years. . . . The bill provides that bonds shall be issued by the State at 4 per cent interest for a term of forty-one years. The money thus obtained shall be loaned to the various counties in the State for highway construction at an interest of 5 per cent, 4 per cent of which shall be devoted to payment of interest on the bonds and I per cent devoted to a sinking fund, which would retire the bonds at maturity. On its face this is a satisfactory proposition for meeting indebtedness, but the viciousness lies in the fact that the roads' surfaces, which might be constructed with such funds, would have been worn out and have disappeared after not more than fifteen years. The State and counties would then have no roads and the original cost of constructing them would still be a debt extending for a period of twenty-six years. It would be again necessary to borrow money by bonds of the same description to build new roads."

Nelson P. Lewis, M. Am. Soc. C. E., in making a report to the Board of Estimate and Apportionment of New York City, advisedly pointed out that "The term of bonds issued for repaving should be no longer than the probable life of the pavement, or still better, the funds for repaving should be included in the annual budget and the city's borrowing capacities reserved for other purposes."

Private Subscription. There are a few instances where highways have been built by private subscription. The largest undertaking of this kind is the Coleman du Pont Road in Dela- 
ware. There have been several roads constructed throughout the country, however, by private capital as a business enterprise. These roads after construction were operated as toll roads, but most of them have been taken over by the States through which they pass and converted into public highways.

\section{Administration ANd Legislation}

There is a marked difference between the systems of administration regulating highway improvement in Europe and in the United States. In Europe the construction and maintenance of highways outside of the large cities in many instances is regulated and controlled by the national government, and where the government does not build national highways, a national board may exist having control in certain matters. Another very pertinent fact is that European administration is in the hands of experienced engineers. In the United States there is no national system of highways, each State acting independently in this matter. Within many States the same lack of centralization of authority is found in the highway work undertaken by the various counties and towns. The administration of the state, county, and town highways is vested in boards or commissions composed of several men, or else the authority rests in the hands of one man. Unfortunately, in the majority of instances, these men are not engineers. Although it is necessary to employ an engineering organization to carry out the work, some of the work is not done on sound engineering principles, due to interference by the lay bodies. Moreover, a great deal of the money spent for construction and maintenance is wasted because of the lack of centralization of control. The different systems of a few of the principal countries of the world will be described which are typical illustrations of general practice.

France. In France the highways are classified as routes nationales (national roads), routes départementales (departmental roads), and chemins vicinaux (vicinal roads). The chemins vicinaux are divided into several subsidiary classes: chemins vicinaux 
de grande communication (roads of great importance), chemins d'intêret commun (roads of common interest), and chemins vicinaux ordinaire (roads of little importance). Jean de Pulligny, M. Am. Soc. C. E., states that, ${ }^{*}$

"For many years the tendency in all départements has been to have only one class of roads, the chemins de grande communication. No more chemins d'intêret commun are created, and every year some routes départementales drop from the official lists and they are thence counted as chemins de grande communication. The length of the routes départementales has thus fallen from 29,500 miles in the year 1869 to 8 , 100 at the present time. On January I, I9II, the road mileage in France was as follows: Routes nationales, 24,000 miles; routes départementales, 8,100 miles; chemins vicinaux, 395,700 miles.

"All of the routes nationales are constructed and maintained by the central government under the direction of the Département National des Ponts et Chaussées, the organization of which is as follows: The inspecteurs généraux, all of whom must reside in Paris, are of two grades. Those of the first grade form a permanent board of which the ministre de travaux publics is the nominal president. The board is actually presided over by a vice-president, an inspecteur-général who is appointed by the ministre. This permanent board is augmented by half of the inspecteurs généraux of the second class, each half serving six months. The board has direct control of all the work of the Département des Ponts et Chaussées in France. Besides the care of the routes nationales the Département has under its supervision all improvements in connection with the bridges, rivers, canals, harbor improvements, the control of the railroads, and attached services in the colonies.

"The board assigns inspecteurs généraux of the second class to special fields of inspection covering the work of several ingénieurs-en-chef, and may in very important cases designate an inspecteur-général of the first class. The ingénieurs-en-chef who

* From 1912-I9I3 Lecture by M. Pulligny, Ingénieur en Chef, Département des Ponts et Chaussées de France, in the Graduate Course in Highway Engineering at Columbia University. 
have charge of several lines of work may thus "be subject to orders from a number of inspecteurs-généraux. The remainder of the organization comprises ingénieurs ordinaires, sous ingénieurs, conducteurs principaux, conducteurs, commis principaux, commis and commis stagiaires. The title ingénieur ordinaire is conferred on men at the time of their graduation from L'École Nationale des Ponts et Chaussées. Sous-ingénieurs, conducteurs, and commis are not graduates of the national school and are not eligible to the grade of Ingénieur des Ponts et Chaussées."

Pulligny also says that "France is divided into eighty-six territorial units called Départements. Each French Département is also a unit for several public services and it is a political unit. It has a governor, called a prefet, appointed by the central government, and an elective body, called conseil général.

"All of the chemins vicinaux within a Département are managed by the prefet of that Département and the necessary expenditures are appropriated by the conseil général. The direct charge of the work is in the hands of a centralized body of competent technical men. In about one-half of the Départements the work is intrusted by the conseils généraux to the body of government engineers who are graduates of L'École Nationale des Ponts et Chaussées. In forty-six of the French Départements special technical bodies under a chief road engineer have been organized to look after the work.

"Each Département is divided into four or five political dis- . tricts headed by a sous-préfet and called an arrondissement. In each capital of these districts resides a district road engineer who works under the direction of the chief road engineer, having charge of all the chemins vicinaux of the arrondissement. Each arrondissement is divided into four or five judicial districts, named Cantons, having also their small capitals. An assistant road engineer, acting under the direction of the district road engineer, looks after all the chemins vicinaux in the Canton. Finally, all the roads in the Canton are divided into sections a few miles long, and in each of these sections works constantly the celebrated French cantonnier or road patrolman, whom all the motorists have noticed with his pickaxe, shovel, broom, and 
wheelbarrow. These cantonniers are under the orders of the assistant road engineer. A few of them, who have a shorter section, look after the work of their neighbors, and are called chefs cantonniers.

"The cantonniers are simple laborers, generally of agricultural training, and no special knowledge is required of them to enter the service. They are only expected to act with respectable behavior, to be able to read and write, and to be steady, trustworthy workers. All the members of the road service, from the patrolmen to the chief engineer, work under a civil service law. When they have once entered the service they can only be dismissed in case of serious misbehavior. They are promoted to a better pay at regular intervals, and when they retire after thirty years of work they receive an old-age pension. The district engineers are generally chosen from the most able and experienced assistant engineers who have been in the service for many years. The chief engineer of the Département may have been previously a district engineer, but it is not obligatory. In some cases he formerly was a civil engineer, a graduate from one of our principal schools, or an architect, or an Ingénieur des Ponts et Chaussées."

Germany. The highways of Germany are under the control of the different States forming the Empire. The various provinces within the States receive state aid for the construction of main roads. In Prussia the work is generally supervised by the Minister of Public Works. The direct administration, however, is in the hands of the provincial authorities, who, in turn, can transfer authority to smaller communal bodies, such as districts and parishes. In Saxony the State is divided into four divisions, each one of which is supervised by an executive officer of the Department of the Interior. The four divisions are further subdivided into twenty-seven districts, the work in each district being administered by important executive officers. The actual work of construction and maintenance throughout the Empire is in the hands of carefully trained technical men.

Great Britain. In Great Britain two classes of highways are generally recognized, namely, main and district roads. The 
classification, however, is not very satisfactory, as there are main roads, which carry only local traffic, and in some parts there are principal trunk roads, which are classified as district roads. The highway administration is in the hands of county councils, which have the care of the main or county roads, and district councils, urban and rural, which have the care of the remainder of the public highways. The cost of the work is paid for by the taxpayers residing in the counties and districts, assisted by grants from the Imperial Exchequer. One very admirable feature of the British system of administration is the power given the Local Government Board relative to the borrowing capacity of a county or district council. Before either can borrow money for highway improvement it must satisfy the following regulations of the Local Government Board:

The sum-borrowed shall not exceed at any time, including all outstanding loans, the assessable value for two years of the district. Where it exceeds the assessable value for one year, the Board does not give its sanction until one of its inspectors has held a local inquiry.... The repayment of the money borrowed must be made within a certain time fixed by the length of life of the proposed work.

In I909 an act was passed by Parliament creating the Road Board of England, composed of five men. This Board was appointed for the purpose of improving the facilities for highway traffic in the United Kingdom. The Road Board, with the approval of the Treasury, has the power to make advances to county councils and other highway authorities for the construction and maintenance of roads. Advances may be made by loan or grant or upon such terms and subject to such conditions as the Board may impose.

Switzerland. The highways in Switzerland come under the direct supervision of the authorities of the separate Cantons. The State exercises no control over the highways except that by reason of the fact that it assists the Cantons financially to some extent, it may impose certain regulations before rendering such assistance. The engineers in direct charge of the work must be technically trained men. 
Other European Countries. In Spain, Italy, Belgium, Austria, and Portugal the scheme of administration of highway construction is very similar in each case to that of France.

United States. In the United States there is no national system of highways, although many bills proposing national participation of the government in the construction of highways have been brought before Congress. The National Highways Association, after a thorough investigation of foreign systems and the several interstate trunk highways traversing the United States, has proposed a system composed of fifty thousand miles of national highways.

The Office of Public Roads and Rural Engineering, which is a branch of the Department of Agriculture, is maintained by the Government for the purpose of the accumulation and dissemination of knowledge with reference to highways. The office is equipped with laboratories for testing certain kinds of road materials. It also supervises the construction of experimental roads in various parts of the country with a view to showing the different localities what can be done with local materials.

States. There are many States which have adopted a system of highways that are paid for either wholly or in part by the State. Highway work undertaken by the various counties and towns within the States is usually carried out without any control on the part of the state authorities unless financial aid has been given by the State. The administration of the work in the various States is usually vested in a commission, a commissioner, or a state engineer, appointed in many cases by the Governor of the State, subject to the approval of the state legislature. Unfortunately, politics play too important a part in these appointments and seriously interfere with the establishment of an efficient organization.

New Jersey was the first State in the United States to adopt a policy of state aid for the construction of highways, the State Highway Department being established in I89I. State aid is not always given in the form of money. There are several States in which the aid consists in furnishing engineering advice and assistance. Only a brief résumé of highway legisia- 
tion as enacted by a few States will be given. The examples cited are typical of the several methods of administering, financing, and developing state, county, and town highways.

Alabama. The State Highway Commission consists of the Professor of Civil Engineering at the Alabama Polytechnic Institute, the State Geologist, and three civilians appointed by the Governor. The Commission appoints a State Highway Engineer, whose duties are to prepare road maps of the State and to give engineering advice and assistance. The annual appropriation minus the expenses of the Commission is divided equally among the different counties of the State. Before any county can obtain its allotment it must appropriate an equal sum.

California. The Department of Engineering consists of an advisory board composed of the Governor, who acts as ex-officio Chairman, the State Engineer, the General Superintendent of State Hospitals, the Chairman of the State Board of Harbor Commissioners of San Francisco, and three members appointed by the Governor. A highway engineer is also appointed by the Governor. The California State Highway Commission is composed of three members of the engineering department, appointed by the Governor. The highway engineer reports to the Commission. An $\$ 18,000,000$ bond issue was made available in I9I0 for the construction of a system of state highways. The counties are required to pay 4 per cent interest on the amount of the bond issue spent within the county, minus a sum depending upon the relation between the bonds matured and the bonds outstanding. The state highways are maintained with the funds derived from license fees on motor-vehicles. Several roads in districts which are too poor to pay for them are constructed and maintained by state appropriations.

Connecticut. A State Highway Commissioner, who is required to be a capable highway builder, is appointed by the Governor with the approval of the senate. The highway commissioner has complete authority with reference to the construction and maintenance of trunk-line state-aid roads. The trunk highways laid out in I9I3 are constructed and maintained at the expense of the State. State aid may be obtained by any 
town upon written application of the selectmen of that town. Towns which have a valuation of over $\$ 1,250,000$ are entitled to receive from the State three-fourths of the cost of construction of roads, under provision of the state-aid act, and towns under $\$ 1,250,000$ valuation receive seven-eighths of the cost. The amount paid by the State for the construction of state-aid highways is limited to $\$ 500,000$ per year. Money for the construction of trunk-line and state-aid highways is obtained from bond issues. Three-fourths of the maintenance of state-aid highways is paid by the State and one-fourth by the towns. All funds received from license fees on motor-vehicles are used for the maintenance of highways.

Georgia. State participation in the construction of highways is under the supervision of the State Prison Commission. This Commission is authorized to purchase road machinery, equip and organize male felony convicts to constitute gangs for county highway work. The convicts are apportioned to the several counties upon the basis of population.

Illinois. The Highway Commission consists of three persons, appointed by the Governor, who serve without pay. A State Engineer is appointed by the Commission. The Commission acts in an advisory capacity and may be consulted by any of the county, city, village, or township highway officials. An appropriation of $\$ 100,000$ per year is made for the support of the work of the Commission, which work includes the preparation of road and bridge plans, estimates, collection of statistics, and experimental work. Annual appropriations are made for the construction of state-aid roads and bridges, the I9I4-I9I5 appropriation being $\$ 700,000$. The State pays one-half the construction of roads and bridges and the county concerned pays one-half. The cost of maintenance of the state-aid roads and bridges is borne by the State.

Maryland. From 1898 to I 904 engineering advice was furnished to the various road officials throughout the State by the Maryland Geological and Economic Survey, which received an annual appropriation from the State of $\$ 10,000$ for this purpose. In 1904 the State voted to appropriate $\$ 200,000$ annually for 
state-aid work, the money to be spent under the direction of the Geological and Economic Survey. The State Roads Commission, which has had charge of the highway work since rgro, consists of six members appointed by the Governor. The work of construction and maintenance is carried out by an engineering organization under a chief engineer. The following bond issues have been approved by the people: I908, $\$ 5,000,000$; I9I0, \$I,000,000; I9I $2, \$ 3,170,000 ;$ I9I $4, \$ 5,000,000$. The funds from these bond issues are used for the construction and maintenance of trunk-line highways. State-aid roads are also constructed in the various counties, the cost being shared equally by the county and the State, the work being done under state supervision. The maintenance of state-aid roads, however, is carried out by the county authorities with state supervision. The funds for state-aid roads are provided by direct appropriation.

Massachusetts. The Massachusetts Highway Commission was formed in 1893 and consists of three members appointed by the Governor. A chief engineer, appointed by the Commission, is in charge of the engineering organization. The first appropriation for the construction of state highways was made in I894. Many bond issues have been voted since I894, the I9I5 issue being at the rate of $\$ 1,000,000$ per year. The State aids in the construction and maintenance of state highways and town roads. The county in which the state highway is located pays 25 per cent of the cost of construction. A sum not exceeding 15 per cent of the amount appropriated by the State may be used in the construction of town roads as follows: 5 per cent in towns having a valuation of less than $\$ 1,000, \infty 00$, the town making no contribution; 5 per cent in towns having a valuation of less than $\$ 1, \infty 00,000$, the town contributing an equal amount; 5 per cent in towns having a valuation of more than $\$ 1, \infty 00, \infty 00$, the town contributing a like amount. No state aid can be given until a petition from the governing body of the town, county, or city in which the road is located has been received and approved by the Commission. Roads declared state highways are maintained at the expense of the State and 
counties. Town roads built with state aid are maintained by the towns. Funds derived from fees, fines, etc., on motor-vehicles are used for the maintenance of highways constructed under the supervision of the Commission.

New Jersey. The State Highway Commission consists of the Governor, President of the Senate, Speaker of the House of the Assembly, State Treasurer, and a Commissioner of Public Roads appointed by the Governor. Under the Commissioner of Public Roads is a State Supervisor who has charge of the engineering work. The State participates in the construction and maintenance of state highways and state-aid county highways. The trunk-line state highways are constructed and maintained at the expense of the State. The State appropriates $\$ 400,000$ annually for state-aid road construction, 40 per cent of the cost of any road being paid for by the State and 60 per cent by the county. The surveys for a road are made by the county engineers at the expense of the county. Before receiving state aid, the plans and construction have to be approved by the Commissioner of Public Roads. County supervisors and county engineers are appointed by the Boards of Freeholders of the various counties.

New York. The State Commission of Highways of New York consists of the Commissioner, who is appointed by the Governor. The highways are divided into four classes: State and county highways, county roads, and town highways. The Commissioner appoints three deputy commissioners, the first deputy having charge of the plans, specifications, and execution of all contracts pertaining to the construction of state and county highways and county roads; the second deputy having charge of the maintenance of state and county highways and county roads; the third deputy having charge of the repair, improvement, and maintenance of town highways and bridges and county roads and bridges in the Indian reservation. The Commissioner also appoints nine division engineers, who have charge of the construction and maintenance of the state and county highways in their respective divisions under the supervision of the deputy having jurisdiction thereof. County superintendents are ap- 
pointed by the boards of supervisors of the various counties, these superintendents being subject to the regulations of the Commissioner. Town superintendents, who are elected at the town meetings, report to the county superintendents. New York ranks first in the amount of money raised for the construction of highways by the authorization of a $\$ 50,000,000$ bond issue in 1906 and by the passage of another $\$ 50,000,000$ bond issue in I9I2. The cost of improving state highways is borne entirely by the State. The cost of improving county highways is distributed as follows: State, 50 per cent; county, 35 per cent; town, I5 per cent. County roads are improved at the expense of the counties but the State contributes 50 per cent of the amount appropriated by counties for maintenance. The appropriation made as state aid to towns for the construction of town highways is based upon the amount of taxes levied per mile of highway within the town. No town under this scheme, however, can receive an amount exceeding $\$ 25$ per mile for the total mileage of the towns outside of the incorporated villages. The maintenance of the state and county highways is under the control of the Commission, an annual appropriation being made to cover this expense. The towns, however, are required to pay $\$ 50$ a year for each mile of state and county highways within their borders towards the expense of maintenance.

Ohio. A State Highway Commissioner is appointed by the Governor. The Commissioner appoints three deputy commissioners, one having charge of a bureau of construction, one having charge of a bureau of maintenance and repair, and one having charge of a bureau of bridges. The Commissioner and deputy commissioners must be civil engineers with experience in the construction and maintenance of roads and bridges. For construction of inter-county highways and main-market roads the State pays 50 per cent, the county 25 per cent, the town I5 per cent, and the abutting property-owners ro per cent. Funds for state aid are raised by direct appropriation and by an annual tax levy of three-tenths of a mill on all taxable property.

Pennsylvania. A Highway Commissioner is appointed by the Governor. He also appoints two deputy commissioners and 
a chief engineer. The other members of the engineering force are appointed by the Commissioner. State highways are built and maintained at the sole expense of the State. State aid may be obtained by a county, and borough or township applying jointly or separately. In the first case, the county and township or borough pay 50 per cent and the State 50 per cent of the cost of construction; in the second case, 50 per cent of the cost is borne by the State and 50 per cent by the county, borough, or township applying. Funds for construction and maintenance are provided by direct appropriation.

Rhode Island. A State Board of Public Roads composed of five civilians, one from each county in the State, was appointed by the Governor in 1902. The Board appoints an engineer. Rhode Island was the first State to establish a system of state trunk highways. Since 1902 several direct appropriations for the work of building state highways have been made by the State and $\$ 1,800,000$ in bond issues have been authorized. A state highway having a width of improved surface of $\mathrm{I}_{4}$ feet is built and maintained entirely at the expense of the State. Should a wider road be desired, the town through which the road passes pays for the extra width over I4 feet. The whole width, however, is maintained by the State. A state-aid law has also been passed, in which the State appropriates a sum equal to one-fifth of a sum raised by the town. The sum raised by the town must be in the way of an annual appropriation and must be equal to or more than a sum of 20 cents on each $\$ 100$ of ratable property of the town. The town is also required to vote that the expenditure of this money shall be under the direction of the State Board and for the maintenance and repair of highways and bridges other than state highways. The proceeds from motor-vehicle fees are used for the maintenance of state highways.

Municipalities. The administration of highways within the cities is usually controlled by the governing body of the city. "The following requisites are necessary in order to secure satisfactory results in highway administration: (I) Centralization of authority over and responsibility for all work relating to 
highways within the administrative district; (2) such flexibility of organization as will permit a concentration of force on any work of pressing importance; (3) administrative units sufficiently large to permit the utilization of an entire force and equipment all of the time, reducing overhead charges to a minimum consistent with efficiency and thoroughness; (4) get rid of the prevalent horror of a bureaucracy. If such a bureaucracy works well, it is a good thing. If it works badly, it is not because it is a bureaucracy, but because it is not well organized; (5) direct and undivided responsibility for every part of the work, each head of a bureau or subdivision to be made to realize, however, that his own particular work should be so done as to help and not to hinder that of other bureaus or divisions; (6) promotion to the headship of bureaus and departments to be made from within the organization when possible, not necessarily according to seniority, but by reason of peculiar fitness. When it is necessary to go outside of the organization to fill such a place, the appointee should be one who has already made good in similar work in some other place; (7) permanent tenure of office for those in responsible charge, so that continuity of purpose and policy may be assured."* In the United States the carrying out of the work is accomplished by three general methods of administration, which are illustrated by a brief review of the practice in Boston, Providence, and St. Louis.

Boston. A chart, shown in Fig. 3, illustrates the difference between the old and new systems of administration in Boston. The old system was abandoned in favor of the new on account of the lack of cooperation between the departments of the City Engineer, the Water Commissioner, and the Superintendent of Streets. These departments acted independently of one another, which led to endless confusion and waste of money. In the new system the direct controlling officer is an EngineerCommissioner of Public Works who reports to the Mayor. Under

* From 1913-1914 Lecture by Nelson P. Lewis, Chief Engineer, Board of Estimate and Apportionment, New York City, in the Graduate Course in Highway Engineering at Columbia University. 
this Commissioner are three deputy commissioners, one having charge of the sewer and water division, one of the highway division, and one of the bridges and ferries division. It is apparent that in this last arrangement the relations of the three
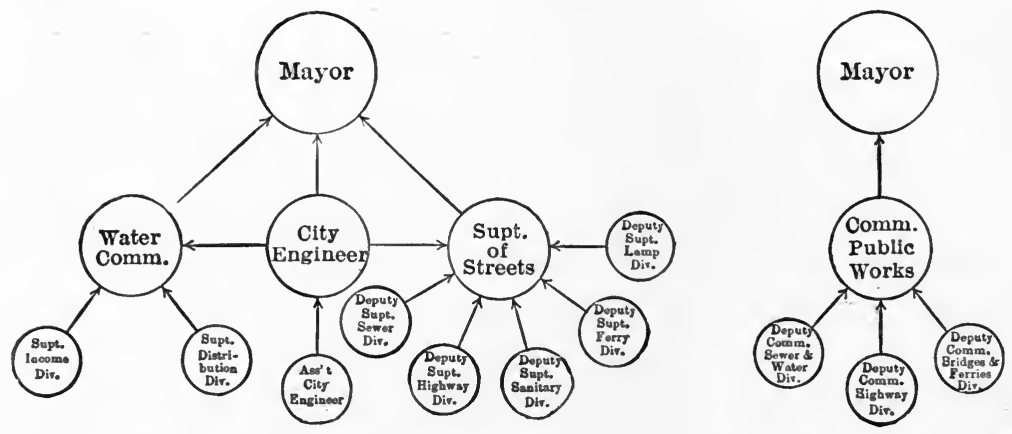

FIG. 3. Old and New Systems of Organization of Public Works Department, City of Boston.

divisions are controlled by one head, who can insist on cooperation and centralization of effort.

Providence. A Commissioner of Public Works, appointed by the City Government, directly controls the work of the engineering department. The City Engineer heads a department, the several divisions of which, such as bridges, sewers, streets, and water-works, are in charge of assistant engineers. The Commissioner of Public Works, who is not an engineer, has the final decision as to the expenditure of money appropriated. The City Engineer reports directly to the Commissioner as to methods of construction, which recommendations are usually carried out.

St. Louis. In this city, a Commission, composed of engineers, supervises all public work. Each division of public work is under the control of a member of the Commission and has its own complete organization. The work of all the divisions is coordinated by the Commission. Since the different members of the Commission cooperate with each other in their various lines of work through the medium of frequent meetings, the result is that all the public work is carried out with a minimum 
amount of delay and friction. Important meetings of the Commission are presided over by the Mayor.

\section{ORGANIZATION}

In order to attain efficiency in all departments of work to be carried out under the jurisdiction of a highway department requires that the duties assigned to the department and the personnel and interrelationship of the several units of the organization should be based upon the following fundamental principles: (I) a highway department should have control of all departments of work relating to the substructure and superstructure of highways within the limits of the right of way; (2) all positions in a highway department, except those of foremen of laborers and laborers, should be occupied by men with varying degrees of engineering training, education, and experience; (3) the personnel and the work of the organization should not be affected by political influence or, from a technical standpoint, by the dictation or influence of a layman or bodies of laymen; (4) the interrelationship of the several units of a highway department should be based upon the axiomatic principles governing the organization of an army, in that there should be a continuation of authority from the most minor position to the administrative, executive, and engineering head of the organization; (5) all positions in a highway department should be filled under civil service regulations, and in order to secure the greatest possible.efficiency and competition for positions, no residence qualifications should apply to any position.

State and County Departments. A state or county highway department should have: (I) control of the construction and maintenance of the highways within its borders which come under its jurisdiction; (2) charge of all surveys, mapping, and design connected with highways and bridges constructed or maintained by the department, and the testing of all materials used on the work of the department; (3) supervision of the super- and substructures of electric and steam railroad companies, telegraph companies, telephone companies, 
water-works companies, and all other public utilities companies, in so far as the control and maintenance of their structures within the limits of highways are concerned; (4) power to formulate the traffic regulations covering the operation of motor-buses, motor-trucks, other types of motor-cars, and all types of horsedrawn vehicles on the public highways.

Inspectors and all engineers having charge of surveys, mapping, design, construction, and maintenance should possess a degree of engineering training, education, and experience, dependent upon the responsibility of the positions which they occupy. As an example of necessary requirements for the higher positions in an organization will be cited the recommendations of Prevost Hubbard and the author while serving as the Advisory Board on Highways to the Department of Efficiency and Economy of the State of New York.

The Commissioner of Highways shall be a civil engineer, who has had responsible charge of the construction and maintenance of highways for at least five years and who is a full member or has fulfilled the requirements for the grade of full member of the American Society of Civil Engineers (a M. Am. Soc. C. E. must be over thirty years of age, have been in active engineering practice for ten years, and have had responsible charge of work for at least five years, and shall be qualified to design as well as to direct engineering works). It was also recommended that under the Commissioner of Highways there shall be three deputy engineers and twelve division engineers, each of whom shall be a civil engineer who has had responsible charge of the construction and maintenance of highways for at least three years and who is or has fulfilled the requirements for the grade of full member in the American Society of Civil Engineers. Each of the deputies shall have charge, under the direction of the Commissioner of Highways, of all work in four divisions. The division engineers shall report in the organization recommended to one of the deputy engineers. In each division there shall be engineers in charge of counties, reporting to a division engineer. Each division engineer shall, in his division, and each county engineer shall, in his county, have charge of 


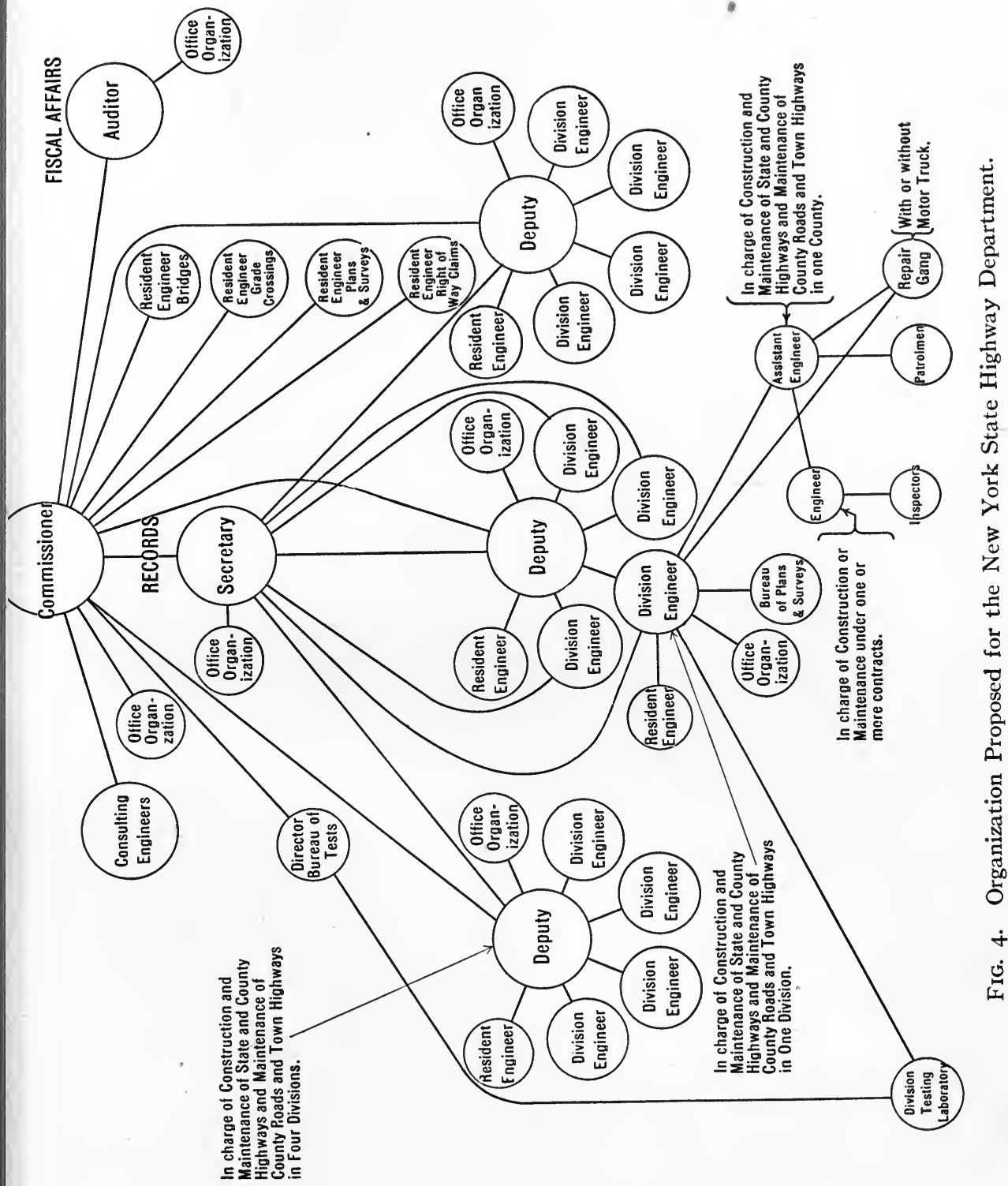




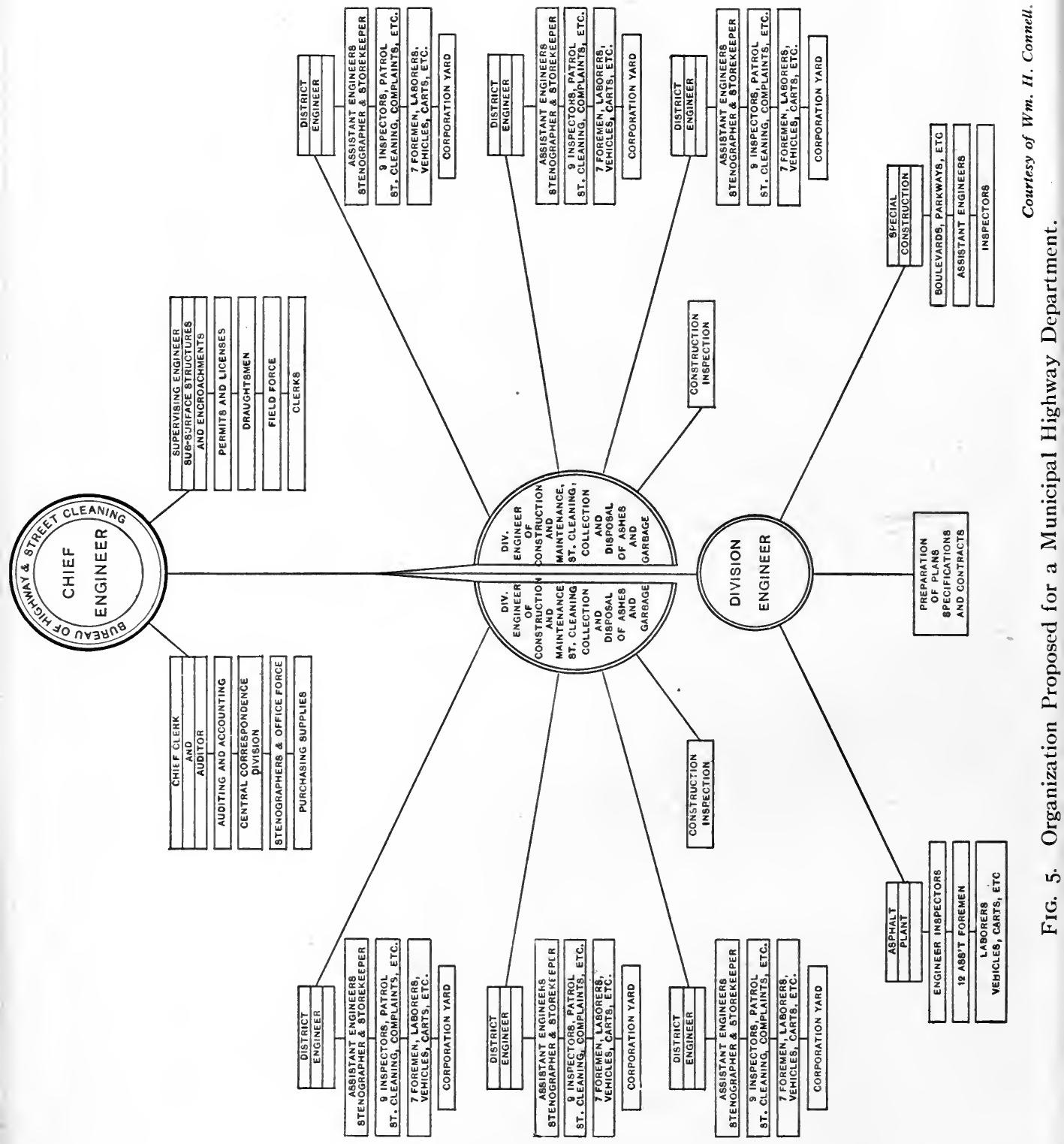


the construction and maintenance of all state and county highways and all state work relating to town highways and bridges. The necessary interrelationship between the several positions in the highway department of a state or county is shown in Fig. 4.

The recommendations were based upon the fundamental principle that those responsible for the expenditure of millions of dollars of the public moneys for the construction and maintenance of highways must have such experience and training as a highway engineer as will ensure that the work, for which each unit of the organization is responsible, shall be accomplished economically and efficiently. Also the recommendations were based on the belief that the desiderata stated above can be best accomplished by continuity of responsibility for a given item of work from the man in personal charge through the county engineer, division engineer, and deputy engineer to the Commissioner of Highways.

Urban District Departments. The fundamental principles underlying a highway organization for a municipality are embodied in Fig. $5^{*}$ and amplified in the following explanatory statement. "The activities coming under the jurisdiction of such a department would be: The design of all work pertaining to the highways, including parkways, park drives, and small highway bridges; all engineering work relative to lines, grades, inspection of construction, etc.; the construction and maintenance of all highways, including street pavements, country roads, parkways, park drives, etc.; the placing of subsurface structures and encroachments, including all underground conduits, pipe lines, service connections, vaults, steps, street signs, stands, etc.; permits and licenses for vehicles of all kinds; street cleaning and snow removal; collection and disposal of ashes; collection and disposal of rubbish; collection and disposal of garbage."*

* William H. Connell, Chief, Bureau of Highways and Street Cleaning of Philadelphia, in the Journal of The Franklin Institute, April, I9I5. 


\section{CHAPTER III}

\section{PRELIMINARY INVESTIGATIONS}

A reconnaissance for a proposed railway includes a careful study of grades, distances, curvature, cost of construction, earning capacity as functions of location. Preliminary investigations in railroad engineering have always been necessary. Such investigations are also of great economic importance in highway engineering. Without having at hand the data secured by preliminary investigations, it is usually impracticable for a highway engineer to design satisfactory and economical highways.

Fundamental Elements. A preliminary investigation should cover the following factors: location, foundation, drainage, æsthetics, width, climatic conditions, traffic census, normal and abnormal speed of various classes of traffic, the nature of horses' shoes and non-skidding devices used, the traffic regulations in force, the probable change in the character and amount of traffic, topographical and geological structure and features, the condition and character of cross-roads, the character of existing surface, the possible diversion of traffic, the months available for construction, local highway materials, the methods of street cleaning and maintenance in vogue, and the character of available plant equipment and labor.

As considerable ambiguity exists in regard to the meaning of the terms highway, road, street, roadway, pavement, crust, and wearing course, the following definitions* are given in order that these terms, as used in this book, may be understood.

"Highway. The entire right of way devoted to public travel, including the sidewalks and other public spaces, if such exist."

"Road. A highway outside of an urban district."

"Street. A highway in an urban district."

"Roadway. That portion of a highway particularly devoted to the use of vehicles."

* 1914 Proceedings, American Society of Civil Engineers, pages 3015 to 3019. 
"Pavement. The wearing course of the roadway or footway, when constructed with a cement or bituminous binder, or composed of blocks or slabs, together with any cushion or 'binder' course."

"Crust. That portion of a macadam or similar roadway above the foundation consisting of the road metal proper with its bonding agent or binder."

"Wearing Course. The course of the crust or pavement exposed to traffic."

Location. Grades, curves, distances, cost of construction, and serviceability to commercial, industrial, agricultural, and social interests are important functions of location. In the case of roads a proper consideration of the above factors requires extended investigations, as it is practicable in many cases to consider several locations, materially reduce grades, eliminate sharp curves, and even select new layouts without entailing excessive property damages. Streets are more definitely located than roads. However, grades should receive careful consideration, as the advantages resulting from grade reductions are in some cases worth many times the property damages incurred.

Foundations. The foundation on which the roadway is to rest is of utmost importance, and hence should receive more than a superficial examination. The failure of many highways has been caused by poor foundations or improper drainage. Experience will have shown what may be expected under certain conditions in localities where highways have been built for a number of years. In new country where no improved highways exist, test pits may be dug at frequent intervals along the proposed location and the material encountered examined. Under certain conditions an old earth road-bed may present a very fair appearance at the time it is observed, but there may be other times of the year when this same piece of road would be nothing more than a veritable mud-hole, seemingly without bottom. A change of line to avoid bad foundations may be very apparent. Much can be learned by careful inquiries.

Drainage. Drainage is so closely allied to foundations that it is rather difficult to discuss one without considering the other. 
Those places where the foundations can be improved by subdrainage should be determined. There will probably be numerous instances where water at the sides of the highway will indicate the presence of ground water in the vicinity which might easily be removed by proper drainage. Much may be learned with regard to the surface drainage also. The engineer

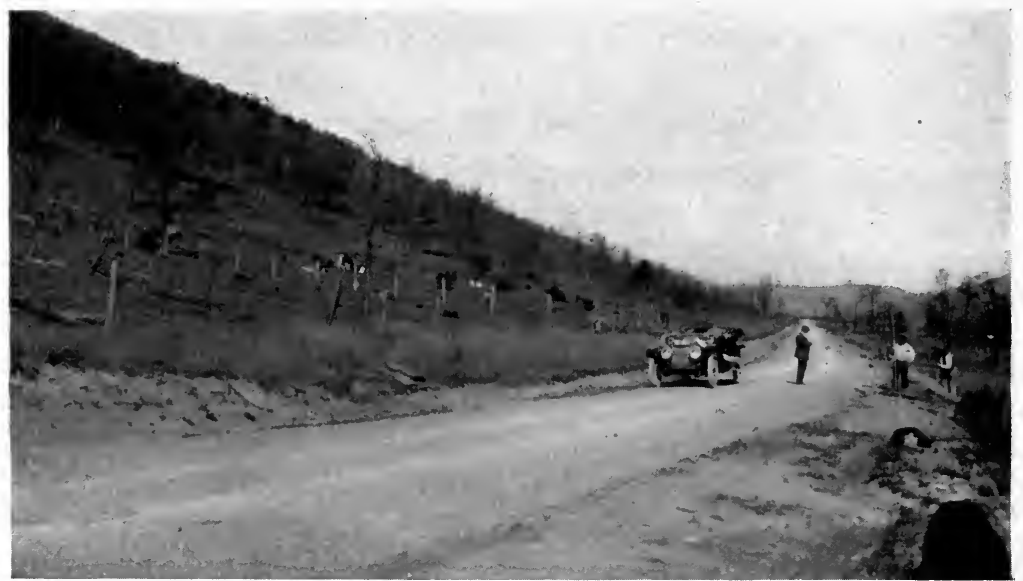

FIG. 6. Clay at Foot of Side Hill. Road Covered with Snow when Survey was Made.

in making his investigation may not be on the highway at a time to note the worst conditions. (See Fig.6.) For instance, water may flow over the street or road at certain points in great storms; there may have been occasions when the middle of the highway has been gullied out by the water to a great depth; some places. that appear to be useless waterways may flow full at certain seasons of the year. Information relative to the above points is extremely helpful in making an intelligent design.

Width. There are many cases where the property has encroached on the lines of the highway to such an extent that if the lines are adhered to only a very narrow carriageway could be built. In some places, where the above conditions are apparent, a study of the deeds and old maps in the recorder's office will be sufficient to determine the correct lines. The 
nature of probable future traffic will largely determine the necessary width of the carriageway. A study of the development of places in the near vicinity, of their relationship with one another, and of their industries will help solve the problem. Had some engineers been far-sighted enough, the narrow streets encountered in our principal cities would never have been built and the costly improvements which are being undertaken at the present time to overcome these "mistakes" would never have been necessary.

Local Materials. It has been said that the ideal engineer is the one who will find one dollar sufficient where the ordinary man would spend two. There is no better opportunity to put this into practice than in highway engineering. A thorough knowledge of the materials available in the locality may suggest some method of construction to be adopted that otherwise would be overlooked. For instance, a locality may be devoid of stone and the cost of importing stone blocks or broken stone may be excessive. There may be certain industries in the near vicinity that accumulate a lot of waste material, such as slag, for example. An investigation of this material might show the practicability of its use in construction. The nature of the soil, the location of gravel-pits, sand-pits, ledges, and quarries will be of great assistance in deciding on the type of construction.

Climatic Conditions. The climatic conditions encountered have to be borne in mind in selecting the type of road or pavement best suited for any particular locality. This is especially true in the case of many of the modern bituminous pavements. A wide range of temperature will necessitate the use of a different bituminous material than where the range is not.so great. The climatic conditions may be such that it will only be practical to carry on the construction in certain months of the year, or it may be possible in some localities to do work throughout the entire year. The snowfall may be so great and the weather so cold that in some sections the highways will be constantly covered with snow during the entire winter season, in which case the cost of maintenance may be materially reduced.

Maintenance. If a road is to be efficiently maintained some 
saving in the first cost might be made. It is unwise, however, to suggest a cheaper form of surfacing. with the expectation of proper maintenance, unless one is thoroughly satisfied that the proper degree of maintenance can be obtained.

Local Environments. The nature of the locality through which the street or road is to pass should be ascertained. For instance, in the vicinity of hospitals or schools it is desirable to have as noiseless and sanitary a pavement as possible. The same quality is appreciated in residential districts. Near docks, on the other hand, the noise feature, although objectionable, is not of so much consequence. The grade of the highway will also influence the selection of the type of surface. On steep grades taking heavily laden vehicles drawn by horses a surface must be furnished which will provide a firm foothold, and at the same time withstand the wear.

Esthetics. In highway designing æsthetics is sadly neglected in this country. We do little to beautify our highways, whereas in some of the European countries the sides of the highway are bordered with beautiful trees and parkings, which not only improve the appearance of the highway, but also make it more comfortable for use. It should be remembered that trees are a valuable asset, and in reconstructing a highway extreme care should be taken not to destroy them. There are places where a slight change of line, grade, or width would preserve trees that otherwise might have to be removed. The purpose for which a highway is to be used should be taken into consideration. For instance, in the case of a proposed park system, an investigation might disclose some very beautiful natural surroundings through which the road should pass. The alignment of the highway in this case should be studied with the idea of changing the natural conditions as little as possible.

The appearance of the finished highway and its relation to the environments should always be kept in mind. Notes should be taken regarding the abutting property and the approaches to the property from the highway. The frontages of many fine country estates along highways have been marred because no attention has been paid to this detail. Within the cities 
the investigation should be made particularly thorough with reference to street intersections. Poorly designed street intersections are an ever present eyesore.

Traffic and Its Classification. One of the most important considerations in a preliminary investigation is that of traffic. The inherent value of statistics relative to traffic on all classes

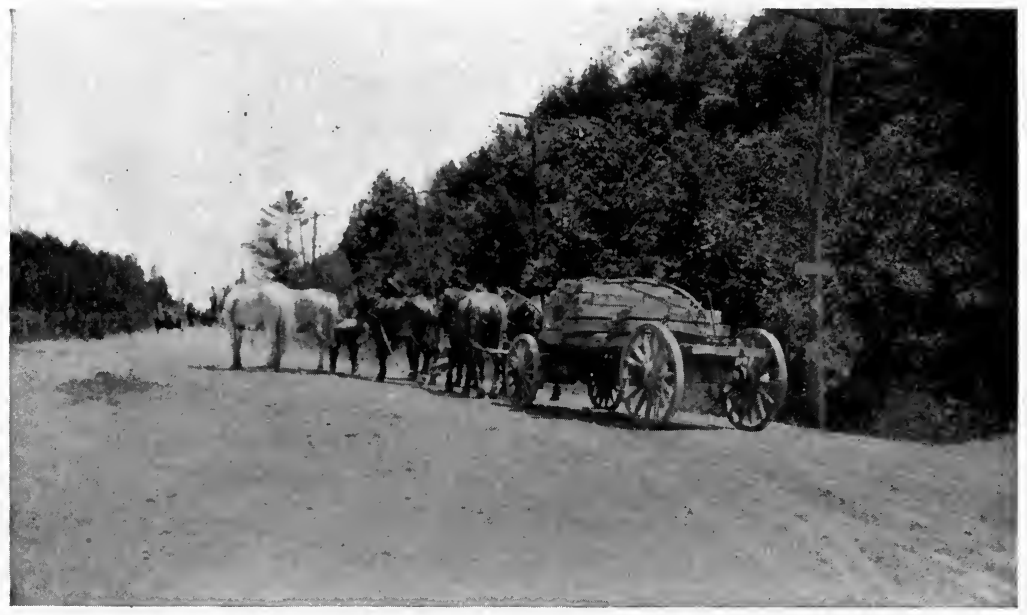

FIG. 7. Heavy Load of Stone on 3-inch Tires.

of highways, obtained previous to construction, is recognized by engineers who are familiar with the problems of modern highway engineering, and who take into careful consideration the economics of construction and maintenance.

Various classifications of the traffic to which the highways are subjected have been proposed from time to time. All classifications have been dependent primarily upon the different effects of various types of traffic upon the several kinds of roads and pavements. Before considering the various groupings of traffic employed and the nature of the information to be ascertained through the medium of a traffic census, the generally recognized effects on roadways of horse-drawn vehicles, touring-cars, motor trucks, motor-buses and traction-engines will be briefly stated. 
Effect of Horse-Drawn Vehicles. The water-bound broken stone road, if built with the proper materials and properly maintained, will successfully withstand the conditions imposed by this class of traffic up to a tonnage life of 100,000 tons per yard of width. In cases where very heavy loads on narrow tires

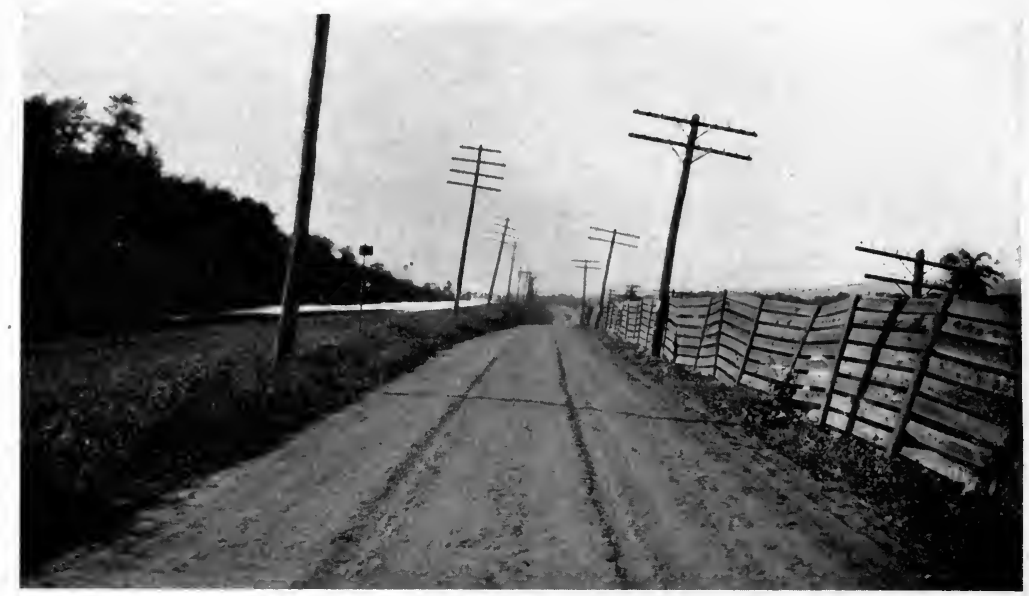

FIG. 8. Ruts Caused by "Tracking."

(see Fig. 7) have been drawn over surfaces in a soft condition the surface has been cut through and totally destroyed. The so-called "horse path" frequently seen on country highways is formed in the center of the road by the horses' feet due to constant tracking. This condition is also due to the use of a soft stone which makes the surface readily susceptible during a dry season to the disintegrating blows of the horses' hoofs. The effect of "tracking" is shown in Figs. 8 and 9.

In connection with certain types of surfaces constructed with bituminous materials the horse-drawn traffic has been noticed to be very destructive. For instance, where the application of a coat of heavy asphaltic oil and stone chips or gravel has been adopted as a method of maintaining the broken stone roads, it has been proved in several instances that it is a failure where it is subjected to a large amount of heavily loaded horse-drawn vehicles. When the traffic is composed largely of horse-drawn 
vehicles, a seal coat of bituminous material has been found necessary to preserve the surface of certain bituminous pavements constructed either by the penetration or mixing method, as the blows of the horses' feet would otherwise dislodge the individual stones of the mosaic surface.

Effect of Touring-Cars. The theory that the destructive force of the motor-car travelling at high speeds is due to the suction developed underneath the tires has never been substantiated. That there is some suction at this point cannot be disputed. The main destructive effect, however, is produced by the driving wheels. This fact was clearly proved by experiments, made by the United States Office of Public Roads, with an automobile of the touring-car type which was driven along a road at varying speeds of from fifteen to seventy miles per hour. Dust raised by the front wheels was of a small and

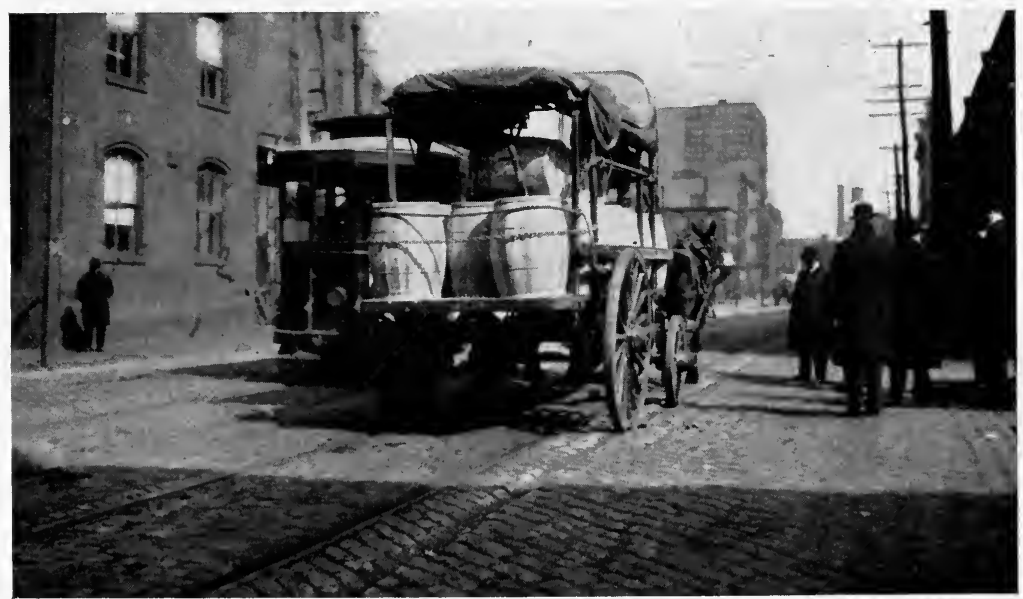

FIG. 9. Wear of Stone Blocks Caused by "Tracking."

practically uniform amount regardless of the speed of the car, while the dust underneath the back wheels increased in a marked degree with the speed.

The destructive agent is a shearing force developed between the wheel and the road. This force is ever present while the car is in motion and increases with the speed and weight. It 
is also known that there is more or less slip to the driving wheels. It has been found that in travelling a certain distance, the rear wheels revolve more times than the front, due to the fact that when the wheels leave the ground in passing over uneven places the engine races. The successive waves across the surface of many water-bound broken stone roads which are subjected to a heavy motor-vehicle traffic are without doubt produced by this constant pounding action. As long as the motor-cars travel in a straight line there is very little side slip unless the road is in a slippery condition. On curves, however, there is a terrific slew of the rear wheels, which is very destructive if the car is travelling at a high speed.

Effect of Motor Trucks. The motor truck is being rapidly adopted by many interests in the United States. (See Fig. Io.) During I9I4 in the State of New York there were over 15,300 motor trucks in operation. This kind of traffic is presenting a very serious problem which must be met in the construction of highways. The trucks are equipped with either a solid smooth tire or a pneumatic tire, a twin tire fitted with rubber blocks or a metal tire. The weights carried vary from 500 pounds to about ${ }_{5}$ tons, making the total weight in the neighborhood of 20 tons for the heaviest trucks, approximately two-thirds of which is carried by the rear axle. The heaviest cars are built to carry their loads at a speed of about fifteen miles per hour. It is apparent that this class of traffic presents conditions which ordinary roadways have not been built to withstand. In order successfully to combat the effect of these heavy loads, more attention must be paid to the construction of the foundations to support the loads, while the surface must be constructed to withstand the grinding action of the wheels.

Motor trucks, as an integral part of a census classification, are also an important factor on account of the relationship of their dimensions to the required width of roadways. According to A. F. Masury, ${ }^{*}$ for trucks of from I to ro tons capacity,

* Chief Engineer, International Motor Company, New York City. 


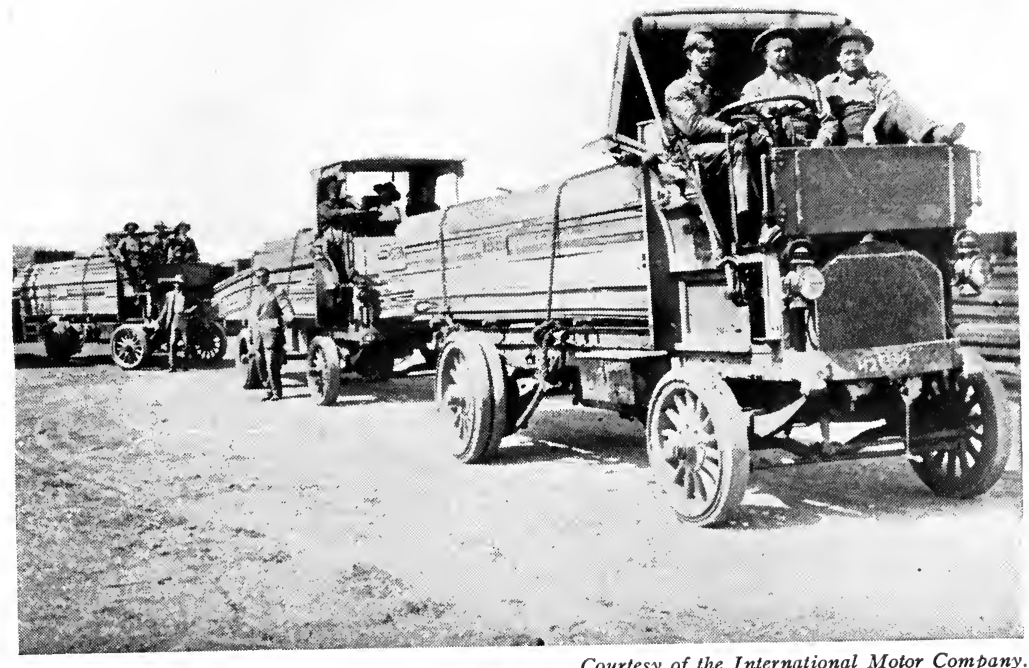

FIG. IO. Commercial Motor Trucks Hauling Lumber.

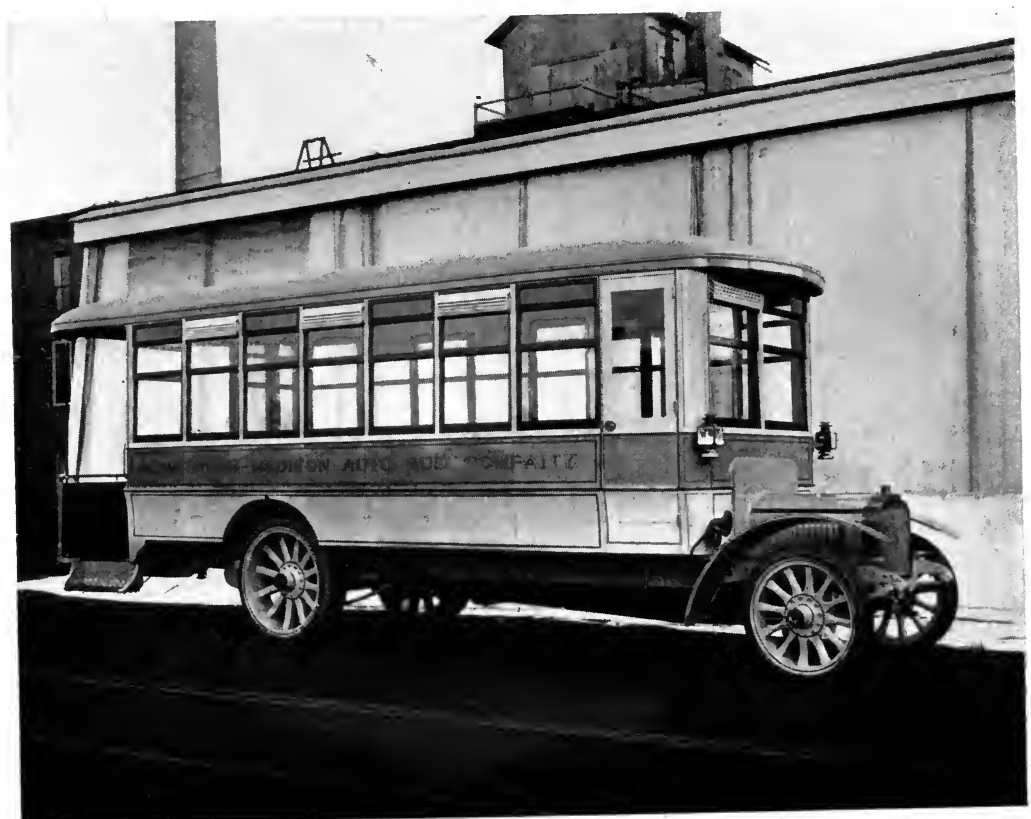

Courtesy of the International Motor Company.

FIG. I I. Closed Motor-Bus. 
the extreme width varies from 68 to 93 inches and the wheel base from $\mathrm{I} 2$ to $\mathrm{I} 6 \mathrm{I} / 2$ feet.

Effect of Motor-Buses. The development of motor-bus traffic in England, France, and Germany has been rapid since I905. In the United States motor-bus traffic had not become an important factor on highways outside of urban districts prior to

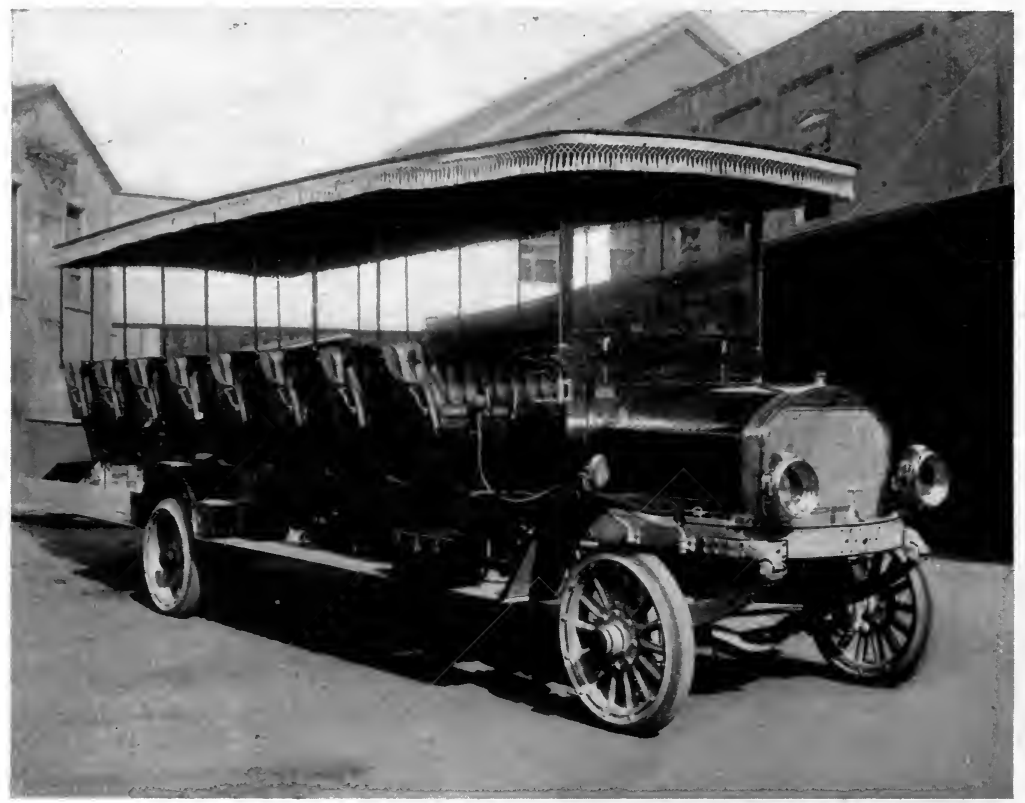

Courtesy of the International Motor Company.

FIG. I2. Open Motor-Bus.

I9I2. The rapid development of motor-bus routes on state and county highways is well illustrated by the status of this type of traffic in the State of New York in I9I4. On the I25 motorbus routes in operation, the motor-buses carried from 5 to 40 passengers, had a rating of horse-power from 20 to 75 , and weighed loaded from $\mathrm{I} / 2$ to 8 tons. (See Figs. I I and I2.) The effect of motor-buses on roadway surfaces is similar to that produced by motor trucks of equal weight travelling at the same speed.

Effect of Traction-Engines. In 1896 a committee of the 
House of Commons of England made a thorough,investigation of the effect of traction-engines on roads in connection with pending regulations governing this class of vehicles. This committee concluded from the evidence which it gathered that, on a highway where either the foundation was bad or the stone was of a poor grade, this kind of traffic caused excessive damage, not only by rutting the road, but also by destroying the shape to such an extent as to require complete reconstruction.

Traction-engine traffic in the United States has caused serious damage to earth, gravel, and broken stone roads, and

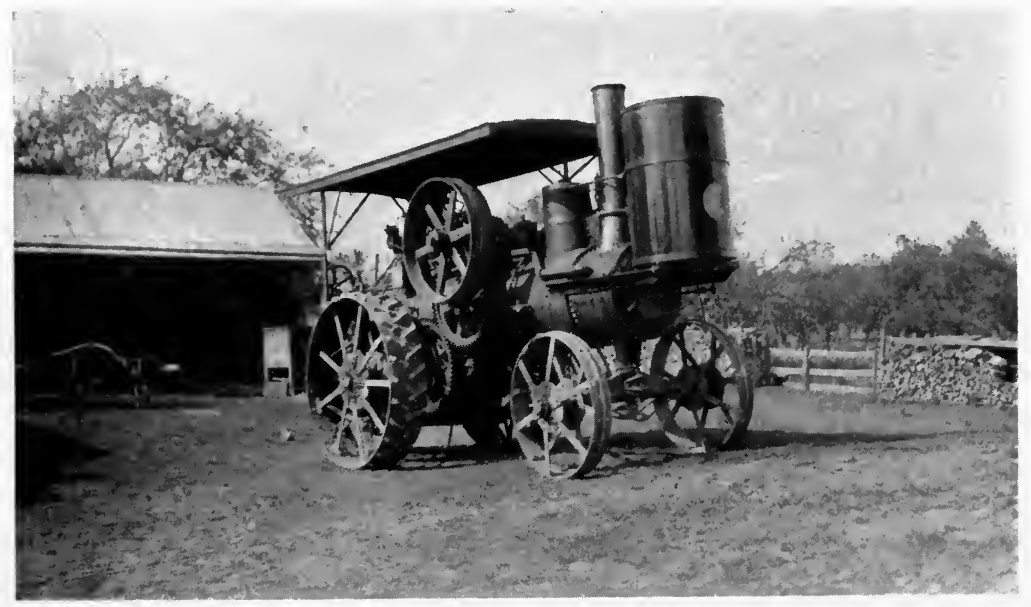

FIG. I3. Traction-Engine.

many types of bituminous surfaces and bituminous pavementsdue to the destructive action of the metal cleats with which the rear wheels of many traction-engines are equipped. (See Fig. I3.)

Loads and Tire Widths. As early as 1823 regulations governing the allowable loads and widths of tires for horse-drawn vehicles were included in the General Turnpike Act of England.

The following regulations relative to traction-engines were prescribed in England in 1896 : the maximum weight of a loaded trailer to be 8 tons, the minimum width of tires in this case to be 8 inches, with an amendment to the effect that a single 
trailer might carry a single piece weighing over 16 tons, provided the width of tires is not less than 8 inches. Tractionengines drawing trailers must have tires which are 2 inches wide for each ton of weight of the traction-engine, unless the diameter of the wheel be over 5 feet, in which case the width of tire may be reduced in such proportions as the diameter is increased. The tires of the driving wheels may be shod with diagonal crossbars or with wooden blocks of certain approved design.

The I904 Motor Car Order of England fixes the limit of weight of a loaded motor-car at 12 tons and a loaded trailer at 8 tons. The width of tire depends upon the size of the wheel and the axle load; for a motor-car the minimum width was fixed at 5 inches and for a trailer at 3 inches. These regulations, however, did not apply to tires which were pneumatic or made of a soft and elastic material. A distinction was also made relative to the speed of the cars depending upon the weight and the kind of tires. A maximum of 8 miles per hour was provided for motor-cars exceeding 3 tons in weight, unladen, or with a registered axle weight laden exceeding 6 tons. The speed was reduced to 5 miles per hour in the case of cars drawing a trailer. The speed was increased to 12 miles an hour for cars equipped with pneumatic or other elastic tires, which did not have the axle weight exceeding 6 tons, and was 8 miles per hour when the axle weight exceeded 6 tons.

In order that vehicles should not damage the roadway, the width of iron tire should be such that the weight per inch of tire width should not exceed 500 pounds for a wheel 2 feet in diameter, with an allowed increase of 30 pounds per inch for each additional 3 inches of diameter.

Some of the heavy loads which have been noted on the streets of New York City are as follows:* Cables weighing 84 tons carried equally on 4 wheels, the truck weight adding 6 tons; girders weighing 65 tons carried mainly on 2 rear wheels of a long truck, the truck weight adding 2 tons for each pair of wheels; an automobile truck carrying ro tons on 4 wheels,

* By Henry B. Seaman, I912 Transactions, American Society of Civil Engineers, pages 321-322. 
the weight of the truck adding 6 tons; a coal truck hauled by 3 horses carrying 7 tons, the truck adding $2 \frac{1}{2}$ tons; trucks which carry the Lidgerwood hoists taking a load of $I_{5}$ tons, the weight of the truck adding 3 tons; the standard truck for general use, hauled by 2 horses, carrying a load of 5 tons and weighing $2 \frac{1}{2}$ tons.

Elements of Classification. The essential elements of any

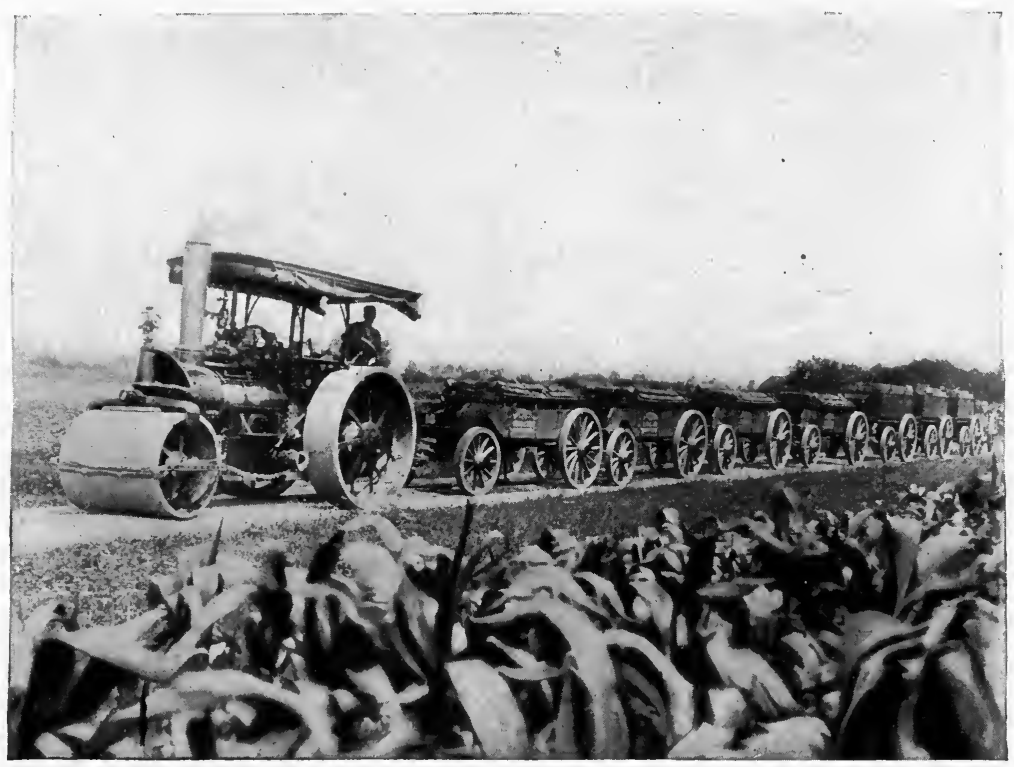

Courtesy of the Buffalo Roller Company.

FIg. 14. An Example of Abnormal Traffic, Roller Drawing Loaded Stone Wagons.

classification of traffic may be stated as follows: (a) differentiation between horse-drawn vehicle traffic and motor-car traffic; (b) a division of each of these classes of traffic into pleasure and commercial traffic; (c) a subdivision of commercial traffic into loaded and unloaded vehicles; $(d)$ the determination of the weight per linear inch of width of tire of all types of commercial traffic, a factor of the utmost importance in the design of the substructure of the $\operatorname{road} ;(e)$ a subdivision of the two classes of horse-drawn vehicle traffic dependent upon the number 
of horses; $(f)$ a subdivision of pleasure motor-car traffic upon the basis of weight and speed, since in many instances the greatest damage to a broken stone road is caused by seven-seat touring-cars, limousines, or landaulets travelling at speeds of 40 to 60 miles per hour; $(\mathrm{g})$ a subdivision of motor truck traffic upon the basis of weight and speed; $(h)$ provision for extraordinary character of local traffic, for example, traction-engines hauling trailers may be common, see Fig. I4, while in other cases motor-bus traffic may be regular and an important feature or special types of commercial traffic such as ice wagons, mill drays, etc., may use the highway.

As an integral part of the requisite investigation preliminary to economical and efficient design, other facts relative to traffic should be obtained, as, for example, the direction of the traffic, the portion of the roadway occupied by various kinds of traffic, the kind of shoes worn by the horses at various seasons of the year, the use of non-skidding devices employed by motorists, and the enforced traffic regulations governing the use of the highway, especially with reference to limitations upon speed and loads to be carried. In connection with the preliminary investigations, an engineer must always consider the change in the character and amount of traffic that is liable to occur after the improvement of a highway. The importance of an estimate of probable traffic cannot be overemphasized.

Methods Used Prior to I9oo. French engineers have for a long time realized the importance of taking a traffic census. A. Moullee states* that "Ten censuses of traffic over the entire country have been undertaken by the Department of Bridges and Roads. The intervals between the taking of these comprehensive data have varied from 5 to 9 years. The first census of national scope was taken in 1844 , although previous to that time traffic data had been collected in certain localities. Traffic censuses of national character will in the future be undertaken every ro years. Previous to the advent of the motor-car the categories of traffic noted underwent little change. Five divi-

* See "Highway Engineering as Presented at the Second International Road Congress, I9ı," by Blanchard and Drowne. 
sions were recognized: first, freight vehicles and those for agricultural purposes when loaded; second, public vehicles for common transport of travellers and luggage; third, empty freight or agricultural carts and private carriages; fourth, unharnessed animals of large size; fifth, light live stock."

The first traffic census in the United States was planned and carried out under the direction of Capt. F. V. Greene in 1885. The traffic was observed on six consecutive days from 7 A.M. to 7 P.M. Night traffic was not counted, and no allowance was made for the same. The classification adopted was as follows:

One-horse carriages, empty or loaded

One-horse wagons, empty or light loaded

One-horse carts, empty less than I ton

One-horse wagons, heavy loaded

One-horse carts, loaded

Two-horse wagons, empty or light loaded

Wagons and trucks drawn by 2 or more horses, heavy loaded

between $\mathrm{I}$ and 3 tons

over 3 tons

There were several censi made in the United States and Canada based on this method. It is self-evident that the above classification is not complete enough to cover modern conditions.

Methods Used Since Igoo. Since the advent of the motorcar, traffic classifications have undergone a transformation. The most comprehensive is that proposed by the Road Board of England. The classification includes the following list of vehicles:

Tramcars (Electric, Steam, or Horse).

Motor Vehicles:

Ordinary Motor-cars (including cabs).

Motor Omnibuses.

Motor Delivery Vans.

Heavy Motor Lorries.

Tractors or Traction-Engines (Trailers are to be counted as additional vehicles, i.e., a traction-engine with two trailers would be entered as 3).

Motor Bicycles and Tricycles.

Any other Motor Vehicles not included under any of the above heads.

Horse-Drawn Vehicles:

Omnibus (including Public Service and Hotel).

Two-wheeled Vehicles (cne horse).

Two-wheeled Vehicles (two horses, or more).

Four-wheeled Vehicles (one horse).

Four-wheeled Vehicles (two horses, or more). 
Other Traffic:

Ordinary Bicycles and Tricycles.

Herds of Cattle (if more than five in number) to be entered as one.

Flock of Sheep and Pigs (if more than five in number) to be entered as one.

Horses (led or ridden).

The following classification recommended by the Special Committee of the American Society of Civil Engineers on "Materials for Road Construction" is typical of American practice.

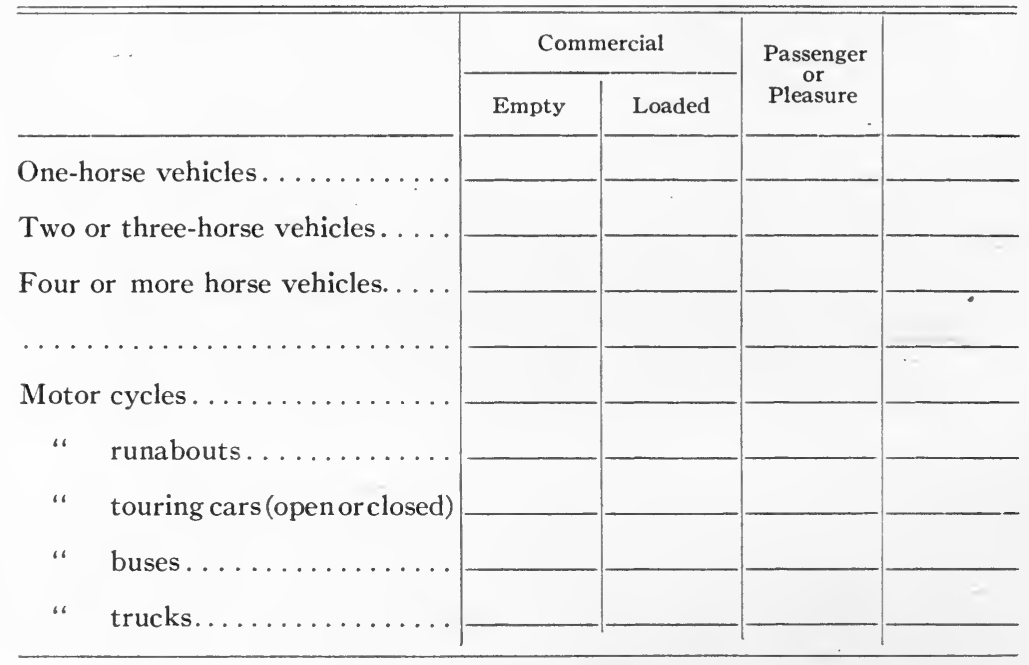

Methods of Taking Traffic Censi. After the classification of the traffic has been adopted, the methods of securing traffic data must be considered. The method selected will be influenced by the amount of time at the disposal of the engineer and the character, amount, and distribution of the traffic to which the highway in question is subjected. In case the location of the highway to be built in a given period is known over a year in advance of construction, a comprehensive plan covering observations throughout the year should be adopted in order to secure complete information. In many instances, however, perhaps only a month will be available in which to make investigations preliminary to design. In either case, it is essential that as complete information as possible should be secured 
relative to the nature of the traffic on any given highway before a plan is adopted.

As the primary object of any traffic census is to secure data covering both normal and abnormal traffic of all classes, it is essential to incorporate in a plan definite provision for securing the above information rather than to depend upon a haphazard selection of days to furnish the facts. As an illustration of varying local conditions may be cited: exceptional horse-drawn vehicle traffic, consisting of produce wagons, between the hours of midnight and 6 A.M. during certain seasons of the year; market days, fair days, and other special events in connection with which both pleasure and commercial traffic may be excessive; periodical heavy shipments by special industries using the highway in hauling raw material or in shipping the manufactured article; through traffic at certain periods of the day, week, or year as, for example, motor-car traffic between residential communities or summer colonies and cities. In many cases it is essential to obtain the following: normal winter traffic, normal summer traffic, and abnormal summer motor-car traffic. It should be borne in mind that from the standpoint of the proper design of the highway, it is necessary to know approximately the total yearly traffic, which is a function of both the normal and abnormal traffic, and also the amount of abnormal traffic of various types at different periods of the year.

Three comprehensive plans for taking traffic census throughout the year have been used: First, to take the traffic in periods of 6 or 7 consecutive days; second, to distribute the recording days throughout a given season by starting on a given day of the week, for example, a Monday, then take the traffic on the Tuesday of the following week or at an interval of ${ }_{5}$ days, and so on during the season; third, for the season from April to October inclusive the traffic could be taken during four periods of 3 days each; one period being in April, May, or June, one in July, one in August, and one in September or October. As local conditions may dictate, either Friday, Saturday, and Sunday or Saturday, Sunday, and Monday could be 
taken, thus ensuring information relative to the usual abnormal Sunday motor-car traffic, while the Friday or Monday traffic would give a fair indication of the normal week-day traffic. In the months from November to March inclusive, two 3-day periods would be taken in certain cases; one in November or December, the other in February or March. This distribution of the periods would furnish statistics of the normal traffic in this season, and would also afford opportunity for a study of traffic detail and the condition of the highway during the winter season.

The number of consecutive hours which should be taken during the day will depend upon local conditions and the period of the year when observations are made. In many cases, especially in municipalities, 24 hours will be absolutely necessary, while in certain cases 8 or I $_{5}$ hours will be satisfactory. It must be borne in mind that the facts ascertained are used as a basis for an estimate of traffic and hence minute detail should not be obtained at unwarranted expense.

What has previously been said in regard to taking traffic outside of cities applies to a method that may be adopted for this purpose within the cities. The method to be adopted in any case, however, will vary, depending upon local conditions. An investigation of the business interests situated on the street, the merchandise which is handled, and the general routes taken by traffic from the railroad centers or docks must be made before it is possible to decide on an intelligent plan for taking the census. In residential districts the problem is more simple and the method used would probably be very similar to that proposed for highways outside of built-up districts.

Traffic Regulations. The existing traffic regulations and their enforcement should be carefully looked into, as, for example, the allowable loads and the prescribed width of tires; whether or not vehicles or tractors with extremely wide tires are required to keep to one side of the center of the road; the speed of motor vehicles, etc.

Diversion of Traffic. The construction of roads and streets often necessitates the diversion of traffic during the period while 
work is being done. In the business districts, it is "possible to close off one or two blocks or to build half the width at a time without inconveniencing the public to any great extent. On roads it is not such an easy matter to provide means for traffic to pass around the work, and if it cannot be accomplished it may preclude the use of some method that would otherwise be used. 


\section{CHAPTER IV \\ SURVEYING, MAPPING AND DESIGN}

\section{SURVEYS FOR ROADS}

General Scope of the Work. Methods of making surveys for highways outside of urban districts vary in detail, depending upon the proposed location of the highway. If the highway is to be located upon land not previously used for such purposes, the survey partakes of the nature of a railroad reconnoissance. If the highway follows approximately the lines of an existing highway, the work of location surveys is materially simplified.

Before a survey is undertaken, the preliminary location should be outlined in accordance with the principles mentioned later under Design. With this information at hand, the chief of the survey party should familiarize himself with existing maps of the locality through which the highway will pass. The United States Geological Survey, in conjunction with several States, has prepared topographical maps that give the contours and location of highways. In many States local maps are available which give topographic details. If a map cannot be obtained and the highway is to be laid out in a new location, a thorough reconnoissance of the locality should first be made as in railroad work, and then one or more survey lines, the number depending upon the unevenness of the country and right of way problems, must be run before the best route can be determined upon.

Unfortunately, surveys for this class of highways are not usually tied in with any system of points previously established by triangulation or by closed traverses. A survey on one road may be made entirely independent of that on another road, since the roads are usually so widely separated that there is 
no important relation between the two. Adjoining surveys on the same road should be connected with each other, but it is not essential that the stationing should be continuous. A map showing the plan of the road system might be prepared in the course of time by combining the connected surveys.

A complete survey includes a transit line and topographic detail, a profile and cross-sections.

The Transit Line. The transit line may or may not coincide with the proposed center line of the new road.

In some instances the transit line may only serve as a reference line on which the rest of the location is based, and as a working line from which the proposed work can be staked out. From the standpoint of convenience this method has several advantages. The traffic conditions may be such that the work will be constantly interrupted unless the line is run along one side of the highway, rather than near the center. In some cases where a car track is located in the road, the transit line may be made to coincide with the line of one of the rails.

The surrounding topographical conditions will govern the advisability of trying to obtain a field location of a center line that will be the best one from every standpoint. In many cases too much time is spent in the field to accomplish this result. If the country is generally flat, and if proper cross-section levels are taken, it will be possible by studying the plans alone to determine upon a final center line which in places might be several feet either side of the transit line, without involving any appreciable error in the stationing; on the other hand, if the country is rough, a change of line from the transit line made in the office will probably necessitate another survey.

Stationing and Referencing. The transit line should start from an initial point which may be a point on some previous transit line or some assumed point carefully tied in with permanent objects. The line is made up of tangents and curves. When the external angle between the tangents is less than ro degrees, the stationing may be measured around the tangents without appreciable error, although a curve may be built at the intersection; when the external angle between the tangents is 
over to degrees, it will be necessary to figure a curve in order to obtain the correct stationing. The line is stationed every 50 or too feet, depending upon the character of the topography and the accuracy desired for the estimate of grading. Points established on the line are liable to be removed or covered up during the construction, hence it is important that the points at the intersections of the tangents should be carefully tied in to objects that are permanent and readily accessible.

Running the Line. There are several methods of running the transit line and of locating topography with reference to it. Only one method will be described which, if used, will give results within the limits of accuracy necessary, and will also be found expeditious. First, carefully plan out the location of the tangents and intersection points. The transit should be set up at the intersections of the tangents from which points the tangents can be run out in both directions. The angle between the tangents should be turned off at least twice and the mean value taken. The magnetic bearings of the tangents should also be taken as a check. The length of each tangent is determined with the steel tape, the measurements being made to the nearest hundredth of a foot. If the angle at the intersection is large enough to warrant the use of a curve, the stations of the point of curve (P. C.) and the point of tangency (P. T.) of the proper curve are figured and marked on the line.

Taking Topography. The topography includes the shape of the land and all the objects such as houses, walls, fences, gutters, curbs, culverts, bridges, catch-basins, trees, monuments, edges of travelled way, poles, ditches, etc., in fact, any object that occurs within the limits of the survey that would be of importance in designing the road.

All topography is located with reference to the tangents. In locating the topography, such as fences, walls, and curbs, it is sufficient to record the stations on the transit line opposite which they begin and end, and the stations at intermediate points which will define their alignment. The offsets are the perpendicular distances measured from these stations on the transit line to the points of the object previously noted. The 


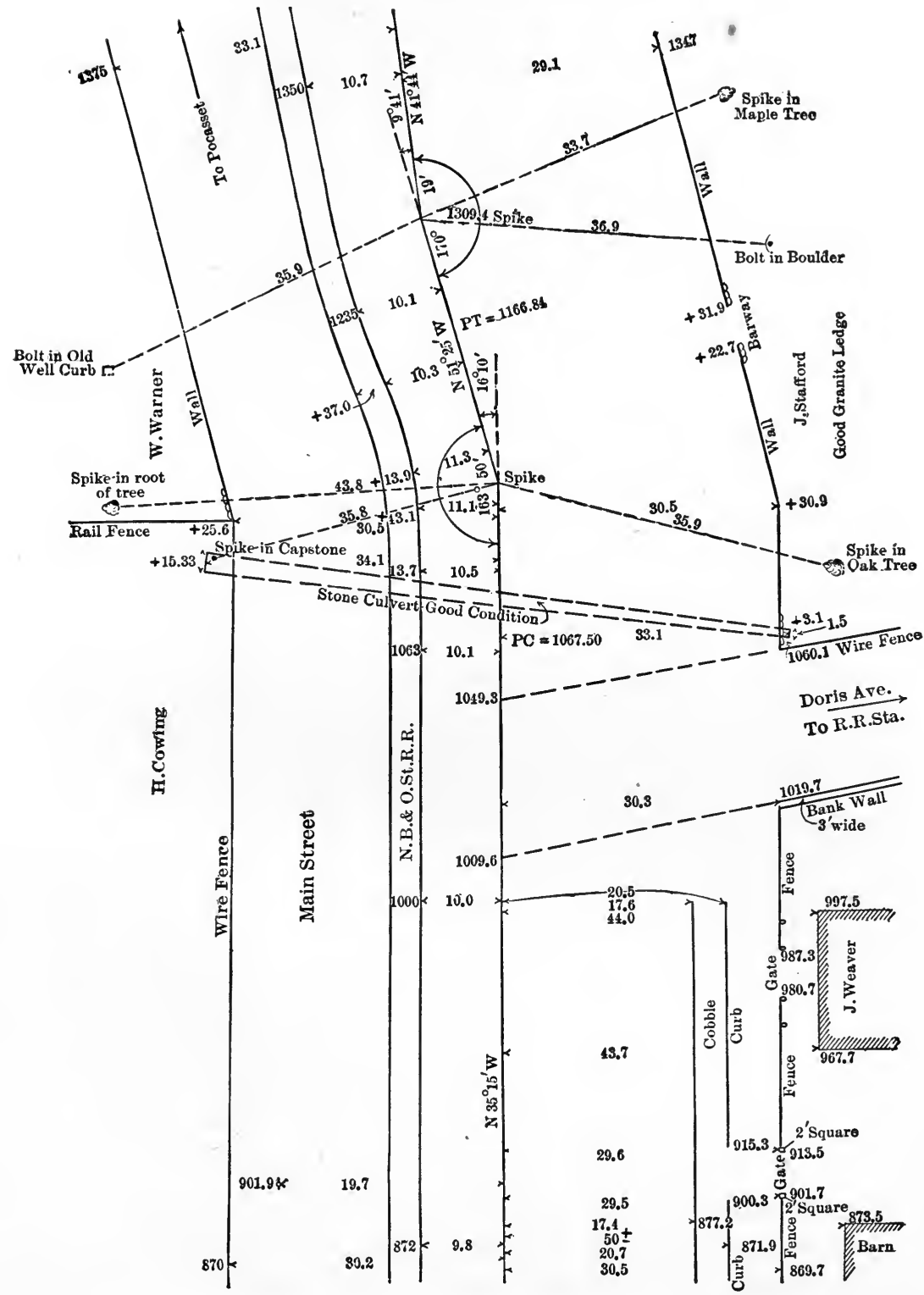

FIG. 15. Sample Page of Transit Notes. 
perpendicular direction will be determined by eye, and if the object is not at too great a distance away the results obtained are sufficiently accurate. Offsets and plus distances for location should never be measured closer than the nearest tenth, and in many instances where the topography is not at all well defined the nearest foot will be sufficient. When the P. C. is reached, the location of the topography should be made from the tangents. The distance along the tangent can be recorded as a plus distance from the P. C. to the intersection. Starting again at the intersection, a plus distance from the latter can be employed until the $\mathrm{P}$. T. is reached beyond which the regular line stationing is again used.

In places of importance, such as squares and villages, where the location by these methods might be somewhat difficult, the topography can be readily obtained by taking angles and distances to the various points or by means of the stadia. The last method will often be found very convenient in locating objects some distance away from the transit line. A sample page of transit notes is shown in Fig. I5, in which many of the points above mentioned are illustrated.

LEVELS. The information required to locate all topography includes what are commonly called "cross-section levels." From the information thus obtained both the profile of the transit line and the shape of the earth's surface at known intervals along the transit line can be plotted.

Bench-Marks. In many States lines of levels have been run starting from a government bench, and bench-marks have been established on these lines at various points so that it is not a difficult matter to get a tide water datum for the levels on any road. If this has not been done, the datum may be assumed. Points for bench-marks should be of a stable and permanent character, and their location should be clearly described so that they may readily be found at any time. At least one permanent bench-mark should be established every I,000 feet along the survey.

Running the Levels. The levels may be taken either with a transit or with a level. The transit, if in adjustment and 
carefully used, is sufficiently accurate for the work, but, of course, it would not be used in establishing a long line of benchlevels. When the rod is held on a bench-mark (B. M.) or a turning point (T. P.), the target should be set as a check and the rod read to the nearest hundredth. In obtaining the elevations of the earth's surface, it is not necessary to use the target nor to read the rod closer than the nearest tenth. The measurements of the plus stations and offsets to points at which levels are taken may be made by means of the metallic tape.

Enough points should be taken to show correctly the configuration of the earth's surface. This may be accomplished by taking elevations at each 50 - or roo-foot station along the transit line, one elevation being taken on the transit.line and sufficient elevations being taken on a line perpendicular to the transit line at these stations to define the changes in slope of the earth's surface. The elevations of car tracks, curbs, gutters, edge of travelled way, bottoms and tops of banks, together with their distances out from the transit line, should be taken in all cases. Care should be taken to extend the levels out far enough on both sides of the transit line sufficiently to cover the proposed construction. Center line profiles should be run along every intersecting street and driveway for a distance of at least 200 to 300 feet from the transit line. Elevations should be taken at the corners of houses, at the ground lines and at the sills where there is any possibility of the improvement disturbing the property. The elevations of the tops and bottoms of all culverts and drains at both ends should be determined. In the case of bridges, elevations should be taken of bridge seats, bridge floors, tops of parapet walls, high water marks, points that will define the stream bed at the bridge and points along the banks of the stream above and below the bridge.

Some engineers prefer, in obtaining cross-section levels, to run a line of profile levels with the instrument on the transit line, and to work up the cross-section levels by means of a hand level.

Staking Grades. Two methods of staking grades are in common use. One method is to drive stakes at the time the 
survey is made. The ground elevations at the stakes and elevations on tops of the stakes are taken. The stakes are driven on each side of the transit line far enough away so that they will not be disturbed during construction. Along tangents the stakes are placed at intervals of either 50 or roo feet. On curves they may be spaced as close as 25 feet, depending upon the length and nature of the curve. When the grade of the road has been established, the grade elevations at the stations where the stakes are driven can be determined in the office. The difference in height between the established grade and the tops of the stakes is recorded on a sheet, which is sent to the inspector on the work, who is thus able to define the grade. In the other method, stakes are not driven until after the grade has been determined in the office. The stakes are then driven as before and notches are cut on the stakes at grade or some even foot above or below grade.

Setring Slope Stakes. Slope stakes, defining the ends of the slopes, should be set where the cuts or fills are heavy. The position of slope stakes can be most easily determined by measuring the distances on the plotted cross-sections from the finished line to the edge of the slope. These same distances can then be laid off in the field at their respective stations. If the work is through a rough country, and no cross-sections had been plotted, the slope stakes would be set by instruments in the field as in railroad work.

Final Surveys. In some cases it is essential to make a survey of the work after completion before making the final payment for the roadway, grading, fencing, culverts, etc. The methods of making such a survey are the same as those described. The information desired is similar in character to that obtained on the first survey except that it refers to the finished work.

\section{Mapping Road Surveys}

The Plan. The survey plan may be plotted on a continuous roll of detail paper in one-mile lengths or on standard size sheets. The transit line is first laid out on the sheet. This 
may be plotted by several methods. One is to compute the coördinates of the several intersecting points of the tangents with reference to one of the tangents as a base line. (See Fig. I6.) The plotting should be carefully done, and as a check the angles between the tangents should be read with a protractor and the length of the tangent should be measured between the points as obtained by the coördinates. Another method which is quite sim-

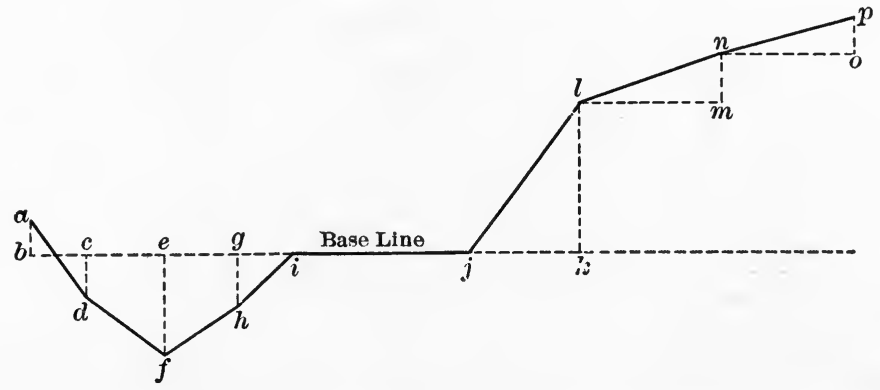

FIG. I6. Coördinate Method of Plotting Transit Line.

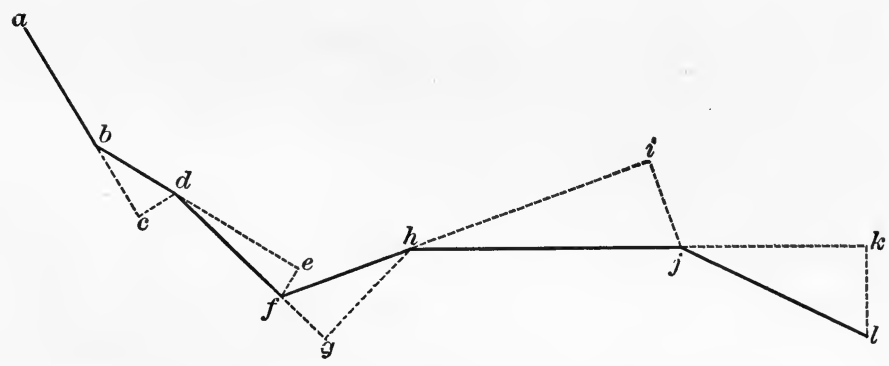

FIG. 17. Tangent Method of Plotting Transit Line.

ilar, fully as accurate, and more rapid, since it eliminates the necessity of drawing a rectangular system of coördinates, is the so-called tangent method in which the lines are run out and the tangential offsets plotted (se̊e Fig. I7). In this case the prolongation of each tangent serves as a base from which the tangential offset is plotted to obtain the next intersection. A very common method is to plot the line by means of a protractor and scale. It is impossible to plot the line accurately by this 
method. When the line has been correctly laia out, the curves should be drawn in and the stations should then be marked off on the line and the survey plotted from the notes. Conventional signs can be adopted for the detailed topography.

The Profile. The profile may be plotted below the plan at the bottom of the sheet. The ground line of the profile should represent the profile of the original surface on the proposed center line of road. If the transit line corresponds with the proposed center line, the elevations taken on the transit line will be the ones used; otherwise, the center line elevations will have to be obtained from the cross-sections. Culverts, bridge openings, elevations of car rails adjacent to the improved surface, manholes, curbs, corner boards of houses, etc., should also be plotted on the profile, so that, when the grade is determined, all the necessary information will be at hand. Sometimes the profile is plotted on translucent profile paper such as is used in railroad work. Time will be saved if this is done, since it will not be necessary to draw a base line and erect verticals from it.

The Cross-Sections. The cross-sections should be plotted either on cross-section or profile paper. The scale used should be as much as $1 / 4$-inch to the foot, since the estimate of cut and fill is made from these cross-sections, and the use of a large scale makes practicable the satisfactory determination of areas.

In some States, where the engineering force is large and the drawings are made at a central office, it is essential for each engineer in charge to have a copy of the plans. This is most readily accomplished by making blue-prints of the original drawings.

\section{Surveys for City Streets}

General Scope of the Work. As streets are closely related to each other and the property bounded by streets is valuable, any inaccuracies in surveys may mean extensive and troublesome litigation. In order to study the situation intelligently and to draw up a plan for a street system, it is necessary to make a topographical survey of the area, which will include 
all existing streets, monuments, property lines, waterways, contours, etc. The extreme accuracy required makes it necessary to use methods differing materially from those which are adaptable for roads. Transits which are graduated much finer than those used in road surveying must be used in running the traverses in this class of work. A transit with a limb divided to read at least 30 seconds and preferably 20 or 10 seconds will give the best results. The tapes used should be standardized by comparison with the standards at Washington or elsewhere.

The Traverse. It is first necessary to project lines over the area from which the existing topography can be taken. One method of doing this is by means of closed traverses. Secondary traverses are run with any of the sides of the first traverse as a base. A third system of traverses might be run from the second, and so on until sufficient lines were obtained to fully cover the area. This method involves some inaccuracies, however, since in balancing the traverses a local error is distributed throughout the entire traverse.

The following method is more accurate. The United States Coast and Geodetic Survey has made triangulation surveys of many of the States of this country. Enough points on the system may generally be found within the city limits to furnish a triangulation system on which the rest of the work can be based. The triangulation work should be done with the utmost refinement and the points established should be permanently monumented. Points on the triangulation system can then be connected by traverse lines, and the accuracy of each traverse definitely determined by calculation. The detailed topography is filled in from these traverse lines which should be chosen so as to facilitate this part of the work.

LEVELS. Bench-marks should be established by running closed circuits of precise levels. The level datum generally taken is mean low tide.

Monumenting the Lines. The topographical survey when completed is mapped. With the aid of these maps a design of the street system can be made. The location of the monuments can then be computed and their position established 
in the field. Monuments of a permanent character should be set in the sidewalk at a certain distance out from the property line, so that they will always be intervisible and readily accessible.

SURVEY FOR Grading. When a street has once been correctly monumented a detailed survey of the street can be made previous to the proposed improvement. The transit line can be referenced in with the existing monuments. Houses and other topography should be located by some accurate method, such as by angles and distances. The cross-section levels can be taken by the same general methods as outlined in road surveying, except more accurate work is required. The center line grade is staked in the same manner as previously described.

Staking Curbs and Grades. There are two methods that are commonly used in staking out curbs. In one the stakes are driven to one side on an offset defining the line of the curb, and the tops of the stakes are made to conform to the grade of the curb. In the other method the stakes are driven on a line as before with their tops flush with the ground and a sheet of instructions is furnished which gives the distance above or below the top of the stake to the grade of the curb. Curbs and gutters are usually constructed in advance of the street pavement. The crown and grade of the pavement may be regulated by setting lines of stakes transversely to the street at intervals sufficiently close to define the desired shape of the surface. In the case of wide streets; street intersections, and public squares, it is advisable to use this method. On the narrow streets, however, the engineer may be furnished with a grade sheet, based on the elevations of the tops of curbs, showing the relative elevations of all controlling points along and across the roadway.

\section{Mapping Street Surveys}

Topographical Map. The topogiaphical survey of the city should be plotted by the system of rectangular coördinates. On this plan should be shown all of the triangulation points, traverse points, as well as all the topography. Such a map might be made to a scale of 200 feet to the inch. With this 
scale it is possible to represent a large area on a sheet of practicable size and have the topography in sufficient detail so that an intelligent study of the street plan as a whole can be made. Sectional plans can be made of any portion of this map to as large a scale as is desired when working out the details of any particular locality. If plane tables are used on the survey, the topography may be plotted in the field. In such a case a scale as large as 50 feet to the inch should be used. The plans, profiles, and cross-sections of the individual streets are plotted in a manner similar to that described for roads.

\section{Design}

Development of Highway Systems. The several classes of highway systems may be designated as follows: national, state, county, town, city, park, and estate. National, county, and town highway systems are governed by the same general principles as those of states, and estate highway systems are very similar to those of parks, hence a consideration of state, city, and park systems will cover all cases.

State Highway Systems. Many of the States in this country lack a broad, comprehensive, and connected system of highways due to several reasons. Some States which construct roads under a state-aid plan are handicapped by the fact that any town or county, which is able to subscribe its share of the money, can demand state aid for the construction of any piece of road within its borders, regardless of its location. The result of this form of legislation is the construction of innumerable short sections of road throughout the State. These roads, in many cases, are only of local benefit, sometimes even restricted to the propert.y owners residing adjacent to them. There are some States, on the other hand, that have adopted a connected system of roads which, when built, will make all parts of the State and its large centers readily accessible.

The design of a system of state trunk highways is simplified if a comprehensive topographical map of the State is at hand, such as is made by the United States Coast and Geodetic Survey. If such maps are not obtainable, a map showing sim- 
ply the roads in plan can be used, but with the latter the study cannot be made in as satisfactory a manner except by doing a large amount of reconnoissance work. The interstate and intrastate trunk lines, the interurban trunk lines, and popular routes of travel should first be laid out. Information should be obtained from the officials in the adjoining States, relative to the main roads in those States, so that the systems in the two States may be connected. The intrastate highways can next be added to the system. These highways pass through towns and connect towns situated within a few miles of each other. Finally, to the system of trunk highways, there should be added the feeders which will develop the commercial, industrial, and agricultural resources of every part of the State. Before deciding to include any section of road in the system, a general idea should be obtained as to the practicability of its construction at a reasonable cost, and it should be ascertained if the road is the best one to be built from the standpoint of the welfare and development of the communities through which it passes.

City Highway Systems. The streets in the older portions of many large cities have practically the same lines to-day as in the first years of the cities' development. As the cities grew, the need for some systematic plan of street development was realized. The result is that in the older portions of some cities the streets will be found to be tortuous and narrow, while in the more recently developed portions the evidence of a systematic plan is apparent.

A street plan is not well designed unless the plan is made to fit the topography and unless proper care is taken of the drainage. Topographical conditions will sometimes preclude the use of a uniform rectangular system if easy grades are to be obtained. The history of the growth and development of large cities should be carefully studied, since it is only from these examples that we can predict what future conditions may impose. A suburb at the present time may in a few years become an important part of the city, and the street plan should be designed on such comprehensive lines that provision is made for growth. 
The Rectangular Plan. The rectangular block system, of which New York City is a good example, has been used in many cities where topographical conditions would permit. (See

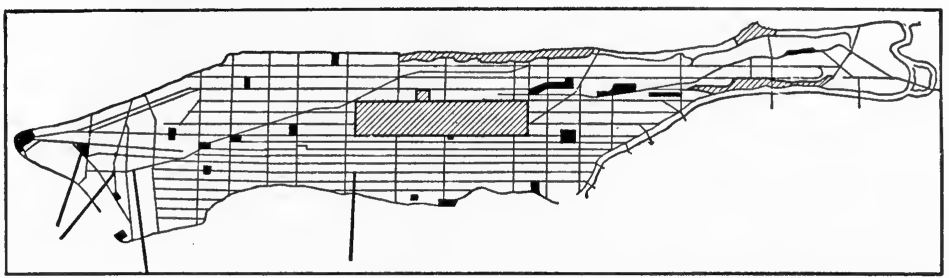

Courtesy of Mr. Nelson P. Lewis.

FIG. I8. Street Plan of New York City.

Fig. 18.) Such a system, however, if entirely devoid of diagonal streets cutting across the rectangular plan, does not accommodate the traffic to the best advantage and renders very little opportunity to improve the appearance of a city. Diagonal

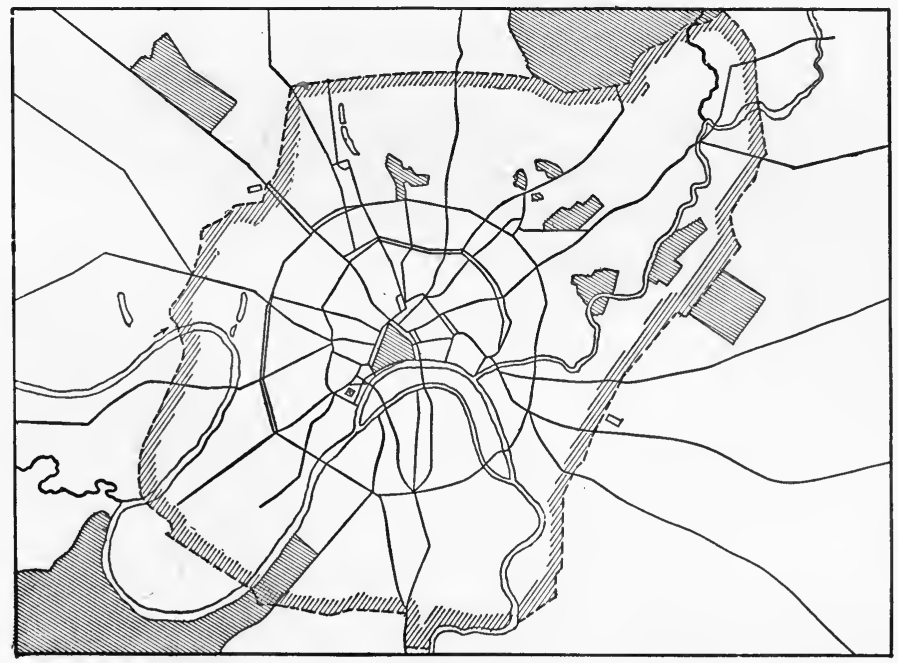

Courtesy of Mr. Nelson P. Lewis.

Fig. I9. Street Plan of Moscow.

streets radiating from the city center to large public squares, and from thence to the outskirts, enable the traffic to move from one part of the city to another with the greatest despatch, 
and tend to relieve the congestion of traffic that might otherwise occur. The squares and centers afford a location for the erection of beautiful public buildings, the diagonal streets leading into the square making a fitting approach to such structures.

The Circumferential Plan. The systems of many European cities, which are pointed to as examples of comprehensive street plans, besides having a rectangular plan intercepted by diagonal streets, have so-called circumferential streets which roughly encircle the city. This is well illustrated by the street plans of such cities as Berlin, Vienna, Paris, and Moscow. (See Fig. I9.)

Park Highway Systems. An ideal park system for any city or community would be one in which all of the spaces reserved for parks are connected with scenic boulevards. In this country the great benefit which may be derived from parks does not seem to have been appreciated until recently. Now, however, many of the States and cities are striving to take advantage of their present opportunities in this direction. Many of the parks will be found on the outskirts of the larger cities, since places which still retain their natural beauty can only be acquired in such localities. To accommodate different sections of the city and to allow for future growth, several such parks should be developed, or at least the reservation of land should be made for this purpose. The different parks may be connected by boulevards and drives, which, if designed in the proper manner and with proper æsthetic effect, become a part of the parks themselves.

The design of the highways of the system is not difficult. Distance, alignment, and grade are not of so much importance as in the case of a highway taking both a pleasure and a commercial traffic. Particular emphasis should be given to the æsthetic possibilities of the highways. This may sometimes involve entirely new layouts, such as roads along the banks of a river, the seashore, or across some area the natural environment of which is especially beautiful.

Scope of Highway Design. A complete design of a given highway comprises the consideration of the following factors: relation to the highway system, location, width, grade, align- 
ment, drainage, foundation, crown, type of surface, and estimate of cost.

Location. The most economical and suitable location of a highway should be considered before it is improved. At this period in the development of a highway no expensive improvements, such as grading, drainage, foundations, pavement, and bridges stand as obstacles to the proposed change of a poor location and, furthermore, a suitable width and right of way on a relocation may be secured at the minimum expense. Methods of securing rights of way vary in the several States, dependent upon their statutes. Some States have laws which permit highways to be located and constructed before landowners are paid for the rights of way. If dissatisfied with the final award of the highway authorities, the owners may appeal to the proper court. This procedure is based on the principle that the expeditious construction of a highway in a desirable location is advantageous to the people as a whole. As a general proposition, the land is acquired economically under this method. In those States where rights of way must be paid for before the highway is constructed, the prices demanded by owners are in many cases exorbitant, and, in addition, the overhead charges are frequently very large as expensive legal and engineering work is often required before adjustments are completed.

In connection with the location of new highways or the relocation of old highways, the following factors should be given careful consideration: (I) the highway should develop to a maximum extent the commercial, agricultural, and industrial interests of the community; (2) the highway should serve the largest number of people practicable; (3) the amount of cut and fill should be reduced to a minimum; (4) good natural drainage should be secured and longitudinal surface drainage obtained by establishing a minimum grade of 0.5 per cent; (5) other conditions permitting, natural stable foundations should be utilized and such natural foundations as low swampy ground, locations subject to overflow and the stratigraphic conditions where there is a tendency of one stratum of soil to slide or slip upon another should be avoided; (6) grades should be as low 
as practicable, as the maximum grade limits the amount of the load which can be moved over a highway; (7) locations encircling hills should be substituted for steep inclines over summits; (8) if the topography is such that there is a continual rise, the grade line should not have a descending grade; (9) long easy curves should be substituted for sharp curves; (Io) in mountainous regions highways should be built on side slopes and avoid, if practicable, northern exposures and locations near stream-beds; (II) dangerous railroad crossings should be avoided.

Widths. A width should be selected which will not only accommodate the present traffic, but also be sufficient to allow for a reasonable future development. In the case of streets, provisions for light and air, room for subsurface structures and car-tracks, as well as accommodations for the traffic of vehicles and pedestrians must be considered. The width of roads is based mainly upon the amount of vehicular traffic. In the case of park highways the basis for design is the same except that the proper æsthetic treatment of the highway may warrant using a width not otherwise justifiable.

Width of Streets. In wholesale districts where the pedestrian travel is light, the sidewalk widths can be reduced and the width thus obtained put into the carriageway. A large commercial truck backed up against the curb will occupy a length of about $13 \frac{1}{2}$ feet. A truck on either side of the street in this position would therefore occupy 27 feet. The width out to out of the ordinary commercial motor-truck is between 6 feet and 8 feet 6 inches. To provide for the easy passage of two lines of vehicles between those backed up against the curbs would thus require an additional width of carriageway of about I7 feet, which would make the total width of carriageway about 44 feet. For streets in retail business districts the pedestrian traffic is of more importance and the sidewalks should be given adequate width. In residential districts a carriageway of from 30 to 36 feet is generally ample. Where a residential street is subjected to a light local traffic consisting principally of delivery wagons and pleasure vehicles, there is no need for a roadway wider than 20 feet. There are several advantages in favor of the smaller 
width. Assuming that the distance between property lines is 60 feet and a 20-foot roadway is constructed, 40 feet is left available for sidewalks and parking spaces. Allowing a width of $\mathrm{r} 2$ feet for each sidewalk, a parking space could be constructed beyond the sidewalk on each side 8 feet in width. This space, if properly treated, would add greatly to the appearance of the street. By reducing the width of roadway the first cost of construction and later maintenance costs are materially reduced. The width of 20 feet is ample for two teams to pass or one to pass when the other is backed against the curb. The parking spaces would be available for the location of underground services, and thus frequent disturbances to the roadway could be avoided. Street widths are generally stated as the distance between property lines. The width taken by each sidewalk in city streets is from one-fourth to one-fifth the total distance between property lines, although this may be reduced in some instances.

Width as Affected by Car Tracks. Wherever possible, it is best to provide a trackway for cars which is separated from the roadway by a barrier or parking space. Where trackways have to be built within the limits of the roadway, the width of the street will determine whether it is best to locate them at the sides of the street or to put them in the center. This subject is considered in detail in Chapter XXI.' A great deal of the passenger traffic in the future may be carried on motor-buses. The use of this type of public conveyance will eliminate the car tracks from the roadway.

Width as Affected by Subsurface Structures. Ample provision must be made for the location of subsurface structures. In business districts these structures become very much congested. Sewers, water and gas pipes, conduits for telegraph and telephone wires, steam and hot water pipes, refrigerating pipes, and tunnels are commonly found in our largest cities. The space underneath the sidewalk from the property line to the curb line and extending to the sidewalk level in many streets of the business districts of American cities is utilized as a vault by the property owner. This prevents using the sidewalk width for the accommodation of subsurface structures and makes it necessary to 
place them within the carriageway. It is evident that the interests of the roadway will be best served by eliminating from it all pipes which are liable to be disturbed to any extent. The expense entailed in constructing pipe galleries on either side of the street for the accommodation of these structures is so great that it becomes prohibitive except in very special cases. This topic will be further considered in Chapter XXI.

Width of Roads. Carriageways of roads which only take a horse-drawn vehicle traffic can be made narrower than those which are subjected to both horse-drawn and motor-car traffic. In the former case a width of 14 to 16 feet gives sufficient clearance between two passing teams. The width out to out of the average touring-car is about six feet, while motor trucks are made as wide as 8 feet 6 inches. A wider roadway is required than for the horse-drawn vehicle traffic in order to allow the machines to pass each other at a fair rate of speed with the proper clearance and still keep on the improved surface. For interstate and intrastate highways a width of improved surface of 18 to 20 feet would probably be none too great, while a width of 14 to 16 feet would be ample for those roads which act as feeders to the classes just mentioned, the smaller width to be used only in case of very light traffic. It is unfortunate that some authorities, charged with the design of state trunk highways subjected to a mixed traffic, have adopted a width of roadway of only 12 feet. (See Fig. 20.) In England the carriageways of main roads are made from 16 to 22 feet wide, while those of the national roads in France are made 24 feet wide. (See Fig. 2I.) There are many existing roads which have a right of way much wider than is necessary. In acquiring a strip of land for a new location a width of 30 feet on each side of the center line is ordinarily sufficient. The shoulders of roads make a suitable place for the location of pipes. There are places, however, where the pipes will have to be located within the carriageway. In such cases, the best location of either the water or gas pipes is at one side of the road so that work incident to these services will not interfere with the traffic.

Width of Park Highways. The same general principles set 


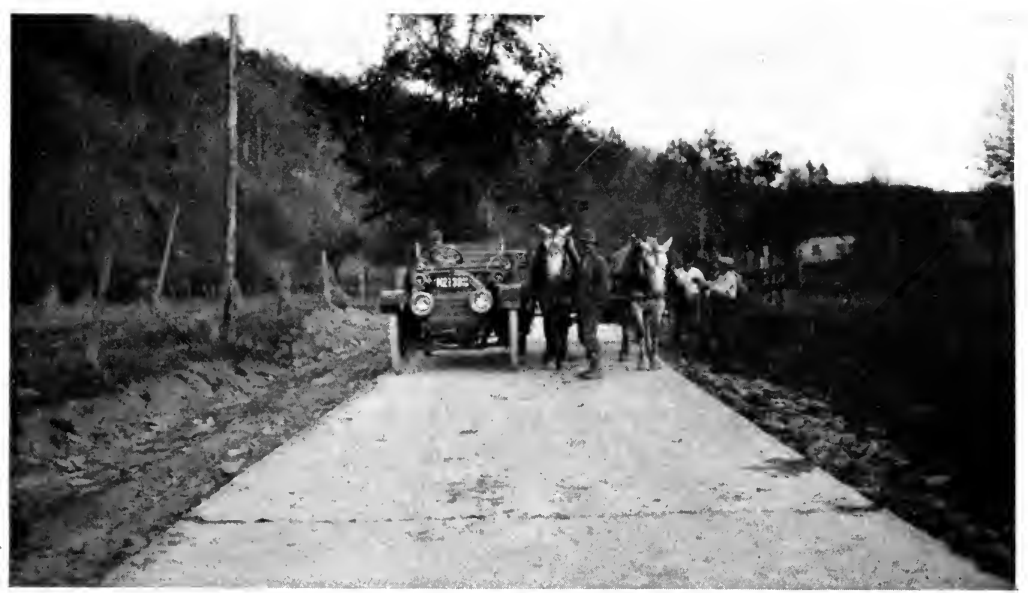

FIG. 20. State Highway. Improved Surface I2 feet Wide.

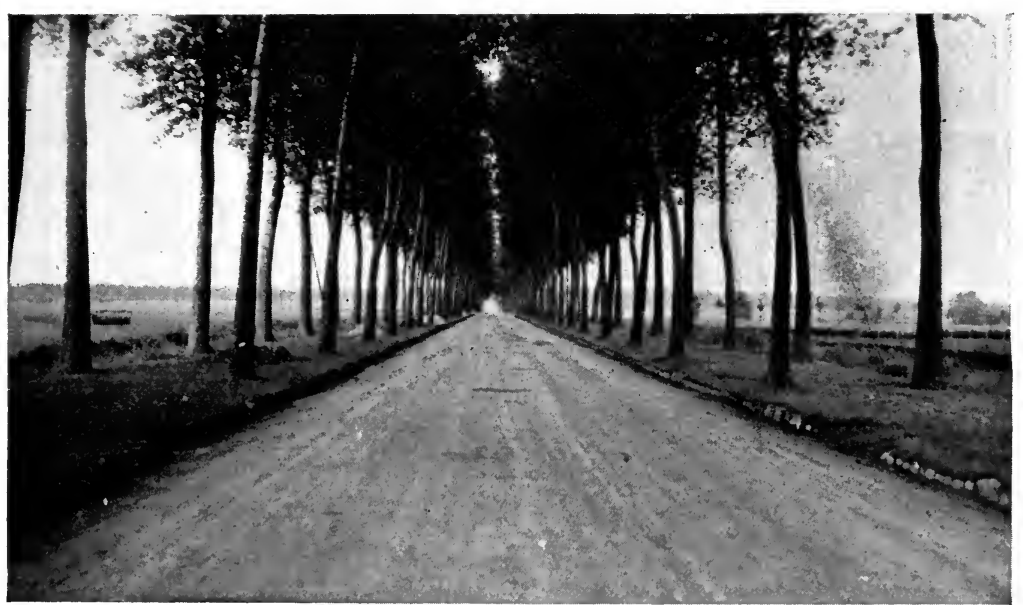

FIG. 2I. National Road, France. Width of Roadway, 24 feet. 
forth relative to the width of streets and roads apply to the highways of parks. It has been previously mentioned, however, that the width adopted is also affected by the consideration of æsthetics. There is no set of rules which can be given covering the relation of width to æsthetics, since the problem is one

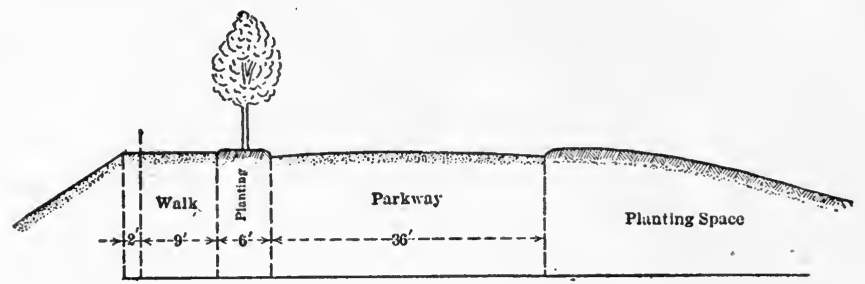

FIG. 22. Typical Section of Park Highway. Massachusetts Metropolitan Park Commission.

largely influenced by local conditions. Many park commissions have adopted standard widths to be used under different conditions. A typical section is shown in Fig. 22.

Grades. In practice the maximum grade may be governed by the loads to be hauled over a given highway, but in many localities a maximum rate of grade is established, which is never exceeded except when the environments and the consideration of cost make it advisable to use a steeper grade. All classes of motor vehicles are so designed that they can climb, without difficulty, practically any grade which would be built for horsedrawn vehicles, hence, only horse-drawn vehicles have to be considered. A horse can exert a pull of I 20 pounds when working steadily, and for a short period this pull may be increased to practically 500 pounds. As the grade increases, the load a horse can pull decreases very rapidly. For instance, on a 6 percent grade a horse can readily pull only about one-half as much as on the level; on a ro percent grade, only one-fourth as much.

The grade must be established so as not to cause damage to the adjoining property and so as to best accommodate intersecting streets or roads. Proper drainage and foundations should receive consideration in grade design. In the case of roads, particularly, it is frequently necessary to raise considerably the 
existing grade in order to obtain a satisfactory foundation. A saving may be effected by taking advantage of an old surface as a foundation, the new grade being established so as to disturb the old roadway as little as possible. Although it is of material advantage to obtain a grade which will make the cuts and fills balance, or in other words, preclude the necessity of any borrow on the work, still it is obvious that many times other considerations are of far greater importance. The advisability and economy of balancing cuts and fills from the standpoint of grading can only be ascertained by comparing the cost of possible overhaul, in moving the earth from one point on the road to another, with the cost of borrow at some nearer point.

Maximum Grades. Grades as high as 20 percent are found in mountainous districts. Many of the State Highway Departments never use grades over 7 percent. Within the cities the grades usually follow quite closely the general topography of the earth's surface, and hence the problem, in this case, is to provide a surface that will be suitable to the traffic. In the Borough of The Bronx, New York City, the grade of sheet asphalt is usually limited to 3 percent, wood block to 3 percent, asphalt block to 6 percent, vitrified brick to 5 percent, while granite block has been laid on grades of I3 percent.

Minimum Grades. The minimum rate of grade varies inversely with the smoothness of a roadway surface. If the roadway surface of a broken stone road is well maintained and a good fall is given to the ditches at the sides, there is no reason why a flat grade cannot be used for a short length. The minimum grade of streets is important from the standpoint of drainage. It is possible in flat places to make the curbs level and to obtain the grade by increasing the depth from the gutter to the top of the curb.

Drawing the Grade. The ground line of the profile should be carefully studied as certain limiting points on the grade line may be established by giving attention to the considerations enumerated above. Grade lines can then be drawn in 
between these points by trial until a final grade is determined which will best fit the conditions.

On roads it is customary to change the grade at some station which is a multiple of 50 or roo feet. This is purely a matter of convenience, however, in that it facilitates the grade com-

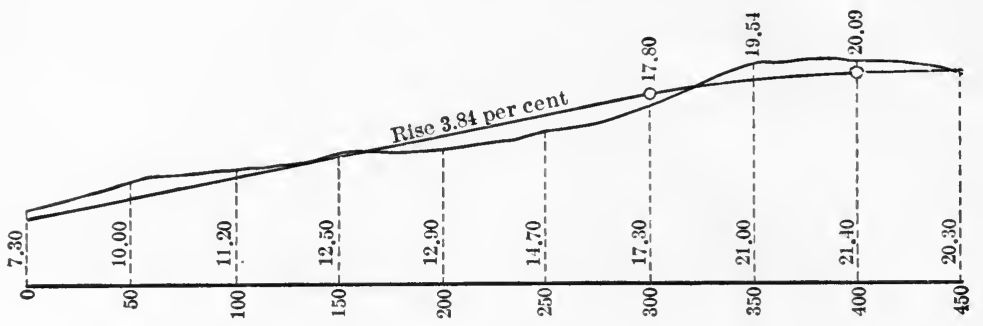

FIG. 23. Sketch Showing Representation of Finished Grade Line.

putations when the grade has to be figured for every 50 -foot station. The grade is shown only on the profile of the drawing. Elevations are written for all stations of vertical curves and for all points denoting a change of grade. The rates of grade are written along the grade line where it is uniform for a distance of Ioo feet or more. Fig. 23 shows the original ground line and the finished grade line and represents one method of recording the grade on the plan.

On streets it is customary to make the grade a straight line between the intersecting streets unless a perfectly flat grade would result, in which case it is usually broken to provide for drainage. This is a general principle, but the topography, cost of construction, damage to abutting property, and the general appearance of the street may prevent its adoption in some cases. Furthermore, it will sometimes be necessary to make slight changes in the grade for the grade table, formed by the intersecting streets, in order to provide an intersection that will not only look well, but will take care of the water and be safe to use. The grades for streets should be established and recorded so that the proper grade can be given for new buildings and other structures which may be built in advance of the street improvement. 
Vertical Curves. In order to avoid the abrupt transition from one grade to another, a vertical curve is put in at the grade intersections, the length of which should be increased as the difference between the rates of the intersecting grades increases.

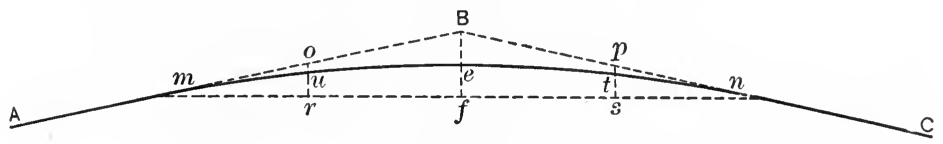

FIG. 24. Vertical Curve.

The parabola is the form of curve which is most generally used. In Fig. 24, two intersecting grades are shown by the lines $A B$ and $B C$ and the vertical curve by the line $m u$ e $t n$.

Design of Street Intersections. The adjustment of grades at street intersections is sometimes a very troublesome problem.

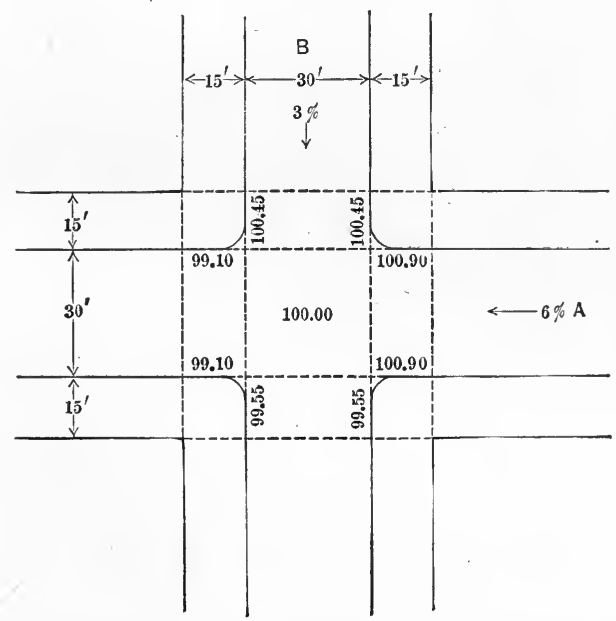

FIG. 25. Elevations at Curb Corners from Intersecting Grades.

The grade usually required to be established by ordinance is that of the center of the street. In order to avoid confusion the grade of the curb corners or of the property corners should also be established. An examination of Fig. 25 will show the importance of recording, not only the elevation of the inter- 
secting centers of streets, but also the two elevations for each curb corner and for each property corner.

Curves. In the design of roads, subjected primarily to horsedrawn vehicle traffic, the proper radius of curve would depend principally upon the overall length of the horses and wagon and the width of the road. It has been found that to permit a vehicle drawn by four horses to keep upon a 12 -foot roadway requires a curve having an inside radius of about roo feet. In designing a road that takes either motor-car traffic alone or a combination of motor-car and horse-drawn vehicle traffic, the safety of the travelling public and the wear of the roadway must be considered. Sharp curves are points at which collisions are very liable to occur, particularly if the view is obstructed. It is natural for all traffic to keep to the inside of the curve, and in the case of the motor vehicles, if the speed is not brought down to about ten or fifteen miles an hour, the slew of the vehicles as they pass around the curve tends to grind out the surface of the roadway. The following conclusion was adopted by the First International Road Congress held in Paris in I908: "The radii of curves should be as great as possible, I64 feet at least; the outside of curves should be slightly raised but so as not to inconvenience ordinary vehicles; no obstructions to the view should be allowed at curves." Fig. 26 is a typical layout, showing the widening of a broken stone road at curves, as adopted by the Los Angeles County Highway Commission in r9ıo. A poor design is shown in Fig. 27.

Sharp curves on streets are unavoidable, since a rectangular block system always forms a large part of the street plan. The radii of the curves at the corners of streets will generally vary from about four to twelve feet. On wide streets the smaller radii can be used, whereas on streets of the minimum width the corners should have the larger radii if possible in order to better accommodate vehicular traffic entering the street.

As previously stated the use of curves on a park system of roads is desirable from the æsthetic standpoint. For instance, a winding road, following the natural contours of the ground 


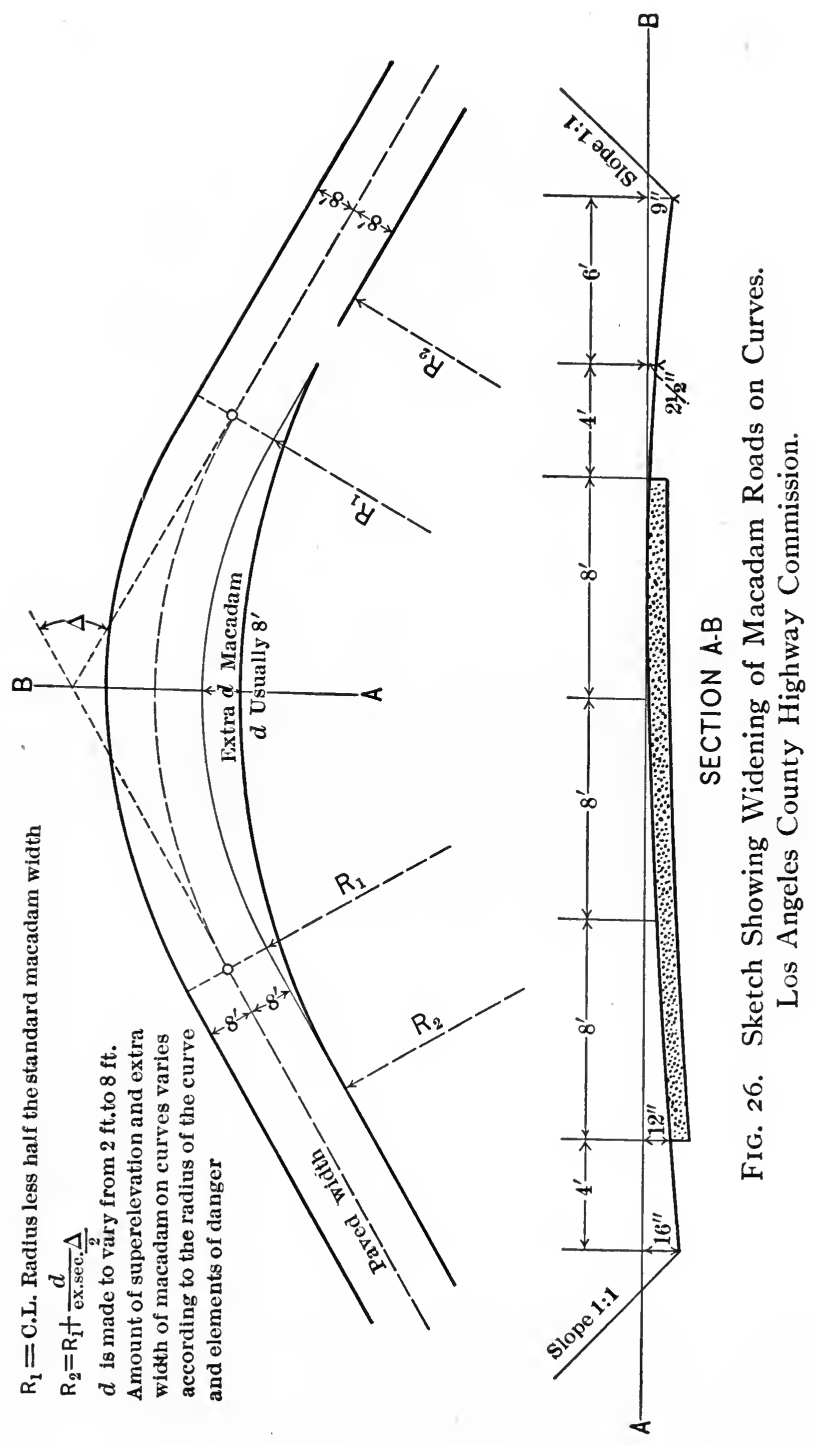


along some lake shore or river bank, tends to emphasize the natural beauties of the surrounding scenery.

Cross-Sections of Roads and Streets. The general form of

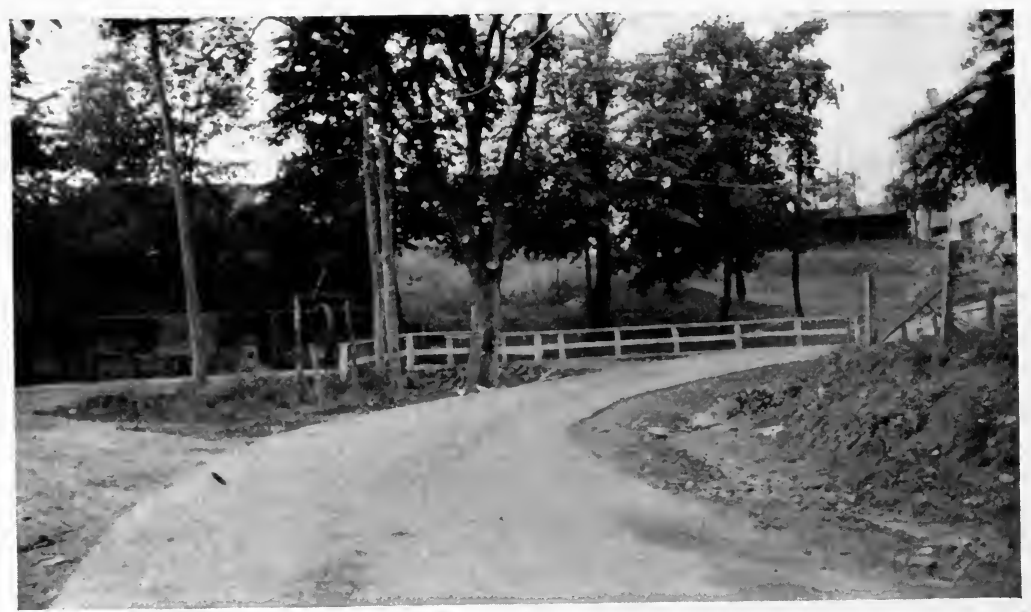

FIG. 27. Example of Poor Curve Design.

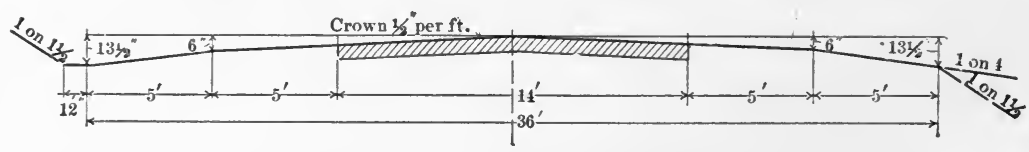

FIG. 28. Standard Road Section. New York State Department of Highways.

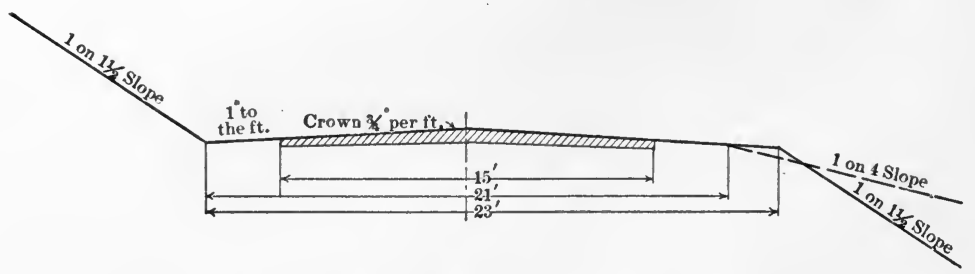

FIG. 29. Standard Road Section. Massachusetts Highway Commission.

the cross-section adopted for a street or a road will depend upon its location and the material of which the roadway is constructed.

Typical cross-sections adopted by two State Highway Departments are shown in Figs. 28 and 29. The slope of the 
banks depends upon the kind of material of which they are composed. As ordinary earth in a dry state has an angle of repose of $\mathrm{I}$ on $\mathrm{I} I / 2$, this slope is in common use for embankments and cuts. It is customary in many States to carry out the shoulders of fills less than 4 feet in height with a I on 4 slope, which practically renders unnecessary the use of a guard-rail.

Crowns. The crown for the roadway surface, see Fig. 30 , is composed of intersecting planes or of arcs of a circular or para-

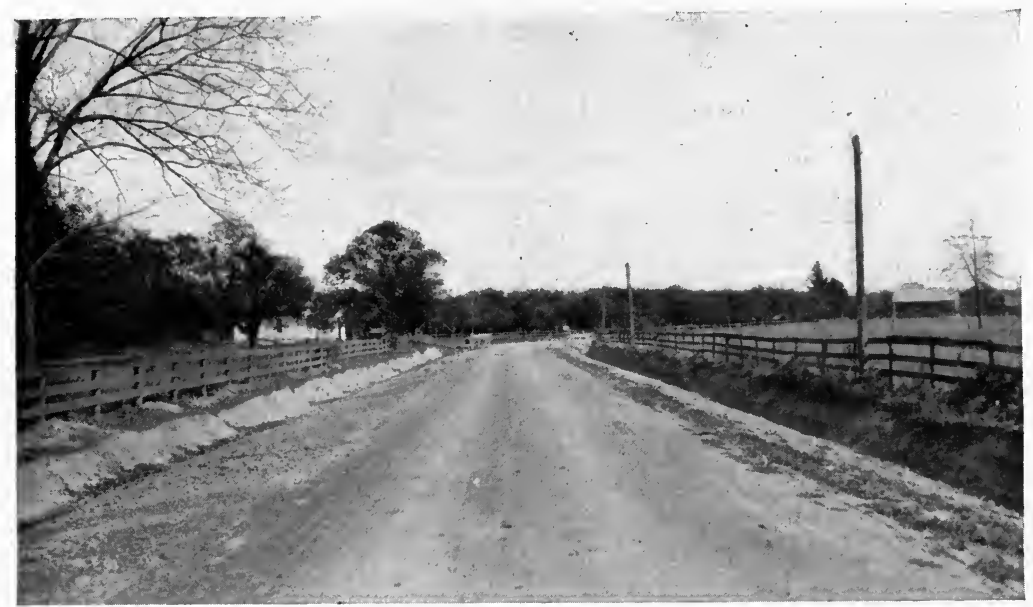

Fig. 30. Cross-Section of Highway Showing Crown of Roadway.

bolic curve. The purpose of a crown is to readily shed the water falling on it without causing inconvenience to traffic. It is a general rule that the smoother the surface the less the requisite amount of crown. A steep crown will cause traffic to concentrate on the center of the carriageway with the result that the surface will not be subjected to an even wear. For surfaces which are not impervious, such as earth and gravel roads, it has been customary to make the crown on steep grades sharper than on the flat grades to prevent water from running down the center of the road. If a heavy crown is used on a road which lies on a steep grade and has a smooth surface, it will be dangerous for the traffic under certain climatic conditions.

Crown Formulas. The derivation of many crown formulas 
is based on a parabolic curve. Some give the total amount of crown, but not its distribution, whereas in others the amount of crown is assumed and the formula gives its distribution. Most formulas do not take the grade of the highway into account or make allowance for the different kinds of pavements.

The following formula, deduced by Joseph W. Dare, ${ }^{*}$ is given as an illustration of the type of formula used in cities throughout the United States:

$$
C=\frac{(W 100-4 P)}{6300+50 P^{2}}
$$

$C=$ crown in inches; $P=$ longitudinal grade expressed as a percentage; $W=$ width of roadway in inches.

The distribution of the above crown, when curbs are level, is obtained by the formula $\frac{8 C}{0.3 R}=d$, where $d=$ the transverse grade, expressed as a percentage, $R=$ width of roadway in feet. In the following diagram,

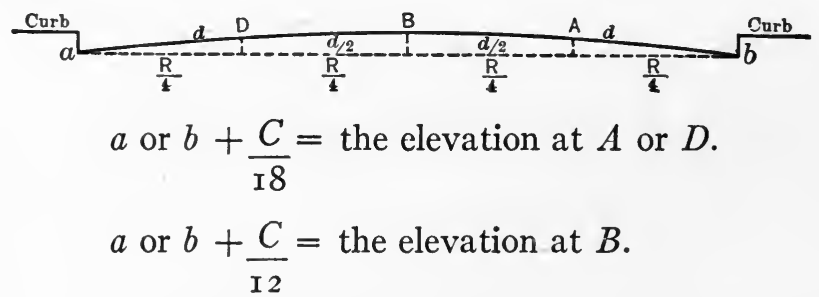

$a$ and $b=$ the elevation at the gutters, expressed in feet and hundredths. In the diagram it is shown that the transverse slope between the crown and quarter point is just one-half what it is between the quarter point and gutter.

Drainage and Foundations. The results of the preliminary examination will furnish much valuable information relative to surface and subdrainage and the foundation. A consideration of these subjects, however, will be given in full in Chapter V.

Selection of Type of Wearing Course. There are many characteristics of the materials used and the methods of construction

* See Trans. Am. Soc. C. E., Vol. 73, page 225. 
employed that influence the selection of the type of road or pavement. This subject will, therefore, not be considered further in this chapter, although it is an important part of the design. The comparison of different types of roads and pavements is considered in detail in Chapter XIX.

Estimates. When the location, width, and grade of the highway and the form of cross-section have been adopted, an estimate can be made of the amount of work to be done and the cost thereof. Complete estimates cover the grading, drainage, foundation, wearing course, and all highway structures. 


\section{CHAPTER V}

\section{GRADING, DRAINAGE, AND FOUNDATIONS}

\section{GRADING}

Object of Grading. Grading operations are used in the construction of all highways, and may be classified under the headings: excavation, embankment, and subgrade. The methods of construction of cuts, fills, and subgrades with various machines are, in most cases, explained later in this chapter in connection with the descriptions of the several machines.

Excavation. In excavating material in order that the crosssection of a highway should conform to the desired lines and grades, the operations vary from the removal of a small amount of material in surface grading to excavations of many feet in depth. Excavation includes, in general, grading of the roadway, ditches, and side slopes. The excavated material is used to fill those parts of the highway which are below the proper grades. Surplus excavation is used in many cases to widen embankments and flatten side slopes.

Embankment. Before the construction of the embankment is begun, trees, large roots, brush, and other objectionable material within the entire area to be covered by the fill should be removed. Where the filling is less than about two feet in depth, all vegetable matter should be removed from the original surface. These requirements are necessary in order to secure an embankment free from soft and spongy pockets. If stone filling is employed, usually the stones should not exceed a half cubic foot in size and the larger stones should be placed in the bottom of the excavation. No large stone should be used within six inches of the surface of the subgrade or shoulders. In the construction of embankments it is of the utmost importance that the materials should be thoroughly compacted in order to avoid 
later settlement. In order to accomplish the desired result, the material to form the embankment should be deposited in thin layers, not over twelve inches in depth, for the full width of the embankment and thoroughly compacted. The compaction is accomplished by machines and loaded wagons used in grading operations being drawn continually over the embankment, and by rolling. Many engineers have obtained the best results by the use of sectional rollers or comparatively light rollers on thin layers of material. In the construction of highways on side hills it is advisable to stagger or roughen the material of the hillside, in order to form a mechanical bond between the material of the fill and the surface of the ground, thus guarding against the slipping of the embankment.

When the excavated material suitable for use in the construction of embankments is insufficient, additional material is obtained from borrow pits or other sources. In cases where the haul of material required for embankments exceeds a given distance, the work entailed is classified as overhaul. If this distance is 2,000 feet, payment for overhaul would be based upon a rate per cubic yard for each roo linear feet greater than 2,000 feet that the material is hauled.

SiDE SLOPES. When the excavations and embankments are on roads, one of the most important details of construction is the formation of the side slopes in such a manner that the crosssection of the highway will practically retain its form. In many cases, in order to avoid washing away of side slopes during heavy rains, the slopes of both excavations and embankments are sowed with grass seed or covered with sod. For all practical purposes, earth, sand, and gravel, when used in either excavation or embankment, will be stable if the side slopes are constructed with an inclination of I on $\mathrm{I} / 2$.

SubGradE. The subgrade consists of "the upper surface of the native foundation on which is placed the road metal or the artificial foundation, in case the latter is provided."* The subgrade is thoroughly compacted by rolling to conform to the

* Dec., I914 Proceedings, Am. Soc. C. E., page 3018. 
lines and grades. All muck, quicksand, soft clay, or spongy material, which will not consolidate under the roller, is removed to such depth as is necessary and the space is refilled with suitable materials from excavations or with other material such as earth, gravel, or broken stone. All hollows and depressions which develop in rolling are filled with suitable material and the process of filling and rolling is repeated until no depressions develop.

Classification of Materials. Different kinds of soils are described under the terms gravel, sand, clay, marl, loam, peat, and muck. It is quite common in grading specifications to classify the materials to be excavated as earth, hardpan, loose rock, and solid rock: earth to include clay, sand, loam, gravel, and all hard material that can be reasonably plowed, and all earthy matter or earth containing loose stones or boulders intermixed, and all other material that does not come under the classification of hardpan, loose or solid rock; hardpan to include all material, not loose or solid rock, that cannot be reasonably plowed on account of its own inherent hardness; loose rock to include all stone and detached rock, found in separate masses, containing not less than I cubic foot, nor more than $1 / 2$ cubic yard, and all slate or other rock soft or loose enough to be removed without blasting, although blasting may occasionally be used; solid rock to include all rock in place and boulders measuring $1 / 2$ cubic yard and over, in removing which it is necessary to resort to drilling and blasting. H. P. Gillette, M. Am. Soc. C. E., subdivides the first class "earth" into three classifications as (I) easy earth, (2) average earth, (3) tough earth. He defines these classes as follows: "To the first class belong loam, sand, and ordinary gravel, which require little or no picking to loosen ready for shovelling. To the second class belong sands and gravels impregnated with an amount of clay or loam that binds the particles together, making it necessary to use a pick or plow drawn by two horses to loosen the earth before shovelling. To the third class belong the compact clays, the hardened crusts of old roads, and all earths so hard that one team of horses can pull a plow through the earth only with the greatest difficulty, 
but that two teams of horses on one plow can loosen with comparative ease." It is apparent that the classification of materials encountered in grading depends largely upon the judgment of the engineer. There are very few large grading contracts completed without frequent disputes arising between the contractor and the engineer with regard to classification of excavation.

Shrinkage of Materials. It is important in grading operations to distinguish between loose measurement and measurement in place. All estimates are generally based on the yardage of material in place. It is a well-established fact that earth when removed from its original position in a bank increases in bulk or swells. It is also well known that when the excavated material is placed in a fill it will shrink and settle so that it will occupy a smaller space than it did originally. The swelling on removal from the original bank will vary generally from about 8 to I 5 percent, but in some cases may be as high as 40 to 50 percent. The shrinkage is variable and depends upon the kind of earth, the manner in which the embankment is made, and the climatic conditions. H. P. Gillette, M. Am. Soc. C. E., states that "Clean sand and gravel swell I4 to I5 percent; loam, loamy sand and gravel swell 20 percent; dense clay and dense mixtures of gravel and clay, 33 to 50 percent, ordinarily about 35 percent; while unusually dense gravel and clay banks swell 50 percent." The same authority says with regard to shrinkage, in considering the different means of compaction, namely, puddling action of water, pounding of hoofs and wheels, and artificial rolling, that "if the puddling action of rains is the only factor, a loose mass of earth will shrink slowly back to its original volume, but an embankment of loose earth will at the end of a year be still about 8 percent greater than the cut it came from. If the embankment is made with small one-horse carts or wheel scrapers, at the end of the work it will occupy 5 to ro percent less space than the cut from which the earth was taken, and in subsequent years will shrink about 2 percent more, often less than 2 percent. If the embankment is made with wagons or dump-carts and made rapidly in dry weather without water, it will shrink about 3 to Io per- 
cent in the year following the completion of the work and very little in subsequent years. The height of the embankment appears to have little effect on its subsequent shrinkage."

Machines. Grading is accomplished with a variety of tools and machines. A brief description of the machines and the methods of operation will be given.

Carts and Wagons. A one-horse tip-cart is generally built with two wheels. The body tips over the axle in discharging its contents. The bodies have a capacity of about $2 \mathrm{I}$ to 24 cubic feet, without side boards. Two-horse tip-carts are operated on the same principle, but are built on four wheels. They hold about $\mathrm{I} / 2$ cubic yards of material, loose measurement.

Patent bottom dump-wagons are made in I, I I $2,2,2 \mathrm{I} / 2$, and 3 cubic yard sizes. The bottom of the wagon is made up generally of two leaves, hinged either to the sides or to the ends of the box. The doors are held in place with chains which are wound up on a windlass operated by the driver. To dump the load, the driver with his foot kicks a release lever and the doors fly open, thus discharging the load. The doors are closed by the driver turning the windlass. While the body of the wagon is generally made of wood, the bottom doors are sometimes made of wood and sometimes of sheet-iron. One of the doors is usually provided with a lip, which overlaps the joint formed by the doors, and thus prevents the material from sifting through.

Road Drags. One of the simplest and cheapest forms of road drags is the split-log drag. A dry red-cedar log is best, although red elm, walnut, box elder, soft maple, and willow make good drags. A log should be from 7 to 8 feet in length and from Io to 12 inches in diameter. The log is split as nearly in half as is practicable, and the heaviest and best slab is used for the front log. The logs are braced together as shown in Fig. 3I. An iron strip is fixed at the ditch end, as shown, and it projects $1 / 2$ inch below the lower edge of the slab at its outermost extremity and is flush with the slab at its other end. A platform for the driver is placed over the cross-braces on which he stands. The boards of the platform are fixed about one inch 
apart to allow any dirt that comes onto the platform to sift through onto the road. The chain is put through the middle of the log at the ditch end and passed over the top of the $\log$ at its other end and fastened to the brace. This allows

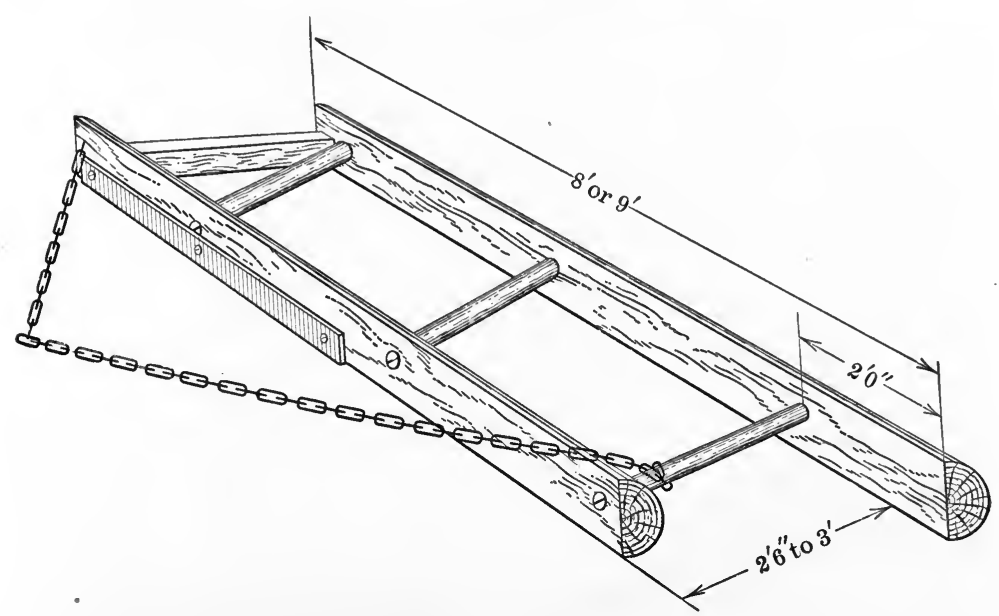

FIG. 31. Split-Log Drag.

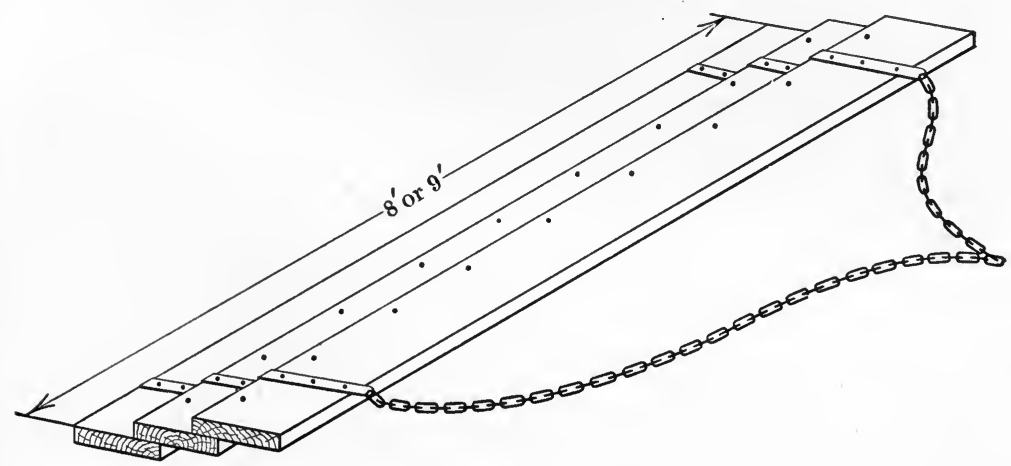

FIG. 32. Lap-Plank Drag.

the material to pass underneath the chain as it runs from the ditch along the log to the center of the road.

A plank-log drag is built in a similar manner to the split-log drag except planks set on edge are used in place of the split logs. The planks are ro to 12 inches wide and 2 to 4 inches 
thick. A lap-plank drag, shown in Fig. 32, is used for smoothing up a road where only a small amount of material is to be moved.

Various forms of steel road drags are manufactured, which have about the same over-all dimensions as the split-log drag described above, the logs or planks being replaced by angle irons or steel plates placed on edge. They weigh considerably more than split-log or plank drags, and for this reason are not preferred by some. Steel drags are often equipped with a lever by means of which the blades can be tilted at any desired angle.

Method of Operation. The team is hitched to the chain so

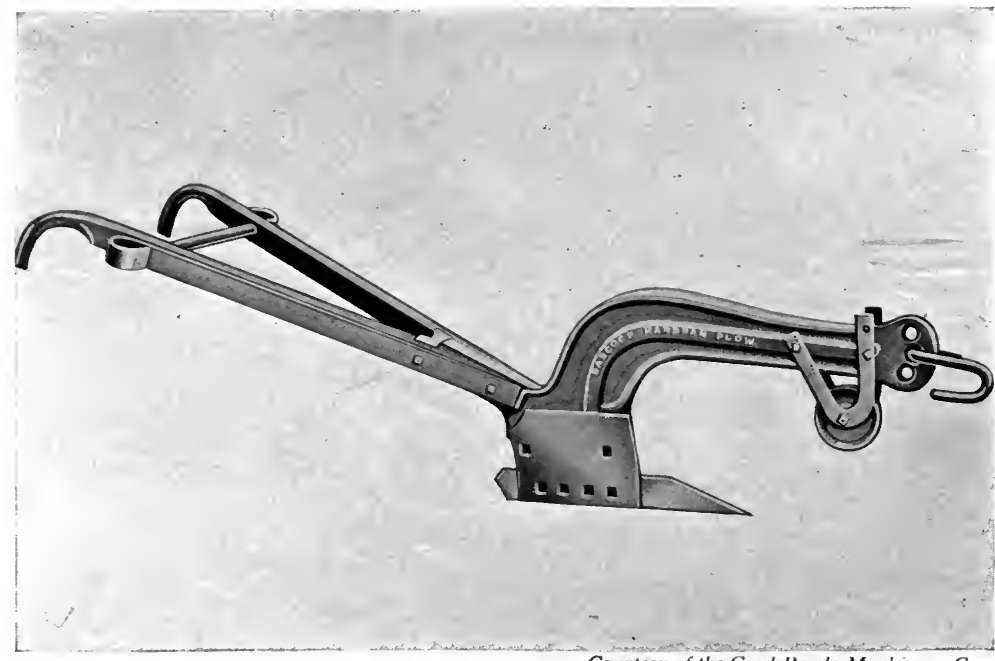

FIG. 33. Rooter Plow.

that the drag will be pulled along the road without a load at an angle of about 45 degrees with the center line, the ditch end always being ahead. If it is desired to make the drag cut deeper, the chain should be lengthened, as it is obvious that the nearer the team is to the drag, the greater will be the tendency to lift it from the ground. The driver generally stands on the drag, when working, and by shifting his weight from one end to the other causes the drag to cut into the soil or to drop the soil being carried along by it. To cut, he shifts his weight mostly on the front runner toward the ditching end; to cut light, he shifts his weight 
toward the rear runner; to drop the earth carried along into a depression, he suddenly shifts his weight to the rear and toward the end of the drag nearest the center of the road.

Plows. The grading plow is so made that the furrow may be turned either to the left or to the right. The function of the shoe or wheel near the front end of the beam is to regulate the depth plowed. An ordinary grading plow will make a furrow about io inches wide and from 6 to 12 inches deep. For breaking up hardpan, old macadam, or other stiff material, a rooter plow, as illustrated in Fig.

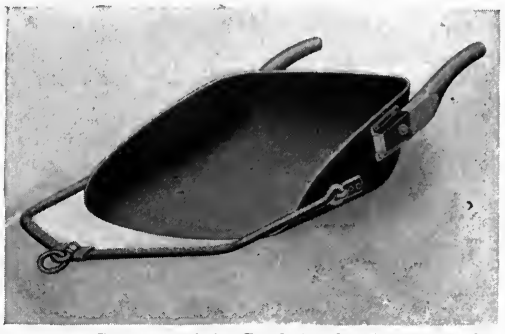

Courtesy of the Good Roads Machinery Co.

FIG. 34. Drag Scraper. 33, is employed. A plow of this kind is generally pulled by a steam roller or a tractor. If horses are used it may require from six to twelve, depending upon the material plowed.

Drag Scrapers. A drag scraper, as shown by Fig. 34, consists of a pressed steel bowl to which a bail and handles

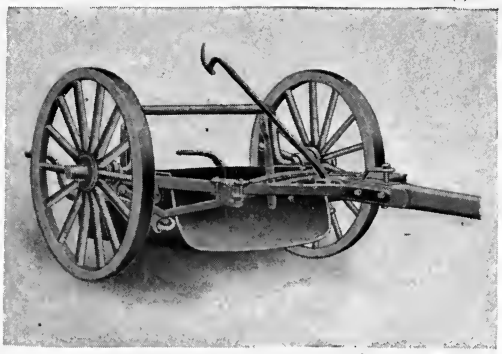

Courtesy of the Good Roads Machinery Co.

FIG. 35. Wheel Scraper. are attached. They have capacities of 3,5 , and 7 cubic feet. These capacities, however, are figured on the basis of loose measurement and for a scraper heaped full. This form of scraper wears out very rapidly on its cutting edge and on the bottom, particularly when working in hardpan or gravel.

Method of Operation. A drag scraper is usually drawn by one or two horses. To load, a man grasps the handles and pushes the cutting edge down into the loosened earth as the scraper is pulled along. Then the full scraper is dragged along on its bottom to the point of dump, where either the driver or a dump- 
man takes hold of one or both of the handles and lifts the scraper so that it turns upside down about its cutting edge.

Wheel Scrapers. A wheel scraper, Fig. 35, is similar in shape to a drag scraper, but the bowl is fixed to two wheels fitted with a pole and is usually drawn by two horses. They have capacities of 9, I2, and I6 cubic feet. Scrapers with four wheels are also manufactured.

Method of Operation. A wheel scraper is operated as follows: as it is pulled through the plowed material in its lowered position, a man grasps the small handles at the rear of the bowl and tilts the bowl so that the cutting edge engages with the earth. When the scraper is full, he pulls down on the long lever at the rear, which raises the bowl from the ground. The lever is

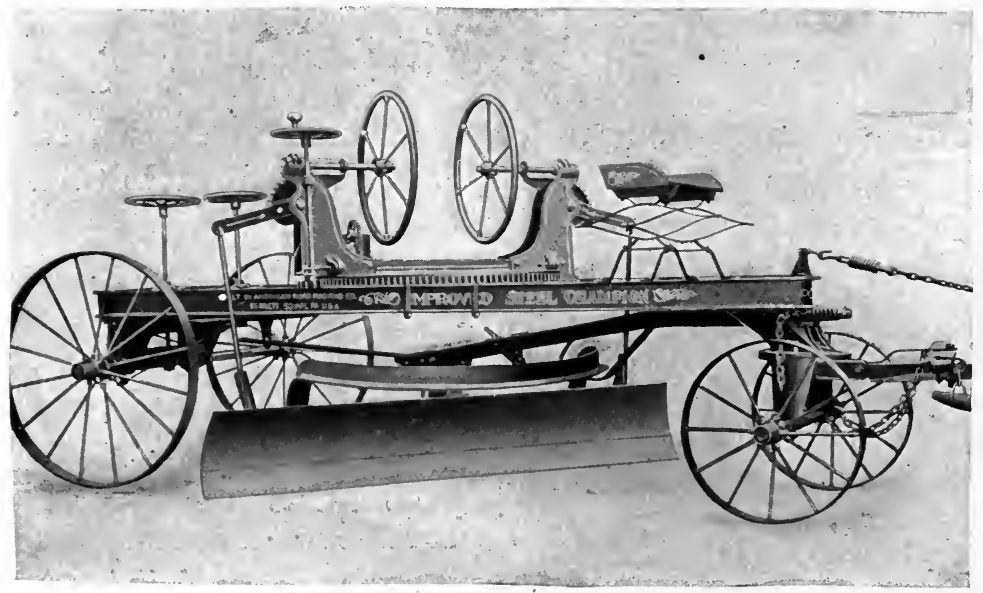

Courtesy of the Good Roads Machinery Co.

FIG. 36. Four-Wheel Road Scraper.

locked by a catch and the scraper is hauled to the dump. On the small-size scrapers no snatch team is used; on the medium size a snatch team is generally used; and on the large size a snatch team is always used. A snatch team consists of a pair of horses, which is hitched to the pole in front of the team dragging the scraper during the process of loading.

Road Scrapers or Graders. There are several different types of road scrapers or road hones. The four-wheel machines, Fig. 
36, have blades from 7 to 8 feet long, made up of two parts, a cutting edge and a mold board. The blade is suspended from a part of a full circular frame attached to the machine. By turning the large wheels the blades may be tilted at any desired angle with the vertical. It is also possible to turn the blade through any desired horizontal angle. In some types of machines the blade is given a forward or backward tilt by attachments fixed directly to the blade, while in others the blade is fixed in this respect, and the tilt is obtained by lowering or raising the front end of the frame over the front axle. It is also possible in some types to shift the blade sideways so as to project beyond the wheels for some distance, which is a great convenience in filling in ditches or cutting down banks. The framework is generally made of steel shapes, although wood is sometimes used. Another feature of many of the four-wheel machines is that the rear axle is made telescopic so that either wheel may be shifted in a lateral direction. This adjustment enables the rear wheels to straddle a furrow or to engage with the side of the banks and thus prevent side slip. In some makes the rear axle is pivoted so that it will turn through a small horizontal angle, helping the machine to keep in place when in the center of the road. There are some types also in which the rear wheels are so fixed to the axle that they may always be made perpendicular to the slope on which the machine is travelling. All of these different adjustments are carried out by one man, who stands on the rear of the machine and operates the various wheels and levers, all of which are within easy reach. Various types of two-wheel scrapers are also manufactured.

Method of Operation. In grading by means of a scraper the dry grass and sod is first burnt off. A cut is then made at the edge of the ditch, using the point of the blade, the latter being set at a sharp angle so that only the point and a very short length of the blade come in contact with the ground. On the next round the blade is lowered to a flatter angle and the earth is moved along the blade toward the center of the road. By making several rounds of the scraper in this manner the roadbed is crowned up at the center. To smooth out the roadbed, 
the surface is first thoroughly harrowed to break up the large lumps, and then the scraper is drawn along the road with the blade set at right angles to the center line of the road. When a reversible machine is used the blade is turned around so that the convex side is ahead. A plow is not necessary in scraper work, since the machine can generally do all the plowing desired with the point of the blade. In order not to get a soft road it is not advisable to move the earth up with the scraper in layers over 4 inches deep. In some cases from one to three furrows are plowed at the ditch side of the road, the material being turned toward the center. The scraper is then set to work at the furrow nearest the center, and it moves over from this furrow toward the center only about as much earth as is loosened by the first round of the scraper. The next furrow is moved over in a similar manner, and the process is repeated until the last furrow is reached, which is moved over in turn. The road is then smoothed out. The four-wheel machines for heavy work require from four to six horses, whereas two horses are used when the work is light. On the lighter two-wheel machines from two to four horses are necessary, depending upon the character of the work.

Elevating Graders. The principal parts of the elevating grader, shown in Fig. 37, are the plow and mold board and the elevating belt. A disk plow is sometimes substituted for the pointed plow. The mold board back of the plow is shaped so as to deliver the furrow to the elevating belt with as little loss as possible. The elevating belt carriers are made in $3^{-}$to 5 -foot sections, so that any length from 15 to 30 feet can be obtained in some of the larger machines. The carrier is run either with gears driven by the wheels or by a gasoline engine set on the rear of the grader. When the carrier is driven by an engine it requires less power to haul the machine.

Method of Operation. For heavy work the grader requires twelve horses, eight being hitched in front and four in the rear, two drivers and two operators on the machine, who operate the various levers controlling the movements of the plow and belt. A 25-horse-power traction engine may be used in place of the 


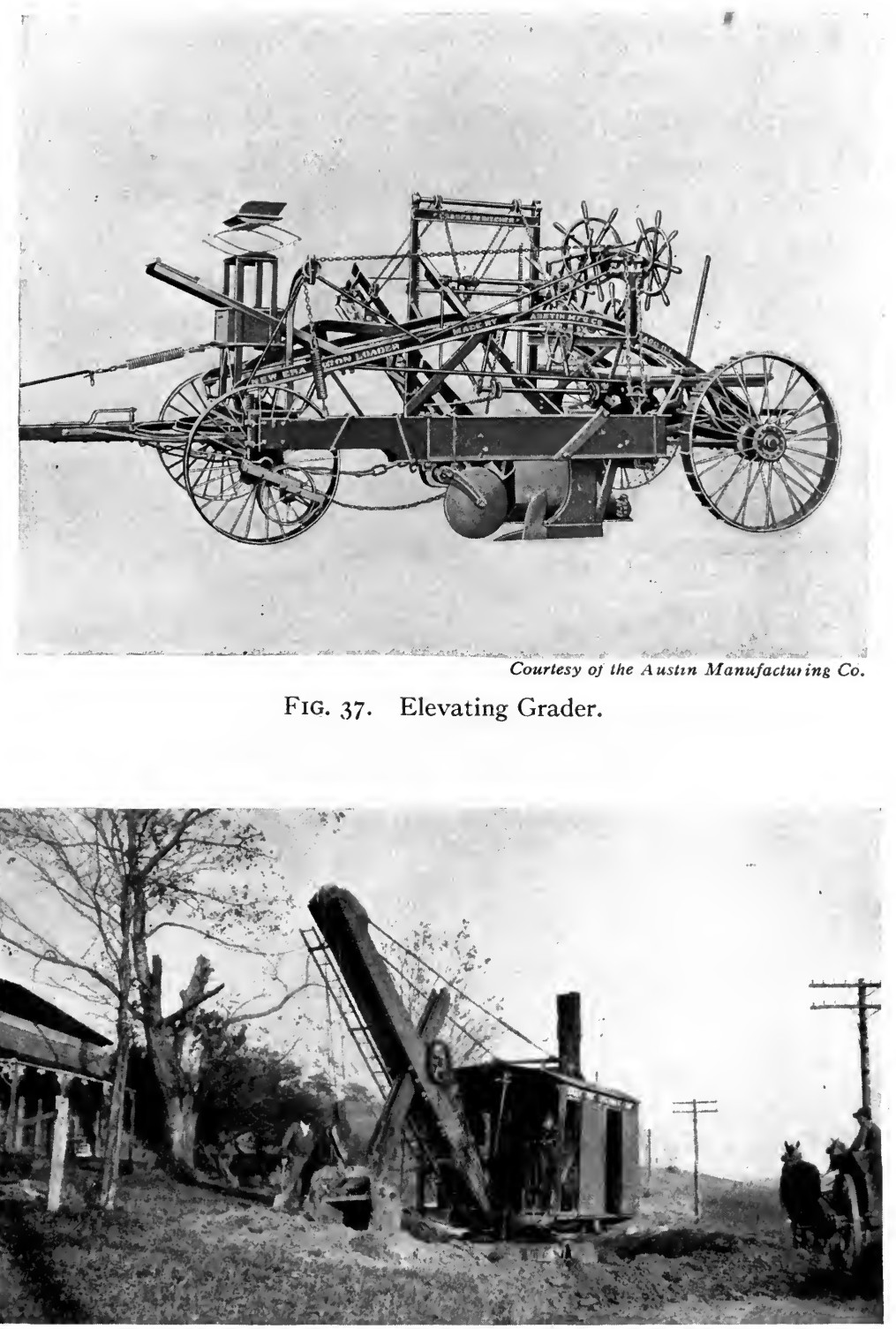

FIG. 38. Steam Shovel Used on Heavy Highway Grading Work. 
horses. The grader, as it moves along, plows up the earth, which is thrown onto the elevating belt and discharged over its end, either onto the road or into wagons.

Steam Shovels. On heavy grading operations steam shovels of the type shown in Fig. 38 are economically employed.

Horse Rollers. A horse roller is generally made with one large roller having a face of about 5 feet and a diameter of about 5 feet. Any weight desired from $2 \frac{1}{2}$ to $5 \frac{1}{2}$ tons, varying by I ton, can be obtained. Additional weight may be placed in the boxes at either end of the frame and the weight

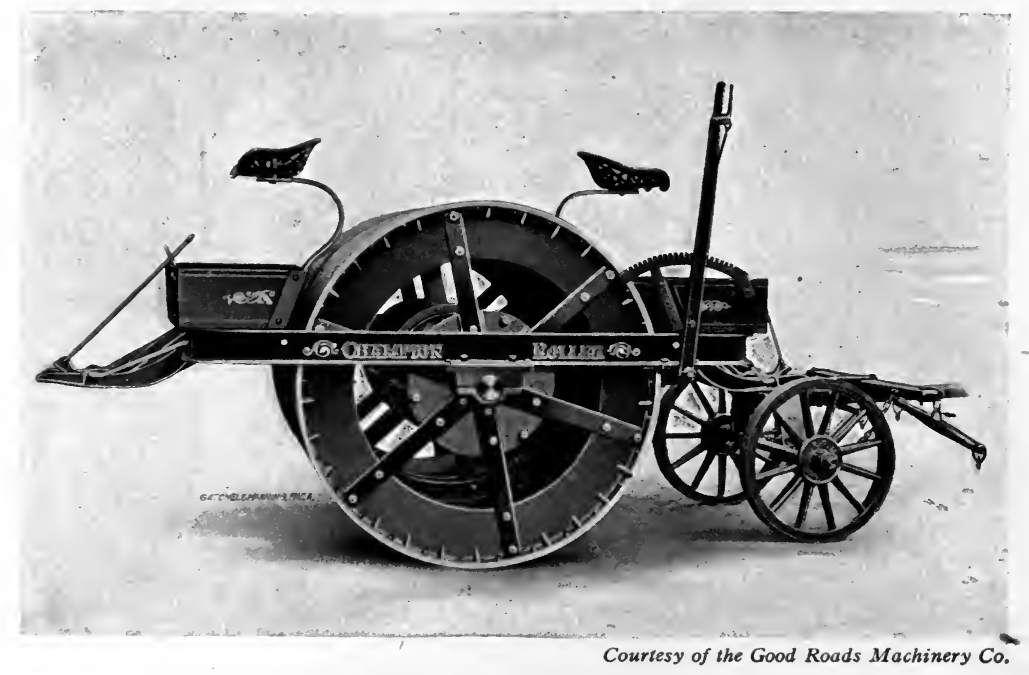

FIG. 39. Horse Roller.

be thus increased by I ton. The roller is made of steel or cast iron. An essential feature of a horse-drawn roller is to have it reversible, so that it can be drawn in either direction. In Fig. 39 the two-wheel truck may be uncoupled and attached to the opposite end of the roller. A grooved roller is sometimes specified, due to the fact that better compression can be obtained than with the smooth-faced roller. The grooves are formed by bars bolted around the face of the roller parallel to the edges and at a small interval apart. 


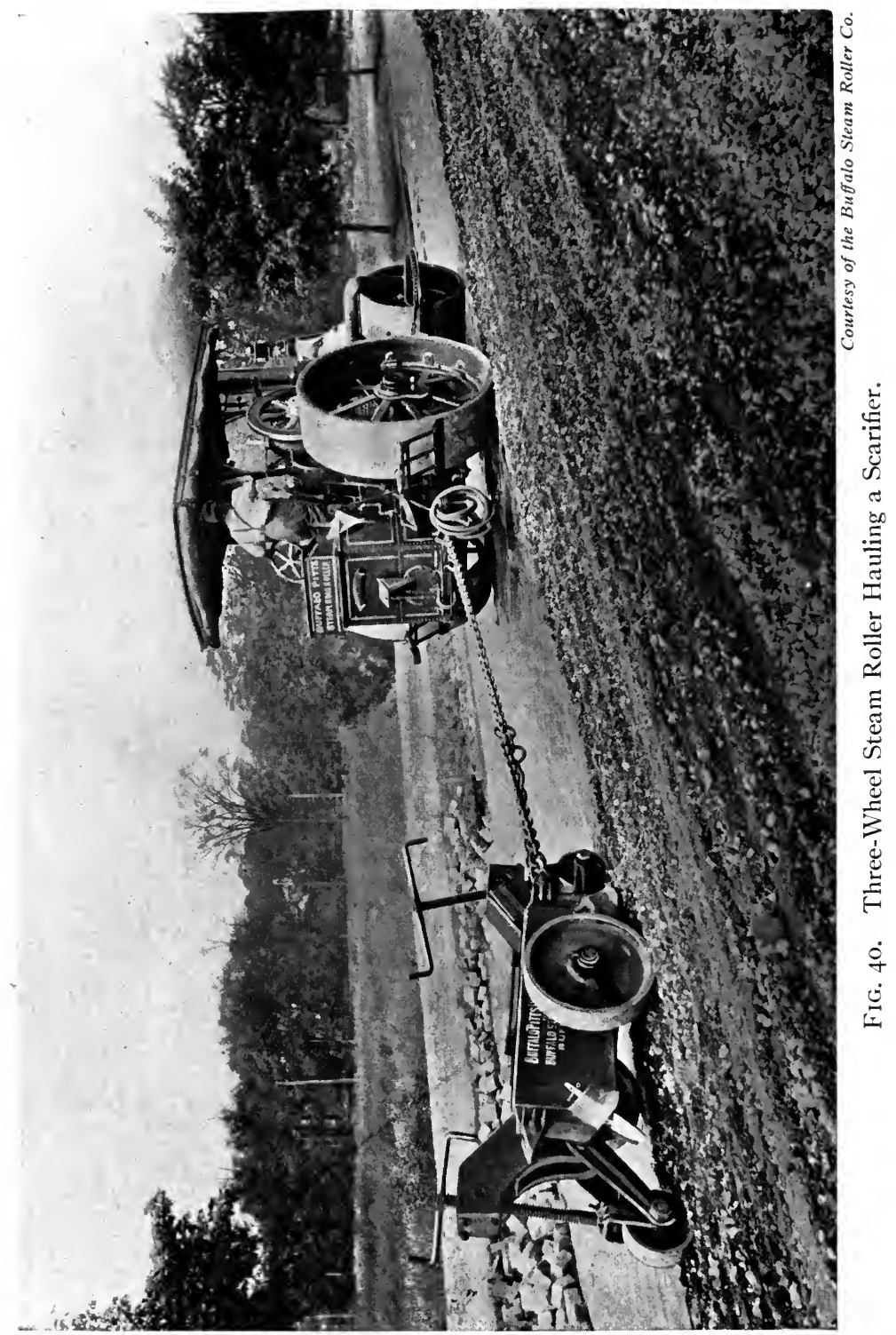




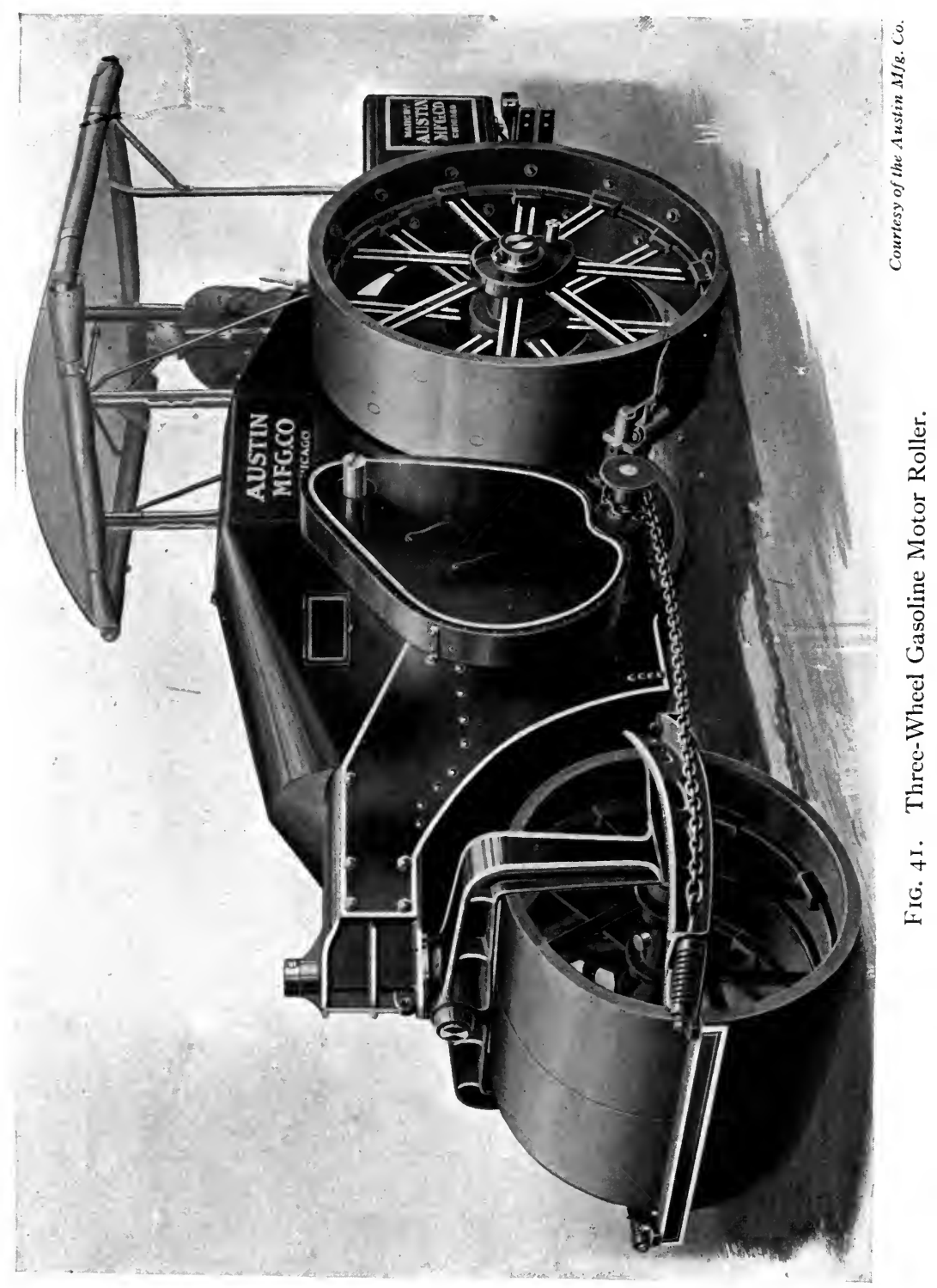


Three-Wheel Rollers. Three-wheel rollers vary in weight from io to 20 tons. The majority of rollers of this type are run by steam, although there are a few makes which are run by gasoline engines. Fig. 40 shows a three-wheel steam roller, and Fig. 4I a three-wheel roller operated by gasoline engine. Rollers are generally furnished with a high and low speed. The low speed is used in rolling embankment, subgrade, telford, etc., while the high speed is used in finishing the surface or in travelling from point to point.

Tandem Rollers. The weight of tandem rollers varies from 3 to 2 tons. These rollers are commonly run by steam, see

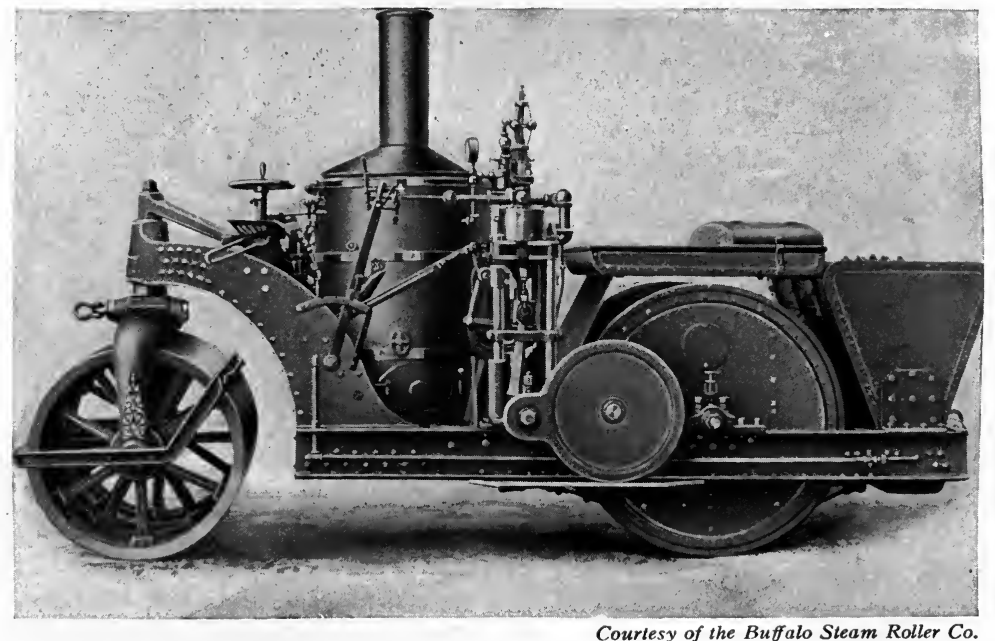

FIG. 42. Tandem Steam Roller.

Fig. 42, although there are some makes, see Fig. 43, which are run by gasoline engines.

Scarifiers. This machine consists of a heavy cast-iron block on two or four wheels which holds a series of steel picks. The block weighs about three tons and the picks can be adjusted in the block or the block itself arranged so that any depth desired up to 5 or 6 inches can be picked up. The picks are arranged in either a straight line or in two lines which, together, form a V. Most of the scarifiers are so designed that it is not 


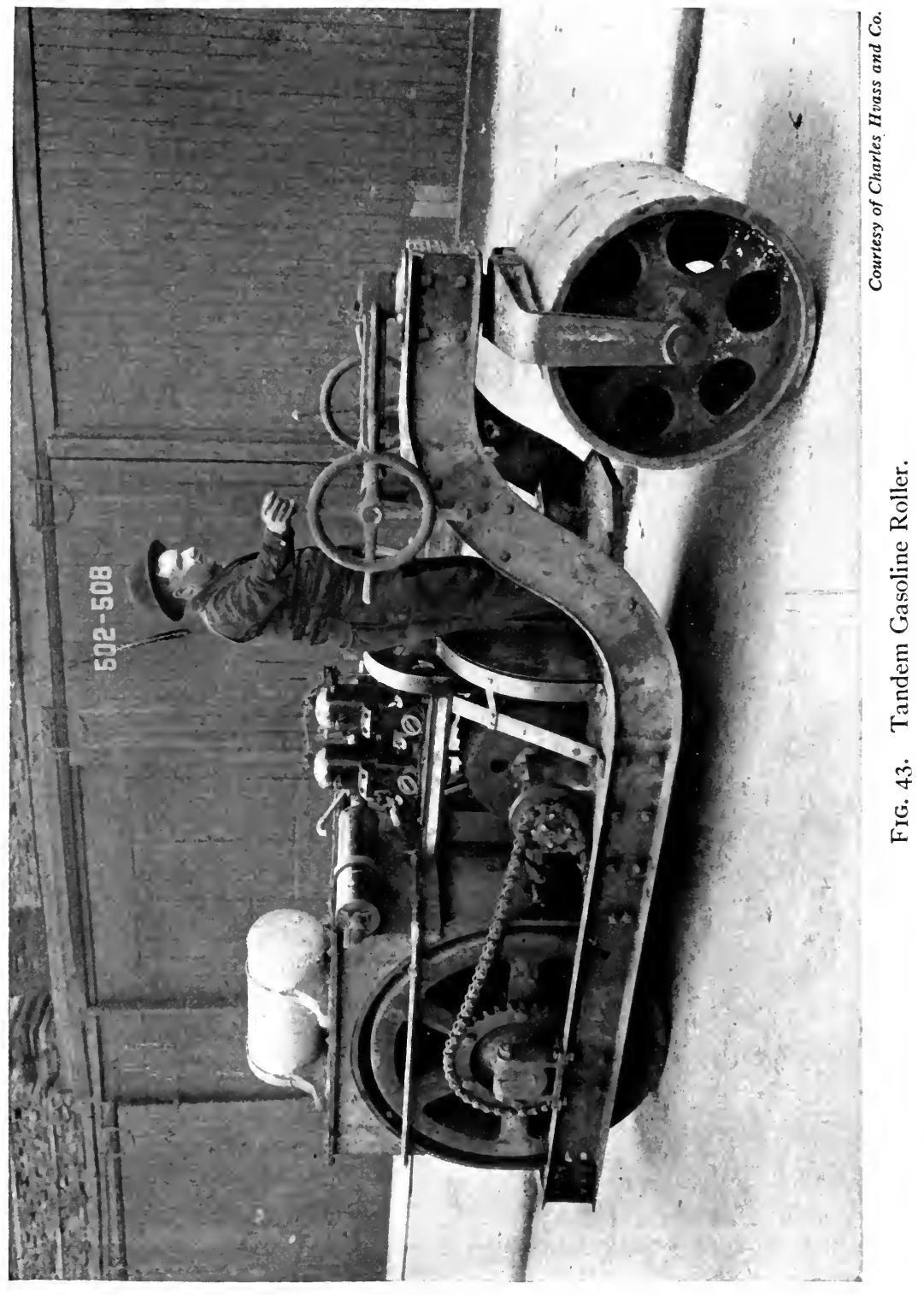


necessary to turn them around. This is accomplished generally by having two sets of picks, one set being used when the machine runs in one direction and the other when in the opposite direction. Scarifiers of this type are towed by a chain hitched to the roller. The arrangement of the picks and the form of the

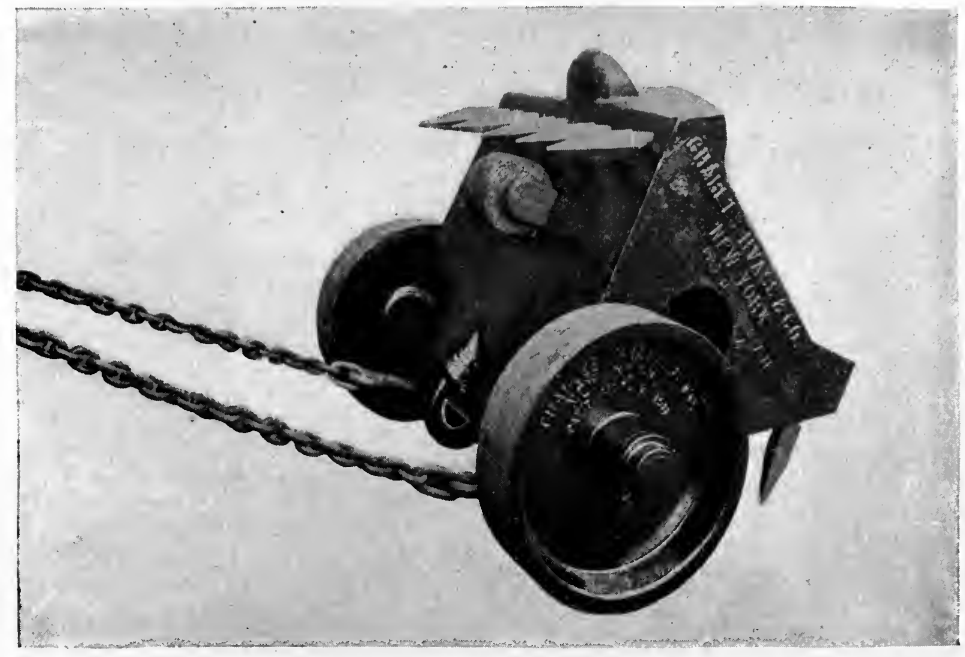

Courlesy of Charles Hvass and Co.

FIG. 44. Hvass Scarifier.

blocks vary, but all of the machines work on the same principle. Figs. 40 and 44 show two American scarifiers which are typical of the block type.

Watering Carts. In the United States the cart used for sprinkling generally consists of a cylindrical tank mounted horizontally on a four-wheel truck. The tank may be made either of wood or of steel. The capacities vary from 350 to $\mathrm{I}, 000$ gallons. Carts with horizontal valves throw the water out in horizontal sheets, while those with vertical valves distribute the water in vertical sheets. (See Fig. 45.)

\section{DrAINAGE}

Object of Drainage. In the construction of any type of road or street, drainage is of the utmost importance, as water 
in the subgrade or on the surface is one of the most destructive agents encountered in the maintenance of highways. Provisions for drainage should be made so that water will neither be retained in the substructure beneath the roadway nor stand on the surface nor at the sides of the roadway. Since the loads which come on a roadway surface must ultimately be borne by the natural soil, it is obvious that a dry condition of the subsoil is a prerequisite for the proper accomplishment of this duty.

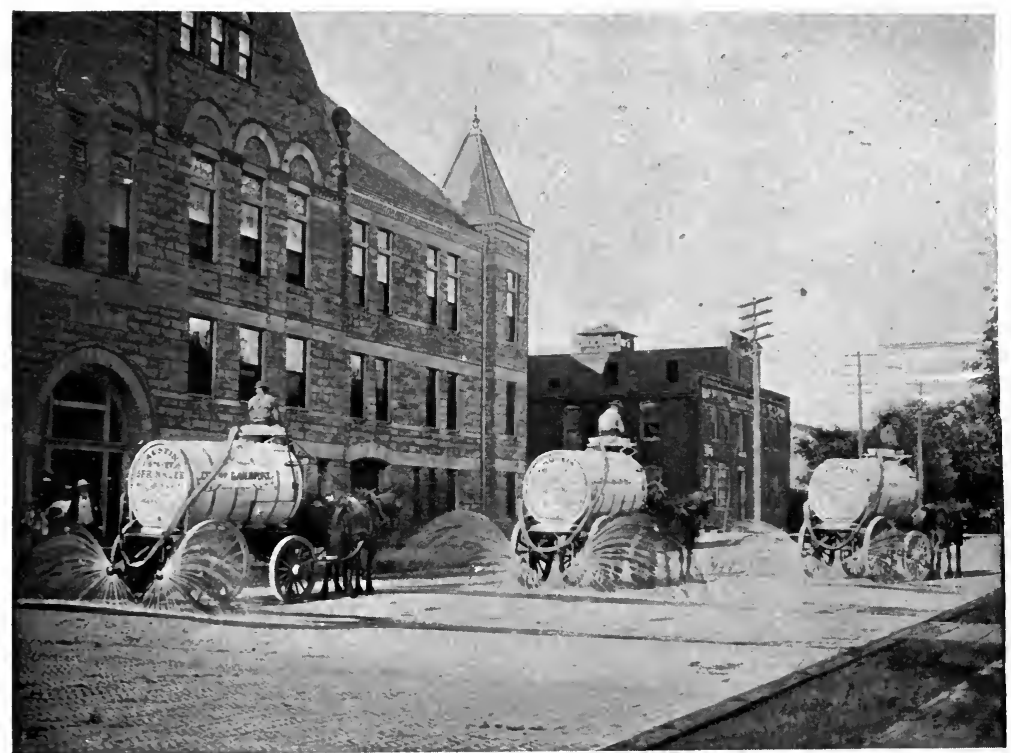

Courtesy of the Austin Mfg. Co.

FIG. 45. Watering Carts.

A soil which is saturated with water will have a very low supporting power. Drainage may be properly considered under two main heads, subdrainage and surface drainage.

Subdrainage. Conditions Encountered. Geological structure, the location of the highway, and the climatic conditions are important factors in subdrainage design. If the subsoil of a highway is of a sandy or gravelly nature and the highway is located on high ground so that the water as it seeps through the soil readily runs off, subdrainage is not necessary. On the other 
hand, a roadway surface of a clayey or other plastic soil, which readily retains water, will become almost impassable unless properly subdrained. Springs, which occur on hillsides, unless led from the highway by subdrains, will soften the subsoil. A stratum of rock may lie near the surface and water may collect in its depressions and tend to soften the overlying road.

If water is allowed to remain in the subsoil in cold weather, the ground freezes and expands, thus loosening the soil. It is quite essential, when the frost comes out of the ground in the spring, to provide means so that the water below the surface, which has accumulated by thawing, will be immediately carried away. Since the thawing action takes place below as well as near the surface, the foundation will soon soften if the resultant water is not removed. Subdrains properly placed will remove this water. The hydrostatic pressure of water in places higher than the level of the highway may force the water slowly up through the soil, which fact may explain the presence of water in a road during a thaw where it was known that the ground when frozen was comparatively dry.

Pipe Drains. One of the best and cheapest methods of accomplishing subdrainage is by means of lines of tile pipe.

The Pipe. The pipe may be made of either cement or vitrified clay. The cement pipes are generally made with plain ends and the vitrified pipes with bell and spigot ends. The pipes are made in $\mathrm{I}$-foot lengths for small diameters and in 2-foot lengths for large diameters.

Determination of Size of Pipe. The requisite size of pipe required depends upon the amount of water to be carried and the grade to which the pipe is laid. There are several formulas by means of which the size can be determined. The assumptions that must be made, however, in applying a formula to any particular case are such as to render an accurate determination of the proper size impossible. For instance, the amount of water to be carried off cannot be more than roughly approximated, and very little reliable data relative to the flow of water in pipes of this kind are obtainable. The amount of water is generally assumed to vary between $\mathrm{I} / 4$ inch and $\mathrm{I}$ inch per acre per 
twenty-four hours on the area to be drained, an average value being $1 / 2$ inch. Experience as to what a tile drain has accomplished in any particular locality is a better guide than any result that may be obtained by formula. It has been well established in practice that the minimum size should be 4 or 5 inches. In places where no drains have been laid, the size of pipe obtained by formulas may serve as a guide in judging of the proper size to be used. The following formula is given by Professor I. O. Baker, M. Am. Soc. C. E.:

$$
A=\mathrm{I} .9 \sqrt{\frac{f d^{5}}{L}}
$$

in which $A$ is the number of acres for which a tile having a diameter of $d$ inches and a fall of $f$ feet in a length of $L$ feet will remove $I$ inch of water in twenty-four hours.

Laying the Pipe. The pipe is usually laid at the sides of the road along the lines of the open ditches and at a depth of $2 \frac{1}{2}$ to 3 feet below the bottom of the ditch. The necessity for a line of pipe at each side of the road is wholly a matter of judgment. Generally on side hills where a subdrain is needed, a single line on the uphill side of the road will serve to cut off the water coming through the soil. On hills the pipe may be laid under the shoulders of the road, since, if placed in the ditch, it is liable to be washed out. On streets that are paved and curbed the pipe is frequently laid underneath the curbs. Another method of constructing pipe drains is to lay lines of pipe at intervals, either transversely or in the form of a V, the ends of the pipes opening into the side ditches. After the pipe is laid the trench is filled with broken stone, gravel, earth, brush, or a combination of these materials. The drains constructed by the Massachusetts and Maryland Highway Commissions are laid as follows: 2 inches of broken stone or gravel which will pass through a $1 / 4$-inch mesh and not through a $1 / 2$-inch mesh is used for a bed; the joints are left open; clean gravel or broken stone of the sizes already described is filled about the pipe and over it for a depth of I foot; the remainder of the trench is filled with stone which will pass through a 3 -inch and not through 
a I-inch screen. (See Fig. 46.) All drains must be carried to a proper outlet, such as a culvert, ditch, or another drain. The minimum grade of pipe is specified by some engineers as 6 inches in roo feet, whereas others will allow as small a fall as $1 / 2$ inch in 100 feet. In clayey soils a tile pipe will drain a width about six times its depth on each side; in porous soils the distance drained on each side may be as much as fifteen or twenty times its depth below the surface.

Cost of Pipe Drains. Pipe drains are generally paid for at a price per linear foot, which

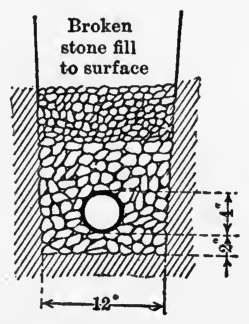
includes the cost of trenching, refilling with FIG. 46. Pipe Drain. gravel or broken stone, the cost of pipe and

laying. Fifty cents is an average price per foot for pipe drains used on state highway work.

Blind and Other Drains. Blind drains are generally constructed by excavating a trench from $\mathrm{I}$ to 2 feet in width. The trench is partially filled with broken stone, gravel, or other porous material. Such drains may be constructed alongside or across the road at intervals. They serve the same purpose as a tile pipe, but they are not as effective as pipe drains, as they are more liable to clog up. The drainage of some soils can be improved by excavating and refilling with a porous material. Generally, however, the depth at which the road must be subdrained is such that to accomplish effective results by this method makes the cost excessive.

Surface Drainage. Side Ditches and Gutters. The transverse slopes or crown of the roadway serve to remove the water from the surface to the ditches or gutters at the side, whence it follows the longitudinal grade to the point of outlet which may be a culvert, natural waterway, or catch-basin. The amount of crown of different types of roads and pavements, methods of obtaining same, and the minimum longitudinal grade have been previously discussed in Chapter IV.

On roads it is usually necessary to construct ditches only in cuts, since on fills the grade of the roadway is raised above the 
general ground level. When the fills are shallow or the road has a steep grade, the construction of gutters may be advisable to protect the shoulder of the road. The ditch or gutter usually has the same grade as that of the center of the road, although on very flat grades the ditch may have a steeper grade than the

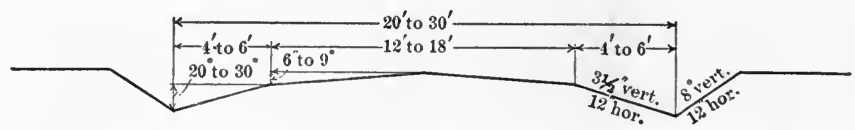

FIG. 47. V-shaped Ditch.

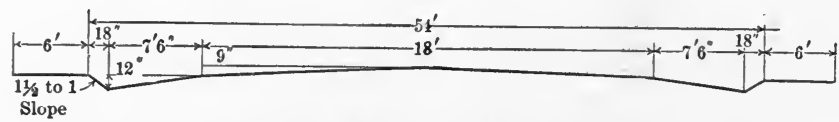

FIG. 48. Wide and Flat Ditch.

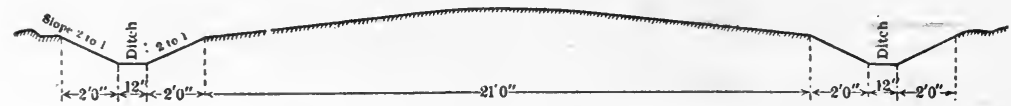

FIG. 49. Ditch with Trapezoidal Section.

roadway. The cross-section of the ditch is usually made in one of the following forms: the V-shaped, the trapezoidal, or the wide flat ditch. The last type is, in reality, formed by a continuation of the slope of the roadway surface. A ditch having a trapezoidal or a V-shaped cross-section will carry more water, but is very much more liable to gully out than one constructed wide and flat. Other advantages of the wide and flat ditch are that it is not so dangerous for the traffic and that it is much easier to construct and maintain, particularly if a road grader is used in accomplishing the work. The width and depth of the ditch depend upon the amount of water to be carried, and vary to some extent with the width of the road. Typical sections of ditches are shown in Figs. 47, 48, and 49.

Water should not be carried too great a distance in a ditch before it is given an outlet, since the amount of water will become so great that the capacity of the ditch will be exceeded, and gullying will result. It is also easier to turn off a small 
amount of water into the adjacent fields without objection on the part of the property owner, than it is to dispose of a large amount in this manner. There are places along the road where the water may be turned off at each side, such places, for instance, as fills with the ground sloping away from the road on both sides. If there is much water to be turned over a bank in this manner it will be necessary to protect the bank from washing out. A small amount of water running down high banks composed of sandy soil is liable to cause great damage, for the small gullies made by the water may rapidly extend back into the roadway surface. The bank should be protected by sod, or a paved gutter should be built down the side of the bank to carry the water. On hills where the grade exceeds 3 percent and the soil is loose and sandy, it may be necessary to pave the ditch with cobble-stone, field-stone, brick, or paving blocks in order to prevent gullying. The construction of gutters used in connection with various pavements is considered in detail in Chapter XX.

\section{Foundations}

Necessity of Foundations. The soil composing the subgrade, which will be designated the natural foundation, eventually supports the weight of traffic on the wearing course of the roadway. Usually the soil does not possess sufficient bearing power to support adequately the wearing course and the traffic which comes upon it. It is necessary, therefore, to utilize an artificial foundation, which has been defined as "that layer of the foundation especially placed on the subgrade for the purpose of reinforcing the supporting power of the latter itself, and composed of material different from that of the subgrade proper." * Thus traffic loads are, under average conditions, transmitted through the wearing course of the roadway to the artificial foundation, and thence to the natural foundation or the subgrade of the highway. It is thus seen that as the traffic loads increase with a given kind of soil or as the supporting power of the natural

* I9I4 Proceedings, Am. Soc. C. E., page 3015. 
foundation decreases, the strength or thickness of the artificial foundation must be increased.

The subject of foundations will be considered under two main heads, namely, natural foundations and artificial foundations. With the exception of earth and sand-clay roads, the construction of all of the more common types of roads and pavements might be described as composed of three distinct steps: the construction of the subgrade or natural foundation, the construction of an artificial foundation, and the construction of the wearing course or pavement. On this assumption, therefore, the lower courses of either a broken stone or a gravel road will be considered as types of artificial foundations.

Natural Foundations. The natural foundation is composed of rock, gravel, or some kind of soil. The different types of rock are considered in Chapter VIII and the characteristics and occurrence of gravel in Chapter VII.

Soil Classification. Soil is defined as "a mixture of fine earthy material with more or less organic matter resulting from the growth and decomposition of vegetation or animal matter."* The majority of soils are of mineral origin and are formed by the breaking down of rocks through the agency of the wind, water, and glaciers in combination with temperature changes, chemical action, and plant growth. Soils may be designated as sedentary or transported. Sedentary soils are those which remain near their source of formation. Transported soils, as the name implies, have been carried by some geological agency, generally either rivers or glaciers, from the place where they were first formed to some other locality. Generally the principal constituents of soil are silica, with varying amounts of alumina, oxides of iron, lime, magnesia, and the alkalies, together with a small amount of organic matter. The common soils encountered in highway work are classified as sand, clay, loam, marl, peat, and muck.

Sand. Sand has been defined as "finely divided rock detritus the particles of which will pass a ro-mesh and be retained on a 200-mesh sieve."*

* Proposed by Committee D-4, Am. Soc. Testing Materials. 
Clay. Clay is "finely divided earth, generally silicious and aluminous, which will pass a 200-mesh sieve."* Clays result mainly from the decomposition of feldspar and micaceous rocks. When wet a clay becomes very plastic and is extremely unstable, and, due to its impermeable qualities, it dries out slowly. A clay becomes hard in drying and contracts to such an extent that areas, where large clay deposits occur, are traversed by wide cracks.

Shale. Shales are chemically of the same composition as clays. They have a laminated structure and are similar in appearance to slates. Shales will rapidly disintegrate on exposure to the atmosphere.

Loam. Loam is "finely divided earthy material containing a considerable proportion of organic matter." $\dagger$ Loams may be any soil between sand and clay, as they contain more or less of each of these materials. They may be classified as heavy clay loams, clay loams, sandy loams, and light sandy loams, depending upon the quality of the sand or clay content. Stockbridge classifies loams as follows: "Heavy clay loam with to to 25 percent of sand; clay loam with 25 to 40 percent of sand; loam with 40 to 60 percent of sand; sandy loam with 60 to 75 percent of . sand; light sandy loam with 75 to 90 percent of sand." In the Middle West a black loam which contains so much clay as to be sticky when wet is known as "gumbo."

Marl. Marl is a term which is applied to all calcareous clays containing a minimum of 15 percent of carbonate of lime and a maximum of 75 percent of clay. The larger the proportion of carbonate of lime, the less plastic is the material until finally it is no longer considered as marl, but is called argillaceous limestone.

Peat and Muck. Peat and muck are generally distinguished from other soils by the presence of humus or vegetable matter. Peat is formed by the decomposition of vegetable matter under water. Humus is the soil resulting from the decomposition of vegetable matter on the surface of the ground.

* I914 Proceedings, Am. Soc. C. E., pages 3013 and 3017.

$\dagger$ I9I4 Proceedings, Am. Soc. C. E., page 3015. 
Loads on the Foundation. The safe loads per square foot specified by Professor William H. Burr, M. Am. Soc. C. E., for foundations are as follows:

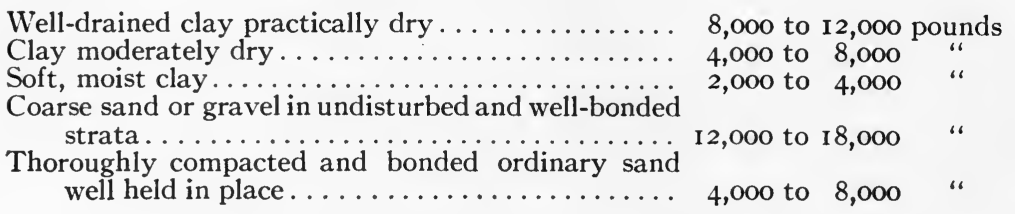

It is generally assumed that the lines of pressure of a load which is supported on an appreciable depth of earth, concrete, stone, or other stable material, will diverge from the point of contact in all directions at an angle of about 45 degrees.

Improving the Natural Foundation. Gravel, clay, and sand make excellent foundations if well drained. A clayey subsoil may be improved by the addition of sand or gravel, while a sandy subsoil may be improved and made more unyielding by the addition of clay. Muck should be removed for a certain depth, varying with local conditions, and replaced with some other material. The availability of materials will usually determine which of the following should be used for adding to or replacing the unsatisfactory soil: broken stone, stone screenings, gravel, sand, shells; cinders, clinkers, brickbats, slag, or clay. Any subsoil will generally be improved by rolling, and such a process will show up weak spots, which should be replaced with other material.

Artificial Foundations. This class of foundations is usually constructed of large stone, gravel, broken stone, slag, hydraulic cement-concrete, or bituminous concrete. Brush and plank have been employed in the construction of foundations through swampy land. Old pavements have frequently been made to serve as foundations for surfaces of some other type. The selection of any particular type is governed principally by considerations of the type of roadway surface to be supported, the traffic to which the surface is subjected, relative cost of available materials, and the natural soil conditions.

Stone Foundations. In this class are included, besides the 
methods originally proposed by Telford and Tresaguet, V-drain foundations and foundations composed of broken stone or similar material.

Telford Foundation. Telford, in constructing broken stone roads, advocated the use of a foundation of large-size stone carefully placed by hand. His method followed that previously adopted by Tresaguet, the principal difference between the two methods being that Telford placed his foundation on a flat subgrade and obtained the crown in the foundation by using stones of different depths from the center to the sides, whereas in Tresaguet's method a subgrade parallel to the finished surface was employed and all the stones were practically of the same depth. Foundations constructed by both methods are now called Telford.

There are conditions under which a Telford foundation will give results that are economical, but its universal use should not be recommended, since experience has demonstrated that a broken stone road without such a foundation on a well-drained and compacted subsoil is fully capable of carrying a considerable traffic. Telford is advisedly used on wet soils where small broken stone would be pushed down into the soft soil.

A Telford foundation is usually constructed on a subgrade, the surface of which is parallel to the finished surface of the road. The stones used vary from 3 to 8 inches in width, 6 to I 5 inches in length, and from 6 to 8 inches in depth. The stones are carefully laid on the subgrade with the greatest length across the road, and the widest edge down. The projecting edges of the stones above the surface are knocked off with a hammer, and the spaces between the stones are packed and wedged with spalls. The whole surface is then rolled with a heavy roller. It is then ready to receive the upper courses of stone. The cost of Telford foundations varies from 35 cents to about \$I per square yard. The thickness of the course and the availability of the material largely affect the cost of this type of foundation.

$V$-Drain Foundation. A V-drain foundation is constructed by excavating the roadway for its full width, from 4 to 8 inches deep at the sides and from $\mathrm{I} 2$ to 18 inches deep at the center, 
thus producing a flattened "V-shaped" trench. This type of construction serves as a drain as well as a foundation. The excavated space is filled with boulders and small stone, as is shown in Fig. 50. The larger stones are placed at the bottom of the trench and the smaller stones at the top. The trench is

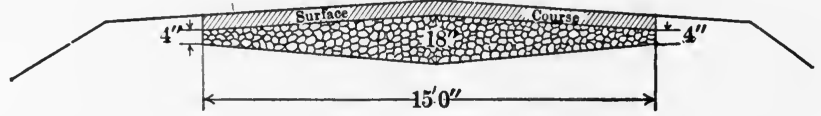

FIG. 50. V-Drain.

intercepted by culverts, constructed across the road at the low points, which take away the water that flows through the $\mathrm{V}$-drain. The price of V-drain is sometimes stated as so much a linear foot, which method is rather indefinite unless the cross-section of drain is known. Contract prices vary from 75 cents to $\$ \mathbf{1 . 2 5}$ per cubic yard.

Broken Stone Foundation. The lower or bottom course of a broken stone road, when the latter is built in two courses, is the foundation for the upper or wearing course. In the United States this course is usually about 4 inches in depth after compaction, but should be as much as 6 to 8 inches in order to take the increased loads due to modern traffic. Where the subsoil is poor or the road is subjected to very heavy traffic, or where it is desired to aid the subdrainage of the road, the lower course should be increased in thickness or an additional course of broken stone should be used. This extra layer, sometimes called the subbottom course, varies from 3 to 18 inches in thickness and is composed of the largest sized products of the crusher or large field-stone, broken boulders, or ledge stone. Gravel, slag, brickbats, cinders, or clinker are often substituted for the broken stone in foundation courses.

Cement-Concrete Foundations. Concrete foundations should ordinarily be used under all types of stone block, brick, sheet asphalt, and bituminous concrete pavements. The thickness of the concrete foundation varies from 4 to 8 inches, 6 inches usually being employed. An 8-inch foundation is 
necessary only when the subsoil is extremely poor or the traffic exceptionally heavy. Whenever a concrete foundation is constructed, traffic should be kept from it for seven to ten days in order to allow it to set up thoroughly. Concrete is manufactured by three methods: mixing, in situ, and grouting.

The Cement-Concrete. Briefly stated, concrete is a mixture of water, hydraulic cement, sand or other fine material, and broken stone or gravel or similar material. The best and strongest concrete will result when the sand is sufficient in quantity to just fill the voids in the stone, and enough cement is used to fill the voids in the sand and stone. An accurate proportioning of the materials can be made only by carefully determining the voids of the various ingredients, and since the sand, stone, and gravel are quite variable in this respect, frequent determinations should be made. It is customary in practice to adopt certain definite proportions such as $\mathrm{I}: 2: 5, \mathrm{x}: 3: 6$, or $\mathrm{I}: 2 \mathrm{x} / 2: 7$; the first figure indicating the number of parts of cement; the second figure, the parts of sand or fine aggregate; and the third, the parts of the coarse aggregate. Two kinds of cement are used, namely, Portland and natural, there being many brands of each. A natural cement does not produce so strong a concrete and it obtains its initial set much quicker than a Portland cement. On this account, and due to the fact that the two cements are nearly equal in price, Portland cement is usually specified to be used in all classes of concrete foundations.

Mixing Method. The cost of a concrete foundation constructed by the mixing method will vary, depending upon the richness of the mix used, the handling of the different materials preliminary and subsequent to the mixing, and upon the method of mixing.

The proportions having been adopted, the various ingredients are measured out by volume and mixed together with water until the desired consistency is obtained. A mixture which may be easily placed with good results will be obtained if enough water is used so that the resultant concrete is somewhat sloppy, but not so much so that any of the water will run away from it, or so much as will cause a segregation of the ingredients. The 
concrete thus mixed is placed upon the prepared roadbed to the required thickness. The concrete is then tamped and smoothed with the backs of shovels until the free mortar rises to the surface. Since in the majority of types of pavements a layer of some kind of material is interposed between the surface of the foundation and the wearing course material, any very slight irregularities in the surface of the foundation will not cause trouble. When a smooth surface is required the concrete should be struck with a template that will give the desired shape. Care should also be taken in conveying the concrete from the place where it is mixed to the place where it is deposited to see that none of the ingredients are segregated. When the foundation is completed it should be kept moist for at least two or three days. When the sun is extremely hot, it may also be necessary to cover the concrete during this period.

Hand Mixing. One method of hand mixing is to spread the sand for a batch in a thin layer in the form of a square or a rectangle on the mixing platform of boards finished with a smooth and tight surface. The required amount of cement is then spread out on the sand and the two are turned with shovels in a dry state until thoroughly mixed. Water is then added and mixed with the sand and cement, thus making a mortar. The mortar is spread out in a thin layer in a manner similar to the way the sand was first spread. The required amount of coarse aggregate, which has been previously wet down, is then brought to the platform and spread out over this layer of mortar. The mortar and the coarse aggregate are then turned until thoroughly mixed.

Machine Mixing. The concrete mixing machine employed in paving work is of the batch or the continuous mixer type. One of the main objections to a continuous mixer is the uncertainty of securing the right proportions of the ingredients. In the continuous machines the mixing is generally accomplished by means of paddles fixed to a revolving shaft which mixes the materials together as they fall into the mixing trough and at the same time pushes them toward the discharge end. Water is added to the mass when it reaches the mixing trough. In the 
case of batch mixers each batch of concrete is mixed separately and the mechanism does not have to be depended upon for the accurate proportioning of the mix. There are several types, similar to that shown in Fig. 5I, which are portable and especially designed for paving work. The mixing drums of batch mixers vary in shape, some being cylindrical, others cubical,

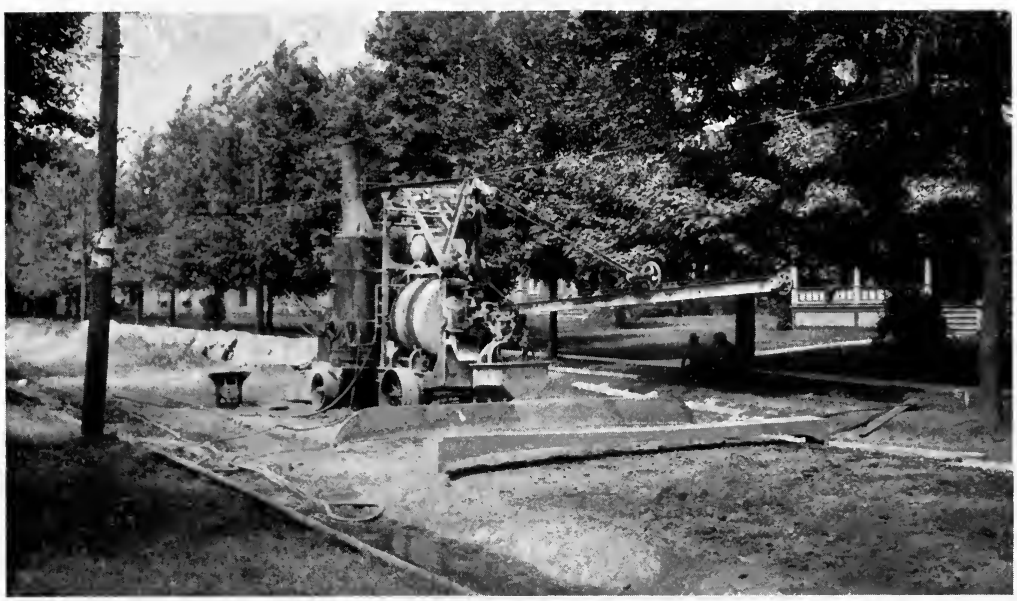

FIG. 5I. Koehring Cement-Concrete Mixer.

and still others conical. In all types the drum revolves, turning the concrete over and over. Some machines are equipped with a swinging steel boom upon which a bucket travels. With this arrangement the concrete may be distributed within the area which can be reached by the boom.

The contract price of a $I: 3: 6$ concrete foundation, mixed and placed, varies from $\$_{5}$ to $\$ 7$ per cubic yard or from about 83 cents to \$I.I6 per square yard, if the foundation is 6 inches thick.

In Situ Method. A second method of construction, known as in situ, consists of spreading and rolling a layer of broken stone of the required thickness in a manner similar to the construction of the bottom course of an ordinary broken stone road. A I : 3 mixture of cement and sand in a dry state is spread over the surface and swept into the voids. The surface is flushed 
with water, rolled, and more dry mortar spread during flushing and rolling until all voids are filled.

Grouting Method. In a third method a layer of broken stone, of sufficient depth to make the requisite thickness of concrete, is deposited on the subgrade. The layer is thoroughly rolled and is then poured with a grout composed of one part cement to four parts sand. The grouting and rolling are continued until the voids in the stone are filled. The Hassam Paving Co., of Worcester, Mass., use special grout-mixing tanks in connection with this kind of work. The grout flows from these tanks through a spout to the point on the road where it is to be used.

Foundations Over Marshes. Sometimes it becomes necessary to carry a road across marsh land which is so unstable that a crowbar will sink into it. When the topography of the land is such that there is no opportunity for subdrainage, some support must be provided for the embankment. Usually there will be more or less settlement, and hence no improved form of surfacing should be placed on the fill until all settlement has ceased.

Old Pavements as Foundations. In New York City and some other municipalities old stone block pavements have been used as foundations for sheet asphalt pavements. In some cases, in order to provide room for the asphalt wearing course, the blocks were taken up and relaid on their sides. It is contended that a large percentage of the repair work on the asphalt pavements in these places is due to the fact that there is more or less movement of the blocks.

Bituminous Concrete Foundations. A bituminous concrete foundation has been used to. some extent as a substitute for a hydraulic cement-concrete foundation for sheet asphalt and other bituminous concrete pavements. Probably the first construction of this kind was used in Washington, D. C., from 1872 to 1887 , when coal-tar pavements were laid quite extensively in that city. In Omaha, in I89r, a 6-inch bituminous foundation for an asphalt pavement was built of broken stone and gravel thoroughly mixed with asphalt. Foundations of a similar character are sometimes used to-day. They are not as strong, however, 
as those of hydraulic cement-concrete and have "the further objection that the wearing course cannot usually be removed without disturbing the foundation.

Foundations for bridges and sidewalks will be considered under the chapters especially devoted to these subjects. 


\section{CHAPTER VI}

\section{EARTH AND SAND-CLAY ROADS}

OCCURRENCE. Earth roads comprise about 90 per cent of the total road mileage in the United States, or approximately 2,000,000 miles. Although many of the States are spending large sums of money in constructing highways with a broken stone or gravel surface or with some type of pavement, it is obvious that the improvement of the total mileage in this manner is a stupendous task and not warranted from the standpoint of either economy or efficiency. The construction and maintenance of earth roads is therefore of great importance, particularly in those sections of the country where money or roadbuilding materials, such as stone and gravel, are wanting. In some States the solution of the good roads problem is based mainly upon the successful construction and maintenance of earth roads.

The labors of those who have made the improvement of earth roads a serious study have led to the construction of sand-clay roads in certain sections. This type has been built with varying degrees of success in different parts of the country, the total mileage in the United States being about 25,000.

\section{SoILS}

The formation of soils and their classification have previously been given in Chapter $\mathrm{V}$, hence in this chapter only their relation to the construction and maintenance of earth roads will be considered. The soil conditions in different parts of the country and even in restricted localities are so variable that what may be an advisable method of construction in one place will not serve in another. Therefore a careful examination of the soil is essential. 
SAND. Sand is practically the only soil that makes a better road surface in a wet than in a dry condition. This fact is well illustrated by the wet sand on a beach between low and high water marks. It is possible to draw loads over this surface without difficulty. A sandy road when dry, however, is as objectionable as a road of clayey soil when wet.

Clay. Clays are of two kinds, ball clay and slaking clay. The ball clay is extremely plastic and, as its name implies, tends to ball or lump up. It will keep its shape even if immersed in water for some time. A slaking clay, on the other hand, does not have this same power of plasticity and is more crumbly in its nature, and more readily miscible with water. It is apparent that the slaking clays do not possess the binding power of the ball clays. A soil which is largely composed of clay acts just the opposite from sand under the same climatic conditions. In dry. weather the surface becomes hard and if kept in proper shape makes a good surface. In continued wet weather, however, the water soaks into the clay and softens it, with the result that the surface no longer can support the traffic.

Sand-Clay. An earth road in which the surface is composed of a soil that is a mixture of sand and clay will be much more satisfactory, under most conditions, than one composed of either of these soils alone. There are many places throughout the country where a top soil is found which is a mixture of these two materials and which serves to make an excellent road. Suitable top soils of this character should be composed of a mixture of clay and sand or gravel which shall not contain stones over $2 \frac{1}{2}$ inches in diameter or an excess of fine sand. The material passing a one-hundred mesh sieve should be plastic when mixed with a small amount of water.

\section{Construction}

The construction of earth and sand-clay roads consists of providing proper drainage through the medium of culverts and drains and the formation of the wearing course.

Drainage. One of the principal faults with a large majority 
of the earth roads in this country is that they are not properly drained. The want of proper drainage allows the surface to become soft after rains and at times when the frost is coming out of the ground, with the result that the traffic soon cuts through and in some cases the roads become practically impassable. If subdrains are employed in an intelligent manner, if the surface is kept shaped up so as to throw the water to the side ditches, and if the culverts and ditches are properly constructed and maintained, there is no difficulty in making an earth road readily passable at all times of year to the traffic for which it is suitable.

General methods of constructing subdrains have been described in Chapter V.

The surface drainage is accomplished by means of the longitudinal grade, the crown of the road, and the side ditches. If practicable the longitudinal grade should not be over 4 percent and under no conditions over 6 percent. The surfaces of earth roads having grades over 4 percent are expensive to maintain after heavy rains on account of the consequent erosion of the surface by rapidly flowing water. Figs. $5^{2}$ and 53 show typical cross-sections of earth roads. The cross-section should be of such form as will render practicable the economic use of the standard types of grading machines described in Chapter V. The sections should be varied with the grade as indicated by the illustrations of cross-section. The design shown in Fig. 54 is based upon the conclusion that erosion of earth ditches will usually occur on grades of over 4 percent. Since the surface of an earth or sand-clay road is not as impervious as those constructed with a material such as stone or gravel, it is generally given more crown. An average crown of about one inch to the foot is common, the surface being shaped to follow a circular or other curve or else formed by two or more intersecting planes. In no case should the ditches be less than 6 feet in width, as narrow ditches soon become clogged and unable to readily carry off the surface water, with the result that the water seeps into the roadway. The depth of the ditch should be at least 2 feet 6 inches below the center of the surface of the roadway 


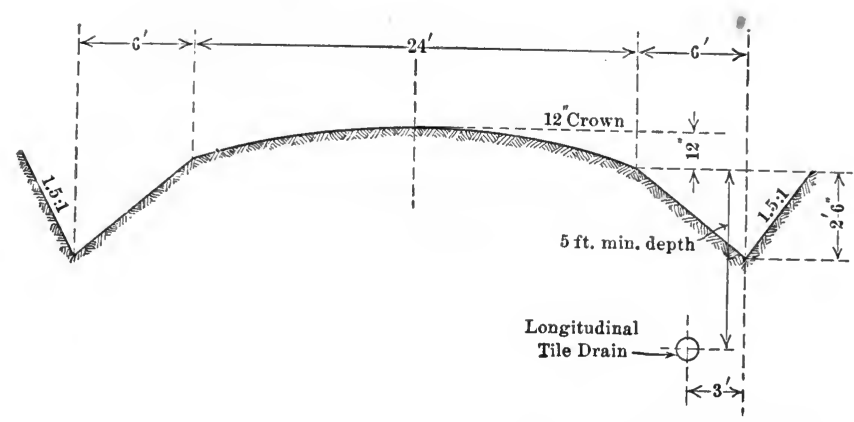

Courtesy of the Engineering News.

.FIG. 52. Iowa State Highway Commission Cross-Section for Earth Roads Having Grades of 2 Percent or Less.

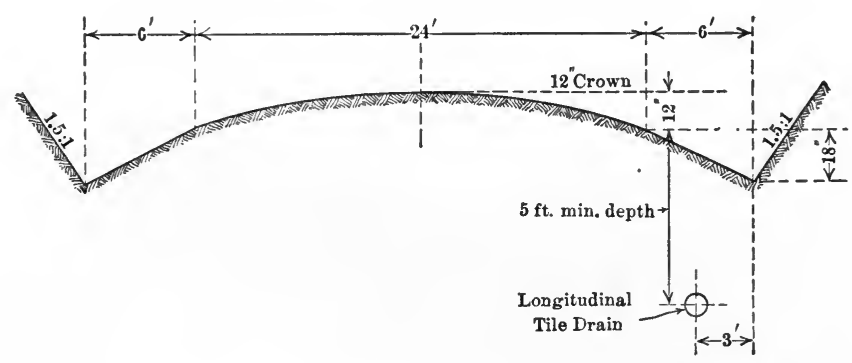

Courtesy of the Engineering News.

Fig. 53. Iowa State Highway Commission Cross-Section for Earth Roads Having Grades Over 2 Percent but Less Than 4 Percent.

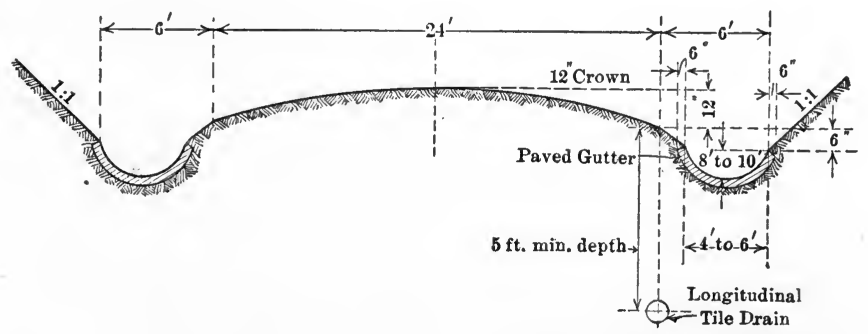

Courtesy of the Engineering News.

FIG. 54. Iowa State Highway Commission Cross-Section for Earth Roads Having Grades of 4 Percent or More. 
in order to provide ample waterway. Offtake ditches or other outlets for the water flowing in the longitudinal ditches should be provided, as otherwise the volume of water will exceed the capacity of the ditches.

Wearing Course of Earth Roads. The method of constructing the wearing course of earth roads varies with the machines available. The fundamentals of construction with adequate plant equipment are well illustrated by the practice of the Iowa State Highway Commission as described by Prof. T. R. Agg.*

"There are the three following classes of roads encountered. in the various counties in Iowa where the elevating grader has proven satisfactory:

"(I) Roads practically level where the new grade line is parallel to the profile on the old road, there being only a few knolls to be removed.

"(2) Roads on which there are a succession of knolls and consequently a succession of cuts and fills most of which do not exceed about two feet in depth.

"(3) Roads where extensive grade-reduction work must be done.

"The outfit necessary for roads of Class I consists of the elevating grader drawn by 6 or 8 teams or by a tractor, a blade grader, a few slips or wheelers, a heavy disk harrow, a heavy straight-tooth harrow, and a split-log or plank drag. If a roller is also available a better road can be constructed than is possible without it. For roads of Classes 2 and 3, a number of dumpwagons are also necessary.

"In starting the construction the first cur is taken ar tne shoulder line, and the material thus removed is deposited near the shoulder line of the opposite side of the road, but, of course, in the roadway.

"Stakes are set for the first cut so that the driver can follow them conveniently. If the outfit is horse-drawn, the stakes are set so that the tongue of the elevating grader will follow them.

*From Engineering News, April 16, 1914. 
If the grader is drawn by a tractor, they are set, so that the front wheel on the steering side will follow them. The exact distance of these stakes from the line of the cut will vary somewhat with the type of elevating grader used, and must be determined before the stakes are set.

"The first cut is a light one and usually one horse of the lead team follows this first furrow and thereby guides the grader in making the succeeding cut. If the grader is drawn by a tractor, a side hitch is used so that the tractor travels on the 'land' side, and a plumb bob is hung from the tractor in such a position that it will follow the furrow and thus serve to assist the driver in steering.

"On roads of Class $\mathrm{I}$, the successive rounds of the elevating grader are made without reference to the slight knolls that occur; and the material deposited on the roadway on top of the knolls is hauled away by slips or wheelers, while the elevating grader is completing its round. A suitable adjustment of the working forces can be made so that the slips or wheelers can be kept up with the grader.

"On roads of Class 2, teams with dump-wagons follow the elevating grader, loading where cuts are to be made and dumping the materials in the fills, the elevating grader continuing its rounds and depositing directly on the road in the low places. Here again a suitable adjustment of working forces must be made so that the elevating grader will not have to wait for the wagons. It is more economical, however, to construct a mile or more of road at a time than it is to turn the elevating grader constantly, as would be necessary if each cut were completed by itself.

"On roads of Class 3, the elevating grader is simply used as a loader for the wagons, and each cut is completed by itself. The economy of the grader in this case depends upon the steepness of the grade and the room for maneuvering.

"As the elevating grader makes successive rounds it gets farther away from the center of the road and, consequently, when it is at the deepest part of the ditch where the heaviest cutting is being done the earth is deposited in the middle of 
the road, where the greatest filling is necessary to give the crown.

"The material deposited on the roadway will consist of many large lumps as well as of sods and fine material. To work this material down to a surface that can be travelled, the clods and sods must be broken up with a disk harrow until small enough to form a satisfactory surface. Often the sods and weeds are collected by harrowing with a stiff-tooth harrow and thrown out with pitchforks.

"To bring the surface to its final shape a few rounds must be made with a blade grader. Then, after the first rain, the surface is smoothed with a road drag and, when partially dry, rolled. Constant dragging is necessary during the first year to keep the road in shape while it is becoming compacted by traffic.

"The cost of constructing earth roads by this method varies from about \$100 per mile for Class I roads, to \$250 per mile for Class 2; while the cost of Class 3 is an exceedingly variable quantity, as is apparent from the nature of the work. As an average of the work done by some of the well organized counties, \$5 5 per mile may be taken."

Wearing Course of Sand-Clay Roads. Top-Soil Roads. Many miles of roads in the South have been surfaced with from 6 to 44 inches of top soil, consisting of a mixture of sand and clay taken from the adjacent fields. * "The subgrade of the roadway is brought to a level or slightly convex cross-section. The sand-clay is then placed in a continuous layer, from Io to I 2 inches thick, the material being spread as fast as delivered and not dumped in piles here and there. This layer is spread for a width of 20 feet for a nominal 3o-foot roadway. After a sufficient quantity has been placed in this manner, an ordinary road machine is drawn along the ditch line, cutting about four inches deep at the outside, and the blade is set so as to cast the material from the ditch against the edge of the sand-clay layer. In this way a shoulder is built up against the sand-clay to hold it in place. This also shapes the ditch. After both sides have been thus shaped, the

*By John C. Koch, 1914 Proceedings, Am. Soc. C. E., page 255. 
road machine, in successive passages, rounds up the cross-section of the sand-clay so as to give proper crown to the roadway and a smooth line from the crown to the ditches. As soon as the road is shaped, traffic and the construction teams begin to compact it, and it rapidly becomes consolidated without the use of a road roller. As the consolidation progresses, ruts are formed, and they should be filled and a proper cross-section maintained by the occasional use of the road machine for a period of about two months. Unless this is done, the road surface will become rutted and rough, and eventually compacted with a concave crown which will prevent proper drainage. After the material has been consolidated into a hard mass, the difficulty of securing a good cross-section is largely increased.

"The cross-section which seems to have given the most generally satisfactory results is a parabolic form with a crown of $1 / 2$ inch per foot, that is, for a roadway surfaced for a width of 20 feet, the crown would be 5 inches, and the height of the center of the road above the ditch (for a road having a width of 30 feet between ditches) would be $7 \frac{1}{2}$ inches. With steeper crowns than this it has been found that the surface cuts into a series of parallel ridges running from the wheel tracks to the ditches and making it very disagreeable for travel. If less crown is given, the provision for wear is too small, and the drainage may not prove satisfactory after a comparatively short time.

"There are many miles of sand-clay roads in Georgia which have cost less than $\$ 500$ per mile for the surfacing in place. They carry heavy country traffic, and the repairs, during a period of 5 years, have not averaged \$5 per mile per year."

Roads with Sandy Subsoil. If a sand-clay road is to be constructed of a sandy subsoil, the roadbed is shaped up to the desired crown. The clay is brought onto the road and spread in a layer of 6 to ro inches at the center, tapering off to a thin layer at the sides. If the construction is begun at the end of the road near the source of supply of the clay, the road will be somewhat compacted during construction by the teams on the work. It is necessary that the clay be thoroughly 
mixed with the sand and that all lumps should be broken up. Dry mixing or covering the clay layer with sand and leaving it for traffic to mix and compact will not secure as quick and as good results as can be obtained by plowing, harrowing, and rolling. The clay should be puddled to secure a thorough mix with the sand and hence water is essential to obtain the best construction. If no water is at hand, the mixing should be completed soon after or during rainy weather.

Roads with Clayey Subsoil. If a sand-clay road is to be constructed of a clayey subsoil, the roadbed is shaped up and drained as in the previous case. The surface is then plowed and pulverized as much as possible to a depth of 4 inches. This surface is covered with a layer of sand 6 to 8 inches thick. In this case the mixing of the clay and the sand should be carried out while the materials are in a dry state. After this preliminary mixing has been accomplished, the further mixing is carried on when the road is wet. The road is finally shaped up and compacted. It must not be expected that as soon as a sand-clay road is completed it will give a perfect surface. It is only by carefully watching the road and adding sand or clay as required that a satisfactory surface will finally be obtained.

BuRnt Clay Roads. In order to improve the roads in some parts of the Southern States where there is no sand, experimental sections have been constructed by burning the very plastic clay of which the roads are composed. The material is plowed up and is piled over a low cribwork of firewood. Alternate layers of wood and earth are built up until a height of about 3 feet is obtained. The length fired at any one time depends upon the number of men available. When the wood burns out the hardened clay is shaped up and compacted.

STRAw RoADS. In the State of Washington clay roads have been improved by shaping and harrowing the road to a smooth surface and then applying a layer of wet wheat straw about 6 inches thick. The straw is cut and mixed with the earth by means of a disk harrow. The roadway is compacted with a steam roller. It has been found necessary to treat the roads in this manner about twice each year. 
Petrolithic Roads. This type of road is formed by mixing the soil in situ with a bituminous material. The earth is plowed up to a depth of at least 6 inches and is thoroughly pulverized, cultivated, and sprinkled with water. Asphaltic oil is applied in one to two coats in the amount of one gallon per square yard. The surface is recrowned with a road grader and tamped with a sheep's foot roller-tamper.

In many cases a layer of broken stone or screened gravel is spread over the roadway and treated with about $1 / 2$ gallon

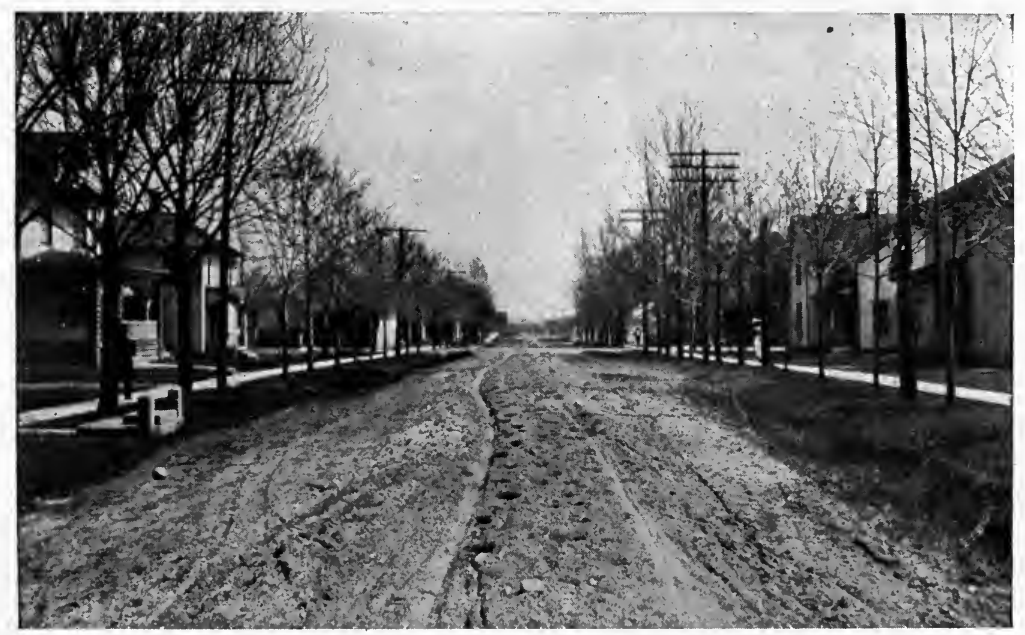

FIG. 55. An Earth Road Under Poor Maintenance.

of asphaltic oil. The surface is then thoroughly harrowed and rolled. Another treatment of oil is applied at the rate of $1 / 4$ gallon per square yard and a $1 / 2$-inch layer of stone screenings or pea gravel is then spread over the surface and rolled with a smooth-faced roller.

\section{Maintenance}

The principal work in maintaining an earth road is to keep the surface smooth and well crowned so as to shed water as rapidly as possible. If any depression forms in the surface, water settles in it and softens the road, with the result that a 
very small depression will work into a large and dangerous hole if not taken care of at once. In repairing holes in an earth road, they should be filled with the same kind of material that is used in the surface, since if a harder material than the surrounding earth is used, the surface will tend to wear un-

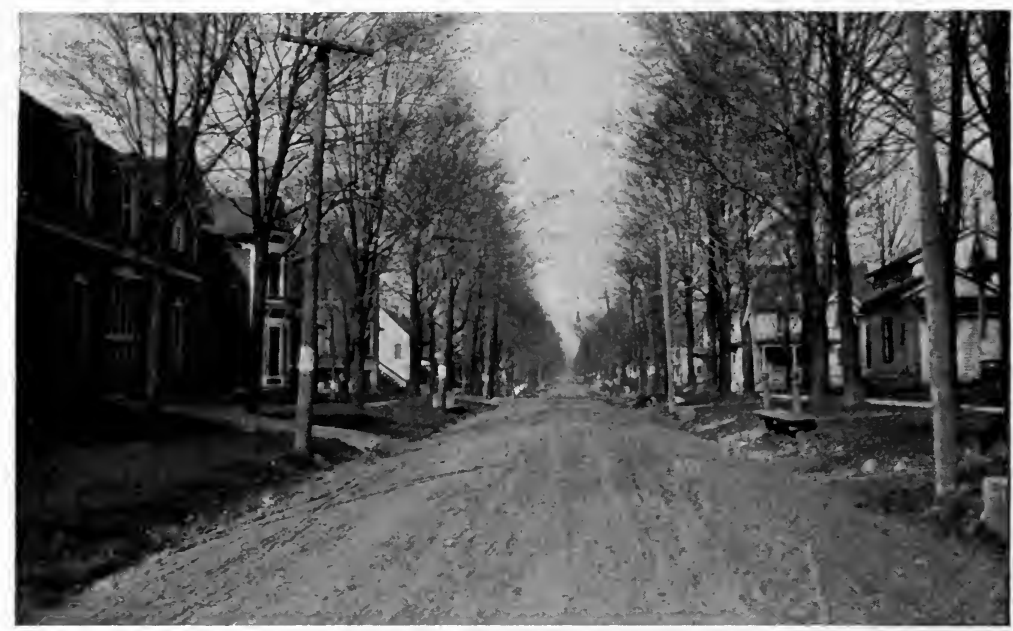

FIG. 56. An Earth Road Under Good Maintenance.

evenly at this point, due to the harder material offering more resistance to traffic. An earth road should have plenty of sunlight and air, and hence the undergrowth at the sides should be kept cut. Ditches and culverts should always be kept clean to give an easy outlet to the water.

DRAGS vs. ScRapers. A large part of the maintenance work, which consists in keeping the road in shape, can be done either by road scrapers and graders or by road drags. Different types of these machines have been described in Chapter V. The road drag has been the salvation of the earth road. An earth road needs frequent care, and since drags can be obtained at an extremely low cost, it is possible for each resident along the road to own one. By having one drag to every 2 to 4 miles of road or less, and encouraging the people to use them frequently, the surface can be kept in a good condition all the 
time. One man with team and drag can keep 20 miles in good condition. Where road scrapers are employed, their number is generally limited so that it is only possible to use them periodically a few times each year on the roads in a community. Frequently the surface may have become so badly worn that considerable work is necessary to get the road in good shape again. If enough scrapers were available so that repairs could be made at opportune times from the standpoint of the good of the road, the results obtained would probably be fully as good as those obtained by using road drags, but the cost of maintenance would be increased.

RoAd DRag Law. The General Assembly of the State of Illinois, in I908, passed a Road Drag Law authorizing the road commissioners in any township to have earth roads dragged at all seasons of the year whenever it was deemed to be beneficial, and to contract with the adjoining land owners for this work at a rate of from 75 cents to $\$ I$ per mile, not less than 20 feet wide, for each time the road was dragged, the higher price to be paid for work done during the months of December, January, February, or March. The law also provides it to be unlawful to place loose earth, weeds, sods, or other vegetable matter on a road which has been dragged without the authority of the road officials; to place any material which will prevent the free flow of water; for any traffic to pass over a surface just dragged until same shall have partially dried out or have frozen, except in those instances where the road is not sufficiently wide to provide a safe by-pass or on roads wide enough so that the wheels will not make a rut nearer than 9 feet to the center of the dragged portion.

In order that all commissioners should follow the same practice, the following instructions were published:

"Roads properly dragged will dry out weeks earlier in the spring than a road not so maintained, and when dried out will be smooth and in excellent condition. Moreover, they will not rut up so readily during the winter. The ordinary country road can be well maintained if dragged at the proper time on an average of twice a month. The dragging will have 
to be more frequent during winter and spring than in summer.

"Unless the road is in the right condition, the work of dragging will be wasted. One thing to be insisted upon is that the work be done at the right moment. The right time is when the road is wet. The muddier it is the better the results. On a road that is in extremely bad condition where the mud is very deep, it is probable that the lap-plank drag can be worked to better advantage. In the summer time and in the early fall, dragging should be done while it is actually raining, for unless the rain is exceptionally heavy and long continued, the water will penetrate the dry roadbed so fast that the surface will be comparatively dry when the drag is used after the rain has stopped, with the result that the road surface will work up in crumbs. When this happens it is a sign the road is too dry. The nearer it is possible to spread the mud over the road as a mortar, much in the same way a mason works mortar with a trowel, the greater the improvement produced. Under no conditions should a road be dragged when it is dry. This merely crumbles up the surface and makes a layer of the loose material which quickly becomes dust and, when wet, is turned into mud and holds the water on the surface of the road. Drag when the road is good and muddy. Don't drag when it is dry. Drag whenever possible at all seasons of the year. If a road is dragged immediately before cold weather, it will freeze in a smooth condition." 


\section{CHAPTER VII}

\section{GRAVEL ROADS}

Development. Highways constructed with a wearing course of gravel have proved suitable for light traffic. In some instances where the traffic consists of light horse-drawn vehicles and touring cars, such as is typical of the traffic on park boulevards, the gravel road has proved to be superior to the broken stone road as it has been less affected by motor-car traffic and is more easily repaired.

Gravel roads are found in every State of the Union. Throughout the United States there have been at least IIo,000 miles of highways improved with roadways of gravel. As there are many sections where rock does not exist from which to manufacture broken stone, the development of gravel roads in such localities has been rapid. In some parts of New England natural gravel roads exist, generally found on gravel ridges.

\section{The Gravel}

Definitions. Throughout this book the terms gravel, bank gravel, sand, and clay will be used to designate the materials described in the following definitions.

Gravel.* Small stones or pebbles which will not pass a Io-mesh sieve.

Bank Gravel.* Gravel found in natural deposits, usually more or less intermixed with sand, clay, etc.; gravelly clay, gravelly sand, clayey gravel, and sandy gravel indicate the varying proportions of the admixture of the finer materials.

Sand. ${ }^{*} \dagger$ Finely divided rock detritus, the particles of which will pass a ro-mesh and be retained on a 200-mesh sieve.

Clay. ${ }^{*} \dagger$ Finely divided earth, generally silicious and aluminous, which will pass a 200-mesh sieve.

Formation AND OCCURRENCE. Gravel is generally found

* Proposed in I9I5 by Committee D-4, American Society for Testing Materials.

† Dec., 1914 Proceedings, Am. Soc. C. E., pages 3013 to 3017 . 
mixed with sands and clays in varying proportions. Most of the gravel in the northern part of the United States is glacial deposit. The district at one time covered by the glacier included all of New England and Canada and that part of the United States north of a line running from a point just south of New York City to the southwest corner of New York State, then closely following the Ohio River to the Missouri River and westward to the Pacific coast. This immense ice sheet in its forward movement sheared off the rocks and carried them along in its path. With the melting and consequent receding of the glacier, the materials picked up in its path were deposited and sometimes further distributed by the water from the melting ice. On account of the large variety of rocks passed over by the glacier and the intermingling and mixing of the worn and abraded pieces by the water, gravels usually vary widely in quality and composition. The glacial rivers aided further to break up and distribute the débris picked up by the glacier. The larger stones are generally quite hard, since the softer stones have been entirely broken up by the abrasive action. Such hard rocks as flint, chert, quartzite, felsite, granite, sandstone, and volcanic rocks occur to a large extent in gravels. Throughout New England, the Adirondack district, and the Appalachian belt south to the limit of the ice sheet in that direction, a "blue gravel" abounds, so-called because it is made up largely of trap rock which was crushed by the glacier and left near the point where it originally existed, and hence has not been much affected by the action of water. Gravel in which the stones are largely composed of quartz is also extremely common, both in New England and some of the middle western States.

ReQuisites of Gravel. A gravel to make a good roadbuilding material should be composed of stones, which are hard and tough and hence will not readily disintegrate under traffic; that vary from a large to a small size, the proportions of the different sizes being such that the voids will be a minimum; and that contain enough binding material to cement the whole mass together. 
Gravel composed of sharp, angular stones, with slightly roughened surfaces, has given particularly satisfactory results.

The Binder. Clay, iron oxide, lime, loam, and finely divided silica constitute the cementing mediums found in gravels. Frequently a mistake is made in selecting a gravel that will pack quickly. An excess of 20 percent of clay in the mass will produce mud during a continued wet spell. Usually r6 percent of clay is sufficient to bind a well graded gravel. To remove an excess of clay, the gravel must be screened and sometimes washed. Iron oxide has been mentioned as one of the cementing materials found in some gravels, occurring as a slight coating on the pebbles. Gravels of this nature make an excellent road material and sometimes compact much more firmly in the road under traffic than in the original bed. The gravels from Paducah, Kentucky, and from Shark River deposits in New Jersey are examples of this type. Similar deposits, in which there is little or no clay present, are found where the cementing material is a lime or a combination of lime and iron ore. In some cases small pebbles, which will crush up during the construction of the road or under the action of traffic, will furnish a binder that firmly cements the larger stones together. Loam and finely divided silica also compose the binding material in some deposits.

As a general rule a bank gravel is better than a stream gravel because its particles are not generally so smooth and because it contains more fine material which will act as a binder. River gravel contains more silica than a bank gravel of the same locality, since the clay has probably been washed out. A gravel which contains too much fine material may be improved by screening, while one which is lacking in binding material can be improved by adding some cementing material such as clay, shale, marl, loam, or stone screenings. An indication of the binding qualities of a gravel may be obtained by noticing the gravel in the bank. Usually, if the bank faces are vertical, and a pick is required to dislodge the gravel, and large chunks may be broken out in which the smaller pebbles are firmly 
cemented together, the gravel will make a satisfactory road material.

Testing Gravel. Unless service tests have proved that a gravel from a particular location is a satisfactory material, the gravel should be tested before being used.

Sampling. Samples of gravel should be taken with the sand or clay just as it occurs in the stream or gravel bank.

Mechanical Analysis. The proportions of the various sizes contained in any one sample can be ascertained by screening the sample through screens and sieves of different sizes, the proportions retained on or passing any screen or sieve being determined by weight. (See Appendix III.)

The screens used in making mechanical analyses of gravel or stone are usually made with round holes having diameters varying from $3 \frac{1}{2}$ inches to $1 / 4$ of an inch in size. The sieves used in making mechanical analyses of sand and other fine materials are made of wire with square holes. The sizes vary from one having to openings to the linear inch down to one having 200 openings. The screens with square holes are designated as ro-mesh, 40-mesh, 200-mesh, etc., depending upon the number of openings per linear inch. The standard sizes of mesh screens for testing sand adopted by the American Society for Testing Materials are given in the following table:

\begin{tabular}{|c|c|c|}
\hline \multirow{2}{*}{ Meshes per Linear INCH $(=2.54 \mathrm{CM})}$. & \multicolumn{2}{|c|}{ DiAMETER OF Wire } \\
\hline & Inch & Mm. \\
\hline $200 \ldots \ldots \ldots \ldots \ldots \ldots \ldots$ & 0.00235 & 0.05969 \\
\hline $100 \ldots \ldots \ldots \ldots \ldots$ & 0.0045 & 0.1143 \\
\hline $80 \ldots$ & 0.00575 & 0.1460 \\
\hline $50 \ldots$ & 0.009 & 0.22865 \\
\hline $40 \ldots \ldots \ldots \ldots \ldots$ & 0.01025 & 0.26035 \\
\hline $30 \ldots$ & 0.01375 & 0.34925 \\
\hline $20 \ldots \ldots \ldots \ldots \ldots$ & 0.0165 & 0.4191 \\
\hline 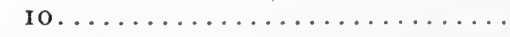 & 0.027 & 0.6958 \\
\hline
\end{tabular}

Care should be taken when a small sample is to be selected from a mass of material to obtain one which will be representa- 
tive of the whole. This will generally involve thoroughly mixing the large mass before taking a sample from it. The sample, which should weigh in pounds about six times the diameter in inches of the largest holes required, should be first dried at a temperature of from $100^{\circ}$ to $110^{\circ} \mathrm{C}$. $\left(212^{\circ}\right.$ to $230^{\circ} \mathrm{F}$.) to constant weight. The gravel should then be separated from the sand, clay, or other fine material by the use of a ro-mesh sieve. The portion retained on the sieve should be passed through such of the following sized screens as are required, the screens to be used in the order named: $3 \frac{1}{2}$ in., 3 in., $2 \frac{1}{2}$ in., 2 in., $\mathrm{I} / 2$ in., $\mathrm{I} / 4$ in., $\mathrm{I}$ in., $3 / 4$ in., $\mathrm{I} / 2$ in., and $\mathrm{I} / 4$ in. The portion passing the ro-mesh sieve should be passed through the following sieves in the order named: 10, 20, 30, 40, 50, 80, 100, and 200-mesh sieve. After the percentages by weight retained on each screen and each sieve have been determined, the mechanical analysis should be recorded as follows:

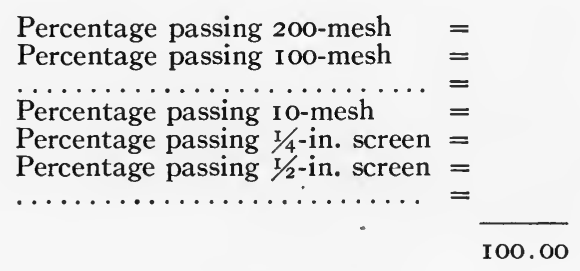

Voids. The voids in a sample may be determined in several ways, which will be described in detail in Chapter VIII.

Quality of the Stone. The character of the stone may be determined by subjecting it to the standard abrasion and cementation tests in a manner similar to that for broken stone. These tests are described in Chapter VIII and Appendix III.

\section{Construction}

Preparation of Subgrade. The subgrade must be so prepared that it offers a firm surface upon which to construct the gravel crust. It is brought to the proper shape by the use of a road grader or otherwise and compacted by rolling. The transverse slope of the subgrade may or may not be parallel 
to the finished surface, since the gravel surface is frequently constructed thinner at the edges than at the center of the road. The crown of a gravel road is made from $1 / 2$ inch to $I$ inch to the foot, $3 / 4$ of an inch to the foot being common practice.

There are two principal methods of construction which will be called the surface method and the trench method.

The SuRface Method. In this method the gravel is brought to the road, dumped on the roadbed, and smoothed out to the desired shape, the larger stone being raked over into the bottom of the crust. A spike-tooth harrow and a road drag scraper have been successfully used in this part of the work.

Width and Depth. The width and depth of the gravel crust will depend upon drainage, foundation, and traffic conditions. A depth of from 8 to $I_{5}$ inches at the center is quite common. As no shoulders are built in the subgrade to hold back the gravel, the edges will spread out during compaction so as to be of very little depth. More uniform results will be obtained if planks are temporarily laid on edge, at a distance apart a little less than the desired width of surface, and the gravel is filled in between these planks to the required depth.

Compacting the Surface. The surface is then rolled, preferably with a grooved roller, until firmly compacted. A gravel road should be compacted from the bottom up, but never with a smooth face roller which has a tendency to compact the uppermost part of the layer before the bottom is consolidated. If the traffic is not too heavy and it can be so regulated as to travel over all parts of the road, it will serve to compact the gravel much better than a smooth face roller. In order to take advantage of the rolling afforded by the traffic, the construction may proceed from the end of the road nearest the source of supply of the gravel. Since the narrow wheels are liable to rut the surface, a man should rake material into the ruts as they are formed and keep the whole surface in as smooth a condition as possible. When the gravel is deposited in one layer the lower part never gets the compaction that it should. It is good practice, therefore, to build the road in courses, compacting each course as it is laid. 
Frequently this method is abused by simply dumping the gravel on the surface, roughly smoothing it out with shovels, and leaving it for traffic to compact without giving it much, if any, further attention. Good results cannot be expected by such a procedure.

Trench Method. In this method a trench is constructed in the subgrade of the same width and depth as the gravel crust. On embankments the distance from the edge of the gravel surface to the edge of the slope of the bank should be at least 3 feet. This part of the roadbed is called the shoulder. In some cases when the gravel surface is deposited in more than one course, the depth of trench is made equal to the thickness of the first course. After the first course has been laid, shoulders are constructed at each side of the same depth as the thickness of the remaining courses. The earth used for the shoulders must be free from roots, stumps, and other vegetable matter. Material which will not compact properly should not be used. The final compaction of the shoulders cannot be accomplished until after the gravel surface has been completed. When finished, the shoulders should have a greater slope than that of the gravel surface, or at least the same slope, so that good surface drainage is obtained from the center of the road to the outside edge of the shoulder.

Constructing the Surface. In this method of construction the road is built up generally in two courses, although sometimes three courses are specified. The number of courses depends upon the depth of the crust. In order to insure good drainage and provide a stable foundation for a gravel wearing course, the first course is sometimes constructed of local broken stone which was not suitable for a wearing course.

Thickness and Sizes of Gravel for Courses. From one to three courses are used in the trench method of constructing gravel roads. The total thicknesses of the several courses depend upon the traffic and the nature of the subgrade. A heavy traffic and a soft subgrade will require the maximum thickness. In some cases the crust is constructed with a uniform thickness while in others a varying thickness is employed, the maximum being at the center of the roadway. 


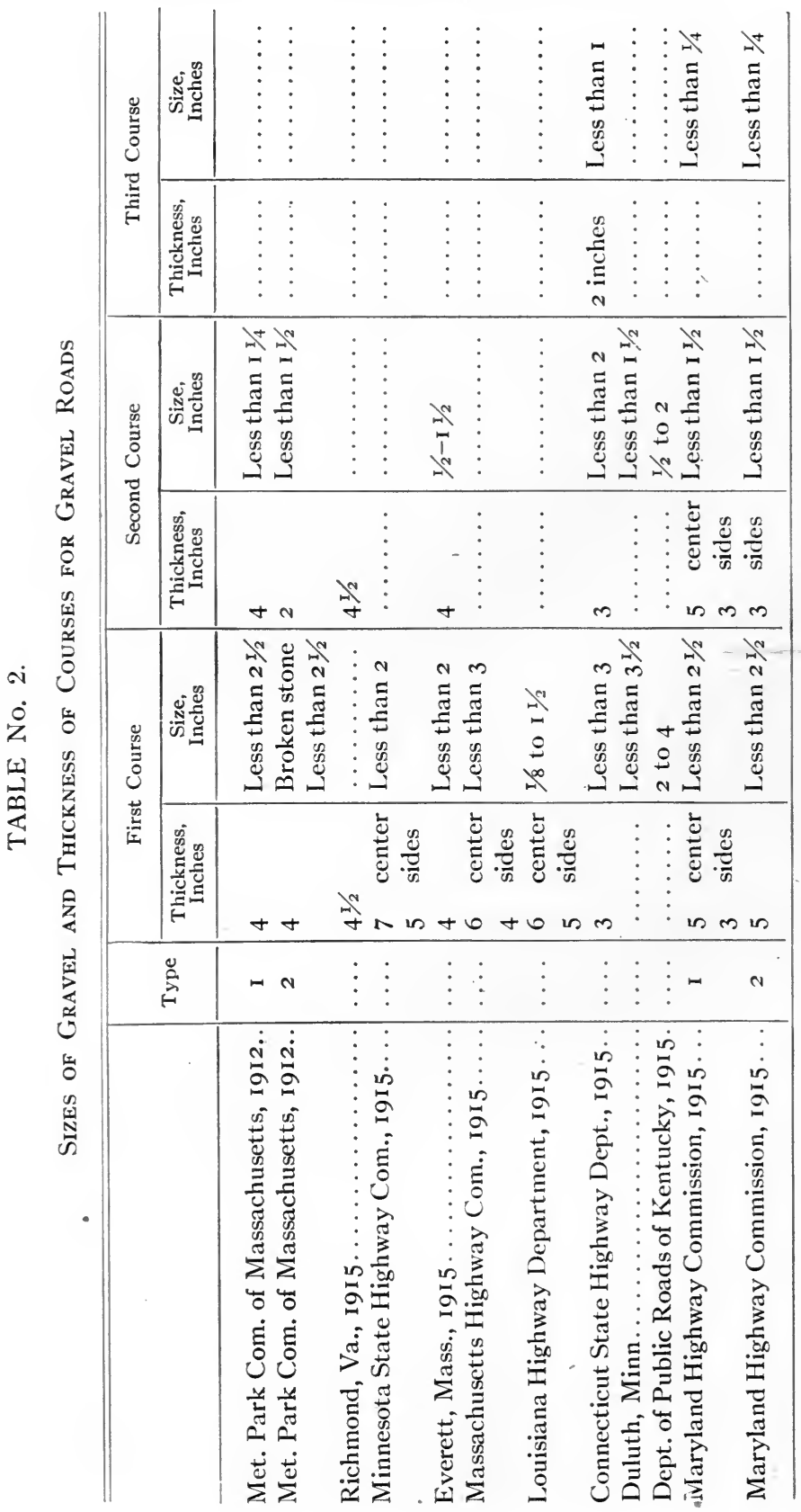


By reference to Table 2 it will be noticed that, in the cases cited, the total thickness of the gravel crust varies from 6 to ro inches. In several departments less gravel is used at the sides than at the center, the maximum variation being Io inches at the center and 6 inches at the sides. If more than one grade of gravel is employed, a product containing the smaller

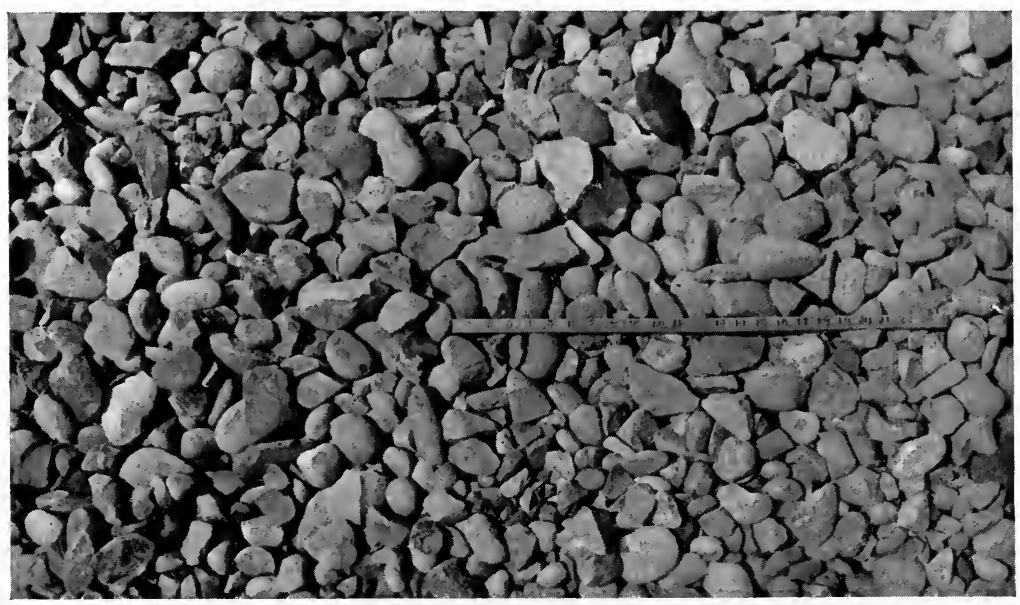

FIG. 57. Lower Course of a Gravel Road Before Being Filled with Fine Material.

particles is used in the wearing course. Whereas considerable variation exists relative to the maximum size to employ in the lower course, see Fig. 57, it has generally been found most satisfactory to use a product which will pass through a I I $/ 2$ inch screen for the wearing course. The sizes employed are governed by the character of the local supplies of gravel, the thicknesses of courses, and the requisites of gravel mentioned at the beginning of this chapter. The above statements are well illustrated by the requirements of the I9I5 Maine State Highway Commission specifications which state that: "TwoCourse Road: Whenever the smaller sizes of stone predominate, the bottom course shall have a thickness of four inches after rolling. This course shall be bonded with fine material before the second course is applied. The second, or top course, 
shall be similar to the bottom course and shall have the same thickness. It shall be bonded with fine material until a firm, hard, smooth surface is produced. Three-Course Road: Whenever the larger sizes of stone predominate, the bottom course shall have a thickness of three inches after rolling. The second course shall be of the same kind of material and of the same thickness. The top course shall have a thickness of two inches after rolling and contain stone not larger than one and one-half inches in size. Each course shall be thoroughly bonded with fine material by mixing, rolling, and sprinkling until a firm, hard, smooth surface is produced." Practice, dependent upon economic considerations and personal views, varies to a large extent relative to the above elements of gravel road construction.

The proper depths of the various courses during construction can be maintained by lines stretched between stakes, or by blocks placed on the surface and the material levelled off to the tops of the blocks.

Cross-Sections. A typical cross-section of a two-course road is shown in Fig. 58, which is the standard section of the Maine State Highway Department.

Screening Gravel. As it is frequently impossible to find a gravel that contains the exact proportions of sizes desired, it is necessary to screen out some of the large or fine material. Screening may be accomplished by hand or by machine. In screening with machinery a bucket elevator can be erected so

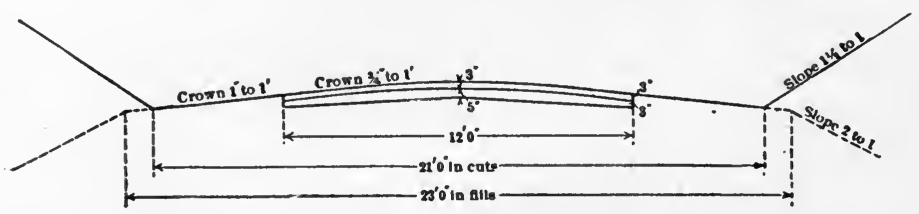

FIG. 58. Cross-Section Gravel Road. Maine State Highway Department.

as to dump the gravel onto a chute screen or a rotary screen, the screened output falling into bins constructed high enough so that wagons can be filled underneath the pockets. The gravel to be screened can be brought to the boot of the elevator 
by wagon, drag or wheel scraper. Frequently in gravel banks containing strata of different sizes of gravel, it is practicable to avoid screening by careful excavation of the several sizes required for the different courses.

Spreading the Gravel. The gravel for each course as it is brought to the road is either dumped to one side of the roadbed and shovelled into place or is shovelled directly from the wagon into place. The gravel may also be spread directly on the roadbed when bottom dump-wagons are used; otherwise a dumping board should be used if it is necessary to dump the gravel on the roadbed. The gravel is shaped up by using either shovels and rakes or a tooth harrow and a road grader. When machines are used a considerable length of gravel should be placed before shaping with the machines, as otherwise their use would not be economical.

Compacting the Gravel. Each course, after it has been shaped up, is thoroughly compacted with a roller, both horse-drawn and power-driven rollers being employed. Sectional rollers, weighing about rooo pounds per foot of width, are very satisfactory for the compaction of gravel. The sheep's foot roller has also been successfully employed. Some engineers do not favor the use of the heaviest types of rollers. Rolling for each course should be continued until a firm and even surface is obtained. If any depressions occur during the rolling, they should be filled up with the same size of material as is used in the course being constructed. The top course is usually puddled with water during the process of rolling. The water when mixed with the binder causes it to produce cement-like qualities. Too much water, however, is detrimental, as it tends to wash out some of the finer binding material and to soften the subgrade. Rolling should always progress from the sides toward the center so as to maintain the crown of the road. Ultimately the rolling should extend over the whole width of road, including the shoulders. Gravel will compact to about 80 percent of its depth, loose measure. Hence, if a finished thickness of 8 inches is desired, it will be necessary to use a total depth of ro inches loose measure in the various courses. 
Cost Data. The cost per square yard of gravel roads usually varies from 30 to 80 cents for thicknesses of from 5 to ro inches. In the following table are given, for several localities throughout America, prices of gravel roads constructed with different thicknesses of gravel.

From Municipal Engineering, June, I9I5

\begin{tabular}{|c|c|c|c|}
\hline City & $\begin{array}{l}\text { Square } \\
\text { Yards }\end{array}$ & $\begin{array}{c}\text { Price per } \\
\text { Square Yard }\end{array}$ & $\begin{array}{c}\text { Total } \\
\text { Thickness of } \\
\text { Gravel Crust } \\
\text { in Inches }\end{array}$ \\
\hline 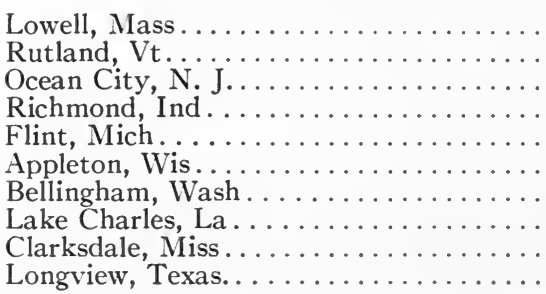 & $\begin{array}{r}82,100 \\
24,300 \\
10,000 \\
23,200 \\
30,855 \\
45,000 \\
20,562 \\
9,000 \\
2,800 \\
3,180\end{array}$ & $\begin{array}{l}\$ 0.20 \\
0.25 \\
0.27 \\
0.40 \\
0.73 \\
0.35 \\
0.40 \\
0.36 \\
0.60 \\
0.55\end{array}$ & $\begin{array}{l}6 \\
6 \\
8 \\
5 \\
\text { I I } \\
\text { I I } \\
9 \\
31 / 2 \\
9 \\
9 \\
8\end{array}$ \\
\hline
\end{tabular}

\section{Maintenance}

It may take several months before a gravel crust is thoroughly compacted, no matter how well it may have been rolled during construction. During this period careful attention should be given to the road, and the ruts and hollows should be patched as soon as they are formed. In times of wet weather or of frost a gravel surface will be soft and rut very easily. As in the case of earth roads, the road drag is one of the best machines with which to maintain a gravel road. Where a road grader would unnecessarily disturb the surface, the road drag serves to simply smooth up the road, fill in the hollows, and push just enough of the material toward the center to maintain the crown. Dragging will be required more frequently for the first year after the road is completed than at any other time. As is the case in all road dragging, the work should be done when the surface is in a moist and soft condition. As the road ages and becomes set, the road drags will not have any effect unless a prolonged period of rain has made the road very soft. 
There are many miles of gravel roads that have, been maintained by means of a road drag at a cost of from $\$ 5$ to $\$$ Io per year per mile.

All patching should be done when the road is in a wet condition, as the new material added will bond to the old and compact much better than when in a dry state. Great care should be taken not to get the patches too high, as such a procedure is liable to create a new hollow just beyond the one patched. As near the same size and kind of material should be used in making the patches as was used in building the course. Constant patching and intelligent work with the road drag serves to keep a gravel road in good passable condition until it is entirely worn out and requires resurfacing.

When resurfacing is necessary, the new gravel is added in a manner similar to new construction. As in patchwork, best results will be obtained by resurfacing when the old road is in a soft condition.

An essential part of the maintenance work is to keep ditches, drains, and culverts clear to provide for the removal of the water which falls onto the road. 


\section{CHAPTER VIII}

\section{BROKEN STONE ROADS}

Broken stone roads are extensively built in all countries where stone is available. Although the water-bound broken stone road can no longer be built and maintained at a reasonable expense when subjected to certain types of traffic, there are many conditions under which it will continue to prove the most economical type of surfacing. The conclusion of the Second International Road Congress (I9Io) with regard to the use of the water-bound type of broken stone road in municipalities was as follows: "Macadam constructed according to the methods of Tresaguet and McAdam causes dust and mud, is expensive to maintain, and is only suitable in large cities for streets where the traffic is not very great or heavy."

\section{Rocks}

Rock Classification. Rocks may be separated into the following classes:

I. Igneous rocks, or those which have been formed by mineral matter flowing upward in a molten condition and cooling near the surface.

2. Aqueous rocks, or those formed through the agency of water, including all sedimentary rocks.

3. Metamorphic rocks, or those rocks changed by dynamic or chemical agencies from their original condition.

Some rocks may be identified with the unaided eye by noting the color, structure, weight, and hardness. By preparing microscopic slides and examining them under a petrographical microscope, it is possible to identify those which cannot be determined by the eye alone.

Definitions. Terms pertaining to rocks are described in the following definitions. 
A morphous. A textural term used to describe a rock structure without definite form or crystalline composition.

Cellular. A textural term used to describe a rock structure containing cells due to weathering out of some constituent.

Colloidal. A textural term used to describe a jelly or gluelike rock structure.

Crystalline. A textural term used to describe a rock structure similar to that of granite

Foliated. A textural term used to describe a rock structure which has a tendency to split along lines of stratification.

Glass. A textural term used to describe an amorphous rock structure formed by the quick chilling of a fused lava.

Granitoid. A textural term used to describe those igneous rocks which are entirely composed of recognizable minerals.

Granular. A textural term used to describe a rock structure made up of distinct grains.

Holycrystalline. A textural term used to describe a rock structure that consists entirely of crystallized minerals.

Laminated. A textural term used to describe a banded structure which is characteristic of many sedimentary rocks.

Massive. A textural term used to describe igneous rocks that show no stratification.

Plutonic Rocks. Rocks which were formed by the cooling or molten mineral matter before it reached the surface.

Porphyritic. A textural term used to describe a compact structure throughout which there are large crystals.

Schistose. A textural term used to describe a rock structure which has a tendency to split along lines of stratification.

Stratified. A textural term used to describe a rock structure composed of parallel layers.

Volcanic Rocks. Rocks which have been formed by mineral matter erupted in a molten condition and cooled on the surface.

Mineral Constituents. A rock is a mineral or combination of minerals. There are a few rocks which are composed entirely of one mineral, but the majority are made up of a combination of two or more minerals. Among the most important chemical compounds occurring in rocks are silicates, 
oxides, carbonates, sulphates, chlorides, phosphates, sulphides, and one native element, graphite. Sedimentary rocks are spoken of as calcareous, siliceous, ferrugineous, or argillaceous according as lime, silica, iron oxides, or clayey matter predominates. Eruptive rocks are spoken of as acidic or basic, the former being those showing more than $6_{5}$ percent silica, and the latter those which show less than 55 percent, but are rich in iron, lime, and magnesian constituents. Among the more common minerals found in rocks are the following: quartz, orthoclase, plagioclase, microcline, augite, hornblende, biotite, muscovite, garnet, kaoline, hypersthene, olivine, epidote, calcite, dolomite, magnetite, chlorite, and serpentine.

The mineral constituents which make up a rock can be determined by means of the crystalline formation, by chemical analysis, by blow-pipeanalysis, and by microscopical examination.

Table No. $3^{*}$ gives the essential and important mineral constituents used in highway construction. Group I to 8 comprises the plutonic igneous rocks, 9 to I4 the volcanic igneous, I 5 to 20 the sedimentary, and 2 I to 34 the metamorphic rocks or crystalline schists.

Trap. The term trap has been defined by Kemp as a useful field name for any dark, finely crystalline igneous rock. The characteristics of the principal rocks usually included under the name of trap are as follows. Andesites are generally gray, greenish, or reddish in color. Their structure when examined under a microscope is found to vary from glassy to holocrystalline. Their principal constituent is plagioclase. Basalts are homogeneous rocks, generally of a dark gray or black color, although red and brown colors are also common. In structure they vary from glassy to holocrystalline. Diabases are holocrystalline in structure and vary in color from green to a dark gray or black. (See Fig. 59.) Peridotite is greenish or black in color with a variable structure that may be either crystalline, granular, or porphyritic.

Diorite. The diorites are granitoid rocks whose essential

* From Table in "Rocks for Road Making," by E. C. E. Lord, U. S. Office of Public Roads Bulletin, No. 31 . 
constituents are plagioclase, feldspar, either labradorite or oligoclase, and hornblende or biotite. They are green, dark gray, or black in color. Gabbros are crystalline granular in structure,

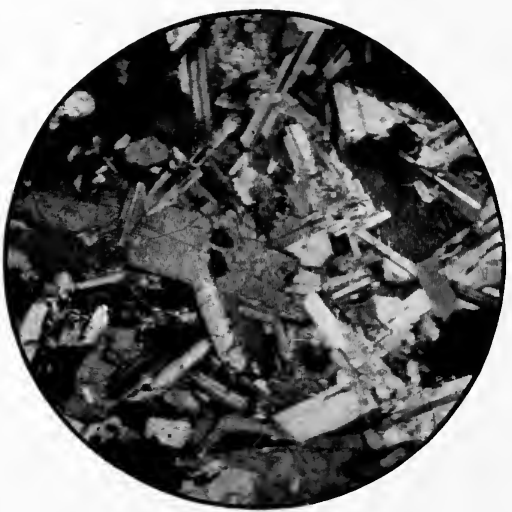

Diabase.

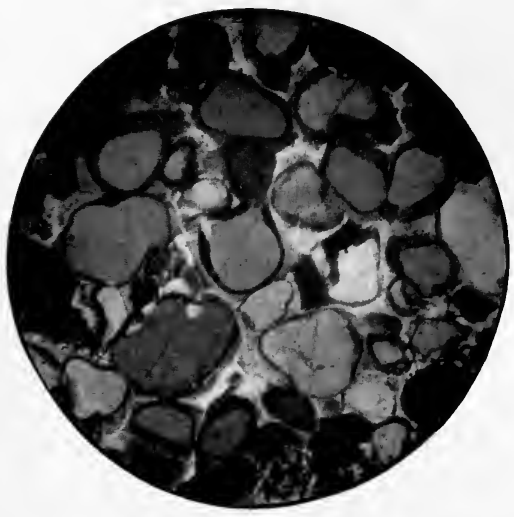

Courtesy of the Department of Geology in Columbia University.

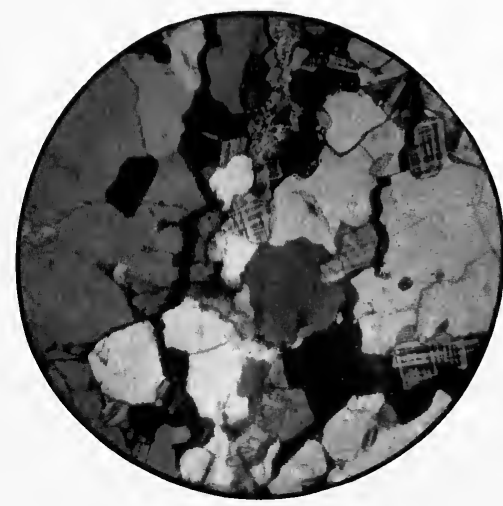

Granite.

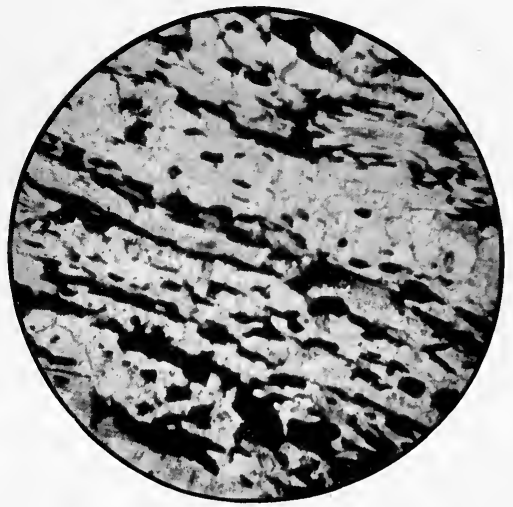
Mica-Schist.

FIG. 59. Microstructure of Four Rocks Used as Highway Materials.

the prevailing color being black green. Its principal constituents are plagioclase, augite, and hornblende.

Granite. The essential constituents of granite are quartz, orthoclase; and plagioclase, combined usually with mica, horn- 


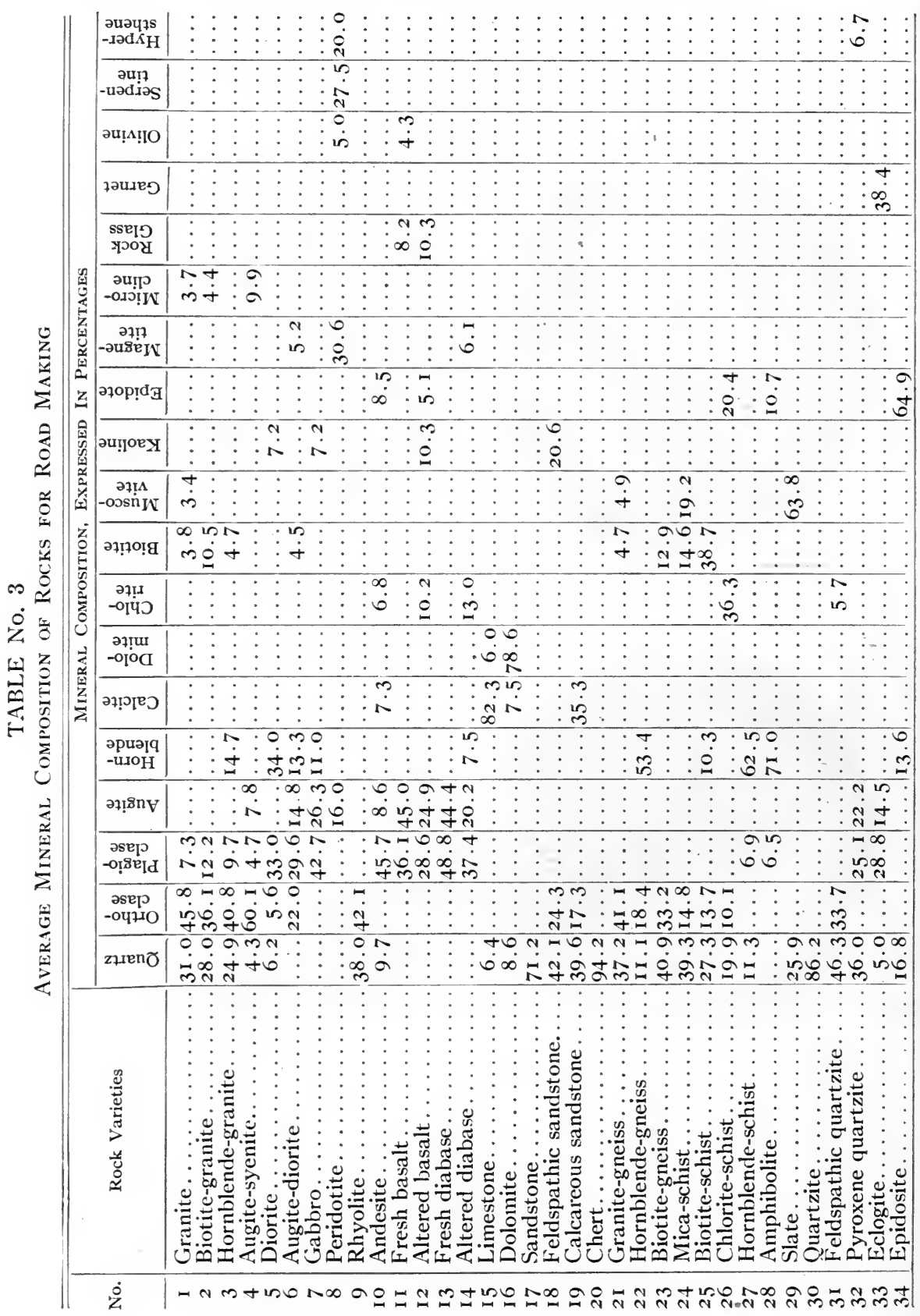


blende, and pyroxene. It is holocrystalline granular in structure. (See Fig. 59.) It may be gray, green, yellow, or red in color, the lighter colors being due to the feldspar and the darker colors due to the mica and hornblende. Quartz porphyries have the same constituents as granite but are porphyritic in structure, having quartz crystals scattered through a ground mass which may be red, gray, yellow, green, black, or white in color.

Syenite. Syenites are of the same composition as granites except that they contain no quartz. In structure and color they are the same as granite.

Gneiss. Gneisses are of a holocrystalline granular structure arranged in parallel bands. Gneisses are practically the same in composition and color as the granites, the principal difference being in the structure. The different varieties, as in granites, are called by the name, of the predominating mineral.

Limestone. Limestones are extremely variable in both color and structure. All shades from white through a gray to a black are common, and sometimes even red and yellow are found. They are stratified in structure and vary from a soft variety to a rock with a dense structure that breaks with a distinct fracture. Chats, a dolomitic limestone, is a term used in the West to denote the tailings of lead mines.

Sandstone. Sandstones, like limestones, are variable both as to color and structure. In color they are red, brown, green, and yellow. Pudding stone or conglomerate is a coarse sandstone. Breccia is similar to conglomerate except that the stones are more angular. Flints, so-called in Great Britain, are found in the upper layers of chalk-pits or in gravel deposits near the chalk areas. They are made up of colloidal and crystalline silica. Chert is a variety of quartz having a flinty structure. Quartzites are metamorphosed sandstones, being brown, red, or green in color. (See Fig. 59.)

Schist. The schists differ from the gneisses principally in the absence of feldspar. Amphibolite has hornblende for its principal constituent and is a tough and often a massive rock. (See Fig. 59.) 
Slate. Slate is an indurated or hardened clay having a foliated structure and generally dark in color.

Fieldstone. Fieldstones are boulders which have been carried along by glaciers and are found mainly in those districts which were covered by great ice sheets. They are composed of a variety of different kinds of rocks.

Properties Rock Should Possess. A rock should possess the following characteristics in order to make a first-class stone for water-bound broken stone roads: It should be tough so as to resist the shocks from the traffic; it should have a good resistance to the wear caused by the grinding action of wheels; it should possess good cementing power; it should break with a clean angular fracture. The various rocks used for building highways are popularly known as trap, granite, limestone, sandstone, and fieldstones.

Trap. Trap rocks are extremely hard and tough and their excellent wearing and binding qualities have caused their widespread use throughout those sections of the country where they are found. When used in the construction of broken stone roads subjected to a light traffic, however, the wear on the stones will not usually be sufficient to make enough binder to hold the stones together.

Granite. Granites, which have a close, even, and granular structure, make good road material for broken stone roads which take a light traffic. If of a coarse structure they are not so desirable, but may be used in the foundation courses.

Limestone. Limestones possess excellent binding qualities but are generally neither hard nor tough and therefore are only suitable for roads having a light traffic.

Sandstone. Sandstones, due to the fact that they are easily broken up under the action of traffic and are usually lacking in binding qualities, are generally not considered as good road material except for the foundation courses. Quartzites, which are metamorphosed sandstones, give better results than sandstones.

Fieldstones. Fieldstones frequently make a satisfactory material for light traffic roads. They are extremely variable in 
composition and hence wearing courses composed of them may wear unevenly.

Testing the Rock. In order to ascertain the value of any rock as a material suitable for highway building, there are several tests that have been developed which give some indication as to what may be expected of a rock when used in the road. The tests are made to determine certain specific characteristics, and although the results of the tests do not always agree with the results obtained in service tests, still they are a great aid in comparing the respective qualities of different stones. There are many variable conditions to which a road is subjected, and since it is difficult to duplicate these conditions by any accelerated mechanical test, the best knowledge in regard to the worth of any rock will be obtained fromobservations of its wear in actual service. Tests are made to determine the physical properties of abra-

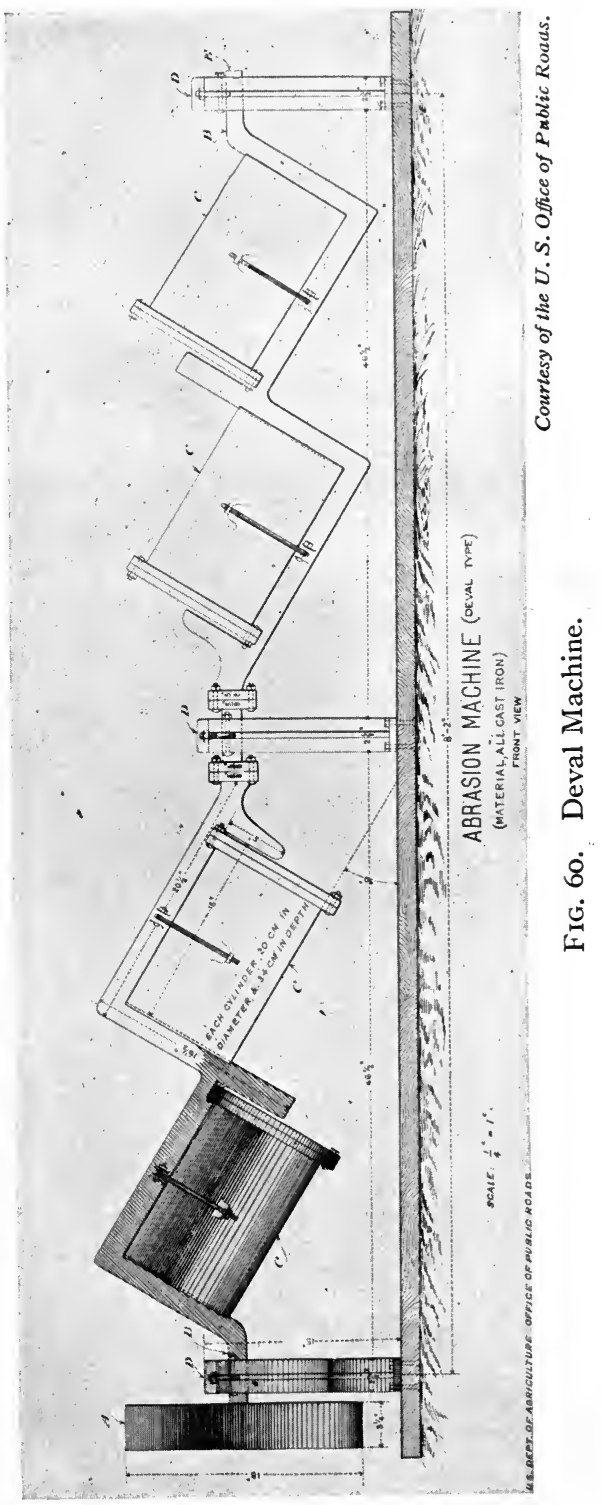


sion, cementing value, toughness, hardness, absorption, and specific gravity. Detailed descriptions of the methods of making the tests have been included in Appendix III. The relative values of the results of tests as listed in the following descriptions are those proposed by the U. S. Office of Public Roads.

Abrasion. This test is made by means of the Deval machine. This machine, Fig. 6o, consists of a series of cylinders or tubs mounted on a shaft with the long axes of the tubs making angles of 30 degrees with the horizontal. Mounting the cylinders in this manner causes the rock to be thrown from one end of the cylinders to the other as the machine revolves. The rock to be tested is broken in nearly uniform pieces, about fifty pieces weighing approximately 5 kilograms constituting a test sample. Ten thousand revolutions of the tubs constitute a test. The material worn off which will pass through a $/ 1 / 16^{-i n c h}$ mesh sieve is considered the amount of wear. This may be expressed either as the percent of the 5 kilograms used in the test, or the French co-

efficient may be given; that is, coefficient of wear $20 \times \frac{20}{W}=\frac{400}{W}$.

$W$ is the weight in grams of the detritus under ${ }_{/ 1}^{\mathrm{I}} 6$ inch in size per kilogram of rock used. A French coefficient of wear of 8 is low, 8 to I3 medium, I4 to 20 high, and above 20 very high.

Cementing Value. The test for cementing value as made by the U. S. Office of Public Roads is as follows: Five hundred grams of the rock to be tested, broken to pass a $1 / 2$-inch mesh sieve, are ground in a ball mill. The addition of water in the ball mill makes the charge into an extremely stiff dough. This dough is removed and placed in a metal die, 25 millimeters in diameter, and subjected to pressure in a hydraulic press. The cylindrical briquette, 25 millimeters in height, is placed in the machine used for testing the briquette, shown in Fig. 6I. In this machine a I-kilogram hammer is raised by a revolving cam to a height of $\mathrm{I}$ centimeter. The hammer falls on a plunger and transmits the energy of its blow through the plunger to the test piece. The instrument is provided with a self-recording 


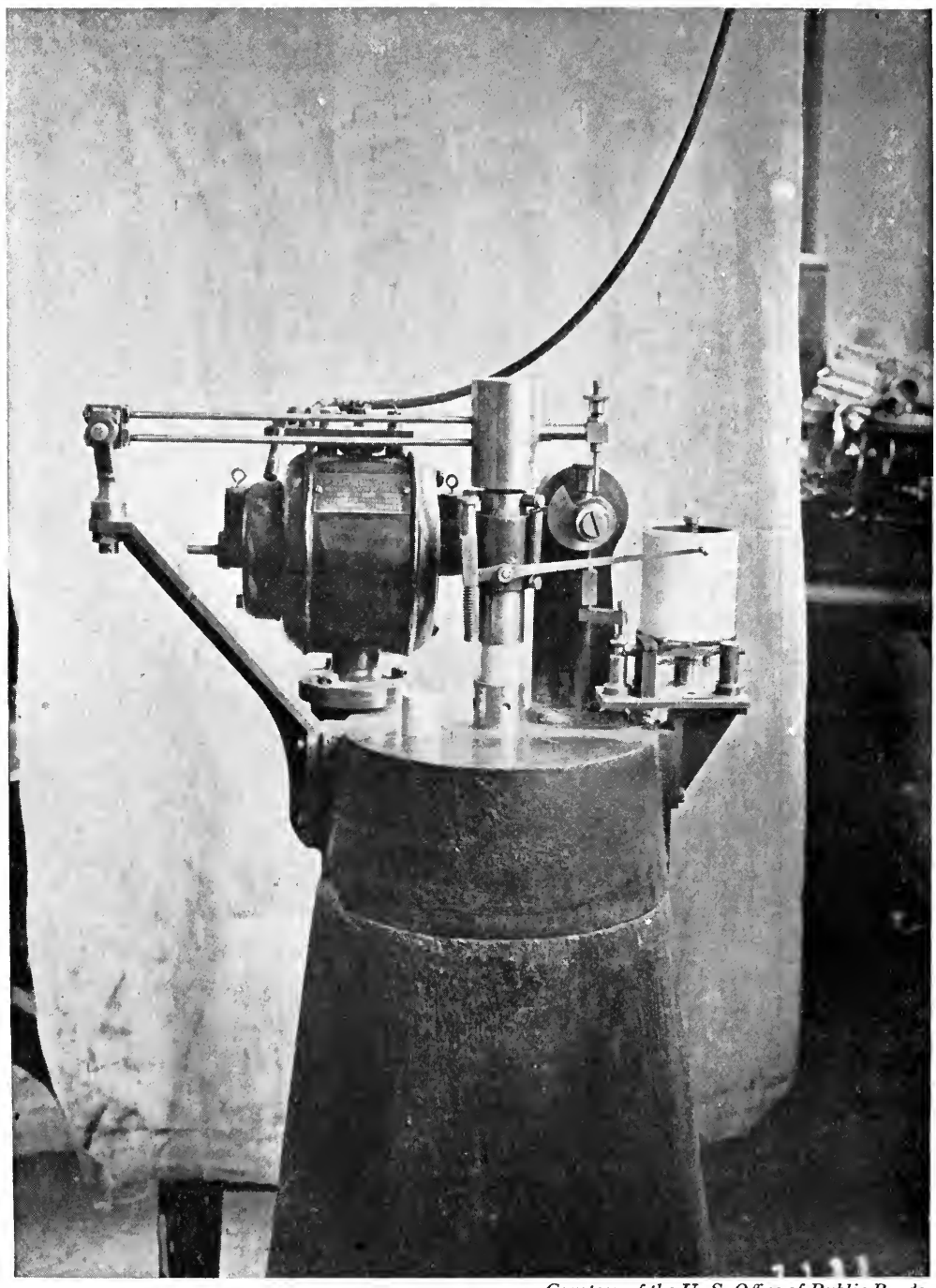

Courtesy of the U.S. Office of Public Roads.

FIG. 6I. Impact Machine for Determining Cementing Value. 
apparatus which registers each blow struck until the test piece fails. The average of the number of blows on 5 briquettes is taken as a result of the test. A result of ro is low, ro to 25 fair, 26 to 75 good, 76 to roo very good, over roo excellent.

Toughness. The test for toughness is made in the machine shown in Fig. 62. The usual test piece consists of a cylinder, 25 millimeters in diameter, and 25 millimeters in height, cut perpendicular to the cleavage of the rock. The test consists of a I-centimeter fall of a hammer weighing 2 kilograms for the first blow, and an increased fall of I centimeter for each succeeding blow until failure of the test piece occurs. The number of blows necessary to destroy the test piece is used to represent the toughness. A result of $\mathrm{I}_{3}$ is low, I3 to $\mathrm{I}_{9}$ medium, and above rg high.

Hardness. The test for hardness is made by means of a Dorry machine, Fig. 63, which consists of a revolving steel disk on which is fed a standard quartz sand, the grains of which pass a $30-$ and are retained on a 40-mesh sieve. A rock core, 25 millimeters, is cut from the rock and its faces ground off level. Two cores are used in each test and are placed in the dies, which are supported by the guide cylinders shown near the funnels. The test piece is first weighed and is then ground on one face for I,000 revolutions, after which it is reversed and the other face ground for the same number of revolutions. The loss in weight of the specimen is determined at the end of each I,, 00 revolutions, and the average loss in weight is used in stating the hardness of the rock, which is expressed by the formula, Hardness $=20-1 / 3 W$, where $W=$ loss in grams per I,000 revolutions. Rocks having a coefficient of hardness below I4 are called soft, from I4 to I 7 medium, above I 7 hard.

Absorption. The amount of water absorbed by a rock is generally expressed as the number of pounds of water absorbed per cubic foot.

Specific Gravity. The specific gravity of rock is determined by the displacement in water method. The specific gravity of rock screenings is determined by means of the Jackson apparatus.

r.esults of Tests. The average results of the abrasion, 


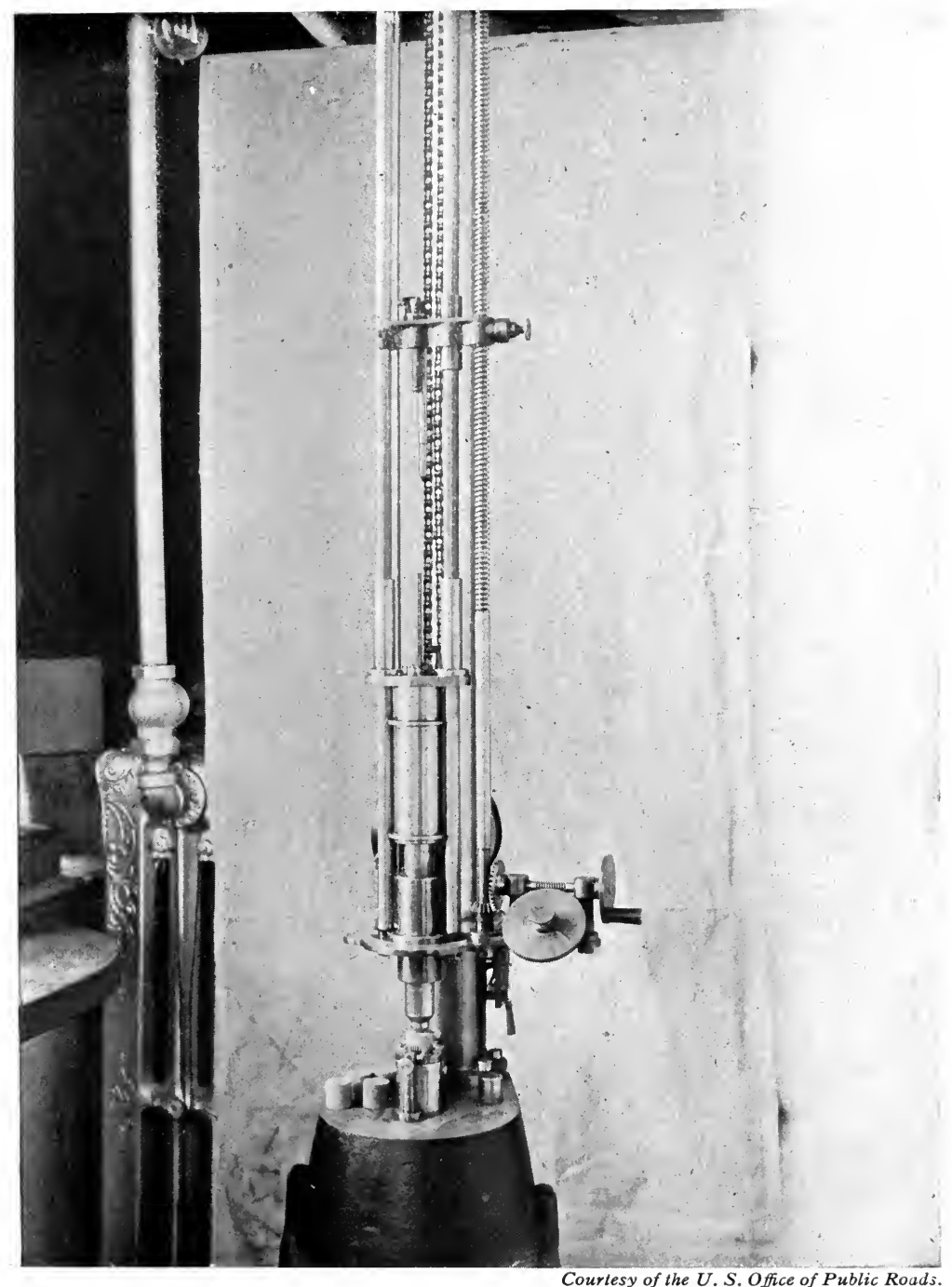

FIg. 62. Page Impact Machine for Determining Toughness. 


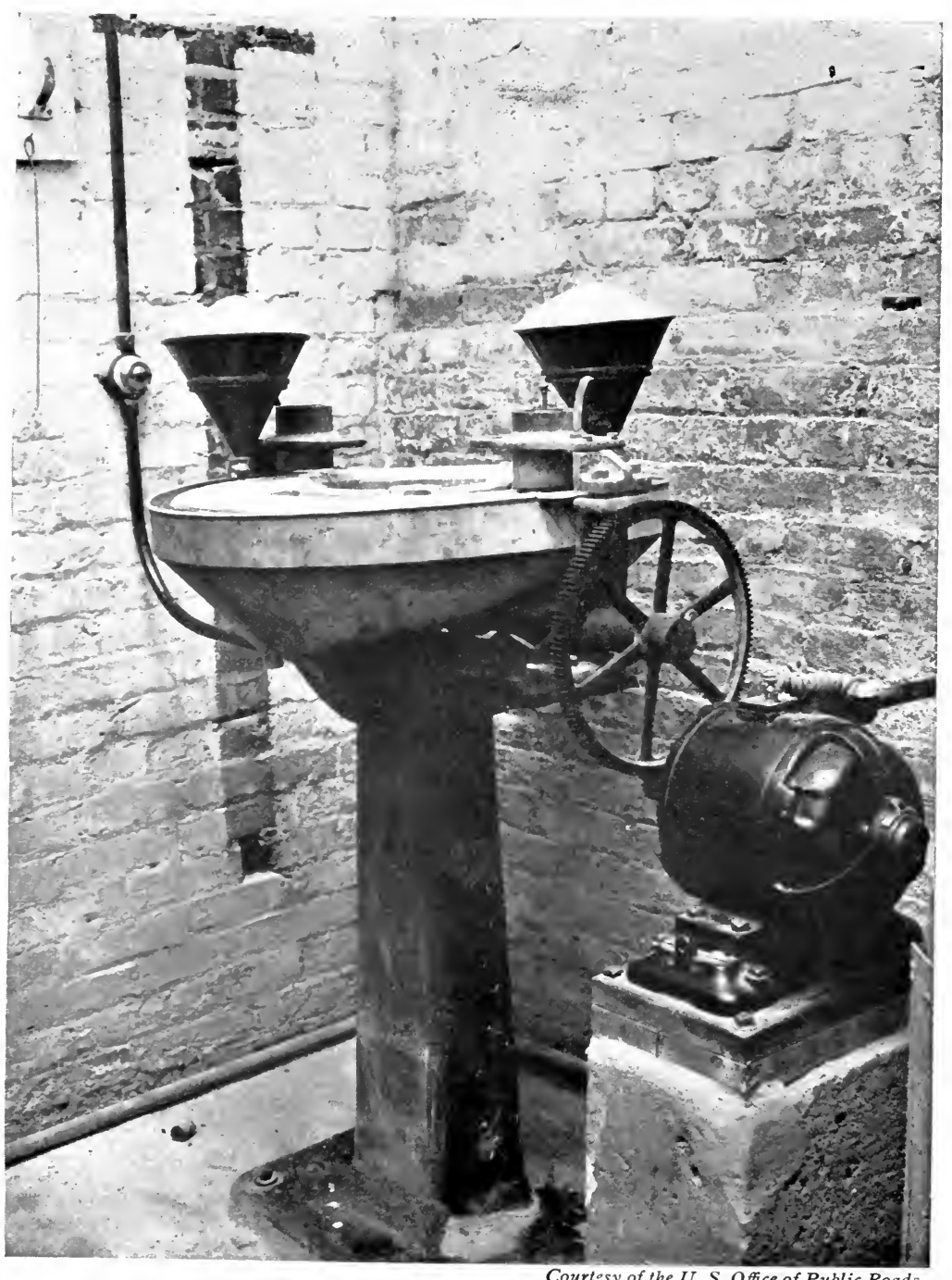

Fig. 63. Dorry Machine. 


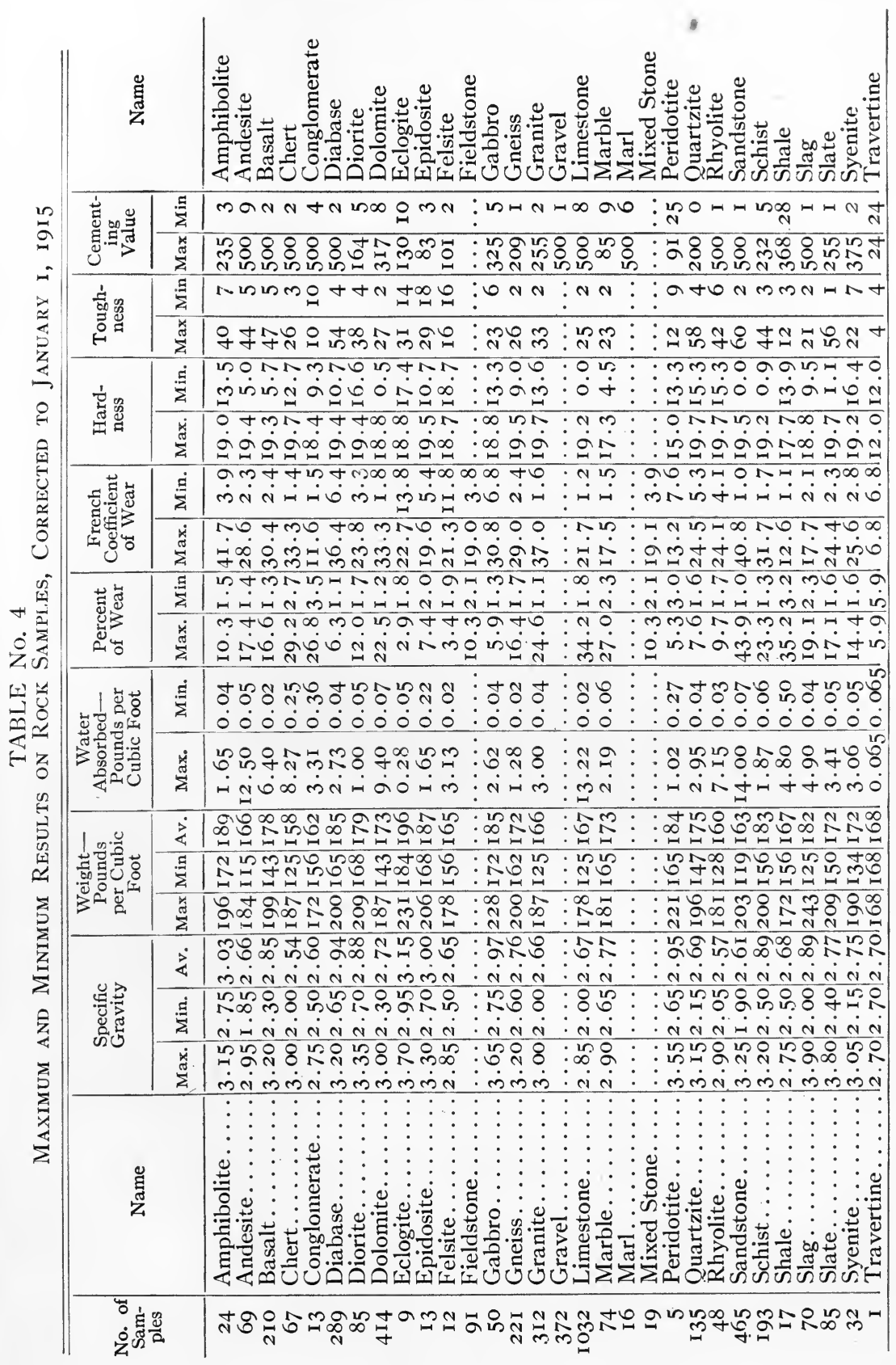


cementing power, toughness, and hardness for the principal rocks used in road building are given in Table No. 4, compiled by the U. S. Office of Public Roads and Rural Engineering.

\section{QuARrying AND CRUShiNG}

STRIPPING THE QUARRY. Before any drilling is commenced in a rock quarry, it is necessary to clean off all dirt and disintegrated material from the rock surface. This is called stripping the quarry. Frequently the ledge is exposed so that there is very litcle of this work to be done. If stripping is not accomplished in a thorough manner and kept well ahead of the drilling and blasting operations, there will always be trouble caused by this dirty material being mixed with the stone.

DrILLING. Drilling is accomplished with hammer drills, churn drills, and power drills.

Hammer Drills. For quarrying purposes a hammer drill is usually held by one man and struck by two others with hammers. Holes in small boulders may be drilled by the same man both holding and striking the drill.

Churn Drills. A churn drill is operated by one or more men, depending upon its weight. In operating a churn drill the man or men raise the drill and allow it to drop on the rock, giving it a slight turn between blows.

Power Drills. Power drills are operated by steam, air, and electricity. In all of these types the drill is given a reciprocating motion, striking many short stroke blows to the minute against the rock face. Between each blow the drill bit is given a partial turn. The drills are generally mounted on tripods as shown in Fig. 64 .

Cost of Drilling. The cost and speed of drilling depend upon the kind of rock, the size of hole, and the depth of hole drilled.

Gillette gives the following as the speed and cost of hammer drilling holes 6 feet deep:

\begin{tabular}{|c|c|c|}
\hline & $\begin{array}{l}\text { Feet in } \\
\text { Io Hours }\end{array}$ & $\begin{array}{l}\text { Cost per } \\
\text { Foot, Cts. }\end{array}$ \\
\hline 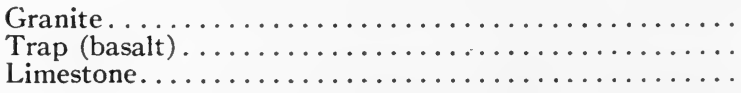 & $\begin{array}{r}7 \\
\text { I } \\
\text { I } 6\end{array}$ & $\begin{array}{l}75 \\
48 \\
33\end{array}$ \\
\hline
\end{tabular}


Power drills may be obtained to drill practically any size of hole from $3 / 4$ of an inch to 3 inches in diameter. As would be expected, these drills are capable of drilling at a much more

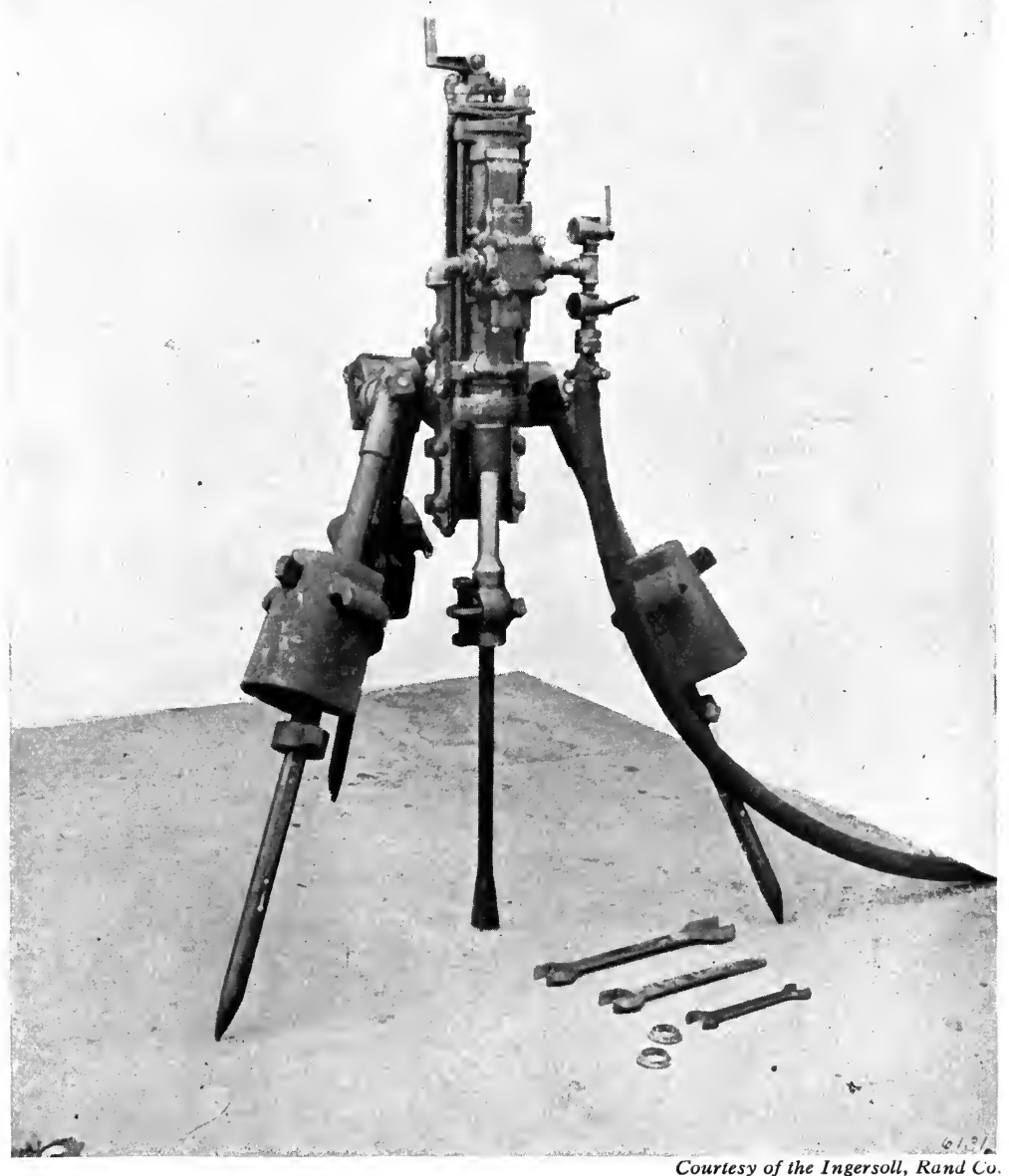

Fig. 64. Steam Drill.

rapid rate than either hammer or churn drills. From about 35 to 75 feet per Io-hour day can be accomplished with a power drill, the rate depending principally upon the kind of rock and the number of set-ups that have to be made. 
Blasting. The explosives used in blasting are powder and dynamite. Gunpowder is a combination of saltpetre, sulphur, and charcoal, saltpetre being the principal constituent. It is exploded by ignition and in doing so develops gases amounting to almost three hundred times its original volume. Dynamite is a mixture of nitroglycerine with an absorbent material. Dynamite has about four times the same explosive force as powder. Dynamite does not explode by ignition, but by percussion. A

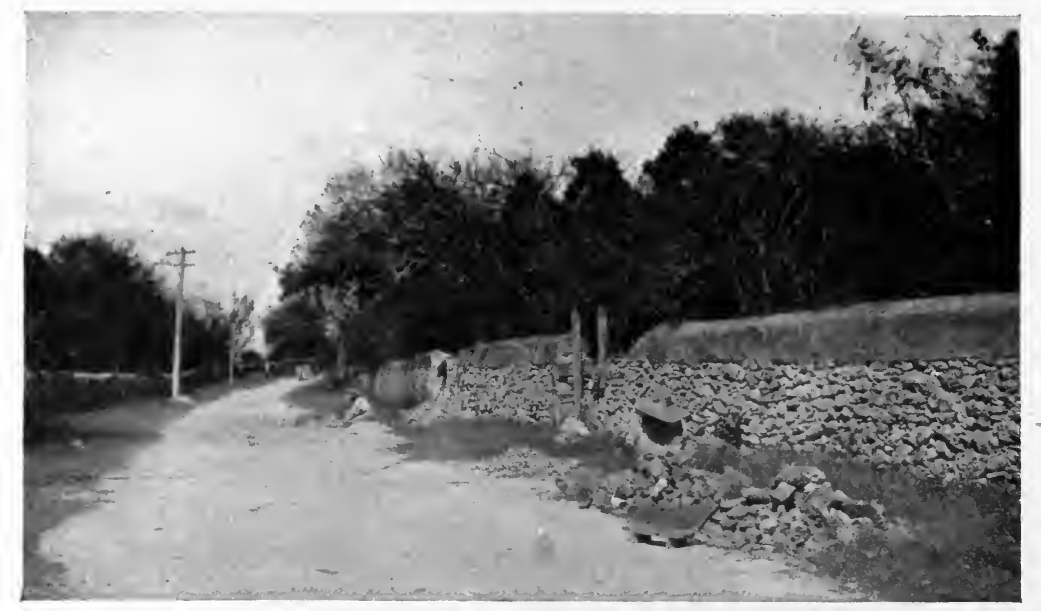

FIG. 65. Breaking Stone with Hand Tools.

fuse is used to explode powder. To explode dynamite a similar fuse is used which explodes a cap. The cap is placed in one of the sticks of dynamite constituting the charge, and the percussion of the cap explodes the dynamite. Instead of using a powder fuse, dynamite is often exploded by means of an electric battery. By this method several charges of dynamite can be set off simultaneously. Prelini states that the energy, released by setting off an explosive, is exerted in all directions or in the form of a sphere, the energy decreasing from the center towards the surface. Blasting alone may break up certain kinds of rocks so that very little sledging is necessary to make the rock of a size suitable to put through a crusher. Ordinarily, however, the pieces have to be broken up by hand into smaller sizes. The 
openings of a jaw crusher of common size is about 8 by 16 inches. When fieldstones are used, the boulders are often of such a size that only sledging is necessary to make them suitable for crushing.

CRUshing Plants. In the early days of road construction, the stone was broken by hand. (See Fig. 65.) Throughout the

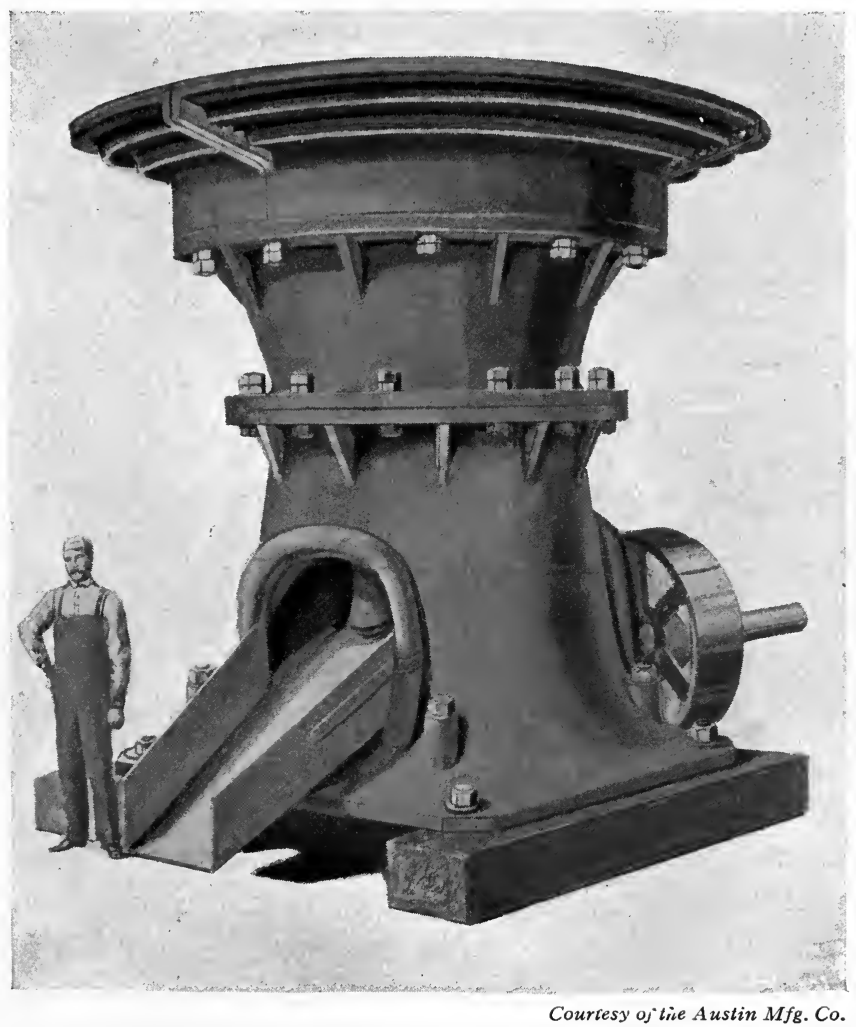

FIG. 66. Gyratory Crusher.

United States mechanical crushers are now used for the manufacture of broken stone. A complete crushing plant for roadbuilding purposes consists of a boiler, engine, crusher, elevator, screen, and storage bins.

Crushers. The crushers are of two distinct types; namely, the gyratory and the jaw crushers. Both types of crushers 
have some means of regulating the openings so that by using the proper opening together with appropriate crushing plates, almost any size of crushed product may be obtained. The size of the crushed product is limited by the smallest opening between the jaws at the outlet end. The gyratory crusher is a more recent invention than the jaw crusher. That the gyratory

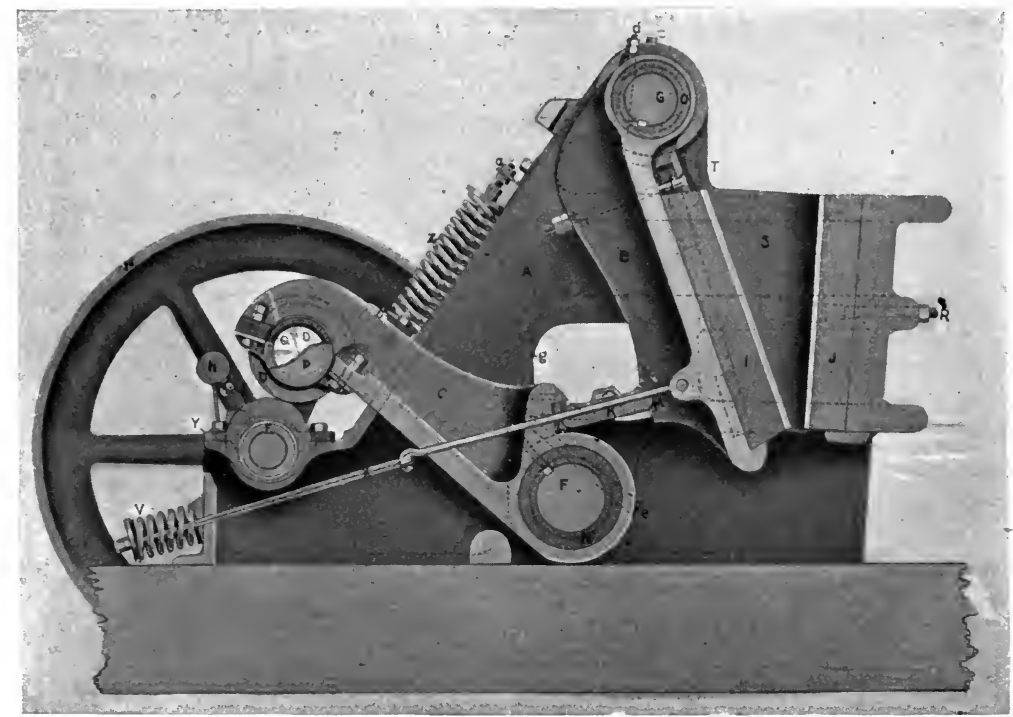

Courlesy of the Good Roads Machinery Co.

FIG. 67. Jaw Crusher, Sectional View.

crusher produces a more uniform product and is a more durable machine are the main advantages claimed for it over the jaw crusher. With the same horse-power, this type of crusher will generally produce a larger output. The type and size of crusher to be used depend upon the nature of the rock to be crushed, the size of the product desired, and the type of plant, that is, permanent or portable.

Gyratory Crushers. The gyratory crusher, see Fig. 66, is extensively used for permanent plants. Its great weight and height have not made it generally adaptable for portable plants, although it is sometimes made for this purpose.

Jaw Crushers. Jaw crushers are largely used for portable 
crushers. Fig. 67 shows a sectional view of this type. They are designated by the size of the jaw openings at the top. The size of 8 by 16 inches is very commonly used.

Boilers and Engines. The crushers may be run by gasolineengines or by steam-engines, the latter being perhaps more common. The steam-engine is generally mounted upon a horizontal boiler which is in turn placed on wheels so that it can be easily transported from place to place.

Elevators and Screens. The stone as it comes from the crusher is carried by means of a bucket elevator to the revolving

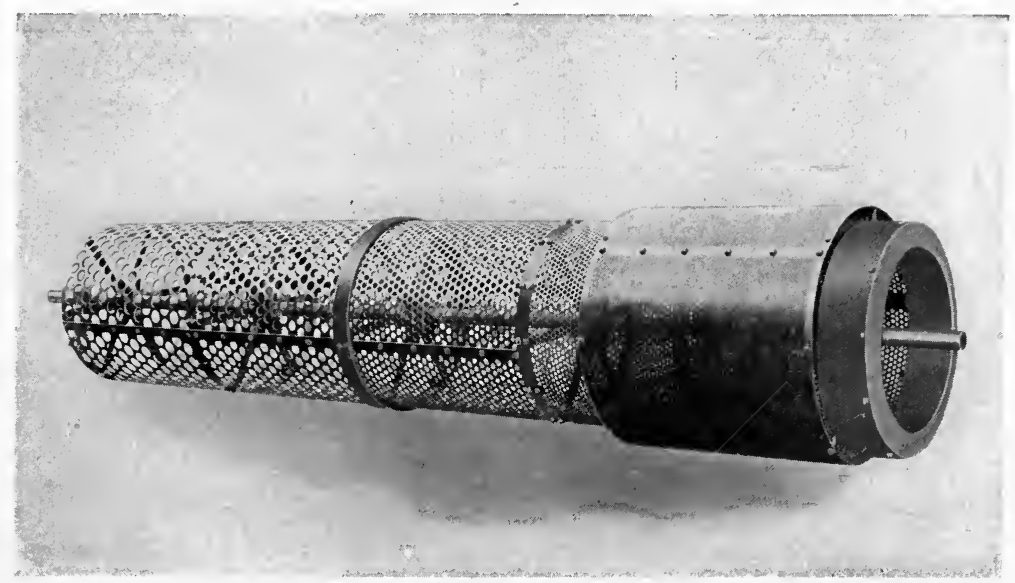

FIG. 68. Rotary Screen.

screen which is located over the bin. Fig. 68 shows a rotary screen equipped with a dust jacket. In portable plants the arrangement of the elevator, the screen, and the bins is such that they can be readily dismantled for transportation purposes. The elevators and screens are made in standard sizes, the lengths depending upon the size of the crusher and bin.

Bins. The portable bins are generally made with three compartments. These bins are made in sizes varying in capacity from ${ }_{3} 3$ to 50 tons. In some of the more modern types of portable bins, provision is made so that the bin can be raised to a height which will allow teams to pass beneath the unloading chutes. 
Voids AND Weights of CRUshed Stone. When rock is crushed it occupies a larger volume than it did in place due to the voids in the mass. The amount of voids is variable, depending upon the proportions of the sizes in the mass. 'The manner in which the stone is placed in a bin, cart, car, or barge, and the length of haul also affect the amount of voids. Gillette gives the following, showing the number of cubic yards of broken stone with varying percentages of voids that can be obtained from one cubic yard of solid rock:

\begin{tabular}{c|c|c|c|c|c|c}
\hline \hline Voids & $30 \%$ & $35 \%$ & $40 \%$ & $45 \%$ & $50 \%$ & $55 \%$ \\
\hline $\begin{array}{l}\text { Cubic yards of broken } \\
\text { stone from I cubic } \\
\text { yard of solid rock... }\end{array}$ & $\mathrm{I} .43$ & $\mathrm{I} .54$ & $\mathrm{I} .67$ & $\mathrm{I.82}$ & $\mathbf{2 . 0 0}$ & $\mathbf{2 . 2 2}$ \\
\hline
\end{tabular}

The specific gravities of the various rocks used for building roads are given in Table No. 4. If the voids in the mass are known, therefore, the weight of any volume can be computed.

The following methods have been used in determining the voids in mineral aggregates.

Pouring Method. In this method a suitable receptacle is filled with the dry aggregate to be tested, the aggregate being firmly compacted. Water is then poured into the receptacle until it is flush with the surface of the compacted aggregate. The amount of water used is considered the amount of voids in the mass of the aggregate.

New York State Method. This method is a modification of the pouring method in that the water is introduced into the bottom rather than into the top of the receptacle. The apparatus consists of a I,ooo-cubic centimeter receptacle open at the top and closed at the bottom, with the exception of a small orifice which is connected by means of a rubber tube to a graduated burette. The aggregate is placed in the receptacle and compacted. The burette is then filled with water. The water is allowed to run into the receptacle through the orifice in the bottom. When the water is flush with the surface of the compacted aggregate the flow is cut off. By means of the burette 
the quantity of water introduced is measured and this amount is considered to represent the voids in the mass.

U. S. Office of Public Roads Method. A I,00o-cubic centimeter cylindrical receptacle, open at both ends, is placed on a sheet of paper and filled with the compacted aggregate. The cylinder is lifted up, allowing the aggregate to remain on the paper. The aggregate is then poured into a 2,000-cubic centimeter graduated flask which has previously been filled with 600 cubic centimeters of water. The displacement of the water in the flask is noted. The amount of voids in the mass is determined by subtracting the final reading of the meniscus from the initial reading plus 1,000 , or $1,000+600-$ the final reading equals the amount of voids.

Schutte Method. In this method a can having the shape of a truncated cone is used. It is necessary in using this method to determine the specific gravity of the aggregate. The weight of the cone, full of the compacted aggregate, is determined, and next the weight of the cone full of water. Knowing the weight of the cone, the net weight of aggregate and water can be found. The weight of the water in the cone multiplied by the specific gravity of the aggregate gives the weight of solid mass of the material of the aggregate having a volume equal to that of the cone. This computed weight minus the weight of the compacted aggregate in the cone gives the amount of voids in the mass.

\section{CONSTRUCTION}

HISTORICAL. The following statements which are quoted from remarks of Tresaguet and McAdam serve to describe the methods which they advocated.

In a paper presented before an assembly of the Départemente des Chaussées in I776, Tresaguet described his method of building roads as follows: "In order to successfully diminish the thickness of the roads and give them sufficient strength to sustain the loads which they have to carry, it is necessary to modify the method of construction. . . . The bottom or earth foundation on which the first layer rests is made parallel to the 
finished surface of the road. The first layer of stone is placed on edge similar to block paving, and is firmly compacted. More stone is likewise placed layer by layer on this course and is broken into coarse pieces, which so interlay that no voids are left. Finally, a top layer 3 inches thick is added. The stones in this layer are of the size of a walnut and are obtained by breaking the stone with small hammers on special anvils. This layer is placed by means of shovels so as to correspond with the desired shape of the road. Particular attention should be given to the choice of stone for this last course since the strength of the pavement depends on it and one cannot be too careful as to the quality of the stone selected. This may necessitate at times a different grade of stone for the top course than that which was used in the lower courses."

McAdam said in various reports presented by him during the period from I8II to I820: "The stone laid in the road is to be loosened up and broken so as no piece shall exceed 6 ounces in weight. The road is then to be laid as flat as possible, a rise of 3 inches from the center to the side is sufficient for a road 30 feet wide. The stones, when loosened in the road, are to be gathered off by means of a strong, heavy rake, ... to the side of the road, and there broken, and on no account are stones to be broken on the road. When the large stones have been removed and none left in the road exceeding 6 ounces, the road is to be put in shape and a rake employed to smooth the surface, which will at the same time bring to the surface the remaining stone and will allow the dirt to go down. When the road is so prepared, the stone that has been broken by the side of the road is then to be carefully spread on it. This is rather a nice operation, and the future quality of the road will greatly depend on the manner in which it is performed. The stone must not be laid down in shovelfuls but scattered over the surface, one shovelful following another, and spreading over a considerable space. Every road is to be made of broken stone without mixture of earth, clay, chalk, or any other matter that will imbibe water, and be affected by frost; nothing is to be laid on the clean stone on pretence of binding; broken stone 
will combine by its own angles into a smooth solid surface that cannot be affected by vicissitudes of weather, or displaced by the action of wheels, which will pass over it without a jolt and consequently without injury. The size of stones for a road has been described in contracts in several different ways, sometimes as the size of a hen's egg, sometimes at half a pound weight. These descriptions are very vague, the first being an indefinite size and the latter depending upon the density of the stone used, and neither being attended to in the execution. The size of stone used on a road must be in due proportion to the space occupied by a wheel of ordinary dimensions on a smooth level surface, this point of contact will be found to be, longitudinally about an inch, and every piece of stone put into a road, which exceeds an inch in any of its dimensions, is mischievous.

"At one time I formed the opinion that the use of a large stone foundation was only a useless expense, but experience has convinced me that it is likewise positively injurious. It is well known to every skilful and observant road maker that if strata of stone of various sizes be placed as a road, the largest stones will constantly work up by the shaking and pressure of traffic, and that the only mode of keeping the stones of a road from motion is to use materials of a uniform size from the bottom. In roads made upon large stones as a foundation, the perpetual motion, or change of position of the material, keeps open many apertures through which the water passes. . . . The first operation in making a road should be the reverse of digging a trench. The road should not be sunk below but rather raised above the ordinary level of the adjacent ground; care should at any rate be taken that there is sufficient fall to take off the water, so that it should always be some inches below the level of the ground upon which the road is intended to be placed. This must be done either by making drains to lower the ground water, or, if that be not practicable, from the nature of the country, then the soil upon which the road is proposed to be laid must be raised by addition so as to be some inches above the level of the water. Having secured the soil from under water, the road maker is next to secure it from rain water, by 
a solid road, made of clean dry stone or flint, so selected, prepared, and laid, as to be perfectly impervious to water. The thickness of such a road is immaterial, as to its strength for carrying weight; this object is already obtained by providing a dry surface. . . . Several new roads have been constructed on this principle within the last three years. . . . None of these roads exceeds 6 inches in thickness, and although that on the great north road is subjected to a very heavy traffic, it has not given way, nor was it affected by the late severe winter."

Size of STone. The sizes of the stone used vary in different specifications. Since nearly all of the broken stone used for highway construction is screened with a rotary screen, it should be noted that the speed at which the screen is revolved, the pitch, the length, and the size of the holes in the screen all influence the grading of the stone into different sizes. The type of crusher used and the kind of rock crushed also influence the amount of the different sizes obtained. The width of the jaw opening of the crusher determines the maximum size of stone which will be obtained from crushing any rock. The stone will be broken into sizes varying from this maximum down to dust.

Common commercial sizes of broken stone are screenings, $3 / 8$-inch chips, $1 / 2,3 / 4,1,11 / 4,11 / 2,2,21 / 4,21 / 2$, and 3 -inch broken stone. In designating the sizes of broken stone, the longest dimensions of the product have been stated or the stone has been described, for instance, as I $1 / 2$-inch stone, etc. A better method of describing the size of stone is to stipulate that it shall pass over a screen having holes of one size and pass through a screen having another size of holes, or that it shall pass a screen having holes of one size and be retained on a screen having another size of holes. At the various quarries in New York State, sizes of crusher-run stone in I9I4 were designated as follows:

SCREenings. That product of the ordinary run of the crusher passing a $1 / 2$-inch or $5 / 8$-inch circular opening including the dust of fracture.

3/8-INCH STONE. Screenings which are screened to remove practically all stone dust passing over a $1 / 4$-inch or $3 / 8$-inch screen. 
$3 / 4-\mathrm{INCH}$ StONE. Crusher run retained on the $1 / 2$-inch or $5 / 8$-inch opening and passing a $11 / 8$-inch or $11 / 4$-inch opening.

I $1 / 2-I N C H$ STONE. Crusher run retained on the $11 / 8$-inch or $11 / 4$-inch opening and passing the $21 / 4$-inch opening.

$21 / 2-\mathrm{INCH}$ STONE. Crusher run retained on the $21 / 4$-inch opening and passing the $3 \frac{1}{4}$-inch opening.

Sizes Used in Different Courses. Broken stone roads are ordinarily built in two or three courses. The larger size products of the crusher are used in the first or foundation course. Gravel and slag are sometimes substituted for broken stone in the foundation course. The size of stone for this course varies from $I$ to 3 inches in longest dimensions. The second course is composed of stone slightly smaller, ranging from $\mathrm{I}$ to 2 inches or from $I / 2$ inch to $I / 4$ inches in their longest dimensions. The top course consists of screenings varying from $1 / 2$ inch down to dust.

The sizes of stone, as specified in some of the different States of the United States, are as follows:

\section{State}

Massachusetts

New Jersey

New York

Maryland
Foundation Course

I $1 / 4$ to $21 / 2$ inches.

$21 / 2$-inch stone or stone that will pass a 3-inch ring, minimum length, 2 inches.

$$
\begin{aligned}
& \text { Through } 3 \frac{1}{2} \text { - inch } \\
& \text { holes. } \\
& 3^{-} \text {to I-inch, maxi- } \\
& \text { mum length, } 3 \text { inches. }
\end{aligned}
$$

UPPER COURSE

$I / 2$ to $I I / 4$ inches.

I $1 / 2$-inch stone or stone that will pass a 2-inch ring, maximum length, 2 inches, minimum length, I inch.

Through $21 / 4$ - inch holes.

I- to 2-inch, maximum length, 2 inches.

Aitken states that the broken stone roads in Great Britain have a foundation layer of stones varying in size from $3^{-}$to $4^{-}$ inch cubes, while the upper course is composed of broken stone varying in size from 2 to $2 \frac{1}{4}$ inches. In France the size of the stones used varies from about $\mathrm{I} / 4$ to 3 inches, the size frequently selected being about $21 / 2$ inches.

Foundation and Subgrade. The lower or foundation course of a broken stone road may be strengthened by a telford base, a V-drain, a subbottom course, see Fig. 69, or by increasing its thickness. The construction of telford and V-drain foundations has been described in Chapter V. It is assumed, of 
course, that the roadbed has been properly drained according to methods set forth in Chapter V. The subgrade is usually a shallow trench composed of two or more planes or a curved surface sloping from the center to the sides. The surface of the subgrade is generally parallel to the finished surface

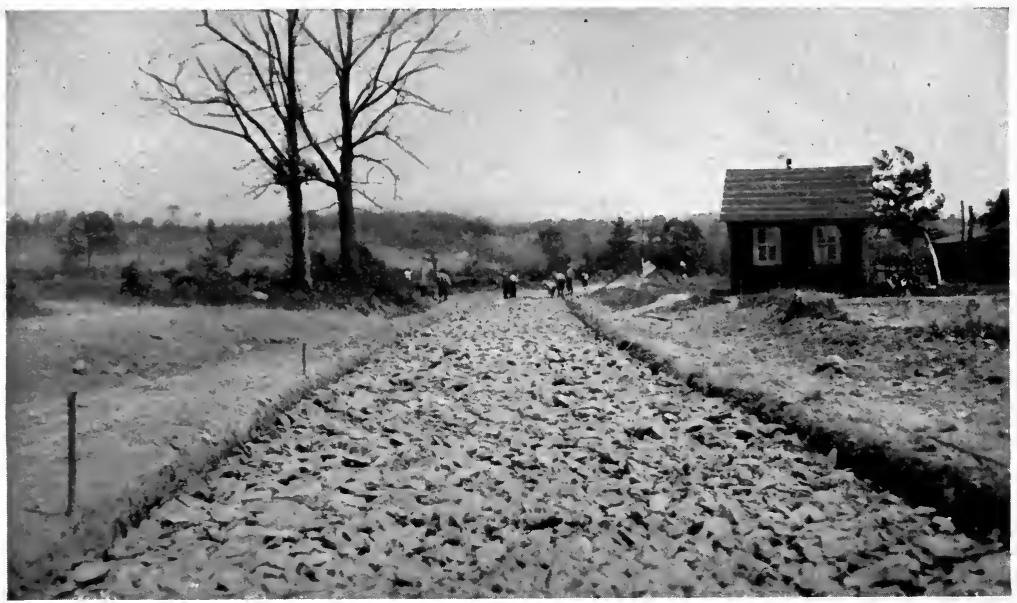

FIG. 69. Subbottom Course.

of the broken stone road, although this is not true when the depth of stone at the edge of the shoulder is made less than at the center. The subgrade has the same width as the broken stone surface. The sides of the trench, which serve to hold the stone in place, are formed by earth shoulders, generally from 3 to 5 feet in width. In places where the edge of the stone is bounded by a curb or gutter, the earth shoulder is generally omitted unless the roadway is extremely wide and only a part of the width is built of broken stone. The subgrade should be brought to true line and grade and be thoroughly compacted with a steam-roller. Any low spots which appear during compaction should be brought up to grade with good material and rerolled.

Form of Section. Formulas for crown or transverse slope suitable for broken stone roads are given in Chapter IV. The crown ordinarily used is from $1 / 2$ to $3 / 4$ of an inch to the foot. Typ- 
ical cross-sections of broken stone roads, as constructed by different State Highway Departments, are shown in Chapter IV.

Hauling the Stone. Stone may be hauled to the road by means of any of the various carts or wagons described in Chapter V. Patent bottom dump-wagons with doors hinged on the sides or on the ends of the wagons are commonly used and serve the purpose in an excellent manner. It is possible with this type of wagon to regulate the size of opening between the bottom doors so that any width of opening up to the maximum can be obtained. By this means it is possible to spread the stone in layers as the wagon is drawn along the road. Similar wagons are built to be used with a traction engine. Wagons of this type generally have a capacity of 3 to 4 cubic yards and are drawn in trains.

LAYING THE Stone. It is apparent that in foreign practice somewhat larger stones are employed for the upper course than are commonly used in this country. In some cases where the stone is not of a particularly good quality, better results may be obtained by placing the smaller stone in the bottom of the road and the larger sized stone on top. There are also cases where the run of the crusher from the coarse sizes down to dust is placed on the road as one course, but this method is not recommended. If the stone is brought in patent bottom dump-wagons, it may be dumped directly upon the subgrade and spread with forks. Stone brought to the work for the upper courses of a road, however, should be dumped on boards and shovelled in place to prevent the segregation of the sizes, which might occur if the stone was dumped directly upon the road from the wagons.

Thickness of Courses. The thickness varies in different specifications and is governed by the amount of traffic which the road is to receive, the kind of broken stone, and the condition of the subgrade. For the foundation course common values are 4,6 , and 8 inches in total thickness after rolling where the subgrade furnishes a good natural foundation. The upper course is generally from 2 to 3 inches in thickness after rolling. The stone surfacing should be made the same thickness through- 
out its width. Some engineers believe in economizing by making the thickness of the stone at the sides from I to 2 inches less than the depth at the center; the theory being that the sides do not receive as much traffic as the center. Under present traffic conditions, and especially where heavy motor trucks are used, the advisability of reducing the thickness of material at the sides is questionable.

In England, Aitken states that the foundation layer of $3^{-}$to 4 -inch stones is made from 6 to 9 inches deep in country districts and is increased to $\mathrm{I} 2$ inches for suburban and town roads. A cushion layer of sand from $I$ to $I \frac{1}{2}$ inches thick is spread over the foundation to prevent the stone in the upper course from being crushed upon the hard foundation. The upper course of broken stone is made from .4 to 6 inches thick and is constructed in two layers when a thickness of 6 inches is used.

Regulating the Thickness. To gauge the thickness of a layer of stone, wooden cubes made equal to the depth of a layer are sometimes placed at intervals across the roadway, the cubes being taken up and moved along as the work progresses. With this method, however, if there are any irregularities in the subgrade or in the foundation course, they will be carried up to the finished surface. A better method of regulating the depths of the different layers is to set strings longitudinally at the proper elevation at the sides and center of the roadway. In this manner the elevations are always tied in with the finished grade and any irregularities can more readily be corrected as they occur.

Rolling the Stone. The courses are each laid to the required thickness and separately rolled before the next course is placed. The roller used in compacting this material should be at least ten tons in weight. Rolling should commence at one edge of the roadway and progress toward the center, the roller travelling in a direction parallel with the center line of the road. After reaching the middle of the road, the roller should pass to the other side, and again work in a similar manner toward the center. This method of rolling keeps the road in shape and prevents 
either pushing the crown out of line or flattening it. Careful rolling is absolutely necessary in order to obtain a good. shape to the road surface. A steam-roller is much more effective than a horse-roller since the latter is lighter and hence cannot compact the surface so thoroughly. Moreover, the horses' hoofs tend to loosen the surface during compaction, which makes it difficult to secure good results. If, in the first passages of the roller over the surface, any low spots are detected, they should immediately be brought to the proper level by the addition of more stone of the same size as is used in the course being rolled, before further compaction takes place. It will be found in rolling that broken stone will be compressed about 33 percent; that is, to make a compacted layer 2 inches thick, 3 inches of broken stone would have to be spread loose.

In some specifications it is stated that the voids in the foundation course shall be filled with stone screenings, sand, or gravel, the fine binding material to be thoroughly swept in, watered, and rolled. No surplus material, however, is allowed to remain on the surface of the foundation course. This method of construction provides a firmer foundation than where the voids between the stones are not so filled. The same treatment is also frequently used to facilitate the rolling of the foundation course where the stone is of such a character that it will not readily compact under the action of the roller.

Applying the Screenings. Screenings are generally used in connection with the construction of the upper course. When this course has been firmly compacted, the surface is covered with a layer of stone screenings and thoroughly sprinkled with water, which washes the screenings into the voids in the stone. More screenings are added as desired and rolling is continued, the surface being sprinkled in front of the roller. When the proper amount of water and screenings has been used, a wave of grout will be pushed along in front of the roller. A coating of screenings should be laid over the entire surface, no more being used than is necessary to cover the stone. The stone screenings resulting from the crushing of the rock with which the first two courses are filled are generally used for the binder. 
When this material is unsuitable, clay, loam, sand, or screenings of a different rock are substituted for it.

Cost. The cost per square yard of broken stone roads varies from 45 cents to $\$$ I.00. In the following table are given, for several localities throughout the United States, the average I9I4 prices of broken stone roads.

From Municipal Engineering, June, 1915.

\begin{tabular}{|c|c|c|c|}
\hline City & $\begin{array}{l}\text { Square } \\
\text { Yards }\end{array}$ & $\begin{array}{c}\text { Price } \\
\text { per } \\
\text { Square Yard }\end{array}$ & $\begin{array}{c}\text { Total } \\
\text { Thickness, } \\
\text { Inches }\end{array}$ \\
\hline 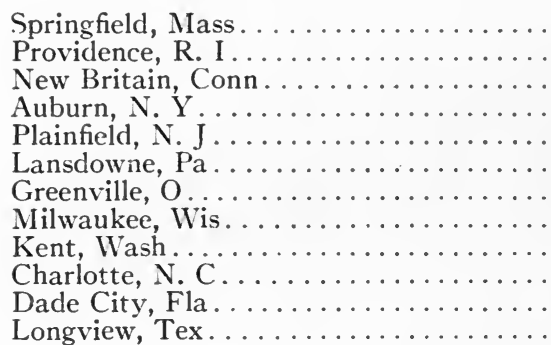 & $\begin{array}{r}6,523 \\
69,600 \\
32,500 \\
36,000 \\
17,900 \\
15,000 \\
5,085 \\
33,022 \\
8,573 \\
17,000 \\
140,000 \\
7,790\end{array}$ & $\begin{array}{l}\$ 0.57 \\
0.63 \\
0.68 \\
0.70 \\
0.57 \\
0.80 \\
0.60 \\
1.05 \\
0.85 \\
0.50 \\
1.40 \\
0.94\end{array}$ & $\begin{array}{l}6 \\
6 \\
7 \\
5 \\
6 \\
6 \\
8 \\
81 / 2 \\
6 \\
6 \\
4 \\
9\end{array}$ \\
\hline
\end{tabular}

Miscellaneous Roads. Slag roads and shell roads have been used to a limited extent throughout the United States. As the details of construction are similar to those employed in the construction of broken stone roads, certain features, peculiar to each, are described in this chapter.

Slag Roads. Blast furnace slags are produced in the manufacture of iron and steel and, in some cases, are very similar in appearance to close-grained igneous rocks. In reducing iron ores, the impurities rise to the surface, as the iron melts in the furnace, and unite with the fluxing material. This material is drawn off in a molten condition and is cooled either in water or in the air. Sometimes it is turned out onto the ground in a semi-molten condition and forms large banks of slag. Blast furnace slag may be excavated from slag banks by means of a steam-shovel, which serves to sufficiently break up the material so that it may be screened. In converting the iron from the blast furnaces into steel by the open-hearth process, 
more flux is used in the process, which rises to the surface of the molten mass as slag. The slag from the open-hearth process is generally run into molds. It has, in some cases, been broken up in a rock crusher into sizes suitable for road work.

Slag is used for foundation courses and in some instances to form the entire road crust. The methods used are similar to those described for the construction of broken stone roads. Slag composes the mineral aggregate of the Tarmac pavements, which are built extensively in the County of Notts and elsewhere in England. This pavement is described in Chapter XII.

Shell Roads. The State of Maryland has built many miles of oyster shell roads along the eastern shore of Chesapeake Bay. The shells are about the only available material for surfacing roads in that locality. Where the shells are simply thrown onto the old roadbed without previously shaping the latter, the results obtained are not very satisfactory. The shells soon push down and the mud works up, producing conditions which are not much better than before the road was improved. If the traffic follows in the same track on a shell road, ruts will be quickly formed and a horse path will be made in the center. If these low places are immediately filled with new shells, it will tend to make the traffic distribute itself over the surface and prevent, to a great extent, subsequent tracking. Shell roads, unless watered or treated with some form of dust palliative or bituminous surface, are liâble to be very dusty.

Good results with this material can be obtained by following the methods used by the Maryland State Roads Commission. The specifications stipulate that the subgrade shall be firm and well rolled. The depth of the first course of shells is either 5 inches or 5 inches at the center and 3 inches at the sides. The depth of the second course is either 3 inches or 5 inches at the center and 3 at the sides. They are spread upon the roadbed with shovels from piles along the road or from a dumping board. They are rolled with an 8-ton roller and are sprinkled with water or bound with sand during the process of rolling until the surface is firmly compacted. The third course is composed of clean, sharp sand, spread just thick enough to cover the 
second course after the latter has been thoroughly compacted. Shell roads cost from 40 to 50 cents per square yard.

\section{Maintenance}

Causes of Wear. Water, if allowed to stand on a broken stone surface, will soften the latter and cause it to rapidly wear out. When the frost is coming out of the ground in the spring,

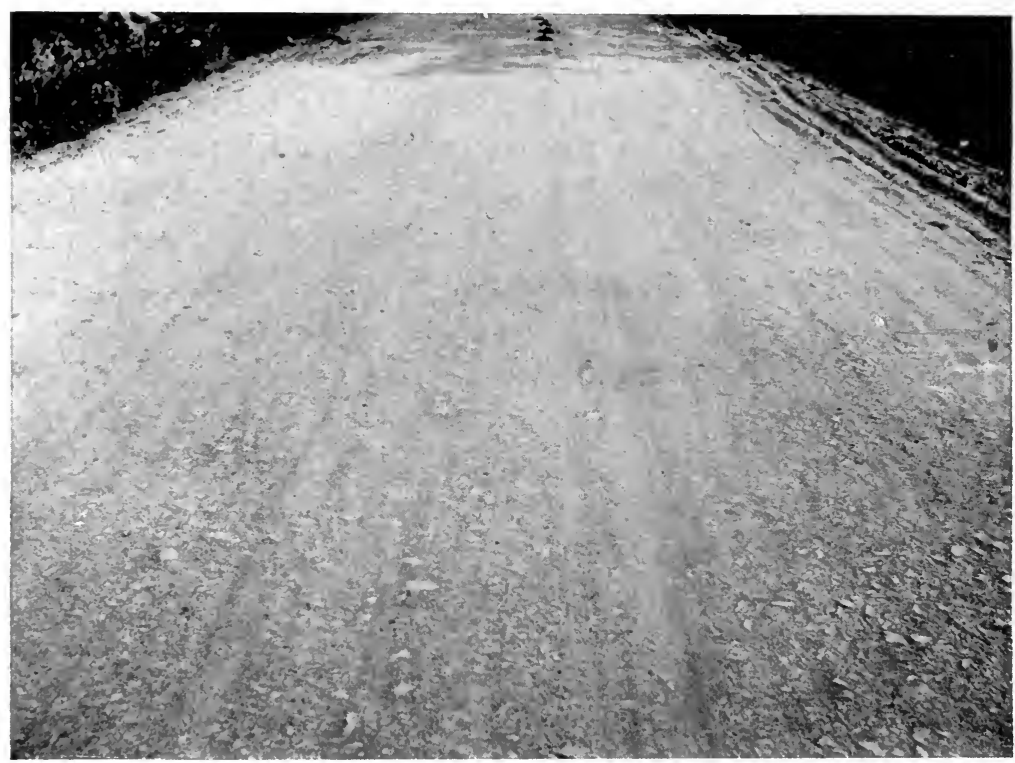

FIG. 70. Mosaic Condition of the Surface of a Broken Stone Road After Binder Has Been Swept Away by Traffic.

the surface will also be in a soft condition and require attention. The effect of horse-drawn vehicle traffic is frequently observed in the formation of the "horse path," so-called, in the center of the road. If the surface is given a flat crown, this will be prevented to some extent since the traffic will be encouraged to use the entire width of surface. If the teams track each other the wheels will form ruts, particularly when the road is in a soft condition. The grinding action of the wheels wears the stone and forms dust which, in a dry state, is swept away 
by the wind, thus leaving the stones in the top course exposed, in which condition they are liable to be displaced by the action of traffic. A heavy traffic of motor-cars travelling at high speed will also cause the broken stone surface to ravel very quickly when the mosaic of the upper course is exposed. Sometimes when the road is in this condition and the weather has been dry, a concentrated motor traffic of only one or two days' dura-

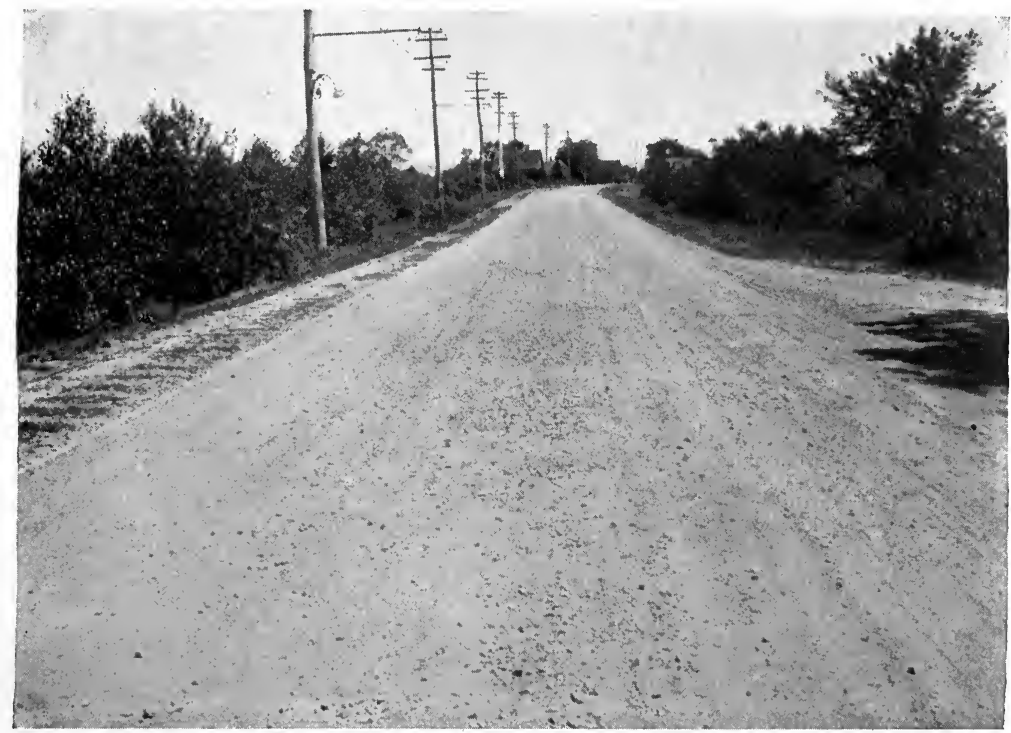

FIG. 7I. Effect of Motor-Car Traffic on the Surface of a Broken Stone Road.

tion will cause ravelling. Fig. 70 shows the mosaic condition of the surface when the binder has been swept away, and Fig. 7 I illustrates how a concentrated motor traffic of short duration will ravel the surface. Fig. 72 shows how the surface is worn out on the inside edge of a curve, as a result of motor-car traffic. A road which is not kept in repair very quickly becomes a bad road. With proper attention, however, the surface can be kept in a passable condition and the life of the road be considerably prolonged.

ORDINARY REPAIRS. To provide against failure from any of the causes enumerated above, the following essential princi- 
ples of maintenance work are given. At all times the surface of the road should be kept smooth. This enables the road to shed water more readily and eliminates shocks which would result from the traffic where the surface is uneven. Any hollows or pot-holes, see Fig. 73, which develop in the surface should be repaired as soon as formed. Particular attention should be

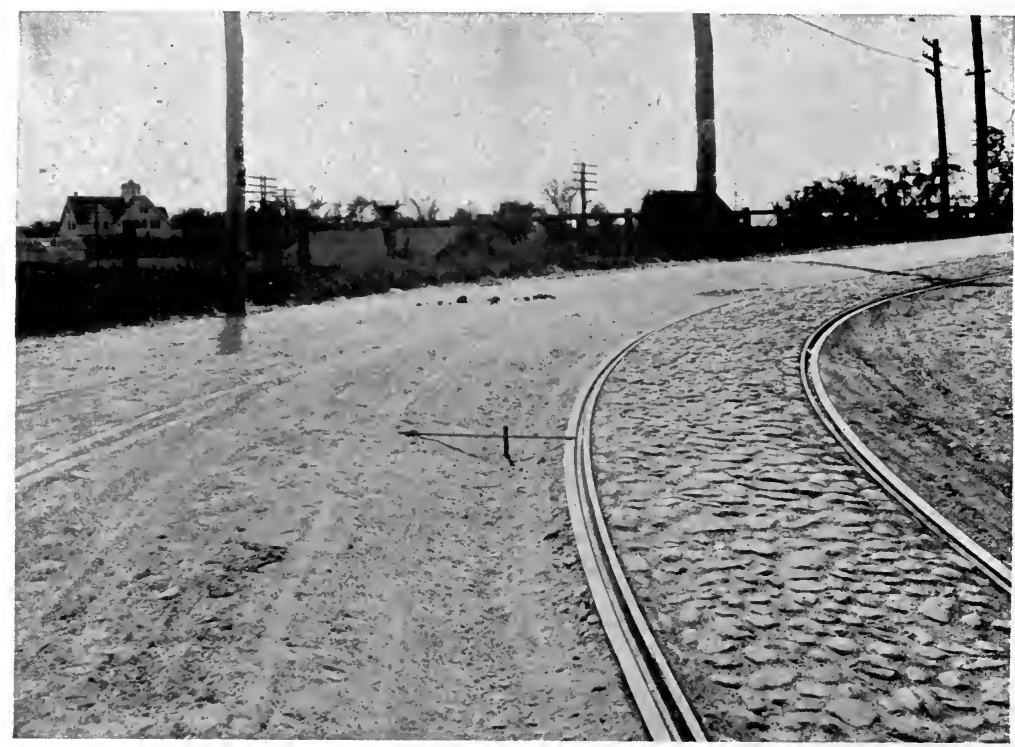

FIG. 72. Wear on the Inside of the Curve Produced by Motor-Car Traffic.

given to eliminating the ruts, since any depressions in the surface hold water, and are enlarged very rapidly by the action of traffic. Broken stone of the same size as is used in the upper course should be used in filling in the depressions and ruts. In France and England, it has been found that, in repairing pot-holes, the best results are obtained if the holes are cut out on the lines of a square or rectangle which is of sufficient area to include the depression, the sides to be cut through for the full depth of the wearing course. The stone is replaced, carefully tamped, filled with screenings, and puddled, or it is incorporated with some bituminous material either before or after placing. Rolling in the spring of the year 
when the road is soft will be of great help in providing a smooth surface for the remainder of the season. An excess of dust or mud on the surface should be removed, since dust is not only very objectionable from the standpoint of comfort to the traffic, but when wet it forms mud, which keeps the surface of the road in a moist condition, sometimes for a long period. On the other

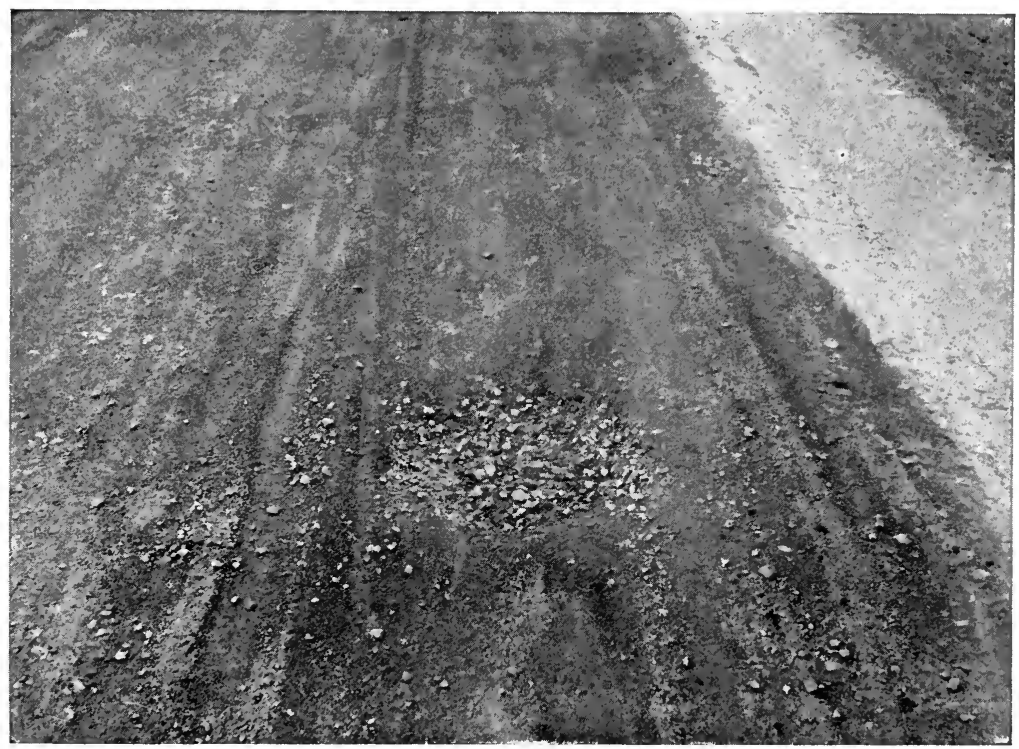

FIG. 73. Pot-hole in the Surface of a Broken Stone Road.

hand, when the upper course of stone presents a mosaic surface, sand, stone screenings, or other binding material should be spread on the surface to prevent ravelling.

The earth shoulder between the stone surfacing and the ditch should be trimmed up from time to time, so that water flowing from the surface of the road will not be impeded in its progress to the ditch. This work can, in many cases, be done in a satisfactory and economic manner by the use of a road scraper. The material removed from the shoulders, however, should never be thrown up into the center of the stone surface. As is the case in earth and gravel roads, the ditches and drains 
should be carefully looked after to provide for the ready flow of water.

The majority of these ordinary repairs should be accomplished under what is called the continuous system of maintenance-that is, a system where the roads are constantly looked after and any necessary repairs are immediately made. Not only is the continuous system of maintenance the cheapest in the end, but it also keeps the road in a good state of repair. The patrol system of maintenance as carried out in France is a good illustration of what can be accomplished by this method. This system is gradually being adopted in different parts of the United States, New York being the first State to adopt this system on extensive lines. There are many municipalities which have very efficient Public Works Departments by means of which the streets are maintained in an excellent manner.

RESURFACING. When the road becomes so badly worn that it is impossible to economically keep it in good condition by the ordinary methods of maintenance, resurfacing is necessary. Unless an average depth of stone of about three inches is to be added, the old broken stone surface should be picked up or scarified so that the new stone will bond with the old. The wheels of a steam-roller are so made that it is possible to insert heavy picks or spikes in the rear wheels. In repairing the state roads in Massachusetts, a common method is to place picks in the wheels of the roller and to drag a heavy spike-harrow behind the roller. A few trips of these machines will loosen up the surface, which is then worked over with a light hand harrow or a farmer's spring-tooth weeder to bring the stone to the surface and to shake the dirt down beneath. The new stone is added wherever required to bring the surface to the proper shape, and the surface is then thoroughly rolled and puddled, as in constructing a new road. The roller picks will loosen the road to a depth of from 4 to 6 inches.

Scarifiers are commonly used in resurfacing work. With some types of scarifiers the picks may be set so that practically any depth from I to 6 inches can be loosened. The scarifier tends to bring the stone to the surface and to shake the dirt 
down underneath. It will be necessary, however, to shape up the surface with a harrow or with rakes. The work of scarifying or picking will be much more readily accomplished if the surface is first soaked with water.

\section{CharaCteristics}

A broken stone road, if properly built of the right kind of stone, is a very economical and satisfactory surface for medium horse-drawn vehicle traffic. It affords an excellent foothold, is noiseless, does not offer much resistance to traffic, and is comfortable to use. In dry weather, however, a broken stone surface is usually dusty unless the surface is treated with a palliative or coated with bituminous material. 


\section{CHAPTER IX}

\section{BITUMINOUS MATERIALS}

Before considering the details of the treatment of surfaces rendered dustless by the application of palliatives and the construction and maintenance of bituminous surfaces, bituminous pavements, and block pavements in connection with which bituminous fillers are employed, the sources, characteristics, and the physical and chemical properties of bituminous materials should be considered. The nomenclature of bituminous materials is introduced at this point in order that the general relationship of materials, their properties and uses, may be understood and in order that the definitions may be readily accessible for consultation during the perusal of this chapter. Only such definitions have been introduced as seem necessary to a clear understanding of the subject matter which follows in this and succeeding chapters. Where definitions have been used which include terms generally found only in technical treatises on the chemistry of hydrocarbons, these terms have been printed in italics and may be omitted in the reading of the definitions without depriving them of their value from an engineering standpoint.

\section{Nomenclature}

Definitions which have been proposed by the Special Committee on "Materials for Road Construction" of the American Society of Civil Engineers are followed by a $\ddagger$ and those which have been adopted by the American Society for Testing Materials or by Committee D-4 on "Standard Tests for Road Materials" of this Society are followed by a $\uparrow$.

General Definitions.

Bitumens are mixtures of native or pyrogenous hydrocarbons and their non-metallic derivatives, which may be gases, liquids, 
viscous liquids, or solids, and which are soluble in carbon disulphide. $\dagger \ddagger$

Bituminous Material. Material containing bitumen as an essential constituent. $\ddagger$

Liquid Bituminous Material. Bituminous material showing a penetration at normal temperature under a load of 50 grams applied for I second of more than 350 . †

Semi-Solid Bituminous Material. Bituminous material showing a penetration at normal temperature under a load of roo grams applied for 5 seconds of more than Io, and under a load of 50 grams applied for I second of not more than $350 . \dagger$

Solid Bituminous Material. Bituminous material showing a penetration at normal temperature under a load of roo grams applied for 5 seconds of not more than ro. $\$$

Dust Layer. Material applied to a roadway for temporarily preventing the formation or dispersion under traffic of distributable dust. $\ddagger$

Palliative. A short-lived dust layer. $\ddagger$

Emulsion. A combination of water and oily material made miscible with water through the action of a saponifying or other agent. $\ddagger$

Flux. Bitumens, generally liquid, used in combination with harder bitumens for the purpose of softening the latter. $\dagger \ddagger$

Cut-Back Products. Petroleum, or tar residuums, which have been fluxed, each with its own or similar distillates. $\ddagger$

Normal Temperature. As applied to laboratory observations of the physical characteristics of bituminous materials, is $25^{\circ} \mathrm{C}$. $\left(77^{\circ} \mathrm{F}.\right) \cdot \dagger$

\section{Asphalts and Petroleums.}

Asphalts. Solid or semi-solid native bitumens, solid or semisolid bitumens obtained by refining petroleum, or solid or semisolid bitumens which are combinations of the bitumens mentioned with petroleums or derivatives thereof, which melt upon the application of heat and which consist of a mixture of hydrocarbons and their derivatives of complex structure, largely cyclic and bridge compounds. $\dagger$

Native Asphalt. Asphalt occurring as such in nature. $\dagger$ 
Petroleum. A natural rock oil composed of hydrocarbons. (The New International Encyclopædia.)

Blown Petroleums. Semi-solid or solid products produced primarily by the action of air upon liquid native bitumens which are heated during the blowing process. $\dagger$

Asphalt Cement. A fluxed or unfluxed asphalt specially prepared as to quality and consistency for direct use in the manufacture of bituminous pavements, and having a penetration at $25^{\circ} \mathrm{C}$. $\left(77^{\circ} \mathrm{F}\right.$.) of between 5 and 250 , under a load of 100 grams applied for 5 seconds. $\dagger$

Rock Asphalt. Sandstone or limestone naturally impregnated with asphalt. $\ddagger$

\section{TARS.}

Tars. Bitumens which yield pitches upon fractional distillation and which are produced as distillates by the destructive distillation of bitumens, pyrobitumens or organic materials. $\dagger$

Coal Tar. The mixture of hydrocarbon distillates, mostly unsaturated ring compounds, produced in the destructive distillation of coal. $\dagger \ddagger$

Gas-House Coal Tar. Coal tar produced in gas-house retorts in the manufacture of illuminating gas from bituminous coal. $\dagger$ t

Coke-Oven Tar. Coal tar produced in by-produce coke ovens in the manufacture of coke from bituminous coal. $†$

Water-Gas Tars. Tars produced by cracking oil vapors at high temperatures in the manufacture of carburetted water-gas. $\dagger$

Refined Tar. Tar freed from water by evaporation or distillation which is continued until the residue is of desired consistency; or a product produced by fluxing tar residuum with tar distillate. $\dagger \ddagger$

Pitches. Solid residues produced in the evaporation or distillation of bitumens, the term being usually applied to residues obtained from tars. $\dagger$

\section{Use of Bituminous Materials.}

Bituminous Surface. A superficial coat of bituminous material with or without the addition of stone or slag chips, gravel, sand, or material of similar character. $\ddagger$ 
Bituminous Pavement. One composed of stone, gravel, sand, shell, or slag, or combinations thereof, and bituminous materials incorporated together. $\ddagger$

Bituminous Macadam Pavement. One having a wearing course of macadam with the interstices filled by penetration methods with a bituminous binder.

Bituminous Concrete Pavement. One composed of stone, gravel, sand, shell, or slag, or combinations thereof, and bituminous materials incorporated together by mixing methods. $f$

Asphalt Block Pavement. One having a wearing course of previously prepared blocks of asphaltic concrete.

Sheet Asphalt Pavement. One having a wearing course composed of asphalt cement and sand of predetermined grading, with or without the addition of fine material, incorporated together by mixing methods. $\ddagger$

Rock Asphalt Pavement. A wearing course composed of broken or pulverized rock asphalt with or without the addition of other bituminous materials. $\ddagger$

The Special Committee of the American Society of Civil Engineers on "Materials for Road Construction,". in its I9I3 Report, advisedly called attention to the misuse of two of the terms mentioned above. "Your Committee, recognizing an unfortunate tendency to use as the generic expression the terms 'bituminous material' and 'bitumen' synonymously, recommends that the term 'bituminous material' be used as a generic expression when referring to road and paving materials containing bitumen and that the term 'bitumen' be used in a restricted sense as covered by the following definition adopted by the American Society for Testing Materials. 'Bitumens are mixtures of native or pyrogenous hydrocarbons and their non-metallic derivatives, which may be gases, liquids, viscous liquids, or solids, and which are soluble in carbon disulphide.' An illustration of ambiguity in the use of the two terms may be found in some descriptions of bituminous pavements where a bituminous cement, only 75 percent soluble in carbon disulphide, was used. In the general description of these pavements, the word 
'bitumen' was used to refer to the material as a whole, while in giving the analysis of the mix, the word 'bitumen' was used to refer only to that portion of the cement soluble in carbon disulphide." In its I9r 5 Report, the Committee strongly advised the discontinuance of the use of the terms "liquid asphalt" and "asphaltic content," as these terms are meaningless in most cases. Committee D-4 of the American Society for Testing Materials has very properly recommended the discontinuance of the use of the term "artificial asphalt" and has stated in its I9I5 Report to the Society that "Liquid Asphalt" is a trade name not subject to definition.

\section{Sources, Mining and Manufacture}

The crude materials from which are manufactured the bituminous materials that are used in the construction and maintenance of roads and pavements may be classified as follows: Rock Asphalts; Asphalts; Petroleums; Gas-House Coal Tars; Coke-Oven Tars; and Water-Gas Tars. Table No. 5, ${ }^{*}$ compiled by Prevost Hubbard, shows graphically the interrelationship between the principal types of bituminous materials and their derivatives. The three bituminous materials, asphalts, petroleums, and tars, form the basis of the table. After water and other impurities have been removed from the crude materials, the three diagrams show the by-products which are obtained by processes of refining. The various portions of this table should be reread in connection with the descriptions of the refining processes used for the manufacture of palliatives, surfacing materials, bituminous cements, and fillers from the several materials.

Rock Asphalts. The rock asphalts in common use in Europe are composed of limestones and sandstones impregnated with 7 to I4 percent of asphalt. The principal sources are in France, Switzerland, Alsace, Sicily, and Germany. The rock asphalts of the United States are found principally in California, Kentucky, Oklahoma, and Utah.

* See Journal of the Franklin Institute, April, I9I2. 

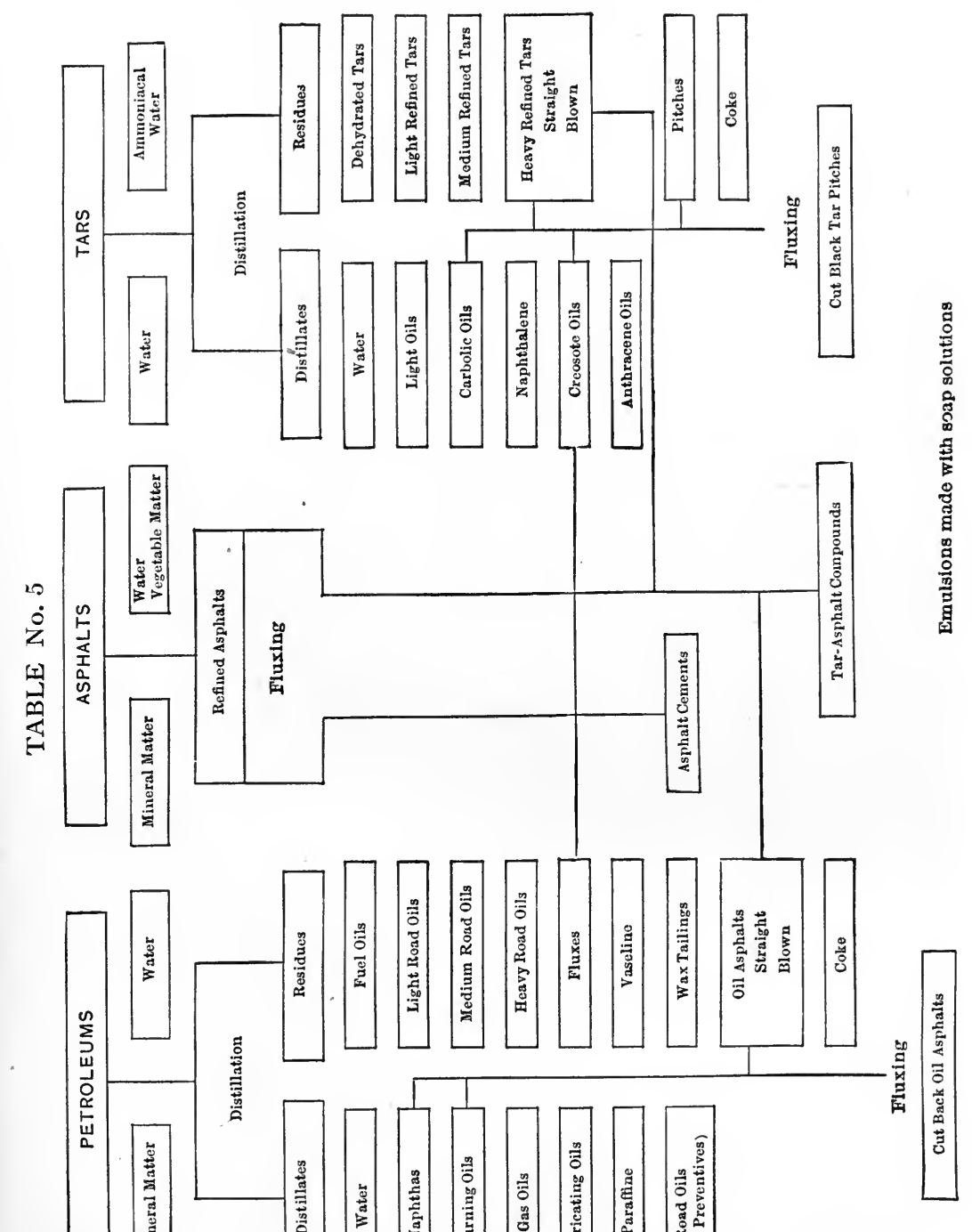
Asphalts. Asphalts, according to the definition previously quoted, may be considered as belonging to one of the three following classes: (I) solid or semi-solid native bitumens; (2) solid or semi-solid bitumens obtained by refining petroleums; (3) solid or semi-solid bitumens which are combinations

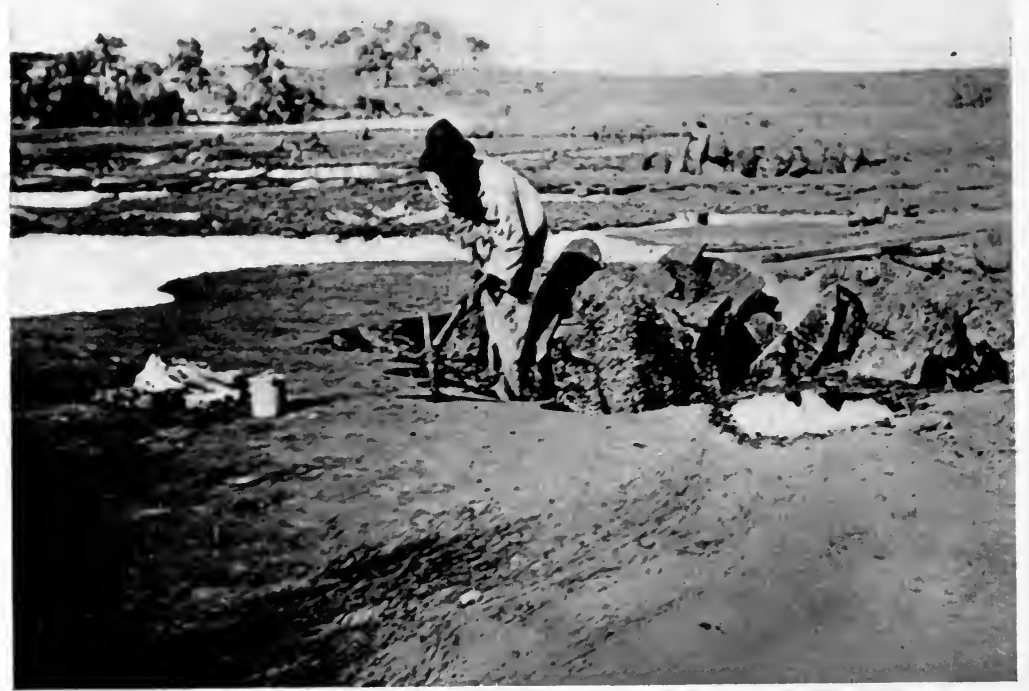

Courtesy of Mr. C. N. Forrest.

FIg. 74. Mining Trinidad Lake Asphalt.

of the bitumens mentioned with petroleums, or derivatives thereof.

The Alcatraz, Bermudez, Cuban, Gilsonite, Maracaibo, and Trinidad asphalt cements contain asphalt as defined under the first group, that is, "asphalts are solid or semi-solid native bitumens, etc."

The asphalts obtained by refining such asphaltic oils as are obtained from the fields of California, Mexico, Southern Illinois, and Texas come within the second group, that is, "asphalts are solid or semi-solid bitumens obtained by refining petroleums, etc." 
The asphalts made from a combination of refined petroleum and Gilsonite, a solid native bitumen, are covered by the third group to which reference has been made, namely, "asphalts are solid or semi-solid bitumens which are combinations of the bitumens mentioned with petroleum or derivatives thereof, etc."

Trinidad and Bermudez Asphalts.* "Trinidad and Bermudez Lake asphalts are denominated native asphalts because they are found in nature in solid form as distinguished from others which are derived from liquid bitumen by industrial processes and become asphalt by reason of the manipulation of such processes. They are also denominated Lake asphalts because they occur upon the surface of the earth in a single mass like so much water or paste in a large bowl or lake.

"The pitch lake of the Island of Trinidad is situated about one mile from the sea, on the highest part of La Brea Point, I38.5 feet above sea level. It lies apparently in the crater of an extinct mud volcano having a nearly circular area of II 4.67 acres. The lake is filled to a depth of more than 135 feet at the center with a uniform mass of asphalt, which must amount to many millions of tons.

"The Bermudez Pitch Lake lies about thirty miles from the northeast coast, in the State of Sucre, Venezuela, which forms the opposite side of the Gulf of Paria from the Island of Trinidad. It covers an area of about $\mathrm{I}, 200$ acres to a maximum depth of Io feet.

"Crude Trinidad and Bermudez Lake asphalt is gathered from the deposits by native laborers who strip off the overlying vegetation when necessary and flake out the asphalt in large chunks with picks or mattocks. (See Fig. 74.) Crude Lake asphalt is transported in bulk in the hold of the steamers which are engaged in that particular trade and carry single cargoes up to as much as five or six thousand tons, if desired. The asphalt when placed in vessels flows together

* See 1913-1914 Lecture by C. N. Forrest, Chief Chemist, Barber Asphalt Paving Company, on "Trinidad nd Bermudez Asphalts," in the Graduate Course in Highway Engineering, at Columbia University. 
and again becomes a solid mass. It has the following general characteristics:

\begin{tabular}{|c|c|c|}
\hline & $\begin{array}{l}\text { Crude } \\
\text { Trinidad } \\
\text { Lake } \\
\text { Asphalt }\end{array}$ & $\begin{array}{c}\text { Crude } \\
\text { Bermudez } \\
\text { Lake } \\
\text { Asphalt }\end{array}$ \\
\hline 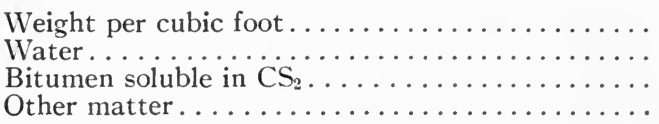 & $\begin{array}{l}75 \mathrm{lbs} . \\
29.0 \% \\
39.0 \% \\
32.0 \%\end{array}$ & $\begin{array}{l}66 \text { lbs. } \\
25.0 \% \\
72.0 \% \\
3.0 \%\end{array}$ \\
\hline
\end{tabular}

"Crude Lake asphalt is refined in order to remove from it those substances which are useless for the purposes for which the refined asphalt is employed. These are chiefly water and a small amount of twigs, branches of trees or other vegetable matter which has accidentally found its way into the lakes. The crude asphalt is too solid to pump through a pipe-line and must therefore be handled in buckets to the refining kettles. The refining kettles are made of steel and are rectangular in shape. They are open at the top in order to facilitate charging with the asphalt and the escape of water. These kettles are I 2 feet by 24 feet by 9 feet 6 inches deep and have a capacity of 70 tons of Trinidad or 50 tons of Bermudez asphalt. They are equipped with steam coils consisting of about 4,000 feet of I $1 / 4$-inch pipe, through which steam under a pressure of I25 to 15.0 pounds is circulated. They are also equipped with a system of perforated pipes laid upon the bottom of the kettle from which live steam is blown through the asphalt in order to hasten the evaporation of water and to prevent sedimentation. The crude asphalt is dumped into such kettles and heated to a temperature of $325^{\circ}$ to $35^{\circ} \mathrm{F}$., which reduces it to a liquid condition, until all water is eliminated and a standard uniform consistency has been reached. From 8 to ro hours is required for the dehydrating process, after which any foreign substances found floating upon the surface of the asphalt are removed by skimming. The refining operation, which is carried on at a relatively low temperature and with a copious live steam agitation, leaves the dehydrated bitumen without alteration and in as 
nearly its natural condition as it is possible to conceive. After it is refined the lake asphalt has the following general characteristics:

Specific Gravity at $77^{\circ} \mathrm{F} \ldots \ldots \ldots \ldots$

Penetration at $77^{\circ} \mathrm{F}$., I oo grams, 5 seconds......

Bitumen soluble in $\mathrm{CS}_{2} \ldots \ldots \ldots \ldots \ldots \ldots$

\begin{tabular}{|c|c}
$\begin{array}{c}\text { Refined } \\
\text { Trinidad } \\
\text { Lake } \\
\text { Asphalt }\end{array}$ & $\begin{array}{c}\text { Refined } \\
\text { Bermudez } \\
\text { Lake } \\
\text { Asphalt }\end{array}$ \\
\hline I .40 & I.08 \\
2 to 4 & I 8 to 20 \\
$56.5 \%$ & $94.4 \%$
\end{tabular}

"Refined lake asphalt is run, while still in a molten condition and at a temperature of about $300^{\circ} \mathrm{F}$., into soft wood barrels which have been previously coated on the inside with clay so that the asphalt will not stick to the wood."

Maracaibo and Cuban Asphalts.* "In Venezuela is located the Maracaibo deposit, about fifty miles inland from the Gulf of Maracaibo. There are a number of deposits in the vicinity and the asphalt appears to originate in maltha or tar springs as does the Bermudez deposit, the maltha having become hardened by exposure to a semi-solid, nearly pure, asphalt. The character of the material is quite different from the Bermudez asphalt; and it is recognizable by its particularly rank odor and the peculiar gummy nature of the impurities with which it is contaminated. The Maracaibo deposit has been of variable commercial importance, possibly on account of the difficulty of access, and its use has been limited in recent years to comparatively few localities.

"On the Island of Cuba there are a large number of deposits of various kinds of asphalts. The only one of large extent is located in the Pinar del Rio province, about forty miles west of Havana and about five miles from Mariel Bay, from which the deposit takes its name. This material has been used in the United States for about ten years and has attained considerable importance. The asphalt of these Mariel deposits is a very hard material resembling, in its crude state, bituminous

* Lester Kirschbraun, Consulting Chemical Engineer, in May, 1912, Journal of the Western Society of Engineers. 
coal. It contains about 56 to 60 percent of pure bitumen and about 40 percent of mineral matter. Like the Trinidad material, there is great uniformity in the proximate composition of the asphalt from different sections of the deposit. The asphalt occurs in immense seams and veins, some of which may be followed for several miles across country by their outcroppings. Certain of the seams lie horizontally, and have been worked by open cuts to a convenient depth, following the seams in their general trend. At another point of outcropping, the material has been obtruded in a vertical direction and the excavation of open pits has followed the crude material downward."

Alcatraz Asphalt.* "In California there are certain deposits of large extent which were, in the early nineties, of considerable importance. Alcatraz asphalt was a well-known brand of such material. The development of the oil-asphalt industry in California made it commercially impracticable to work these natural asphalt deposits, and there is now no solid natural California asphalt upon the market."

Gilsonite Asphalt. $\dagger$ "Gilsonite is a solid native bitumen found in the United States in Utah and Colorado. It breaks with a concoidal fracture and has a reddish-brown streak. This material is found in fissure veins varying in thickness from a few inches to 5 or 6 feet. (See Fig. 75.) On account of being very brittle it is easy to mine, the most common method being by the use of picks. Successful results have been obtained by using steam, which is turned into certain workings of the mine long enough to cause the Gilsonite to expand and soften. As the Gilsonite cools, after the steam is shut off, it contracts and breaks into chunks. It is then brought to the surface of the mine and put into burlap sacks which, when full, weigh from 200 to 300 pounds each.

* Lester Kirschbraun, Consulting Chemical Engineer, in May, I912, Journal of the Western Society of Engineers.

† From I912-1913 Lecture by H. B. Pullar, General Manager, The Pioneer Asphalt Company, on "The Mining of Gilsonite and the Manufacture of Gilsonite Asphalt" in the Graduate Course in Highway Engineering, at Columbia University. 
"The following analysis is typical of Gilsonite?

Specific gravity ..................... I.033

Melting point ....................... $291^{\circ} \mathrm{F}$.

Bitumen soluble in carbon disulphide.......... $99.58 \%$

"In the manufacture of Gilsonite products various proportions of Gilsonite are used, depending upon the quality and

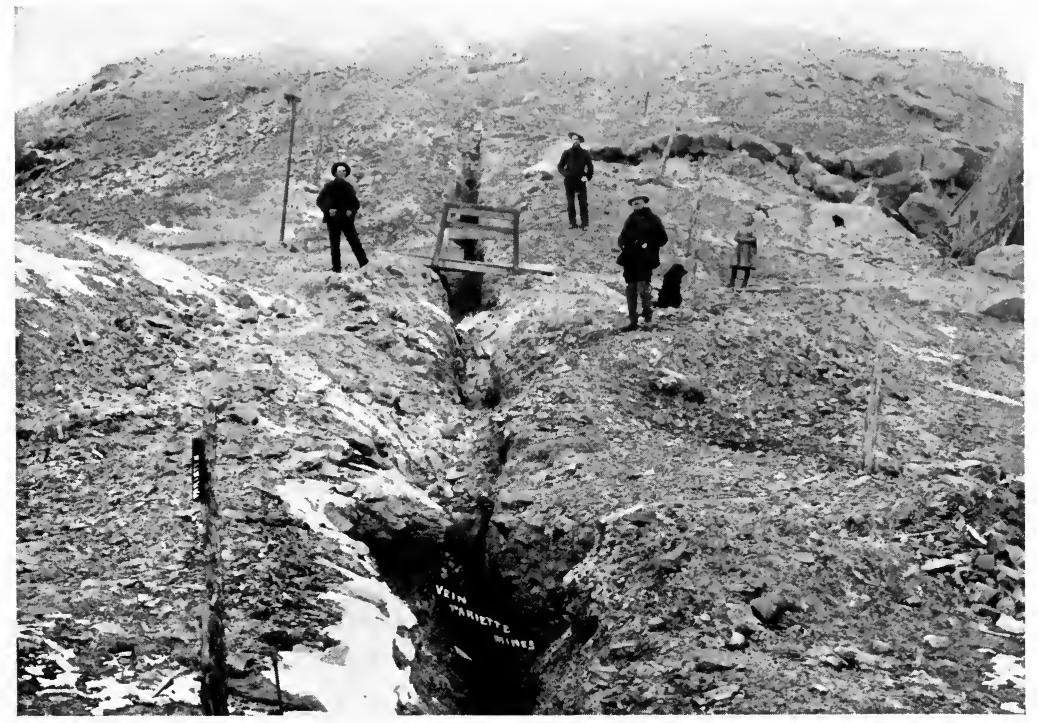

Courtesy of Mr. H. B. Pullar.

FIG. 75. Veins of Gilsonite Asphalt.

consistency of the material desired. Gilsonite rapidly combines with heavy residuum oil, the best results being obtained from fluxing Gilsonite with a semi-asphaltic or asphaltic base oil, although for certain purposes paraffin oils prove most desirable. In producing asphalt products from Gilsonite, the oil must be of a suitable quality and must be carefully prepared without cracking. The best method for determining this is by the use of a microscope, as any cracking which takes place in the oil shows up in specks of free carbon under the microscope.

"The oil is heated to a temperature of not less than $425^{\circ} \mathrm{F}$., at which temperature the Gilsonite is slowly added and dis- 
tributed throughout the mass of oil as much as possible. The oil should be in a state of agitation as this is of considerable assistance in rapidly melting the Gilsonite which goes into a perfect solution with the hot oil, making a homogeneous mass and changing materially the characteristics of the oil. Gilsonite adds life to the product and prevents the oil, to a very large extent, from oxidizing or hardening up.

"In a great many instances, and especially in producing those products which are little affected by changes in temperature, the oil is first treated with air before the Gilsonite is added. Treating the oil with air tends to very materially change the characteristics of the oil, the batch gradually thickening until it becomes a semi-solid. The length of treatment depends upon the consistency of the material desired and varies from to to 40 hours. In this treatment with air, the oil is first put into a semi-open still and brought to a temperature of $350^{\circ} \mathrm{F}$., at which temperature air is gradually added to the batch. The temperature rises until it reaches about $425^{\circ} \mathrm{F}$., which temperature is maintained for a period of time, depending upon the results desired."

Petroleums.* "The petroleum oils of this country are generally classed into three groups, known as paraffin, semi-asphaltic, and asphalt petroleums. The oils of the Pennsylvania fields are paraffin base oils. Those of the Illinois, Kansas, Oklahoma and Gulf fields are semi-asphaltic to varying degrees. The California oils are generally considered asphaltic. No artificial asphalt is made from the Pennsylvania or paraffin oils, but large quantities are produced from the oils of the semi-asphaltic and California group.

"The earliest oil asphalt of this country was produced as a by-product from the straight distillation of California crude petroleums. The early asphalt so produced fell into disrepute on account of the careless manner of production, the lack of uniformity, and the inferiority of the product through improper methods of distillation. The demand for a better quality has

* Lester Kirschbraun, Consulting Chemical Engineer, in May, I9I2, Journal of the Western Society of Engineers. 
induced improvement in refining methods, which has resulted in recent years in superior products being prepared especially for paving purposes.

"There are at present two methods used in preparing oil asphalts, which methods are more or less adaptable according to the character of the oil operated upon. The first method is that of ordinary distillation of the crude petroleum with the use of saturated steam, the distillation being carried on until the solid or asphaltic portion of the oil remains. The distillation is carried on in large stills holding from 300 to $\mathrm{I}, 000$ barrels of oil. Steam is injected into the bottom of the stills through perforated pipes to effect agitation and assist in the removal of the volatile oils. In the best practice, steam is also injected at the top of the stills to facilitate carrying off the heavy oil vapors, and to prevent their decomposition by condensation and dropping back into the hot oil. The maximum temperature employed in careful practice rarely exceeds $700^{\circ} \mathrm{F}$. The material in the stills is brought to the desired consistency and run into cooling stills or through pipes cooled by oil used for succeeding charges. Sometimes the material from several stills is run into one large receiving still, where it is mixed with other batches and a greater degree of uniformity thereby attained. Aside from the kind of oil used, the value of the product of this distillation process depends upon the various means of preventing local overheating and decomposition, the amount and efficient distribution of steam injected, the time of the distillation, and the temperatures employed. There are commercial asphalts prepared in this way from California, Mexico, and Texas oils.

"This brings us to a second method of preparation of asphaltic products by air blowing. That method has been developed particularly through an effort to utilize petroleum residuums of the character not reducible by the distillation process described. Asphalts prepared by this method are commercially known as blown-oil asphalts. In the preparation of blown-oil asphalts, petroleum residuum is the raw material. This petroleum residuum is prepared as the residue from the distillation of crude 
petroleums with steam through the lubricating oil fractions, and is continued in the best practice, with the removal of as much of the vaseline (if present) as can be accomplished without decomposition. The air-blowing operation is conducted in open kettles equipped with perforated pipes along the bottom. The residuum is kept at a temperature much below that at which normally it distills, and air is injected into the mass through the perforated pipes, producing a violent agitation and intimate contact between the residuum and air. The injection of air under these conditions produces, among other reactions, oxidation and condensation of the hydrocarbons of the residuum. The oil treated gradually thickens and the process is continued until a product of the desired consistency is obtained. A significant characteristic of the process is that there is no material loss during the operation."

TARS. The refined tars and pitches used in the construction and maintenance of various types of roads and pavements are manufactured from gas-house coal tars, coke-oven tars, and water-gas tars.

Gas-House Coal Tar.* "In classifying coal tars for use in road work it is customary to group them, in accordance with the method of manufacture, into gas-house tars and coke-oven tars. The following table (abstracted) gives roughly the characteristic differences in the two tars:

\begin{tabular}{|c|c|c|}
\hline & $\begin{array}{l}\text { Gas tar } \\
\text { Percent }\end{array}$ & $\begin{array}{c}\text { Coke oven tar } \\
\text { Percent }\end{array}$ \\
\hline Creosote oil... & 8.6 & 14.5 \\
\hline Anthracene oil.... & $17 \cdot 4$ & $27 \cdot 3$ \\
\hline 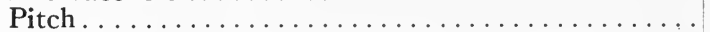 & 58.4 & $44 \cdot 3$ \\
\hline Carbon.... . & $15^{-25}$ & $5^{-8}$ \\
\hline
\end{tabular}

"As gas houses are usually run for the production of the largest possible yield of gas from a ton of coal, the highest possible temperatures are employed, and the tar produced has, in consequence, usually a maximum amount of free carbon. This,

* See 1912-1913 Lecture by Philip P. Sharples, Chief Chemist, Barrett Manufacturing Company, on "The Manufacture of Refined Coal Tar," in the Graduate Course in Highway Engineering at Columbia University. 
however, is not always so and low carbon tars may be made at gas houses. Very recently there has been installed at a number of gas houses in the United States a new form of retort, differing essentially from the older small horizontal retort. These new retorts are either inclined or vertical, to permit of the handling of the coke by gravity and by mechanical means. The form of the retort leads to low temperatures in the coking of the coal, and the escape of the tar and gases through comparatively cool passages. The tars resulting from these forms of ovens may show even lower carbons than the cokeoven tars.

"The collection of the tar as it is evolved from the retort is essentially the same in principle in the two types of gas plants. The tar, owing to the high temperature, goes off as a vapor mingled with the gases. Condensed, however, at a comparatively high temperature, the greater part is deposited in the large collecting gas main known as the hydraulic main, where it is trapped and led to the storage tank. Some further part is deposited in the condensers, where the temperature of the gas is brought down by passing over water-cooled surfaces to a workable temperature. Part of the tar, however, is so finely divided mechanically that it is carried on by the stream of the gas through the condensers. The method of removing the last particles of tar from the gas varies greatly in different plants but usually a system of baffle plates is used which coalesces the particles of tar by impinging them upon the opposed plates. The tar collected in these several places is all conducted to the same storage tank.

"The first process in refining tar is the removal of the water. The presence of a large amount of water leads to frothing in the still, making the process of distillation extremely slow, and in case the still actually froths over, to the loss of the charge. The most successful method in use at the present time is to pass the tar in thin films, at about the temperature of boiling water, through vacuum chambers. This results in the elimination of a large percentage of water, and also to the driving off of some of the light oils, which are condensed and recovered 
from the vapors. But it is usually not possible even by this method to reduce the water below I percent.

"After the stills are charged with the correct blend of tars to produce the desired results, the fires are started and the mixture heated carefully to about $100^{\circ} \mathrm{C}$. The water, together with the light oils, is driven off. The distillation once started continues to about $220^{\circ} \mathrm{C}$. Then the flow of the liquor becomes less and the temperature is increased until the oil begins to come off freely once more.

"In the manufacture of the very lightest refined road tars the distillation is carried only to the point where the water is completely driven off. In England and on the Continent this constitutes the major portion of the refined tar used for road purposes, applicable to surface treatment of a road, especially where a very thin coat is desired. In case the material to be manufactured is to be used for road construction, the firing on the still is continued much longer, and much more of the oil taken off. It is customary in this case, in order that the viscosity of the material may be closely regulated, to subdue the fire before the end point is reached. Then, in order to raise the viscosity to the required point, air or steam is blown through the hot tar in the still, to remove further oils and bring the tar to the desired consistency. This 'blowing,' as it is called, becomes much more important as the melting point of the pitch is increased. With pitches used in paving work the blowing of the tar is commenced much earlier than the finishing point, in order to agitate the contents of the still and prevent the deposition of carbon on the bottom. If this carbon is allowed to deposit, local heating of the plates takes place and the still is quickly ruined.

"After the tests in the laboratory have shown the refined tar to be of the correct consistency, the material is either run off by gravity to cooling tanks, or in case the stills are on a low level, it is forced over by compressed air or by steam pressure, into the coolers. The coolers are simply iron tanks open on all sides, so as to allow the free circulation of air and a quick cooling of the pitch. The cooling, however, even under favorable cir- 
cumstances, requires a long time, and in the case of large cooling tanks several days elapse before the tar is of a temperature safe to run into barrels."

Coke-Oven Tar." "There are two general types of coke ovens in use at present, in one of which no attempt is made to recover the volatile products of the coal. This is the oldest form of oven, known as the 'beehive,' and is extensively used in this country to-day. It is constructed of brick and, as its name implies, has the form of a beehive. Bituminous coal is placed in this oven or kiln and a part of it burned in order to carbonize the remainder, while the volatile products, such as gas, ammonia, and tar, are allowed to escape through an opening in the top of the kiln where they are lost in flame and smoke. Coke ovens in which the by-products are saved are now used to some extent in this country, and sooner or later will undoubtedly replace the old-style oven entirely, and thus increase our output of tar enormously."

Water-Gas Tar. ' "The manufacture of water gas depends upon the reaction between water vapor and incandescent carbon. The result of this reaction is what is known as water or blue gas, composed of about equal parts of hydrogen and carbon monoxide. This gas has a heating value of about $300 \mathrm{~B} . \mathrm{T}$. U. per cubic foot, but it is non-luminous, so that for use in the open-flame burners it has to be enriched by the addition of some hydrocarbon. Water gas as we now know it is manufactured in an internally fired generator and the enriching hydrocarbon is added in the form of oil in vessels called respectively the carbureter and the superheater.

"When the tar which leaves the generating apparatus in the form of a vapor comes in contact with the water in the wash box of the machine, the greater portion is condensed. Some of it, however, remains in the form of mist, which is

* See Circular 97, U. S. Office of Public Roads, "Coke-Oven Tars of the United States," by Prevost Hubbard.

† See 1912-1913 Lecture by W. H. Fulweiler, Chief Chemist, United Gas Improvement Company, on "The Manufacture of Refined Water-Gas Tar," in the Graduate Course in Highway Engineering at Columbia University. 
removed from the gas in the condensers and tar extractors, along with a considerable portion of the excess steam in the water gas. Owing to the low gravity of the crude tar, it does not immediately separate from the water and is, therefore, passed through tanks provided with baffling plates where it is partially separated from the water. It is then stored in large tanks, where under the influence of gravity the tar gradually rises to the surface, practically free from water.

"The water-gas tar is charged into a fire still, and the distillation commenced. The first fraction cut is known as light oil, and has a gravity of 0.953 , then comes the naphthalene oil of about 0.990 . The next fraction cut is dead oil, which has a gravity of about I.OI, and following this comes creosoting oil, with a gravity of about I.05. The distillation is finished at the end of the creosoting oil cut. The residue remaining in the still is either road tar or a pitch, depending upon the temperature at which the distillation ceases. Varying grades of road tar or pitch result, according to the temperature at which distillation ceases. The higher the distillation temperature, of course, the harder the grade of pitch will be made.

"The road compound as it comes from the stills is run off into closed coolers, where its temperature is reduced, and is then combined with the required amount of asphalt or heavy oil, according to the grade of material that is being made. In all this work the material is handled by what are known as blow cases, in which compressed air is the actuating medium instead of pumps. The mixing is done by an especially arranged series of nozzles operated with compressed air."

\section{Tests and Specifications for Physical and Chemical} Properties

Various tests have been devised in order to determine the physical and chemical properties of bituminous materials. Tests are made for control of the manufacture of bituminous materials, to obtain a record of the properties of materials used, and are employed in specifications to secure the materials desired for 
use in the construction and maintenance of roads and pavements. In this chapter the typical tests used are mentioned or explained and brief interpretations of the results of such tests are given.

LISTS of TESTS. It is desirable in connection with investigations covering service tests of bituminous materials to be used in the construction of various types of surfaces and pavements to have at hand a complete record of the chemical and physical properties of the materials. For such purposes the Special Committee on "Materials for Road Construction" of the American Society of Civil Engineers, in its I9I5 Report, recommended the adoption of the following lists of tests, as including all those probably of value in determining and recording the characteristics of the bituminous materials used in this connection:

\section{Tars.}

Specific gravity at $25^{\circ} \mathrm{C}$. $\left(77^{\circ} \mathrm{F}\right.$.).

Flash point.

Solubility in $\mathrm{CS}_{2}$ (carbon disulphide).

Consistency at $4^{\circ}$ C. $\left(39^{\circ}\right.$ F. $), 25^{\circ}$ C. $\left(77^{\circ}\right.$ F. $), 46^{\circ} \mathrm{C}$. (I $5^{\circ} \mathrm{F}$.), $98^{\circ} \mathrm{C}$. $\left(208^{\circ} \mathrm{F}\right.$.).

Melting point.

Loss on evaporation at $163^{\circ} \mathrm{C} .\left(325^{\circ} \mathrm{F}\right.$.).

Consistency of residue at $4^{\circ} \mathrm{C} .\left(39^{\circ} \mathrm{F}\right.$ ), $25^{\circ} \mathrm{C} .\left(77^{\circ} \mathrm{F}\right.$. $)$, $46^{\circ} \mathrm{C}$. (II $5^{\circ} \mathrm{F}$ ), $98^{\circ} \mathrm{C} .\left(208^{\circ} \mathrm{F}\right.$.).

Melting point of residue.

Distillation.

Consistency of residue at $4^{\circ} \mathrm{C} .\left(39^{\circ} \mathrm{F}.\right), 25^{\circ} \mathrm{C} .\left(77^{\circ} \mathrm{F}.\right)$, $46^{\circ} \mathrm{C}$. (II $5^{\circ} \mathrm{F}$ ), $98^{\circ} \mathrm{C}$. $\left(208^{\circ} \mathrm{F}\right.$.).

Melting point of residue.

\section{Asphaltic Materials.}

Specific gravity at $25^{\circ} \mathrm{C}$. $\left(77^{\circ} \mathrm{F}\right.$.).

Flash point.

Solubility in $\mathrm{CS}_{2}$ (carbon disulphide).

Solubility of bitumen in $\mathrm{CCl}_{4}$ (carbon tetrachloride).

Solubility of bitumen in petroleum naphtha.

Character of residue on glass. 
Consistency at $4^{\circ}$ C. $\left(39^{\circ}\right.$ F. $), 25^{\circ}$ C. $\left(77^{\circ}\right.$ F. $), 46^{\circ} \mathrm{C}$. ( I $55^{\circ}$ F.), $98^{\circ}$ C. $\left(208^{\circ}\right.$ F.).

Melting point.

Ductility at $4^{\circ} \mathrm{C}$. $\left(39^{\circ} \mathrm{F}\right.$.), and $25^{\circ} \mathrm{C}$. $\left(77^{\circ} \mathrm{F}\right.$.).

Fixed carbon content.

Paraffin content.

Loss on evaporation at $163^{\circ} \mathrm{C} .\left(325^{\circ} \mathrm{F}\right.$. $)$.

Consistency of residue at $4^{\circ} \mathrm{C} .\left(39^{\circ} \mathrm{F}\right.$. $), 25^{\circ} \mathrm{C} .\left(77^{\circ} \mathrm{F}\right.$. $)$, $46^{\circ} \mathrm{C}$. ( $\left(\right.$ I $55^{\circ} \mathrm{F}$.).

Melting point of residue.

Ductility of residue at $4^{\circ} \mathrm{C} .\left(39^{\circ} \mathrm{F}\right.$. $)$, and $25^{\circ} \mathrm{C} .\left(77^{\circ} \mathrm{F}\right.$.).

The tests used in a given specification depend upon the kind of bituminous material employed and the method used. For example, a specification for a refined tar to be used as a bituminous cement in a bituminous concrete pavement in which the aggregate consists of broken stone composing one product of a stonecrushing plant, would include reference to tests for specific gravity, solubility in carbon disulphide, consistency with the New York Testing Laboratory float apparatus or with a penetrometer, melting point, distillation, specific gravity of total distillate and melting point of pitch residue remaining after distillation. In the case of an asphalt cement to be used in the above type of construction, the tests referred to in the specifications would include specific gravity, flash point, penetration at $4^{\circ} \mathrm{C}$., $25^{\circ} \mathrm{C}$., and $46^{\circ} \mathrm{C}$., melting point or consistency with the New York Testing Laboratory float apparatus, loss on evaporation at $163^{\circ} \mathrm{C}$. and penetration of the residue from evaporation, solubility in carbon disulphide, solubility of bitumen in carbon tetrachloride, solubility of bitumen in paraffin naphtha, and fixed carbon.

For the purposes of this chapter it is not necessary to describe tests, the names of which give an indication of the method of performing the tests. Such tests as specific gravity, solubility in carbon disulphide, carbon tetrachloride, petroleum naphtha, evaporation, and distillation will, therefore, not be described. Brief explanations of the other tests included in the above lists will be given. Detailed descriptions of methods of conducting 
all of the tests for tars and asphaltic materials covered by the above lists are given in Appendix II.

Flash Point. The material is placed in a cup fitted with a glass cover having a small opening. The temperature of the material is raised and a testing flame is inserted in the opening of the cover from time to time. The appearance, for a few seconds, of a faint bluish flame over the entire surface of the bituminous material will show that the flash point has been reached and the temperature at this point is recorded.

Melting Point. The material is melted and molded into a $1 / 2$-inch cube. The cube is placed on a wire and suspended one inch above the bottom of a beaker. The temperature of the cube is then raised until the material softens and touches the bottom of the beaker. The temperature at this point of the operation is considered the melting point of the material.

Consistency. The consistency of bituminous materials is determined by the Engler viscosimeter, the New York Testing Laboratory float apparatus, or the penetrometer.

With the Engler Viscosimeter the viscosity of liquid bituminous materials is determined by noting the time which is required for a given amount of the material, having a given temperature, to flow through a very small orifice. The result of the test should be expressed as specific viscosity, which equals the ratio of the number of seconds required for the passage of a given volume of the bituminous material at the temperature used divided by the number of seconds required for the passage of the same volume of water at $25^{\circ} \mathrm{C}$. $\left(77^{\circ} \mathrm{F}\right.$.).

The New York Testing Laboratory Float Apparatus consists of an aluminum float and a brass collar. The collar is filled with bituminous material and screwed into the bottom of the aluminum float and the apparatus placed on the surface of a water bath. As the plug of bituminous material in the collar becomes warm and fluid, due to the heat from the water bath which is maintained at any temperature desired for the test, it is gradually forced upward and out of the collar until water gains entrance to the saucer and causes it to sink. The time in seconds be- 
tween placing the apparatus on the water and when the float sinks is taken as the measure of consistency.

The Penetration Test is made by measuring the distance a weighted standard needle will penetrate into the material at a given temperature in a given period of time. The temperatures, weights, and periods of time which are employed to a considerable extent are as follows: penetration at $4^{\circ} \mathrm{C}$. with a weight of 200 grams for I minute; penetration at $25^{\circ} \mathrm{C}$. with a weight of Io0 grams for 5 seconds; penetration at $46^{\circ} \mathrm{C}$. with a weight of 50 grams for 5 seconds. When the penetration of a material is mentioned without reference to temperature, weight of the load, or time, it is understood that reference is made to the penetration at the normal temperature of $25^{\circ} \mathrm{C}$. $\left(77^{\circ} \mathrm{F}\right.$.) with a weight of 100 grams for 5 seconds. The unit of penetration is $0.1 \mathrm{~mm}$. In literature and specifications the penetration is referred to in terms of the above unit either as a penetration of $6.4 \mathrm{~mm}$. or 64 .

Ductility. In the ductility test a briquette of the material is formed in a standard briquette mold. The briquette with clips attached is placed in a ductility testing machine filled with water at a temperature of $4^{\circ} \mathrm{C}$. or $25^{\circ} \mathrm{C}$. The briquette is then pulled apart at a uniform rate and the distance in centimeters registered at the time of rupture of the thread of bituminous material is taken as the measure of ductility.

Fixed Carbon. Fixed carbon is the organic matter of the residual coke obtained upon burning hydrocarbon products in a covered vessel in the absence of free oxygen.

Paraffin. The percentage of paraffin in a bituminous material is determined by a somewhat complex chemical test, which is fully described in Appendix II.

INTERPRETATION OF RESUlts OF TESTS. Unless otherwise stated the quoted interpretations of the results of tests are by Prevost Hubbard,* being abstracts from a "Communication" on the subject, "Various Materials in Use for the Purposes of

* Chemical Engineer, U. S. Office of Public Roads and Rural Engineering, and Lecturer in Highway Engineering Chemistry, Graduate Course in Highway Engineering, Columbia University. 
Construction and Maintenance; Conditions to be Fulfilled; Tests; Units to be Adopted," which was presented for the United States to the Second International Road Congress.

Specific Gravity. "It is of value mainly as a means of identinication, but when considered in connection with other tests is often of service in determining the suitability of the material for road purposes. As applied to oil and oil products, the specific gravity is a rough indication of the amount of heavy hydrocarbons which give body to the material. Crude petroleums vary in specific gravity from 0.73 to 0.98 and slightly higher, paraffin oils as a rule having the lowest specific gravity and asphaltic oils the highest. The former have practically no value for road work, while the latter constitute the most desirable type. Oils containing a semi-asphaltic base hold an intermediate position and will usually run higher in specific gravity than the paraffin oils and lower than the truly asphaltic oils.

"Crude coal tars vary in specific gravity from I.O to I.22 and sometimes higher, while crude water-gas tars lie between r.০o and r.Io. In coal tars, the specific gravity is largely dependent upon the percentage of free carbon or soot which it contains, those of low specific gravity holding but little and those of high specific gravity holding a large amount of free carbon. Thus a crude tar having a specific gravity of less than I.I5 will usually show less than $\mathrm{I} 2$ percent free carbon, while those running as high as 1.22 will have 30 percent and over. In refined tars specific gravity naturally increases with consistency, both because the lighter hydrocarbons and water have been removed and because the relative proportion of free carbon has been increased in the residue. In such products for a given consistency a low specific gravity is to be preferred to a high one. This is not true, however, when considering refined products of different consistencies, as in such cases, while the percentage of free carbon might be the same, the most desirable product might show the highest specific gravity for the reasons mentioned above."

Flash Point. "This determination is of little value other 
than as a quick means of differentiating between the heavy crude oils and cut-back products and the fluid residuums, although it also indicates the point to which a refined oil has been distilled. Crude oils have, of course, a lower flash point than residual oils, and among the crude oils themselves those of a paraffin nature usually flash at a. lower temperature than the asphaltic. The former may run as low as ordinary temperature, while the latter are sometimes as high as $135^{\circ} \mathrm{C}$. Some crude asphaltic oils will, however, show quite as low flash point as the paraffin oils, so that no great dependence can be placed upon this difference in crude petroleums. The flash point of residual road oils commonly exceeds $200^{\circ} \mathrm{C}$., while that of cut-back products will vary greatly, according to the flash point of the flux and the percentage and character of the heavier residual product. Thus, in a certain instance, when 90 percent of a distillate having a flash point of $100^{\circ} \mathrm{C}$. was mixed with Io percent of an oil asphalt having a flash point of $260^{\circ} \mathrm{C}$., the flash point of the resulting mixture was raised to $143^{\circ} \mathrm{C}$, and the addition of 60 percent of the heavier product only increased this temperature by 5 degrees. Great care should, of course, be taken when heating low flash point oils in an open kettle or tank that the oil does not catch fire. Such oils, however, rarely require heating before application, as they are usually quite fluid when cold."

Melting Point. "A determination of the melting point of solid bitumens is mainly of value as a means of identification and for control work on the part of manufacturers. The melting point of a bitumen is directly related to its hardness and brittleness, but the relations are not the same for all classes. Thus, at normal temperature, a blown oil with a melting point of $50^{\circ} \mathrm{C}$. is neither hard nor brittle, while a tar pitch is both. As the melting point rises, however, they both become harder and more brittle. The climate under which a bitumen is to serve as a road binder should be considered in connection with its melting point, and this is particularly true of tar products."

Consistency. Maximum and minimum limits covering consistency are essential parts of all specifications for bituminous 
materials. Such limitations are of particular value since it is possible by their use to secure the grade of a given type of bituminous material which is most suitable for any method of use, and, furthermore, because it is practicable thus to ensure reasonable uniformity in the consistency of the bituminous material supplied for a given piece of work. It is apparent that the range in limits should be as narrow as the practicable manufacture of the bituminous materials will permit.

The utilization of the various standard methods employed for the determination of consistency, that is, with the Engler Viscosimeter, the New York Testing Laboratory Float Apparatus, and the penetrometer, depends upon the characteristics of the materials. For example, the Engler Viscosimeter is generally employed to determine the consistency of liquid bitúminous materials; the New York Testing Laboratory Float Test for the determination of the consistency of semi-solid and solid tars and pitches; and in most cases the penetrometer for the determination of the consistency of semi-solid and solid asphaltic materials. "Penetration determinations are seldom made upon tars because their surface tension is so high that even approximately correct penetrations cannot be recorded and the presence of free carbon in varying quantities affects the results very considerably." In order to show the methods of stating consistency and the variations in consistency of a given type of material dependent upon its use, the following examples are given:

Coal-Gas Tar for Cold Application to Broken Stone and Gravel Roads. When tested by means of the Engler Viscosimeter at $40^{\circ} \mathrm{C}$. ( $104^{\circ} \mathrm{F}$.) the specific viscosity of the first $50 \mathrm{cc}$. passing the orifice of the viscosimeter shall be not less than 8 nor more than 13 .

Coal-Gas Tar for the Construction of Bituminous Surfaces on Broken Stone and Gravel Roads. When tested by means of the New York Testing Laboratory Float Apparatus, the float shall not sink in water maintained at $50^{\circ} \mathrm{C}$. ( $\left(122^{\circ} \mathrm{F}\right.$.) in less than 40 seconds nor more than roo seconds.

Coal-Gas-Tar Cement for Use in the Construction of Bituminous Macadam Pavements. When tested by means of the New York 
Testing Laboratory Float Apparatus, the float shall not sink in water maintained at $50^{\circ} \mathrm{C}$. $\left(122^{\circ} \mathrm{F}\right.$.) in less than 150 seconds nor more than 180 seconds.

Asphalt Cement (one type). When tested with a standard No. 2 needle by means of a Dow Penetrometer (or other penetrometer giving the same results as the Dow machine), it shall show penetrations within the following limits for the conditions stated.

For Use in the Construction of Bituminous Macadam Pavements: roo-gram load, 5 seconds, at $25^{\circ} \mathrm{C}$. $\left(77^{\circ} \mathrm{F}\right.$.), from 100 to I 20 ; 200-gram load, I minute, at $4^{\circ} \mathrm{C}$. $\left(39^{\circ} \mathrm{F}\right.$.), not less than 50 .

For Use in the Construction of Bituminous Concrete Pavements Having an Aggregate Composed of One Product of a Stone-Crushing Plant Varying in Size from 1/8 to I 1/4 Inches: Ioo-gram load, 5 seconds, at $25^{\circ} \mathrm{C}$. ( $77^{\circ} \mathrm{F}$.), from 75 to 90 ; 200-gram load, I minute, at $4^{\circ} \mathrm{C}$. $\left(39^{\circ} \mathrm{F}\right.$.), not less than 35 ; 50-gram load, 5 seconds, at $46^{\circ} \mathrm{C}$. (II $5^{\circ} \mathrm{F}$.), not more than $25^{\circ}$.

For Use in the Construction of Sheet Asphalt Pavements: 1oogram load, 5 seconds, at $25^{\circ} \mathrm{C}$. $\left(77^{\circ} \mathrm{F}\right.$.), from 65 to 75 ; 200gram load, I minute, at $4^{\circ} \mathrm{C}$. $\left(39^{\circ} \mathrm{F}\right.$.), not less than $35 ; 50$-gram load, 5 seconds, at $46^{\circ} \mathrm{C}$. (II $5^{\circ} \mathrm{F}$.), not more than $25^{\circ}$.

For Use as Filler in Brick and Stone Block Pavements: 1о0gram load, 5 seconds, at $25^{\circ} \mathrm{C}$. $\left(77^{\circ} \mathrm{F}\right.$.), from 30 to $40 ; 200-$ gram load, I minute, at $4^{\circ} \mathrm{C}$. $\left(39^{\circ} \mathrm{F}\right.$.), not less than $\mathrm{I} 8$; 50-gram load, 5 seconds, at $46^{\circ} \mathrm{C}$. (II $5^{\circ} \mathrm{F}$.), not more than 70 .

Distillation. "The distillation test as applied to tars is a very valuable one, both for the purpose of ascertaining their road-building properties and method of preparation if they are refined products. All crude tars contain water which, of course, appears in the first fraction to $110^{\circ} \mathrm{C}$. In coal tars this water is ammoniacal, while in water-gas tars it is not. No tar containing water should be employed as a permanent binder, and even in temporary binders its presence is detrimental."

Solubility in Carbon Disulphide. "For practical purposes all organic matter soluble in cold carbon disulphide is considered as bitumen. Fluid oils are almost completely soluble in this ma- 
terial, and also blown oils and oil pitches, unless they have been cracked to the point of producing free carbon. The solubility of the bitumen itself is entirely independent of its character and consistency, so that the amount and character of insoluble material are of most interest in this test. This material is of no value from the standpoint of road work, but indicates whether an asphalt has been employed in the preparation of the binder, also whether a product has been destructively distilled during its preparation, the determining factor in the former case being the amount of mineral matter present and the amount of organic material in the absence of mineral matter in the latter case. It is, of course, possible to adulterate a preparation so as to give misleading results, unless the analyst is familiar with the characteristics which the addition of various solid native bitumens will produce in oils of different types.

"Tars, with the exception of those produced in blast furnaces, contain only a small fraction of one percent mineral matter. Practically all material insoluble in carbon disulphide is, therefore, organic material, commonly known as free carbon. Water-gas tars or oil tars as they are often called will usually contain less than this amount even when refined to a specific gravity of I.I7, and crude water-gas tar seldom exceeds 2 percent free carbon. Most crude coke-oven tars will carry from 4 to ro percent free carbon, unless they have been produced at very high temperatures, while the modern gas-house coal tars rarely show less than 15 percent and sometimes run as high as 30 percent and over."

Solubility in 88 Degree Baumé Naphtha. "As applied to oils and oil products, this determination is of value as indicating the amount of body-forming hydrocarbons which give mechanical stability to the material. No oils carrying less than 4 percent naphtha-insoluble bitumen will prove of service other than as dust preventives. Crude paraffin oils are almost entirely dissolved by this solvent, while the asphaltic oils contain very appreciable amounts of naphtha-insoluble bitumen. Residual oils carry larger quantities than the crude oils from which they are produced, and blown oils in particular show very high per- 
centages of insoluble hydrocarbons, sometimes running as high as 25 or 30 percent. In this type of oil the naphtha-insoluble bitumen increases with the amount of blowing to which the oil has been subjected.

"Asphaltic cements containing appreciable quantities of these solid products will necessarily show relatively high percentages of bitumen insoluble in naphtha. While the binding value of asphaltic oils and cements is undoubtedly dependent upon the presence of the naphtha-insoluble hydrocarbons, variations in the character of these hydrocarbons exert a marked influence upon the characteristics of the original material. Bitumens insoluble in naphtha are commonly known as asphaltenes, while those soluble are called malthenes. It should be understood, however, that both terms cover a multitude of hydrocarbons which vary greatly among themselves. The character of the naphtha-soluble bitumen is of interest from the standpoint of road treatment, that which is sticky after the solvent has been evaporated indicating better road-building qualities in the original material than that which is greasy."

Evaporation. "This test is a purely arbitrary one, but when applied to road oils will often prove of considerable value. It is believed that the loss in weight thus produced is a fair comparative indication of loss by volatilization suffered by the material in the course of time when applied to the road, also that the character of the residue is similar to that eventually left in the road. A determination of the consistency of this residue should, if possible, be made, and particular attention paid as to whether it is of a greasy or sticky nature. The volatilization test is not a quantitative determination of any one class of volatile oils present in the original material, but only of its tendency to give up these volatile oils. If the material has a certain consistency which it is desired to maintain after application, it should show a low volatilization and should not be subject to hardening by oxidation or other causes. A determination of penetration of the residue as compared with that of the original material is of value in determining this fact. A material which must be soft and sometimes fluid on account 
of the desired method of application and character of the road treated, should very properly suffer high loss by volatilization in order that it may be capable of attaining proper consistency under service conditions.

"Fluid products to be used in the surface treatment of roads need not necessarily show a high loss by volatilization nor a great increase in the consistency of their residues, although the latter is a desirable property. They are mainly of value as dust preventives and binders for the thin coat of fine material upon the road surface and cannot affect the character of the road proper unless applied in large quantities. If their residues are not of a sticky nature, they will, however, produce an undesirable surface condition in wet weather unless applied in very small quantities. In general, all residues should be sticky or adhesive, as otherwise they will act more as lubricants than as road binders. A paraffin oil will produce a greasy residue; an asphaltic oil will produce one that is sticky. While the latter may be successfully employed in road-work, the former is worthless for this purpose.

"In certain instances, determinations of the so-called asphalt contents of oils have been made by driving off volatiles until the residue is of a certain consistency. To produce this residue, it is often necessary to subject the bitumen to such high temperatures that chemical changes take place which would never occur under service conditions. For this reason the test is not a determination of the actual asphalt contents, but only of the ability of the oil to produce an asphaltic base of given consistency under the action of high temperatures. Such a test is, therefore, misleading and has resulted in much confusion among road engineers as to the relative binding value of oils."

Fixed Carbon. "The fixed carbon determination shows much the same thing as that for naphtha-insoluble bitumen, as it serves as an indication of the mechanical stability of an oil. Paraffin oils show but little fixed carbon, while the asphaltic oils run higher and the asphalts still higher. The terms 'fixed carbon' and 'free carbon' should not be confused, as they have entirely different meanings. Free carbon always exists as such 
in the material, while fixed carbon is the coke resulting from the ignition of the bitumen in the absence of oxygen. Fixed carbon determinations are seldom made upon tars, as the presence of free carbon interferes with this test. Owing to a misconception as to what fixed carbon represents, specifications have sometimes been made limiting the percentage of this substance to a very low figure. Providing that free carbon is absent, comparatively high percentages of fixed carbon are a rather desirable property in oils, for the reason mentioned, especially if they are to be used in construction work."

Paraffin. Interpretation of Test by A. W. Dow, M. Am. Inst. Chem. E., and Francis P. Smith, M. Am. Soc. C. E** "We are decidedly of the opinion that the scale paraffin test per se should not be regarded as a measure of value of bituminous compounds for road-making or paving purposes:

"(I) Because there is no evidence to show that the finding of scale paraffin by the modified Holde method, in which the material under examination is first distilled in the laboratory, is proof that scale paraffin or any detrimental form of paraffin is present in the bituminous material.

"(2) Because there is no evidence to prove that paraffin of any kind is a deleterious constituent for a bituminous-road cement."

Utilization of Tests in Specifications. $\dagger$ "The ultimate utilization of tests for the purpose of selecting material for a given use makes it necessary that (I) the test limits adopted shall specifically define the material, and (2) that the material thus defined shall have previously proved satisfactory for that particular use.

"The individual tests required by specifications for bituminous road and paving materials may serve one or more of the three following purposes:

* See Engineering News, June 8, I9I I, pages 680-683.

$\dagger$ By Prevost Hubbard, Chemical Engineer, U. S. Office of Public Roads and Rural Engineering and Lecturer in Highway Engineering Chemistry, Graduate Course in Highway Engineering, Columbia University, 1913 Proceedings, American Road Builders' Association, pages 213-216. 
" (I) They may directly indicate the suitability for a given use of the material specified.

"(2) They may serve as a means of identifying the source of a material, or even the material itself.

"(3) They may serve to control uniformity in the preparation or manufacture of a material.

"The first of these purposes is undoubtedly the most important and is usually the only one considered by the lay mind. In the case of bituminous materials, this purpose is only partly accomplished by a comparatively few tests. As examples, may be mentioned tests of consistency, such as the penetration test, the float test, and the test for viscosity. Such tests can only be of maximum value, however, when applied to a specific type of bituminous material and when considered in connection with other tests which, by themselves, may not directly indicate suitability. Thus, for a certain type of bituminous concrete pavement the proper penetration limits at $25^{\circ} \mathrm{C}$. for a California asphalt may lie between 7.0 and 9.0 millimeters, while the proper penetration limits for a fluxed Bermudez asphalt to be used in exactly the same type of pavement and under the same conditions, may be entirely different, say, from I4.0 to I6.0 millimeters. It is evident that to attempt to cover the penetration limits for both materials under one specification would be useless. In the first place, such test limits as 7.0 to I6.0 millimeters are so wide as to insure but little uniformity in different lots of the same material; and in the second place, an entirely unsuitable material of one class might be supplied under the maximum test limit of the other class. The fallacy of blanket specifications, which have already been advocated to a considerable extent, is thus easily demonstrated.

"If a penetration test is essential under the conditions just mentioned, it is apparent that recourse must be had to separate type specifications; and if this is so the specifications must contain either tests or test limits which will describe certain peculiarities of the type specified, that are not common to other types. In many cases this cannot be done by means of a single test and two or more such tests will be required. 
"This brings us to a consideration of the second purpose previously mentioned, i. e., the use of tests as a means of identification. There are a number of such tests, among which may be mentioned specific gravity, melting point, solubility in carbon disulphide, fixed carbon, etc. So far as the usual test records are concerned, the specific gravity of a bituminous road or paving material is one of the most important characteristics used to determine its identity, and this is particularly true if its specific gravity is considered in connection with the consistency of the material and sometimes its solubility in carbon disulphide. Thus, a bituminous material with a specific gravity of 0.99 and penetration of 7.0 millimeters at $25^{\circ} \mathrm{C}$. must be a blown product. Fluid consistency and high specific gravity, say 1.25, in a tar serves to identify it as a coal tar, and the identification is strengthened if its solubility in carbon disulphide is low, say 75 percent. High fixed carbon in most asphalt cements produced from Mexican petroleums is a distinguishing characteristic. Relatively low fixed carbon in good asphalt cements of the same consistency produced from California petroleums, serve to differentiate them from the Mexican products. Here, again, the necessity or desirability of different test limits is apparent, for if the amount of fixed carbon yielded by a California asphalt cement was as high as 16 percent often found in Mexican asphalt cements, indications would point very strongly to injury of the former, due to excessive temperatures having been employed in the process of manufacture.

"This leads us into the third purpose for which tests may be made to serve-control of uniformity in the preparation or manufacture of a material. Among such tests may be mentioned those for determining flash point, loss by volatilization, distillation, solubility in given grades of paraffin naphthas and solubility in carbon tetrachloride. Practically all of the other tests previously enumerated may also be made to serve this end. No one by itself will, however, necessarily accomplish this purpose, no matter how close the test limits are drawn. This is mainly due to the fact that products of innumerably varied and complex characteristics may be produced 
from a given crude material by modifying the methods of manufacture.

"In the preparation or interpretation of any specifications for bituminous road or paving materials, an appreciation of the interrelation of tests and test limits is as necessary as an understanding of the individual significance of the tests themselves, and yet those who should be most familiar with such matters often fail to consider the possible relation which a given test may bear to others with which it is associated in specifications. The interrelation of tests and test limits is something which the layman may not readily comprehend, and this has often resulted in his innocent acceptance and enforcement of unjustly discriminative specifications prepared or suggested by those who have an object to attain."

The I9I3 Report* of the Special Committee on "Bituminous Materials for Road Construction" of the American Society of Civil Engineers contained the following recommendations relative to the advisability of using separate specifications for different types of bituminous materials instead of using one specification covering many types of one class of materials.

"Your Committee has especially considered during the past year the various methods of writing specifications covering the physical and chemical properties of bituminous materials for use in the construction of bituminous surfaces and bituminous pavements. Many of these properties vary to a remarkable degree, dependent primarily upon the source of the material and the methods employed in refining. It is recognized that it is often essential to specify narrow limitations of certain properties in order to secure desired chemical and physical characteristics and uniformity in the manufactured material. It is not in many cases practicable to specify the same limitations except for materials obtained from the same or similar sources and prepared in the same manner.

"Therefore it is suggested that for the present at least, whenever comprehensive specifications are to be prepared so as to

* See February, I9I3 Proceedings, Am. Soc. C. E. 
admit a variety of types of materials, separate specifications as may be necessary be prepared for each type. As an illustration, the specification for the bituminous cement to be used in the construction of a bituminous pavement by the mixing method might contain independent specifications covering, within narrow limits, the physical and chemical properties of each of the following bituminous materials: refined water-gas tars, refined coalgas tars, mixtures of tars, asphalts containing native bitumen from one or more sources, asphalts obtained by refining petroleum from one or more sources, and asphalts which are solid or semi-solid compounds composed of the bitumens mentioned with petroleums or derivatives thereof." 


\section{CHAPTER $\mathrm{X}$}

\section{DUST PREVENTION AND BITUMINOUS SURFACES}

\section{Dust Prevention}

Classification of Surface Treatment Methods. A palliative used as a dust preventive or dust layer on the surface of a roadway may be defined as "material applied to a roadway for temporarily preventing the formation or dispersion under traffic of distributable dust."* A bituminous surface has been described as "a superficial coat of bituminous material with or without the addition of stone or slag chips, gravel, sand, or material of similar character." $\dagger$ While it is evident that the reapplication of asphaltic oils, tars, and certain emulsions may form bituminous surfaces, the methods of construction considered under this latter title will be confined to those treatments which result in the formation of bituminous surfaces which are efficacious under ordinary conditions for at least one year.

Development. In $187 \mathrm{I}$, Francou of Auch, France, spread tar on the roadway surface and then set fire to it in order to volatilize parts of the tar. In 1896, Girardeau, having noticed the good results obtained when a cold tar application was acted upon by the heat of the sun, applied hot tar to a roadway surface. It was in I9or that systematic experiments were carried out by Dr. Guglielminetti at Monte Carlo, Geneva, and Nice, using coal tar and brushing the same into the road surface. In Europe, the campaign against dust and the deterioration of road surfaces, caused primarily by motor-car traffic, was thus inaugurated by Dr. Guglielminetti. The results of his successful experiments with superficial tarring at Monaco were published throughout all Europe. In the following year trials were carried out at Champigny by the engineers of the Department

*Dec., 1914 Proceedings, Am. Soc. C. E., page 3014.

† Dec., I9I4 Proceedings, Am. Soc. C. E., page 3012. 
of Roads and Bridges of France. In the I903 report on these trials, the French engineers formulated all the basic principles of superficial tarring.

It might be said that dust suppression was the main cause of the development of the method of surface treatment. While in Europe it led to superficial tarring, in this country the first trials of this method were made with light oils. Oil was used for this purpose in 1894 at Santa Barbara, California. Further trials were made in 1898 , and oils were used to a very slight extent in different parts of the country up to I905. After 1905 the use of oils as a dust palliative rapidly increased in the United States. Surface tarring has been used in this country since I906.

Formation of Dust. The nature of the work to be accomplished in laying dust must be understood before details of methods can be properly considered. In this connection it is necessary to know the sources of the different kinds of dust on the surfaces of roadways. A self-evident source of dust is the mechanical abrasion of the road metal by traffic. It is manifest that the degree of abrasion will depend upon the amount and nature of the traffic, the kind of material used, and the method of construction and maintenance employed. Other sources of dust due to traffic are the deposition of dirt which has adhered to the wheels of vehicles coming from adjacent earth, gravel, or broken stone roadways, from the leakage of the contents of loaded vehicles both in transit and while loading and unloading, and the excrements of animals. The decay of twigs, bark, and leaves, and the deposition of pollen, seeds, and spores of various plants result in the formation of appreciable amounts of dust. Mineral matter applied to the surfaces of certain pavements to prevent slipperiness is a constant source of dust. Mills where pulverizing is carried on, textile establishments, and foundries are prolific sources of dust, while soot and fine ashes from chimneys find their way to the streets. From the nature of these sources it is apparent that the composition of street dust is complex.

EFfects of Dust. The ways in which dust acts as an enemy to the public welfare may be summarized as follows: 
first, the formation of heavy dust clouds by traffic to such an extent as to obscure a view of the roadway; second, when wet, the formation of mud which may cause skidding of wheels and dangerous footing for both man and beast; third, the lowering in real estate values where it occurs in large quantities; fourth, the soiling of clothing and other personal property; fifth, its action as an abrasive agent upon certain surfaces; sixth, its harmful effect on plant life; and seventh, as a distributor of disease germs.

The Pathogenic Effects of Dust have been given extensive study by the medical profession. From what has been said relative to the sources of dust, it is obvious that it is made up of organic and inorganic matter. If germ cultures are prepared from air, bacterial life of different kinds will be found present in quantities which are sometimes startling. Although it is very commonly believed that dust is full of tuberculosis germs, many bacteriologists are not positive on this point. Dr. T. Mitchell Prudden states that "It is certain that in the country and also in cities whose streets are kept decently clean, there is less danger of harm from the inhalation of germs of consumption or of any other disease, because the constant purifying agency of wind and air currents will either soon sweep away the dust or so largely dilute it that it will be practically free from disease germs, the sources of which are so comparatively limited. If, however, the streets of cities be or are allowed to remain filthy, so that abundant and pretty constant clouds are encountered by those passing through them; if the streets are not properly sprinkled before sweeping, either by machine or hand; if ignorant or careless street cleaners are allowed to scatter clouds of dust about them as they sweep or shovel or transport the pulverized filth, the chances of inhalation of dangerous dust particles are proportionately increased. But on the whole, the risk of infection out of doors from dust, even in crowded towns, unless they are notably filthy, is not actually very great." Dust, however, may aid in the contraction of tuberculosis even though it contains no tubercle bacilli. The constant inhalation of dust will irritate the pulmonary organs 
so as to render them more susceptible to the attack of the tubercle bacilli, which are frequently lodged in the mucous membranes of healthy individuals. Various delicate membranes are irritated by the simple mechanical action of the dust. The membranes of the respiratory organs are susceptible to this influence, especially if a person be asthmatic. The membranes of the eye are also frequently seriously irritated by dust. In foreign countries where the dust problem has been successfully solved, physicians report a marked falling off in the number of cases of conjunctivitis.

Use of Palliatives. European engineers appreciate the true value of palliatives, as both at the First International Road Congress held in Paris in 1908 and at the Second Congress held in Brussels in I9ro, conclusions were adopted to the effect "that emulsions of tars or oils, hygroscopic salts, etc., are really efficient, but, unfortunately, only for a short time. Therefore their use should be limited to special cases, such as race courses, festivals, processions, etc." Palliatives are used efficiently in America on earth, sand-clay, gravel, and broken stone roadways of certain classes of highways. Many consider that palliatives should be used only in connection with earth, sand-clay, and gravel roadways, broken stone roadways subjected to light horse-drawn vehicles and a few motor vehicles per day, and for broken stone roadways in poor repair. The prevention of dust on bituminous, cement-concrete, brick, wood block, and stone block pavements should not be accomplished by using palliatives. The use of palliatives on pavements is wrong in principle. Sanitary conditions require the constant removal of filth from roadways, and if this is removed periodically by flushing or other means, the effectiveness of dust-laying processes is curtailed. Furthermore, the fine dust which necessitates the use of palliatives should be removed. Dust prevention on pavements is primarily a problem in street cleaning and will be considered in detail in the chapter covering that subject.

It is evident that the field of usefulness of palliatives is limited. This field will grow comparatively smaller in the future as the mileage of good roads and pavements increases, 
as the economics of construction and maintenance is understood, and as the inherent value of the various methods for the elimination of dust is recognized.

In Europe attention to æsthetics has resulted in the use of palliatives where otherwise bituminous surfaces would have been employed. At the birthplace of the campaign against dust by the use of superficial tarring, namely, in the Principality of Monaco, ordinary watering is used to lay the dust on the boulevards surrounding the beautiful gardens in front of the Monte Carlo Casino. The watering of these surfaces once per hour serves to lay the dust, cool the atmosphere, and furnish a roadway surface which is in harmony with its magnificent environments.

Classification of Palliatives. Palliatives, which are in common use as dust preventives, include water, sea-water, salt solutions, calcium chloride, tar and oil emulsions, and light oils and tars. As oils and tars are included in this classification, the distinction between treatments with palliatives and the construction of bituminous surfaces should be borne in mind.

Water. Water is an effective dust layer when properly applied under the direction of engineers who supervise the details of the method of application. Due to the brief period of efficiency of one application, the use of water as a dust layer is limited from an economical standpoint. Furthermore, it has been demonstrated by many service tests that watering, even when properly accomplished, will not preserve broken stone or gravel roads when the traffic consists of rapidly moving motorcars. Based on the above conclusion, it is seen that watering of highways outside urban districts is generally impracticable since the cost of watering where waterworks systems do not exist, is prohibitive on account of the long hauls from the source of water supply, and as there are few communities where regulations covering the maximum rate of speed are enforced except in built-up districts.

Watering for the purpose of dust laying is not regarded favorably in many municipalities because this class of work, being in the hands of inexperienced and untrained laymen, is 
done in an inefficient and costly manner. Generally the details of watering are left to ignorant and irresponsible drivers of watering-carts. Under these conditions it is not surprising that watering means muddy streets to most citizens.

There is an efficient and economical manner of accomplishing every method of construction and maintenance of highways. Watering is no exception to the rule. The broken stone or gravel roadway should be kept repaired so that its surface is free from pot-holes, ruts and other depressions. Surplus dust must be removed before the water is applied. Watering-carts must be used with which water may be distributed uniformly ard in small amounts per square yard of roadway. Pressure distributors, similar in design to machines used for the application of light tars and oils, may be economically employed for this purpose. Instead of flooding the surface, it should only be dampened. Dependent upon climatic conditions and local peculiarities of a given street, such as the character of the roadway surface, shade trees, buildings, etc., from one to eight applications per day will be required to lay the dust and keep the street from being objectionably dusty. The annual cost of watering in the manner described from May to October will range from 2 to $3 \frac{\mathrm{T}}{2}$ cents per square yard.

Sea-Water. The use of salt water has not been developed sufficiently to establish its value and rating as a dust palliative. It has been tried in a number of instances in coast towns and cities, usually being applied with the ordinary watering-cart. In one instance it was found that in dry weather it formed a hard, salty scale, while in wet weather the mud contained so much salt that it injured the iron and varnish of vehicles. In another case it was found that sea-water was about three times as effective as fresh water in preventing dust and, when properly applied, had no injurious effects on the surface of the roadway.

Calcium Chloride. This material is a by-product in the ammonia-soda process of manufacturing common washing soda and in other industrial processes. It is shipped in granulated form in air-tight steel drums. Calcium chloride is used in two 
ways in connection with dust laying: first, by the "wet" method and, second, by the "dry" method. When applied dry to the cleaned road surface, see Fig. 76, a distributing apparatus, such as a lime spreader, should be employed. From $3 / 4$ to $\mathrm{r} / 2$ pounds per square yard are used for one application. Usually two applications per season in the North will give good results. The

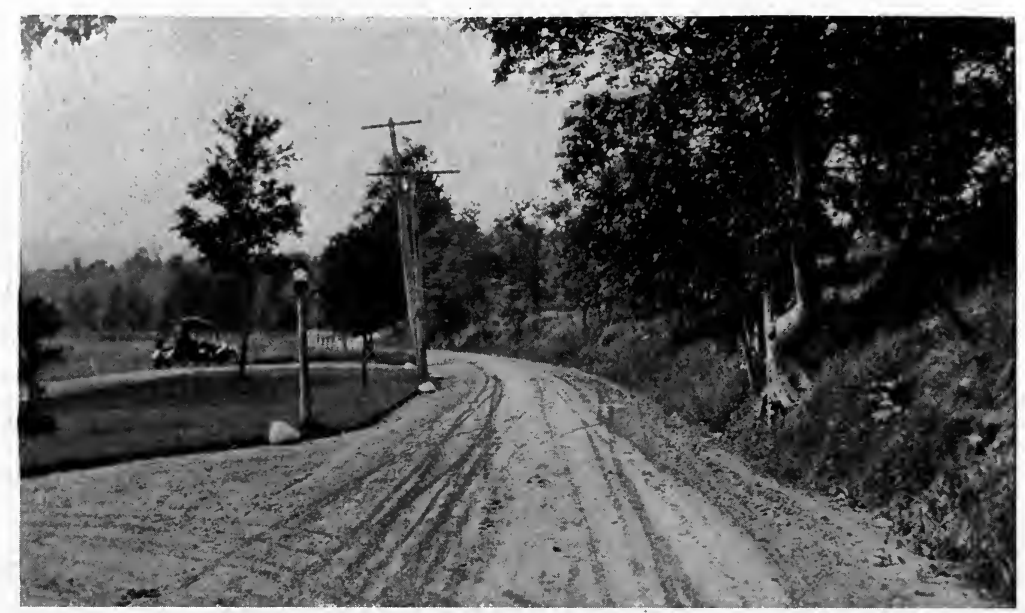

FIG. 76. Application of Calcium Chloride by the "Dry" Method.

cost per season varies from $\mathrm{I} .75$ to 4 cents per square yard. When applied wet, the calcium chloride is dissolved at the rate of I pound to I gallon of water, using about one-third gallon of solution per square yard. For the application of the solution ordinary watering-carts are generally used, although with pressure distributors it is practicable to secure more uniform distribution. The usual method is to use two applications along the center of the street and one at the sides. To secure freedom from dust about ten applications should be used per season in Northern States.

The most scientific work which has been done with calcium chloride was that carried on by a Committee of Judges of the Roads Improvement Association of England in 1909 and I9ro. After exhaustive experiments the following conclusions were de- 
duced: "We are of opinion that the results of the tests of calcium chloride applied in granular form by the 'dry' method have shown that it is a very effective dust layer; that the treatment has the ill effects of causing, during the winter months, an abnormal quantity of sticky mud, a decided.tendency to licking up, and a disintegrating action upon the macadam surface."

Emulsions. Palliatives belonging to this class are mixtures of oil, water and a saponifying agent. The saponifying agent

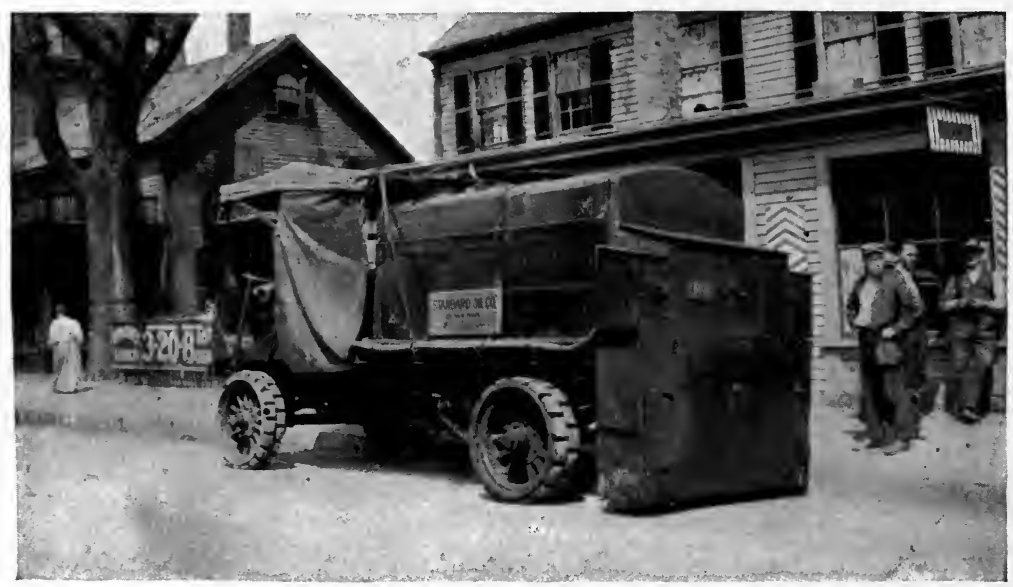

FIG. 77. Pressure Distributor Used for Applying Light Oils.

forms a chemical solution with the water. The mixture is readily miscible with the oil. Alkalies such as potash, soda, ammonia, and various soap solutions are the agents most commonly used with oils. A concentrated emulsion might consist of 5 percent soap, 30 percent water and 65 percent oil. Twenty percent of this emulsion with 80 percent water might be used for the first application and a 5 to ro percent solution for retreatments. Oil emulsions are commonly used although tar emulsions are employed to a small extent in this country. Distribution is usually made with an ordinary watering-cart on the unprepared surface, although better results may be obtained by cleaning the roadway surface and using some type of pressure distributor. Sometimes a light sand coat has been added, but as a rule the 
surface is left uncovered. From six to ten treatments are used in a season, extending from April to October. The cost varies from $\mathrm{I} .5$ to 3 cents per square yard for the season.

Light Oils and Light Tars. In this group of palliatives may be included crude and refined petroleums, water-gas tars, coalgas tars, and certain proprietary compounds. Light oils were employed in 1898 in Los Angeles and Algeris for the purpose of laying dust. Their use has developed rapidly in America

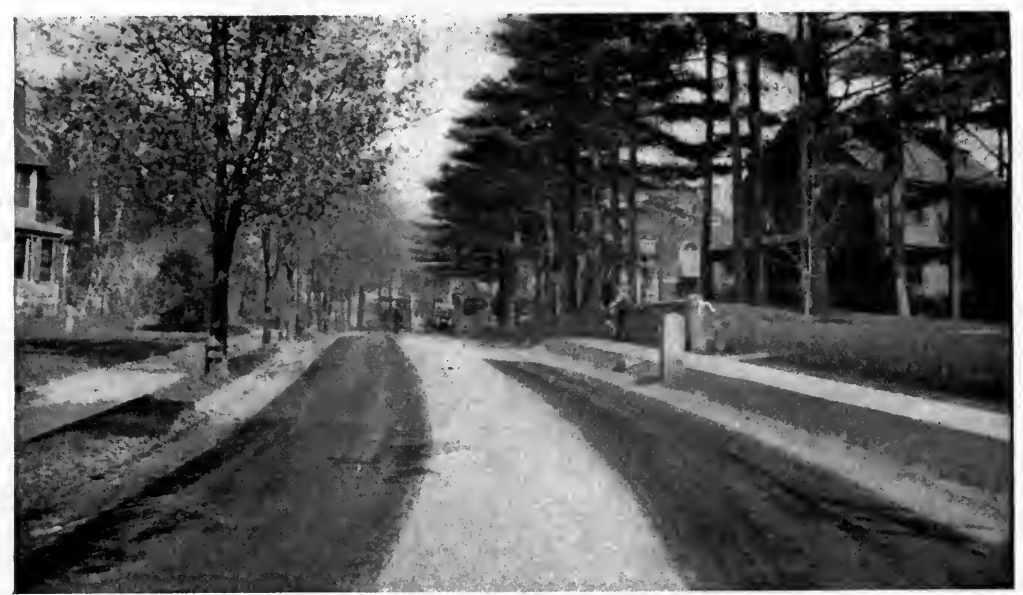

FIG. 78. Surface of Roadway Showing Uniform Application of Light Oil.

due to the large supply available, while in Europe very little oil has been used as the price of oil is comparatively high. The tendency in Europe has been to discard all types of palliatives and to employ in their place bituminous surfaces which will be efficacious for at least a year.

Light oils and light tars having proper physical and chemical properties are efficient dust layers. They should be used in small amounts as palliatives, otherwise a soft greasy surface will result. The material is usually $^{\circ}$ applied cold, using ordinary sprinkler carts or distributors, of either the gravity or pressure type. In order that this class of palliatives should be distributed economically and satisfactorily, pressure distributors should be used which are equipped with suitable hoods to pro- 
tect pedestrians and property from the fine spray accompanying distribution, and which are capable of distributing the material in as small amounts as $1 / 8$ of a gallon per square yard. The accompanying photographs, see Figs. 77 and 78 , show respectively a distributor of the type described and an efficient application of a light oil. There would be few complaints of ruination of clothes and house furnishings, filthy streets, and disagreeable odors if this method of distribution was universally employed.

Light oils and light tars are effective for six weeks to two months if properly applied. The amount used per square yard should be between $/ / 5$ and $1 / 8$ of a gallon, dependent on the kind of material and the condition of the surface of the roadway. If more than this amount is used, the oil may work down into the wearing course and, serving as a lubricant, cause disintegration by the formation of a loose surface. They should not be employed after November I in the Northern States as a muddy, greasy surface would probably form on the roadway. during a part of the winter. It has been claimed that by the use of light oils, broken stone water-bound roadways could be preserved under high-speed motor-car traffic. This fallacy has caused a large waste of public funds in many cases, since the broken stone roadway has begun to disintegrate within two to three weeks after the application of the oil, although the effectiveness of the application as a dust layer was apparent for six weeks.

In I909 over 75 miles of the state highways of Rhode Island were oiled. The quantity of oil used per square yard was 0.2 gallon, and the average cost per application was about 0.9 cents per square yard. In Philadelphia, during I9I4, the cost per treatment of 0.2 gallon per square yard averaged I.I3 cents.

Although there are many proprietary palliatives on the market, they will not be considered, first, because they appear to be of more or less transitory character, and, second, because the fundamental principles underlying the use of palliatives have been explained. 


\section{Bituminous Surfaces}

Bituminous surfaces are used on broken stone and gravel roads, on bituminous and cement-concrete pavements, and to a certain extent on brick and wood block pavements. In this chapter will be considered methods of constructing and maintaining bituminous surfaces on broken stone and gravel roads, while bituminous surfaces on bituminous macadam pavements, bituminous concrete pavements, asphalt block pavements, cement-concrete pavements, brick and wood block pavements will be treated in the chapters devoted to the several pavements.

Bituminous Materials. The different kinds of bituminous materials used are asphaltic oils, asphalts, crude and refined water-gas tars, crude and refined coal-gas tars, combinations of refined tars, and combinations of refined tars and asphalts.

There has been noted a growing objection to the use of materials, for the construction of bituminous surfaces, which require from two to six weeks to set up to such an extent that tracking will not occur. Materials, which have given satisfactory results from this standpoint, are refined coal tars and water-gas tars, asphalts, combinations of asphaltic materials and refined tars, and cut-back asphaltic oils. Within 24 to 48 hours, bituminous surfaces constructed with the foregoing materials, using from $1 / 4$ to $1 / 2$ gallon per square yard and a thin covering of stone chips, have set up so that no tracking is noticeable.

Construction. Preparation of Road Surface. Before constructing a bituminous surface on a broken stone or gravel road, all depressions, pot-holes, ruts, or other irregularities should be filled with thoroughly compacted bituminous-coated stone so that the whole surface of the roadway is even. All surplus dust must be removed so that the larger pieces of broken stone of the roadway surface are exposed but without breaking the bond. This cleaning process is accomplished by the use of horse sweepers and fine bass brooms, with coarse fibre brooms and fine bass brooms, see Fig. 79, or by a vacuum process. If there is caked 
mud on the surface of the roadway, wet brushing will prove advantageous. It is apparent that the character of the cleaned surface will be affected by the method which was used in the

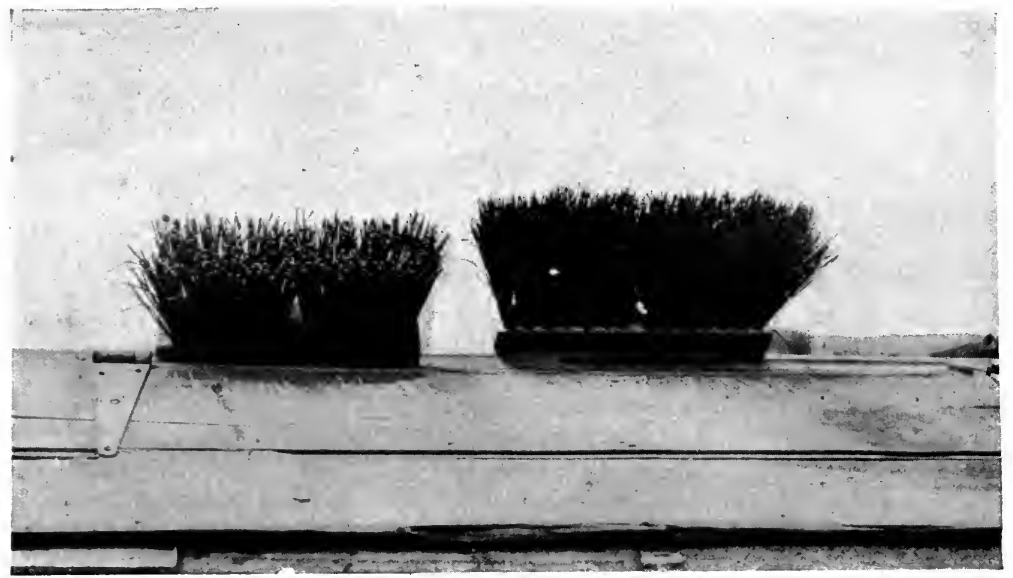

FIG. 79. Coarse Fibre Broom (left) and Bass Fibre Broom (right).

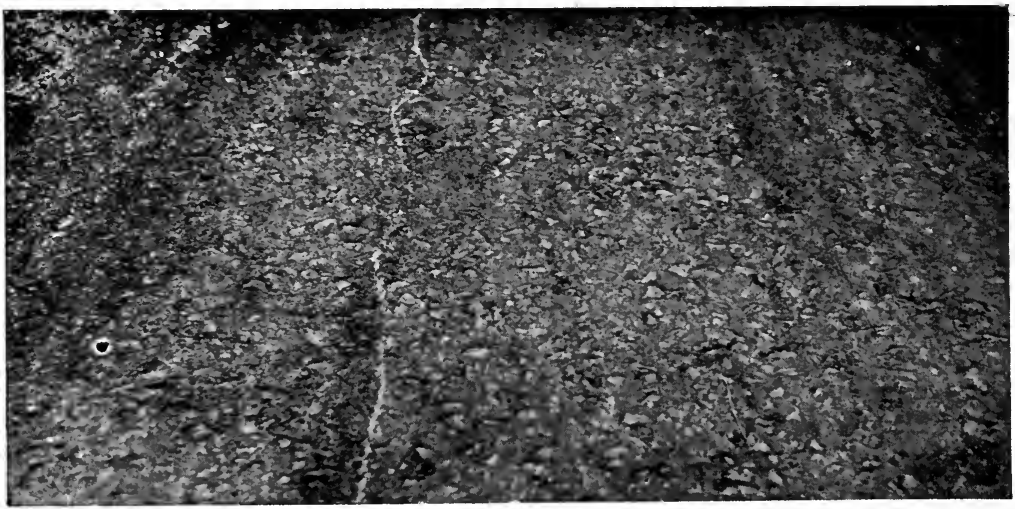

FIG. 8o. Surface of Macadam Road Showing Large Broken Stone.

original construction of the roadway. If the practice of French engineers in using large-size stone varying from an inch to $2 \frac{1}{2}$ inches in longest dimensions for the top course of a broken stone road is followed, and the stone is hard and tough, the desired surface, see Fig. 80, can be easily secured. The large 
stones in such a roadway are exposed and the layer of dust, so characteristic of broken stone surfaces composed of small stone, has thus been practically eliminated. A clean mosaic surface is of the utmost importance from the standpoint of the formation of a satisfactory bond between the broken stone and the bituminous material. The maintenance of bituminous surfaces on wearing courses of large broken stone is economical, since after the bituminous surface wears away in spots, the mechanically interlocked large stones will of themselves generally have sufficient stability to withstand the effects of traffic until retreated. On the other hand, if the top course of a broken stone road has been constructed of a product of the crusher, varying in size from $1 / 4$ to $\mathrm{I} / 4$ inch material, it will be very difficult to secure a clean surface. When the bituminous material is applied the roadway surface should be bone dry. If the surface is damp it will be difficult to secure a good bond.

Application of Bituminous Material. Distribution of the bituminous material is accomplished by two methods. Flow by gravity is utilized in one method and mechanical pressure in the other. The use of gravity distributors has not been developed to its fullest extent in America, in that the use of mechanical brushes or the brushing of the material into the road by hand brooming has never been adopted extensively. The advantages claimed for pressure distributors are: aid in cleaning the surface of the roadway, even application, distribution of small amounts per square yard, and satisfactory adhesion obtained between the bituminous material and the surface of the roadway. By brushing after gravity distribution, it is possible to distribute uniformly $1 / 4$ to $/ / 5$ of a gallon per square yard of many of the bituminous materials used for the construction of bituminous surfaces. In some cases, when the distribution is accomplished by hand brooming, the adhesion of the material to the road metal is as good as when the material is applied under pressure.

Amount of Bituminous Material. As a general rule from $1 / 4$ to $1 / 2$ gallon per square yard is used for the first treatment. In some cases, however, as small an amount as $1 / 8$ of a gallon 
per square yard is employed. The amount applied per treatment depends upon the kind of bituminous material, the character and condition of the surface, and the details of the method of application.

Top Dressing. The superficial coat of bituminous material is usually covered with either coarse sand, fine gravel, or stone

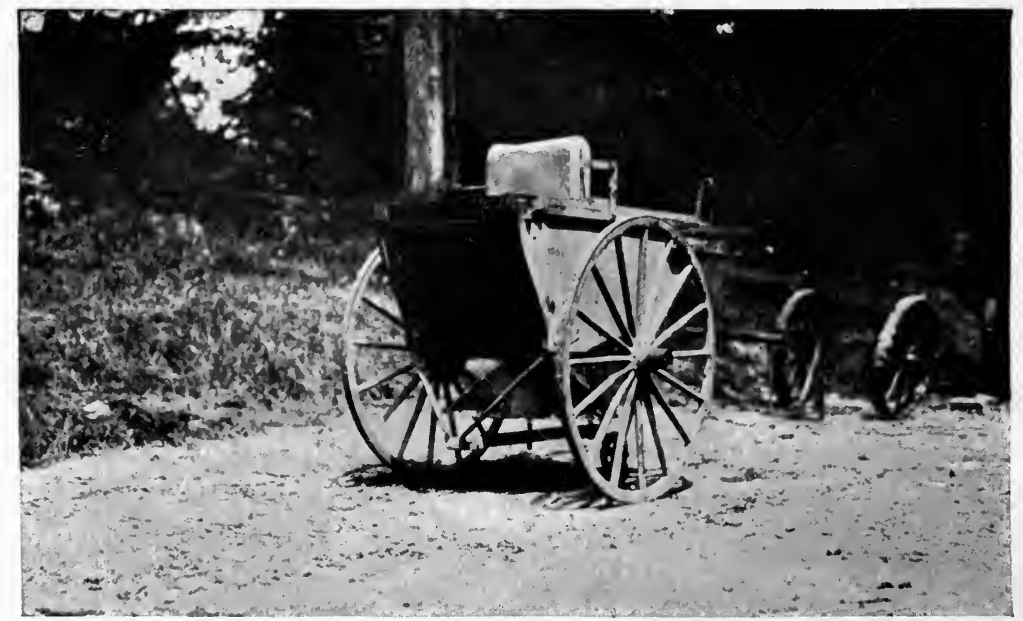

FIG. 8I. Warren Brothers Hand-drawn Sand or Stone-Chip Distributor.

chips varying from $1 / 8$ of an inch to $1 / 2$ an inch in longest dimensions. The amount of sand, stone chips, or gravel used per square yard depends upon the quantity and kind of the bituminous material. From 7 to $I_{5}$ pounds per square yard have been used satisfactorily. Top dressing is distributed by hand and machine methods. In the machines, see Fig. 8r, employed for this purpose, the mineral matter falls on a revolving cone beneath the body of the wagon and is thus uniformly spread over the surface.

Cost Data. The cost of constructing a bituminous surface varies from 4 to Io cents per square yard.

Maintenance. The life of a bituminous surface and its economical use depend primarily upon traffic conditions, the method of construction, and the nature of the bituminous mate- 
rial used. With the heavier grades of bituminous materials adaptable for this work, if the road is subjected to a normal traffic for which the method and material are economical and suitable, retreatment is necessary every one or two years. Under traffic conditions demanding some other type of construction, it may be necessary to retreat the road twice each year, as is done in the case of the Avenue du Bois de Boulogne in Paris. Retreatments can generally be accomplished by using a smaller amount of bituminous material, usually about half the amount used in the first treatment. The same care should be taken in preparing the road surface as is done in the original treatment. Continuous repairing methods are, of course, productive of the most satisfactory results. As it is difficult to barricade a road after small repairs have been made, a method should be used which will prevent displacement of the road metal employed in patching.

Mechanical Appliances. The appliances used in the distribution of bituminous materials may be classified as gravity distributors and pressure distributors. As the demand developed for a heavier binder, both for surface treatment and penetration work, machines especially designed for distributing these materials began to appear. The market is supplied with so many different types, each one of which is claimed to be "the distributor," that a thorough investigation is essential preceding the purchase of machines for various classes of work.

Gravity Distributors. In this subdivision will be considered pouring cans, tanks with hose attached, and distributing machines.

Pouring Cans. With the use of pouring cans alone it is difficult to secure uniform application of the bituminous material. If the application of the material is immediately followed by vigorous brushing with fibre push brooms, very satisfactory surfaces can be obtained. The use of these methods will result in a high labor cost due to two factors, the high cost of labor, especially in the United States, and the slow progress made. Cans should be used with which may be secured the maximum uniformity of application attainable by this method of distribution. (See Fig. 82.) 
Hand-Drawn Gravity Distributors. The advantages of handdrawn distributors over pouring cans are the more uniform

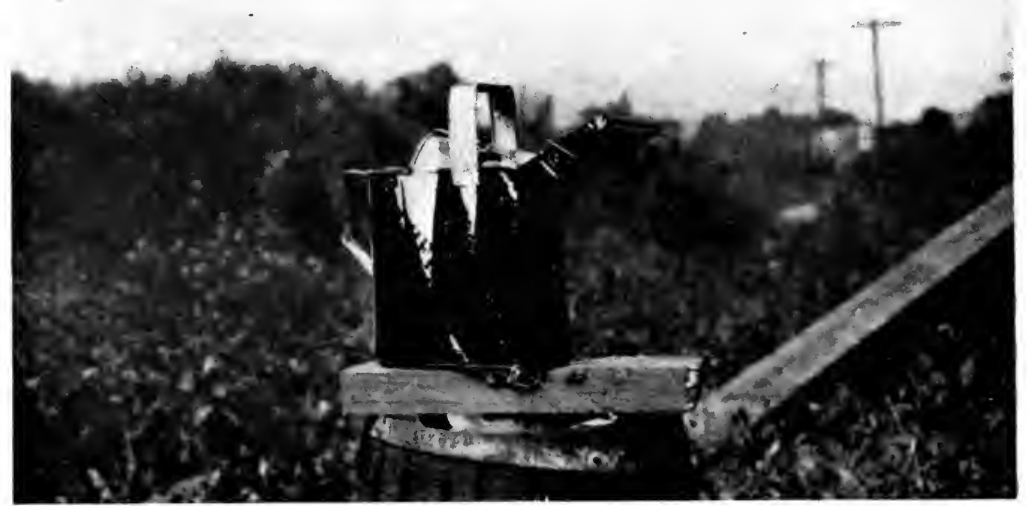

FIG. 82. "Perfection" Pouring Can with which Bituminous Material is Distributed in a Sheet.

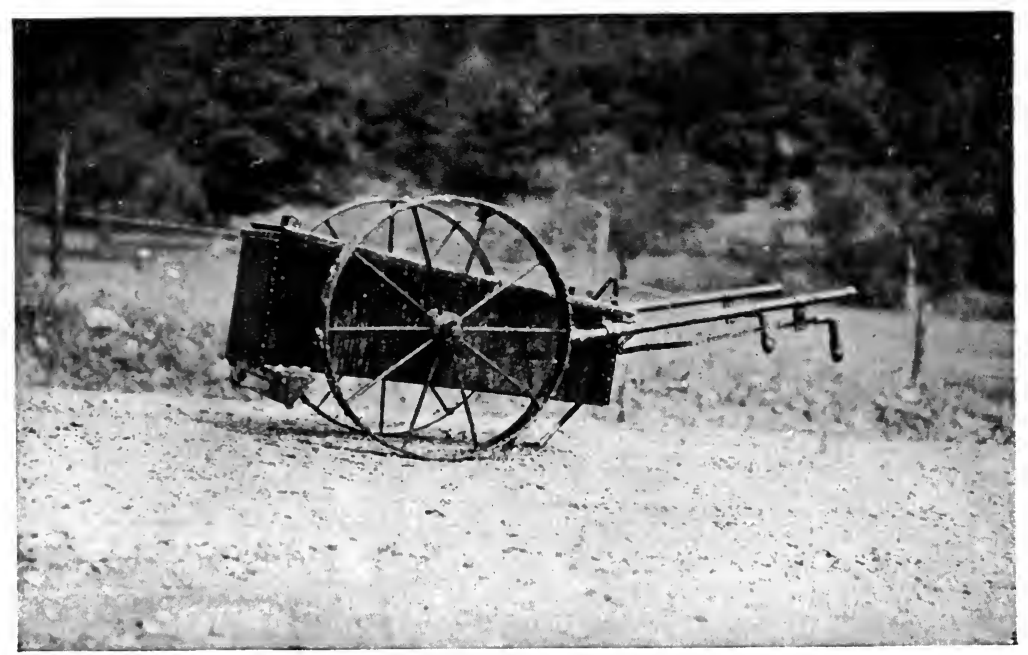

FIG. 83. "Eldus" Hand-drawn Distributor. (American Machine.)

distribution of material, the elimination, to a certain extent, of the personal equation, more rapid work, and the practicability 
of keeping the bituminous material at a higher and more even temperature. (See Fig. 83.) A hand-drawn gravity distributor, as shown in Fig. 84, was introduced in France in 1903.

Tanks with Hose Attached. If a tank from which the bituminous material flows by gravity through a hose and nozzle

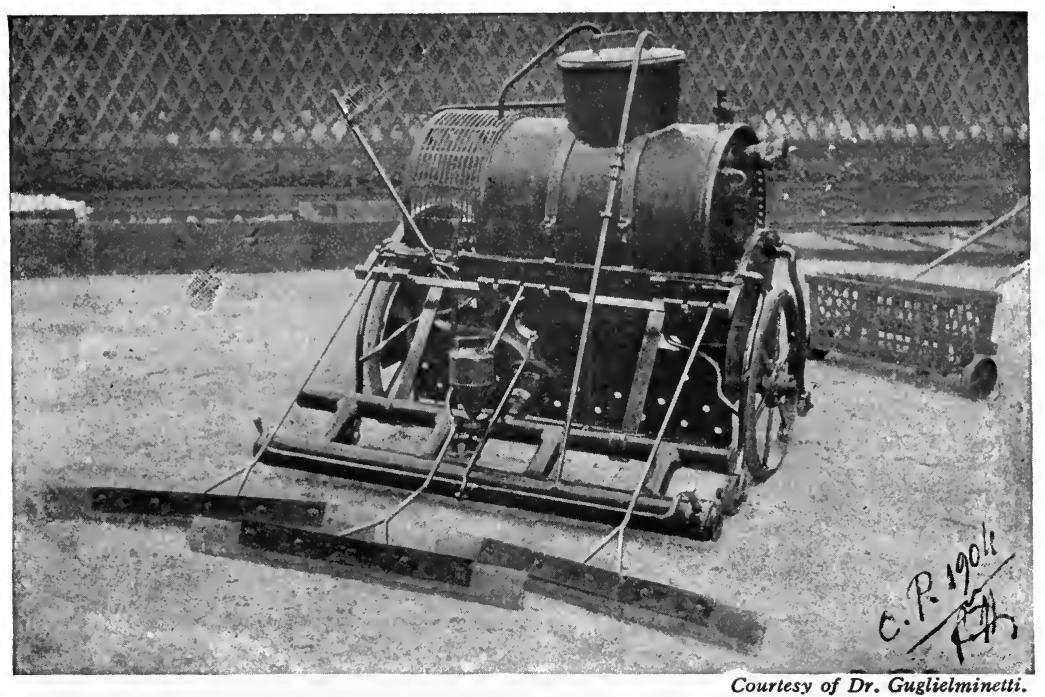

FIG. 84. French Hand-drawn Distributor.

onto the road is used, brushing is necessary to secure satisfactory distribution.

Machines with Distributing Apparatus. Watering carts were first used in the United States for distributing the light oils and tars for suppressing the dust. The ordinary spray attachments on the carts were not very satisfactory for distributing this class of material. Attention was then directed to modifying the distributing device, still using the wooden-tank wagon. Practically all of the modifications consisted in substituting for water sprinklers one or more horizontal pipes pierced with small holes. These pipes were attached to the outlet pipe of the tank and were placed parallel to the back axle at the rear of the tank. The pipes were usually about the same length as the gauge of the rear wheels. The material flowed through these pipes in 
small vertical streams onto the road surface. Hence, in distributing small quantities, the road surface would not be entirely covered with the material. Traffic worked the material around on the road surface so that in the course of time a fairly satisfactory result might be obtained. In some American machines,

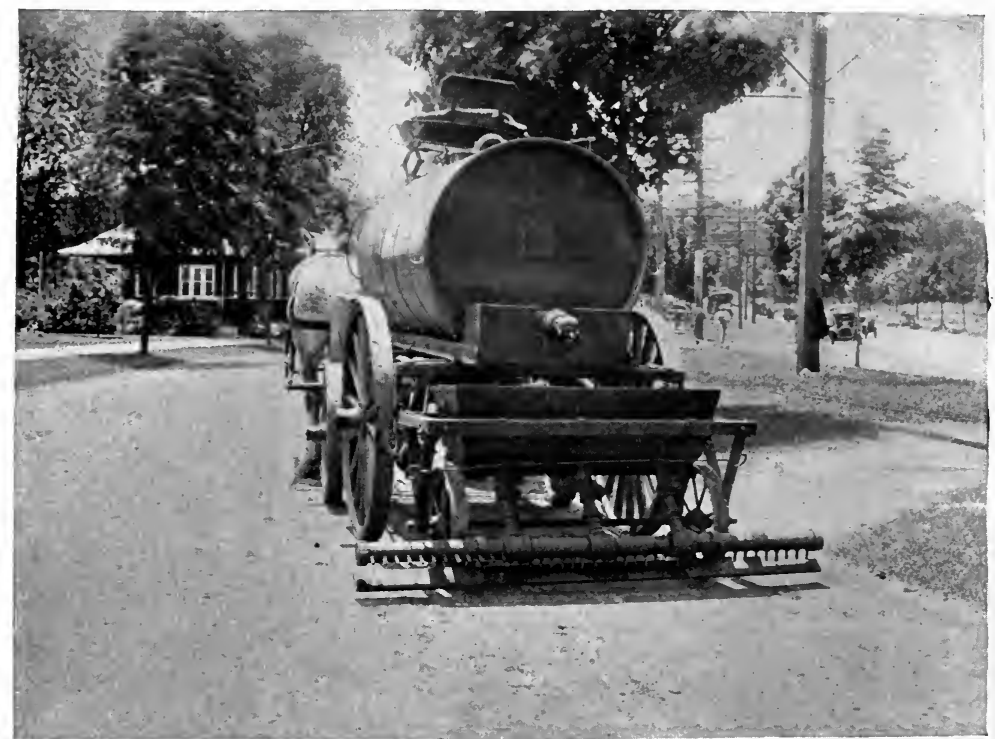

FIG. 85. The A. T. C. Gravity Distributor.

see Fig. 85, the material flows from pipes onto a flash board and from the board to the surface of the roadway in the form of a sheet.

The general practice in Europe in using machines of this type is to follow the distribution by brushing the material into the road. This is done either by hand brooming or by brooms which are attached directly behind the distributor. The brooms are either of the drag or rotary type. The machines are made to be drawn by hand or by horse. (See Fig. 86.)

Pressure Distributors. The various types of distributing machines of this class may be grouped in the following subdivisions: hand-drawn distributors; pressure tanks to which are 
attached hose and spraying devices or horizontal distributing apparatus; and machines equipped with mechanical powerpumps between the tank and the distributing apparatus.

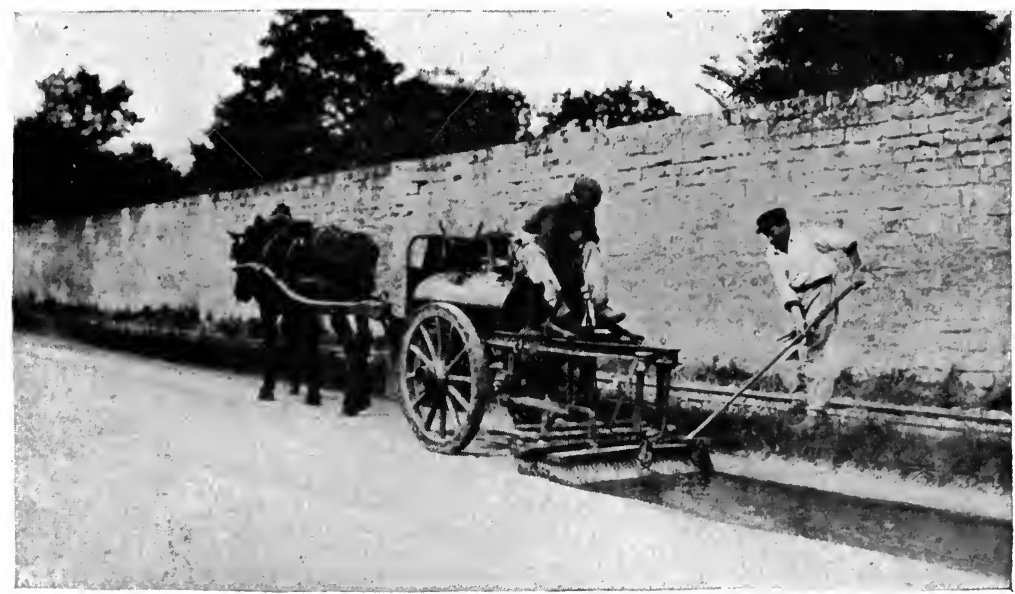

FIG. 86. Lassailly Gravity Distributor. (French Machine.)

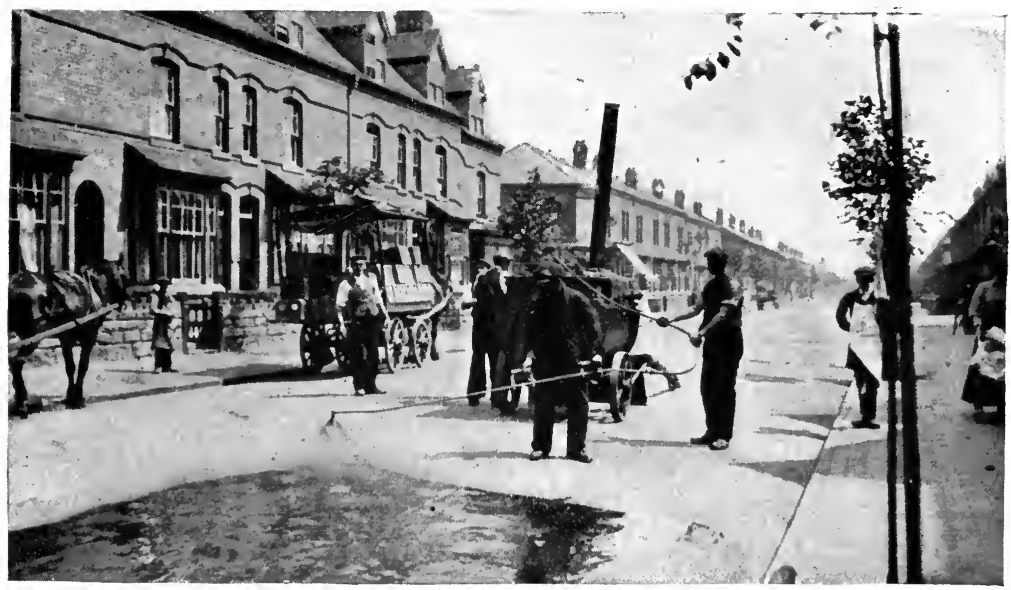

Fig. 87. English Hand-drawn Pressure Distributor.

Hand-Drawn Pressure Distributors. In the European machines, an example of which is shown in Fig. 87, the material is pumped from the tank through a length of flexible hose to 
the outlet end of which is fixed an iron pipe fitted with one or more nozzles. The nozzle is of such a form that the material is thrown in a fine cone-shaped spray. In one type of American machine, shown in Fig. 88, the heated material is pumped into the distributor and applied to the roadway surface by pressure from a tank of compressed air.

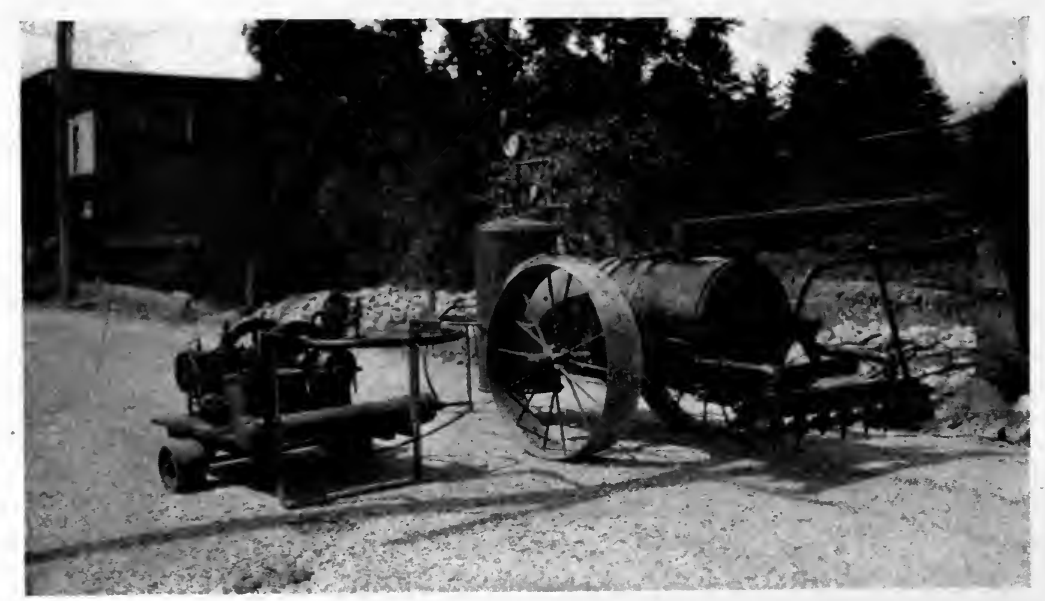

FIG. 88. "Cyclone" Pressure Distributor.

Pressure Tanks. These machines consist of steel tank wagons equipped with steam coils and with either a flexible hose with a nozzle attached or a system of pipes equipped with nozzles. The tanks are hauled by a steam roller which supplies steam for heating the material in the tank and furnishes the steam for the pressure. The bituminous material is forced out by the pressure of the steam between the material and the top of the tank. (See Fig. 89.)

Pressure Distributors Equipped with Mechanical Power Pumps. Several pressure machines of this type have been invented in the United States. The distributing devices of all of these machines are alike in having horizontal pipes fitted with nozzles. The machines differ somewhat in the way the pressure is obtained and applied. Pumps, run by a sprocket-drive attachment on the rear axle, see Fig. 90, by steam and by gasoline, 
are utilized. Horses and steam-rollers are used, for hauling. Some distributors are mounted on motor trucks. (See Fig. 9r.)

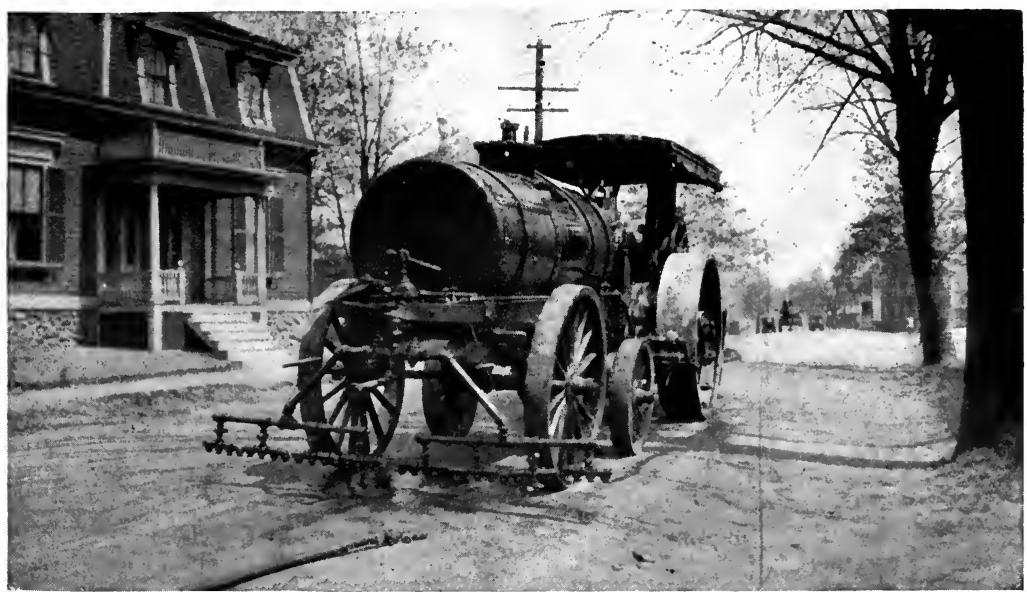

FIg. 89. Pillsbury Pressure Distributor. (American Machine.)

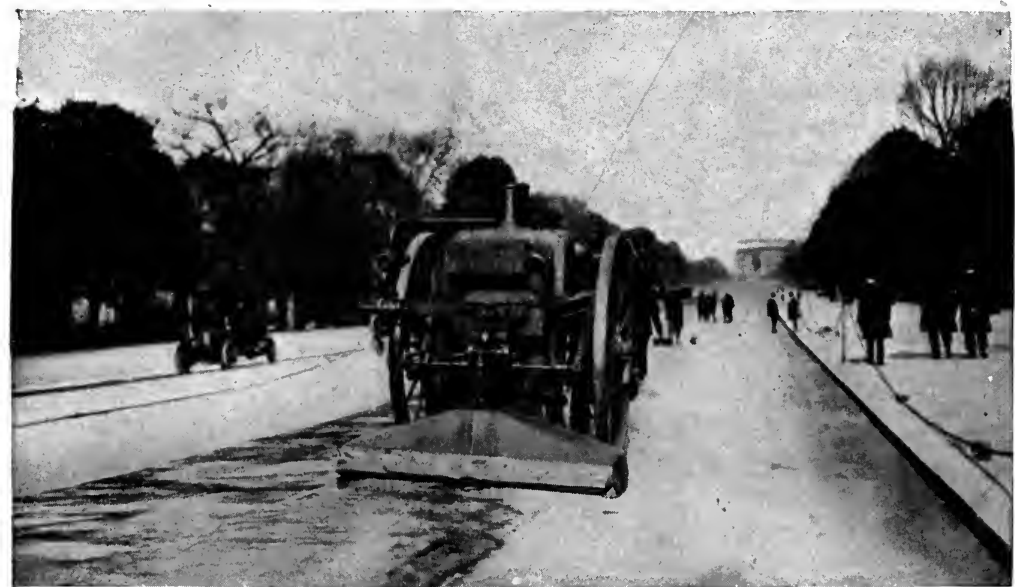

FIG. 90. Hedeline and Voisembert Pressure Distributor. (French Machine.)

Characteristics. Advantages. A properly constructed bituminous surface on a broken stone or gravel road is impervious and is easily cleaned. It increases the durability of the road, yields no dust due to abrasion of the roadway surface, 


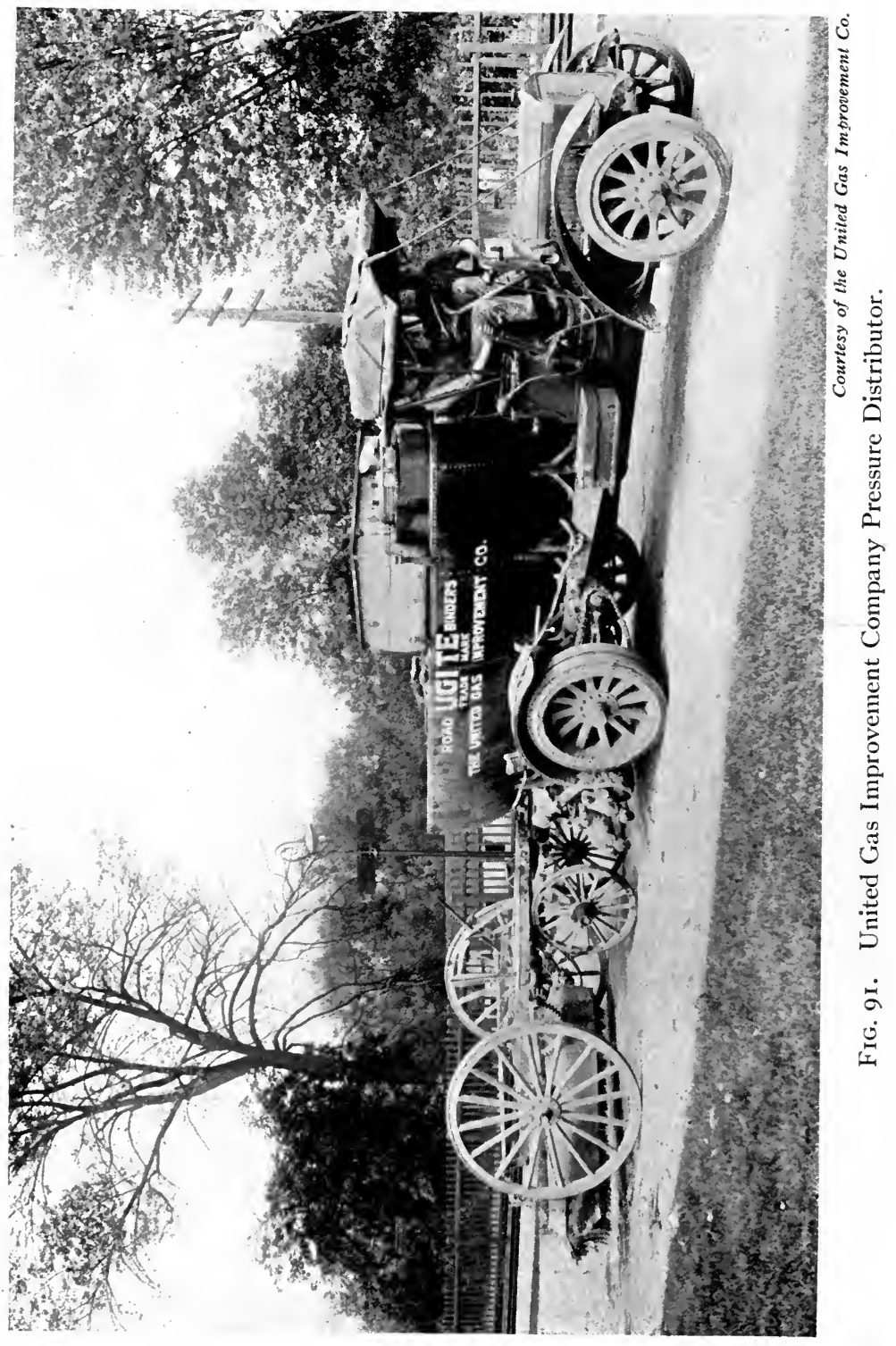


and enables the crown to be reduced. The ease of traction and the character of foothold will depend upon the kind and amount of the bituminous material used and the grade of the road. When asphaltic materials are used the noise caused by horse-drawn vehicles is comparable to that characteristic of wood-block pavements subjected to the same kind of traffic, while bituminous surfaces constructed with a thin coat of tar give forth much more noise, in some cases comparable to that emanating from the impact of horse-drawn vehicle traffic on sheet asphalt pavements. It is self-evident that the various types of bituminous surfaces are adaptable to many conditions, hence complete preliminary investigations are requisite before the kind of material and the details of the method of construction are adopted.

Disadvantages of Tar Surfaces. Slipperiness. Some objection has been raised in England to superficially tar-coated roads, due to alleged slipperiness. Without doubt much slipperiness is due to a smooth coat of tar, the ideal mosaic surface of tar and stones not being secured. Heavy traffic and late tarring contribute to greasiness of a road with consequent slipperiness, since tar applied late in the year and subjected to heavy traffic works up into an emulsion more readily than tar which was applied at the beginning of the season and has set hard by winter.

Danger to Fish Life. There is no danger of pollution of fish streams if proper precautions are taken during the treatment of a road and if refined tar is employed. It has been shown that if crude tars, having considerable ammoniacal liquor, are used in a manner which will permit of portions of the tar being washed into the stream, it will result in killing certain kinds of fish, trout being especially susceptible.

Injury to Vegetation. The opinion has been expressed by many that superficial tarring does not injure vegetation except from the possible prevention of the percolation of water through the road surface to the roots of trees. Although certain horticulturists in France have claimed that tarred dust injures vegetation, proof of this assertion has not as yet been presented. 
Disadvantages of Asphaltic Oils. Among the disadvantages of using asphaltic oil of certain types may be mentioned the ruining of carriage varnish, clothing, and floor coverings by the black greasy mud which is characteristic of roads treated with many asphaltic oils.

Failures of Bituminous Surfaces. The causes of failure of bituminous surfaces are numerous. They may be considered

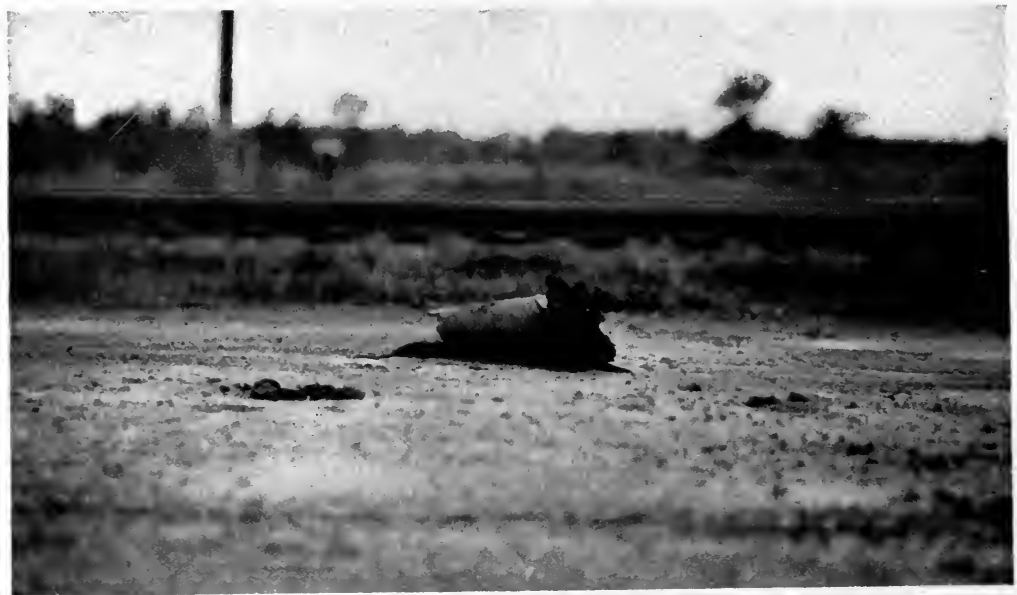

FIG. 92. Failure of Asphaltic Oil Mat Surface Due to Poor Adhesion Caused by Oil Being Applied to Damp Surface.

from the standpoint of the condition and character of the original surface, the material used, the method of construction, and local conditions.

Condition of Surface. The failure of bituminous surfaces from the standpoint of the character of the original surface is many times due to failure on the part of those in charge to place the surface in satisfactory condition before the application of the bituminous material. Many cases are noted where bituminous materials are applied over a surface in which are found many pot-holes and ruts, or which is dirty, due either to accumulated dust and dirt or to the original method of construction. In many cases a damp condition of the surface has resulted in failure. (See Fig. 92.) 
Bituminous Material. From the standpoint of the physical and chemical properties of the material, many instances may be cited in which failure is due to materials not having the proper characteristics for the conditions under which they are employed. The large percentage of volatile constituents contained in certain asphaltic oils has rendered surfaces constructed with them unsatisfactory because of the long period required

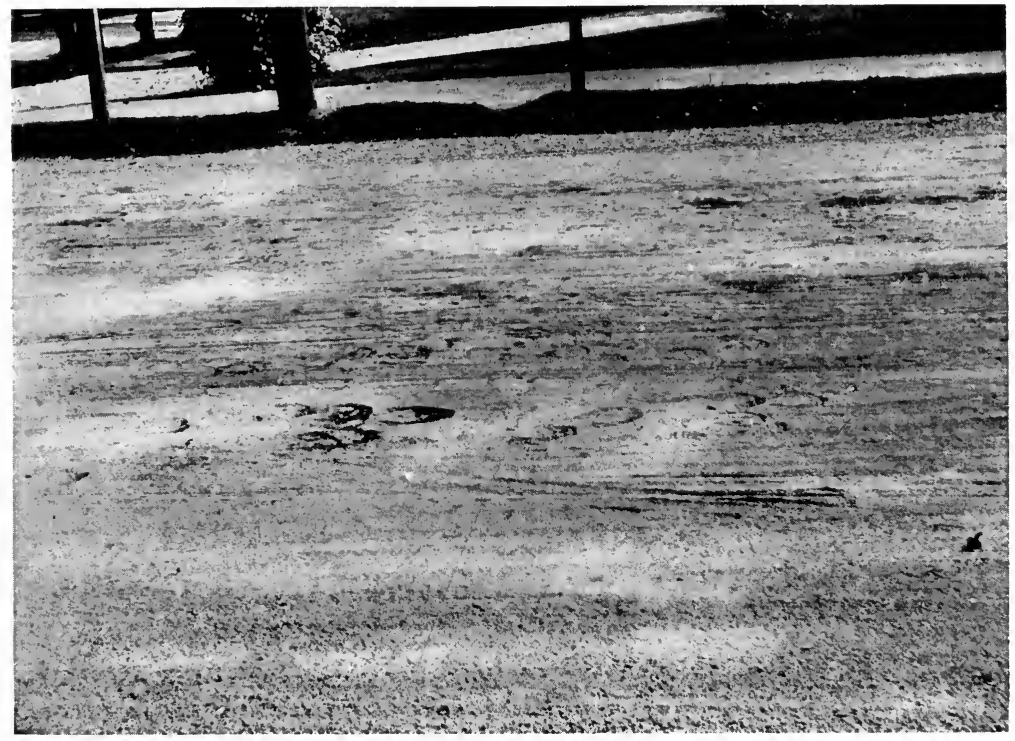

FIG. 93. Failure of Bituminous Surface Due to Using an Excess of Bituminous Material.

for these surfaces to "set up" so that the bituminous material will not track or the carpet thus formed will not creep and form waves and humps. In certain cases the use of light oils on tar or asphalt surfaces has softened the original bituminous surface to such an extent as to render the road or pavement unsatisfactory for use.

Construction Methods. From the standpoint of construction, failures are due both to the use of too small an amount of the bituminous material and to an excess of material. Fig. 93 shows the effect of using too much material. Improper application, 
resulting in uneven distribution, is accountable for many failures of bituminous surfaces, while in other cases a lack of sufficient covering of stone chips or material of a similar character has rendered the surface sticky and mushy.

Unsuitability. There are numerous instances where bituminous surfaces have been adopted under conditions which call

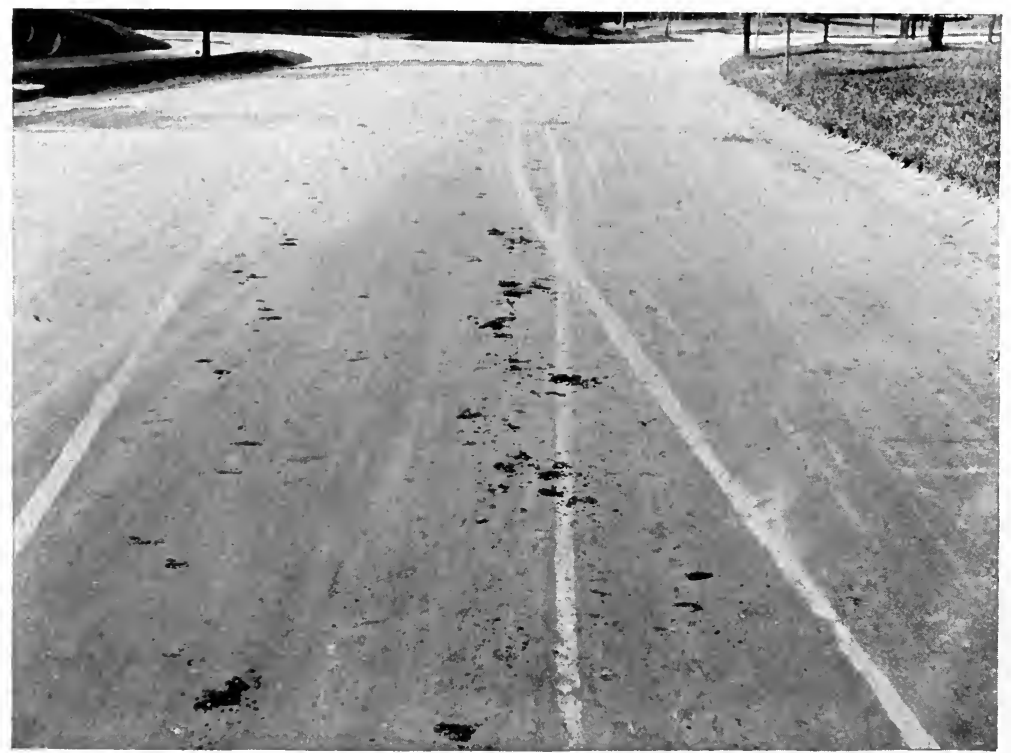

FIG. 94. Calk Holes in a Bituminous Mat Surface.

for the construction of bituminous concrete pavements or even some type of block pavements. A mat type of construction, which has been employed to a considerable extent, has proved inefficacious in cases where the amount of motor-car traffic was not sufficient to iron out satisfactorily the calk holes caused by the horse-drawn vehicle traffic. Fig. 94 shows the effect of the impact of horses' feet on some mat surfaces. 


\section{CHAPTER XI}

\section{BITUMINOUS MACADAM PAVEMENTS}

A bituminous macadam pavement is "one having a wearing course of macadam with the interstices filled by penetration methods with a bituminous binder."* "In connection with the interpretation of this definition it should be noted that the term macadam refers to "a road crust composed of stone or similar material broken into irregular angular fragments compacted together so as to be interlocked and mechanically bound to the utmost possible extent." *

DevelopmeNt. In I820 a bituminous macadam pavement, constructed with a tar cement, was laid in London. The penetration method of constructing bituminous pavements has been used extensively in the United States since I908 in building roads and residential streets, due to its low first cost and the rapidity with which it may be constructed with proper plant equipment and under favorable climatic conditions.

\section{Bituminous Materials}

The bituminous materials, used in the construction of bituminous pavements built by penetration methods, include asphalts, heavy asphaltic oils, refined water-gas tars, refined coal-gas tars, combinations of refined tars, and combinations of refined tars and asphalts.

\section{Construction}

SUBGRADE. The subgrade for bituminous macadam pavements should be prepared in accordance with the principles outlined in Chapter V.

Methods of Construction With Broken Stone. In the construction of bituminous macadam pavements it is desired

* Dec., I9I4 Proceedings, Am. Soc. C. E., pages 3011 to 3016. 
to secure, (I) a stable wearing course consisting of broken stone or similar material thoroughly rolled so that it will be well compacted and keyed together and with the several sizes of material, uniformly distributed, and (2) a uniform distribution and penetration of the bituminous material within the upper two or three inches of the crust. Several methods of construction have been devised with a view to meeting the above prerequisites. Due to lack of uniformity in the dehsity of the wearing course of broken stone and in the amount of bituminous material applied per square yard by the many methods employed, it is, however, obvious that uniform incorporation of the binder with the road metal is difficult to secure.

The pavement is generally built in two or three courses, the foundation course or courses being from 4 to 8 inches thick after rolling, and the top course from 2 to 3 inches after rolling. The foundation is usually composed of the product of a crusher which passes over a screen with $1 \mathrm{x} / 2$-inch circular holes and through a screen with $2 \frac{1}{2}$-inch circular holes, or over a $2 \frac{1}{2}$-inch and through a $3^{\mathrm{I}} / 2$-inch screen, or over and through screens having openings of similar dimensions. The foundation should be thoroughly compacted with a ro- to 15 -ton roller prior to the construction of the wearing course. The manner of finishing this course varies in the several methods, as will be noted later.

In the various methods of constructing the wearing course, the bituminous material is distributed by hand-pouring applications, gravity distributors and pressure distributors. (See Figs. 95 and 96 and also distributors described and illustrated in Chapter X.) It is evident that uniform application of the bituminous material will depend upon the method of distribution employed. To secure uniform distribution and to provide for such details as means of control of proper pressure and temperature and prevention of rutting of the wearing course during construction, the American Society of Municipal Imırovements prescribed in its I9I4 specifications the following requirements: "The pressure distributor employed shall be so designated and operated as to distribute the bituminous materials specified uniformly under a pressure of not less than twenty (20) pounds 


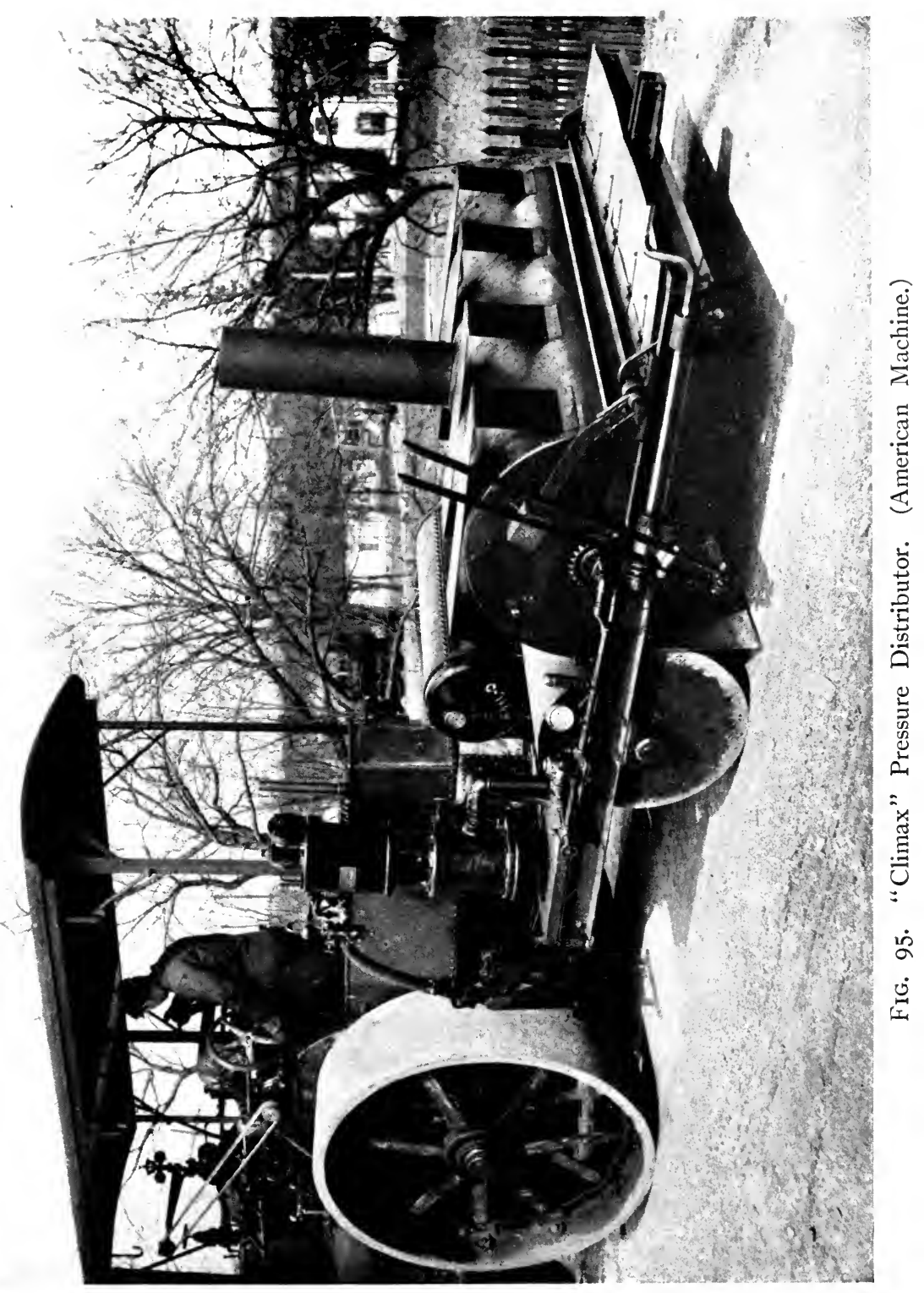


nor more than seventy-five (75) pounds per square inch in the amount and between the limits of temperature specified. It shall be supplied with an accurate stationary thermometer in the tank containing the bituminous material and with an accurate pressure gauge so located as to be easily observed by the Engineer while walking beside the distributor. It shall be so

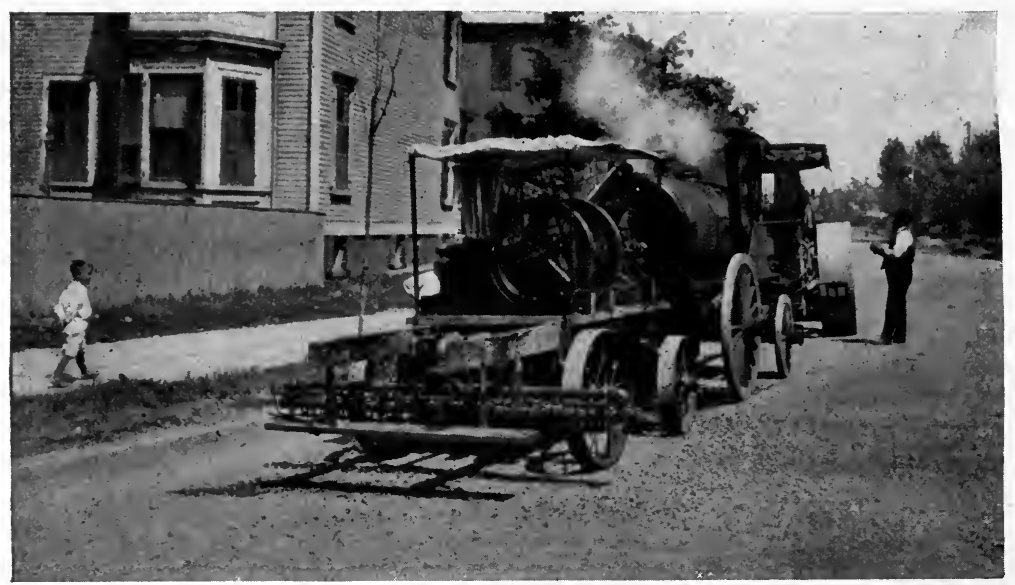

Frg. 96. Ward Pressure Distributor. (American Machine.)

operated that, at the termination of each run, the bituminous material will be at once shut off. It shall be so designed that the normal width of application shall be not less than six (6) feet and so that it will be possible on either side of the machine to apply widths of not more than two (2) feet. The distributor shall be provided with wheels having tires each of which shall not be less than eighteen (I8) inches in width, the allowed maximum pressure per square inch of tire being dependent upon the following relationship between the aforesaid pressure and the diameter of the wheel: For a two (2) foot diameter wheel, two hundred and fifty (250) pounds shall be the maximum pressure per linear inch of width of tire per wheel, an additional pressure of twenty (20) pounds per inch being allowed for each additional three (3) inches in diameter." 
The crown of bituminous macadam pavements should not exceed $1 / 2$ inch to the foot.

Method A. The wearing course, which is laid on the foundation course as described above, consists of crusher-run stone, ranging in size from $\mathrm{I} / 4$ to $\mathrm{I} / 2$ inch in longest dimensions. A typical mechanical analysis of this type of crusher-run stone follows:

\begin{tabular}{|c|c|c|c|c|c|}
\hline Passing & $1 / 4-$ & nch & screen & trace & \\
\hline “" & $1 / 2$ & & “ & I 8.9 & percent \\
\hline “" & $3 / 4$ & “ & “ & $43 . I$ & “" \\
\hline “" & I & “" & “ & 34.4 & “" \\
\hline “" & I $1 / 4$ & “ & “" & 3.6 & "“ \\
\hline
\end{tabular}

After the wearing course is laid the bituminous material is appliẹ, either before or after the broken stone is rolled, some favoring the former method because of the greater depth of penetration secured. The wearing course should, however, be thoroughly rolled prior to the application of the bituminous material in order to secure a well compacted and stable course of broken stone, mechanically interlocked and bound together. If the rolling is postponed until after the application of the bituminous material, the wheels of the roller may have to be wet or oiled to avoid picking up the surface. When the wearing course is rolled preceding the application of the bituminous material, a coat of mineral matter is spread over the surface and the course is again rolled. In certain cases this method is also followed where the upper course is not rolled preceding the application of the bituminous material. The necessity of a seal coat or a second application of a bituminous material is determined by the traffic conditions. The surface should be given a seal coat if it is to be subjected to a heavy combined horsedrawn vehicle and motor-car traffic. In order to render the surface more stable and less affected by changes in temperature, the material used for the seal coat, in some cases, has a lower penetration and a higher melting point than that used in the first application. Certain asphalts and combinations of asphalts and refined tars, semi-solid at normal temperature, have been used with success for this purpose. The total amount of 
bituminous material per square yard used in this method varies from 2 to 3 gallons.

Method B. In case the metalling of the upper course is a uniform product of about $\mathrm{I}$ or $\mathrm{I} / 2$ inches in size, it is deposited in a layer of the required thickness on the foundation course and lightly rolled. The voids are greater in this case than when

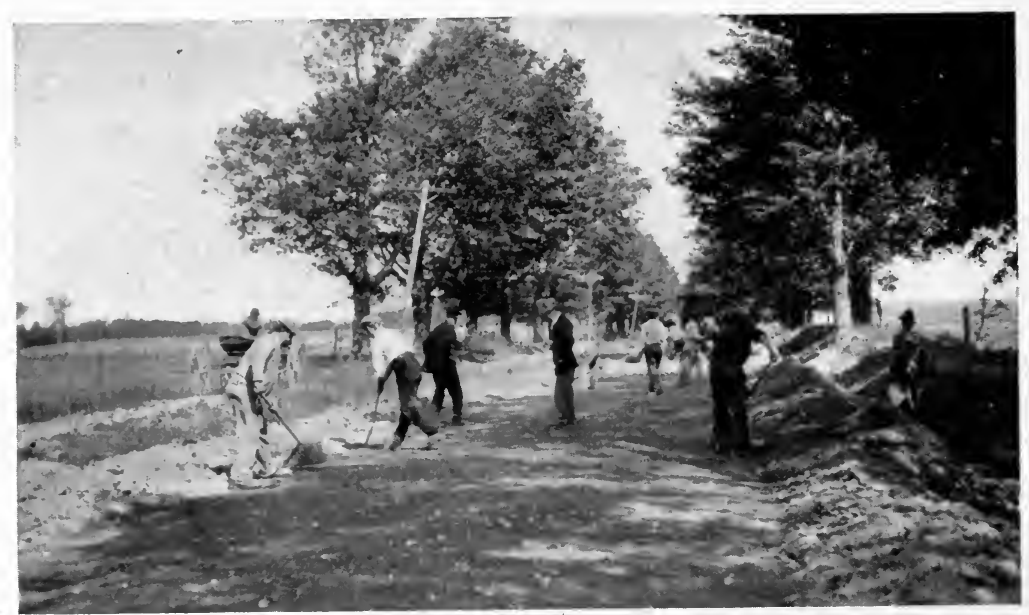

FIG. 97. Voids of Upper Part of Foundation Course Being Filled with Sand.

the wearing course of Method A is used, hence with Method B it is usually practicable to secure more penetration. The course is, however, not as stable as that of Method A. The bituminous material is then applied in an amount from $\mathrm{I} / 2$ to 2 gallons per square yard and $3 / 8$-inch stone chips are spread on the surface and thoroughly rolled. The surface is next broomed with stiff brooms, removing all excess chips, and another coat of bituminous material, from $1 / 2$ to I gallon per square yard, is applied, covered with a layer of stone chips, and rolled. This method is also used with metal of the upper course varying from $I \frac{I}{2}$ to $2 \frac{I}{2}$ inches, in which case $3 / 4$-inch stone is used in place of $3 / 8$-inch chips.

Method C. In this case the voids in the upper part of the foundation course are filled with sand or small sized broken 
stone. (See Fig. 97.) After rolling, the excess sand or broken stone is broomed off, and the upper course of metalling is spread and lightly rolled. Coarse sand, stone chips, or gravel is then spread and broomed until the voids of the metalling are filled to the surface. The bituminous material is then applied, using from $I$ to $I / 2$ gallons per square yard. This coat is covered with a layer of sand, gravel, or screened stone chips, and thoroughly rolled. 'This method is often used when the material composing the upper surface is of a large and uniform size. Sometimes a seal coat of from $1 / 2$ to I gallon of bituminous material is used with this method.

Method D. When the metalling of the top course is of a large and uniform size, another method employed is to place a layer of sand $3 / 4$-inch thick, on the bottom course, the voids of which have been filled. The bituminous material is then distributed on this.layer, using about I gallon per square yard. The upper course of metalling is immediately placed on the mastic and rolled. Continued rolling forces the material of the upper course down and draws the bituminous mastic up into the voids. A coat of bituminous material of a lower penetration, using about $\mathrm{I} 3 / 4$ gallons to the square yard, is then applied to the surface of the upper course. A layer of $3 / 8$-inch stone, $\mathrm{r} / 2$ to $3 / 4$ inch thick, is spread over this and rolled. The work may stop here or may be carried on a step further by brooming off the excess $3 / 8$-inch. stone, afterwards applying another coat of bituminous material, $1 / 2$ gallon per square yard, adding a layer of screened stone chips and rolling the same. This form of construction, when refined coal-gas tar is used, is known in this country as the "Modern Pavement." The Gladwell system, as used in England, is essentially the same in principle except that a course of screened stone chips mixed with bituminous material is substituted for the sand layer and its coat of bituminous material.

Method E. A bituminous macadam pavement called "Pitchmac" by its originator, J. A. Brodie, M. Inst. C. E., City Engineer of Liverpool, has been used in England. It is constructed on a foundation of stone. The wearing course of broken stone 
varies from 2 to $4 \frac{1}{2}$ inches in depth, dependent upon traffic conditions. If the wearing course is from 2 to 3 inches in thickness, it is constructed in one layer, and if from 4 to $4 \frac{\mathrm{I}}{2} \mathrm{2}$ inches, in two layers. The single layer and, in the case of two layers, the upper layer is composed of broken stone ranging in size from $\mathrm{I} / 4$ to $2 \frac{1}{2}$ inches. After thorough rolling the bituminous material is applied to the single layer or each of the layers of

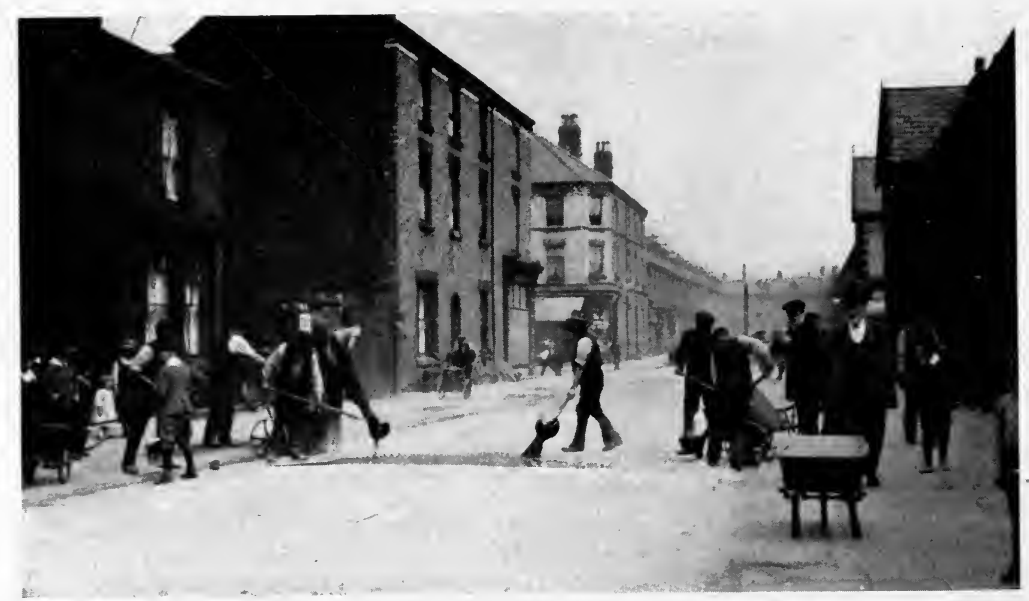

FIG. 98. Construction of "Pitchmac" Pavement in Liverpool.

the two-layer wearing course. (See Fig. 98.) The bituminous compound consists of hot sand mixed with a combination of coal-tar pitch, refined tar, creosote oil, rosin, and Portland cement. From I $1 / 4$ to 2 gallons per square yard are used for the one-layer wearing course and from $3 \frac{1}{4}$ to $3 \frac{1}{2}$ gallons for two layers. To assist in completely filling the voids, chips varying in size from $3 / 8$ to $3 / 4$ inch are applied during the rolling of the bituminous grouted layer.

Bituminous Gravel Pavements. The use of gravel in the construction of bituminous pavements by penetration methods has been usually limited to those localities where broken stone costs more than gravel. It is self-evident that it is impracticable to secure the same keying effect with gravel as can generally be obtained with broken stone. 
Cost Data. The cost of bituminous pavements, built by penetration methods, varies with the amount and kind of bituminous material and road metal used, and the method of construction employed. An average cost, using a total of 2 to $23 / 4$ gallons of bituminous material per square yard, varies from 25 to 40 cents per square yard in excess of the cost of water-bound broken stone roads, or from 70 cents to $\$ 1.25$ per square yard.

In the following table are given, for several localities throughout America, the average I9I4 prices of bituminous macadam pavements and foundations constructed with various total thicknesses of broken stone.

From Engineering and Contracting, April 7, I9I5

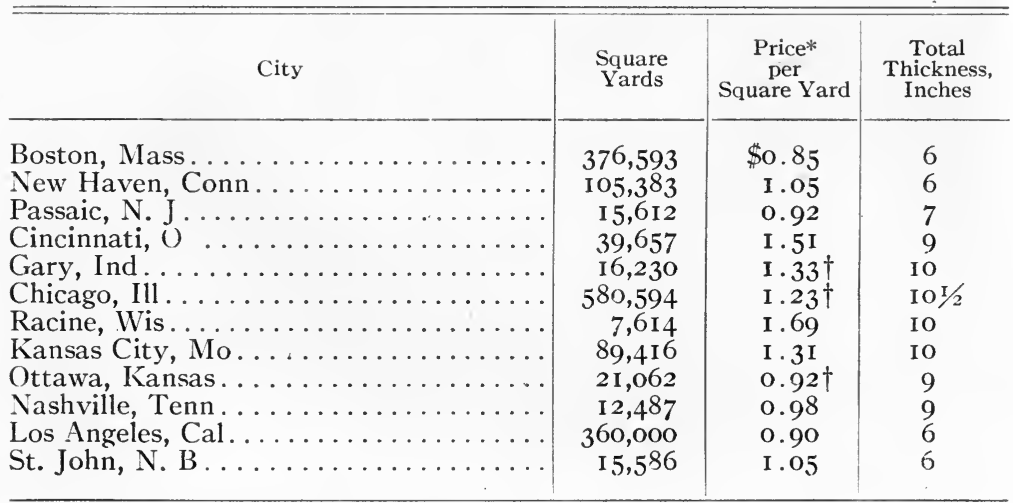

* Price covers pavement, foundation, and grading.

$\dagger$ Does not include grading.

\section{Maintenance}

The maintenance of many bituminous macadam pavements requires covering spots with sand, gravel, or stone chips, where either an uneven distribution or an uneven penetration has caused an excess of bituminous material to exude on the surface. Places which disintegrate should be cut out with perpendicular sides and refilled with either a mixed aggregate or by building the hole up with successive layers of road metal and bituminous material, the former method, however, giving the better results. Light oils and light tars should never be used for repairing 
holes, see Fig. 99, as the patches thus formed will not be stable and hence will soon be displaced by traffic. At varied intervals it is economical to renew the bituminous surface on the pavement by using from $1 / 4$ to $3 / 4$ gallon of the proper type of bituminous material per square yard. It will be found that

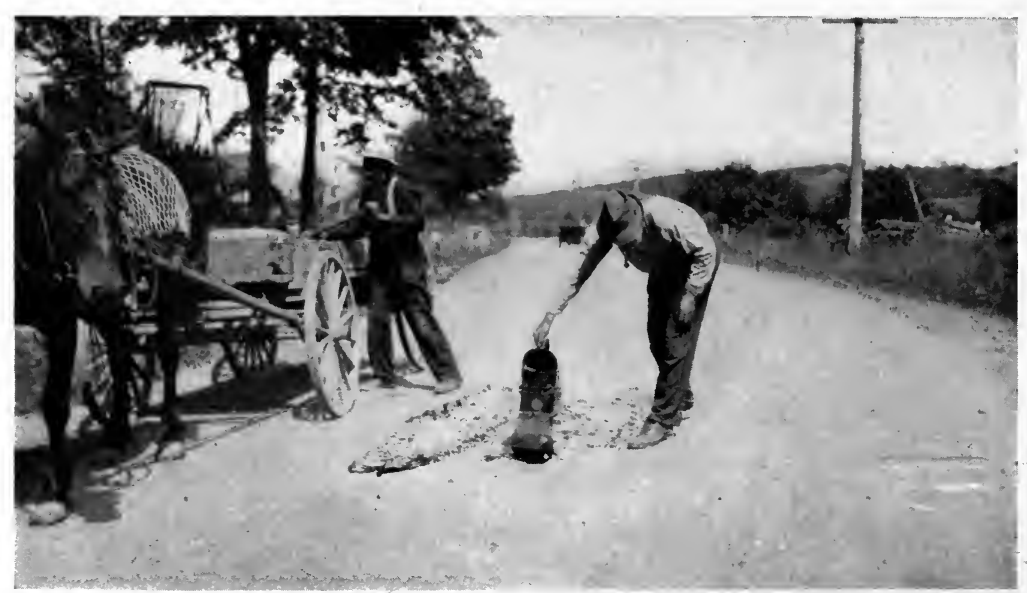

FIG. 99. Improper Method of Repairing Holes. Depressions Filled with Broken Stone and Light Oil.

the patrol system of maintenance will materially prolong the life of the pavement.

\section{Characteristics}

Advantages. The advantages incident to the construction of bituminous surfaces on broken stone and gravel roads enumerated in Chapter $\mathrm{X}$ are also characteristic of bituminous macadam and bituminous gravel pavements. It is advisable to emphasize that many bituminous pavements constructed by penetration methods possess the following advantages: suitability for horse-drawn as well as motor-car travel; freedom from dust when in exposed localities; low external and internal wear of road metal; low cost of cleaning, watering, and in many cases, of repairs; imperviousness and a certain degree of density of 
the wearing course; noiselessness and low traction with certain types of bituminous materials; very good sanitary qualities.

Disadvantages. Among the disadvantages attendant upon

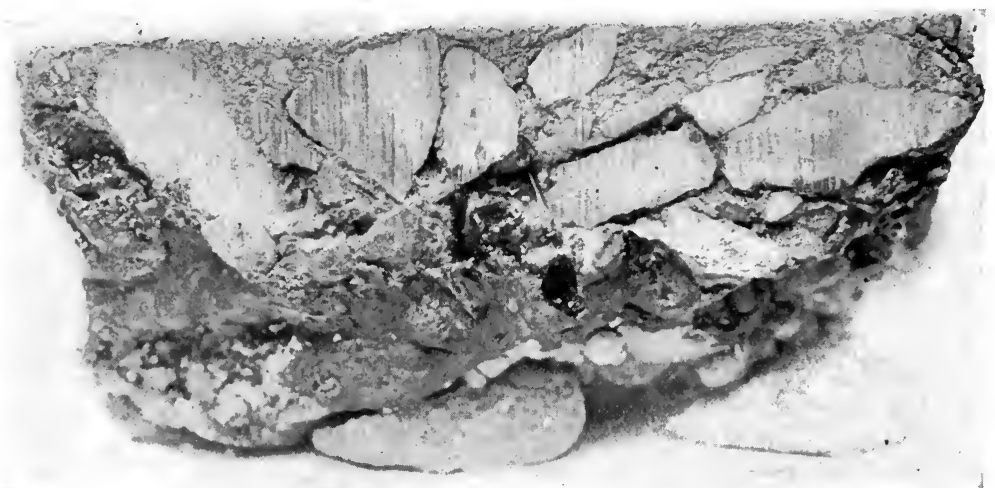

FIG. Ioo. Section Showing Uneven Penetration.

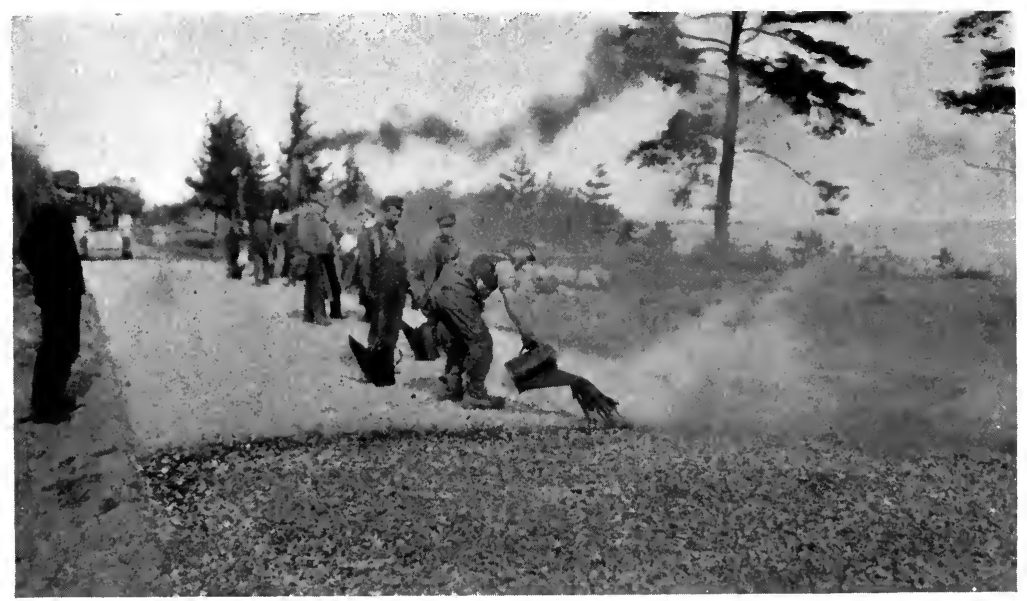

FIG. Ior. Example of Uneven Distribution of Bituminous Material.

the use of bituminous macadam and gravel pavements should be noted: increase in cost over bituminous surfaces on macadam and gravel roads; slipperiness when some bituminous binders are used on certain grades; dependence upon climatic condi- 
tions in order to carry on construction properly; variability in results and lack of uniformity in composition of wearing surface secured, due to uneven penetration, see Fig. roo; uneven distribution, see Figs. Ior and IO2, and segregation of road metal.

Causes of Failure. The causes of failure of bituminous macadam and bituminous gravel pavements may be considered under the following heads, bituminous material and methods of construction.

Bituminous Material. Unfortunately many are the instances where unsuitable bituminous materials have been employed. (See Fig. I03.) Many engineers having charge of bituminous work do not appreciate the fact that different types of bituminous materials have entirely different physical properties and require entirely different treatment in use, although they may have been purchased under one and the same specification covering chemical and physical properties. In some cases entirely unjustifiable combinations of materials are employed. For instance, in one case an asphalt of excellent characteristics was used for the first application, while for the second application an asphaltic oil having decidedly solvent and fluxing properties was employed. The result is shown in Fig. I04. Overheating of the material has likewise proved the cause of many failures, as the properties of the materials are sometimes changed and in many cases the materials are ruined.

Methods of Construction. Insufficient rolling has caused many failures. Others are due to the uneven distribution of the bituminous material in some cases when horse-drawn or power-driven distributors are employed. This type of failure, however, is more frequently due to the improper use of handpouring pots and hand-drawn distributors. Many unsatisfactory bituminous macadam pavements result from the use of the wrong sizes of broken stone. (See Fig. 105.) Failures due to the rapid formation of fine cracks caused by the rocking movement of the individual stones under traffic, finally resulting in ravelling and general disintegration, are of common occurrence. Segregation of sizes of stone preventing uniform penetration results in "lean" or weak spots in some cases and "fat" 


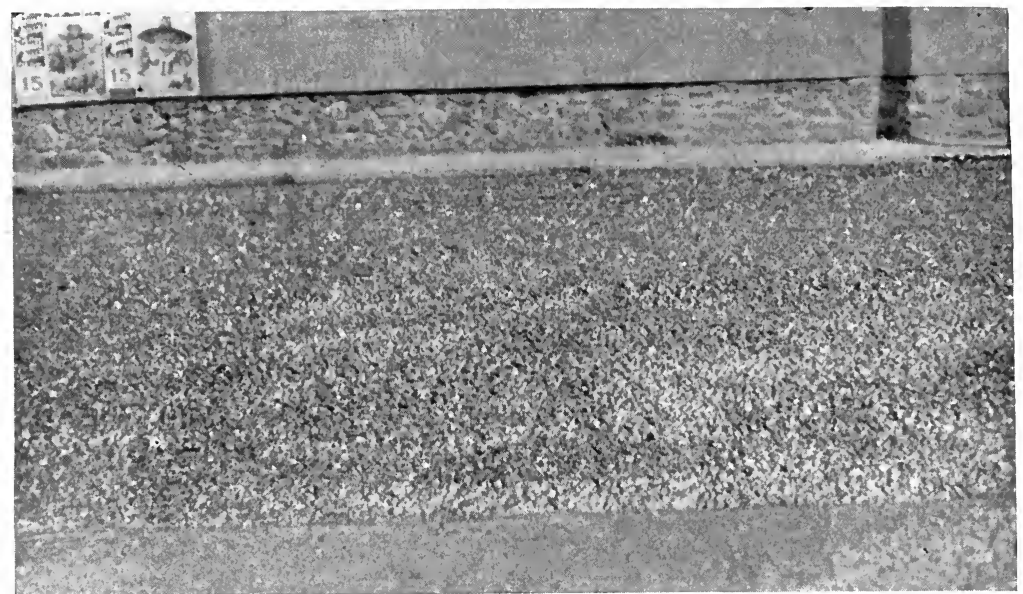

FIG. I02. An Illustration of Uneven Distribution of Bituminous Material.

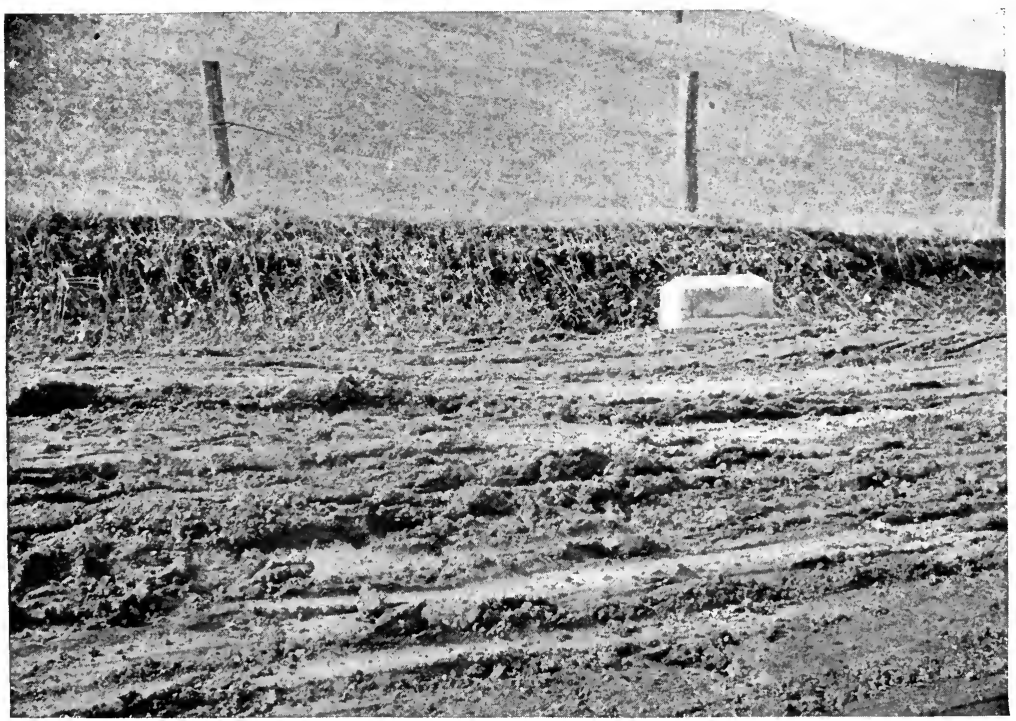

FIG. I03. Surface of Soft Broken Stone and Asphaltic Oil Subjected to Horse-drawn Vehicle Traffic. 
spots in others. In certain cases after a rain the construction has been carried on before the broken stone immediately below

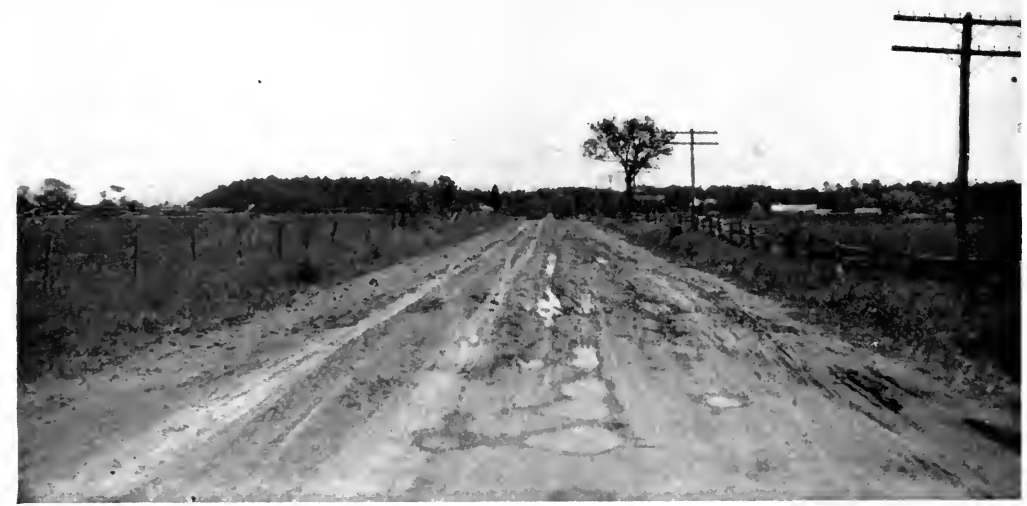

FIG. I04. Result of Using Improper Combination of Bituminous Materials.

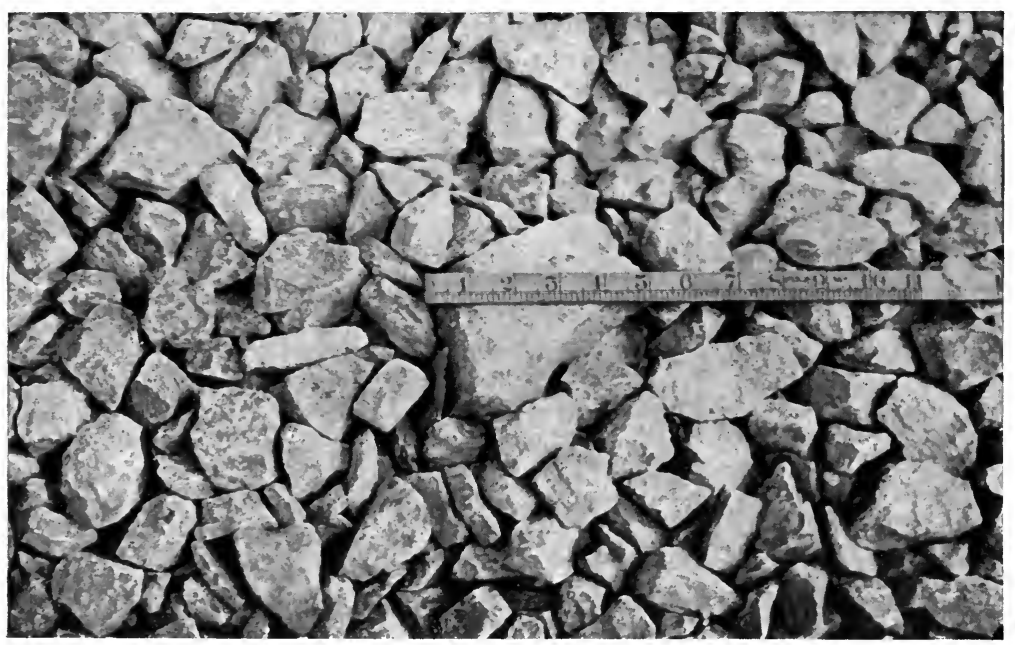

FIG. 105. Surface of Large Broken Stone Prior to Application of Bituminous Material.

the surface has dried out. Many of the causes attributed to the failures of bituminous surfaces may likewise apply to bituminous macadam and bituminous gravel pavements. 


\section{CHAPTER XII}

\section{BITUMINOUS CONCRETE PAVEMENTS}

"Bituminous concrete pavements are those having a wearing surface composed of stone, gravel, sand, shell, or slag, or combinations thereof, and bituminous materials incorporated together by mixing methods." *

Development. The first bituminous concrete pavement was probably constructed about I 840 in Nottingham, England, while in the United States the first construction of this type of pavement was at Knoxville, Tenn., in I866. From I870 to I 875 there were about 70,000 square yards of bituminous concrete pavements laid in Washington, D. C. From I888 to I893 many yards of coal-tar distillate pavements were laid in Washington because Congress had prohibited the use of sheet asphalt pavements in the District of Columbia. From I880 to I89I several sections of bituminous concrete pavements, using coaltar as the bituminous cement, were laid in Ontario, Canada. Another early bituminous concrete pavement was built in Concord, New Hampshire, and is still in use to-day. During the closing period of the nineteenth century attention was directed in England to the details of construction of bituminous concrete pavements for use on highways outside of built-up districts. In the United States at the opening of the twentieth century, Fred J. Warren urged the use of bituminous concrete as a pavement for streets in competition with sheet asphalt, wood block, and brick pavements. Based on experimental work during I906, 1907, and I908, Rhode Island in 1909 was the first State to adopt the bituminous concrete pavement as a standard type of construction for use on state highways. Since rgro there has been a rapidly growing appreciation of the inherent value of the many different types of bituminous concrete pavements for

*Dec., I9I4 Proceedings, Am. Soc. C. E., page 30I I. 
use on roads and streets. Instances of development in this field of construction will be cited later, in connection with each of the types of bituminous concrete pavements.

\section{Mineral Aggregates}

Bituminous concrete pavements differ principally in the character of the mineral aggregate and the kind of bituminous material of which the wearing course is composed. Leaving out of consideration sheet asphalt, bituminous concrete pavements

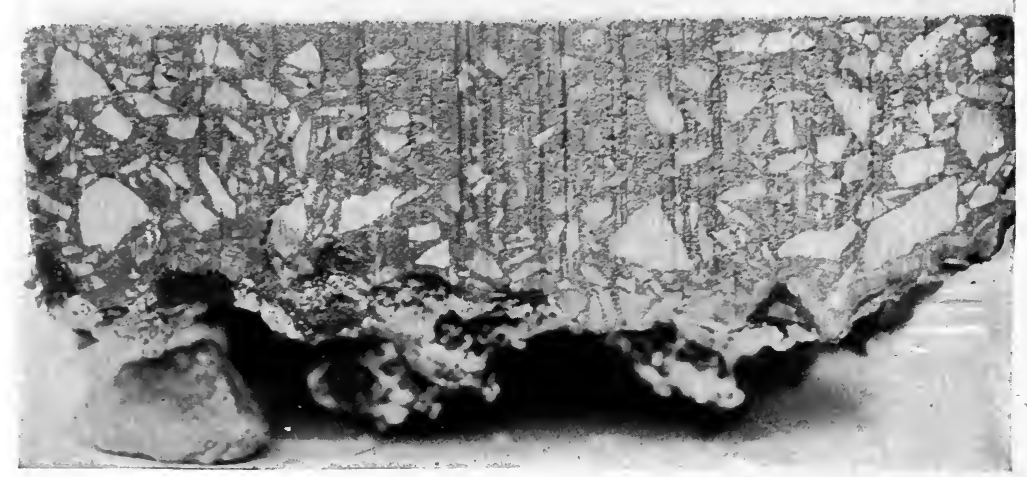

Courtesy of Wm. H. Connell.

FIg. I06. Cross-section Bituminous Concrete Pavement. Class I. B.

may be divided into the following classes and subdivisions based upon the character of the mineral aggregate employed.

Class I. Mineral aggregates composed of broken stone, either alone or in combination with sand.

A. Broken stone composing one product of a crushing plant.

B. Combinations of broken stone composing one product of a crushing plant and fine mineral matter, such as sand or stone screenings. (See Fig. I06.)

C. Mechanically graded aggregates of broken stone, either alone or combined with sand, with or without other mineral matter.

Class 2. Mineral aggregates composed of gravel or gravel and sand.

A. Run of the gravel bank. 
B. Combinations of screened sizes.

Class 3. Mineral aggregates composed of such materials as slag, shell, or cinders.

Class I. A. Pavements of this type have been constructed of one or more courses of bituminous coated metal with and without seal coats of bituminous materials. During the period from 1869 to 1875 many patents were granted by the United States Government covering bituminous concrete of this type.

Patent No. II4,I72, granted to F. E. Mathews in I87 I, contains the following description of a two-layer bituminous concrete pavement:

"When laid on an ordinary foundation the concrete should be laid in two layers or coats and should be from 6 to 8 inches thick when finished.

"For the first layer the stone used in making the concrete may be such as would pass through a screen having a 3 -inch mesh; about six measures of the stone should be mixed with one measure of the asphalt mixture and this layer should be about 4 inches thick.

"For the second layer or coat the stone should pass through a screen having a $\mathrm{I} / 2$-inch mesh, and be mixed with the asphalt mixture in the proportion of about four parts of the former to one part of the latter, and the second layer should be from 2 to 3 inches thick.

"Fine sand or any suitable fine hard substance may be sprinkled over the last coat just before or after rolling, to give the pavement a smooth compact surface."

Many descriptions of old pavements of this type may be found in technical literature. As an illustration may be cited the following specification used in England in the latter part of the nineteenth century: "The hot stone, when ready for mixing, is screened into material of three sizes, I to 2 inches for the body, $I / 2$ to $I$ inch for the intermediate coat, and $1 / 4$ to $1 / 2$ inch for the top dressing. The coarsest material is used in a layer 3 to 4 inches thick, the intermediate size forms a coat of about $3 / 4$ of an inch, and the top dressing is used in the thinnest layer possible, with a view to filling all interstices. Afterward a dressing 
of $1 / 4$-inch and smaller granite screenings is scattered broadcast, and the traffic at once allowed on the road to work this top dressing into the tarred material. Each of the layers is rolled separately with a Io-ton roller."

Naturally, Class I. A. has been very popular, due to its simplicity. Excellent pavements have been constructed by this

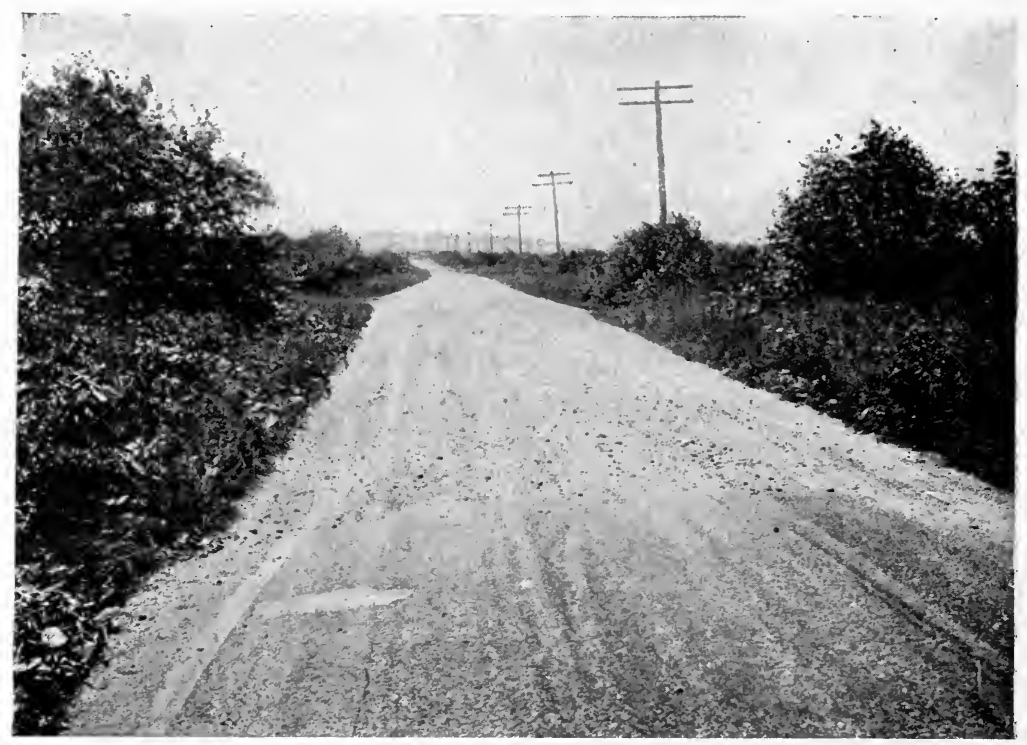

FIG. 107. Upper Part, Water-bound Broken Stone Road. Lower Part, Bituminous Concrete Pavement, Class I. A., without Seal Coat, Rhode Island State Highway.

method where the aggregate consisted of one product of a stonecrushing plant having the following characteristics based upon a mechanical analysis: all the stone passed a $1 / 1 / 4$-inch screen; not over 25 percent passed a $\mathrm{I} / 4$-inch screen and was retained on a $3 / 4$-inch screen; and not over 5 vercent passed a $1 / 8$-inch screen.

The State Board of Public Roads of Rhode Island has used Class I. A. since 1906. (See Fig. I07.) The road metal was furnished under the following specification: "The bottom course shall consist of stone from $\mathrm{I} / 4$ inches to $2 \frac{\mathrm{I}}{2}$ inches in. 
their longest dimensions, the upper course of stone from $1 / 2$ to I $/ 4$ inches in their longest dimensions." The product of the crusher which met this specification for the stone of the wearing surface was obtained from the ordinary type of crushing plant, the broken stone usually passing over a $3 / 4$ - to $1 / 2$-inch screen and through a $\mathrm{I} / 2$-inch screen. A mechanical analysis of a typical product used in Rhode Island is given below.

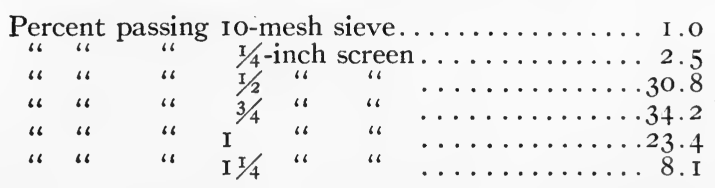

Class I. B. This type, that is, one having an aggregate which is a combination of broken stone composing one product of a stone-crushing plant mixed with fine material, such as sand, screenings, or material of a similar character, has been described many times in early technical literature. For example, the following description was published over thirty years ago: "The manner of preparing, treating, and laying the asphalt mass is as follows: He took asphalt, one hundred and twentyfive parts; petroleum-oil, twenty-five parts. These substances were melted and thoroughly incorporated together, and to this mixture he added, in a heated state, sand or powdered stone, $75^{\circ}$ parts, and gravel or broken stone, also heated, I,IO0 parts. The whole was then thoroughly mixed."

Pavements of this type have been used by many engineers. In Washington, D. C., bituminous concrete pavements have been constructed in accordance with the following specifications covering the mineral aggregate: "The paving material shall be composed of crushed trap rock screenings, concrete sand, and mineral dust in the following proportions: Trap rock screenings, two parts; concrete sand, one part, and mineral dust, at least 5 percent of the above aggregate; mixed with asphaltic cement." The trap rock screenings referred to above varied in size from I inch to screenings and were devoid of dust. Detailed specifications were given also with reference to the character of the sand and the mineral dust. 
Class I. C. Specifications for pavements of this type call for mechanically graded aggregates of broken stone, either alone or combined with sand, with or without other mineral matter. From a historical standpoint reference is made to the description of the "Excelsior Pavement," as it includes the characteristic features of this class, namely, that "several sizes are mixed to form a close mass without cavities." This description is made up of pertinent abstracts from a book entitled "The Excelsior Pavement," the advertisement of which is dated $187 \mathrm{I}$.

"The Excelsior Pavement consists of a broken stone, or McAdam base, covered with a concrete surface, which being close, smooth, and coherent, presents but little resistance to travel, and permits no movement among the stones that compose it; therefore, scarcely any dust or mud is formed; its superiority over others is manifest.

"The resisting material may be sand for the surface, gravel or broken stone mixed with sand for the middle, and larger stone for the bottom, or bed; broken stone alone is preferred, sizes being chosen which best form a compact structure, smooth on top, and strong throughout. Small fragments are not generally required. Several sizes are mixed to form a close mass without cavities, the coarser stone being put beneath. This material should be carefully selected for its strength and resistance, and contain no dirt or other foreign matter.

"The sand, gravel, or broken stone (of different degrees of coarseness, as laid at or below the surface) should be sharp, clean, and hard; the cement should be uniform, fluid and adherent during mixture; and the compound should condense and harden rapidly under manipulation; being composed of the greatest amount of rock, and the least of cement, which will form a mass most resembling stone itself."

In 1907 the author discovered a printed specification in the Library of the American Society of Civil Engineers entitled "Specifications for the Excelsior Pavement." The following excerpt covers the description of the mineral aggregate:

"Broken stones are preferred for the whole pavement, and shall alone be used for the covering. The greatest dimension of 
stones for the base (except as hereinafter noted) shall be between 3 inches and $1 / 4$ inch, and for the covering between 2 inches and $/ 20$ of an inch; the sizes shall be mixed in proportion, varying with the size to form a close mass, which, when dry and compact, can absorb not more than 20 percent of water."

It is evident that the definition of bituminous concrete pavements of Class I. C. covers many different combinations of sizes of road-metal used for the mineral aggregate of the wearing surface. Some of the combinations in use will be described.

Specifications, Topeka. Since I9I I many thousands of yards of pavement of Class I. C. have been laid under the so-called "Topeka" specifications. A decree was signed in I9ro by certain city officials and representatives of the Warren Brothers Company covering the use of the "Topeka" mineral aggregate. The following quotation is from the decree to which reference has been made: "It appearing to the court that of the mineral matter used in the pavements actually constructed in the cities of Topeka and Emporia, Kansas, no particles of stone were used that would not pass a screen with openings $1 / 2$ inch in diameter, and that less than Io per cent of the stone or coarse sand used would be retained upon a screen with openings $1 / 4$ inch in diameter, and the remaining mineral matter used being finer than $\mathrm{I} / 4 \mathrm{inch}$; and it further appearing that pavements constructed by the use of mineral particles as above described do not infringe the claims of complainant's patent No. 727,505, sued upon in this case; ... And it further appearing that the pavements as actually constructed in the cities of Topeka and Emporia, Kansas, do not infringe the claims of complainant's patent No. 727,505 , sued upon in this case, and that any pavements hereafter constructed in substantial compliance with the following formula, to wit:

"Bitumen, from 7 percent to II percent.

Mineral aggregate, passing 200-mesh screen, from 5 percent to i I percent.

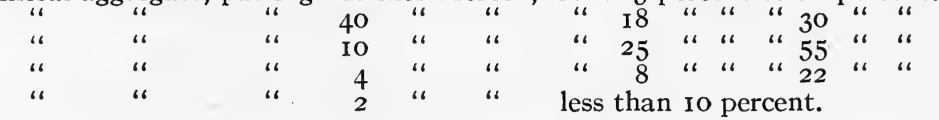


Sieves to be used in the order named would not infringe the claims of said patent."

Specifications, Asphalt Block. For many years a bituminous concrete having the essential features of the "Topeka" grading has been used in the form of asphalt blocks. The following specifications were adopted in I9I I by the Association for Standardizing Paving Specifications:

"The size of the block shall be I2 inches long, 5 wide and 3 deep. Blocks exceeding the following limits of permissible variation from the above measurements will be rejected: Length from II $7 / 8$ to I $21 / 8$ inches, width from $4^{15 / 16}$ to $5 / 16$ inches, depth from $2^{15 / 16}$ to $3^{1 / 16}$ inches. The blocks shall be composed of asphalt cement, filler, and crushed trap rock or hard limestone.

"The filler shall be thoroughly dry limestone dust or Portland cement, the whole of which shall pass a 30-mesh per linear inch sieve, 85 percent shall pass a Ioo-mesh per linear inch sieve, and at least 66 percent shall pass a 200-mesh per linear inch sieve. Not less than 7 percent of this filler shall be used in the mixture from which the blocks are made. The crushed rock used shall be of good quality of freshly crushed hard trap rock or hard limestone free from all weathered and other soft material. It must be clean and free from any adhering dust, clay, or other foreign matter.

"The asphalt cement, dust, and rock shall be thoroughly mixed while hot in such proportions as to give a block containing not more than 8.5 percent or less than 5.5 percent of bitumen soluble in carbon disulphide, and at least I2 percent of mineral matter passing a 200-mesh sieve."

Specifications, Bitulithic. Since the beginning of the twentieth century a large amount of a proprietary pavement known as "Bitulithic" has been laid in the United States. As described by Fred J. Warren, the wearing surface, which usually has a thickness of about 2 inches after compression, is constructed as follows: "The mineral or stone part is dried and heated in a modern dryer and is then separated by screening with a rotary screen into its sizes, varying from fine dust, which is less than I/ 200 of an inch in diameter, to the largest size used. The several 
sizes of stone are then mixed in predetermined "proportions, so as to reduce the voids to about ro percent, in a modern 'twin pug' steam power mixer, and the hot bituminous cement is added in the mixer in sufficient quantity to not only coat every particle and fill all of the remaining voids but with enough surplus to furnish to the mixture after compression a rubbery and slightly flexible condition."

Specifications proposed by the Warren Brothers Company covering the aggregate are cited.

"Mineral Aggregate. Upon the roughened surface of the concrete prepared as above specified there shall be laid the following wearing surface composed of hard, crushed stone, sand, and bituminous cement to have the thickness when compressed of 2 inches.

"In preparing the mineral aggregate for the above wearing surface the following method and apparatus shall be used: The maximum size stone should be about one-half the thickness of the wearing surface. The several grades and sizes of mineral aggregate shall be accurately measured in proportions previously determined by laboratory tests to give the best results, that is, the most dense mixture of mineral aggregate and one having inherent stability, heated in a rotary mechanical heater, so designed as to keep each batch by itself until heated, and then pass into a rotary mixer; or the varying sizes of stone approximately proportioned shall be fed into an elevator terminating and discharging into a rotary dryer, and after heating, the stone shall be elevated and passed through a rotary screen having sections with various sized openings. The minimum screen opening shall be $\mathrm{I} /$ ro inch and the maximum shall not be greater than $I / 2$ inch. The difference in the width of openings in successive sections shall not exceed $1 / 4$ inch in sections having openings smaller than $1 / 2$ inch and shall not exceed $1 / 2$ inch in sections having openings greater than $1 / 2$ inch. The several sizes of stone thus separated by the screen sections shall pass into a bin containing sections or compartments corresponding to the screen sections. From these compartments the stone shall be drawn into a weigh box, resting on a multi-beam scale. 
The several sizes of mineral aggregate, after being separately weighed or measured as above, shall be dropped into a 'twin pug' or other approved form of mixer. In the mixer bitulithic cement shall be added in sufficient quantity to coat all particles and fill such voids as remain unfilled by the proportionment of the mineral aggregate. The aggregate shall be so proportioned as to secure in the aggregate inherent stability, density, freedom from voids, and resistance to displacement, and a mixture which when combined with the bitulithic cement and compacted together will form a bituminous street pavement structure containing mixed mineral ingredients of such grades as to give the structure inherent stability, and one in which the largest and smallest pieces are associated with each other indiscriminately throughout the structure, and in which the plastic bituminous composition permeates the entire mass, uniting the various sized particles thereof; filling the voids and forming the wearing surface. If the crushed stone does not contain enough finely divided particles to fill the small voids in the aggregate the deficiency of these finely divided particles shall be made up by the addition of sand or other suitable fine mineral matter."

Class 2. Mineral aggregates of this type are composed of gravel, either run of the bank or graded mixtures of gravel and sand. Unless finished with an adequate seal coat, the fine gravel of the surface is liable to be dislodged if the traffic includes horse-drawn vehicles. It is also evident that the interlocking of broken stone upon which the stability of many types of pavements depends is a desideratum which is very difficult to obtain with a gravel aggregate.

Class 3. A mineral aggregate of slag has been used to a considerable extent in England since I900. Although laid by various municipalities, the largest amount has been used in connection with the construction of "Tarmac." One of the "Tarmac" plants is located at Wolverhampton, adjacent to that of a company producing large quantities of blast-furnace slag. The large molds of slag are transported by small cars from the iron works on a narrow gauge track and dumped near the "Tarmac" works and allowed to cool. These large blocks are 
broken by sledge-hammers to a size suitable for the crusher, to which point the broken slag is taken by an inclined railway. It is crushed and screened into sizes varying from $I / 4$ to $2 \frac{1}{2}$ inches and dropped into bins and thence into a mixing machine, where it is mixed with a tar compound. Since the slag is warm even after it has been crushed, no heating preliminary to mixing is necessary.

A large amount of "Tarmac" has been used in the County of Nottingham. None of the roads are painted when constructed. They present an excellent non-slippery mosaic surface. The maximum grade on which this material has been used in this locality is $\mathrm{I}$ in 30 . The pavements are built in two courses of a total thickness of $4 \frac{1}{2}$ inches and with a standard crown of $1 / 4$ inch to the foot. The lower course is $23 / 4$ inches in thickness, composed of pieces of slags, ranging from $\mathrm{I} / 4$ to $2 \mathrm{I} / 2$ inches in size, and the upper course is $\mathrm{I} / 4$ inches in thickness, composed of pieces of slag ranging from $1 / 2$ to $I \frac{1}{4}$ inches in size. The cost complete averages about 85 cents per square yard.

In certain cases more than two layers of bituminous coated slag are employed. The construction of one pavement of this type will be described. The location of the road was the main shore boulevard at Brighton-on-Sea on the south coast of England. The details of construction follow: On a well-compacted gravel foundation was spread a scattering of bituminous coated chips; the bottom layer, composed of $3 \frac{1}{2}$ inches loose of $1 / 2$ to $2 \mathrm{I} / 2$-inch bituminous coated slag, was rolled; the second course consisted of $2 \frac{1}{2}$ inches loose of $1 / 2$ - to $1 / 4$-inch bituminous coated slag, which course was thoroughly compacted; the third course was composed of $1 / 2$-inch of $1 / 4-$ to $1 / 2$-inch bituminous coated slag chips, which layer was thoroughly rolled; the pavement was finished by rolling a top dressing of uncoated slag screenings.

\section{Bituminous Materials}

Bituminous Cements. The bituminous materials used in the construction of bituminous concrete pavements are asphalts, 
refined water-gas tars, refined coal tars, combinations of tars, and combinations of tars and asphalts.

Bitumen Content in Wearing Course Mixtures. In specifications and records of work the bitumen content is expressed in one of two ways: first, as the number of gallons per square yard or cubic yard of mineral aggregate; and, second, as a certain percentage by weight of the wearing course mixture. It is apparent that the volumetric amount of bituminous cement used by the second method materially depends upon the specific gravities of both the mineral aggregate and the bituminous cement. The problem thus presented to the engineer during construction and to the chemist in reporting upon an analysis of a wearing course mixture has been considered by Prevost Hubbard, and is briefly discussed in the following abstracts of a paper by him.*

"An engineer who superintends the construction of a bituminous road or pavement can, of course, state the volume proportions of the constituents which he uses in a given mix, but if the bituminous material contains considerable mineral matter, or organic matter not bitumen, he encounters a serious difficulty in stating the actual proportions of aggregate and bitumen. On the other hand, the chemist who examines a mix can state the weight proportions of aggregate and bitumen, but will often be unable to determine the exact volume proportions in cubic yards and gallons used, owing to considerable variations in the volume of a unit weight of aggregate in different stages of compaction. If the bituminous material originally used contains an unknown amount of mineral matter or organic matter not bitumen, he may also be unable to determine accurately the proportions (either by weight or by volume) of the original constituents which entered into the mix.

"While the subject would seem to be in a more or less chaotic condition in so far as extreme accuracy is concerned, it appears to the author that a much more rational basis of comparison is possible than that ordinarily used. He would, therefore, sug-

* "The Bitumen Content of Coarse Bituminous Aggregates," Proceedings, VI Congress International Association for Testing Materials. 
gest that in the examination of a prepared bituminous mix the chemist always report the specific gravity of both aggregate and pure extracted bitumen in addition to the usual results. If this suggestion is followed it is believed that an intelligent comparison of different bituminous mixes can be made with little difficulty.

"For example, we may consider a case where wide variations exist in the specific gravity of both aggregate and bituminous material for two different mixes. For a basis of comparison it may be assumed that the two aggregates are found to be practically identical in so far as grading is concerned, and that the percentage by weight and the consistency of the bitumens are the same. According to the ordinary interpretation of results these mixtures would be equivalents. If, however, it is found that the first mix is composed of an aggregate with a specific gravity of 2.50 while the extracted bitumen shows a specific gravity of I.I 7 , and that the aggregate of the second mix has a specific gravity of 3.50 while the extracted bitumen shows a specific gravity of 0.960 , the percentage of each constituent divided by its specific gravity would then give a rational volume proportion, as follows:

\begin{tabular}{|c|c|c|c|c|c|}
\hline Constituents & $\begin{array}{l}\text { Percent } \\
\text { by Wt. }\end{array}$ & $\begin{array}{l}\text { Specific } \\
\text { Gravity }\end{array}$ & $\begin{array}{l}\% \text { Wt. } \\
\text { Sp. Gr. }\end{array}$ & $=\begin{array}{c}\text { Rational } \\
\text { Proportion }\end{array}$ & $\begin{array}{l}\text { Rational } \\
\text { Percent }\end{array}$ \\
\hline $\begin{array}{l}\text { First mix: } \\
\quad \text { Aggregate.... }\end{array}$ & 94 & $2 \cdot 5^{0}$ & $\frac{94}{2.50}$ & $=37.6$ & 88.0 \\
\hline Extracted bitumen & $\frac{6}{100}$ & I. I 7 & $\frac{6}{1.17}$ & $5 . I$ & I 2.0 \\
\hline $\begin{array}{l}\text { Second mix: } \\
\text { Aggregate.... }\end{array}$ & 94 & $3 \cdot 5^{\circ}$ & $\frac{94}{3 \cdot 50}$ & $=26.9$ & 81.0 \\
\hline Extracted bitumen & $\frac{6}{100}$ & 0.96 & $\frac{6}{0.96}$ & 6.3 & 19.0 \\
\hline
\end{tabular}

"By the determination of what has been termed the rational percent, it is evident that the first mix has a bitumen equivalent of about two-thirds that of the second mix, although the percentages by weight are the same. The rational variation, 7 percent, is certainly sufficient to mean the difference between success and failure for certain bituminous aggregates. 
"In conclusion, it may be stated that the rational percent of bitumen will not only serve as an improved means of comparing different bituminous aggregates which are examined, but may be used to advantage in calculating in advance the proper proportions for a mix if the properties of the constituents of the mix are previously determined."

\section{Construction}

Subgrade and Foundation. The subgrade for all types of bituminous concrete pavements should be prepared in ac-

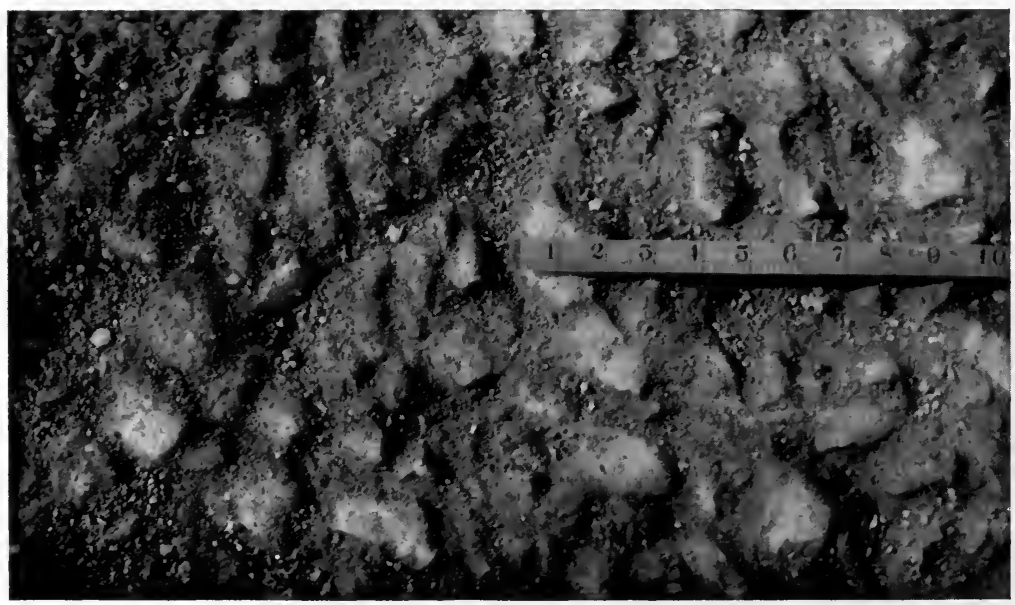

FIG. I08. Surface of Filled Broken Stone Foundation for Wearing Course of Bituminous Concrete, Class I. A., Ashokan Highway, Board of Water Supply of the City of New York.

cordance with the principles outlined in Chapter V. Satisfactory results have been secured under certain traffic and other local conditions by using a broken stone foundation course varying from 4 to 8 inches in depth for bituminous concrete pavements of Classes I. A. and I. B. (See Fig. 108.) Commercial traffic will require a cement-concrete foundation course for these classes. Where Class I. C. can be economically employed, the cement-concrete foundation will be required. Large sums have 
been wasted by laying this type of bituminous concrete pavement on inadequate foundations. Bituminous concrete pavements of Classes 2. B., 2. C., and 3. are usually laid upon foundation courses composed of the same kind of road metal as forms the mineral aggregate. The details of the construction of foundation courses of various types have been explained in Chapter V.

Wearing Course. The details of the manufacture and laying of the wearing course will depend to a certain extent upon the type of bituminous concrete pavement employed and the kind of bituminous cement used. There are, however, certain fundamental methods which are common to all classes of construction.

The mineral aggregate, consisting of one or more grades of broken stone, sand, or similar materials or combinations thereof,

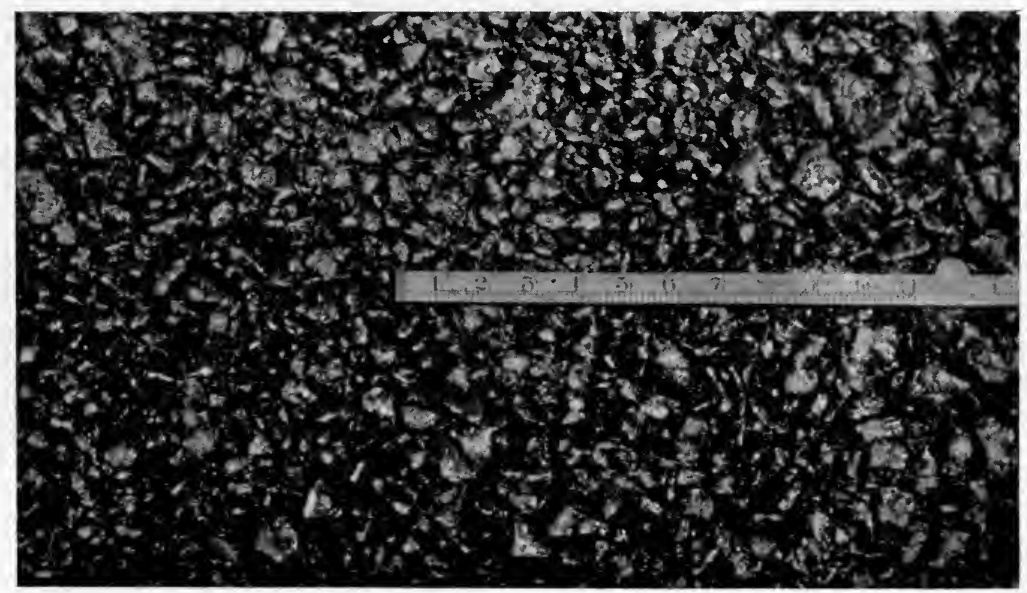

FIG. I09. Surface of Compacted Wearing Course of Bituminous Concrete, Class I. A., Ashokan Highway, Board of Water Supply of the City of New York.

is carefully weighed or its volume determined and mixed with a given weight or volume of bituminous cement in a type of mixer suitable for the particular class of aggregate and kind of bituminous cement employed. In the best methods of construction, the mineral aggregate is heated prior to placing it in the 
mixer. The aggregate is heated to a temperature which will dry it and allow the component particles to be readily coated with the hot bituminous cement. The amount of bitumen employed varies from 5 to 8 percent for bituminous concrete pavements having aggregates composed of one product of a stone-crushing plant to 7 to I I percent for Topeka bituminous concrete pavements. After the mineral aggregate is thoroughly

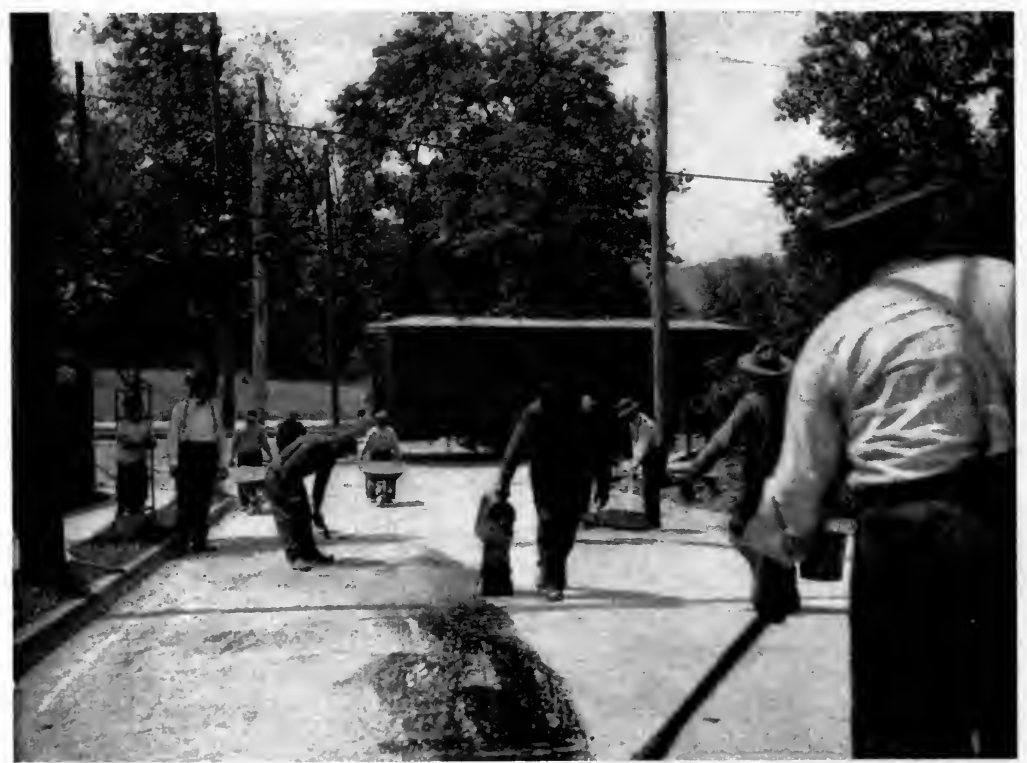

Courlesy of Mr. Philip P. Sharples.

FIG. I Io. Application of Seal Coat on Wearing Course of Topeka Bituminous Concrete with Pouring Can and Squeegee.

coated in the mixer, it is transported by wheel-barrows, wagons, or trucks and deposited on dumping boards which have been placed upon the prepared foundation. The bituminous concrete is placed by shovels and raked to an even thickness and is then thoroughly compacted by rolling. (See Fig. Io9.) Many engineers prefer to use a tandem roller, as it is practicable, under average conditions, to shape up the wearing course more satisfactorily with this type than with a three-wheel roller. The weight of the roller used varies from 7 to 8 tons for Topeka 
bituminous concrete to 9 to 12 tons for other types of bituminous concrete pavements.

Seal Coat. After the bituminous concrete bas been thoroughly compacted and the surface is dry and clean, a seal coat is applied on the surface of many types of pavements. The bituminous cement is distributed by using pouring-pots, see Fig. I Io, or hand-drawn gravity or pressure distributors followed by

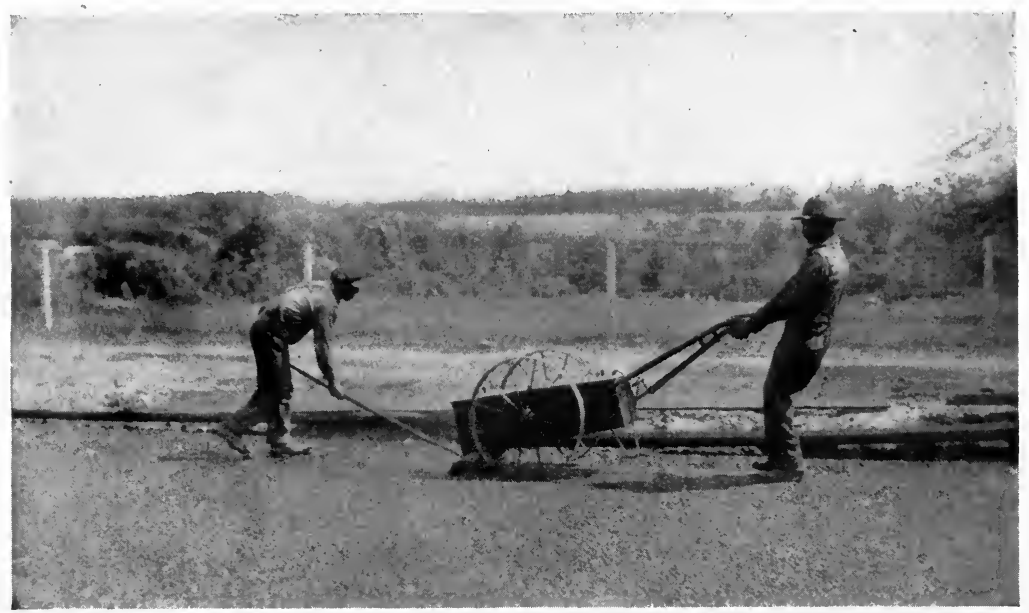

FIG. I I I. Application of Seal Coat on Wearing Course of Bituminous Concrete, Class I. A., with Hand-drawn Distributor and Squeegee.

brushing or squeegeeing, see Fig. III. The amount of seal coat varies from about $1 / 8$ of a gallon per square yard, if used on Topeka bituminous concrete pavement, to from $1 / 2$ to I gallon per square yard for a bituminous concrete pavement having an aggregate composed of one product of a stone-crushing plant. (See Fig. II2.) As soon as practicable a thin layer of clean, dry stone chips is applied over the surface of the seal coat and thoroughly rolled.

The value of the use of seal coats of bituminous materials on bituminous pavements was appreciated by some of the pioneers in this field of highway improvement. In a book entitled "Bituminous Concrete Pavements," published in 1876 , N. B. Abbot 
presents the following pertinent discussion on this detail of construction:

"It is the practice of most of the concrete-pavement men to finish the surface with a top-dressing of dry sand, rolled into the surface; or of hydraulic cement, swept in with a broom.

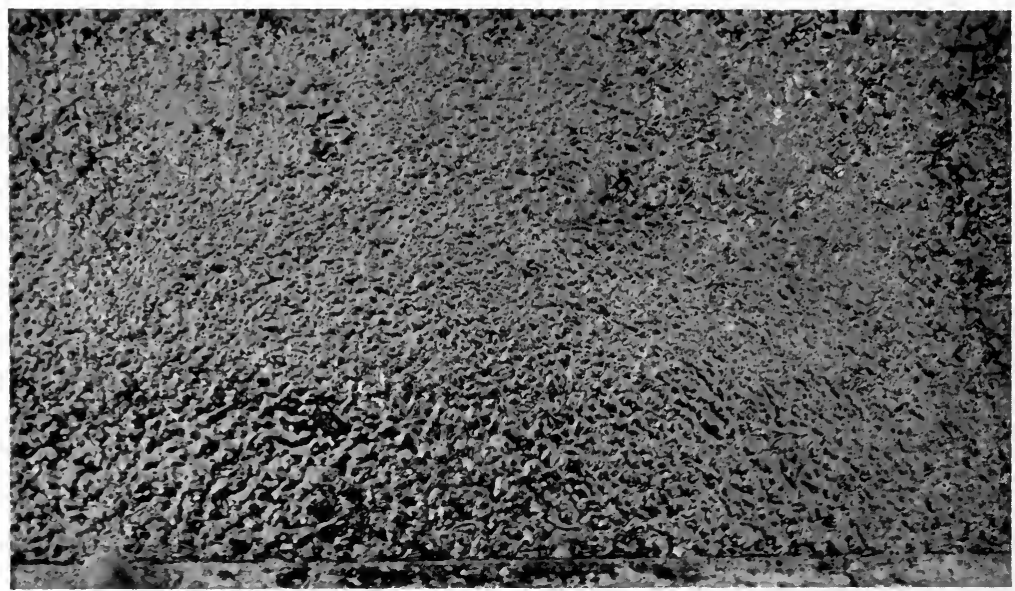

FIG. I I2. Surface of Seal Coat on Wearing Course of Bituminous Concrete, Class I. A., Ashokan Highway, Board of Water Supply of the City of New York.

I became early satisfied that some better plan of finishing was needed. The most compact concretes are more or less porous on the surface; and though these pores are filled with the sand or cement used for top-dressing, neither of these materials being waterproof, in wet weather the water penetrates the pavement, street dirt mingles with the water, and a disintegrating process begins, which soon results in breaks and unevenness of surface. In winter, particularly, the moisture, having penetrated the pavement, freezes and thaws, and decay is hastened. It is just as essential that a concrete pavement should be waterproof as that a roof should not leak. My experiments in this direction resulted in what is known as the Abbot Grit Surface, which was patented June $\mathrm{I} 7, \mathrm{I} 873$. This improvement consists in spreading a hot liquid composition over the surface of the pave- 
ment after it is rolled, into which is placed clean, dry grit or sand. This sand is immediately rolled into the surface while the composition is warm, and a tough coating is thereby formed, which not only prevents the pavement from being slippery, but effectually closes every pore in the surface, and makes it impossible for moisture to penetrate."

In I909 a series of experimental sections was constructed on a state road subjected to mixed traffic of about roo horse-

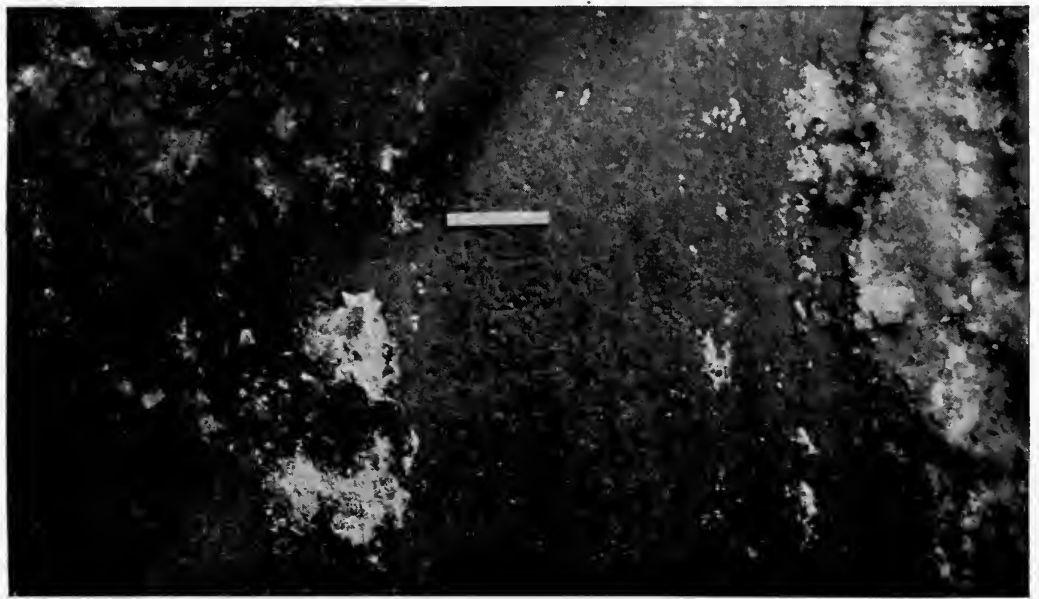

FIG. II3. Asphalt Seal Coat.

drawn vehicles and from 250 to 300 motor-cars per day, many of the motor-vehicles being of the large touring-car type and travelling at high speeds. These experimental sections were constructed to determine the most economical and satisfactory bituminous material to be used for the cement in the mix and for the seal coat for bituminous concrete pavements subjected to the above class of traffic. Asphalt, refined water-gas tar, refined coal tars, and combinations of refined coal tars and asphalts were employed in the construction of the sections, the same material being used for the binder and the seal coat. The results secured from these experiments, based upon an examination in I9I2, indicate that for this class of combination traffic or for horse-drawn vehicle traffic exclusively, the seal coat should 
consist of an asphalt, see Fig. II3, as being more economical and efficacious than refined coal-gas tar, see Fig. II4, or a

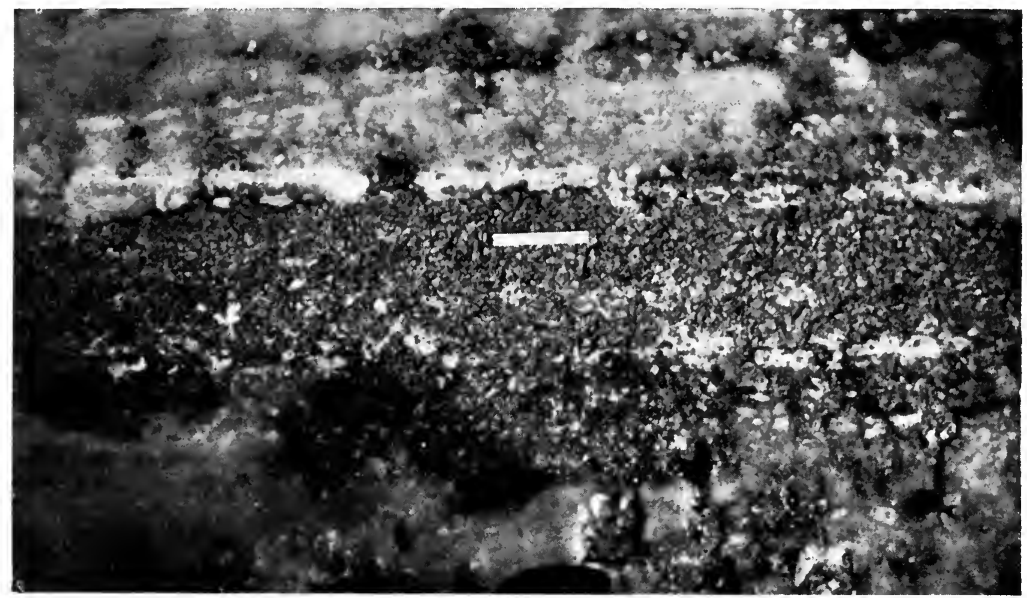

Fig. 114. Coal-Gas Tar Seal Coat.

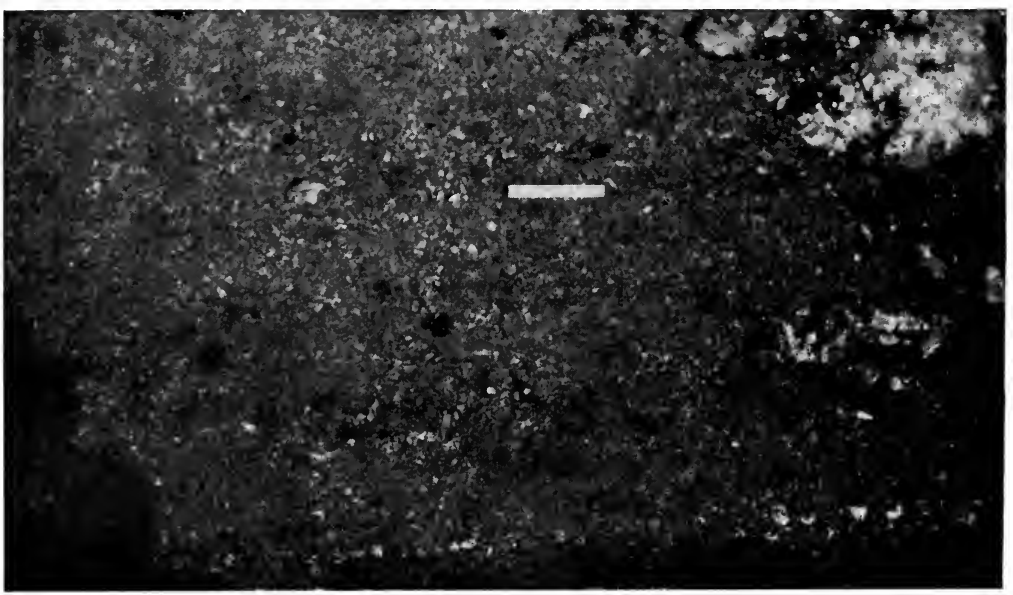

FIG. I I5. Tar-Asphalt Seal Coat.

combination of refined tar and asphalt, see Fig. I I5. (Ice covers a portion of the surface shown in Figs. II3, II4, and II5.) The same conclusion has been reached based on the results of experimental sections constructed in the Borough of Queens in 
I9I I. In this particular instance a bituminous" concrete, with tar used as the cement and seal coat, required retreatment with a seal coat in I9r2, while the section constructed with tar as the cement and asphalt as the seal coat did not require a new seal coat when inspected in I9I5.

Manufacture and Laying of Asphalt Blocks. Asphalt blocks, as heretofore stated, consist of a hard mineral aggregate, a filler and a suitable asphalt cement. It has been found that freshly crushed trap rock or copper conglomerate makes the most satisfactory and durable mineral aggregate. The heated trap-rock, filler, usually limestone dust, and asphalt cement are mixed in a pug-mill mixer. The mixed material is then fed into a hydraulic press, where it is subjected to a pressure per block of between 225 and 240 tons. The block, after being cooled under water, is ready for use. Many blocks are manufactured in standard sizes of $\mathrm{I} 2$ inches long, 5 inches wide, and 2, $2 \frac{1}{2}$, and 3 inches thick. Before the blocks are shipped they are subjected to one or more of the following tests: specific gravity, penetration of block, determination of percentage and character of bitumen, grading of mineral aggregate, and water absorption. The Hastings Pavement Company uses, in connection with its tests, a modified form of the Talbot-Jones-Smith brick rattler, as shown in Fig. II6. This test is conducted at temperatures of $25^{\circ} \mathrm{F}$. and $90^{\circ} \mathrm{F}$. Fifty pounds of cast-iron cubes are used in the test to produce a pounding, grinding action on the ring of asphalt blocks which is bolted in the cylinder of the machine. The rattler is run for 10,000 revolutions. The blocks should be laid in a cement-mortar cushion, $1 / 2$ inch in thickness, covering a cement-concrete foundation, 5 to 6 inches in thickness, and rolled with a 9- to I 2 -ton tandem roller. (See Fig. II7.) The pavement is finished by brooming sand into the joints as thoroughly as possible.

Mechanical Appliances. To meet the demand for a mixing plant with which various types of mineral aggregates can be economically heated and mixed with bituminous material, several machines have been designed in the United States. The requirements of engineers vary to a considerable extent, due to 


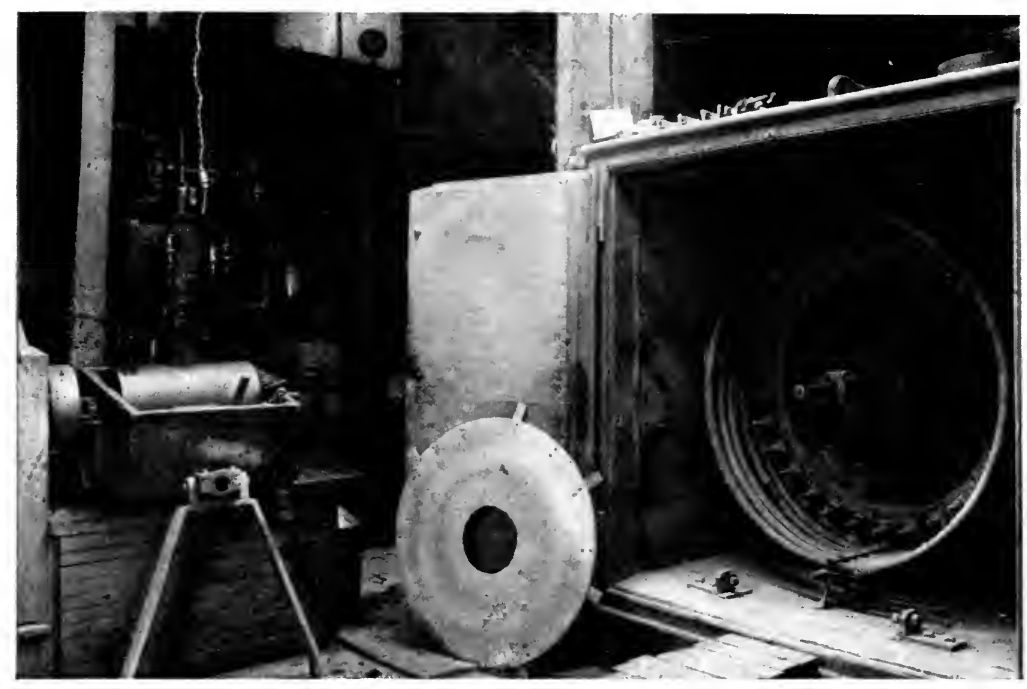

Courtesy of the Hastings Pavement Co.

Fig. II6. Talbot-Jones-Smith Brick Rattler Used in Testing Asphalt Blocks.

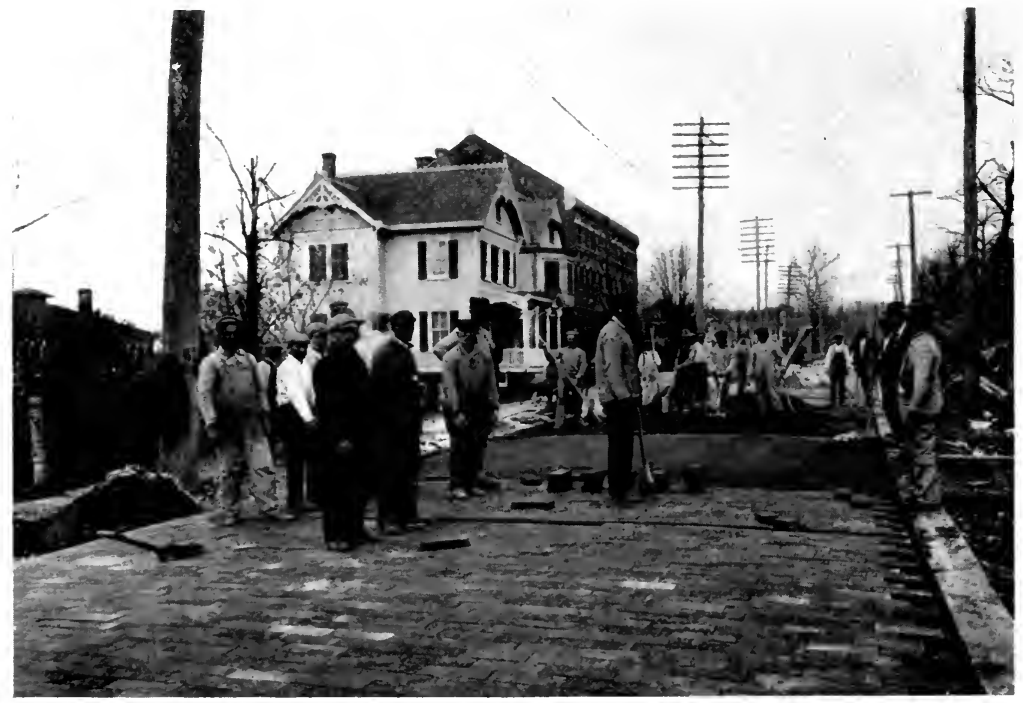

Courtesy of the Hastings Pavement Co.

FIG. II7. Construction of Asphalt Block Pavement. 
the different kinds of aggregate and bituminous materials employed.

Mixing plants may be divided into four classes: first, cementconcrete mixers; second, cement-concrete mixers with heating attachments; third, dryers, storage bins, and mixers; fourth, dryers, storage bins, weighing devices, and mixers.

Cement-Concrete Mixers. Unheated broken stone has been mixed with tars or heavy asphaltic oils in the ordinary type of

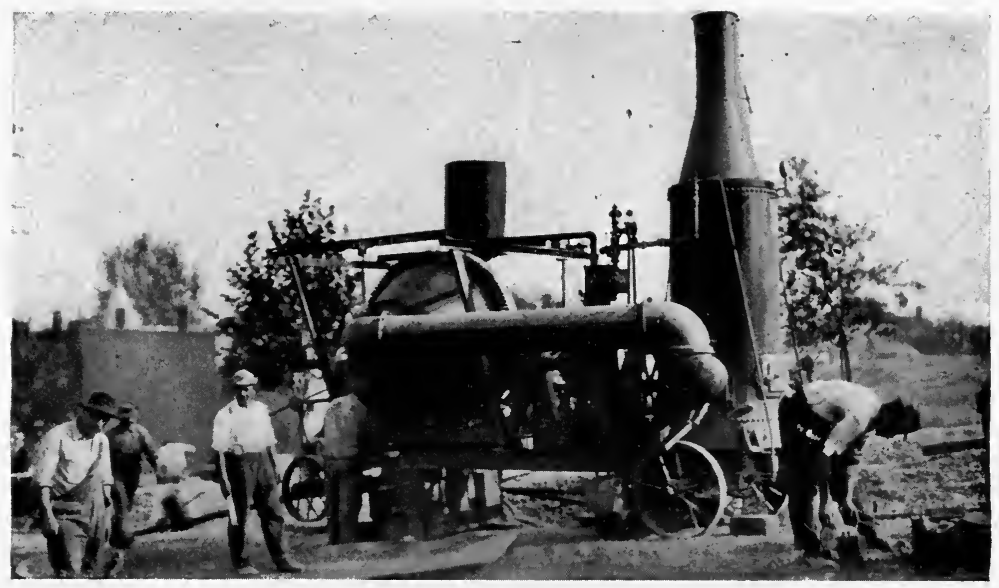

FIG. 118. "Smith" Hot Mixer.

concrete mixer. With this type of plant asphalt cements of low penetration at normal temperatures cannot be mixed with unheated aggregates, as it is generally impracticable to coat the unheated broken stone with the hot asphalt cement. This class of mixers should not be used for the construction of bituminous concrete pavements.

Cement-Concrete Mixers with Heating Attachments. There are several different types of this class of mixing plant in current use. In one type, see Fig. II8, the heat, in the form of hot air, is passed into the mixer by means of a large iron pipe, which runs from the fire-box to the outlet end of the mixer. A second type, see Fig. II9, consists of a cylindrical mixer mounted on a four-wheeled truck. Heat is obtained from a hot-air jacket 
entirely surrounding the cylinder except on the ends and by means of a kerosene torch inserted within the drum. In a third type, hot air obtained by the combustion of oil in air is led from the combustion chamber into the mixing cube. After the mineral aggregate is heated the bituminous cement is added.

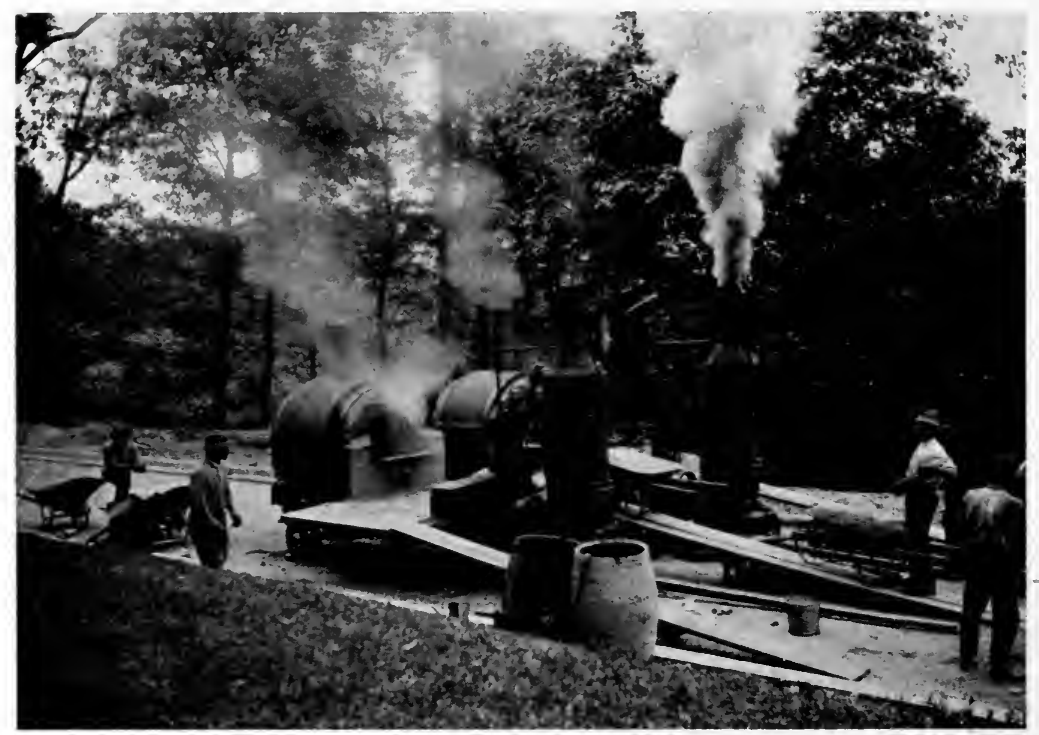

FIG. 1 19. "Rapid" Mixers.

Courtesy of Mr. Philip P. Sharples.

A fourth method of utilizing concrete mixers is to use a rotary dryer, as a part of the plant, for drying the aggregate.

Dryers, Storage Bins, and Mixers. In several types of plants the aggregate is heated in rotary dryers from which the dried material is transported by elevators to storage bins. In some cases the aggregate is raised to the storage bins before being dried. As required, the aggregate falls by gravity into the mixer. The heat for the dryers and the mixer is obtained by direct heat from fire-boxes or by oil-burning apparatus.

Dryers, Storage Bins, Weighing Devices, and Mixers. In a complete plant, see Figs. I20 and I2I, for the manufacture of bituminous concrete, the aggregate is carried by bucket-elevators to rotary dryers, where it is dried and the dust exhausted; from 


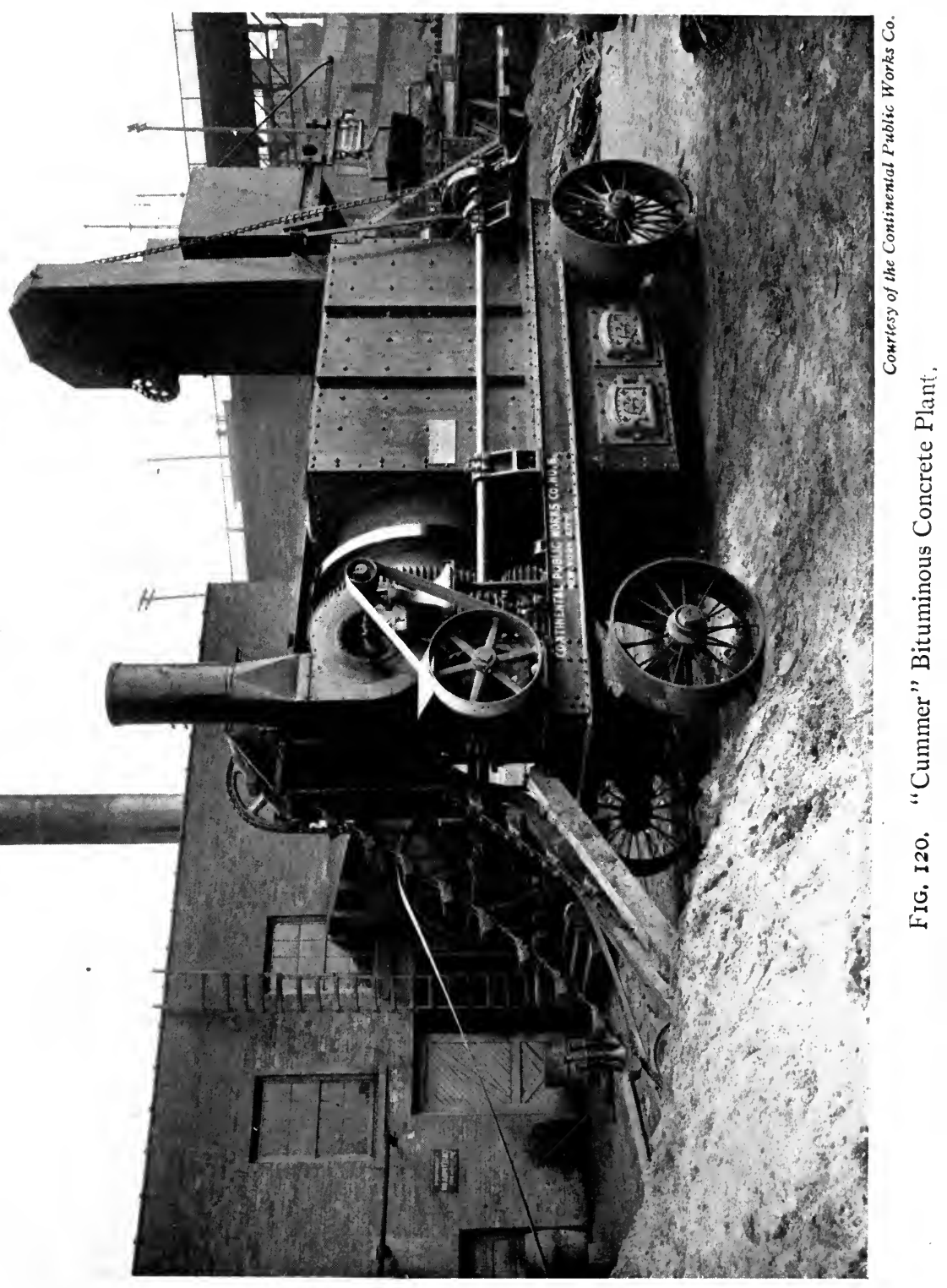




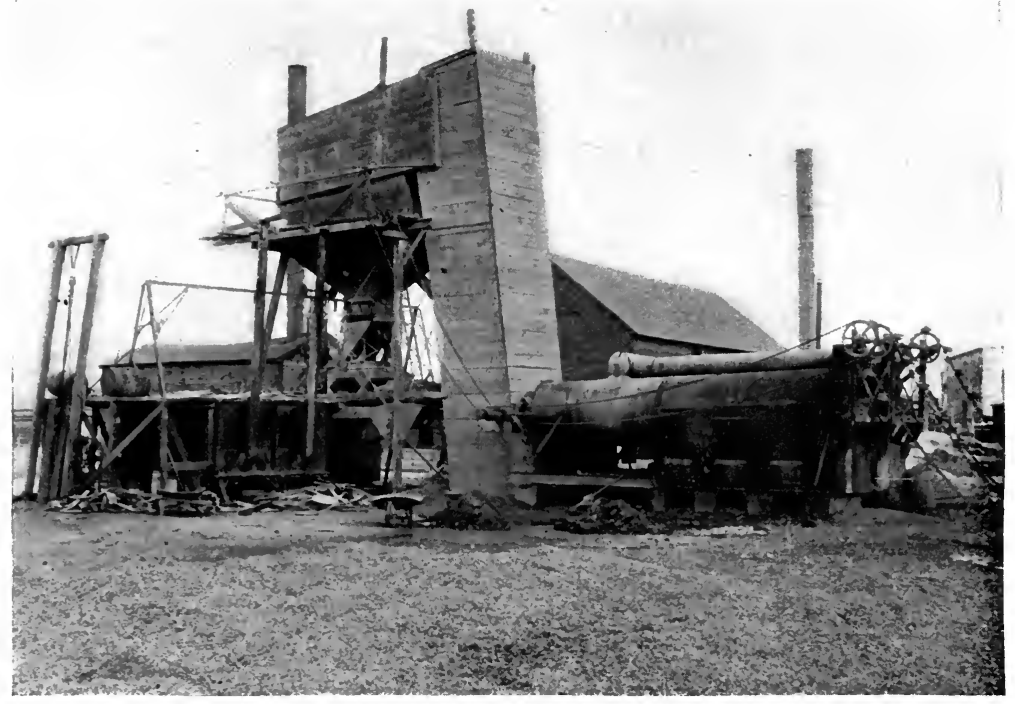

FIG. 121. Warren Brothers' Mixing Plant.

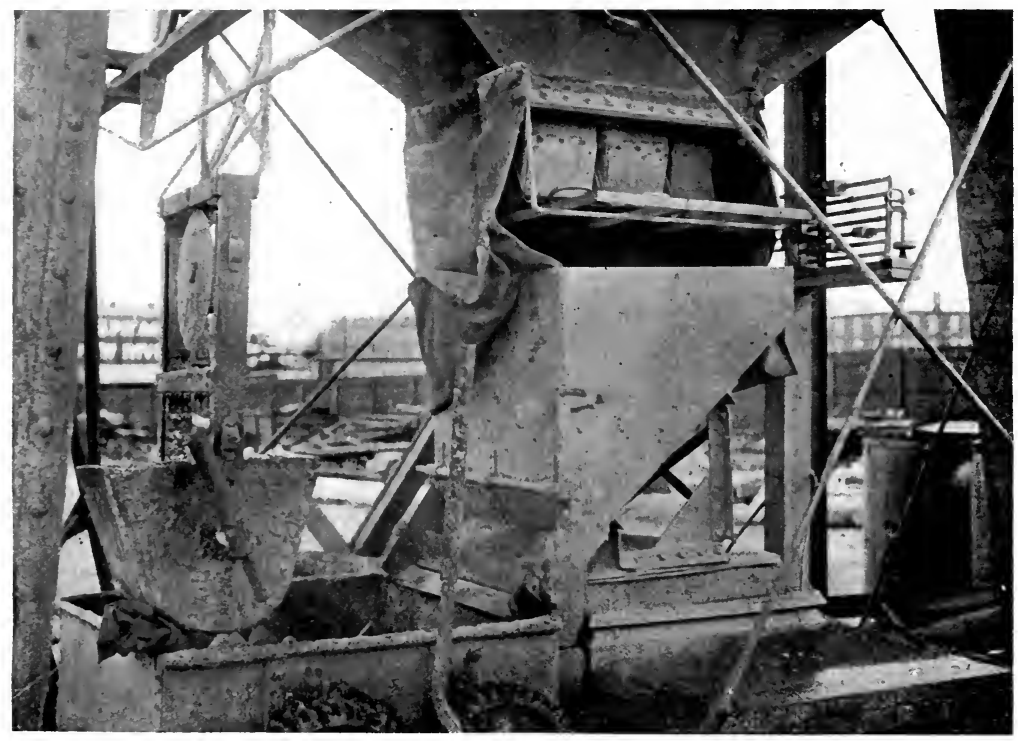

FIG. 122. Weighing Device and Pug Mill Mixer, Warren Brothers' Mixing Plant. 
the dryer the aggregate is raised to the storage bins by elevators; when required the aggregate is drawn from the bins to a weighing device, see Fig. I22, and from there deposited into a mixer.

Cost Data. The cost of bituminous concrete pavements varies with the kind and quantity of bituminous material used, the character of the aggregate and the method of construction employed. Using an aggregate of stone varying from $1 / 8$ to $\mathrm{I} / 4$ inches in longest dimensions, mixed with 1.5 gallons of bituminous material per square yard, and with a flush coat of $3 / 4$ gallon per square yard, the cost of a 2-inch wearing course would be about 30 to 50 cents per square yard in excess of water-bound broken stone roads. The cost of pavements of Classes I. B. and I. C. varies from $\$ 1.25$ to $\$ 2.25$ per square yard, including foundations and light grading. In the following tables are given, for several localities throughout America, the average r9I4 prices of bituminous concrete pavements and foundations.

\section{Topeka Bituminous Concrete Pavements.}

From Engineering and Contracting, April 7, 1915

\begin{tabular}{|c|c|c|c|c|c|c|}
\hline \multirow{2}{*}{ City } & \multirow{2}{*}{$\begin{array}{l}\text { Square } \\
\text { Yards }\end{array}$} & \multirow{2}{*}{$\begin{array}{c}\text { Price* } \\
\text { per } \\
\text { Sq. Yd. }\end{array}$} & \multirow{2}{*}{$\begin{array}{l}\text { Guar- } \\
\text { antee, } \\
\text { Years }\end{array}$} & \multirow{2}{*}{$\begin{array}{l}\text { Wearing } \\
\text { Course } \\
\text { Thickness, } \\
\text { Inches }\end{array}$} & \multicolumn{2}{|c|}{ Concrete Foundation } \\
\hline & & & & & $\begin{array}{l}\text { Thickness } \\
\text { Inches }\end{array}$ & $\begin{array}{l}\text { Propor- } \\
\text { tions }\end{array}$ \\
\hline Pittsfield, Mass. & 30,567 & $\$ 1.94$ & 5 & 3 & 5 & I $: 3: 6$ \\
\hline Trenton, N. J .... & 50,183 & I .47 & .5 & 2 & 5 & $I: 3: 6$ \\
\hline Minneapolis, Minn. & $+2,622$ & I. 75 & & 2 & 5 & I $: 3: 6$ \\
\hline Des Moines, Ia .... & 5,965 & I. $92 \dagger$ & 5 & 3 & 5 & I $: 3: 6$ \\
\hline Greenville, Tex. & 30,000 & I. $59 \dagger$ & 5 & 2 & 4 & $1: 7$ \\
\hline
\end{tabular}

* Price covers pavement, foundation, and shaping subgrade.

$\dagger$ Does not include shaping subgrade.

\section{Bitulithic Pavements.}

From Engineering and Contracting, April 7, I9I5

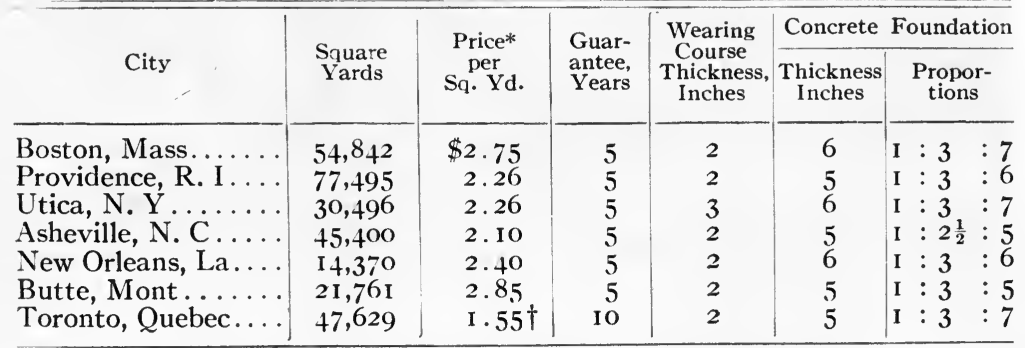

* Price covers pavement, foundation, and shaping subgrade. † Does not include shaping subgrade. 
Asphalt Block Pavements.

From Engineering and Contracting, April 7, I915

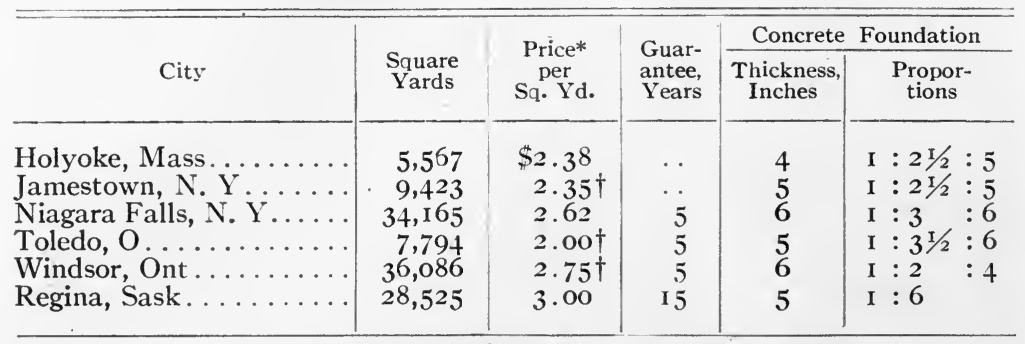

* Price covers pavement, foundation, and shaping subgrade.

$\uparrow$ Does not include shaping subgrade.

\section{Maintenance}

The maintenance of bituminous concrete pavements is accomplished in a manner similar to that described in the chapter on Bituminous Macadam Pavements. (See Fig. I 23.)

\section{Characteristics}

Advantages. All of the advantages resulting from the construction of bituminous surfaces on macadam and gravel roads

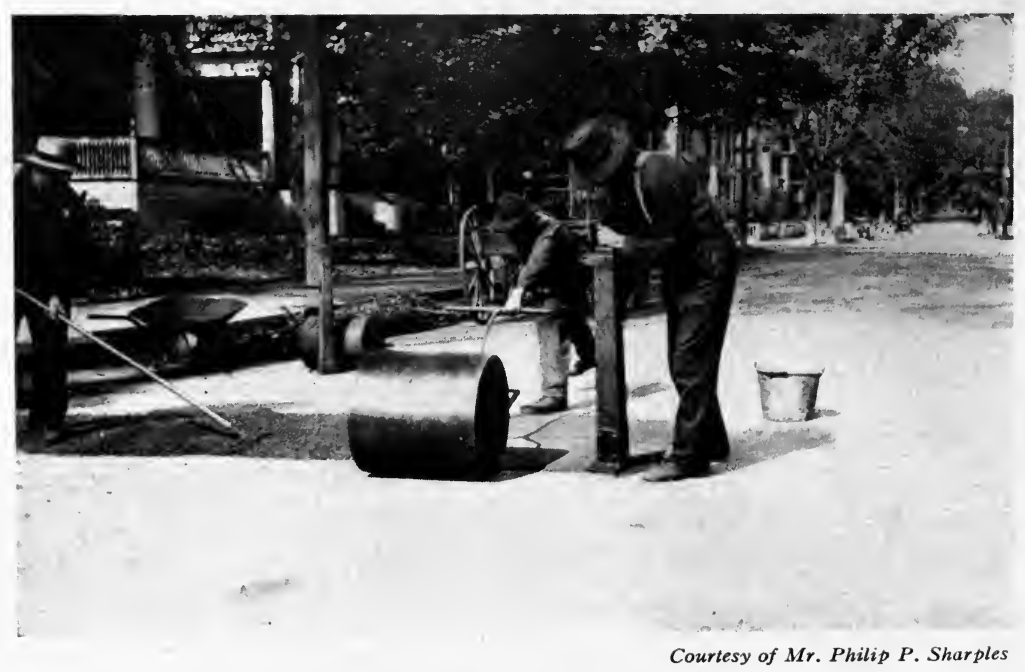

FIG. 123. Repairing a Trench Opening in a Bituminous Concrete Pavement. 
and of bituminous macadam pavements may be cited verbatim with reference to bituminous concrete pavements. Bituminous concrete pavements are usually more stable and durable than other types of bituminous pavements. By the use of modern mixing plants, it is practicable to lay certain types of bitu-

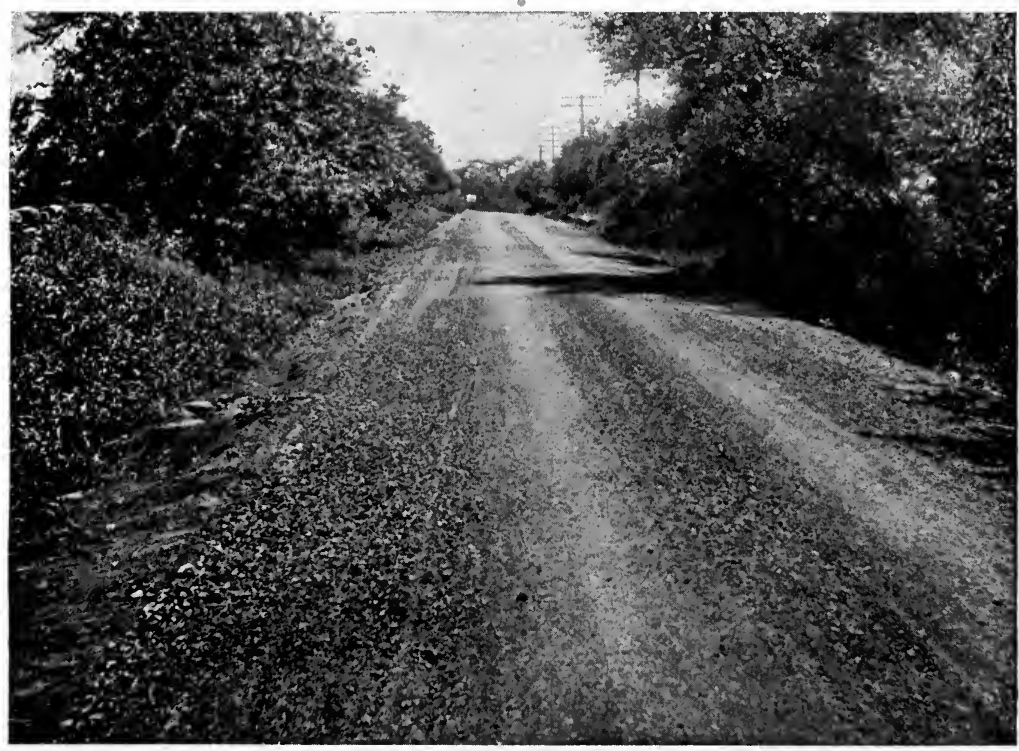

FIG. 124. Result of Using a Poor Grade of Tar.

minous concrete pavements of Class r. A. as economically as it is possible ordinarily to build bituminous macadam pavements.

Disadvantages. Slipperiness with seal coats of some bituminous materials may occur and thus prove a disadvantage. It is evident that skilled supervision is required, which may be difficult to secure.

Causes of Failure. It should be noted that the percentage of failures of bituminous concrete pavements is much smaller than in the case of bituminous macadam pavements. Failures may be considered from the standpoint of the materials employed and methods of construction adopted. Failures have 
occurred because the type of pavement used was not suitable for the traffic or other local conditions.

Materials. Poor and unsuitable materials have been accountable for certain failures. In some cases an apparent cause of failure has been an excess of flux or of the volatile constituents

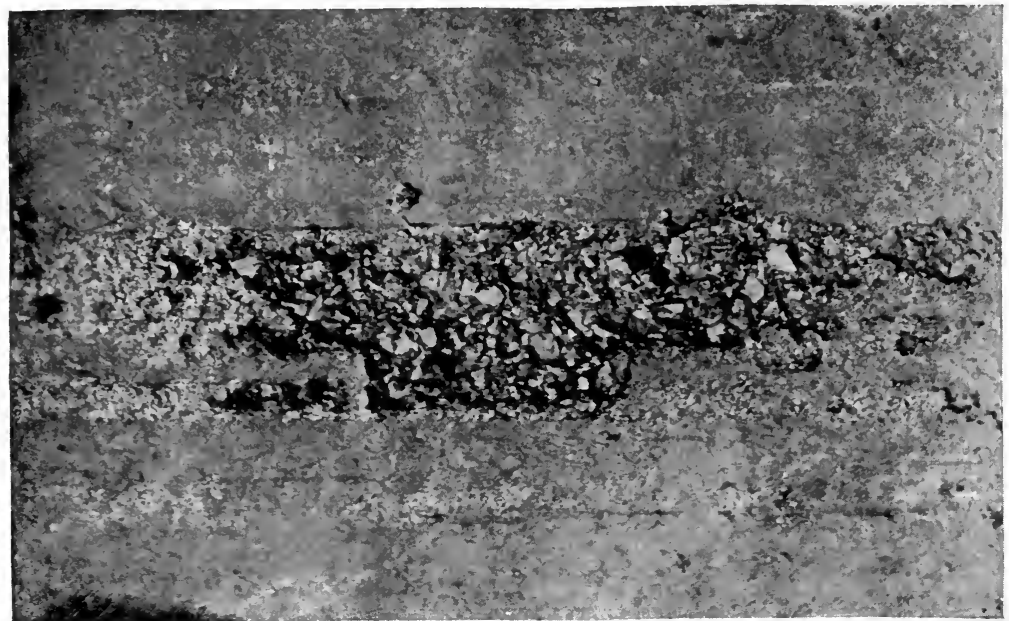

FIG. 125. Soft Seal Coat Torn up Due to Adhesion to Tires.

in asphalt cements. Pavements constructed with such materials are frequently wavy, due to the movement of the surface under heavy traffic. Many of the above causes of failure would be eliminated if engineers would devote more time to a consideration of the physical and chemical properties of the materials which they employ. (See Figs. I24 and 125.) If a bituminous material laboratory is not connected with the department, it should be neither expensive nor difficult to secure certified analyses made by reputable chemical engineers.

Either too large broken stone or stone of too uniform size may cause a failure. Especially is this the case with very hard and tough broken stone. The rocking of the stone causes the formation of fine cracks which eventually lead to disintegration. Poor combinations of sizes of broken stone and sand have re- 
sulted in segregation during mixing, transportation, or spreading, resulting in a pavement of varying density and stability.

Construction. Many cases are reported where materials have been overheated due to the belief that all materials may be and even should be heated to the same temperature before using and that it is impossible to injure bituminous materials by heating to high temperatures. Overheating of the mineral aggregate has caused burning of the bituminous material in some instances or the formation of a thin film of bituminous material over the broken stone which is not of sufficient amount to bind the adjacent stones together. The use of a wet aggregate will result in a poor mix with consequent unsatisfactory results. In many instances the seal coat has not been applied uniformly. The result is either uneconomical, due to the necessity of a second application before 75 per cent of the surface requires retreatment, or the disintegration of the pavement whenever bare spots occur in pavements where a coarse aggregate was used and where there is considerable horse-drawn vehicle traffic. Some failures have been caused by using with unheated stone bituminous cements which will not adhere satisfactorily or which mix only with great difficulty under such conditions. Many failures are due to poor foundations.

Careful consideration of the causes of failures will result in material benefit, inasmuch as a comprehensive knowledge of the various causes of failure is one of the most valuable assets of engineers having in charge the construction and maintenance of bituminous surfaces and bituminous pavements. 


\section{CHAPTER XIII}

\section{SHEET ASPHALT AND ROCK ASPHALT PAVEMENTS}

"Sheet asphalt pavements are those having a wearing course composed of asphalt cement and sand of predetermined grading, with or without the addition of fine material, incorporated together by mixing methods."* The wearing course is usually laid upon a binder course of bituminous concrete which in the case of first-class pavements has been laid upon a cement-concrete

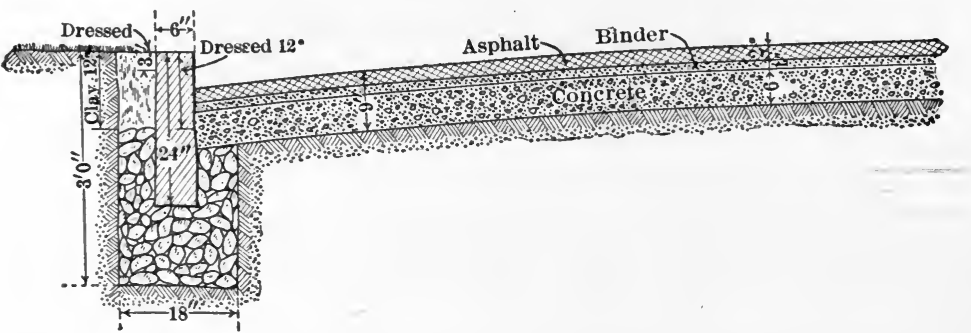

FIG. 126. Section Showing Construction of Sheet Asphalt Pavement in Pittsburg, Pa.

foundation. The component parts of a sheet asphalt pavement are clearly shown in Fig. I26. In some cases the binder course is omitted.

"Rock asphalt pavements are those having a wearing course composed of broken or pulverized rock asphalt with or without the addition of other bituminous materials."* A rock asphalt pavement composed of pulverized rock asphalt has the same appearance as a sheet asphalt pavement.

Development. The first extensive use of pulverized rock asphalt for paving streets was in Paris in 1854 , although there are records of its use for this purpose as early as 1838 . From I854 to I867 a considerable yardage of this kind of pavement was constructed, but it was not until 1867 that it was used on

* Dec., I9r4 Proceedings, Am. Soc. C. E., pages 3017-30r8. 298 
a large scale. The rock asphalt used in the first pavements was known as Val de Travers. Later, another rock asphalt known as Seyssel rock was used with equal success. The first asphalt pavement in London was constructed in 1869, a Val de Travers asphalt rock being used. By the close of 1873 the total square yards paved with rock asphalt was about 61,000. The success of these early pavements led to the trial of this material in America. The excessive cost of importing the material from Europe led to the development of the modern sheet asphalt pavement. The first experiment with this type of asphalt pavement was tried out in Newark, N. J., in I870. In I876 Pennsylvania Avenue, Washington, D. C., was surfaced with this material. This was the first real test on a large scale of the sheet asphalt pavement. Until I882, however, only a few cities laid sheet asphalt, but from that time its use has increased so rapidly that it is now one of the most widely used and popular kinds of pavement. Although there are several rock asphalt deposits within the borders of the United States, some of which would make a good pavement similar to those constructed in Europe, this material has never been used to any great extent. The freight charges in most instances would make the cost much more than that of the artificial mixture.

\section{Materials for Sheet Asphalt Pavements}

Asphalt Cement. The bituminous material which is used in the construction of sheet asphalt pavements is known as asphalt cement. In the trade it is commonly called $A$. C. The asphalt cements used in the United States and Canada are described by the following definition:

"Asphalt Cement.* A fluxed or unfluxed asphaltic material, especially prepared as to quality and consistency, suitable for direct use in the manufacture of asphaltic pavements, and having a penetration of between 5 and 250."

In order to have a clear idea of the meaning of this term, the interrelationship of the terms covered by the following definitions should be considered.

* Dec., I9I4 Proceedings, Am. Soc. C. E., pages 301 I to 3015. 
"Asphalt.* $\dagger$ Solid or semi-solid native bitumens, solid or semi-solid bitumens obtained by refining petroleums, or solid or semi-solid bitumens which are combinations of the bitumens mentioned, with petroleums or derivatives thereof, which melt on the application of heat, and which consist of a mixture of hydrocarbons and their derivatives of complex structure, largely cyclic and bridge compounds."

"Bitumens* $\dagger$ are mixtures of native or pyrogenous hydrocarbons and their non-metallic derivatives, which may be gases, liquids, viscous liquids, or solids, and which are soluble in carbon disulphide."

"Flux.* $\dagger$ Bitumens, generally liquid, used in combination with harder bitumens for the purpose of softening the latter."

Many specifications for sheet-asphalt pavements have included clauses covering the chemical and physical properties of refined asphalt (R.A.), flux, and asphalt cement. Furthermore, some specifications have covered the method by which the refined asphalt and flux should be combined in order to form the asphalt cement. There is a marked tendency among engineers and chemists to place emphasis upon the specification for the asphalt cement and omit specifications for the refined asphalt and the flux. This practice is based on the belief that comprehensive and suitable specifications covering the physical and chemical properties of the asphalt cement are sufficient, as the " $A$. $C$." is the bituminous material which is used in the pavement.

Binder Stone. The following description of binder stone used in the construction of the binder course is typical of American practice. The broken stone for the binder course should be clean, hard, rough surfaced, and sharp angled, of compact surface and uniform grain. It should be subjected to abrasion tests and toughness tests by the engineer in accordance with methods adopted by the American Society for Testing Materials, August I 5, I908. It should show a "French coefficient of wear" of not less than 7.0; its toughness shall be not less than 6.0.

* Dec., I914 Proceedings, Am. Soc. C. E., pages 3011 to 3015.

$\dagger$ Proposed by Committee D-4, American Society for Testing Materials. 
It should all pass a screen with $\mathrm{I} / 4$-inch cirçular openings, and not over $\mathrm{I}_{5}$ per cent shall exceed $\mathrm{I} / 4$ inches in largest dimension. No fragments should exceed 2 inches in largest dimension. The stone might be so graded as to show the following mesh composition:

Passing ro mesh,

I 5 to 35 percent.

Passing $1 / 2$ " screen and retained on Io mesh, Io to 35 percent,

Passing $\mathrm{I}^{\prime \prime}$ and retained on $1 / 2^{\prime \prime}$ screen, 20 to 60 percent.

Passing $\mathrm{I} / \mathrm{4}^{\prime \prime}$ and retained on $\mathrm{I}^{\prime \prime}$ screen, 15 to 55 percent.
Total passing $1 / 2{ }^{\prime \prime}$ screen, 25 to 50

\begin{tabular}{c|l} 
percent. & $\begin{array}{l}\text { Total passing } \\
\text { Total passing } I / / 4 \prime\end{array}$ \\
I" screen, 45 \\
to 85 percent
\end{tabular} and retained on
and to 75 percent.

If the stone does not contain the proper amount of material passing the $1 / 2$-inch, the deficiency may be made up by the addition of sand so that the resulting mixture will conform with the above requirements.

The above limits as to mesh compositions are intended to provide for such permissible variations as may be rendered necessary by the available sources of supply and the character of the work to be done. The mesh composition and character of the stone may be varied, within the limits above specified, depending upon the kind of asphalt used and the traffic conditions upon the street or streets to be paved.

Sand aNd Filler for Wearing Surface. The following description of sand and filler may be considered typical for the materials of a wearing course to be subjected to medium traffic. The sand should be clean, hard grained, and moderately sharp. The product used may be of one grade or a mixture of two or more grades, but should show the following mesh composition:

$\left.\begin{array}{l}\text { Passing } 200 \text { mesh } \\ \text { Passing } 100 \text { mesh and retained on } 200 \text { mesh } 14 \text { to } 25 \% \\ \text { Passing } 80 \text { mesh and retained on } 100 \text { mesh } 6 \text { to } 21 \% \\ \text { Passing } 50 \text { mesh and retained on } 80 \text { mesh } 15 \text { to } 30 \% \\ \text { Passing } 40 \text { mesh an retained on } 50 \text { mesh } 10 \text { to } 25 \% \\ \text { Passing } 30 \text { mesh and retained on } 40 \text { mesh } 8 \text { to } 20 \% \\ \text { Passing } 20 \text { mesh and retained on } 30 \text { mesh } 5 \text { to } 15 \% \\ \text { Passing } 10 \text { mesh and retained on } 20 \text { mesh } 2 \text { to } 15 \%\end{array}\right\} 20$ to to $50 \%$

The mineral filler should be thoroughly dry limestone dust, Dolomite dust, or Portland cement. It should all pass a 30- 
mesh per linear inch sieve, and at least 66 percent should pass a 200-mesh per linear inch sieve.

\section{Construction}

Sheet Asphalt Pavements. Subgrade and Foundation. It is essential that the foundation for sheet asphalt should be firm and unyielding since the weight of traffic must be carried by it. A I : $2: 5$ to I : $3: 7$ cement-concrete is used, being 4 to 8 inches in thickness, depending upon the amount of traffic and subsoil conditions. The concrete must be thoroughly set before the binder course is laid. Bituminous concrete has been used in a number of instances, in which cases the binder course is not needed. This type of foundation is not advised, since the bond between it and the wearing course is so firm that the latter can only be removed with difficulty when repairs are necessary, and, furthermore, the foundation is not sufficiently stable in most instances where sheet asphalt is economically employed. A 4-inch to 6-inch broken stone road coated with asphalt or coal tar has been used. This practice should not be followed.

Binder Course. Upon the foundation the binder course is laid so as to be I to $\mathrm{I} / 2$ inches thick after rolling, about 40 per cent being allowed for compression. This course is usually composed of broken stone, sand, and asphalt cement or broken stone and asphalt cement. The material is brought on to the street in covered dump wagons, at $200^{\circ}$ to $325^{\circ} \mathrm{F}$., depending upon the type of asphalt cement used, deposited, and smoothed down with hot shovels and rakes. It is then compacted with a tandem-roller. Although 5- to 8-ton rollers are used, more satisfactory compaction is secured by employing Io- to I2-ton tandem-rollers.

Wearing Course. The aggregate consists of a finely graded sand and fine filler such as stone dust or Portland cement. Volcanic dust has also been used as a filler with satisfactory results. The wearing course, consisting of the aggregate and the asphalt cement, is usually $\mathrm{I} / 2$ to 2 inches in depth after rolling. The amount of bitumen used varies from 9 to 13 per- 
cent. It is brought on to the street at $280^{\circ}$ to $325^{\circ} \mathrm{F}$., depending upon the type of asphalt cement used, dumped, and spread on the binder surface, and then tamped around all manholes, gutters, and curbs, and rolled with a tandem-roller weighing 5 to ro tons. A continued rolling is very essential, as a constant kneading action is necessary to secure a well-compacted surface. Special care must be taken along street-car rails to secure thorough compaction. Usually one to three courses of stone block or brick are laid next the rail. Eighteen to 24 inches adjoining the curb are often painted with hot asphalt cement to secure imperviousness to water.

Asphalt Plants. A complete plant includes a cold-sand elevator, a dryer, a hot-sand elevator, a hot-sand storage bin with screen, an asphalt elevator, a flux tank, melting tanks, draw-off tanks, a sand-measuring box, a dust elevator, bin and measuring box, an asphalt cement bucket, and a mixer. In large plants agitation in the melting tanks is necessary in order to prevent burning, especially when the asphalt cement is heated by direct fire. Agitation may be accomplished by blowing air or superheated steam through the asphalt cement, or by mechanical means. In the case of asphalt cements containing considerable foreign material, it is advisable to use mechanical agitation or a combination of mechanical agitation and the injection of air or superheated steam in order to prevent the impurities from settling to the bottom of the melting tanks. The mixing device of this type of plant consists of a semi-cylindrical trough for holding the materials to be mixed together. A series of paddle wheels revolves on a horizontal axle which is fixed at either end within the trough. These paddles agitate the ingredients and thus produce the mix. The parts are all suitably arranged so that the operations follow one another in such a manner that none of the ingredients of the mixture have to be handled by hand from the time they are placed in the receiving end of the machine until they leave the outlet end. (See Fig. I27.)

Rock Asphalt Pavements. European Practice. In Europe practically all of the asphalt pavements are constructed with a wearing course of pulverized rock asphalt. The naturally 


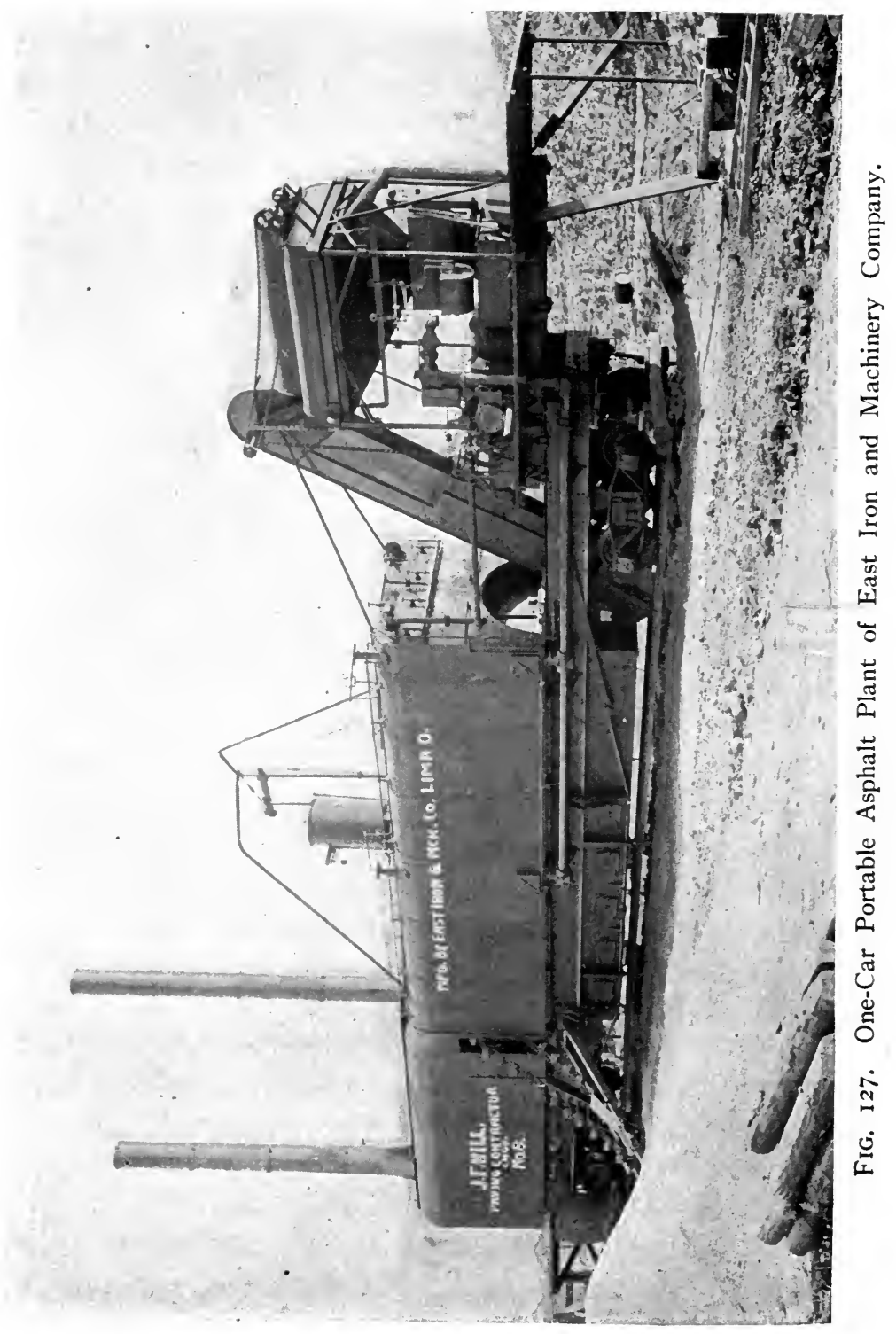


impregnated rock is obtained from the Val de Travers, Seyssel, Vorwohle, Limmer, or Ragusa mines. The method of construction employed in Europe is as follows: After the rock asphalt is pulverized, the powder is placed in slow, revolving cylinders and subjected to a heat of from $250^{\circ}$ to $280^{\circ} \mathrm{F}$., the object being to drive off the moisture. This powder is spread on a foundation to a depth of 2 inches or 3 inches, raked even, and tamped with hot rams or tampers weighing about twelve pounds, and finally rolled with a ro-ton roller.

American Practice. Borough of Manhattan. The I9I2 specifications of the Borough of Manhattan, New York City, allowed the use of rock asphalt under the conditions here cited.

"Should any of the rock asphalts be used, the material shall be a natural bituminous limestone or sandstone, or a mixture of the two, and shall be prepared and laid in the following manner: The lumps of rock, after being mixed in the proper proportions, shall be finely crushed and pulverized, and the powder passed through a 20-mesh sieve. In case of the use of any asphaltic limestone, or of a mixture of an asphaltic limestone and an asphaltic sandstone, nothing whatever shall be added to or taken from the powder obtained by grinding the natural bituminous rock. The rock shall contain from 9 to I 2 percent of natural bitumen. This powder shall be heated in a suitable apparatus to $200^{\circ}$ or $250^{\circ} \mathrm{F}$., and must be brought to the ground at a temperature of not less than $180^{\circ} \mathrm{F}$. in carts made for the purpose, and carefully spread, as specified for refined asphalt pavement, to such a depth that after having received its ultimate compression it will have a thickness of $2 \frac{1}{2}$ inches when laid on concrete. When the foundation is other than concrete it shall be laid on a I-inch binder course, as heretofore described, and the net thickness of the rock asphalt wearing surface after compression shall be 2 inches. The surface shall be rendered perfectly even by tamping, smoothing, and rolling with heated appliances of approved design."

Broken Rock Asphalt. Rock asphalt is sometimes employed in the United States in the same manner as broken stone is used. One method of construction is to lay on the foundation 
course of broken stone a $2 \frac{1}{2}$-inch course of $\mathrm{I}$-inch to 2 -inch stone and roll just enough to render firm. Broken rock asphalt, containing 7 to ro percent bitumen, is then raked on from dumping boards to a depth of $1 / 2$ inch and rolled in, and finally a second course I inch deep is laid and rolled; or the whole may be laid in one course $I \frac{1}{2}$ inches thick. Old macadam roads may be resurfaced by first scarifying and then applying a course of crushed rock asphalt as in new construction.

Cost Data. The average cost of sheet asphalt pavements on cement-concrete foundation varies from $\$ \mathrm{I} .50$ to $\$ 2.25$ per square yard. In the following table are given, for séveral localities throughout America, the average I9I4 prices of sheet asphalt pavements and foundations constructed with various thicknesses of wearing courses, binder courses, and cementconcrete foundations.

From Engineering and Contracting, April 7, I9I5

\begin{tabular}{|c|c|c|c|c|c|c|c|}
\hline \multirow[b]{2}{*}{ City } & \multirow[b]{2}{*}{$\begin{array}{l}\text { Square } \\
\text { Yards }\end{array}$} & \multirow{2}{*}{$\begin{array}{l}\text { Price* } \\
\text { per } \\
\text { Square } \\
\text { Yard }\end{array}$} & \multirow{2}{*}{$\begin{array}{l}\text { Guar- } \\
\text { antee, } \\
\text { Years }\end{array}$} & \multirow{2}{*}{$\begin{array}{c}\text { Wear- } \\
\text { ing } \\
\text { Course } \\
\text { Thick- } \\
\text { ness, } \\
\text { Inches }\end{array}$} & \multirow{2}{*}{$\begin{array}{l}\text { Binder } \\
\text { Course } \\
\text { Thick- } \\
\text { ness, } \\
\text { Inches }\end{array}$} & \multicolumn{2}{|c|}{$\begin{array}{l}\text { Concrete } \\
\text { Foundation }\end{array}$} \\
\hline & & & & & & $\begin{array}{l}\text { Thick- } \\
\text { ness, } \\
\text { Inches }\end{array}$ & $\begin{array}{l}\text { Propor- } \\
\text { tions }\end{array}$ \\
\hline Boston, Mass ... & 27,423 & $\$ 3.00$ & 5 & $1 / 2$ & $11 / 2$ & 6 & I $: 3: 7$ \\
\hline Brooklyn, N. Y...... & 680,877 & I. 76 & 5 & 2 & I & 6 & $I: 3: 6$ \\
\hline Atlantic City, N. J... & I 50,572 & 1.75 & 5 & $11 / 2$ & $I 1 / 2$ & & I $: 3: 6$ \\
\hline Philadelphia, Pa..... & 314,778 & I.9I & 5 & 2 & I & 6 & I : $3:$ \\
\hline Columbus, $\mathrm{O} \ldots \ldots$ & I30, I 8 & 2. oo† & 5 & 2 & I & 6 & I : $3:$ \\
\hline Highland Park, Mich. & 45,485 & I. 62 & 5 & $11 / 2$ & I & 6 & I : $3:$ \\
\hline Ioines, Ia... . . & $55,2 \mathrm{C}$ & I. $92 \dagger$ & 5 & $11 / 2$ & I & 5 & I $: 3:$ \\
\hline Washington, D. C. . . & 28,2 & I. $699^{\dagger}$ & 5 & $11 / 2$ & $11 / 2$ & 6 & I $: 3:$ \\
\hline Charlo te, N. C.... & 40,000 & I. $54 \dagger$ & 5 & 2 & I & 4 & I $: 3:$ \\
\hline Ку.. & 29,955 & I.90 & 5 & 2 & I & 6 & I $: 3: 6$ \\
\hline & 97,972 & I. $80 \dagger$ & . & I $1 / 2$ & 2 & 6 & I : $3: 6$ \\
\hline Portland, Ore. & 40,447 & I. $54 \dagger$ & IO & 2 & I & 5 & I $: 3: 6$ \\
\hline
\end{tabular}

* Price covers pavement, foundation, and preparation of subgrade.

$\dagger$ Does not include preparation of subgrade.

\section{Maintenance}

Sheet Asphalt Pavements. Failures of sheet asphalt pavements are usually due either to defective foundation, dirt on the binder, too soft asphalt in binder, frost, gas, kerosene or oil, fires, poor construction, or lack of sufficient traffic. 
Explanations of several causes of deterioration of sheet asphalt pavements are given in the following excêrpts.*

"The proper maintenance of an asphalt pavement involves the making of such repairs to it from time to time as are necessary in order that it may continue to render efficient service as a safe and smooth roadway or street.

"The deterioration which eventually renders these repairs necessary commences as soon as the pavement is laid and may be broadly classified under the following heads:

"I. Defects due to the wear and tear of traffic.

"2. Defects caused by the deterioration, through age and exposure, of the bituminous cementing materials used.

"3. Defects in construction.

"Traffic Deterioration. Under traffic the surface of the pavement is abraded and gradually wears off and the mineral particles exposed on the top are more or less crushed and broken. Under heavy traffic and unfavorable weather conditions, these crushed grains become active centers of disintegration. The crushed particles are not bound together by the asphalt cement and are soon swept away. The holes thus made in the pavement serve to retain the moisture and the edges of the holes are eventually more or less broken down, thus enlarging the hole. The effect of this action, which at first glance appears trivial, has been so well established by years of investigation and experience that it has become axiomatic in the paving industry that the heavier the traffic the finer must be the particles composing the mineral aggregate. In hot weather the caulks on horses' shoes sometimes mark up the pavement to a very considerable extent, but the subsequent action of vehicular traffic wears these marks out almost completely. Nevertheless, in a community unaccustomed to sheet asphalt pavements, the appearance of these caulk marks in a new pavement is always regarded as an ominous sign presaging its speedy destruction and failure. As a matter of fact, if the pavement, especially

* See 1912-1913 Lecture by Francis P. Smith on "Maintenance of Sheet Asphalt Pavements," in the Graduate Course in Highway Engineering at Columbia University. 
when newly laid, were not soft enough to show these marks, it would be an almost infallible sign that the asphalt cement used in it was too hard and that the total life of the pavement would be less than if a softer asphalt cement had been used. Traffic on a pavement always compresses it and increases its density, and for this reason a two-year-old pavement will always mark up less than a new one. The pressure per square inch exerted by the comparatively narrow tire of a heavily loaded vehicle is much greater than that exerted by the heaviest steamroller used in the laying of sheet asphalt pavements. Even if this were not the case, the kneading action produced by narrow tires passing many times over the surface would always give greater compression than could be obtained by the action of the broad tires of a steam-roller.

"When the traffic is confined to a comparatively narrow space and is always in the same direction, a distinct pushing force is exerted on the pavement. Whenever the pavement lacks inherent stability, due to an improper mineral aggregate or bitumen which is lacking in cementing value from natural causes or the rotting action of gas or water, or a combination of these defects, very distinct waves or bumps will be produced by the action of heavy traffic. Investigation will almost always show defective binder in these spots, or too soft an asphalt cement, or too great a thickness of pavement owing to an error in the grade of the concrete.

"Effect of Ageing and Exposure. All bituminous materials used in paving work deteriorate upon exposure to the elements and to the rotting action of escaping gas, water, and street liquids. The lighter oils contained in them gradually volatilize, thus hardening the remaining bitumen. In order to guard against this and prolong the effective life of the pavement, the asphalt cement used in its construction is made as soft as possible without rendering the pavement too mushy when new.

"Some asphalts are more easily rotted by water action than are others. With such asphalts it is more than ever necessary to make the pavement as dense as possible to prevent the water from getting into it. Generally speaking, with all asphalts the 
wetter the climatic or other conditions, the denser and richer in bitumen should the mixture be made. Where water is allowed to remain in the gutters, the rotting will frequently be very rapid and this will be still more marked if, as in some towns, the dirty wash-water from houses is discharged into the gutters. Too frequent washing of a pavement with water at a high pressure is also bad, as the abrasive action of such a jet is very considerable and acts in the same way as the stream from a hydraulic nozzle.

"Gas leaks produce a very similar result and the gas sometimes travels a long distance from the point of leakage before it actually comes in contact with the pavement.

"Another cause for the deterioration of sheet asphalt pavement is lack of traffic. Pavements laid on outlying residence streets and culs-de-sac with little or no traffic crack much more quickly than if they were subjected to a moderate traffic, which appears to be necessary to keep the life in the pavement. This is probably due to the fact that the surface is not in such cases kept at the maximum density by the action of traffic and gradually becomes porous, thus facilitating the evaporation of the lighter oils, and also to the fact that the kneading action of traffic, like the continual use of a rubber band, tends to keep the life, so to speak, in the bitumen, and equalizes the stresses set up by contraction and expansion.

"Defects in Construction. Unless the foundation is rigid and of sufficient strength to carry the weight of the traffic passing over the finished pavement, no sheet asphalt wearing surface will give satisfactory service. (See Fig. 128.) Being plastic at all normal temperatures, the wearing surface will not bridge over any depressions formed by the sinking or failure of the foundation, but will sink with it.

"The best modern practice calls for the use of the tight binder, as it gives a much firmer foundation for the wearing surface and will not be broken up and loosened from the concrete by the passage over it of the teams hauling the hot surface mixture. Poor binder will break up very easily--sometimes it can be kicked up, and the hauling of the hot surface mixture 
over it will damage it very seriously. Surface mixture laid on a binder of this kind which has been badly broken up might almost as well be laid on loose broken stone and will not give satisfactory service under heavy traffic. The binder should of course be thoroughly compressed with a steam-roller before laying the wearing surface on it. Lack of compression will

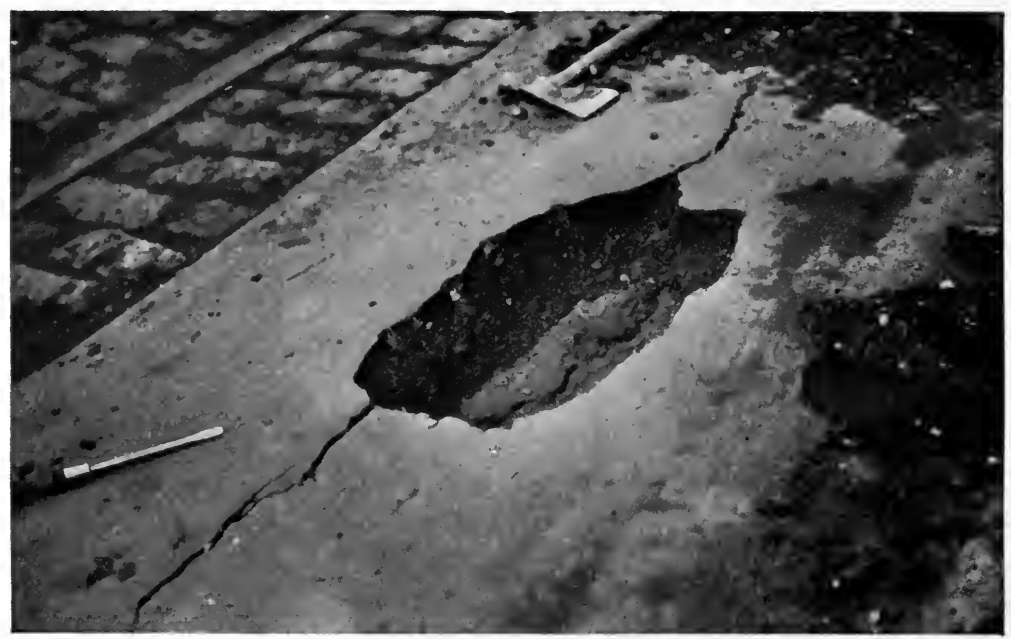

FIG. 128. Crack in Concrete Foundation Due to Poorly Drained Subgrade.

produce an unsatisfactory foundation for the wearing surface, and, as previously mentioned, binder which is too cold or made with too hard an asphalt cement or an insufficient quantity of asphalt cement cannot be properly compressed into a dense, tough mass. Before laying the surface mixture on the finished binder course, the latter should be dry and swept clean of dirt; otherwise the layer of wearing surface will not adhere properly to it."

Repairs and Conditions of Guarantee. From the I9I4 specifications of the American Society of Municipal Improvements the following quotations are taken which cover the methods to be used in repairing sheet asphalt pavements and the condition of the pavement, at the end of the guarantee period, which should be insisted upon. 


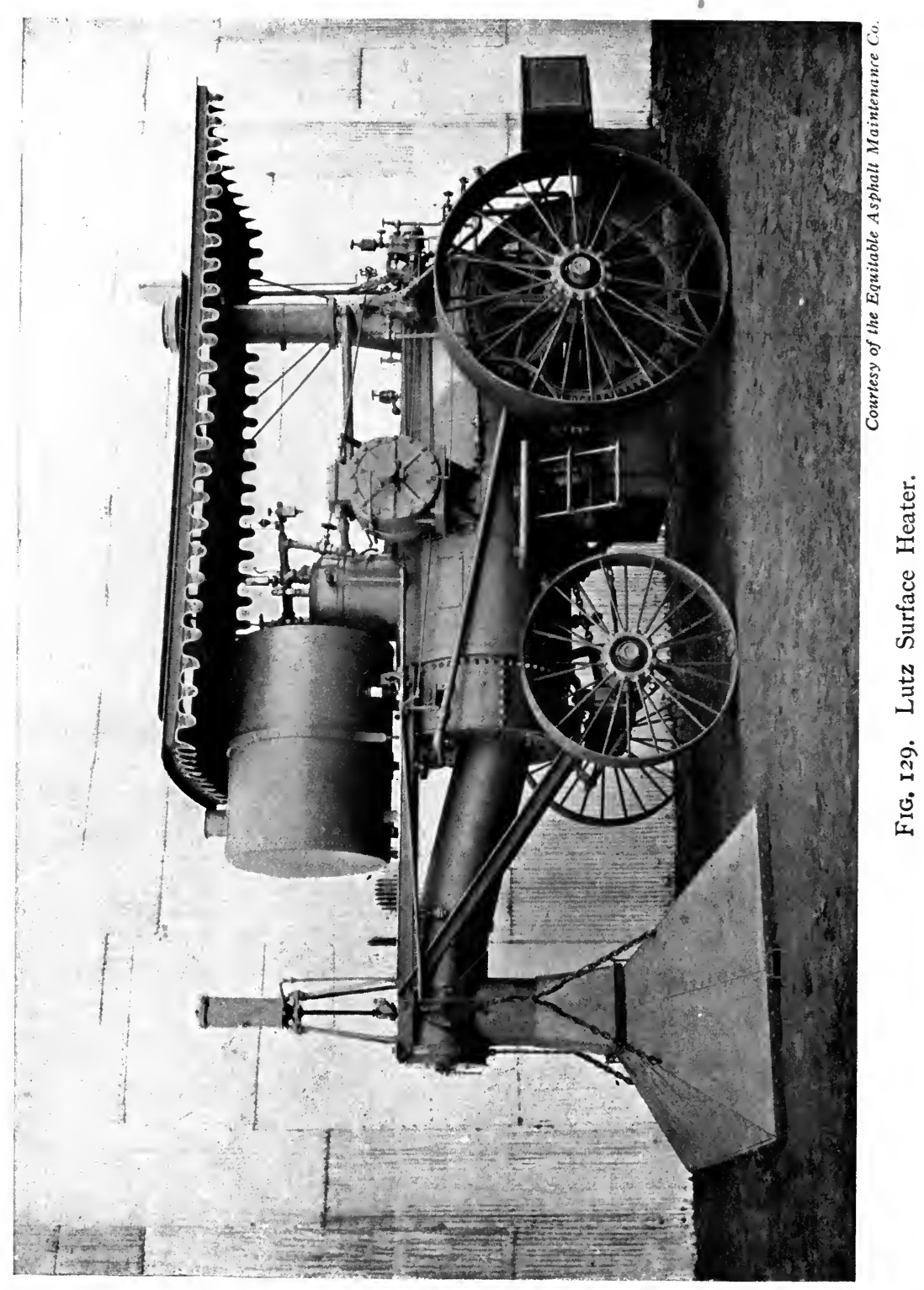


"Repairing. Repairs, except as provided for below, shall in all cases be made by cutting out the defective binder and wearing surface down to the concrete and replacing them by new and freshly prepared binder and wearing surface made and laid in strict accordance with these specifications.

"Whenever any defects are caused by the failure of the foundation, the pavement, including such foundation, shall be

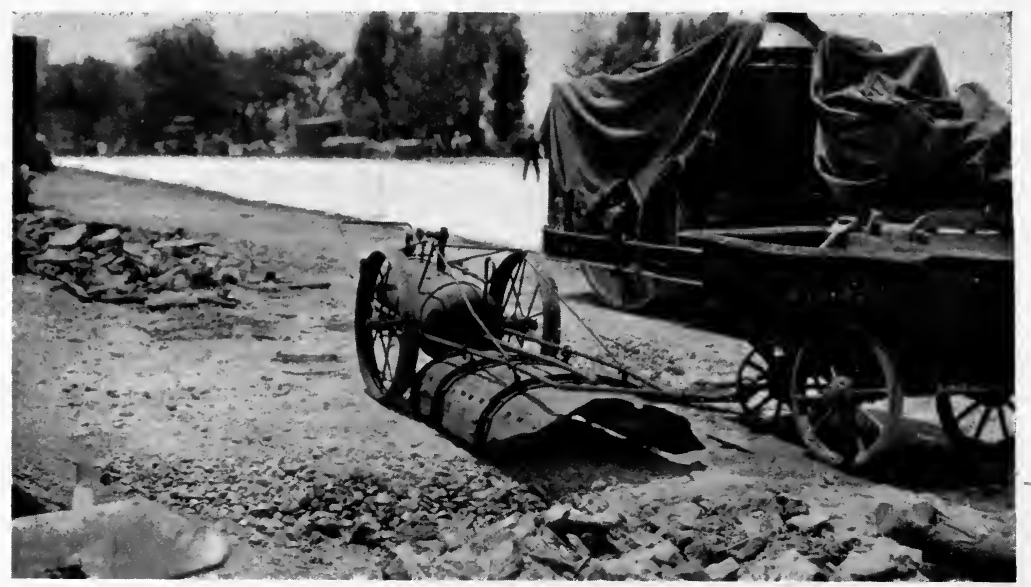

FIG. I30. Hand-drawn Surface Heater.

taken up and relaid with freshly prepared material made and laid in strict accordance with these specifications.

"In all cases the surface of the finished repair shall be at the grade of the adjoining pavement" and in accordance with the contour of the street.

"The surface-heater method of repairing may be used only in those cases where the repairs are not rendered necessary by:

(a) Failure of concrete.

(b) Failure of the binder.

(c) Failure caused by the disintegration of the lower portion of the wearing surface.

"Whenever the surface heater, see Figs. I29 and I30, method is employed, all defective surface shall be removed before replacing it with new material. In all cases the old surface shall be 
removed to a depth of not less than $1 / 4$ inch and the new surface must, when compressed, be not less than $1 / 2$ inch in thickness. The heat shall be applied in such a manner as not to injure the remaining pavement. All burnt and loose material shall at once be completely removed and, while the remaining portion of the old pavement is still warm, shall be replaced by new and freshly prepared wearing surface made and laid in strict accordance with these specifications.

"Conditions at Expiration of Guarantee. In addition to the proper maintenance of the pavement during the period of guarantee, the contractor shall, at his own expense, just before the expiration of the guarantee period, make such repairs as may be necessary to produce a pavement which shall:

"(a) Have a contour substantially conforming to that of the pavement as first laid and free from depressions of any kind exceeding $3 / 8$ of an inch in depth as measured between any two points 4 feet apart on a line conforming substantially to the original contour of the street.

"(b) Be free from cracks or depressions showing disintegration of the surface mixture.

"(c) Contain no disintegrated surface mixture.

"(d) Not have been reduced in thickness more than $3 / 8$ of an inch in any part.

"(e) Have a foundation free from such cracks or defects as will cause disintegration or settling of the pavement or impair its usefulness as a roadway."

\section{Characteristics}

Sheet Asphalt Pavement. This type of pavement, when properly constructed on a cement-concrete foundation, is durable under heavy traffic such as is characteristic of the streets of shopping districts in large municipalities. It is very low in tractive resistance, easy to clean, and is non-productive of dust from abrasion of the wearing course. It is usually slippery on grades over 3 to 4 percent. When in good condition very little . noise results from the passage of the wheels of vehicles, but 
horses' hoofs striking the pavement give off a sharp metallic noise.

Rock Asphalt Pavement. The European pavements constructed of pulverized rock asphalt possess the characteristics of sheet asphalt pavements except that they are more slippery. 


\section{CHAPTER XIV}

\section{CEMENT-CONCRETE PAVEMENTS}

Development. The first piece of cement-concrete pavement was laid in Inverness, Scotland, in 1865 , as an experimental section, being about one hundred and fifty feet long. In I866 another experiment was tried in Edinburgh. Cement-concrete pavements have not been adopted as a standard type in Europe.

The first cement-concrete pavement in the United States was laid in Bellefontaine, Ohio, in I893. It was not until I900, however, that this material was used to any great extent. The work of the highway department of Wayne County, Michigan, has been notable from the standpoint of development of efficient methods of construction and maintenance. At the close of I9I4 the county had constructed over roo miles of cement-concrete pavements. During r9r4 the approximate amount laid in the United States comprised about seventeen million square yards. During the past few years it has been demonstrated that the application of a bituminous surface to the pavement makes it more desirable. The construction of satisfactory bituminous surfaces on this class of pavement is, however, very difficult.

\section{The Cement-Concrete}

IngRedients AND Proportioning. The materials used for the aggregate of a cement-concrete, pavement are generally sand and either broken stone or gravel. The broken stone employed should be obtained by crushing hard, tough rock. Preferably the stone should be composed of naturally graded sizes and free from dust or dirt. Sometimes, however, the run of the crusher may be used, including the dust, which is acceptable provided that part of the stone below $1 / 4$ inch in size is reckoned as fine aggregate in making up the proportions. What has been 
said relative to broken stone applies as well to gravel, since a screened gravel with the fine material eliminated allows a more accurate determination of the correct proportions. Some engineers prefer stone and others gravel, either being allowed in some specifications. The sand used should be clean, sharp, and coarse, free from loam, clay, and any vegetable or organic matter. The cement should be a first-class Portland cement that will meet the standard specifications of the American Society of Civil Engineers. Care should be taken to use clean water, since water which contains any alkalies or acids will be detrimental to the concrete. The theory of the correct proportioning of concrete has been briefly stated in Chapter V. The proportions which were given in connection with the construction of concrete foundations are not rich enough in either cement or mortar to make satisfactory concrete which is to be subjected to the abrasive and impact forces of traffic. The proportions used for cement-concrete pavements vary from $I: I \frac{1}{2}: 3$ to I $: 3: 6$.

\section{Construction}

Subgrade and Foundation. Cement-concrete pavements should be laid only on a well-compacted and well-drained subgrade. If the subgrade is of clay, it should be replaced with clinker, broken stone, cinders, gravel, or some other suitable material. The surface should usually be made flat and should be thoroughly rolled with a medium-weight roller. Prior to the deposition of concrete the subgrade should be thoroughly wet, otherwise the subgrade will absorb water from the concrete, thus preventing a uniform set and decreasing its strength. In replacing old broken stone roads with a cementconcrete pavement, it is possible to dig up the broken stone roadway, screen the broken stone, and use it as the aggregate in the concrete. In Chapter $\mathrm{V}$ the subject of foundations was considered from two standpoints, natural and artificial. In this connection it was assumed that the lower course of a broken stone road was an artificial foundation for the upper course. A similar condition exists in some cement-concrete pavements 
which are built in two courses, the upper one being the wearing course and the lower one the artificial foundation."

Constructing the Pavement. The formulas for the amount and distribution of crown are given in Chapter IV. Usually the average transverse slope does not exceed $1 / 4$ inch per foot. There is a variety of methods of constructing a cement-concrete pavement. Mixing and grouting methods are employed. In the mixing method the entire thickness of the concrete may be deposited at one time or the pavement may be constructed in two courses. In the grouting method the aggregate is laid, rolled in place, and filled with a cement grout. In a few instances, steel reinforcement has been used in pavements built by both the mixing and the grouting methods. Another type of construction which has been used is that of molding concrete into small cubes and laying the same as a small block pavement. The practice of painting the concrete surface with a coat of bituminous material has given good results in some instances.

Mixing Methods. In cement-concrete pavements constructed by the mixing method, the concrete is deposited in one or two layers. Both methods have been tried in Wayne County, Michigan, the construction of two-course pavements having been abandoned. It is evident that in constructing a two-course pavement there will be a plane of weakness between the two courses. Although it is possible in the two-course method to construct the top with a richer mix, this hardly offsets the advantages derived from having the entire depth of concrete deposited at one time.

The mixing of concrete by machine has been considered in Chapter V. In the construction of cement-concrete pavements continuous mixers should not be used as it is impracticable to secure uniform results. Under average conditions the best results are secured with a batch mixer to which is attached a boom carrying a travelling bucket. Segregation of the aggregate does not occur to any marked degree when this type of mixer is used. The mixing machines should be run on planks so that the subgrade will not be disturbed. The general rules 
which were given in Chapter $\mathrm{V}$ relative to handling the mixed concrete during construction and its treatment after being laid apply as well to constructing cement-concrete pavements. More attention should be paid to obtaining a smooth and regular surface in constructing cement-concrete pavements than is usually accorded concrete foundations. The use of heavy templates

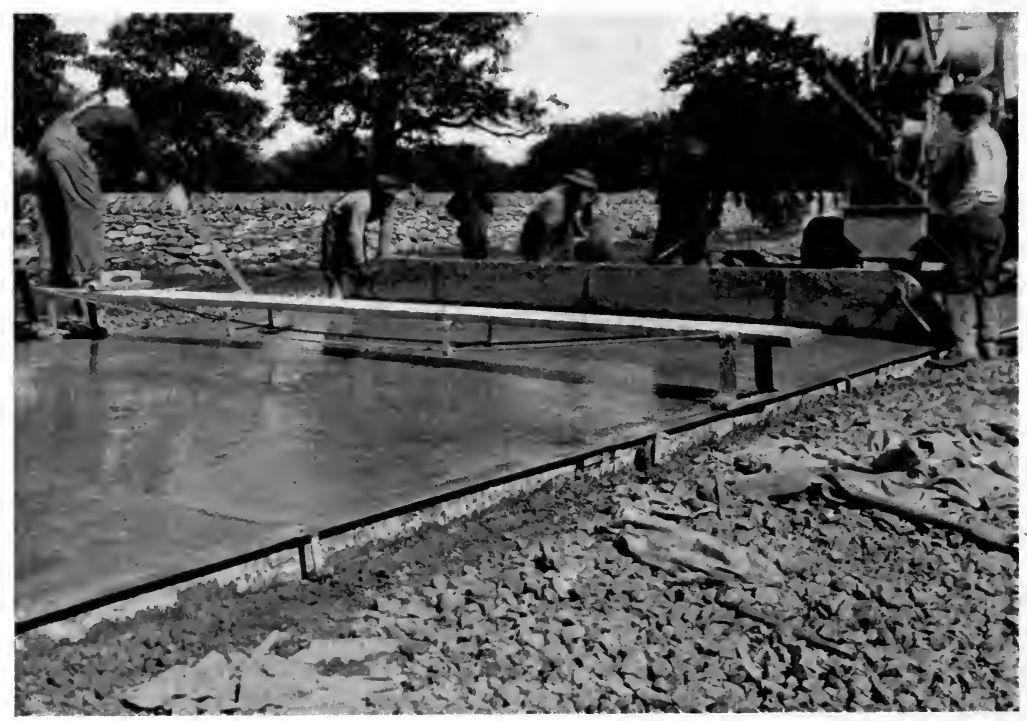

Courtesy of the Association of A merican Portland Cement Manufacturers.

FIG. I3I. Template and Bridge Used in the Construction of Cement-Concrete Pavements.

to strike the surface of the concrete and of bridges which span the concrete surface, thus enabling the laborers to work over the surface without standing on it, should be insisted upon. (See Fig. I3I.) A slightly roughened surface may be obtained by marking the concrete, before it sets hard, with a grooving tool, by the use of a wood float, or by brooming the surface with a rather stiff broom. It is also important to protect the surface from too rapid drying out while the concrete is curing, otherwise shrinkage cracks are liable to occur. This is accomplished sometimes by covering the pavement as soon as it has 
taken its initial set with a canvas which is kept moist for a few hours. The canvas is then removed and the surface is covered with a layer of sand or earth which is kept thoroughly moist for a period of two weeks.

One-Course Method. A one-course pavement is constructed in Wayne County, Michigan, in the following manner: The concrete is mixed in the proportions of $\mathrm{I}: \mathrm{I} / 2: 3$, and is laid on a flat subgrade to a depth of 6 inches at the sides and 8 inches in the center. The ingredients are machine mixed and the concrete is placed and tamped on a firmly compacted subgrade. The surface is struck off with a plank template similar to the one shown in Fig. I3I. Each day's work is finished up to a transverse expansion joint, such joints being constructed every 25 feet along the pavement.

Two-Course Method. A common method of constructing a two-course pavement may be described as follows: A layer of concrete, which will be 4 inches thick after compaction, is placed on the previously prepared subgrade. The proportions of the ingredients in this layer are variable, but a mixture of I : $2 \frac{\mathrm{I}}{2}: 5$ may be considered average practice. After this layer has been shaped up and tamped, and before it has begun to set, a wearing course, 2 inches in thickness, is constructed upon it. The composition of the wearing course is also quite variable. It may consist of a mixture of sand and cement or it may be composed of a mixture of sand, small-sized crushed stone, and cement. Cement and sand mixed in the proportions of I : 2 have been used. Surface mixtures of which broken stone formed a part have been made up of one part cement, one part sand, and one part of $1 / 4$ - to $1 / 2$-inch chips. Other features of the construction do not differ essentially from those described under one-course methods.

The Blome concrete pavements are constructed as a twocourse pavement, the lower course being from 5 to 6 inches thick and the wearing surface being about $\mathrm{I} 3 / 4$ inches thick. The wearing surface is composed of one part cement to one and one-half parts of aggregate, which is made up of 50 percent of I/4-inch, 30 percent of $1 / 8$-inch, and 20 percent of $1 / 16$-inch 
granite screenings. The surface, after it is laid, is cut into $4 \frac{1}{2}$ - by 9 -inch blocks by special grooving tools, the grooves being $1 / 2$-inch wide and $1 / 4$-inch deep.

Reinforced Pavements. Reinforced concrete pavements are usually constructed by the two-course method. The reinforcement usually consists of woven wire or expanded metal, although a mesh work of small round bars is sometimes used. The reinforcement is universally placed between the base and the wearing surface. This type of pavement may be said to be in an experimental stage. In practically all instances where pavements have been constructed in this manner both longitudinal expansion joints at the curbs and transverse expansion joints across the pavement have been built at intervals. Some engineers also use reinforcement in cement-concrete pavements over 25 feet in width instead of using a longitudinal expansion joint in the center.

Oil Cement-Concrete. In order to make the concrete more waterproof, and at the same time to enable it to resist the changes of temperature more effectively, experimental pavements of oil cement-concrete have been built. The pavement is constructed in the same manner as the ordinary concrete pavements built by the mixing method, except that a fluid residual petroleum is added to the mix in an amount varying from to to 18 percent of the weight of the cement. The addition of oil weakens the strength of the concrete, although it makes the concrete more impervious. This method of construction has not shown any advantages which would warrant its adoption.

Expansion Joints. Both longitudinal joints along the curbs and transverse joints should be provided. There will be more or less contraction and expansion of the concrete due to changes of temperature, variation in the moisture content of concrete, and variation in the condition and character of the subgrade. If expansion joints are not present, when the concrete contracts, the tensile strength of the concrete will be exceeded and the pavement will crack; when it expands it will tend to crush, spall, or bulge. Fig. 132 shows a crack in a cement-concrete pavement due to contraction. If the expansion 
produces forces that are in excess of the compressive strength of the concrete, the concrete will crush along the crack. The edges of the joints must be protected from the abrasive action of the traffic, and it is obvious that the joints should be filled with a material that will allow some movement between the joints as the pavement expands and contracts.

The width of the longitudinal joints will depend somewhat upon the width of the pavement. They are usually made from

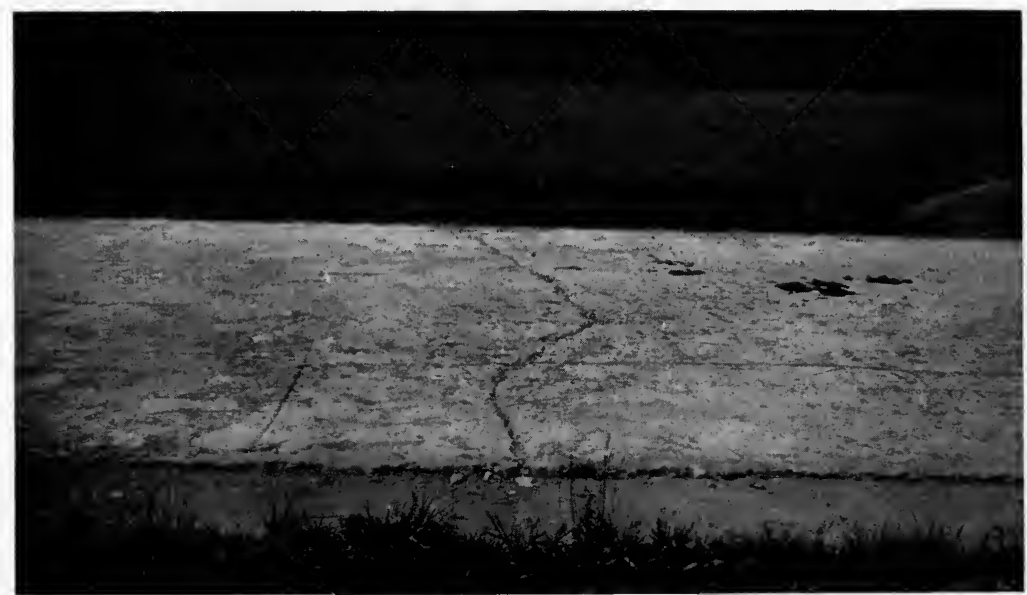

FIG. I32. Crack in Cement-Concrete Pavement Due to Contraction.

$\mathrm{I} / 2$ to $\mathrm{I} / 2$ inches wide and are filled with a bituminous filler or a patented expansion joint is employed. The width of the transverse joints depends upon the distance between them. It is considered better practice to construct narrow joints at short intervals apart rather than wide ones far apart. Transverse joints are placed from $\mathrm{I}_{5}$ to 50 feet apart, 25 feet being an average distance.

In constructing concrete roads in Michigan several kinds of transverse expansion joints have been used. The joints have been filled with two thicknesses of three-ply tar paper, with $1 / 4$-inch boards of southern pine, and with a composition of asphalt, still wax, and pitch. To protect the edges of the joints, 
angle irons have been built into the surface of the road. The use of angle irons proved so satisfactory in Wayne County,

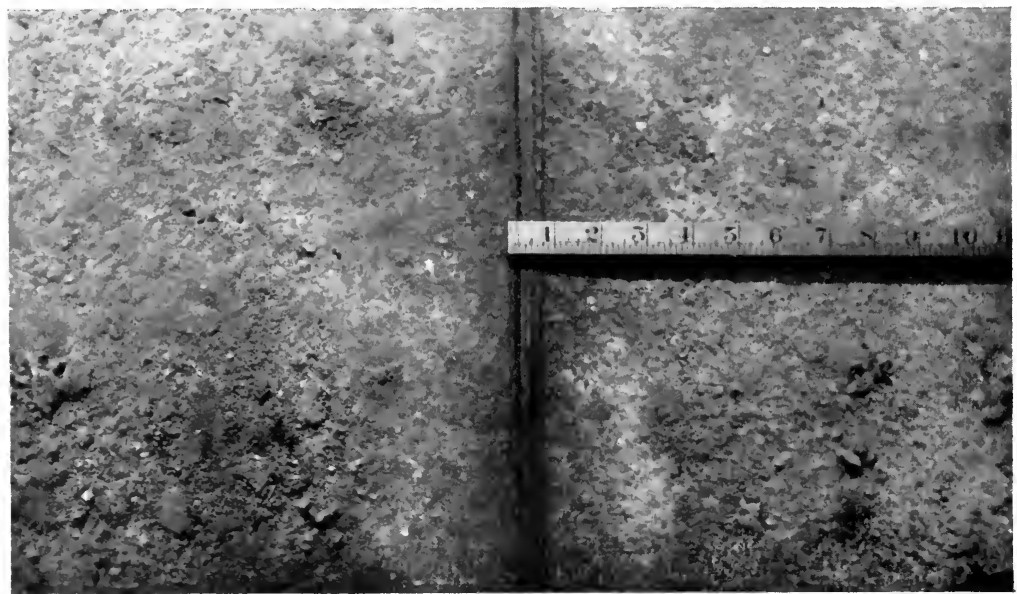

FIG. I33. Expansion-Contraction Joint in Cement-Concrete Pavement.

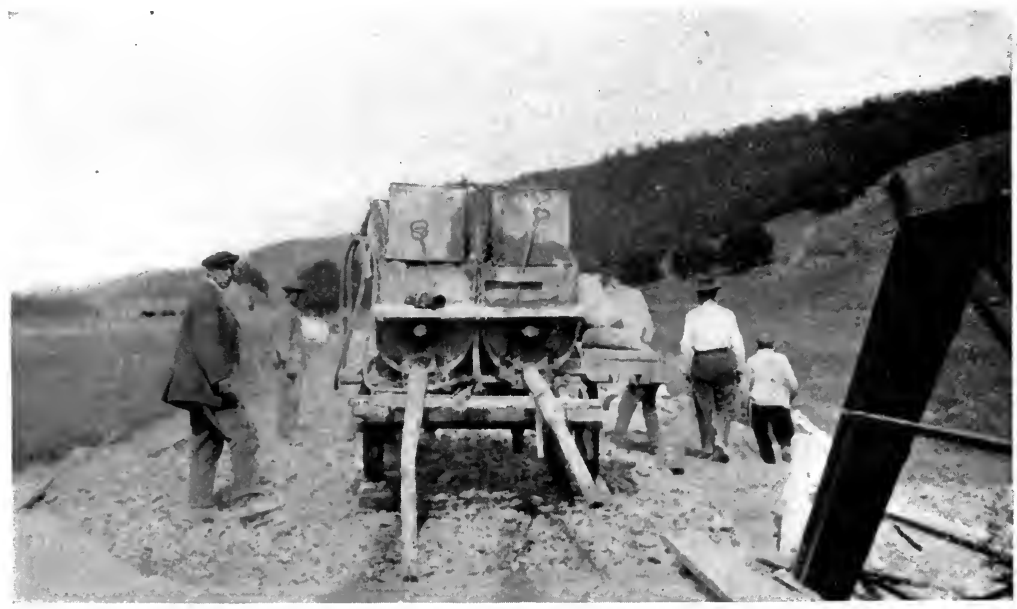

Fig. I34. Hassam Cement Grout Mixer and Distributor.

Michigan, that a modified form of angle iron was developed which was used in all of the I9I2 pavements constructed of concrete. It consists of two soft steel plates, $1 / 2$-inch thick and 
3 inches wide, which are clamped to a dividing board, the top edge of which is shaped to conform to the crown of the finished road. The plates are provided with means to tie them securely to the concrete base and wearing surface. Between the plates are placed two thicknesses of three-ply asphalted cement felt about one-fourth inch thick which extends the entire depth of the concrete. (See Fig. I33.)

Grouting Method. Pavements constructed by the grouting method are generally built in two courses. This method of

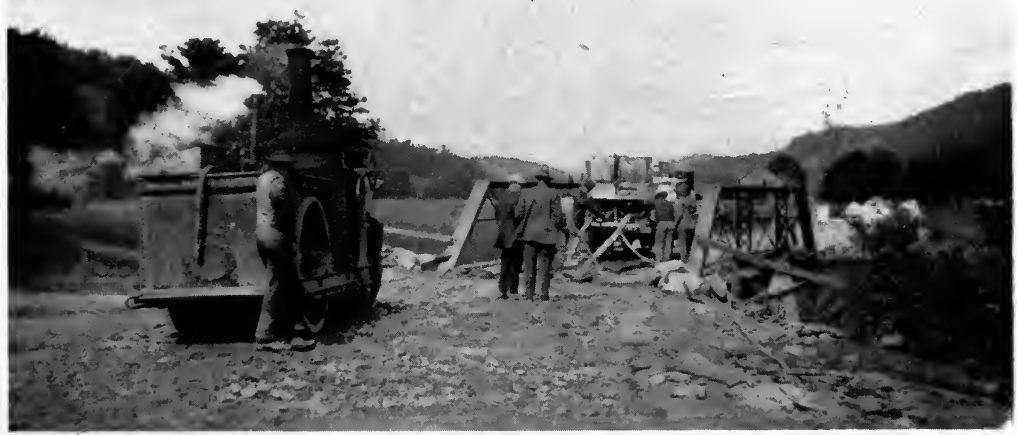

FIG. I35. Rolling Hassam Cement-Concrete Pavement.

construction has been developed by the Hassam Paving Company. A layer of broken stone ranging in size from $\mathrm{I} / 4$ to $2 \frac{1}{2}$ inches is placed on the surface and rolled to a thickness of 4 inches so that the top will be 2 inches below the finished grade of the pavement. This course is poured with a grout composed of one part cement and three parts sand. The grout is machine mixed, and is mechanically agitated during the process of pouring, so that there is never any segregation of the cement and sand. The grout mixers, see Fig. 134, are drawn along the roadway and the grout flows from the machines. through a pipe to the surface. During the process of grouting, rolling is continued, see Fig. I35, and grout is poured until the 
voids in the stone are well filled. On top of this surface a wearing course is constructed which consists of a 2-inch layer of trap rock. This is first rolled and laid in a similar manner to that of the first course, except that a thin grout composed of one part of cement and two parts of sand is used. The pavement is finished off by brooming and brushing into the surface a thick grout composed of one part cement, one part sand, and one part pea-size trap rock. The pavement is thoroughly rolled

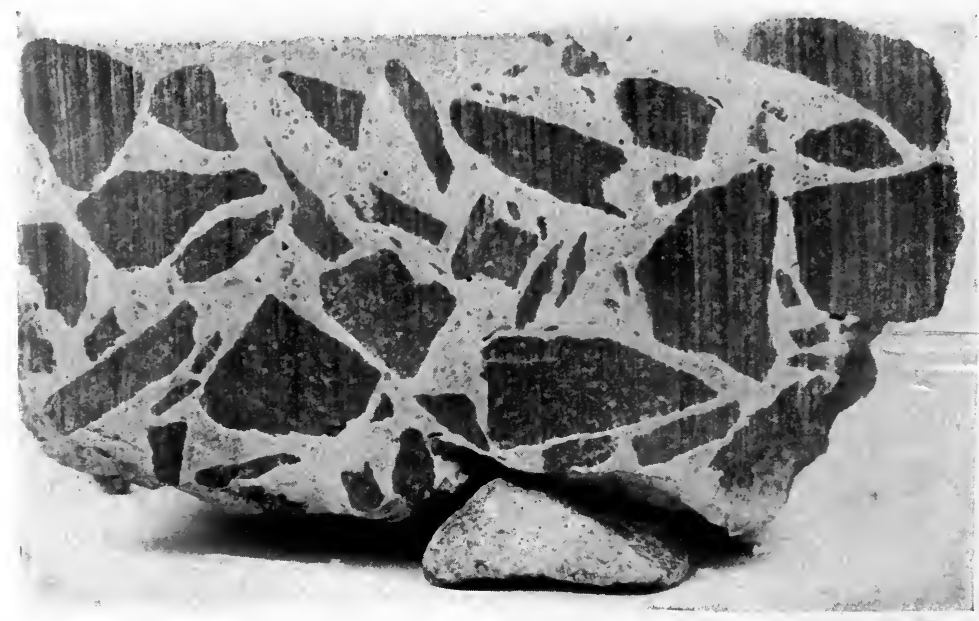

Courtesy of Wm. H. Connell

FIG. I36. Section of Cement-Concrete Pavement Constructed by the Grouting Method.

until the voids are filled in each instance and the surface has become smooth. Fig. I36 shows a section cut from a pavement constructed by this method. The Long Island Motor Parkway is one example of a pavement constructed by the Hassam method, except that in this case woven wire reinforcement was used and the stone was laid in one course. The total depth of this pavement is 5 inches, and $2 \frac{1}{2}$ inches from the surface is placed the sheet of woven wire reinforcement which extends the full width of the roadway.

Bituminous Surfaces on Concrete. A bituminous surface constructed on the surface of a concrete pavement protects the 
surface of the concrete from abrasive action of traffic, offers a better foothold with certain kinds of bituminous materials, eliminates the dust which is otherwise liable to form on a concrete surface, and does away with the objectionable glare which results when a strong sunlight shines on the concrete. The bituminous material used is either a refined tar, a tar-asphalt, or an asphalt cement. It is applied to the surface in the amount of $\mathrm{x} / 2$ gallon per square yard, and spread by means of hand

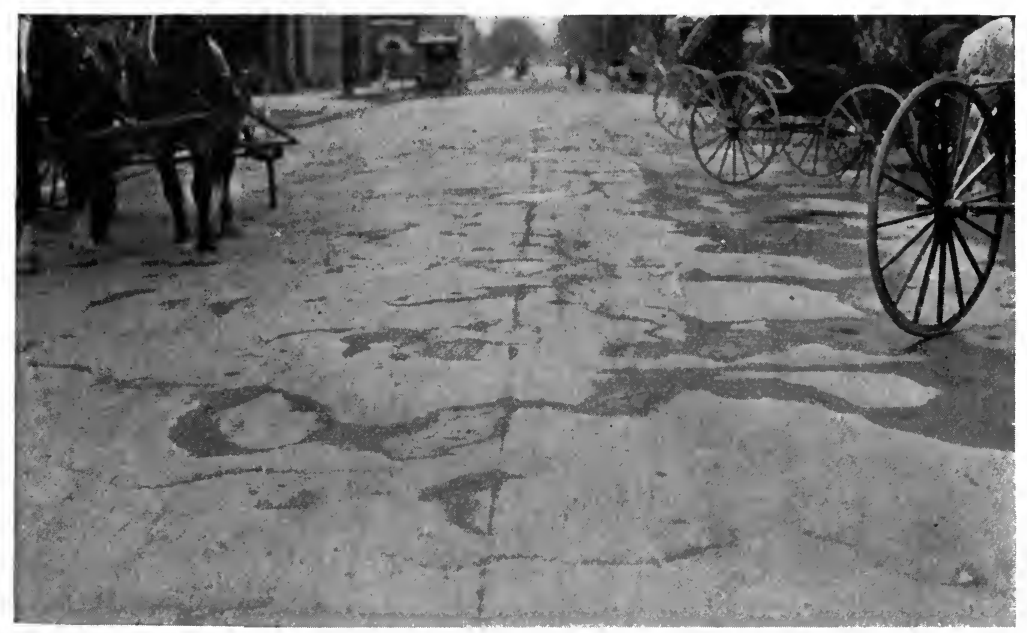

FIG. I37. Failure of a Bituminous Surface on a Cement-Concrete Pavement.

methods or by distributing machines. It is considered that the best bond and most even surface is secured by applying the bituminous material by a pressure machine in two applications of $1 / 4$ gallon each. The bituminous material is sometimes swept in with either a rotary sweeper or with hand brooms. It is then covered with sand or fine-stone chips to a depth of $3 / 8$ to $1 / 2$ an inch. Fig. 137 shows a failure of a bituminous surface on a cement-concrete pavement due to the use of a bituminous material which would not adhere to the concrete.

Cost Data. Cement-concrete pavements 5 to 6 inches in thickness usually cost between $\$ 1.00$ and $\$ 1.80$ per square yard. In the following table are given, for several localities throughout 
America, I9I4 prices of cement-concrete pavements with the types of construction used and the total thicknesses of the concrete.

From Engineering and Contracting, April 7, I9̊ı 5

\begin{tabular}{|c|c|c|c|c|c|c|}
\hline City & $\begin{array}{l}\text { Square } \\
\text { Yards }\end{array}$ & $\begin{array}{l}\text { Price* } \\
\text { per } \\
\text { Sq. Yd. }\end{array}$ & $\begin{array}{l}\text { Guar- } \\
\text { antee, } \\
\text { Years }\end{array}$ & $\begin{array}{c}\text { Type } \\
\text { of } \\
\text { Pavement }\end{array}$ & $\begin{array}{l}\text { Thick- } \\
\text { ness, } \\
\text { Inches }\end{array}$ & Proportionsł \\
\hline Meriden, Conn.... & 17,386 & $\$$ I . 28 & 5 & I-course & $61 / 2$ & $1: 2: 4$ \\
\hline Binghamton, N. Y. . & 6,439 & 1.52 & 3 & I-course & 7 & $1: 11 / 2: 3$ \\
\hline Pittsburgh, Pa..... & 2,950 & I. 39 & I & I-course & 6 & $1: 2: 3$ \\
\hline Sandusky, O... & 8,700 & I. $30 \dagger$ & 5 & 2 -course & 8 & $1: 11 / 2: 3$ \\
\hline Detroit, Mich...... & 170,160 & 2.28 & & 2-course & 7 & $1: 3: 6$ \\
\hline Minneapolis, Minn. . & 64,886 & $1 \cdot 30$ & . & I-course & 7 & $1: 11 / 2: 3$ \\
\hline Kansas City, Mo... & 365,323 & 0.973 & 5 & I-course & 6 & I $: 21 / 2: 4^{1} / 2$ \\
\hline Lincoln, Neb .... & I,95I & I. 40 & 2 & 2 -course & 6 & $1: 3: 6$ \\
\hline Columbia, S. C. & 2,969 & I. 35 & $\cdots$ & 2-course & 6 & $1: 21 / 2: 5$ \\
\hline Palo Alto, Cal. . & 47,600 & 1.22 & $\ldots$ & I-course & 5 & $1: 2: 4$ \\
\hline Portland, Ore...... & 68,919 & I. $24 \dagger$ & 10 & I-course & 6 & $1: 2: 4$ \\
\hline IVestmount, Quebec & 5,235 & 2.75 & $\ldots$ & 2-course & 6 & $I: 21 / 2: 5$ \\
\hline
\end{tabular}

* Price covers pavement, foundation and shaping subgrade.

† Does not include shaping subgrade.

$\ddagger$ Proportions for' I-course pavement or for bottom course of 2-course pavement.

\section{Maintenance}

It is not surprising that the effects of traffic on concrete pavements are very variable, when the variety of mixtures and methods of construction used in constructing this type of pavement in different parts of the country are considered. Uneven places may wear in the surface, as shown in Fig. I38, where the concrete is not uniform in character. Unless careful supervision is exercised, bad spots are very liable to occur, due to a poor mixture or a segregation of the ingredients when the concrete is placed. Once such a place starts to wear away, it grows in extent very rapidly, the abrasive action of the traffic grinding out the good concrete. Such places should, therefore, be immediately repaired, which is best accomplished by cutting them out for a depth of at least 3 inches and refilling with either cement or bituminous concrete, depending primarily upon the traffic conditions. If all loose material is taken out of the cut and the surfaces of the opening are thoroughly scrubbed with water to remove the dust, it is practicable to make an excellent patch. It is useless to try and level them up with the surrounding 
surface by putting a little mortar in the depression. Places where cracks have formed should also be given very close attention, since the edges of the cracks and the surface adjacent to them soon wear away. Filling the cracks with a bituminous filler will serve to protect the edges and prevent water from seeping down through the pavement to the subgrade. Care

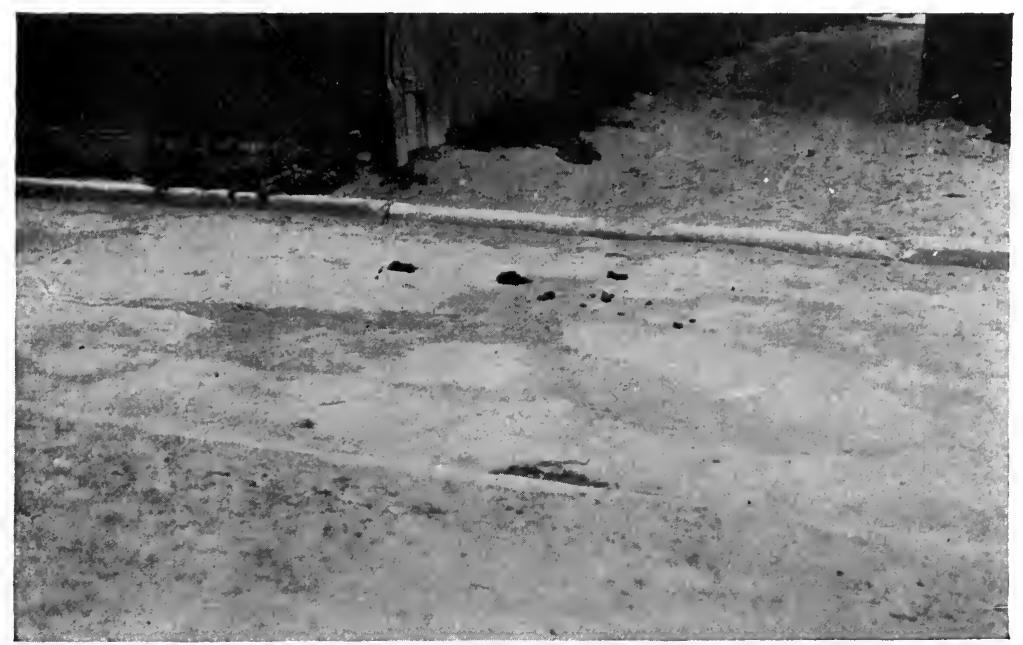

FIG. 138. Uneven Wear of a Cement-Concrete Pavement.

should also be taken to have the expansion joints always filled flush with a bituminous filler. Methods of constructing and maintaining bituminous surfaces have been explained in Chapter X.

\section{Characteristics}

A cement-concrete pavement furnishes a smooth surface which is easy to clean and is not productive of much dust, but it is somewhat noisy. If properly constructed it can carry a heavy traffic of motor trucks and affords a fair foothold for horses. The surface of the concrete can be covered with a coat of bituminous material into which is rolled a layer of stone chips. This treatment will serve to prolong the life of the road, will usually render it non-slippery under all climatic conditions, and will make it less noisy. 


\section{CHAPTER XV \\ WOOD BLOCK PAVEMENTS}

Development. Russia is credited as being the first country to use a pavement constructed with wood blocks. Although wood has been used in this country in the construction of both corduroy and plank roads, neither type could hardly be called a wood pavement as the term is now understood. The first wood block pavements in this country were laid in New York and Philadelphia about 1835 , in England about 1838 , and in

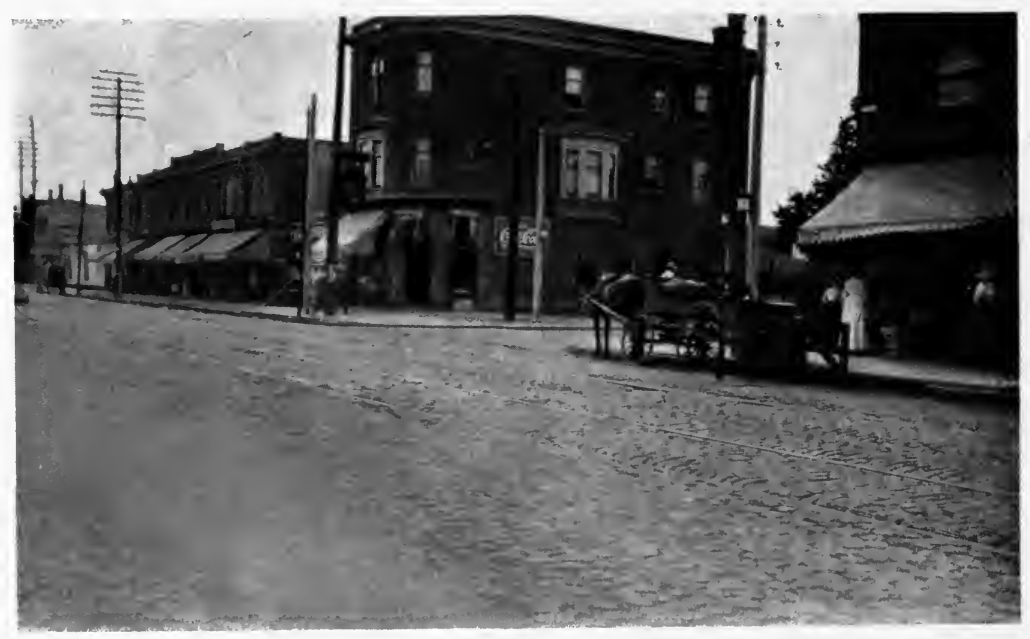

Fig. I39. Wood Block Pavement Constructed with Round Cedar Blocks.

Paris about i880. The blocks first used were round or hexagonal in shape. Round cedar blocks were extensively used in the Middle West some years ago. (See Fig. I39.) The patent office contains many records of different types of wood block pavements that were patented at different times since 1840 . One of the first pavements in which rectangular blocks were used was called the 
Nicholson pavement. It was laid in many cities of this country between I860 and I870, and was perhaps the most successful wood pavement up to that time. The blocks, which were 3 inches thick and 6 inches long, were laid in parallel courses with I-inch joints on a plank subbase and the joints were filled with hot gravel and coal tar. Little care was taken in selecting the wood for the blocks, and it was not until 1872 that a concrete foundation was used. In the development of this type of pavement it was found that the rectangular block was the best shape to use, while other details of construction, such as proper foundation and joint fillers, were found to have a direct bearing on the success of the pavement. It has also been satisfactorily demonstrated that the life of the pavement is considerably increased if the blocks are treated by some preservative process. The success of the present type, which has been developed by the gradual improvement of the early methods of construction, is evidenced by the large amounts that have been laid in London, Paris, and the United States. It has been extensively used in many of the largest cities of this country, among which might be cited Greater New York, Philadelphia, Boston, Chicago, Minneapolis, Detroit, Cincinnati, Toledo, and Indianapolis. It has also proven to be an excellent pavement for surfacing the roadways of bridges, many instances of which may be found.

\section{THE Wood}

Woods Commonly Used. Very little thought was given to the kind of wood used in the earlier types of pavements, and without doubt this fact hastened the failure of many of the pavements constructed. The "Nicholson" pavement was sometimes constructed of blocks made of soft pine. Round cedar blocks were originally used for paving the streets of Chicago. Among the other woods which have been used in various cities of the United States may be mentioned oak, cypress, hemlock, Washington red cedar, cottonwood, mesquite, Osage orange, redwood, Douglas fir, tamarack, long-leaf yellow pine, shortleaf pine, Norway pine, and black gum. A' great many of the wood pavements in England are constructed with Swedish deal. 
Experiments have been also tried there with camphor wood from Borneo, oak, beech, and both Australian and American red gum. The Australian woods, jarrah and karri, which are extremely hard and dense, were first used in London about I89r. Now they are used only to a slight extent in England, the softer woods being preferred. The wood pavements of Australia, however, are largely constructed of jarrah, which is one of the principal woods of that country. In France, pine of Landes and of Gascogne are used to a great extent. Red pine of Nord, or Sylvestre pine, commonly but improperly called red fir of Nord, is also used. Little attention was given to the proper seasoning of the wood used in the earlier pavements, and only in rare instances were the blocks treated with materials which serve to preserve the wood. The importance of these details has been realized in the development of the modern wood pavement, so that to-day very few blocks are laid which are not made from carefully selected wood and subjected to some preservative process.

Experience has shown that there are only a few woods in this country with which it is commercially possible to make good blocks. Specifications differ slightly, but the best practice admits the use of southern yellow pine, Norway pine, tamarack, and black gum. In order to secure pavements of uniform quality it is necessary to use only good grade timber free from loose knots, worm and knot holes, and shakes.

Causes of Decay. The decay of wood is due to a low form of plant life called fungi. The fungi attack the wood from the outside, and if the wood is in the right condition for the spore to grow, they will ultimately penetrate the entire structure of the wood. There are three classes of fungi, one of which attacks all parts of the wood structure, another attacks the cellulose, the third, which is the most common, attacks only the lignin, which is the name of the many organic substances which are incrusted around the cellulose. The fungi dissolve the lignin and the cellulose and make food for their development. Heat, air, and moisture are all necessary for the existence of the fungic growth. 
Wood Preservation. Since air and heat, in most climates, are always present, it is necessary to eliminate the moisture as the first step in destroying the fungus life. In fact, this is partially accomplished when timber is seasoned. The timber is piled so as to permit free circulation of air around each piece, and, in this manner, the moisture content can be reduced from I5 to I8 percent. Kiln drying will still further reduce the moisture content, but timber, whether air-dried or kiln-dried, will reabsorb moisture when exposed to it. A more effective method of timber preservation is to treat the timber with some preservative which will change the organic matter in the inner structure so that it will not serve as food for the fungi. The use of a preservative treatment will not only preserve the wood from decay but will also fill the pores and prevent the absorption of other fluids. This is a very desirable property for wood blocks to possess, since it tends to minimize expansion, to increase the resistance to wear, and to make the pavement more sanitary.

Preservatives. The preservatives used are copper sulphate, zinc chloride, creosote, and bichloride of mercury. The process of using zinc chloride is also known as burnettizing, and that one in which bichloride is used is known as kyanizing. The use of copper sulphate has been practically given up, and there are only a few places which use the bichloride process, so that, practically speaking, the processes in the United States are restricted to those using creosote and zinc chloride. Of these two the creosoting process is by far the most common, and is better, particularly if the wood is to be used where it will be wet, since the zinc chloride is soluble in water and will leach out of the wood.

Creosote. Creosote may be obtained by the distillation of coal tar, wood tar, or water-gas tar. Mixtures of coal-tar creosote oils and water-gas tar creosotes, creosote oils and resin, and creosote oils and coal-tar pitch have also been employed. It has been realized for some time that the success of a wood pavement depends largely upon the character and quantity of the creosote oil used in treating the blocks. The function of the oil is to preserve the wood against decay and prevent 
expansion and contraction for a long period of time. One of the most successful wood pavements that has been laid, the Tremont Street pavement in Boston, was constructed with blocks impregnated with a mixture of one-half creosote oil and one-half resin. Similar pavements were laid on the streets of lower New York up to Igo4. The object of incorporating the resin in the creosote was to hold the preservative in the block. In 1907 the proportion of resin in the creosote was reduced to 25 percent in the New York specifications, and in Igog it was decided that an oil with a gravity of I.I2 did not need the resin component.

The creosote oil used abroad is lighter, as a general rule, than that recommended for use in this country, the gravity being about 1.07. In Paris and Germany some blocks are immersed in a bath composed of a mixture of coal-gas tar and heavy oil.

Manufacture of Blocks. Planks of the required crosssection are cut up into blocks by a machine specially designed for this purpose. The machine consists of a series of circular saws spaced at a distance apart depending upon the size of the block to be cut. The bed of the machine is wide enough to take a long plank, which is cut into blocks by its passage over the saws. Some plants have a capacity as high as 240,000 blocks per day. Fig. I 40 shows an interior view of the municipal wood block plant in Paris.

Size of Blocks. Most of the wood blocks are rectangular in shape and are so cut as to enable a smooth pavement to be laid with the rows of blocks of uniform width. It is necessary to carefully specify the allowable variation from dimensions of the block to secure the desired results. A requirement, typical of American practice, might read as follows: The wood block shall be rectangular in shape and of the following dimensions, viz., not less than 6 nor more than 9 inches, but averaging from $7 \frac{\mathrm{T}}{2}$ to 8 inches in length; not less than $3 \frac{1}{2}$ nor more than 4 inches, but with a maximum variation of not more than $1 / 8$ inch in width; not less than 3 nor more than 4 inches, but with a maximum variation of not more than $/ / 16$ inch in depth. 
The size of blocks used in Europe varies from $23 / 4$ to 4 inches in width, from 7 to $1 \mathrm{I} 3 / 4$ inches in length, and from $43 / 4$ to

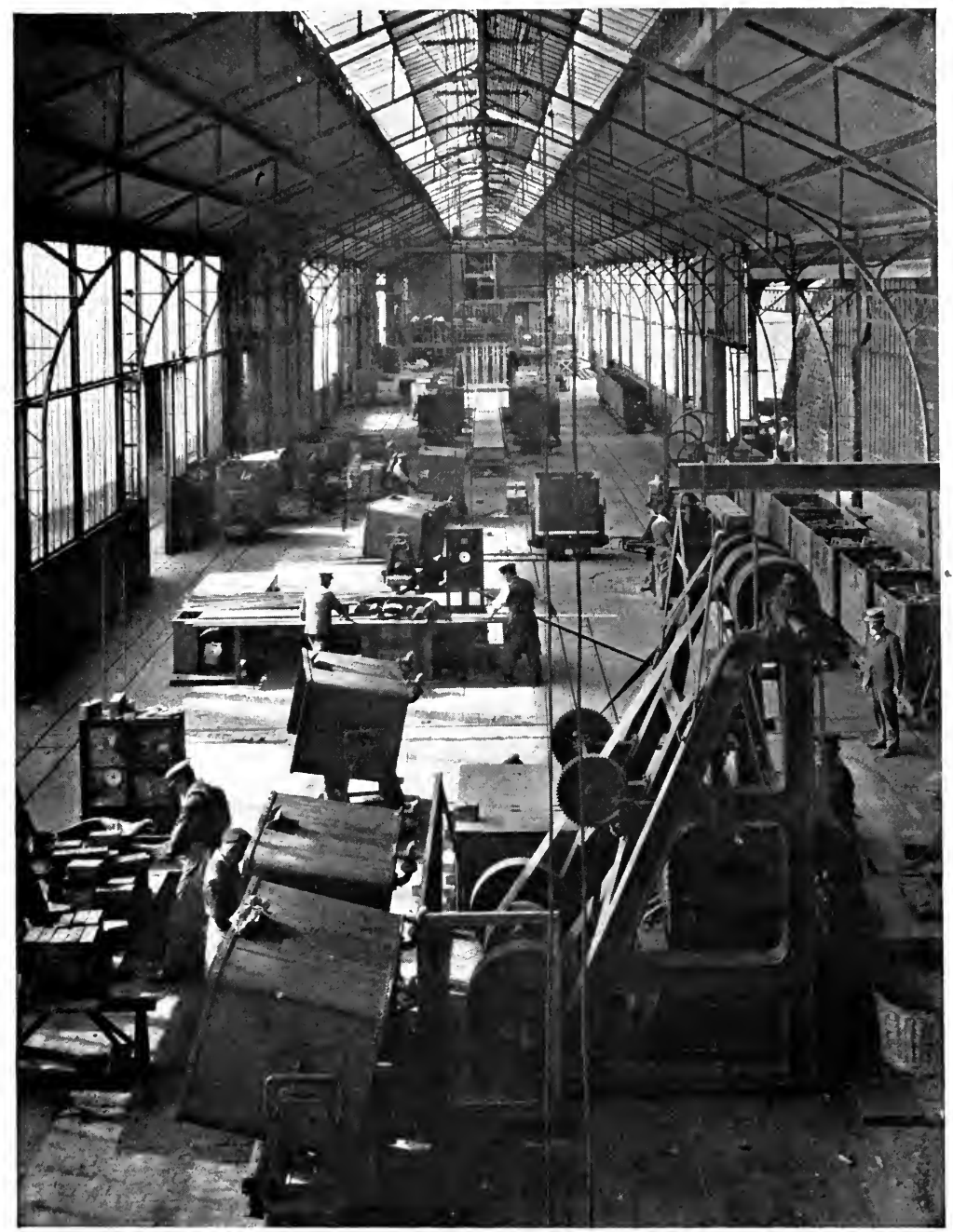

FIg. I40. Saws at Municipal Wood Block Plant, Paris, France.

7 inches in height. The size used in Paris is approximately 3 inches wide by 9 inches long by 6 inches deep.

Treating the Blocks. There are two methods in use for 
impregnating the blocks with the preservative fluid: the pressure process and the open-tank process.

Pressure Process. In the pressure process, which is used almost exclusively in treating wood blocks in the United States, the blocks are placed in large iron cylinders which are capable of withstanding pressure. A low steam pressure is maintained for a time, which softens the sap. The steam, together with whatever matter it has dissolved out of the wood, is blown out of the cylinder and a vacuum is established which serves to draw out more of the sap which has been softened by the steam. When this step has been completed, the preservative fluid is admitted to the cylinder and steam pressure is again applied. The blocks are completely immersed in the oil, which is forced into the blocks under a sustained pressure of 100 pounds or more per square inch until the charge as a whole has absorbed the requisite amount of oil. The pressure varies, depending upon the kind of wood, nature of the preservative, and the amount it is desired that the blocks shall absorb. The amounts of preservative used in the United States vary from I6 to 22 pounds per cubic foot of wood. It has been found that it takes on the average about 26 pounds of oil per cubic foot to make a block absolutely waterproof. For this reason blocks which are treated with a less amount should be put into place as quickly as possible, so that they will have no chance to dry out. On streets of heavy traffic I6- to 20-pound treatments have been found satisfactory. An amount as low as ro pounds has been commonly used abroad in this process.

Open-Tank Process. In the open-tank process, the blocks are placed in a tank which is filled with hot preservative and left for a period of time which varies from a few minutes to an hour, depending upon the kind of wood and the depth of impregnation desired. The tank is then drained off and the blocks are allowed to drip. This method is used to a large extent in France.

Testing the Blocks. The French practice is to conduct careful tests for resistance to wear when saturated with water, resistance to compression and impact, and to determine the 
amount of water the treated wood will absorb. In this country the most common tests are the amount of clear water absorbed in a certain length of time and the analysis of the preservative.

Water Absorption. The success of many wood block pavements is attributed to rigid requirements covering the amount of water which the blocks will absorb under stated conditions. Blow-outs of wood block pavements occurring after heavy rains have been undoubtedly caused, in most cases, by the absorption of large amounts of water by improperly treated blocks. The treated blocks should show such waterproof qualities that, after being dried in an oven at a temperature of $38^{\circ} \mathrm{C}$. (100 $\mathrm{F}$.) for a period of twenty-four hours, weighed and then immersed in clear water for a period of twenty-four hours and again weighed, the gain in weight should not be more than $3 \frac{1}{2}$ percent when tested at the place where manufactured and not more than 5 percent when samples are taken from the blocks delivered on the work. Tests have shown that blocks will absorb sometimes as much as roo percent more water a few weeks after treatment than they will within a few hours after creosoting.

Amount of Preservative Fluid. In order to make sure that the preservative treatment has thoroughly impregnated the wood, several blocks in each charge should be split open and examined.

\section{Construction}

Subgrade and Foundation. The roadbed is excavated to the required grade. It is assumed that all subdrains, catchbasins, inlets, curbs, etc., have been constructed. The subgrade is shaped to the surface of the finished pavement and is carefully rolled and compacted. Any poor material which does not compact properly should be removed and replaced with material of good quality.

On the subgrade is constructed the concrete foundation, built generally by the mixing method as described in Chapter V. The thickness of the foundation varies from 4 to 8 inches, depending principally upon the traffic, the average depth being 6 inches. A thickness of 9 inches has been recommended in 
England for streets subjected to the traffic of heavy motoromnibuses. The concrete foundation, like the subgrade, is built parallel to the finished surface of the pavement. The amount of crown to be used can be determined from the formulas in Chapter V. Fig. I4I shows a cross-section of a wood block pavement as constructed in Pittsburg, $\mathrm{Pa}$. It is important that the concrete should be finished evenly in order to secure a

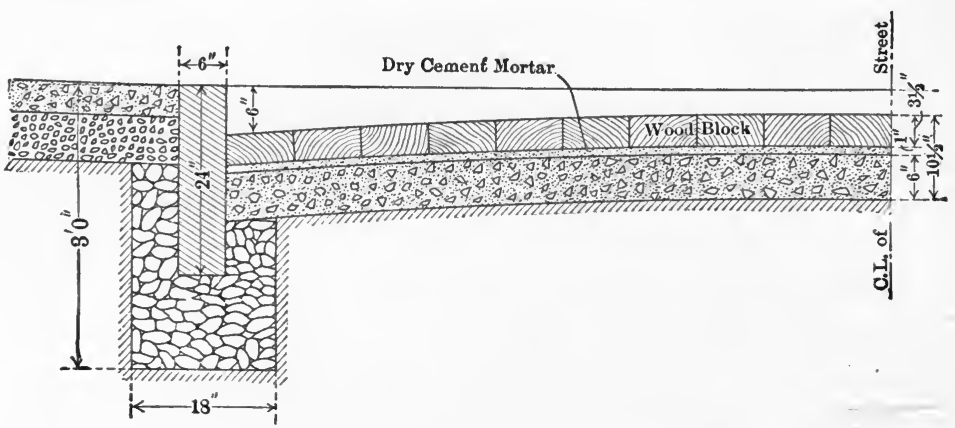

FIG. I4I. Section Showing Construction of Wood Block Pavement in Pittsburg, $\mathrm{Pa}$.

smooth finished pavement. This can readily be done, if the stones are depressed and the mortar brought to the surface, by striking off the surface of the foundation with a wooden template before the concrete sets up. During the time that the concrete is setting it should be kept wet, particularly in hot weather, and in cold weather should be protected from freezing.

Cushion Layer. The French practice is to place a thin layer of mortar on the surface of the concrete foundation before it sets up and to make this surface so regular and smooth that the wood blocks can be laid directly upon it without any intermediate layer of material. The layer of mortar becomes, in fact, a part of the foundation. The practice in America, however, is to place either a layer of sand or mortar on the concrete foundation after the latter has set up. The cushion is made from $1 / 2$ to $I$ inch in thickness. The object of either kind of cushion is to provide an even surface in the finished pavement. The mortar cushion is also used to waterproof the bottom of 
the blocks. A sand cushion may give some trouble if the pavement is constructed with open joints, since there is a possibility of water leaching down through the joints displacing the sand.

LAYING THE Blociss. The blocks are laid upon the prepared sand or mortar cushion, carefully set with the fibre of the wood vertical, and in straight parallel courses at right angles to the edge of the curb. The blocks are set loosely together on the cushion, usually breaking joints about 3 inches with no joints exceeding $1 / 8$ inch in width. Expansion joints are usually constructed parallel with and next to each curb or edging. The width of each joint is about one inch for widths of 20 feet and less and is increased for greater widths. On heavy traffic streets some engineers omit the expansion joint. Many pavements, which have not bulged, have thus been constructed in New York City. The blocks are compacted by rolling with a tandem-roller of from 3 to 5 tons weight until the surface becomes smooth and conforms with the required crown of the roadway. The success of the wood block pavements in Minneapolis is supposed to be due, in part, to the fact that the blocks are laid as soon as possible after they are received on the street and are then kept wet by sprinkling.

In the Middle West a large amount of wood block pavement is constructed by laying the blocks parallel to lines that make either an angle of 45 or $67 \frac{1}{2}$ degrees to the curb rather than on lines at 90 degrees to the curb line, as is the practice in the East. The engineers who advocate laying the blocks on angular lines believe that the pavement is benefited because the joints are not so severely exposed to blows of horses' hoofs. These claims, however, do not seem to have been sufficiently well substantiated to warrant the general adoption of this method of laying the blocks. It is more expensive to lay the pavement in this manner, since skew blocks must be cut to fit the curbs at the ends of each row of blocks. When the blocks are laid on lines making 90 degrees with the curb lines, specifications frequently require transverse expansion joints, I inch in width, every 50 or roo feet. 
The practice in Europe is to dip the bottoms of the treated blocks in hot tar or asphalt and lay them directly upon the surface of the concrete foundation, which has been given a perfectly smooth and even surface. Sometimes the foundation is mopped with bituminous material and the blocks are laid directly upon it without being dipped. By means of strips of wood a space $1 / 8$ to $3 / 8$ of an inch wide is left between the rows of blocks. The joints are filled with hot pitch, which is brushed out as soon as it is applied, so that the joints remain only half full. Clean gravel, from $1 / 8$ to $3 / 8$ of an inch in size, is spread on and broomed into the joints so as to fill the upper half and enough is left on the surface to take up the excess of bituminous material. In some instances the blocks are laid close together and the surface is coated with a thin layer of tar or tar-asphalt on which is spread a layer of sharp sand or gravel. This is rolled in and forms a durable coating that protects the blocks and reduces slipperiness. Sand and gravel are frequently applied to the surface during the life of the pavement.

It is the practice in St. Louis to omit both the sand and the mortar cushion. The concrete foundation, which has been prepared with an extremely smooth and regular surface, is given a coat of hot bituminous material directly before placing the blocks upon it. Each block as it is set into place is dipped on one side and one end in the same bituminous material that is used to cover the foundation. The side and end of the blocks that are dipped are placed against the adjacent side and end of blocks previously laid which were not dipped. By this method the foundation is waterproofed as well as the underside of the blocks, while the troubles arising from expansion are reduced. The cost of laying blocks by this method is more than where either the sand or mortar cushion is used.

Filling The JoInTs. After the blocks have been thoroughly rolled, the joints are filled with a fine sand, a cement grout, or some form of bituminous material.

Sand Filler. According to George W. Tillson, M. Am. Soc. C. E., "The first joint filler used in modern wooden pavements

* See Trans. Am. Soc. C. E., Vol. LXXV, pages 530-532. 
was sand. Afterward Portland cement grout and bituminous fillers were used. The speaker has always used sand. Wood blocks are so regular in form that they lie closely together in the pavement and need a filler only to keep them in place. It may. be said that with a sand filler the pavement will not be waterproof, but experience seems to demonstrate that the blocks, under traffic, soon mat together, making a surface which is practically continuous. The speaker recently examined a pavement of this character which had been subjected to light traffic for some seven or eight years, during which time it had been perfectly satisfactory. The sand should be fine and thoroughly dry when applied, so that the joints will be entirely filled. Should oil at any time exude from the blocks, the sand will assist in absorbing it."

Grout Filler. "Where a cement grout is used, it is made of equal parts of fine sand and the best Portland cement, carefully mixed, and swept into the joints until they are completely filled. The pavement is then covered with sand, and the grout should be allowed to set for at least seven days before the pavement is used. If the blocks are disturbed before the grout has set, the filling becomes of no more value than sand, and, as far as its absorptive properties are concerned, is even of less value."

Bituminous Filler. "Coal-tar pitch, asphalt, and special bituminous fillers are also used quite extensively by different cities, the idea being to make the pavement waterproof as well as to provide for some slight expansion of the blocks. Where such fillers have been used and excessive bleeding has occurred, much of it has been attributed to the bituminous filler."

Cost Data. Prices per square yard for wood block pavements with $5^{-}$to 6 -inch cement-concrete foundations usually vary from $\$ 2.50$ to $\$ 3.50$. In the following table are given, for several localities throughout America, I9I4 prices of wood block pavements constructed with various types of fillers and different thicknesses of foundations. 
From Engineering and Contracting, April 7, 1915

\begin{tabular}{|c|c|c|c|c|c|c|c|}
\hline \multirow{2}{*}{ City } & \multirow{2}{*}{$\begin{array}{l}\text { Square } \\
\text { Yards }\end{array}$} & \multirow{2}{*}{$\begin{array}{l}\text { Price* } \\
\text { per } \\
\text { Square } \\
\text { Yard }\end{array}$} & \multirow{2}{*}{$\begin{array}{l}\text { Guar- } \\
\text { antee, } \\
\text { Years }\end{array}$} & \multirow{2}{*}{$\begin{array}{l}\text { Kind } \\
\text { of } \\
\text { Filler }\end{array}$} & \multicolumn{3}{|c|}{$\begin{array}{l}\text { Concrete } \\
\text { Foundation }\end{array}$} \\
\hline & & & & & $\begin{array}{l}\text { Thick- } \\
\text { ness, } \\
\text { Inches }\end{array}$ & $\begin{array}{c}\text { Propor } \\
\text { tions }\end{array}$ & \\
\hline Springfield, Mass. & I0,884 & $\$ 3.04$ & $\cdots$ & Sand & 5 & I $: 3$ & \\
\hline Meriden, Conn ... & 44,331 & 3.20 & 5 & Sand & 6 & $I: 21 / 2$ & \\
\hline Philadelphia, $\mathrm{Pa}$. & 31,224 & 3.28 & 5 & Sand & 6 & I $: 3$ & \\
\hline Pittsburgh, Pa.. & 6,236 & $3.0 \mathrm{I}$ & 5 & Cem'tGrout & 6 & I $: 3$ & \\
\hline Akron, $U_{\ldots} \ldots$ & I 8,840 & $2.64 \dagger$ & 2 & Tar & 6 & I $: 3$ & $: 6$ \\
\hline Chicago, Ill... & I39,9 I4 & $3.12 \dagger$ & 5 & Pitch & 6 & I $: 3$ & $: 6$ \\
\hline Detroit, Mich ...... & 262,969 & 2.48 & $\cdots$ & Tar & 6 & I $: 3$ & $: 6$ \\
\hline Minneapolis, Minn. . & 204,655 & 2.40 & & Pitch & 5 & I $: 3$ & $: 6$ \\
\hline St. Paul, Minn... . . & 269,969 & 2.60 & . & Pitch & 5 & I $: 3$ & \\
\hline Louisville, Ky . & 9, I 33 & $3.17 \dagger$ & 5 & Asphalt & 0 & I : 3 & $: 7$ \\
\hline Portland, Ore ....... & I 2,108 & $2.60 \dagger$ & 20 & Cem't Grout & 6 & I $: 3$ & $: 6$ \\
\hline So. Vancouver, B. C. & 65,743 & $3 \cdot 55$ & I5 & Pitch & 6 & I $: 3$ & $: 6$ \\
\hline
\end{tabular}

* Price covers pavement, foundation, and shaping subgrade.

$\dagger$ Does not include shaping subgrade.

\section{Mainti nance}

Bleeding of Pavements. One of the principal troubles with wood block pavements is the oozing out of the preservative fluid, particularly during warm weather. (See Fig. 142.) The bleeding is attributed to the character and quality of the preservative fluid used, the effect of traffic, the expansive effect of heat on the blocks, and the use of too much preservative fluid per cubic foot. The pavement while in this condition is extremely objectionable, but it generally proves satisfactory after two or three years, when the bleeding usually ceases. In Norfolk, Va., where the oil oozed from the surface of woodblock pavements, dry sand was applied and, when it became thoroughly saturated, was scraped off and a second application of sand was made. The pavements in Norfolk were treated with 25 pounds of preservative per cubic foot. The wood pavement on Market Street in Philadelphia acted in a similar manner. The blocks were treated with 24 pounds of oil per cubic foot. At the present time, however, the pavements in both of these cities are in excellent condition. If the blocks are properly treated, pavements do not generally ooze much longer than the first few months of hot weather, although there 
are some instances where pavements have oozed for four or more years. In these cases the oil seems to run out, not only during hot weather, but also during the early spring and late fall.

REPAIRS To SURFAcE. The other maintenance work required consists of removing poor blocks and of raising low spots and lowering the pavement in places which have bulged up. Places

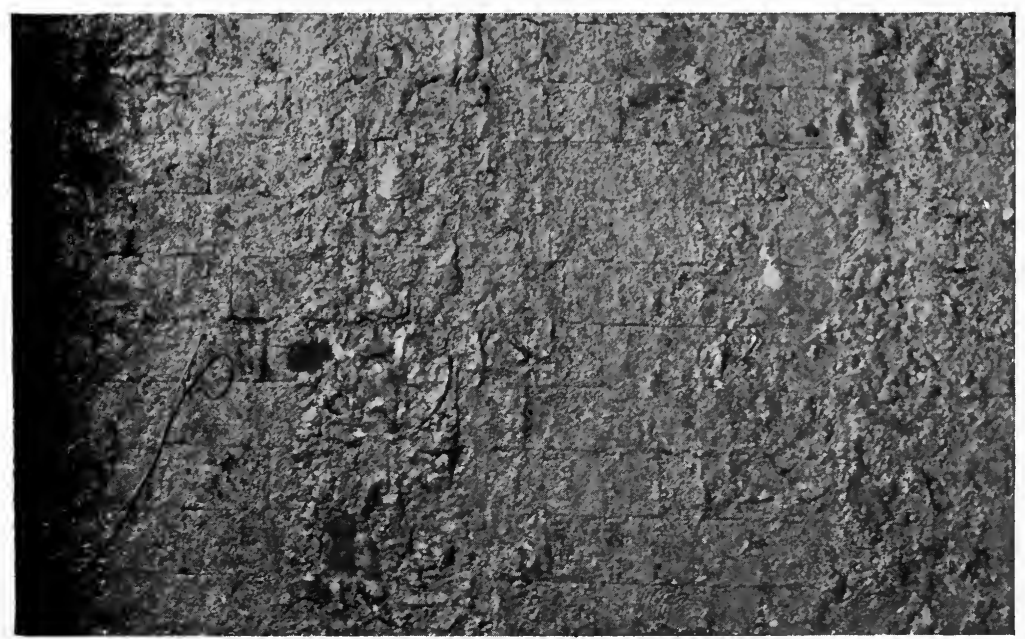

FIG. I42. Bleeding on the Surface of a Wood Block Pavement.

which have bulged up can generally be attributed to the lack of adequate expansion joints. This fault is accentuated if the blocks absorb water to any great extent.

Prevention Against Slipperiness. During wet and frosty weather it will be frequently necessary to spread a light coating of sand over the pavement in order to prevent it from becoming slippery. In France and England, wood pavements have been covered with a bituminous surface to reduce slipperiness and preserve the surface.

Relaying. The life of some of the wood pavements in Paris has been prolonged by taking up blocks after several years of service and sending them to the municipal plant, where the tops are sawed off so that the blocks are again of uniform 
depth, and then relaying these blocks with the original bottom surface as the wearing surface.

Cost of Maintenance. The wear of wood block pavements is very remarkable. A block taken from a street in Chicago, which had been down for six years and subjected to the traffic of many 6-and 8-ton loads, was found to measure 3.9 inches on the one end and 3.85 inches on the other, its original depth being 4 inches. There are wood pavements in Chicago which are ten years old and apparently good for another ten years.

There are two wood paved streets in St. Louis which were laid in 1903 that, in I910, were in excellent condition, the total repair charges on the 60,000 square yards of pavement for, the seven years being only \$2.Io. The streets, while not receiving the heaviest traffic, are subjected to considerable hauling in the form of ice, coal, and building material wagons.

In 1900, Tremont Street, Boston, which carries a heavy traffic, was constructed partly with wood block. In I9I5 it was in very satisfactory condition. Its life should be between twenty and twenty-five years.

In Paris, on the streets which are subjected to as many as 65,000 teams per day, or 3,400 per yard of width, the wear is, on the average, 0.4 of an inch per year: The average life of pine-paving blocks, which have not been treated under pressure, is about eight years. Some wood blocks, which have been creosoted under pressure have given satisfactory service for fifteen years.

\section{Characteristics}

A wood block pavement built with blocks, that have been treated with a preservative and properly constructed, makes an excellent pavement which stands up under heavy traffic. This fact has been substantiated in many places, not only in this country, but also in France and England. It is much less noisy than a stone-block, brick, or an asphalt pavement. From the standpoint of the tenants of buildings along the street, this feature of a wood block pavement is distinctly appreciated. 
Some teamsters, however, object to wood block pavement on account of its slipperiness. It is only fair to state that this condition is noticed principally at times when the pavement is in a slightly moist condition, but under the same conditions it is probably not much more slippery than an asphalt pavement. When too much preservative fluid has been used in treating the blocks, some inconvenience and unpleasantness is very liable to be experienced, due to bleeding. If properly constructed it presents a smooth surface, which is readily cleaned. 


\section{CHAPTER XVI \\ BRICK PAVEMENTS}

Development. Probably the first brick pavements were constructed in Holland. Although this type of construction has been employed in Holland for over a century, the use of brick pavements in other parts of Europe is very limited. The brick pavement was introduced into the United States by the construction of a short experimental section in Charlestown, W. Va., in 1870. This was followed by another experimental piece laid in Bloomington, Ill., in 1875 , and a few other sections laid from time to time, up to $188_{5}$, in different cities of the Middle West. Philadelphia was the first large city to use brick pavement, a section being laid in 1887 . The use of this kind of pavement then began to increase rapidly, and at the present time there are very few large cities in the country which do not have some of their streets paved with this material. A census of the pavements laid in I910, in the United States, showed that brick was one of the most popular forms of pavement. From this census it was found that while sheet asphalt ranked first from the standpoint of yardage in the 460 cities reported, brick was a close second. It is natural that the greatest yardage should occur in those cities throughout the Central States, since this locality abounds with clay and shale deposits suitable for the manufacture of paving brick.

The early brick pavements were constructed without a concrete foundation and with a sand filler. In the development of this type of pavement which has taken place since 1885, considerable attention has been given to the manufacture of the brick itself. Current practice usually requires a concrete foundation and generally some other filler than sand. Credit should be given to the National Paving Brick Manufacturers' Association for the material improvement of methods of manufacture 
and many details of construction, and the standardization of the rattler test.

\section{The Brick}

Brick Clays and Shales. A clay to be used for the manufacture of brick should be fusible, plastic, and capable of being heated to a high temperature without losing its shape. Surface clays, therefore, are very little used, although they are extensively employed in the manufacture of building brick.

Most of the paving brick are now made from shale. Shales are chemically of the same composition as clays, but have become hardened and have a laminated structure. They are found in large deposits in stratified beds. To make a satisfactory vitrified paving brick a shale should have approximately the following composition, which is an average of fifty shales from different sources that are used for this purpose: silica, 56 percent; alumina, 22.5; water and other volatile constituents, 8.5; and such fluxing constituents as sesquioxide of iron, lime, magnesia, etc., I3.0 percent. An excess of silica will cause weakness and brittleness, while an excess of alumina will cause shrinking, cracking, and warping.

Manufacture of Brick. The shales are usually obtained by open pit excavations, a steam shovel being used if the plant is large enough to warrant an outfit of this kind. The shale is generally crushed by rolls 4 feet in diameter and 12 inches wide running within a revolving pan, 9 feet in diameter, that has a grated bottom. The shale, as it is crushed, is screened through a 4 to 8 -mesh sieve. The screened material is mixed with water in a pug mill to the right state of consistency. The pug mill is a long trough through which runs a heavy revolving shaft equipped with a series of wide blades. The plastic shale, as it leaves the pug mill, is forced by an auger through a die which forms a continuous bar of stiff shale of the desired crosssection and this is cut into bricks of the required size by an automatic cutter. The dies and cutting apparatus are so arranged that the bricks are cut off with a side cut. In the manufacture of wire-cut-lug-brick, lugs are cut in the sides by means 


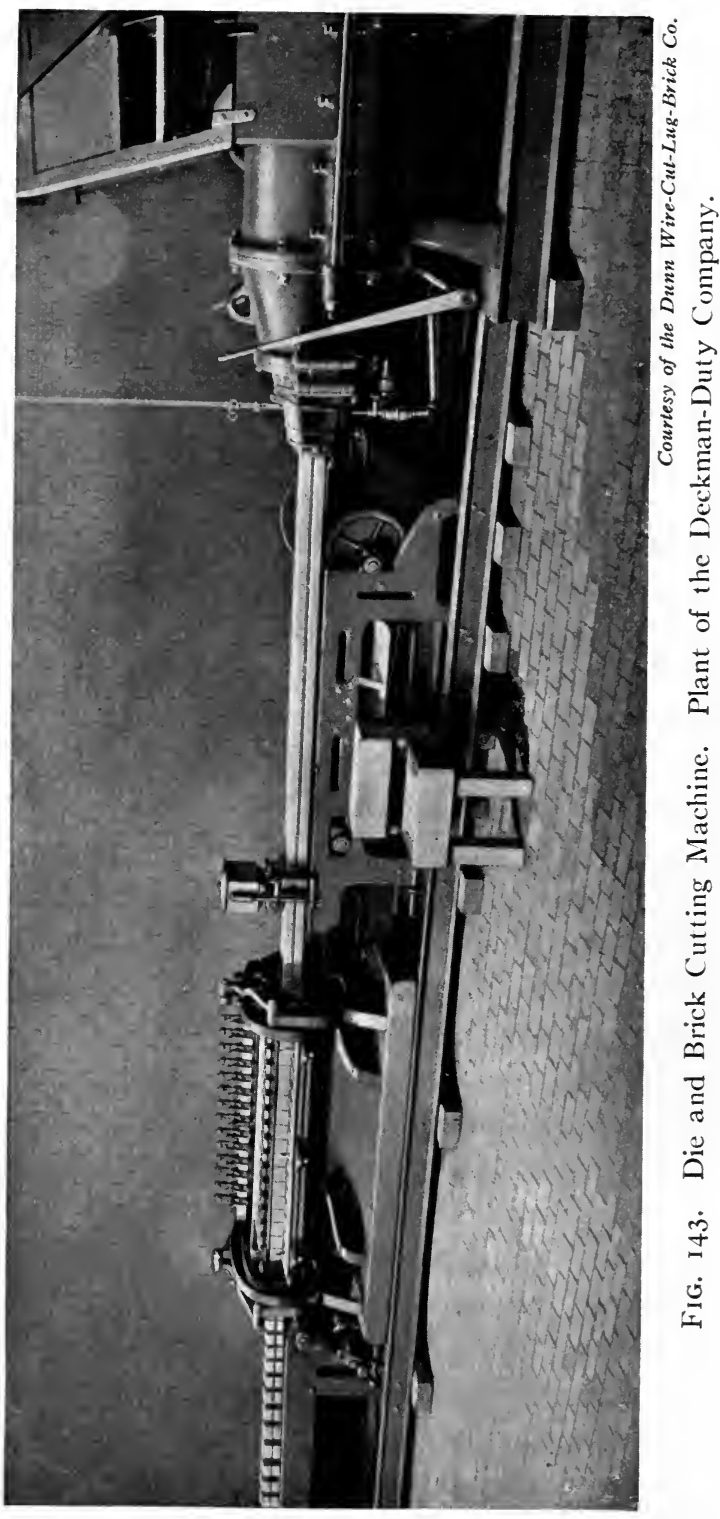


of wires travelling through guides. (See Fig. I43.) "Verticalfibre" brick, which are not repressed, have lugs formed on the side by means of the die. In another method of manufacture, the bricks, after being cut from the clay bar, are repressed in a die, during which process the edges of the brick are rounded off and lugs, grooves, and the brand mark are stamped on the sides of the brick. Bricks made by this method are called "repressed." The function of lugs on a paving brick is to provide space between the bricks for the filler. The brand marks are sometimes raised and serve the same purpose as lugs.

The bricks, as they leave the cutting or repressing machine, are piled on cars in a manner that will allow free circulation of air between them, and are then hauled to a drying chamber, which is heated either by hot air or by steam pipes. It takes from eighteen to sixty hours to dry the bricks properly, depending upon the kind of clay and the plant arrangement. The bricks are burned from seven to ten days at a temperature of from $\mathrm{I}, 500^{\circ}$ to $2,000^{\circ} \mathrm{F}$., at which temperature the clay finally completely coalesces or vitrifies. It is at this point that the brick, when slightly cooled, has obtained its maximum toughness and cross-breaking strength. The temperature which is necessary to vitrify the brick is maintained in the kiln until the bricks are thoroughly heated through to the center. The kiln is then tightly closed and the bricks are allowed to cool off very slowly. This part of the process is called annealing, and to obtain a tough brick requires from seven to ten days cooling in the kilns. The bricks are then sorted into different lots, the No. I paving brick generally being found in the uppermost layers in the kiln.

The color of the paving brick is governed largely by the material from which the brick is made, the degree of temperature which is reached in vitrifying the brick, and the kind of fuel that is used. The outside color of a brick is also changed by the sand that is used to prevent the brick from sticking to the dies or to each other in the kiln. As a rule, shales make a brick either red or brown, while the impurer clays give different shades of buff. 
Size and Character of Brick. Two sizes of brick are used. The large size, usually designated as blocks, ordinarily has dimensions within the following limits: width, 3 to $33 / 4$ inches; depth, $3 \frac{3}{4}$ to $4 \frac{1}{4}$ inches; length, $81 / 2$ to $9 \frac{1}{2}$ inches. The average dimensions of the small size, commonly called brick, are $2 \frac{1}{2}$ inches in width, 4 inches in depth, and $81 / 2$ inches in length. Specifications usually allow, in a given shipment of brick, a variation of $1 / 4$ inch in width and depth, and $1 / 2$ inch in length. The dimensions of vertical-fibre brick average 4 inches in width, $8 \mathrm{r} / 2$ inches in length, and from $2 \frac{1}{2}$ to 4 inches in depth. These brick are usually laid flat, while the types previously mentioned are ordinarily laid on edge. When the edges of the brick are rounded the radius should not exceed $3 / 16$ inch. Bricks should have lugs on one side only and of such dimensions that the transverse joints will be uniform in width, not less than $3 / 16$ inch nor more than $3 / 8$ inch. Practically all specifications require that the brick should be thoroughly annealed, tough, durable, regular in size and shape, and evenly burned. When broken, the brick should show a dense, stone-like body, free from lime, air pockets, cracks, or marked laminations. Kiln marks should not exceed $3 / 16$ of an inch, one edge at least to show but slight marks. All bricks so distorted in burning as to lay unevenly in the pavement should be rejected. The brick should always be carefully unloaded by hand and stacked in piles at the sides of the streets outside of the limits of work. The number of brick that it will take to make a square, yard of pavement depends upon the size of brick and the width of joints. When laid flat about 35 blocks per square yard are required, and if laid on edge an average of 45 blocks is used.

Testing THE BRICK. It is possible by means of tests to determine the quality of a brick proposed for use in a pavement. The most important test employed is made with the rattler and gives some indication of how the brick will wear when subjected to the action of traffic. The specifications of the American Society of Municipal Improvements call for no other test than the rattler test since it is believed that if a brick is 
sufficiently hard and tough to pass this test successfully, it is of such a quality that it will successfully meet the requirements of other tests. The other tests which are sometimes made are the absorption, cross-breaking, and crushing-strength tests.

The Rattler Test. The standard rattler is a machine which consists essentially of an iron barrel about 28 inches in diameter and of about the same length. The abrasive charge consists of two sizes of spherical shot, the larger size being about 3.75 inches in diameter when new, and weighing about $7 \frac{1}{2}$ pounds each, the smaller size being 1.875 inches in diameter, and weighing 0.95 pound each. Ten of the large shot are used and enough of the small shot to bring the weight up to a total of 300 pounds. The bricks are first dried for a period of at least thee hours at a temperature of $100^{\circ} \mathrm{F}$. Ten bricks are weighed and then placed in the rattler with the charge of spherical shot. The rattler is revolved for $\mathrm{I}, 800$ revolutions at a rate of $29 \mathrm{I} / 2$ to $30 \mathrm{~L} / 2$ revolutions per minute. The bricks are then taken out and their loss in weight is determined. No piece of brick should be weighed which is under one pound in weight.

Many specifications require that, in the rattler test, the brick shall lose not more than 22 percent of their weight. In order to insure that brick of uniform quality is supplied for a given pavement, in addition to the above requirement, there should be an additional stipulation that the maximum loss in the rattler test in any one brick should not exceed 27 percent. Another method of covering this requirement is to state that the maximum and minimum losses on the individual brick should not vary more than ten points.

Absorption Test. The absorption test is made on five bricks which have been through the rattler test and whose weights are known. They are immersed in water for forty-eight hours and then weighed again. From these weights, before and after immersion, the percent of water absorbed can be computed. Specifications generally do not allow over $3 \frac{1}{2}$ percent absorption.

Cross-Breaking Test. The cross-breaking test is made by placing a brick on edge on supports which are 6 inches apart. The breaking load is applied at the center of the brick. The 
average of the result on ten bricks is used in computing the modulus of rupture. $\quad R=\frac{3 W L \text {, }}{2 b d^{2}}$ where $W$ is the average breaking load in pounds, $L$ the length between supports expressed in inches, $b$ the breadth, and $d$ the depth in inches.

\section{Construction}

Subgrade. The subgrade should be prepared with the same care that is shown in building all types of pavements. All poor

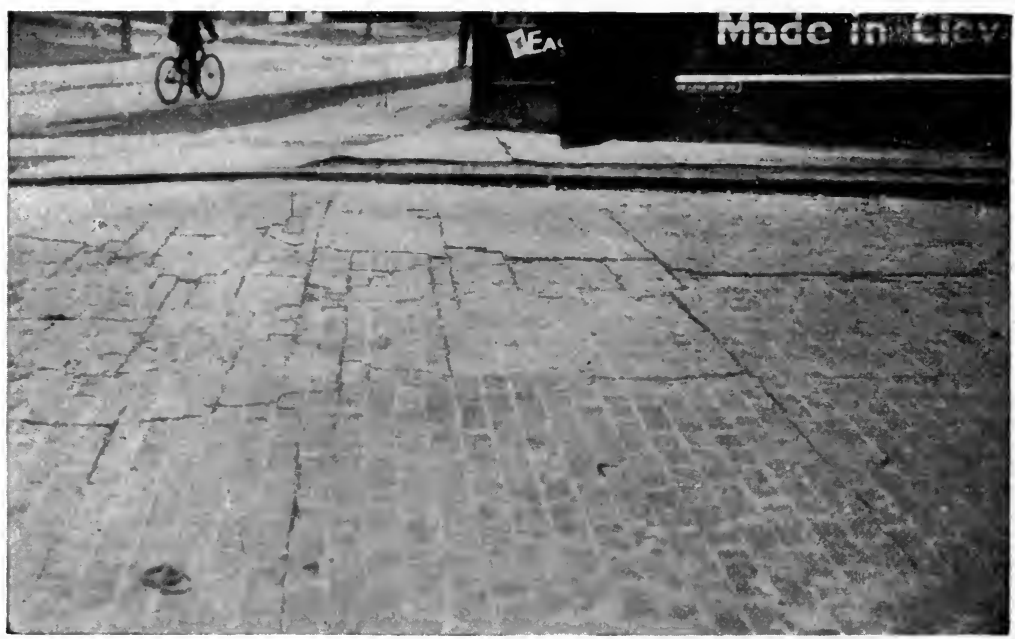

FIG. I44. Result of Constructing a Brick Pavement on a Sand Foundation.

material should be replaced with material of a good character and the whole thoroughly compacted to correspond to the shape of the finished surface of the pavement.

Foundation. On streets it is generally customary to construct a brick pavement on a cement-concrete foundation, a description of which is given in Chapter V. An average thickness for the foundation is 6 inches. In constructing brick pavements on roads in Ohio and in Pennsylvania, a 4-inch concrete foundation has been used. It is believed by some engineers that in locations where the traffic is not heavy, either broken 
stone or good gravel, well compacted, will serve satisfactorily as a foundation. This is not considered good practice. If the bricks are' laid directly upon a sandy subgrade the surface will soon become uneven. (See Fig. 144.) The National Paving Brick

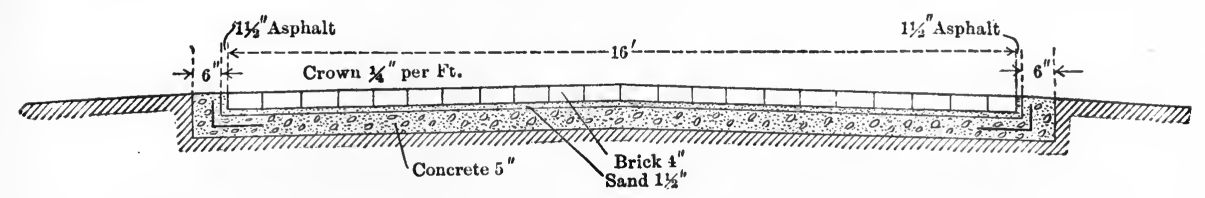

Fig. 145. Standard Section of Brick Pavement, New York State Department of Highways.

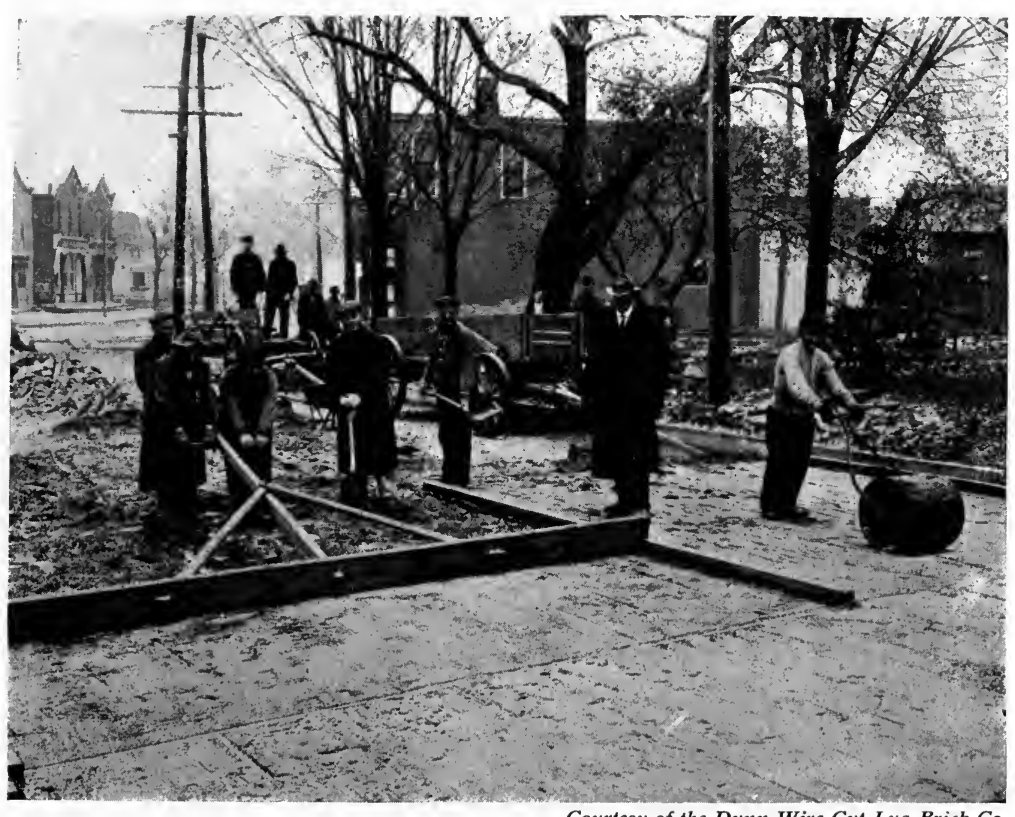

FIG. I46. Smoothing off the Sand Cushion.

Manufacturers' Association specify two kinds of foundation, one of concrete and the other of No. 2 paving block, laid flat. The latter foundation is constructed by covering the subgrade with a layer of sand 2 inches in thickness and laying the bricks flat- 
wise upon this sand bed, filling the joints with a cement filler composed of two parts of clean sand and one part of Portland cement. This type of foundation has given satisfactory results in some instances, but it is almost as expensive to construct as concrete. When a brick pavement is to be laid where no curbs exist, a concrete shoulder or edging is built which serves to prevent the brick from moving laterally and holds the sand cushion in position. Fig. I45 shows the standard section used by the New York State Department of Highways. The foundation is constructed with the same crown as the surface. Formulas for the amount and distribution of the crown have been given in Chapter IV.

Cushion. Sandy material, which contains no particles that will not pass a $1 / 4$-inch screen, is spread on the foundation in such amount that it will have a thickness of $\mathrm{I} / 2$ to 2 inches when the cushion is completed. After being carefully levelled off by means of a template so that the surface of the sand is parallel to the finished surface of the pavement, it is then rolled with a light roller. (See Fig. 146.) Some cushions are prepared by first rolling the sand and then drawing a template over the surface, the process being repeated until a firm, even surface is secured. A well compacted, even sand cushion is one of the most important details in the construction of brick pavements.

LAYING THE BRICK. The bricks are laid on the sand cushion and generally at right angles to the curb, except at street intersections. If the bricks are laid across the intersection on lines at right angles to the center line, it is apparent that the traffic entering from the cross street will travel in a direction parallel with the long side of the bricks. This causes a greater wear at the joints than when the bricks are laid as in Fig. 147.

When the bricks are laid at right angles to the curb, they are placed on edge close together with the joints broken by at least three inches. Care should always be taken to place the lug sides on the same side of the course: On the completion of every fourth course, the brick should be driven together so as to secure tight joints and straight courses. The end joints 
are made tight by the use of a bar between the end of each row and the curb. To avoid disturbing the sand cushion the laborers should stand on the bricks as they are laid. The required crown of the pavement is obtained by the aid of strings, stakes, or board templates.

Rolling. When the pavement has been prepared as above described, and thoroughly swept, it is ready for rolling. A

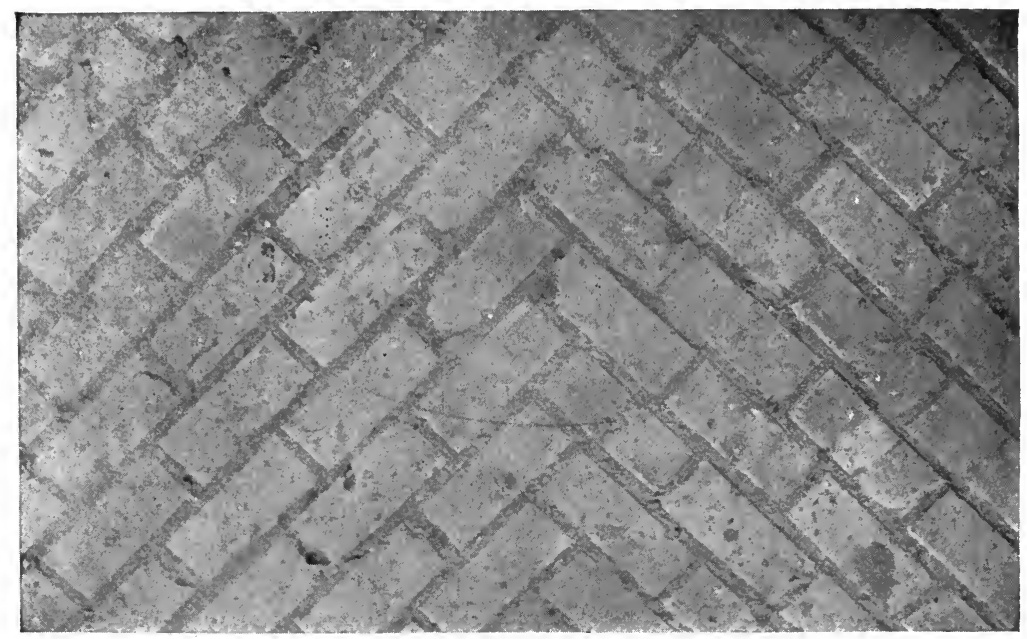

FIG. I47. One Method of Laying Bricks at Street Intersections. Joints Filled with Asphalt.

tandem roller weighing not less than 3 nor more than 5 tons is generally used. Rolling is commenced near the curb, the roller travelling parallel to the curb, back and forth at a slow speed and gradually working across the surface toward the center. When the center is reached, the roller starts at the opposite curb and rolling again progresses to the center as before. Rolling is continued as described until the bricks are firmly fixed. Cross rolling is usually required wherein the roller travels in a direction at 45 degrees from curb to curb and then in the opposite 45-degree direction. Any broken or unsatisfactory brick which are found during the work of rolling are replaced. Upon completion of the rolling, the surface may be 
tested with a ro-foot straight edge. Some specifications require the removal and relaying of any parts that show a depression exceeding $1 / 4$ of an inch when tested by this method.

Expansion Joints. To allow for expansion of the pavement it is common practice to insert boards between the curb and the pavement which will provide a space from $I$ to $I / 2$ inches wide. After the pavement is otherwise completed, the board or boards are removed and this space is thoroughly cleaned out and filled with a bituminous filler. Some specifications also provide for a transverse expansion joint, constructed in a similar manner, at a distance of every 25 to 50 feet. Transverse expansion is sometimes provided for in a cement grout-filled pavement by filling with a bituminous filler the joints of four to six adjacent rows of blocks about every 25 feet along the street. Unless great care is taken in providing for the expansion of the pavement, serious trouble may ensue, particularly where the pavements are subjected to marked changes of temperature. If the pavements are constructed in the hottest months of the year, the bricks, being in an expanded condition when laid, will not expand as much after the pavement is constructed as when they are laid in a cold season. When a brick pavement cannot expand in its normal plane, the brick wearing course arches up over the sand cushion. The pavement under this condition becomes noisy, and frequently cracks are formed in the surface. In some cases the expansion is sufficient to force the pavement up several feet.

Jornt Fillers. After the pavement has been rolled, the joints should be filled with some suitable material. Sand, cement grout, coal-tar pitch, and asphalt have been used as joint fillers.

Sand was used for a joint filler in the earliest type of brick pavements. In many places where traffic was not heavy, it was successful, but it does not protect the joints from wear nor does it provide a waterproof surface.

Cement grout filler is strongly recommended by the National Paving Brick Manufacturers' Association. This type of filler, however, is difficult to apply. If improperly used successful results cannot be expected. To quote Will P. Blair, Secretary 
of the National Paving Brick Manufacturers' Association, "the following practices have come under my observation: I have seen the filler dipped from the mixing box with a bucket and carried many steps. In such case, the sand was on its way to the bottom of the bucket and the cement was making for the top.

"I have seen the mixture placed in a cradle or rocking box and in the time intervening the turning of the box, the sand and cement were undergoing a like separation, and as the box was turned the richer mixture of cement flowed ahead and the weaker and sandy portion remained near' the box.

"I have seen the water applied before the mixture, in a dry state, reached an even shade, thus preventing the proper adhesion of the particles.

"To remedy the thickening of the mixture, I have seen it entirely ruined by throwing upon the street the water from an open nozzle, which served only to float the cement away from the sand.

"I have seen the mixture put upon the street much faster than it could be swept in.

"I have seen the mixture prepared in a dry street in large quantities at intervals of a few feet upon the brick, and the water applied and the sweeping-in process undertaken simultaneously.

"I have seen the mixture made up in such large batches that it required a sweeping of several feet before it could be made to disappear in the interstices. In such cases, the last that went in was but very little better than pure sand.

"I have taken a quantity of sand from the supply to be used for filler purposes and found that it contained 33 percent of soil. Thus I might enumerate for hours the manner, method, and means of applying the cement filler in the interstices of a brick street, each and every one of which was but to insure failure, and in none of which is economy to the contractor subserved."

Trouble which may arise from expansion of grout-filled pavements has already been mentioned. Fig. I48 shows a poor brick in a grout-filled pavement. To remove this brick will probably require the destruction of at least two of the adjacent bricks. Fig. I49 shows how the cement grout is chipped out 
between some joints by the horse-drawn traffic. Fig. I50 shows a grout-filled pavement which has expanded longitudinally and

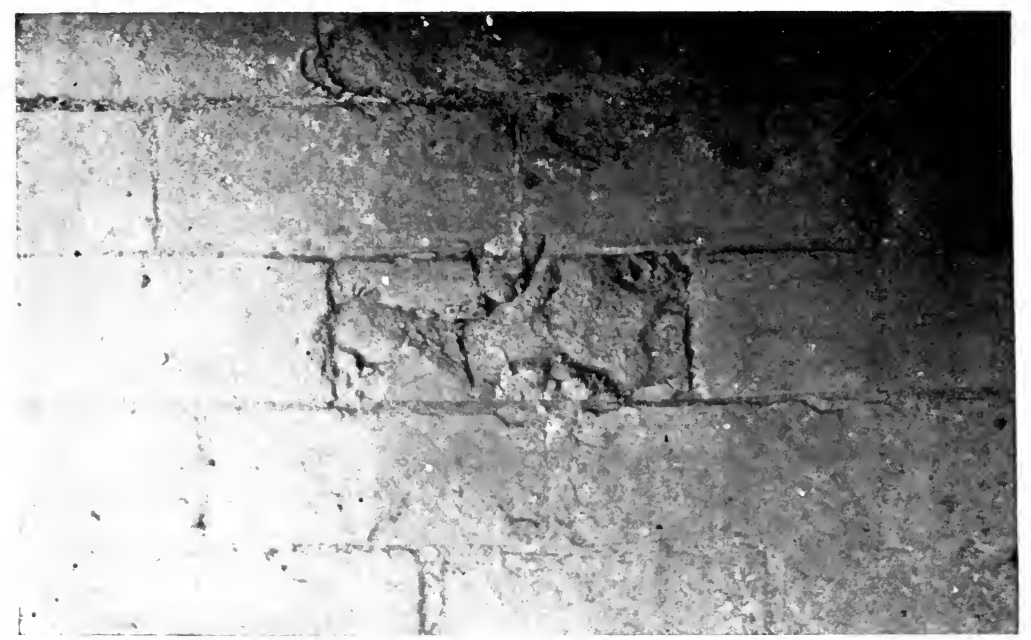

FIG. I48. Poor Brick in a Cement Grout-filled Pavement.

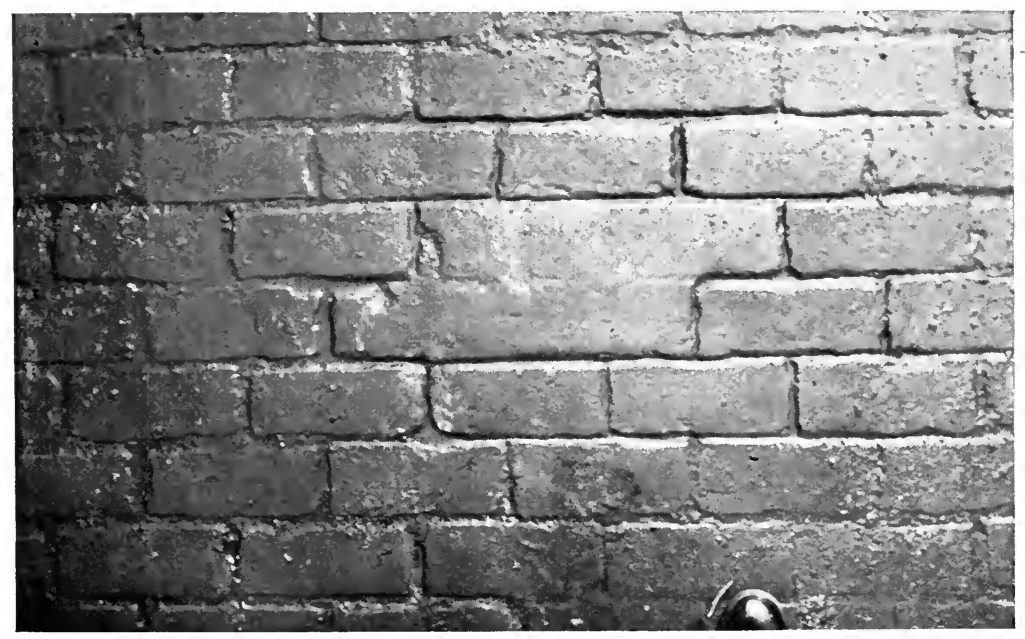

FIG. I49. Chipping Out of Grout Filler in the Joints by Horse-drawn Traffic.

slightly arched up at more or less regular intervals, the limits of which are marked by the dark transverse streaks in the photograph. Fig. I 5 I shows a properly cement grout-filled 


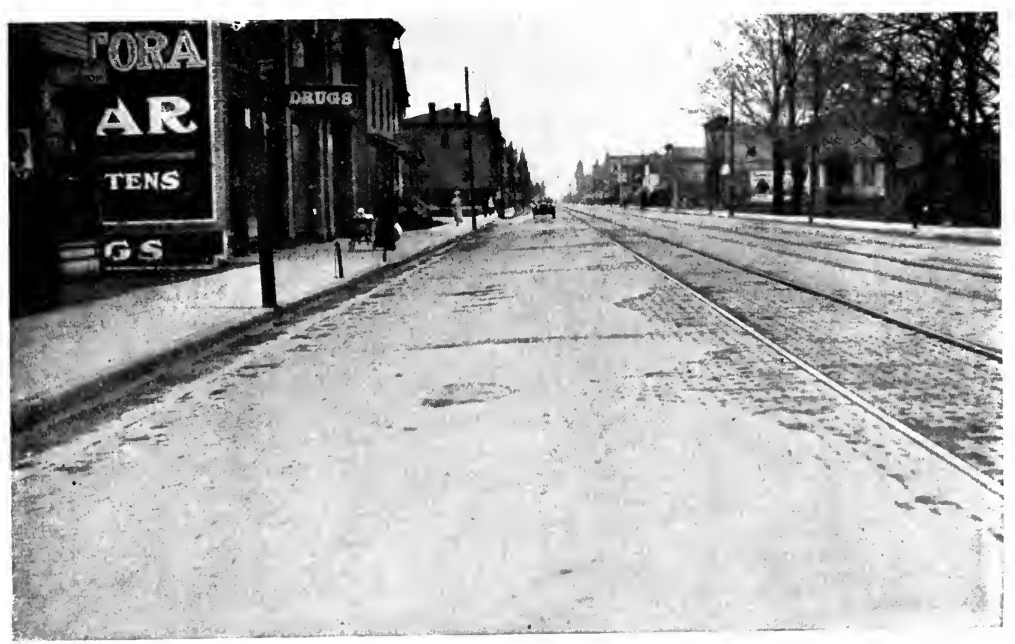

FIG. I50. Longitudinal Expansion in a Grout-filled Pavement.

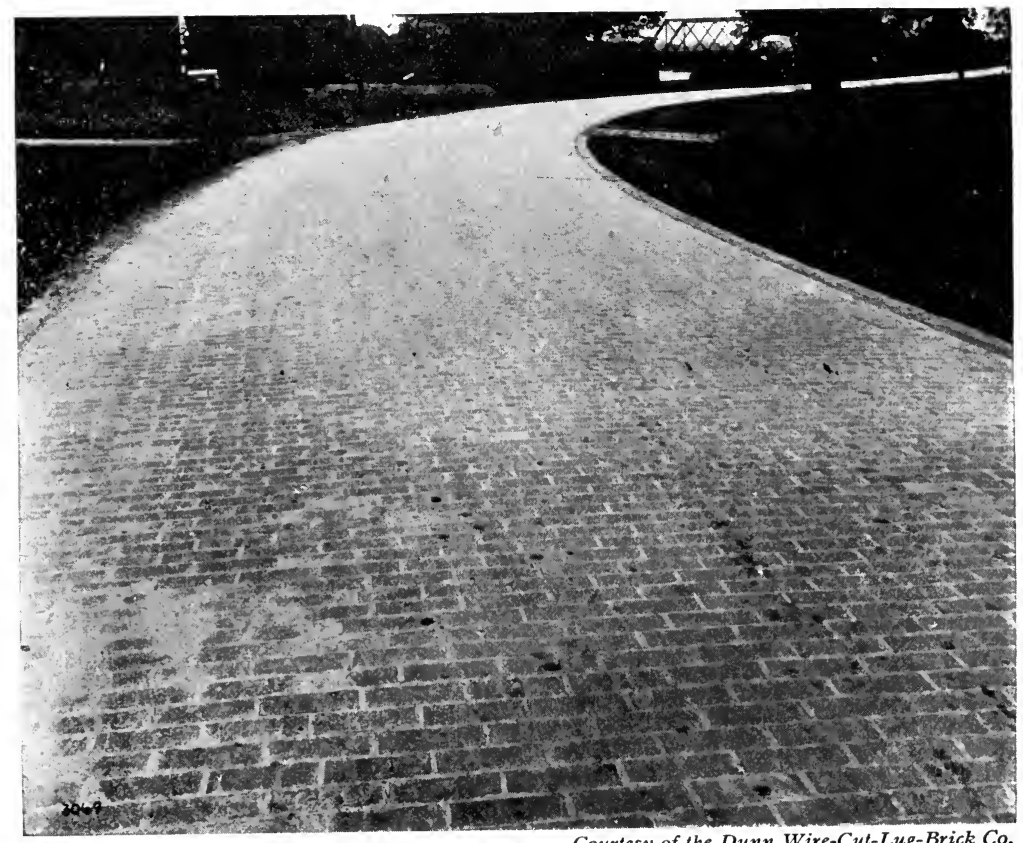

Courtesy of the Dunn Wire-Cut-Lug-Brick Co.

Fig. I5I. Cement Grout-filled Wire-Cut-Lug-Brick Pavement on New York State Highway. 
pavement. Fig. $\mathrm{I}_{52}$ is a construction view showing the way the grout is applied in filling the joints according to approved methods.

The use of some types of bituminous filler presents several advantages. No transverse expansion joints are necessary and a large amount of the expansion troubles are eliminated. The pavement can be used as soon as it is constructed, whereas when a grout filler is used the pavement must be kept closed to traffic for a period of from ten days to two weeks. Another advantage of the bituminous filler is that in making any openings in the pavement, the bricks can be taken out with less breakage than where the joints are filled with a cement grout. Due to the fact that there is very little trouble from expansion, the pavement is less noisy. Fig. I47 shows the surface of a brick pavement properly constructed with a bituminous filler. Fig. I53 shows a joint-filler can, which is conical-shaped and equipped with a rod to regulate the flow of the material. With this type of can excellent results can be obtained.

Cost Data. The cost per square yard of brick pavement and a 6-inch cement-concrete foundation varies from $\$ 1.75$ to $\$ 2.75$. In the following table are given, for several localities throughout America, I9I4 prices of brick pavements constructed with various types of fillers and different thicknesses of sand cushions and cement-concrete foundations.

From Engineering and Contracting, April 7, 1915

\begin{tabular}{|c|c|c|c|c|c|c|c|c|}
\hline \multirow[b]{2}{*}{ City } & \multirow[b]{2}{*}{$\begin{array}{l}\text { Square } \\
\text { Yards }\end{array}$} & \multirow[b]{2}{*}{$\begin{array}{l}\text { Price* } \\
\text { per } \\
\text { Square } \\
\text { Yard }\end{array}$} & \multirow[b]{2}{*}{ 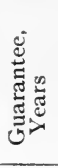 } & \multirow[b]{2}{*}{$\begin{array}{l}\text { Kind of } \\
\text { Filler }\end{array}$} & \multirow{2}{*}{ 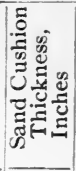 } & \multicolumn{3}{|c|}{$\begin{array}{c}\text { Concrete } \\
\text { Foundations }\end{array}$} \\
\hline & & & & & & 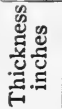 & $\begin{array}{c}\text { Propor } \\
\text { tions }\end{array}$ & \\
\hline Pittsfield, Mass. & I, I 30 & $\$ 2.90$ & 5 & Cement Grout & $11 / 2$ & 6 & I :3 & \\
\hline Syracuse, N. Y. . & 87,720 & 2.19 & 2 & Cement Grout & I & 6 & $1: 3$ & \\
\hline Philadelphia, Pa... . & 80,762 & 2.74 & 5 & Cement Grout & $11 / 2$ & 6 & I:3 & 6 \\
\hline Pittsburgh, $\mathrm{Pa} \ldots$. & I I, 829 & 2.01 & I & Bituminous & I & 6 & I:3 & 6 \\
\hline Canton, $\mathrm{O} \ldots$ & 100,728 & I. 63 & I & Tar & 2 & 5 & $1: 3$ & \\
\hline Toledo, O. & $68,5 \mathrm{I} 4$ & I $87 \dagger$ & 5 & Asphalt & $11 / 2$ & 5 & $1: 31 / 2$ & $2: 6$ \\
\hline Moline, Ill : . . . . . & 66,619 & 2. II & 5 & Asphalt & 2 & 5 & I :3 & \\
\hline Grand Rapids,Mich. & 42,099 & I. $85^{\dagger}$ & 5 & Cement Grout & $11 / 2$ & 6 & $I: 31 / 2$ & $2: 7$ \\
\hline Minneapolis, Minn. & 10,634 & 2.25 & & Asphalt & I & 5 & I :3 & \\
\hline Louisville, Ky . . . . . & 82,962 & I . $78 \dagger$ & 5 & Cement Grout & $11 / 2$ & 6 & $I: 3$ & \\
\hline Portland, Ore. & 34,184 & $2.34 \dagger$ & 20 & Cement Grout & I & 6 & $1: 3$ & \\
\hline Toronto, Ont. & 38,417 & $2.07 \dagger$ & IO & Cement Grout & $11 / 2$ & 5 & $I: 3$ & :7 \\
\hline
\end{tabular}

* Price covers pavement, foundation, and shaping subgrade.

† Does not include shaping subgrade. 


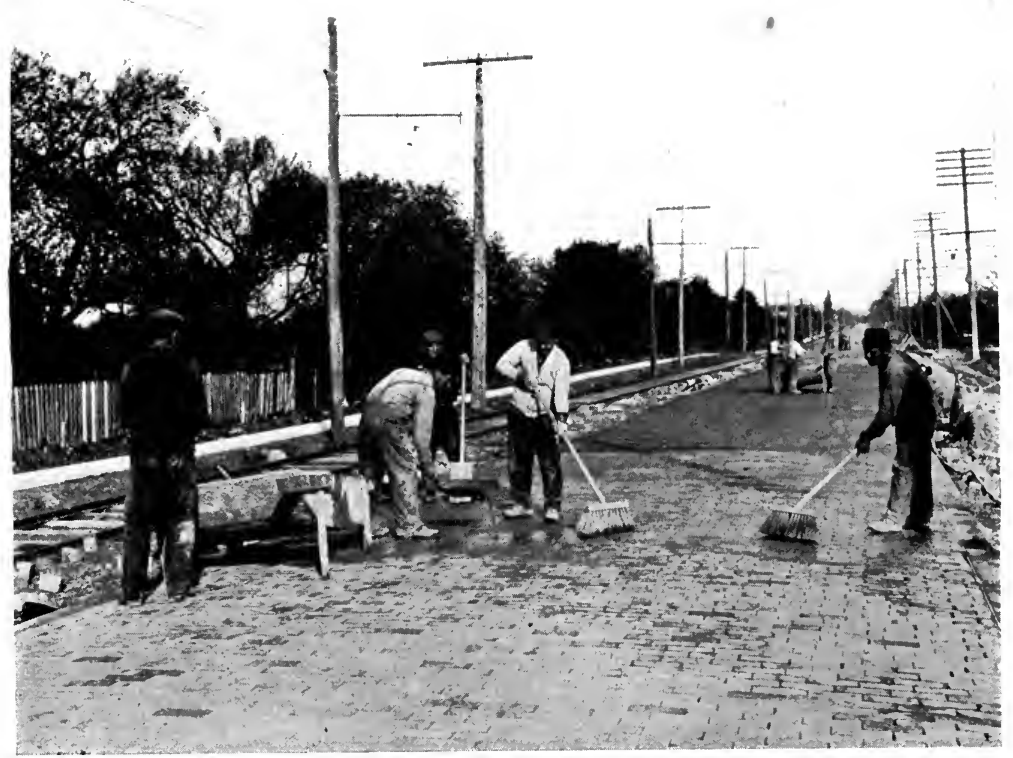

Courtesy of the Dunn Wire-Cut-Lug-Brick Co.

FIG. I52. Application of Cement Grout Filler.

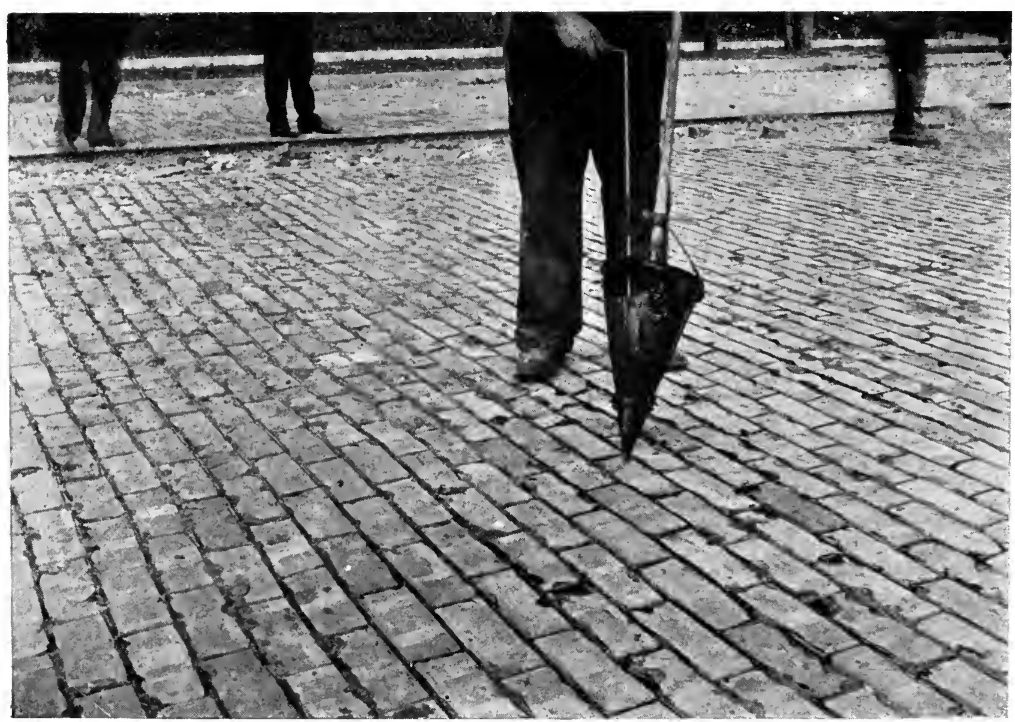

Fig. I53. Asphalt Filler Pouring Can 


\section{Maintenance}

The maintenance of a brick pavement consists mainly in replacing poor brick, repairing joints and rectifying any low spots which appear in the surface due to poor drainage and foundation. When heaving occurs due to expansion, the pavement may bulge up and necessitate extensive repairs. Sometimes by cutting out one or two rows of bricks the pavement will settle down again on the sand cushion. In Minneapolis,

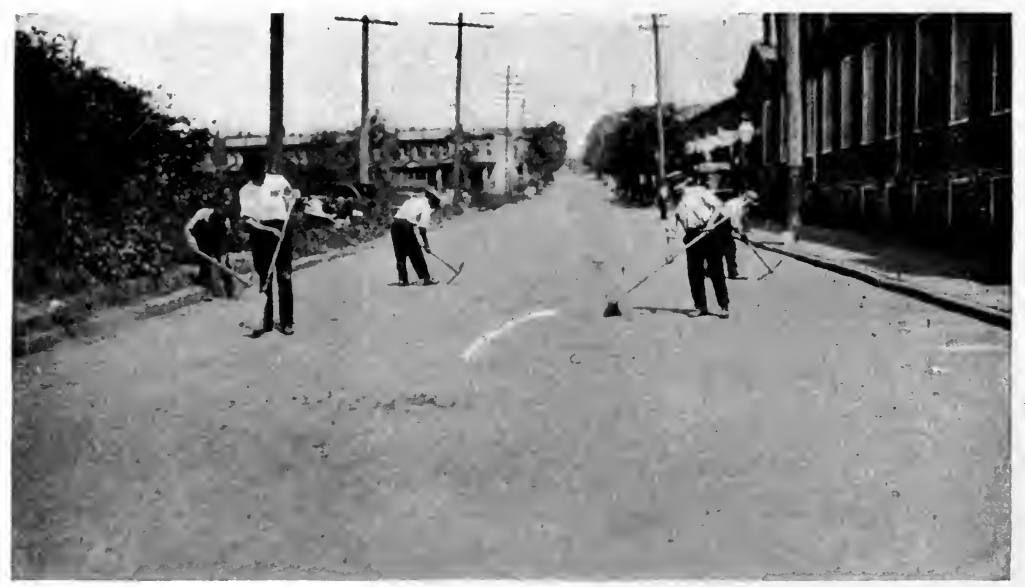

FIG. 154. Cleaning Joints Prior to Application of Bituminous Material.

where the surface of a brick pavement had become somewhat rough, due either to the uneven wear of the brick or to wear at the edges, a bituminous surface was applied and covered with a layer of screened chips. This surface has not only served to protect the brick from further wear but has also improved the foothold and lessened the noise of traffic. See . Figs. I54

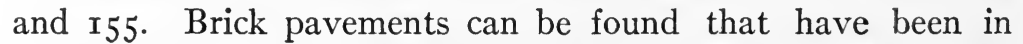
use for twenty years and are still in good condition. Where the traffic conditions are not too severe and the pavement has been properly constructed, a brick pavement will wear for a long time with practically no expense for maintenance, provided the forces of contraction and expansion are not sufficient to disrupt the surface. 


\section{Characteristics}

A brick pavement, when properly constructed on a concrete foundation, is very durable unless the traffic is extremely heavy. If properly built with a bituminous or cement grout filler the surface wears smooth, offers light resistance to traction, is easy to clean, produces no dust, and furnishes a fair foothold for horses. If proper allowances are not made for expansion and contraction when cement grout filler is used, the pavement is

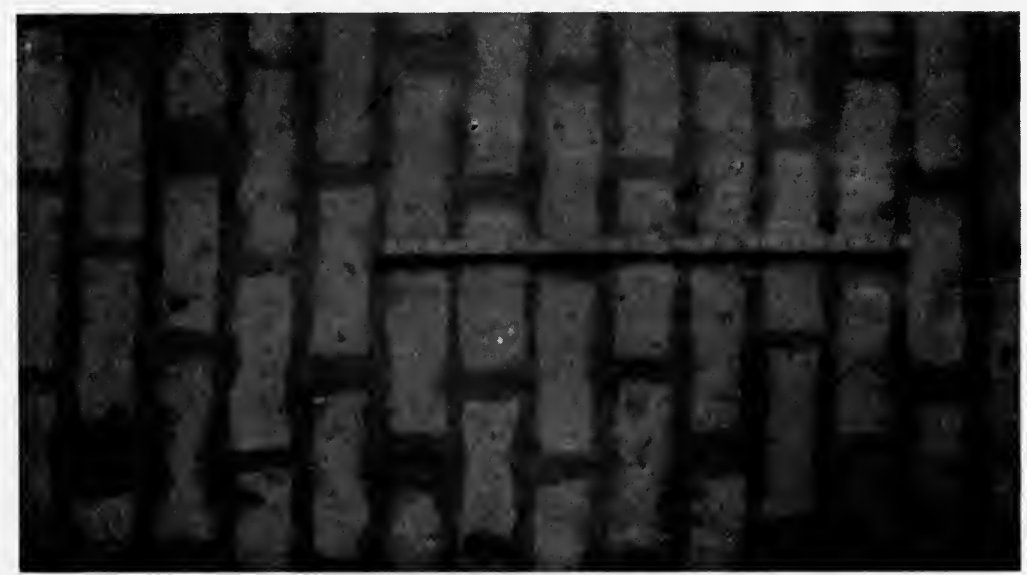

Fig. 155. Surface of Badly Worn Brick Pavement, Showing Condition, After Three Years' Service, of Joints Repaired with Asphalt Filler.

liable to arch itself above the sand cushion and become noisy, which is a decided objection. A bituminous filler prevents the occurrence of such a condition, but unless the proper kind of bituminous filler is used, the edges of the bricks wear and round off under the action of traffic. In some of the smaller cities, brick pavements have been successfully used for business streets, while in some of the largest cities its use is restricted to residential streets. Although in Chapter IV it was stated that a maximum grade of about 5 percent was adopted for brick pavements in some localities, this type of pavement has been used on much steeper grades. In fact, in I9Io, there were 
several instances where brick pavements were constructed on grades of to percent and more. If a grout filler is used on steep grades, the pavement may become very slippery. A bituminous filler will be found to be of material advantage in such cases. In the I9I5 highway specifications of the Board of Water Supply of New York City, hillside blocks or blocks having one edge bevelled are required on grades of over 5 percent. 


\section{CHAPTER XVII}

\section{STONE BLOCK PAVEMENTS}

Development. According to existing records, stone block was the first material used for paving roadways. A historical review of the types used prior to about A.D. I840 has already been covered in Chapter I. As stated in that chapter, Telford, in 1824 , was apparently the first to recognize the value of a stable foundation and small size blocks cut in such a manner as to give close joints. London appears to be the first city to develop this type of pavement. Mortar joints were first used in 1840 , while later, about 1872 , a method of construction was adopted in which a concrete foundation, and tar and gravel joints were employed.

Belgian block pavement was used in European cities about the middle of the nineteenth century, while in 1859 it came into common use in New York. Belgian blocks, so-called because they were first used in Belgium, were similar to truncated pyramids in shape, having bases of 5 to 6 inches square, and depths of from 7 to 8 inches. As it was impossible to maintain a smooth surface with these irregular shaped blocks, the rectangular block pavement was ultimately adopted. This shape of block was first used in New York City about i 876. Due to the fact that the first Belgian block pavements laid in New York were constructed with blocks of trap rock taken from the Palisades on the Hudson, all trap rock block pavements were called Belgian block pavements, regardless of the shape of the block.

In the more recent development of the rectangular stone block pavement more attention has been paid to the surface finish and sizes of the blocks, the joint filler, and the foundation. The blocks are generally required to be laid on a concrete foundation, and sand, tar and gravel, pitch, asphalt, and cement grout are used as fillers. Within the past few years the use of small 
block pavements has developed in certain parts of Europe. Both 4 -inch cubes and smaller setts, approximating $23 / 4$-inch cubes, have been employed in this construction.

\section{Stone Blocks}

The Stone. The blocks, while generally being made from granite, are sometimes cut from sandstone, quartzite, and trap rock. The stone blocks should be of such quality that they will resist shocks, crushing, and weathering and will not wear round and smooth under the action of traffic. They should be of uniform quality and texture, without seams, scales, or discolorations.

The planes of cleavage of granite are such that it is easy to make blocks from it. The trap rocks are harder and tougher than the granites and are not so easily made into blocks. Sandstone blocks are not usually suitable for streets taking very heavy traffic. They do not wear round like the granite blocks, but more uniformly, although sometimes very rapidly. The Medina and Potsdam sandstones, which are found in New York State, have been used in pavements to a considerable extent throughout the State. In Rochester, N. Y., dressed Medina stone has been used with excellent results on the main streets taking a heavy traffic. A large amount of quartzite has been laid in Chicago with good results.

Manufacture of THE Blocks. The majority of stone blocks are made with hand tools. Large blocks of stone are split up into sizes desired by the use of plugs and feathers. The faces of the blocks are then hammer-dressed until smooth enough to comply with the specifications. The small sized blocks used in the construction of Kleinpflaster and Durax pavements are cut out by the machine shown in Fig. 156 .

Considerable care has to be taken in making blocks for a first-class pavement. The blocks should be dressed so as to be rectangular on the faces, having parallel sides and ends with approximately right angle edges. Some specifications do not allow depressions on the face exceeding $1 / 4$ of an inch. If the 


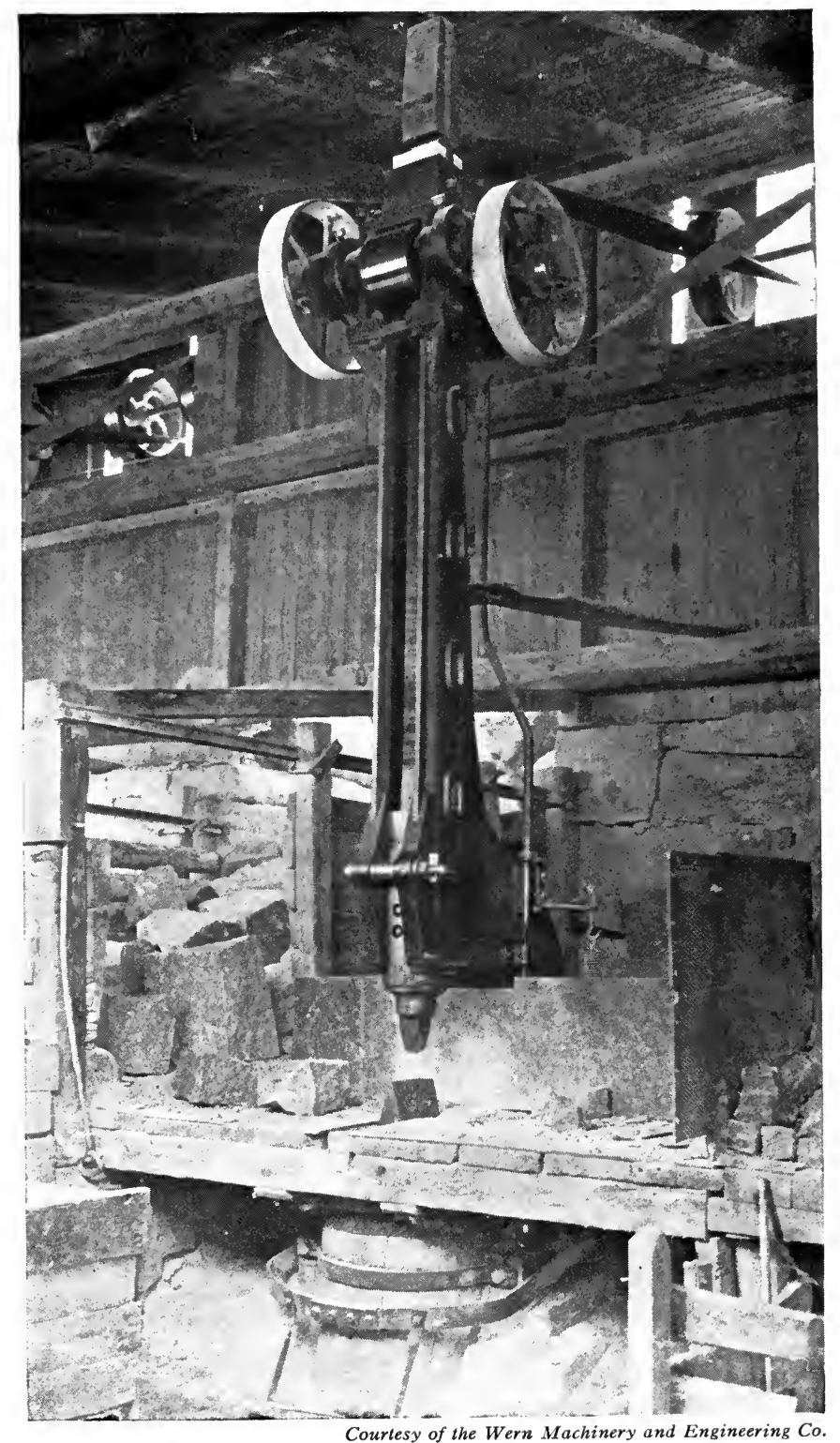

FIG. 156. Machine Used for Cutting Durax and Kleinpflaster Blocks. 
faces are very rough, it is impossible to obtain close and even joints in the pavement.

Size of Blocks. The size of blocks is quite variable. In the United States large standard blocks for a first-class pavement are from 5 to 8 inches deep, 3 to $4 \frac{1}{2}$ inches wide, and from 8 to 12 inches long. A block, 4 to $4 \frac{1}{2}$ inches deep, $3^{1 / 2}$ to 4 inches wide, and 6 to 12 inches long, is used by some engineers on steep grades as a continuation of broken stone roads, brick, wood block, bituminous concrete, and other types of bituminous pavements.

In Liverpool, England, blocks for heavy traffic streets are 6 inches deep, 3 inches wide, and 5 to 6 inches long. In Birmingham, England, blocks which are approximately 4-inch cubes are used. The stone blocks used in France are either cubical or rectangular in shape and of very variable dimensions, the lengths varying from 6 to 9 inches, the widths from 4 to 8 inches, and the depths from 6 to 9 inches.

The rough cubical blocks for Kleinpflaster and Durax pavements are somewhat similar in size. Those for Kleinpflaster are about $2 \frac{1}{4}$ by $21 / 4$ by $23 / 4$ inches while the blocks for the Durax pavement vary from $23 / 4$ to $3 \frac{1}{2}$ inches.

Tests for Stone Block. No standard tests for the physical properties of stone block have been adopted in the United States. The qualities of the stone of which a block is composed, however, can be determined by submitting it to the abrasion, hardness, and toughness tests as made on rock from which broken stone is manufactured. These tests have been described in Chapter VIII. The crushing strength of the stone is the only characteristic that is determined by some engineers.

\section{Construction}

Subgrade and Foundation. The subgrade should be prepared according to the same general directions that have been given in previous chapters. Since a stone block pavement is usually the type recommended to take the heaviest kind of commercial traffic, a cement-concrete foundation should be used. 
Different methods of constructing concrete foundations have been described in Chapter V. Although the mixing method is the one generally used, in certain parts of the country the grouting method has been used to a considerable extent in constructing foundations for this type of pavement. Unless stone block pavements, which are constructed on sand, gravel, or broken stone foundations, are given constant attention, the blocks soon get out of place, the edges of the blocks become rounded off, the surface becomes very uneven, and ultimately the pavement reaches a condition where it is not much better than one composed of cobblestones.

Kleinpflaster and Durax pavements have been built on concrete foundations. These types of small block pavements have also been built, when subjected to light traffic, on foundations of broken stone, gravel, and on old broken stone roads which have been properly shaped up.

The surface of the foundation is usually constructed parallel to the surface of the finished pavement. In Chapter IV will be found formulas giving the amount and distribution of the crown.

Cushion LAYer. A cushion, composed of dry, clean sand, is spread on the concrete foundation previous to laying the blocks. The purpose of the cushion is to hold the blocks at the bottom, to make practical the laying of blocks of uneven depth, and to take up any small irregularities in the foundation. The thickness of the cushion will depend somewhat upon the character of the blocks used, 2 inches being a common value when the blocks are quite regular in shape.

LAYING THE BLOCKS. The blocks are placed on the sand cushion as closely as possible, usually in straight parallel courses with the long dimensions perpendicular to the curbs. The paver uses a special form of hammer, one end of which has a flat blade. He scoops out, with the blade end of the hammer, a place in the sand cushion for the block to rest in, places the block and hits it a few taps, so that its surface is even with that of the adjacent blocks. (See Fig. 157.) The blocks in one row should break joints with the blocks in another row by at least 3 inches. 
At street intersections, in order to prevent the traffic of the cross streets from travelling parallel to the long joints and thus forming grooves, the blocks are laid with their long dimensions parallel to one or both of the diagonals of the square formed by the intersecting streets. The blocks may be laid to the desired crown by the use of strings, cross-section stakes, or a board template. After placing the blocks to the proper

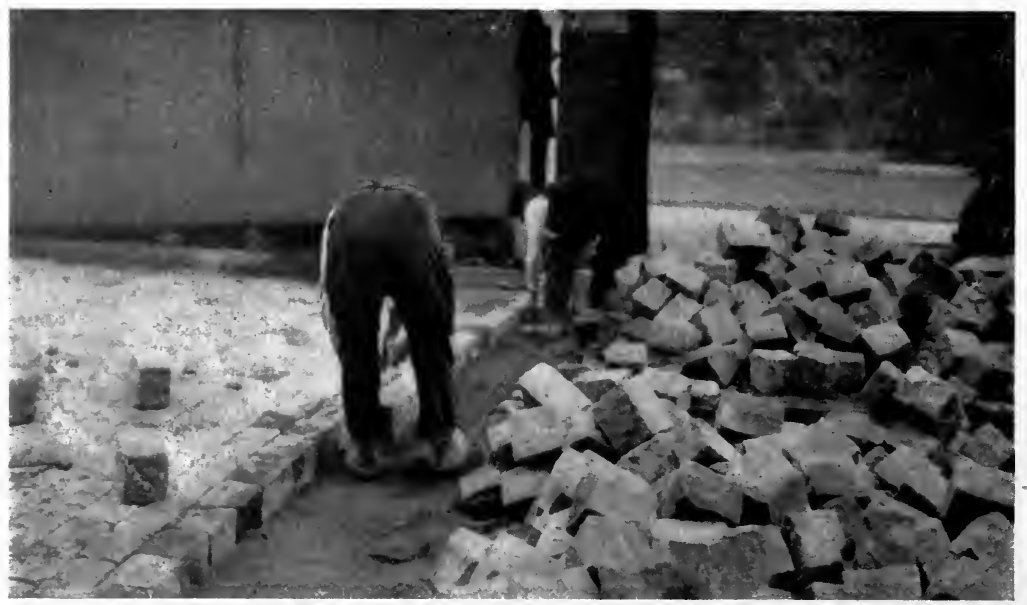

FIG. I57. Construction of Stone Block Pavement in Hamburg, Germany.

lines they are thoroughly tamped with a tamper weighing from 60 to 70 pounds until no further settlement occurs. The joints are then filled with the material which has been selected for this purpose. Fig. $5_{5} 8$ is a cross-section of a stone block pavement as constructed by the City of Pittsburg, Pa., and serves to show the general arrangement of the foundation, the cushion layer, and the blocks.

The small setts of Kleinpflaster and Durax pavements are laid in circular or parabolic arcs, see Figs. 159 and 160 , hence the joints are continually broken in the direction of travel, thus reducing the noise of traffic.

Filling THE JoInts. Sand, tar and gravel, pitch, asphalt, and cement grout are used to fill the joints of stone block pave- 
ment. The object of the filler is to make the pavement waterproof, to completely fill the joints in order to eliminate recesses in which filth might collect, and to protect the edges of the block.

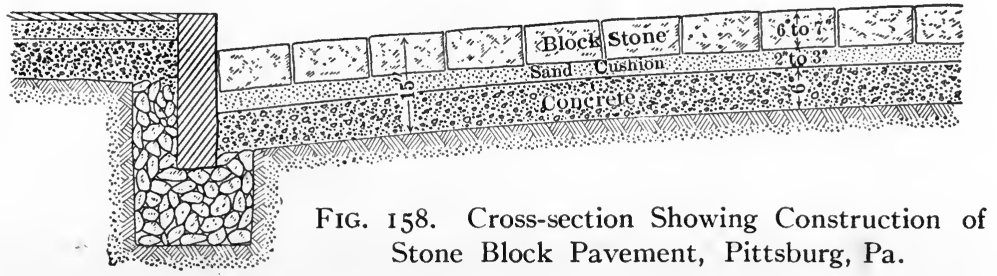

Sand should not be used as it does not satisfy any of the functions of an efficient filler.

Tar and gravel, pitch and asphalt have all been satisfactorily used for fillers. It is absolutely necessary, however, that the

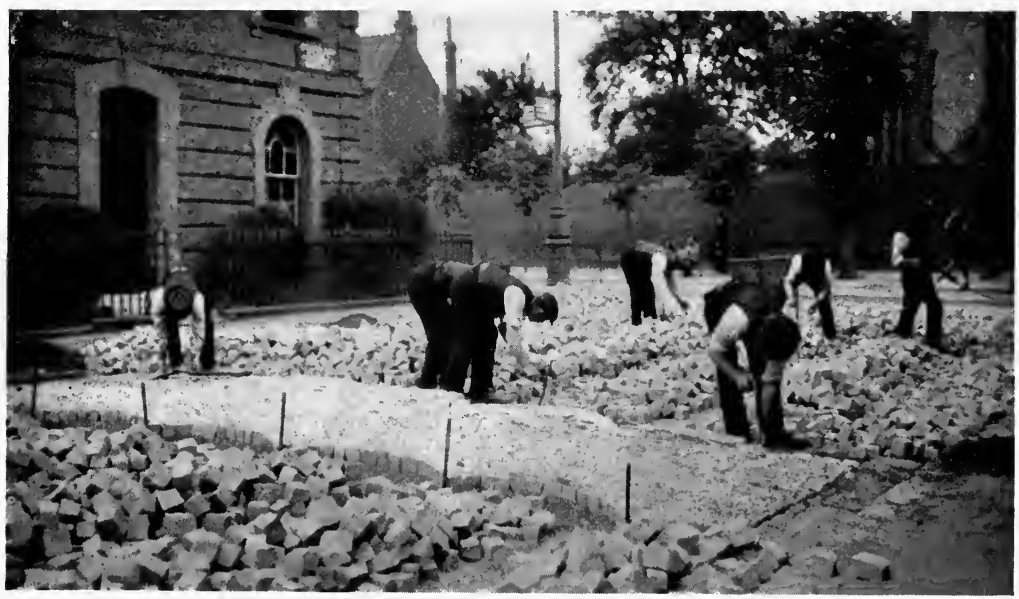

FIG. 159. Construction of a Durax Pavement near London.

bituminous filler should possess such properties that it will not soften to the point of flowing in summer nor harden in winter so that it will be brittle and chip out under the blows of horses' feet. The use of a bituminous filler makes the pavement less noisy than when a grout filler is used and enables repairs to be 
made at a minimum cost, as the blocks may be readily removed.

Cement-grout filler, when properly mixed and applied, has given very satisfactory results from the standpoints of producing a sanitary pavement and protecting the edges of the block. It does, however, materially increase the slipperiness of the surface and makes repairs for street openings expensive and difficult, as the blocks have to be broken up in order to remove them, and it is impracticable, in many cases, to keep traffic off

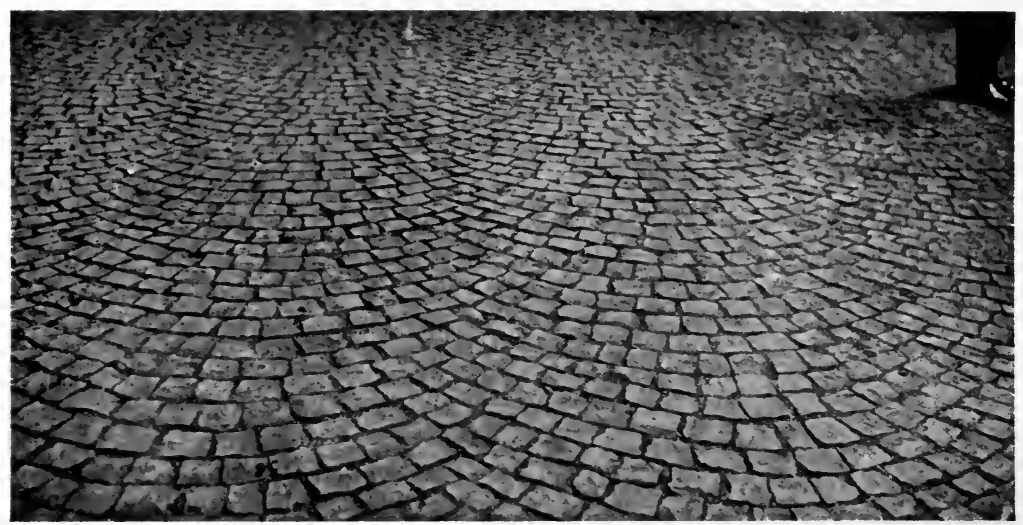

FIG. I60. Surface of Durax Pavement on the Chelsea Embankment, London.

the repairs until the grout has set up. Many improperly groutfilled granite block pavements have become rough within a few years due to the cement grout being rapidly chipped out by the blows of horses' feet.

The methods of using bituminous and cement grout fillers have been described in Chapter XVI.

Cost Data. The average cost of constructing stone block pavements on a Portland cement-concrete foundation, 5 to 6 inches thick, varies from $\$ 2.50$ to $\$ 3.75$ per square yard. In the following table are given, for several localities throughout America, the average I9I4 prices of stone block pavements constructed with various types of fillers and thicknesses of foundations. 
From Engineering and Contracting, April 7, 1915

\begin{tabular}{|c|c|c|c|c|c|c|}
\hline \multirow{2}{*}{ City } & \multirow{2}{*}{$\begin{array}{l}\text { Square } \\
\text { Yards }\end{array}$} & \multirow{2}{*}{$\begin{array}{c}\text { Price* } \\
\text { per } \\
\text { Square } \\
\text { Yard }\end{array}$} & \multirow{2}{*}{ 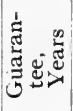 } & \multirow{2}{*}{$\begin{array}{l}\text { Kind of } \\
\text { Filler }\end{array}$} & \multicolumn{2}{|c|}{$\begin{array}{l}\text { Concrete } \\
\text { Foundation }\end{array}$} \\
\hline & & & & & $\begin{array}{l}\text { Thick- } \\
\text { ness, In. }\end{array}$ & $\begin{array}{l}\text { Propor- } \\
\text { tions }\end{array}$ \\
\hline Cambridge, & 8,584 & $\$ 3$ & - & Cement Grout & 6 & I: $3: 5$ \\
\hline Malc & I 3,388 & 2.96 & 5 & Cement Grout & 5 & I : $21 / 2: 5$ \\
\hline ter & 20,60 & $3 \cdot 35$ & & Cement Grout & 5 & I : $3: 6$ \\
\hline IIC, & 10,3 & $3 \cdot 3$ & $\cdots$ & Cement Grout & 6 & I $: 3$ \\
\hline o, N.Y. & $5,8 \mathrm{c}$ & 3.96 & IO & Cement Grout & 6 & I :IO \\
\hline $\mathrm{n}, \mathrm{N} . \mathrm{Y}$ & I I 2,62 & $3 \cdot 46$ & I & Tar & 6 & I $: 3$ \\
\hline Eliz & $8 \mathrm{I}, 828$ & $3 \cdot 35$ & 5 & Cement Grout & 6 & I : 3 \\
\hline Philadelphia, Pa . & 10,742 & $3 \cdot 75$ & 5 & Cement Grout & 6 & I: 3 \\
\hline Pittsburgh, $\mathrm{Pa} \ldots$ & 19,76 & 3.18 & I & Bituminous & 6 & I : 3 \\
\hline Chice & 40,340 & $3 \cdot 7^{\dagger \dagger}$ & 2 & Pitch & 6 & I : 3 \\
\hline Dul & 6,258 & $2.75 \dagger$ & . & Cement Grout & 5 & I $: 3$ \\
\hline San Francisco, Cal & 22,049 & 3.28 & & Asphalt & 6 & I : $2 \frac{1}{2}: 7$ \\
\hline
\end{tabular}

* Price covers pavement, foundation, and shaping subgrade.

$\uparrow$ Does not include shaping subgrade.

Stone Trackways. Trackways have been built, both in this country and abroad, of stone slabs, brick, concrete blocks,

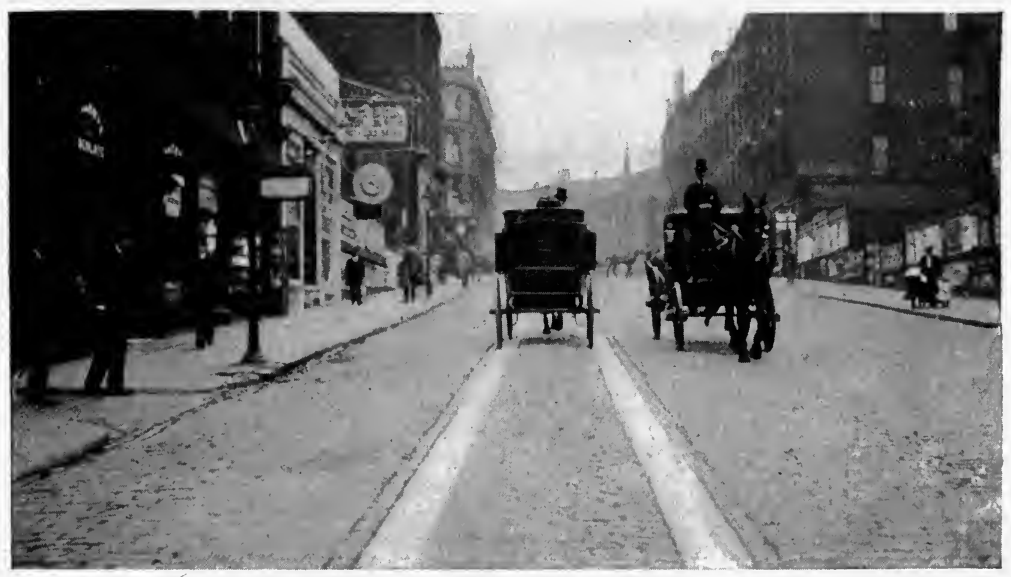

FIG. I6I. Stone Trackway in Glasgow, Scotland.

steel shapes, and other materials. Stone trackways were used on one of the old toll roads in New York State as early as I83I. The slabs, which measured 24 inches in width by 4 inches in thickness, were laid with a gauge which would accommodate the vehicles. The space between them was paved with cobble- 
stone. Trackways of rectangular stone blocks, averaging 12 inches wide, 6 inches thick, and of varying lengths, have been used in some cities of England and Scotland on steep hills or where the traffic is exceptionally heavy. Fig. I6I shows one of these trackways on a street in Glasgow. Granite trackways, made of slabs 2 feet wide, I foot thick, spaced 4 feet apart on centers, are used in several cities in Switzerland.

Cobblestone Pavements. Cobblestone pavements are now rarely laid except on unimportant streets or alleys. Hard,

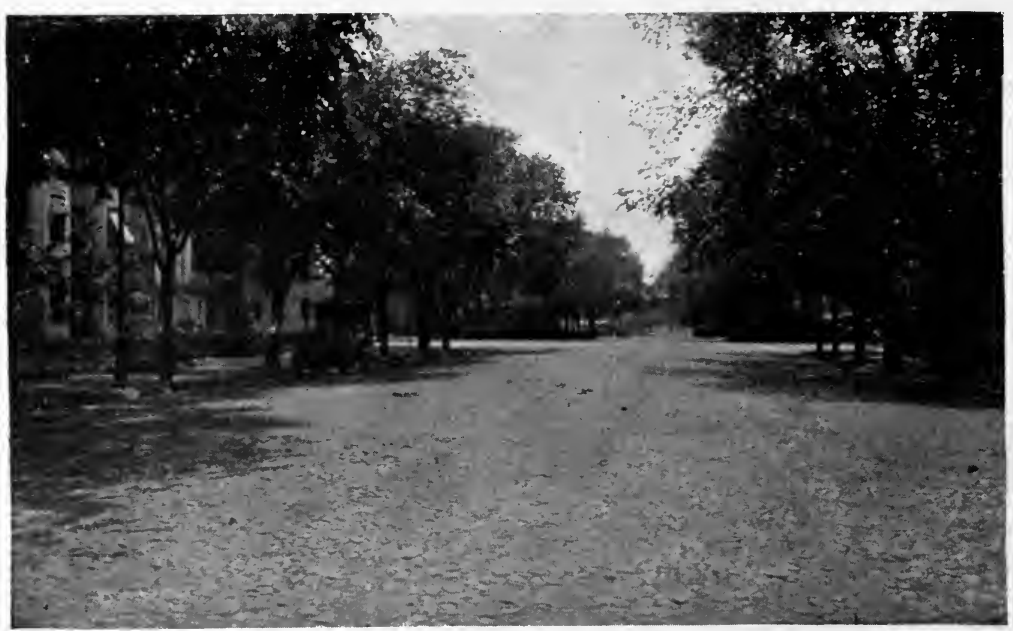

Fig. I62. Cobblestone Pavement.

durable stones ranging from 5 to io inches in depth and from 4 to 8 inches across the head are used. The stones are laid on a bed of loamy sand about six inches thick, and are set compactly together so as to break joints as much as possible. The surface is then covered with sand, which is swept into the joints, after which the stones are tamped with a rammer weighing about 50 pounds. When there is no further settlement of the stone, the surface is covered with a layer of sand about $1 / 2$ an inch in depth. A cobblestone pavement, if subjected to a heavy traffic, soon becomes very uneven. Fig. I62 shows a typical 
cobblestone pavement. The cost of this type of pavement is from 60 to 70 cents per square yard.

Clinker and Slag Block Pavements. About 33 percent of the total refuse of a refuse destructor remains, after burning, as clinker. Many experiments have been tried to utilize clinker commercially. It has been ground and used as sand and has also been broken up and pressed into bricks, paving blocks and

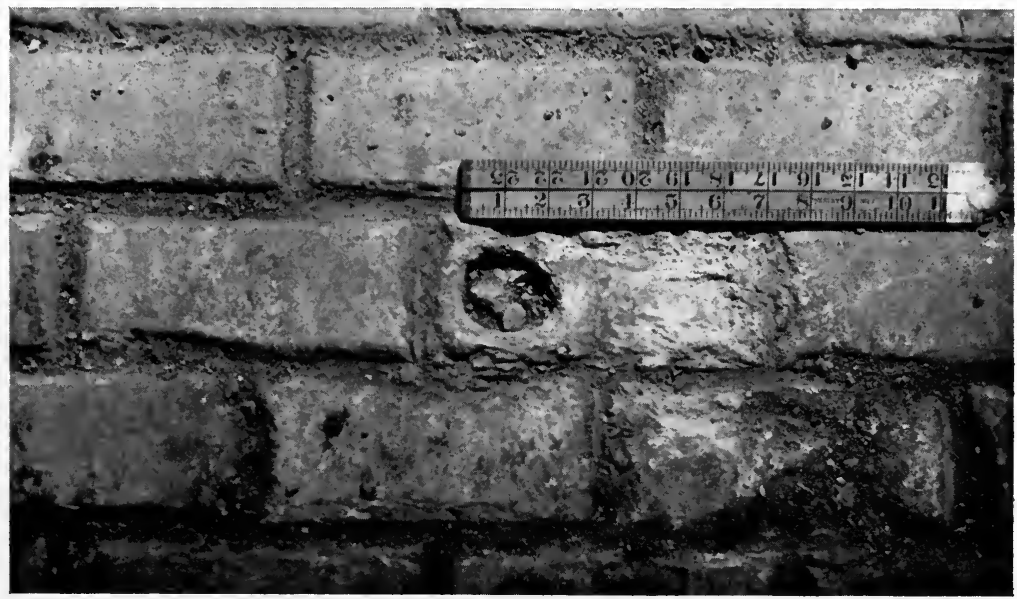

FIG. I63. Blow-hole in Slag Block.

slabs, either a cement or bituminous material being added to bind the fine particles together. These bricks, blocks, and slabs have been used in building construction and in pavements for streets and sidewalks. Blocks manufactured with clinker and a hydraulic cement as a binder, in the proportions of three parts of clinker to one part of cement and one to eight parts of fine dust, have not made a very satisfactory pavement in the Borough of Finsbury, England, when subjected to a heavy traffic. In fact, many square yards of this pavement had to be taken up after it had been down for only two years.

Molded slag blocks have been used in England and the United States for the construction of pavements. The details of construction of slag block pavements are similar to those used in the construction of stone block pavements. Careful 
culling of the blocks is required in order to reject those which contain blow-holes. (See Fig. 163.) These blow-holes in many blocks are not visible on the surface but are soon disclosed under the action of horse-drawn vehicle traffic.

\section{Maintenance}

The maintenance of a stone block pavement, see Fig. I64, if properly constructed, is negligible for a few years. The life of

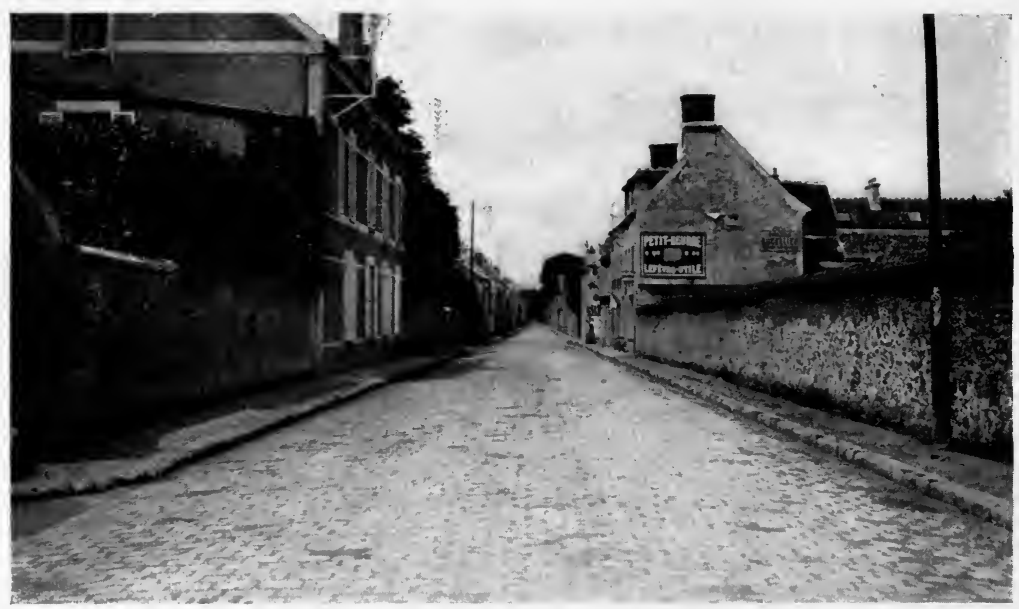

Fig. I64. A Well Maintained Stone Block Pavement on a National Highway in France.

a granite block pavement constructed on a concrete foundation is estimated to be about twenty-five years. The average annual maintenance cost of stone block pavements will vary from about 2.0 to o. I cents per square yard. When the blocks become worn so that the surface is extremely uneven, it is possible to take the blocks up, redress them, and relay them as a new pavement. The cost of relaying granite block paving, including a concrete base and recutting blocks, is estimated at $\$ 2$ per square yard. The cost is about $\$ 2.50$ per square yard. when not more than 25 percent of new blocks are substituted for the old ones which are unfit for relaying. 


\section{Characteristics.}

The chief advantage of a stone block pavement is its durability. Such a pavement if properly constructed is able to withstand the heaviest kind of traffic and is well adapted for use on those streets which are subjected to the traffic of docking districts. A stone block pavement is about the only pavement which can be used on very steep grades and furnish a good foothold for horses. There were several instances where it has been used on grades of II percent and in one case the grade was about i9 percent. When the stones are rounded off from wear or when a grout filler is used the pavement may be somewhat slippery soon after completion, particularly when it is slightly wet. The chief defect of the average stone block pavement is its rough and noisy surface. When the blocks get out of place and the filler does not protect the edges of the blocks from wear, the blocks become rounded off at the joints and a rough surface results. When in this condition the pavement is not sanitary, since it is hard to clean and the joints afford a place for the collection of all kinds of filth. 


\section{CHAPTER XVIII}

\section{STREET CLEANING AND SNOW REMOVAL}

\section{Street Cleaning}

Public health, safety, and convenience require that roadways should be kept clean. The close relationship existing between dust laying and street cleaning is obvious. On certain types of roadways such as earth, gravel, and broken stone, the problem is a combination of cleaning and dust laying. On such pavements as brick, stone block, cement-concrete, wood block, bituminous macadam, bituminous concrete, and sheet asphalt, only methods of cleaning need to be considered. In the former class after the surface is cleaned dust remains which must be treated to prevent its being a nuisance. In the latter case such efficient methods of cleaning should be employed as to remove all distributable dust. The method of cleaning, therefore, depends primarily upon the kind of roadway. There are other factors which influence the selection of the method, such as the character and amount of traffic, the environments of the highway, and other local conditions. A general description of the various methods in use in the United States is presented, followed by a discussion of methods applicable to each of the several types of roads and pavements and brief references to American and European practice.

Hand Cleaning. Hand cleaning is done either by gangs or patrols, usually during the daytime. In the first-named method the roadway is cleaned at frequent intervals, while in the latter case a patrolman has a certain district to clean each day. Each patrolman has a push broom, shovel, and can or bag carrier in which to collect the refuse. The principal disadvantage of the gang method is that the streets are in an objectionable condition for the greater part of the interval between consecutive cleaning operations. In the patrol system the material is col- 
lected in cans or bags and placed to one side or $_{8}$ is swept into heaps at the side of the street, each awaiting the arrival of wagons to carry the refuse to the dumping grounds. In almost every city in Europe may be found a patrol system well organized and highly efficient, but in the United States poor supervision and general indifference on the part of the public

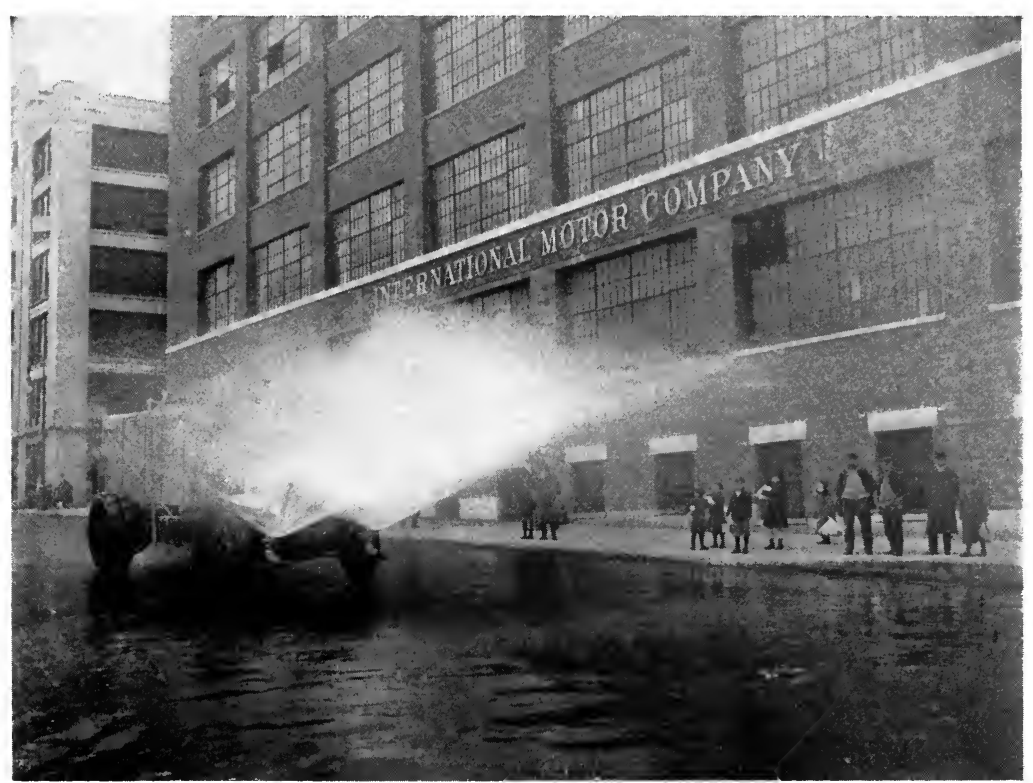

Courtesy of Mr. A. F. Masury.

FIG. I65. Motor Truck Pressure Sprinkler.

result in the lax and shiftless systems encountered in so many of our smaller cities.

The ordinary push broom, about sixteen inches wide, is universally used in street cleaning operations. The head is filled with split bamboo, rattan, hickory, or steel wire. One edge of the broomhead is sometimes fitted with a steel scraper. These brooms are used for heavy sweeping. For lighter and more thorough sweeping the head is filled with bass wood, which is more pliable than some of the other forms of filling. In Europe hand brooms made out of birch or other twigs are still used 
to some extent for light sweeping. Sweepings may be collected in galvanized iron cans or in bags which are later removed by wagons. Cans for holding sweepings are fixed to a wheel truck in such a manner that they can be attached and detached from the truck by a very simple operation. A dust pan is also attached, into which the sweepings are broomed.

Machine Sweeping. Horse sweepers are employed in many cases, the work being done generally at night. Such

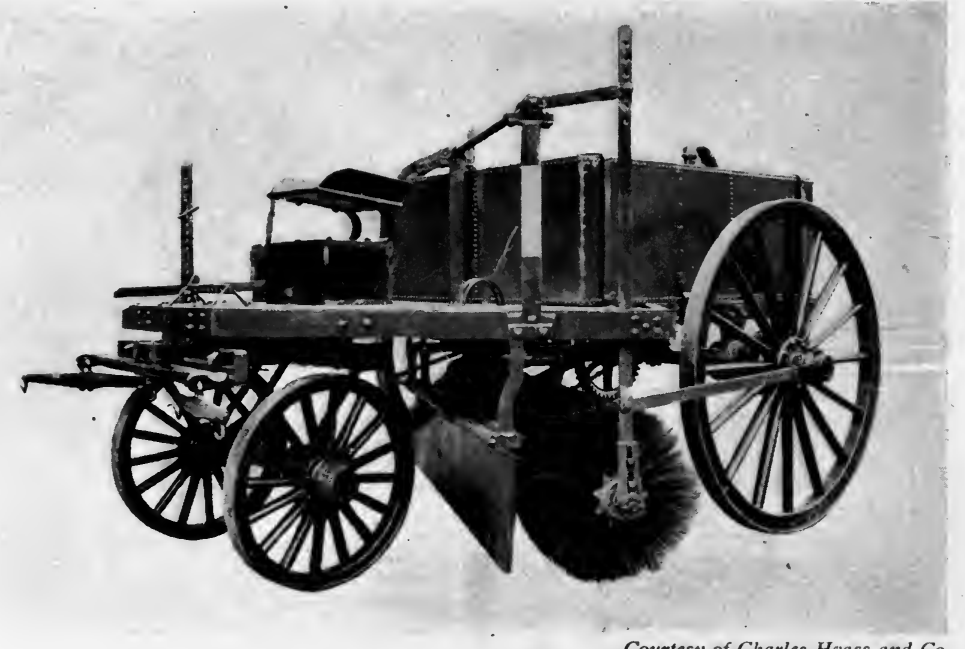

FIG. 166. Rotary Sweeper and Sprinkler.

sweeping should always be preceded by sprinkling to ensure the laying of the dust. Horse-drawn sprinklers have been previously described in Chapter V. Motor truck sprinklers, as shown in Fig. $6_{5}$, some of which have the sprinkling attachment on the front of the machine instead of in the rear, are used in Europe and, to a limited extent, in the United States. There are numerous combined sweepers and sprinklers, both horse-drawn and motor-propelled, in use in Europe and a few cities of the United States. This treatment alone is efficient on streets subjected to light traffic, but on the heavier travelled thoroughfares it should be supplemented by hand sweeping during the day. A pavement in 
good repair is essential for best results with a mechanical sweeper.

Rotary horse-drawn sweepers, see Fig. I66, are made to sweep widths varying from 6 to 9 feet. By means of levers operated by the driver the broom can be made to engage the road surface with either a light or heavy pressure. The brooms are filled with rattan, split bamboo, or hickory. Several types of pick-up sweepers have been designed and used. One of the most successful is pushed by hand and consists of a rotary brush geared to the wheels. The brush is covered in with a hood and operates on the carpet sweeper principle, throwing the sweepings into a pan which is a part of the machine. The sweeper will clean at one passage a strip 30 inches wide. Motor pick-up sweepers, which have been used in Europe, as a rule have been found to give satisfactory results, although the cost of operation has not been accurately estimated. These machines are generally provided with a water tank which sprays the dust just before it is picked up.

Hose Fuushing. Hose flushing is employed to a considerable extent in Europe and to a limited extent in this country. Flushing is accomplished by applying a stream of water to the surface with a broad, sweeping motion. In addition the pavement is scrubbed with rubber squeegees worked by hand to remove any adhering solid matter. The squeegees are made of wood or metal with a rubber edge varying from I 2 to 20 inches in width. The material is carried in suspension to the sewer through the nearest catch-basin. This treatment is particularly efficacious in removing all fine dirt, but it necessitates the preliminary removal of all coarse material which otherwise would eventually clog the average sewer.

Machine Scrubbing and Flushing. Sprinkling combined with the use of a rotary scrubber or squeegee is satisfactorily used on smooth pavements for the removal of dust. Some machines are equipped with attachments for sprinkling the pavement just in advance of a rotary squeegee. (See Fig. I67.) There are also various types of flushing machines used on sheet and block pavements which throw the water in broad, fan-shaped 
sprays over the surface, thus washing the dirt into the gutters and eventually into the sewers. (See Fig. I68.)

Methods Applicable to Various Types of Roads aNd Pavements in URban Districts. Earth, gravel, and broken stone roadways are cleaned by gangs or patrolmen with push

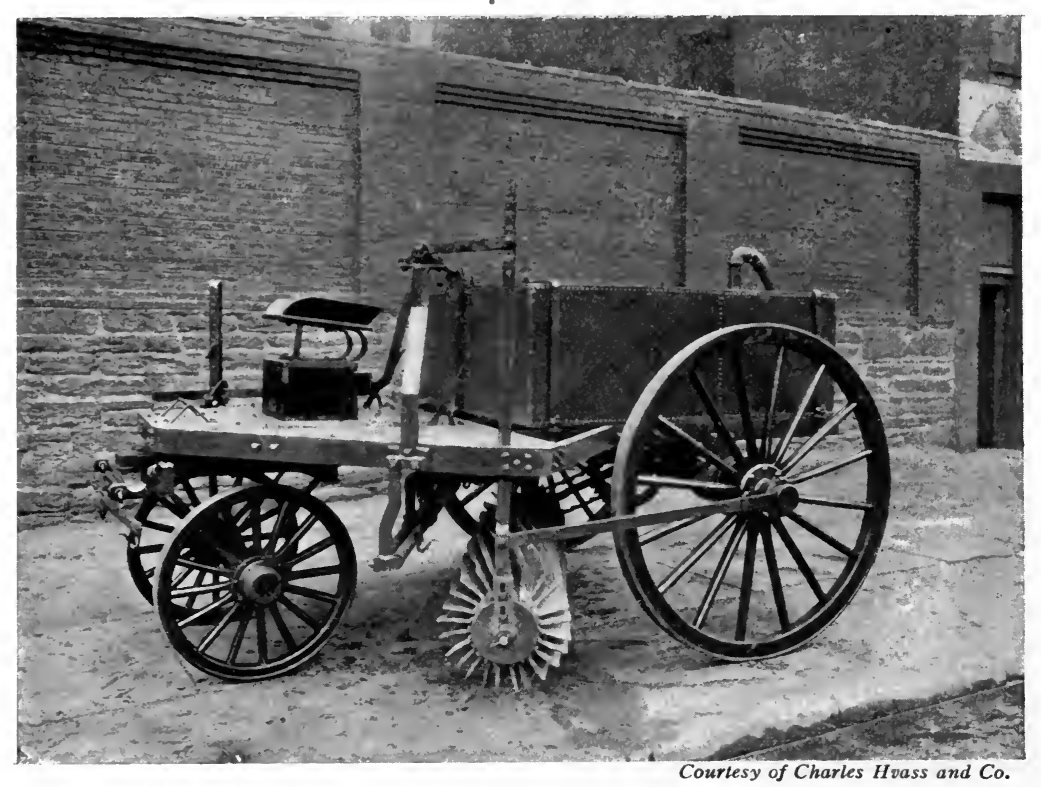

FIG. I67. Rotary Squeegee.

brooms or by horse-drawn or motor-driven rotary sweepers. Bituminous surfaces, and good brick, bituminous and wood block pavements are cleaned of coarse dirt by gangs or patrolmen during the day and by hose flushing and squeegeeing or by rotary scrubbers or squeegees during the night. Brick, in poor condition, and stone block pavements are cleaned during the day by gangs or patrolmen and during the night with rotary brushes and hand or machine flushing methods. In all the methods the dirt is forced to the gutters and is usually removed by gangs with wagons following the machines.

NEw York. The cleaning is done under the direction of the Department of Street Cleaning. The streets are cleaned 
mainly by hand sweeping, the laborers working under the patrol system. Each laborer is supplied with a can carrier, a push broom, and short handled broom, a long handled scraper and a dust pan. Each patrolman has a certain definite area that he must keep clean, the length varying from a few hundred feet to one mile, depending upon the type of pavement and the traffic. Most of the hand sweeping is accomplished in the day-

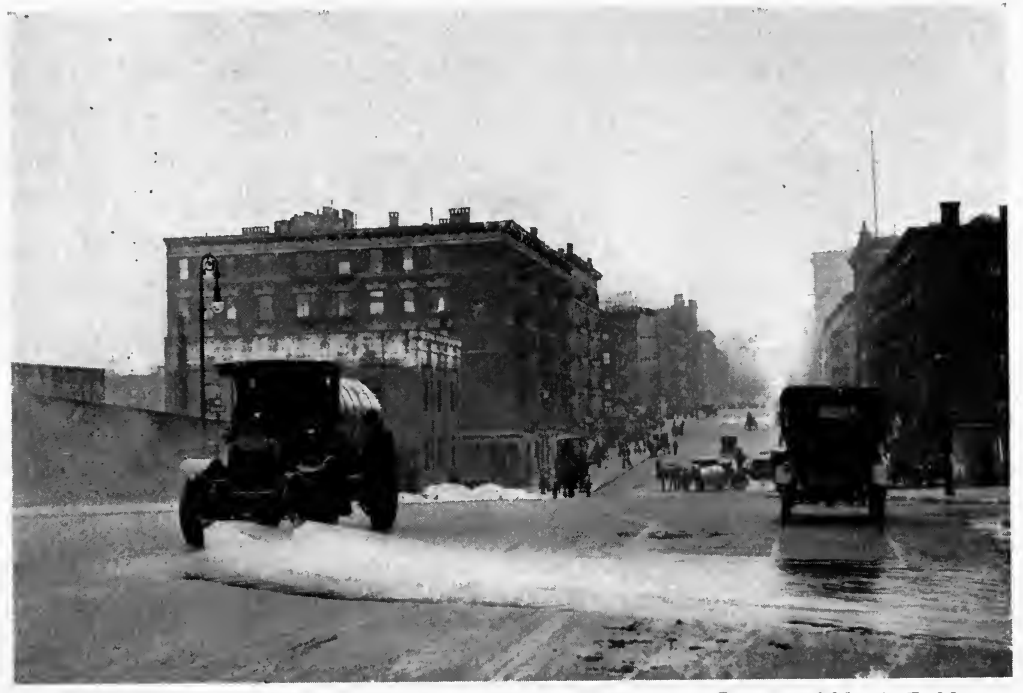

Courtesy of Mr. A. F. Masury.

FIG. I68. Motor Truck Flushing Machine.

time without previous sprinkling. Horse-drawn sweepers and squeegees are employed to a limited extent, the work being done mostly at night. During the daytime, in the summer months, a few streets of the city in the crowded districts are flushed, either by hose or by machine.

Philadelphia. Broken stone roads are cleaned by brushing coarse dirt into the gutters, once a week, once in two weeks, or once a month, dependent upon traffic and location. Pavements are cleaned every day, every other day, every third day, or once a week, dependent upon traffic, location, and other local conditions. Smooth bituminous pavements, brick pavements in 
good condition, and wood block pavements are cleaned by patrolmen with brooms and with rotary squeegees. Wavy bituminous pavements, brick pavements in poor condition, and stone block pavements are hand and machine broomed and cleansed with power flushers.

Boston. The business streets are swept by machine sweepers each day, shortly after midnight. The streets are then flushed with flushing machines. During the daytime the streets are kept clean by hand patrol.

Washington, D. C. The work is under the supervision of the Division of Street Cleaning, which is a part of the engineering department of the District. All of the streets in the central portion of the city are cleaned by hand patrol each day, with the exception of Sundays and holidays. In this work each street is actually swept over about three times. The streets outside of the section which is cleaned by hand patrol are sprinkled and swept by machine sweepers about three times a week. Alleys are cleaned about once a week, and unpaved streets are cleaned about once every ten days. The streets in the central portion of the city, besides being cleaned by hand patrol, are sprinkled and gone over with a rotary squeegee about three times in two weeks. The streets in the hand patrol section are paved largely with sheet asphalt and asphalt block. The streets which are paved with stone block or cobble are cleaned with pressure flushing machines.

Great Britain. Yabbicom* has described the methods of street cleaning typical of twenty towns of England, including five of the boroughs of the City of London, and fifteen towns outside of the great metropolis, including such cities as Liverpool, Manchester, Edinburgh, and Belfast. He found that 32 percent of the streets in sixteen of these towns are paved with stone setts, 3 percent with wood paving, 5 percent with various materials, including asphalt, and 60 percent with broken stone. The principal streets in all of the towns are cleaned at least once each day, and more frequently when necessary. The second-class streets are swept three times a week, while

* Report No. 34, Second International Road Congress, Brussels, I9Io. 
the suburban roads are cleaned in some places only once a week. The streets are swept during the night in eight towns, during the day in seven, and during both day and night in five. Street orderlies, mostly boys, are employed during the daytime in each town to pick up the litter and sweep up horse droppings. The refuse gathered by the street orderlies is placed in small hand-carts and dumped at some depot, or it is placed in bins which are constructed above or below the level of the pavement. Street sweeping is generally preceded by sprinkling when the streets are dry. Motor vehicles, as well as those drawn by horses, are used for watering in Westminster and Cardiff. Records from twenty towns showed that horse-drawn sweepers are used in fourteen to clean the broken stone roads.

In London the street cleaning is done under the direction of the Engineering Bureau of the Public Health Department. Each night the streets of the city are washed by hose flushing or by water-carts, the work being done between the hours of 8 P.M. and 6 A.M. Men broom or squeegee the surface during the process of washing. During the daytime the streets are swept by hand with brooms in dry weather and squeegeed in wet weather. The streets are also patrolled by "orderly" boys.

France. In Paris the street cleaning is done under the direction of the Department of Public Works. Between 4 A.M. and 7 A.M. many streets are watered and then swept with horsedrawn sweepers and the sidewalks are swept with hand brooms. The refuse is either swept to the gutters or collected and placed in pits and removed by carts. During the day some streets are swept with hand brooms, the material being brushed into the gutters, where it is carried away to the sewers by water flushing. Horse-drawn squeegees are employed for cleaning asphalt and wood pavements.

Germany. In Berlin a special committee of the City Council has charge of the street cleaning operations. Rotary machine brooms are used to sweep the streets at night, beginning at II.30 P.M. During the day the streets are sprinkled by motor wagons and horse-drawn carts. Watering is immediately followed by cleaning with horse-drawn and motor-driven 
rotary squeegees. In those places where the water is not removed by the machine squeegees, the pavements are cleaned by men or boys with hand brooms or squeegees. Although several machines which dampen, sweep, and take up the material have been used, they have not proved to be very satisfactory.

\section{Snow Removal}

The methods used in dealing with snow on highways are influenced to a great extent by climatic conditions. There are localities in northern climates or in high altitudes where the snowfall is heavy and the cold is so intense and constant that the snow does not melt appreciably until spring. In such places it is not so much a question of removing the snow as it is of making the highways passable. The drifts are cut through or smoothed out and the whole roadway is compacted by a light roller.

In practically all of the large cities of the United States, and many of those of Europe, it is the practice to remove the snow from the business districts as soon as possible. If not efficiently removed a heavy snowfall will not only cause extreme inconvenience to the public, but it may seriously impede and hinder the traffic and business of a city.

A great deal of attention is given in European cities to planning a scheme of organization early in the season to perform the work of removing the snow, so that it may be accomplished without any unnecessary delays. Many times district depots are established with an equipment of tools and implements sufficient to do the work in that district. Laborers are hired with the understanding that when the snow commences to fall they are to report to a particular station for work. The work can be efficiently attacked in this way, as the superintendent of the district knows beforehand just what means he will have at hand to carry it out. In many places both in Europe and in this country, it is customary to let out the work of snow removal by contract. The method for paying for contract work varies in different communities. In some places the area of the roadway surface is determined 
and a price agreed upon for each inch of thickness of snow, including the cost of sweeping and transporting to the dumping place. Another method is to obtain a price per cubic yard of snow swept and heaped along the road and a separate price for the transportation. Some times an overhaul clause is included in the contracts.

Removal BY Machines. In cleaning the roadways with machines, the snow is pushed towards the gutters. The snow

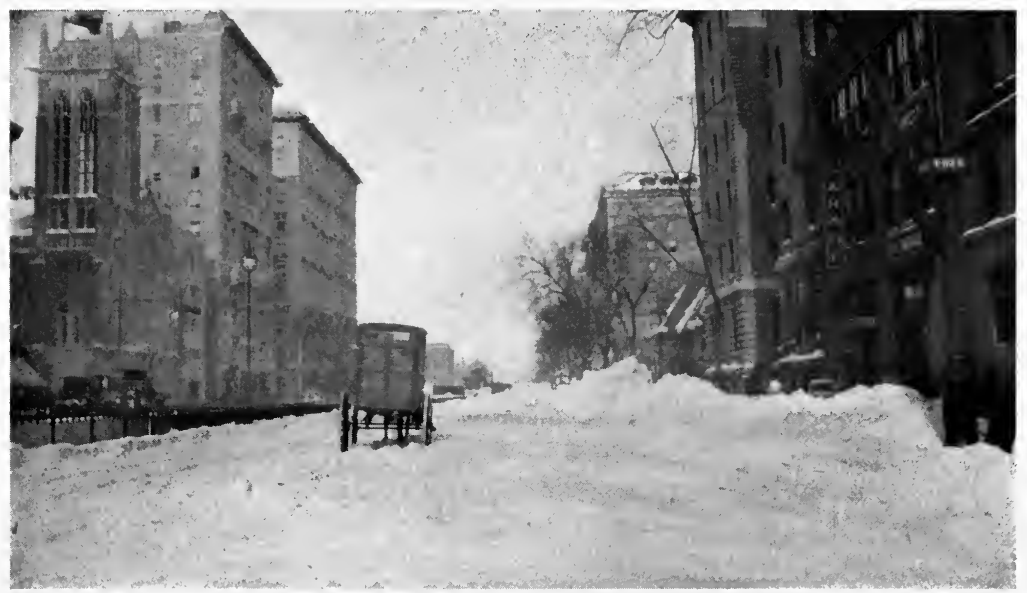

FIG. I69. Large Snow Drifts at Curbs.

from the sidewalks is also moved to the same point, with the result that a drift is formed. These drifts will assume large proportions when a heavy snowfall occurs and will not only restrict the limit of traveled way, but also hinder the surface drainage. (See Fig. I69.) When the snow starts to melt the water will back up into the cellars of the abutting property unless considerable care is taken to keep a passage clear for the water to flow to the catch-basins or other inlets. The removal of the snow which has been thus gathered is accomplished in several ways. In light storms the drifts are gathered into large separate piles which are later removed by wagons. When the drifts are large they are removed by wagons without previous piling. The snow is taken by the wagon to some 
natural waterway, or is dumped on vacant lots, or discharged through manholes into the sewers under certain conditions. Although various machines have been devised for the purpose of melting the snow gathered together in this manner, none of them have been successful, at least from an economical standpoint.

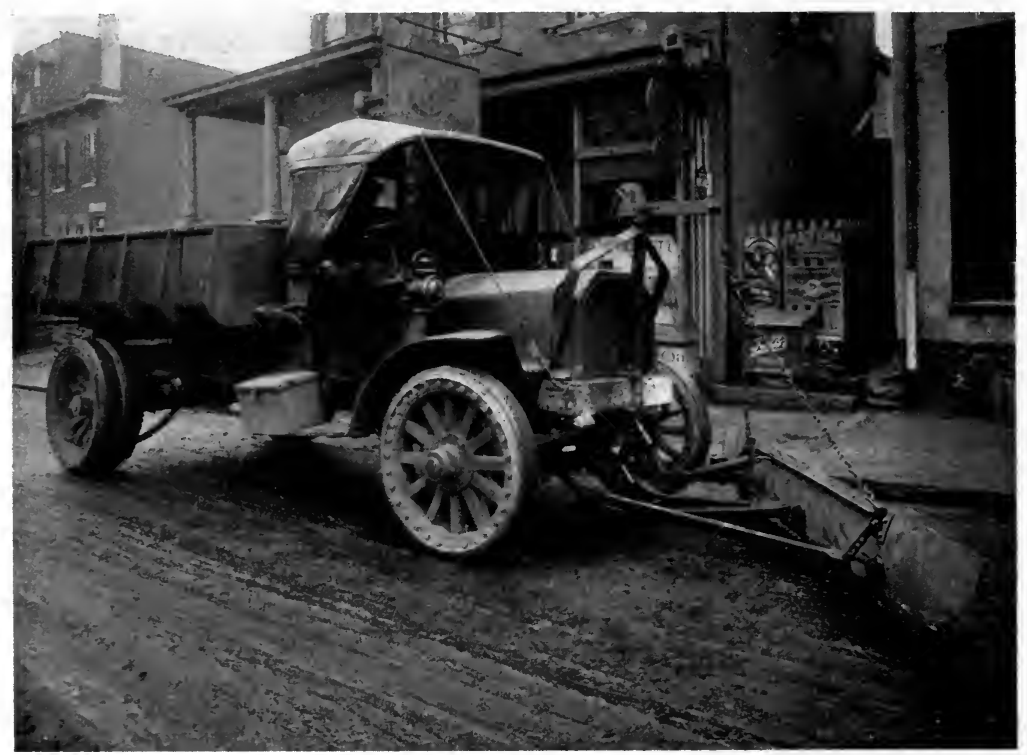

Courtesy of Mr. William H. Connell.

Fig. 170. Snow Plow Attached to a Motor Truck.

Removal by Plows. As a general rule the streets on which car tracks are located are cleaned first. Various types of plows, see Figs. I 70 and I I I, are used for this purpose in several American cities. The traction companies naturally try to keep the cars moving and the snow no sooner begins to fall than special cars, equipped with brushes or plows, are sent over the different lines to clear the tracks. It is this principle of starting work of removal before the snow attains any depth that makes their efforts so uniformly successful. It is a rare occurrence for the cars to be blocked for any length of time except in the most severe storms. The work done by the traction companies is of the utmost assistance to vehicular 
traffic. In many of our American cities, after a heavy fall of snow, the cleared trackway is the only place which is accessible for vehicular traffic. In Vienna the tramways are controlled by the municipality, and it is the practice there to plow the snow from the roadway toward the gutter at the

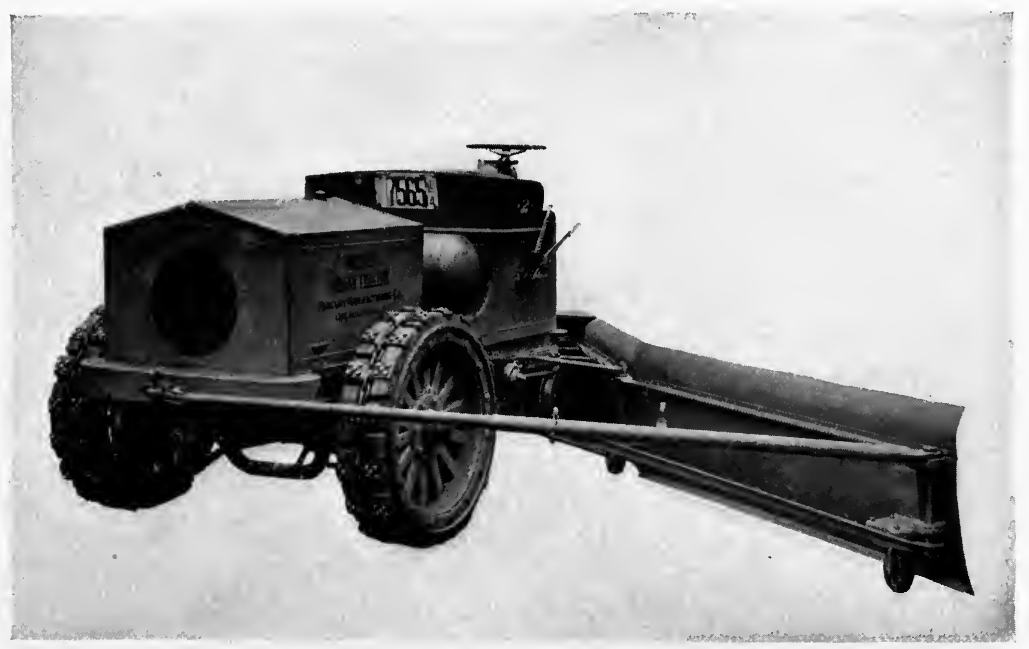

Courtesy of the Mercury Mfg. Co.

FIg. I71. Motor Tractor Snow Plow.

same time it is removed from the trackway. This is accomplished by coupling two plows to the car. The plows consist of platforms mounted on four wheels, underneath which are a series of horizontal rods to which are attached vertical blades capable of being raised or lowered. When the plows are used in pairs, one is drawn at one side and just behind the other in such a way as to clear two widths at one passage. Ordinary V-shaped plows are used extensively to clear a path for vehicles on highways not occupied by car tracks.

Removal by Sweepers. Rotary brushes can be successfully used to remove light falls of snow. In Paris these sweepers are used for snowfalls from $1 / 2$ to $\mathrm{I}$ inch in thickness. Rotary brushes are also used by the traction companies in clearing snow from the tracks, in which case the brush is generally run 
by a motor. One objection to horse-drawn sweepers for snow removal is that the speed of the brush is not fast enough to prevent the bristles from becoming choked up with snow. Road scrapers can be used sometimes very advantageously in doing this work. (See Fig. I72.)

Removal by USE of Salt. The use of salt in connection

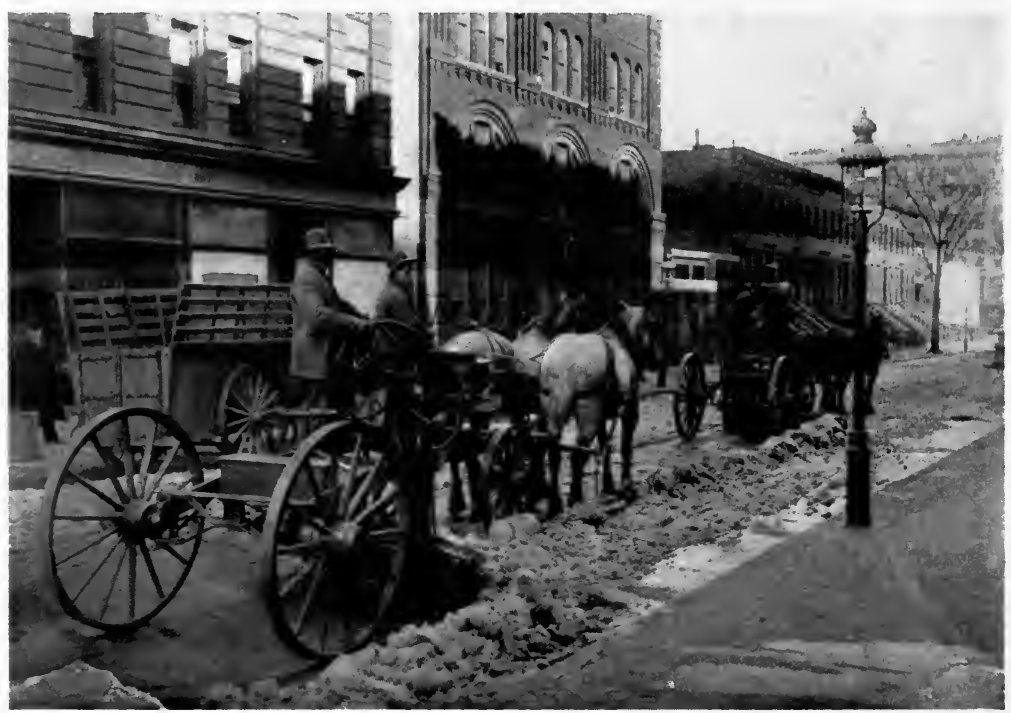

Courtesy of Mr. William H. Connell.

FIG. I72. Road Scrapers Used to Remove Snow.

with snow removal is objected to by some on account of the intense cold produced and its injurious effects on shoe leather and horses' hoofs. In Paris, however, as soon as the snowfall occurs, the workmen commence at once to spread rock salt on the roadways. The salt produces a thawing action after the traffic has mixed it with the snow. The mixture of snow and salt is then swept to the gutters by sweeping machines, after which it is flushed into the sewers.

Removal by Flushing. The practice of flushing is quite common in many European cities. Flushing is not carried on when the temperature is below the freezing point on account of the danger of ice forming in the sewers. 


\section{CHAPTER XIX}

\section{COMPARISON OF ROADS AND PAVEMENTS}

The determination of the most economical and efficient method of construction and maintenance to be employed on different highways constitutes one of the most important subjects which the highway engineer has to consider. The solution of the problem depends upon many variable factors, all of which must be given due consideration and the proper value attached to each. The great variety of materials and methods of construction and maintenance used, together with the absence of such essential information as traffic censi, cost data, etc., makes it a difficult matter to reduce, for a given location, all of the different types of roads and pavements to a comparable basis.

Development. The small amount of scientific comparison of roads and pavements which has been undertaken in the United States is attributable to many causes, among which may be noted the following:

First. Political interference in the selection of the men placed in control of highway work, and with the work of design, construction, and maintenance of roads and streets, and the interference by controlling bodies of laymen in the legitimate work of the highway engineer.

Second. The continual change in the personnel of the engineering staff in control of highway work.

Third. Division of responsibility in the supervision of highway work, particularly in municipalities, but also applicable in some states, as, for instance, those in which the state department supervises the design and construction, while the responsibility for maintenance is placed upon the county or town.

Fourth. The search by many officials for a panacea for the treatment of all classes of roads and streets.

Fifth. The comparatively small number of well-trained high- 
way engineers who have devoted the requisite time and energy to the problems of economics, administration, organization, construction, and maintenance connected with highway engineering.

Sixth. The comparatively infinitesimal amount of investigation which has been considered necessary as preliminary to the design of a road or street or a system of highways.

Seventh. A confusion of ideas on the part of many as to the reasons for the success or failure of a given road or pavement.

Essentials of an Ideal Road or Pavement. An ideal road or pavement should be durable, noiseleśs, suitable for users, easily cleaned and made dustless, non-slippery for horses and all classes of vehicles under varying climatic conditions, easily maintained, should yield neither dust nor mud, have a low tractive resistance, low first cost, low annual cost, low maintenance charge, and an æsthetic and impervious surface.

A consideration of these important characteristics reveals the lack of accurate data which are available relative to each. However, certain information is at hand which materially aids in a comparison of roads and pavements from different standpoints.

Durability. The life of a road or pavement is expressed either in terms of (a) the number of years during which it can be maintained in a satisfactory condition at a cost per year which has not reached an amount so that reconstruction is economical or, (b) the total number of tons per yard or foot of width that the road or pavement is subjected to during its life. As durability is a function of a number of variables among which the amount of traffic is of primary importance, method (b) usually conveys more information than the first method.

In employing method (a), based on practice in central western cities, the following average values for "life" have been assigned to several types of roads and pavements. In each case the estimated life is based on the supposition that the road

* Hugh J. Fixmer, Division Engineer, Chicago Board of Local Improvements, in I9I5 Proceedings Illinois Society of Engineers and Surveyors, pages $55-56$. 
or pavement is used under suitable local conditions as indicated in the second column.

\begin{tabular}{|c|c|c|}
\hline Type of Road or Pavement & Suitable Street & $\begin{array}{l}\text { Life in } \\
\text { Years }\end{array}$ \\
\hline Granite block. .... & Heavy traffic . . . . & 30 \\
\hline Creosoted wood block & Business..... & $15^{-20}$ \\
\hline Brick.......... & Car line.. & 20 \\
\hline Sheet asphalt. ... & Residential............ & I6 \\
\hline Asphaltic concrete. & Residential and boulevards . & $12-20$ \\
\hline Cement-concrete..... & Light traffic . . . . . . . . & 6-10 \\
\hline Bituminous macadam. & Light traffic $\ldots \ldots \ldots$ & 8 \\
\hline Broken stone........ & Light traffic ....... & 4 \\
\hline
\end{tabular}

Method (b) is employed by John A. Brodie, City Engineer of Liverpool, in a comparison of the tonnage life of different kinds of stone block pavements and broken stone roads.

"Taking heavy traffic streets first, experience shows that accurately dressed setts - 6 inches deep by 6 inches to 8 inches long by 4 inches wide, laid on a sound concrete foundation, at least 8 inches deep, with a small sand bed between the underside of the sett and the concrete, the joints being thoroughly racked with hard shingle and afterwards grouted with a permanent pitch mixture, which prevents any movement in the stones, and renders the whole surface perfectly impervious to weathergive a life equal to at least seven and one-half million tons per yard width, and under these conditions this life has often been exceeded.

"It is at present impossible to say whether an equal tonnagelife can be obtained from the similar shallower 4-inch class of construction in streets taking, say, 60,000 tons per yard of width, as this would mean a life exceeding roo years; but experience shows that the total average wear of the setts has been exceedingly small, and it is a fact that many such streets exist in Liverpool to-day, having a life of from 25 to 30 years without requiring any important repairs during that time due to wear of the material.

"When the same quality of stone is used in ordinary macadam laid 6 inches to 7 inches deep on a sound, hand-packed foundation, experience shows that the tonnage-life of the surface before 
requiring to be recoated is enormously decreased, and instead of seven and one-half millions, a figure about 100,000 tons only, or about 75 times less than the result for setts previously given, has been obtained on a street of moderate traffic-a somewhat startling difference."

Sanitary Qualities. The sanitariness of a road or pavement is based on its imperviousness, smoothness, and freedom from dust and mud. From the standpoint of the public health, noiselessness might properly be considered under this head, as it affects the health of nervous people.

The several roads and pavements may be classified as follows, the groups being given in the order of their desirable sanitary properties: first group, sheet asphalt, bituminous concrete, cement-concrete; second group, creosoted wood block, bituminous macadam, bituminous surface, stone block and brick, with well-filled joints; third group, broken stone, gravel; earth, stone block and brick, with open joints.

Noiselessness.* "A quiet pavement has become particularly important at this time. With the strenuous life of the modern cities the nerves of the workers must be protected, and it is the testimony of all brain workers that noise is a great disturber. Constant ${ }^{-}$complaints are coming to city departments not only of the great disturbance to the nerves of the workers but actual loss of time in schools, offices, and court rooms, and interruptions in churches on account of the noise over rough pavements. Hospitals all complain of the noise on account of the damage done to patients.

"Of the different kinds of pavements herein stated, one of wood blocks is least noisy, followed by asphalt, asphalt block, bitulithic, brick, and granite as the most noisy. It often happens, however, that on account of grades or extremely heavy traffic it is necessary to lay granite even where a quiet pavement is desired. In this case special care must be used to reduce the amount of noise to a minimum."

Slipperiness. The comparison of pavements from the standpoint of slipperiness has naturally been confined by early investi-

* George W. Tillson in Engineering and Contracting, October I8, I9II. 
gators to the effect on horses. It is evident that future investigations along this line should include consideration of slipperiness for all classes of vehicles under varying climatic conditions. From the former viewpoint, that is, with reference to horses, stone block with joints filled with a bituminous filler ranks first as a non-slippery pavement. Hillside vitrified brick or ordinary vitrified block constructed with a bituminous filler is adaptable for steep grades. The other pavements and roads rank in the following order as non-slippery; gravel, broken stone, bituminous concrete, stone block, and brick with cement grouted joints, bituminous macadam, bituminous surfaces, sheet asphalt, and wood block. The table gives a general idea relative to the maximum grades on which it is permissible to use different types of roads and pavements.

\begin{tabular}{|c|c|}
\hline $\begin{array}{l}\text { iranite block pavement with bituminous filled } \\
\text { joints } \ldots \ldots \ldots\end{array}$ & \\
\hline Brick pavement with bituminous filled joints...... & Io to 15 \\
\hline 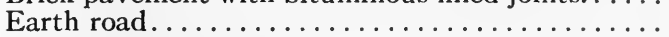 & IO \\
\hline ad... & 7 to $10 \%$ \\
\hline e rc & \\
\hline inous concrete pavement............ & 5 to 8 \\
\hline 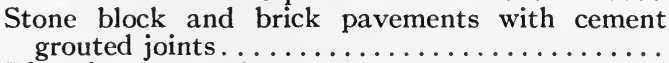 & \\
\hline t) & 3 to \\
\hline & \\
\hline surface & $3 \mathrm{t}$ \\
\hline & 3 to \\
\hline blor & 2 to 3 \\
\hline
\end{tabular}

Haywood Report. In I873 William Haywood submitted a report to the Sewer Commissioners of London which included a comprehensive comparison of rock asphalt, granite block, and wood block pavements from the standpoint of relative slipperiness. As a description of methods of investigating slipperiness the report is of interest to American engineers, but the conclusions stated cannot be used to advantage, as one of the types of construction, rock asphalt, is not in common use in America. Mr. Haywood's reports are included in the United States Special Consular Reports entitled "Streets and Highways in Foreign Countries."

Resistance to Traffic. The tractive force required to draw vehicles over a given type of road or pavement is of importance 
as a factor in the selection of the wearing surface. Naturally, the weight to be attached to this factor will depend to a certain extent upon the character of the traffic which will use the highway. Investigations have been conducted upon which have been based certain conclusions which may serve as general guides.

The effect of grade and the character of the surface on tractive force based on experiments conducted with a horse-drawn dynamometer wagon are covered in the following conclusions*:

"There are so many variables that enter in to affect the draft of any vehicle, that it is difficult, in a test made under actual working conditions, to separate the effect of any one of the many, for the same reason it is not safe to put too much confidence in the results obtained from a limited number of tests, or to compare the results made by different persons under unlike conditions and at widely varying times. Some of the variables that are sure to enter in, are: I, the team; 2, the driver; 3, nature of surface; 4, conditions of the surface; 5 , grade; 6 , width of tire; 7 , diameter of wheel; 8 , design and condition of vehicle; 9 , magnitude of load; ro, curves; r r, slopes.

"The tests conducted under the supervision of the writer, since 1908, have been run with a traction dynamometer wagon. The dynamometer proper is suspended from the bed of a Studebaker truck about midway between the front and rear axles. The pull is transmitted by the tongue directly to the dynamometer, which pulls on the rear axle. The draft is measured by the compression of two carefully calibrated coil springs, and is transmitted through gears to a brass point which marks the record on sensitized paper operated by friction rolls, but over a flat platen.

"Grades. Increasing the grade decreases the load that can be hauled, in each of three ways:

r. The required pull per ton is increased.

2. The possible pull of the horse is decreased by the effort required for the horse to raise his own weight through the grade.

3. The effective pull of the horse is diminished by a change in the angle of the application of the pull.

* Prof. E. B. McCormick in Southern Good Roads, January, I913. 
"There are no ways of overcoming the first two losses; the third, however, can be nearly if not entirely eliminated by a change in the methods of hitching. A comparison of the figures in the following table will show very clearly the decrease of a effective work with the increase of grades. The first column shows the actual pounds of pull required to draw a gross load of 5,270 pounds over a dry, hard earth road, solid, and well compacted, no dust, and using $1 \frac{1}{2}$-inch tires. These figures are from a test made at the Kansas State Agricultural College on August 12, I9r2. The third column gives pounds pull required per ton as figured from values in the second column. The fourth column gives draft in pounds per ton as taken from results of tests on macadam roads. The fifth column shows the possible pull of a 2,800 pound-team on the different grades. These figures assume that a team can exert a pull equal to one-third of its weight for a short time, on the level, and that on grades the tractive effort of the team decreases an amount equal to the grade resistance due to its weight, as calculated by the formula:

$$
X=\frac{W}{3}-\frac{W}{100} G
$$

Where $W=$ Weight of Team

$X=$ Tractive Effort of Team

$G=$ Percent of Grade

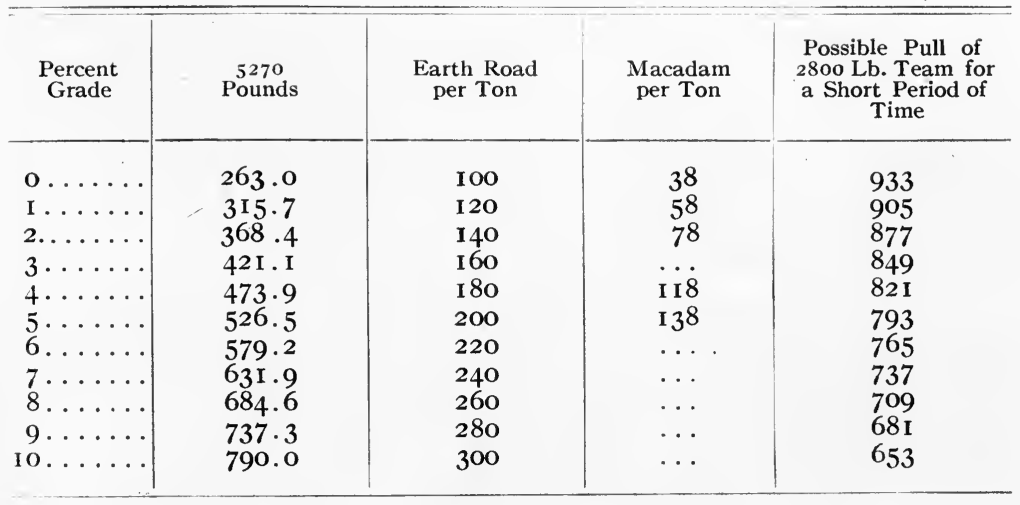


"A comparison of these figures will show that the necessary pull on a ro percent grade, over that on a level, is 200 percent for an earth road, while the decrease in effective pull for any given team is nearly 30 percent, and that for a dirt road any given team can pull on a Io percent grade only two-ninths of the load that it can draw on the level.

"It must be remembered that while a team may exert an effort equal to one-third (or even one-half) its weight for a short length of time, it cannot do so for an extended period. The value in such case, as given by different authors, varies one-tenth to one-fifth the weight of the team.

"It is customary to state the probable pull of a horse or team in terms of its weight. This, of course, is not accurate, as a well-trained team of 2,000 pounds will oftentimes outpull a poorly trained team of 2,600 pounds or 2,700 pounds."

Materials. Based upon the results obtained by various investigators, Professor McCormick has compiled a table to show the relationship existing between different wearing surfaces and the tractive force in pounds per ton. Only a part of the table is given here.

\begin{tabular}{|c|c|}
\hline Surface & $\begin{array}{l}\text { Tractive Force } \\
\text { per Ton }\end{array}$ \\
\hline Earth packed and dry & . I IOO \\
\hline Earth-muddy . . . . . . & 190 \\
\hline Sand-loose......... & 320 \\
\hline Gravel-good. & $5 \mathrm{I}$ \\
\hline Gravel-loose . . . . . . . & 147 \\
\hline Macadam-average. . & 46 \\
\hline Sheet asphalt....... & 38 \\
\hline Asphaltic concrete... & 40 \\
\hline Vitrified brick-new. . & 56 \\
\hline Wood block-good... & 33 \\
\hline
\end{tabular}

Annual Cost. The relative economy of different types of roads and pavements can only be ascertained by comparing the annual costs. The annual cost is a combination of the following variables: interest on the initial cost of the roadway, the annual maintenance charge and an annuity which will in $N$ years, the so-called life of the road, provide a fund equal to the cost of reconstruction. If $C=$ annual cost, $A=$ first cost, $r=$ rate of interest, $I=$ annual maintenance charge, and $x=$ annu- 
ity, the annual cost may be expressed by the formula

$$
C=A r+I+x \text {. }
$$

In the case of types of roads permitting partial reconstruction every $M$ years, a second annuity $y$ should be included in the above formula to take care of this periodical reconstruction through $N$ years or the total life of the road. In order to make a fair comparison of the different methods the same standard of maintenance should be used in each case.

Although theoretically the pavement giving the lowest annual cost would be the most economical one to build, there are other financial considerations which sometimes make it necessary to select some other type of pavement. For instance, the amount of money at hand for the improvement may not be sufficient to pay for the first cost of construction of a pavement which would give the lowest annual cost. Again, a road or pavement that might be the most economical would require such frequent repairs as to interfere with the traffic and business conducted on it.

From the foregoing discussion it is evident that the annual maintenance charge $(I)$ and the annuity $(x)$ are the variable factors to which it is difficult to assign definite values in many cases. First cost, although varying to a marked degree for different classes of pavements in various localities, may be assigned definite values. The initial costs of various roads and pavements have been considered in the preceding chapters, and hence will not be repeated here.

Maintenance. Unfortunately the standards of maintenance vary widely throughout this country. Hence, reports relative to the cost of this item as a factor of annual cost are of little value except in those cases where it is known what the highway officials mean by the statement, "the road is well maintained." The ideal maintenance, which should be striven for in every case, is a method by which the surface of the highway is kept in as good condition as when accepted on the completion of construction. It is self-evident that it is only possible to conform to this ideal by the adoption of the principle of continuous maintenance. 
Annuity. The factor, annuity, is a function of the variable, the life of the road or pavement, which was discussed under the property, durability, in the first part of the chapter.

Example. As an illustration of the application of the formula, the annual cost of a granite block pavement laid on a 6-inch concrete base will be computed. It will be assumed that the first cost is $\$ 3.50$ per square yard; interest, 4 percent; annual maintenance cost, 2.4 cents; life, 25 years; and at the end of this period it will be assumed that new blocks will be laid on the old concrete foundation at a cost of $\$ 2.50$ per square yard, and that in this manner the life of the pavement is renewed for another 25 years. The annual cost for 50 years, considering the whole pavement to be renewed at the end of that period, will be as follows: $C=\$ 3.50 \times 0.04+0.024+0.023+0.060=$ $\$ 0.247$ for the first 25 years, $C=\$ 0.187$ for the second 25 years, and the mean of these gives $C=\$ 0.217$ average for 50 years.

Methods of Comparison. The primary object of a detailed comparison of the relative merits of various roads and pavements is to enable the engineer to determine within certain limits the method of construction and, in some cases, the method of maintenance which are adaptable to local conditions from the standpoints of economy and efficiency.

\begin{tabular}{|c|c|c|c|c|c|c|c|c|c|c|c|c|c|}
\hline & 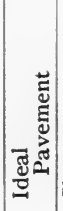 & 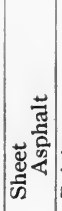 & 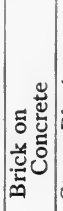 & 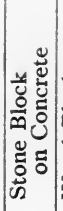 & 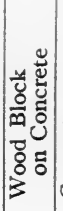 & . & . & | & 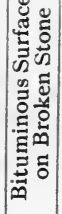 & 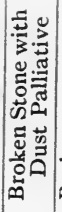 & 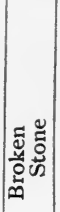 & 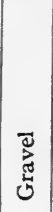 & 苟 \\
\hline First cost . . . . & I0 & 3 & 5 & I & I & 6 & 7 & 7 & 8 & 9 & 9 & 9 & IO \\
\hline Ease of traction. & Io & IO & 8 & 3 & 9 & 9 & 9 & 8 & 8 & 6 & 6 & 5 & 2 \\
\hline Non-slipperiness. & 10 & 4 & 8 & 7 & 4 & 6 & 7 & 7 & 7 & 8 & IO & Io & 10 \\
\hline Ease of cleaning. & Io & Io & 9 & 7 & 9 & 8 & 9 & 9 & 9 & 3 & 3 & I & I \\
\hline Noiselessness. . . . . . & IO & 7 & 6 & 3 & 9 & 6 & 9 & 9 & 9 & IO & Io & 10 & IO \\
\hline Non-productive of dust.. & IO & Io & 9 & 8 & 7 & 7 & 9 & 8 & 8 & 6 & 4 & 3 & I \\
\hline
\end{tabular}

As an aid in comparison it is advisable to have at hand a table covering numerical values of certain factors which are susceptible to such form of comparison. The above table, which illustrates the treatment of the problem along these lines 
of investigation, gives assigned values for some of these characteristics of the different types of roads and pavements on the basis of ten for the value of the characteristic in an ideal pavement.

It is necessary for each engineer to modify tabular information of this character in order that the values shall be based upon local conditions. For instance, it is obvious that the numerical values assigned to "First Cost" will vary materially in different sections. It is likewise apparent that it is impracticable to blindly add up numerical values with the expectation that the type having the highest value is the pavement to be employed. In the great majority of cases one or more factors will also have a greater weight than certain other properties. Of course it is possible to weight the values of a table and then obtain totals for comparison. The totals obtained by the summation of numerical values of properties referred to in the above table must, however, be supplemented by values attributed to factors which are not covered in the table, due to their complex and variable character. As examples of such factors may be cited cost of maintenance, durability, etc., which properties are intimately related to local conditions pertaining to a given highway.

Some engineers develop a classification for local conditions based on the foregoing principles and as each individual problem arises assign the highway in question to a given class.

John A. Brodie, M. Inst. C. E., while Borough Engineer and Surveyor of Blackpool, England, divided the streets within his district into five classes, and determined the amount of traffic for which each class was suitable. His conclusions were. as follows:

"Class No. I. Foundation of Portland cement-concrete 7 inches thick, covered with granite setts 5 inches to 6 inches in length, 3 inches in width, and 6 inches in depth; jointed with fine, dry gravel and boiling pitch and creosote oil.

"This class is suitable for main suburban roads with traffic up to 200,000 tons per yard width of carriageway per annum; impervious to moisture; noisy, but clean; gradients up to I in 40 . 
"Class No. 2. Foundations of Portland cement-concrete 6 inches in depth, covered by specially selected Karri or Jarrah blocks 6 inches to 8 inches in length, 3 inches in width, $4 \frac{1}{2}$ inches in depth, laid close, direct on concrete, and grouted with boiling pitch and creosote oil.

"Suitable for first-class shop streets, with traffic of about 100,000 tons per yard width per annum; practically impervious, noiseless, clean, and dustless; gradients up to I in 40.

"Class No. 3. Foundations of hand-packed rubble 8 inches in depth, covered with 5 inches of tar-macadam.

"Suitable for residential streets having a light traffic of 20,000 tons per yard width per annum; impervious, noiseless, clean, and dustless; gradients up to $\mathrm{I}$ in 24 .

"Class No. 4. Foundation similar to No. 3, but 7 inches deep, with $2 \frac{1}{2}$-inch gauge water-bound granite, to a finished depth of 5 inches, blinded with fine granite chippings.

"Suitable for ordinary residential front streets with a light traffic of about 5,000 tons per yard width per annum; pervious, comparatively noiseless, dusty, and sloppy; gradients up to $\mathrm{I}$ in $\mathrm{I} 2$.

"Class No. 5. Foundations similar to Nos. 3 and 4, 7 inches in depth, covered with Haslingden setts, 6 inches to 8 inches in length, 4 inches to 6 inches in width, and 6 inches in depth; jointed with dry gravel and boiling pitch and creosote oil; laid with a concave cross-section and channel in center.

"Suitable for back (or secondary access) streets 9 feet to I8 feet in width, with a traffic of 60,000 tons per yard width per annum; impervious, clean, and dustless; very noisy; gradients up to $I$ in $I 2$.

"It is not claimed that the above classified carriageway specifications are the best under all circumstances, but only that they are probably the most suitable for the author's district, or for use under similar conditions."

Records AND Cost DATA. It is apparent that records and cost data are essential if an intelligent comparison is to be made of the relative value of different types of roads and pavements. 
* "Cost records of highway work should indicate as clearly as possible the proportion of the expense chargeable to:

I. Permanent betterments, such as land purchases, grading, the improvement of lines and grades, masonry and steel bridges and culverts. This part of the work once done may be considered permanent or sufficiently durable to outlast more than a single generation.

2. Curbing, gutter pavement, fencing, guard rails, wooden bridges, concrete foundation, planting, etc., all of which may need periodical repairs, but will probably last twenty years at least.

3. The roadway surface, which will begin to deteriorate at once, and will need constant attention and periodical renewal.

"For each piece of work the records should include:

I. The character and first cost of the materials.

2. Cost of delivery on the work, with kind of transportation and distance hauled.

3. Cost of labor of all classes and the quality of same.

4. Cost of present value of plant and equipment, with allowance for depreciation due to the work under construction and not previously marked off.

5. All overhead charges, including engineering and inspection.

6. Cost of bonds, permits, etc.

7. All delays due to weather, failure to receive materials, strikes, or other causes.

8. A precise description of the methods employed and of the surface treatment of the road.

9. A statement as to the results obtained, the probable causes of failures or unsatisfactory work, and the means employed to correct or remedy them.

Io. The manner in which the funds to pay for the work are raised, whether by cash appropriations, by the issue of bonds, with length of term and rate of interest, or by money advanced in anticipation of the collection of assessments for benefit."

* Nelson P. Lewis, Chief Engineer of the Board of Estimate and Apportionment, New York City, I9I4 Transactions Am. Soc. C. E. 
In order to give some idea of the detailed information relative to each section of highway which should be recorded, the I9I4 construction and the I909 maintenance report forms used by the Special Committee of the American Society of Civil Engineers on "Materials for Road Construction" are cited as illustrations of forms in current use.

\section{BITUMINOUS MATERIALS FOR ROAD CONSTRUCTION AND STANDARDS FOR THEIR TEST AND USE.}

SPecial Committee of the American Society of Civil Engineers

Please address reply to

A. H. BlanchaRD,

Secretary of Committee,

Columbia University,

New York City.
Committee:

IV. W. CROSBY,

H. K. BISHOP, Chairman;

A. H. Blanchard,

A. W. Dean,

N. P. LEwIS,

C. J. Tilden,

G. W. TillsoN.

Data Concerning the Use of Bituminous Materials in Surfaces and Pavements.

GeNeral INFORMATION.

State. . . . . . . . . . . . . . . . . . . . . . . . . . . .

Town or City . . . . . . . . . . . . . . . . . . . . . . . . . . . . .

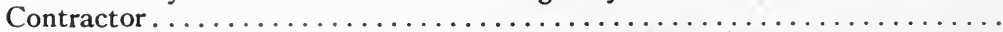

Length of Work..............Width of Metal (Average) .........

Date of Beginning .................... (of use of

Bituminous Materials)

Method of Construction (state character of foundation, thickness of courses, kinds and quantities of road metal and of bituminous materials used, methods used, and approximate maximum grades).

(Attach copy of specifications if available.)

\section{AVERAGE DAILY TRAFFIC AS DETERMINED BY CENSUS}

TAKEN FOR.......HOURS ON Following DATES

\begin{tabular}{|c|c|c|c|c|}
\hline \multirow[t]{2}{*}{ 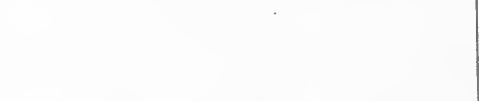 } & \multicolumn{2}{|c|}{ COMMERCIAL } & \multirow{2}{*}{$\begin{array}{l}\text { Passenger } \\
\text { or } \\
\text { Pleasure }\end{array}$} & \\
\hline & Empty & Loaded & & \\
\hline $\begin{array}{l}\text { One-horse vehicles ... } \ldots \ldots \ldots \ldots \\
\text { Two or three-horse vehicles........ } \\
\text { Four or more horse vehicles....... }\end{array}$ & $\begin{array}{l}\cdots \cdots \\
\cdots \\
\cdots \\
\cdots\end{array}$ & $\begin{array}{l}\cdots \cdots \\
\cdots \cdots \\
\cdots \cdots\end{array}$ & $\begin{array}{l}\cdots \cdots \\
\cdots \cdots \\
\cdots \cdots\end{array}$ & $\begin{array}{l}\cdots \cdots \\
\cdots \cdots \\
\cdots \\
\cdots\end{array}$ \\
\hline 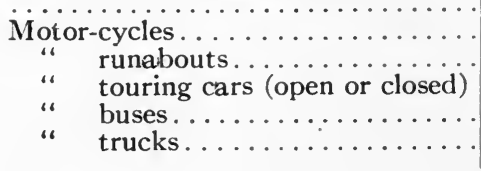 & $\mid \begin{array}{l}\cdots \cdots \\
\cdots \cdots \\
\cdots \cdots \\
\cdots \cdots \\
\cdots \cdots \\
\cdots \cdots\end{array}$ & $\begin{array}{l}\cdots \cdots \\
\cdots \cdots \\
\cdots \cdots \\
\cdots \cdots \\
\cdots \cdots \\
\cdots \cdots\end{array}$ & $\begin{array}{l}\cdots \cdots \\
\ldots \ldots \\
\cdots \\
\cdots \\
\cdots \\
\cdots \cdots \\
\ldots \ldots\end{array}$ & $\begin{array}{l}\cdots \cdots \\
\cdots \cdots \\
\cdots \\
\cdots \\
\cdots \\
\cdots \cdots \\
\ldots \ldots\end{array}$ \\
\hline
\end{tabular}


Are widths of tires on horse-drawn vehicles regulated by law or ordinance? If so, please state regulations on separate sheet.

If no traffic census is available, give estimate of traffic.

Total cost of bituminous surface or pavement, $\$ \ldots \ldots$.

Cost per square yard, $\$ \ldots$. Average thickness, in inches.......

Average wages per day, of common labor, \$... Working day of . . . . hours. Description of Bituminous Material used.

(State type, trade name, company purchased from, and if supplied by contractor or otherwise.)

(If a nalysis is available, please attach copy of same.)

REMARKS: (Including notes as to speed, tire widths, and any preponderance of traffic at certain hours.)

Name

Title.

Address

Date...................

Reporting Officer.

AMERICAN SOCIETY OF CIVIL ENGINEERS.

\section{Special Committee on \\ Bituminous MAterials for RoAd Construction.}

Please address reply to

A. H. BlanchaRD,

Secretary,

Columbia University,

New York City.
Committee:

W. W. Crosby,

H. K. Bishop,

A. W. DEAN,

A. H. BlanchaRd,

Secretary.

To

The Committee again acknowledges its indebtedness for co-operation in reporting on the construction of roads, in connection with which bituminous materials were used. The information furnished is of great value, but in order to make it more fully available it seems advisable to request the supplementary information on the points by the following form.

The general information previously furnished has been filled in by the Secretary.

It is the intention of the Committee to ask annually for reports, each to cover a year of observation, and it is hoped that this form will be returned as soon as data covering a year are available. 
Report on Results of the Use of Bituminous Materials in RoAd Construction.

General Information.

(Required for identification with previous reports.)

State. County

Town Road.

Contractor

Kind of bituminous material

Trade name.

Method.

Dates between which work was done.

to

Period Covered by this Report

From.

to

Class of Highway or Nature of Traffic.

Amount of Traffic or Traffic Census for. Hours (Average)* Dates of census

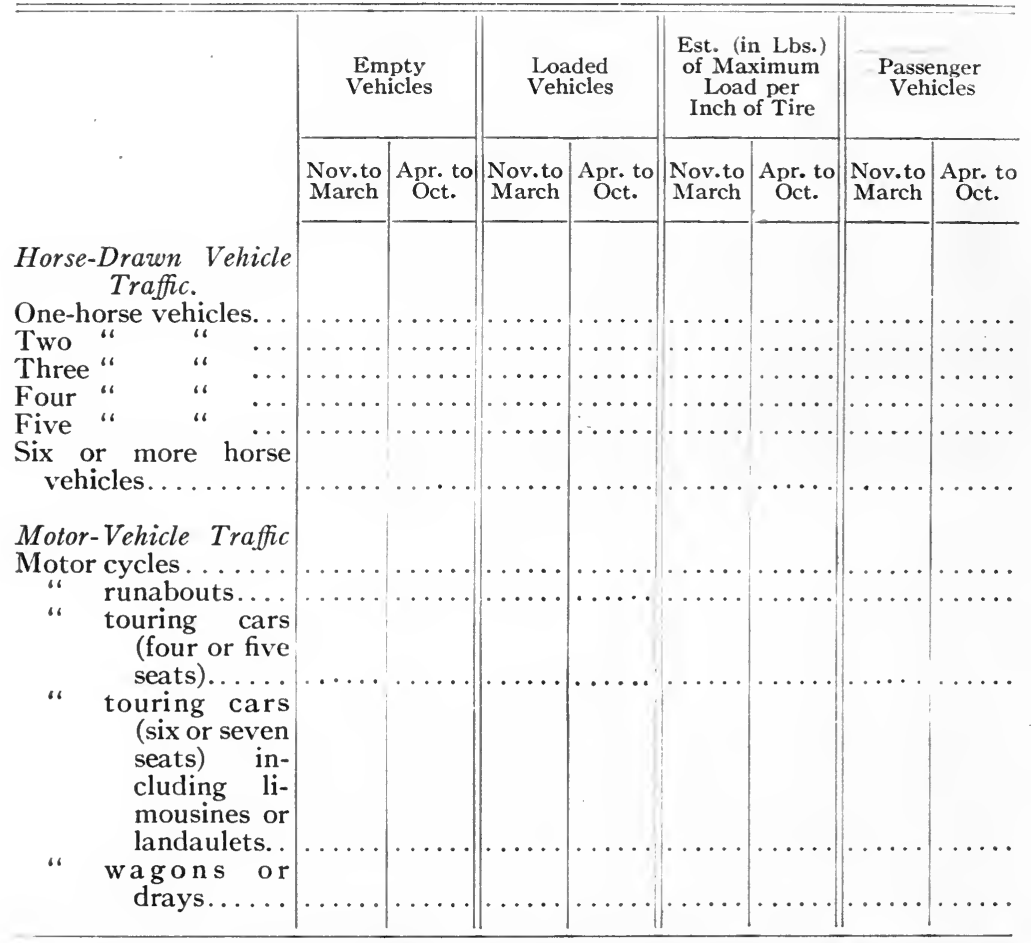

* If possible, "average" should be arrived at from two or three separate determinations. State number of determinations from which average is secured. 
(I) Date of opening road to traffic, or average length of time after completion before sections of road were opened to traffic.

(2) Has the surface begun to disintegrate? If so, when and in what manner? What was the probable cause?

(3) Has any displacement of the surface been manifest in the shape of ruts, waves, etc.?

(4) Was the surface objectionably soft in hot weather? If so, state air temperature; also state maximum temperature at which surface was satisfactory.

(5) Is the tractive effort increased by the presence of the bituminous material?

(6) Was the surface slippery for horses or motor cars in (I) cold weather; (2) when wet; (3) on frosty mornings?

(7) Are the stones of the top course of the macadam visible? If so, to what extent?

(8) Has the surface worn differently adjacent to curbs and car rails than it has in the traveled ways?

(9) During what period covered by this report was the surface coated with snow or ice?

(Io) Maximum depth of frost in this period.

(II) Amount of rainfall for the period covered by this report.

(I2) Has the surface been artificially watered? If so, to what extent?

(i3) Has surface been cleaned? If so, to what extent?

(I4) Is road shaded or exposed?

(I5) Cost and character of maintenance during period covered by this report.

(I6) Your general opinion on the results secured on the above road and any information not covered properly by the above is desired.

(Please Write Answers to Foregoing Questions, Referring to Each by Number.)

Name

Title.

Address...............................

Date....................... 


\section{CHAPTER XX}

\section{SIDEWALKS, CURBS, AND GUTTERS}

The design and construction of sidewalks, curbs, and gutters constitute an important part of the work of a highway engineer.

\section{SidewALKS}

Essential QUalities. There are several essential qualities which a sidewalk should possess. The surface should be smooth, non-slippery, non-porous, agreeable in color, low in first cost and annual cost, easy to clean, and constructed of a material which will wear well. When used on a business street the material should be sufficiently strong to resist the shocks from falling bodies and of such a character that repairs can be easily made.

WIDTh of SidewalK. Sidewalks in business districts usually extend from property lines to curbs. In residential districts this same arrangement may be used or a space for a grass plot or row of trees may be left between the edge of the sidewalk and the curb. In some cases on roads, the walk is entirely omitted or restricted to a narrow, footworn path on the side of the highway. The widths of sidewalks from property line to curb vary from 6 to 20 feet, the usual width for each sidewalk being from one-fifth to one-sixth of the distance between property lines. For a further discussion of the relation of the width of sidewalk to width of street see Chapter IV.

Slope of Sidewalks. It is essential that sidewalks be pitched so as to shed the water which falls upon them. This is generally accomplished by sloping the walk from the property line to the curb by an amount varying from $1 / 8$ to $1 / 2$ inch per foot, depending upon the kind of material with which the surface of the walk is constructed. In some cases the high point of 
the walk is made near the center and the surface is pitched both ways. This arrangement, however, has the disadvantage of throwing part of the water towards the property, of being objectionable in appearance, and uncomfortable to walk upon.

Materials, Construction, Cost Data. The materials used in the construstion of sidewalk surfaces are artificial flags, asphalt mastic, brick, cinders, cement-concrete, gravel, small stone setts, stone flagging, tar-concrete, tile, and various artificial preparations.

Asphalt Mastic. This type of pavement is constructed in France by preparing a mastic from a combination of rock asphalt and a refined asphalt fluxed with an asphaltic base petroleum. Sufficient fluxed asphalt is mixed with the powdered rock asphalt so that the mixture will contain 20 percent of bitumen. A layer of this mixture, of about one inch in thickness, is placed on a cement-concrete foundation, which consists of about four inches of concrete and a layer of cement mortar from $\mathrm{I} / 2$ to $\mathrm{I}$ inch in thickness. A scattering of gravel is spread on the surface and lightly rolled into the asphalt mastic while the latter is still warm.

Cost. The average cost of this pavement in France is approximately \$I per square yard. The cost of a similar pavement in England is about \$1.40 per square yard.

Characteristics. Footways constructed with an asphalt mastic have many points of excellence. They are practically nonabsorbent, very smooth, without joints, pleasant to walk upon, and easily maintained and repaired. A thickness of mastic of $3 / 4$ of an inch will last from five to ten years and sometimes longer on streets where the traffic is not heavy.

Brick and Tile. The bricks or tiles used in sidewalk construction are usually made of burned clay, although tile made of compressed asphalt is used to some extent. Frequently the surfaces of the brick or clay tile are stamped in the process of repressing with some figure of fancy design in order to add to the appearance of the finished walk. In France the usual size of tiles used is 5 to $5^{1} / 2$ inches square and $I / 4$ to $I \frac{1}{2}$ inches thick. In the Netherlands the brick are 7 inches long by $3 \frac{1}{2}$ inches wide by 2 inches deep. In the United States bricks of 
the ordinary building size are frequently used. Brick sidewalks should be given the same care in construction as is accorded a brick pavement. The best results will be obtained if the bricks are laid on a thin sand cushion, about $\mathrm{I} / 2$ inches in depth, which is spread over an accurately surfaced concrete foundation, 4 inches thick, and the joints are filled with a bituminous filler. The bricks are usually laid flat rather than on edge, and with their longest dimensions either at right angles or diagonally to the curb line. Another popular arrangement is to lay the bricks by the so-called herring-bone method. Frequently brick side-

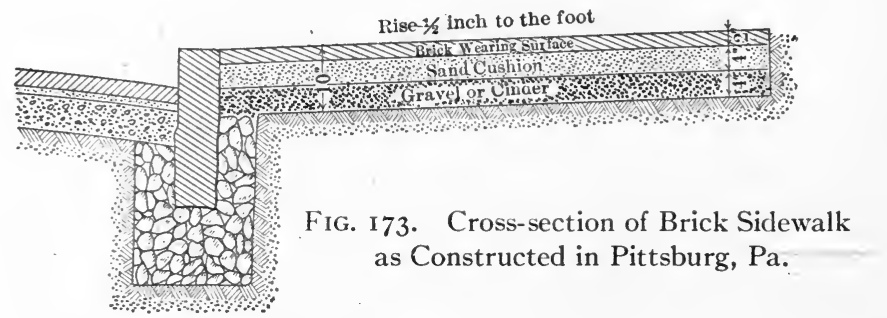

walks are laid on a bed of sand placed in an earth trench and the joints filled with sand. It is not surprising to find that a brick sidewalk constructed in this manner soon loses its shape, due to the displacement of the bricks. 'If a concrete foundation is not used a foundation of good gravel or cinders should be employed underneath the sand cushion. This type is shown in Fig. I73, which is the standard brick sidewalk as constructed in Pittsburg, $\mathrm{Pa}$.

Cost. The cost of tile paving in England, the tiles being Io inches by 5 inches by $2 \frac{1}{2}$ inches, is $\$ 1.62$ per square yard. The cost of constructing tile pavements in France, the tiles being bedded in mortar and the joints filled with mortar, varies from \$I.30 to \$I.50 per square yard. The cost of brick sidewalks in Holland, the bricks being laid in a sand bed on a concrete foundation about 4 inches thick and the joints filled with a cement grout, is about 87 cents per square yard. In the United States the cost of brick sidewalks on a 4 -inch concrete foundation with a bituminous filler is about \$I.75 per square yard. 
Characteristics. When properly constructed, brick sidewalks are very satisfactory. They are non-slippery, wear well, are easy to repair, are comfortable to walk upon when smooth, and are easily cleaned.

Cinders. Cinder sidewalks are built in Chicago by depositing the cinders in three layers, the first layer being 9 inches deep and composed of coarse material, the second layer 3 inches deep and composed of fine cinders, and the third layer consisting of fine cinders in sufficient amount to form a crown to the surface. Each layer is thoroughly tamped or rolled. Cinder sidewalks may be built very cheaply and make a satisfactory surface in outlying districts. It is also possible to use the cinder sidewalk as a foundation for some other type of surface at a later date.

Cement-Concrete. Cement-concrete sidewalks have become very popular in the United States since I910. In business districts where vaults are constructed beneath the sidewalks, the surface is frequently composed of reinforced concrete slabs in which are placed plate glass shapes for the purpose of lighting the vault.

The Concrete. The concrete is a mixture of Portland cement, sand, and broken stone, gravel, or slag.

Subgrade. Concrete sidewalks should be provided with a well drained foundation. The depth of excavation to the subgrade will depend upon the climatic conditions and the nature of the ground. In places where frosts occur, it may be necessary to excavate the ground for a depth of 12 inches or more, whereas in places where there is no frost, 4 to 6 inches will be sufficient. Care should be taken in completing the subgrade that the material is thoroughly compacted and that all soft and defective places are removed and filled with good material. On the completed subgrade is built a subbase, the thickness of which may be I 2 inches or more in cold climates and 2 or 3 inches in some cases where the soil conditions are particularly favorable. A material which is largely used for a subbase is cinders. Broken stone, sand, gravel, slag, and other materials are also used. Many times, in reconstructing old tar-concrete sidewalks, the old 
surface is broken up and put into the subbase. The subbase should be thoroughly compacted. In using such materials as cinders or sand, they should be wet down during the process of ramming or rolling. In some cases it may be advisable to drain the subbase. This is accomplished by either laying tile drains or blind stone drains.

Placing the Concrete. The concrete is usually deposited in two layers, a base layer and a wearing course. The thickness of

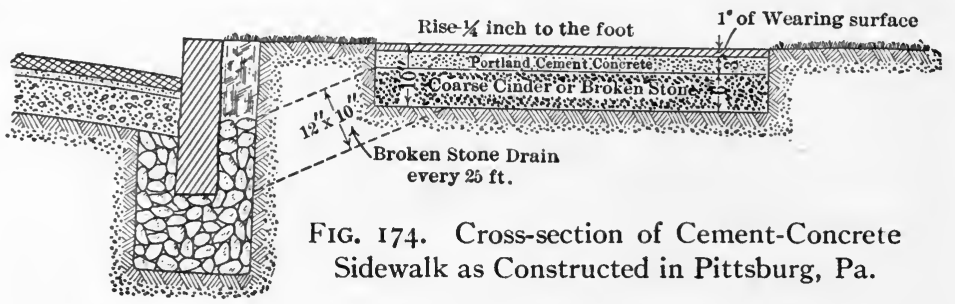

the two courses will depend upon the traffic conditions, the climatic conditions, and whether or not the sidewalk is situated in a place where heavy goods are handled on it. The minimum total thickness of concrete is usually about $3 \frac{1}{2}$ inches, made up of a base course 3 inches thick and a wearing course $1 / 2$ inch thick. In cases where the traffic conditions are severe or there is much frost, the total thickness may be made as much as 6 inches, the wearing surface being from $I$ to 2 inches thick. The standard construction in residential districts of Pittsburg, Pa., is shown in Fig. I74.

The general principles relative to mixing, handling, and placing concrete, which have been previously mentioned in Chapters V and XIV, apply as well to concrete used in sidewalk construction. There are a few points, however, which are peculiar to sidewalk work. The concrete should never be laid as a monolithic mass unless reinforced with steel, but should be divided into separate sections by joints extending through the full depth of the concrete. The correct size of slabs has been found to be one which does not contain over 36 square feet of surface and is not over 6 feet in any one direction. The sections are obtained by constructing either wooden or steel 
forms on the subgrade corresponding in shape and size to the section desired. The forms must be well braced and of sufficient

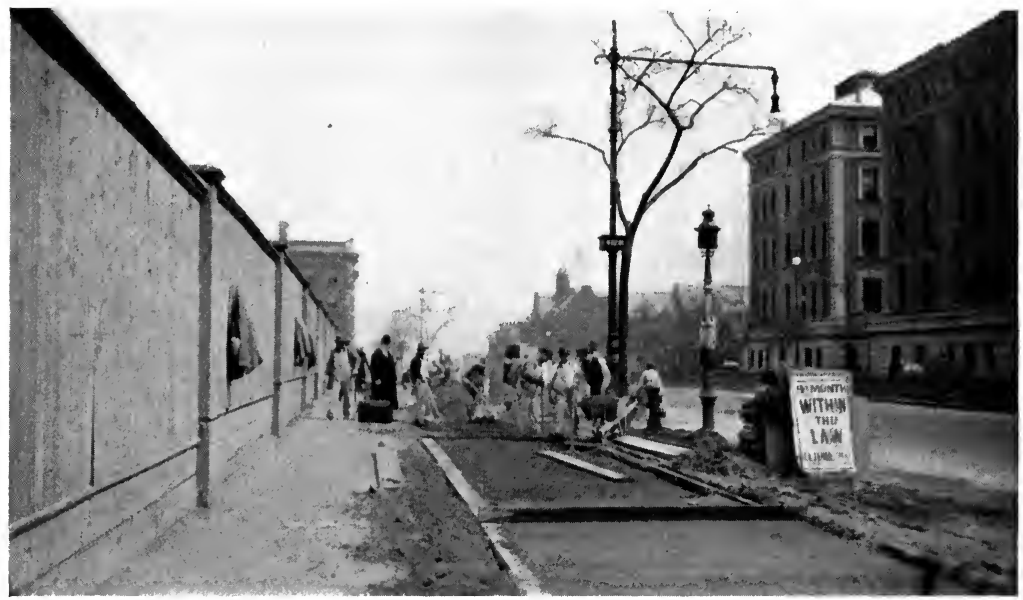

FIG. 175: Straight-Edge Used in Construction of Cement-Concrete Sidewalks.

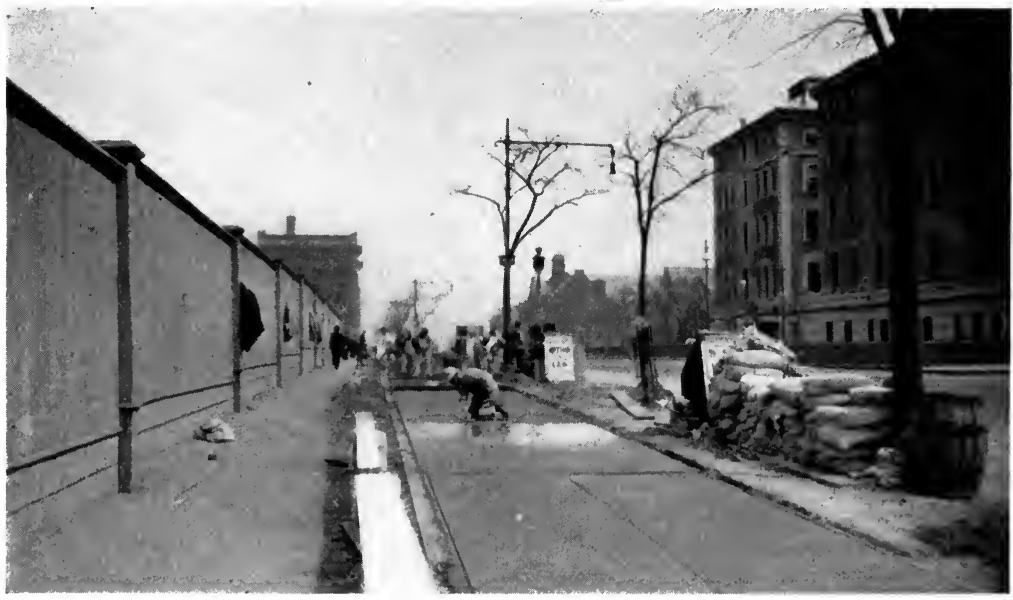

FIG. I76. Use of Float in the Construction of the Surface of Cement-Concrete Sidewalks.

rigidity so as to resist springing out of shape as the concrete is placed in them. The cross-forms or those which come on the 
lines of the joints between adjacent slabs, are preferably made of $1 / 4$-inch metal and of a depth corresponding to the full thickness of the proposed walk. When metal cross-forms are used, the slabs may be built up to a form on each side, and when the concrete has set the metal strip may be withdrawn. When wooden cross-forms are used, every other slab is built, and after completion the cross-forms are removed and the other sections are constructed. The joints are formed by laying pieces of tar paper against the faces of the first set of slabs.

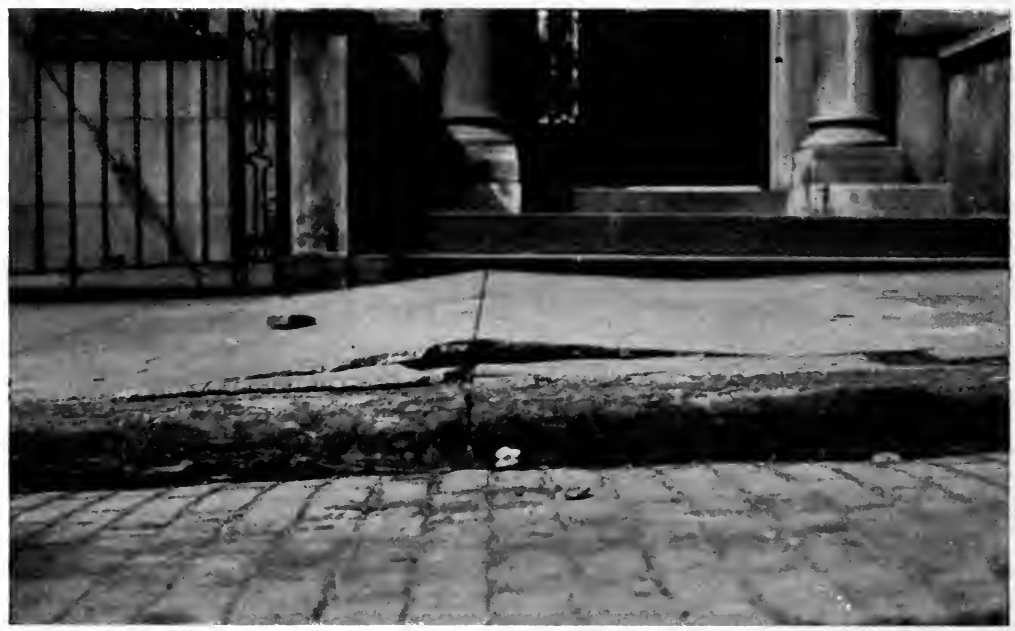

FIG. 177. Bulging of Cement-Concrete Sidewalk, due to Expansion.

The concrete for the base course should be thoroughly tamped in the forms until the required thickness is obtained. Before the concrete in the base course sets up the wearing course should be spread upon it. The concrete in the wearing course is mixed wetter than that in the base course. It is shaped and spread by means of a straight-edge, the ends of which generally rest on the forms. (See Fig. 175.) The surface is then smoothed off with trowels or a wooden float. (See Fig. 176.) To roughen the surface a little sand may be scattered over it and worked in during the process of smoothing. A soft brush or some form of grooving tool may be used to mark the surface. 
Traffic should be barred from the sidewalk for a week, during which time the surface should be frequently moistened. The surface should also be covered with a tarpaulin or otherwise protected for two days after completion.

Cost. The cost of cement-concrete sidewalks, including excavation and a cinder or gravel foundation, varies from about 80 cents to $\$ \mathrm{r} .50$ per square yard.

Characteristics. Concrete possesses several advantages as a sidewalk material. In the first place, the materials with which

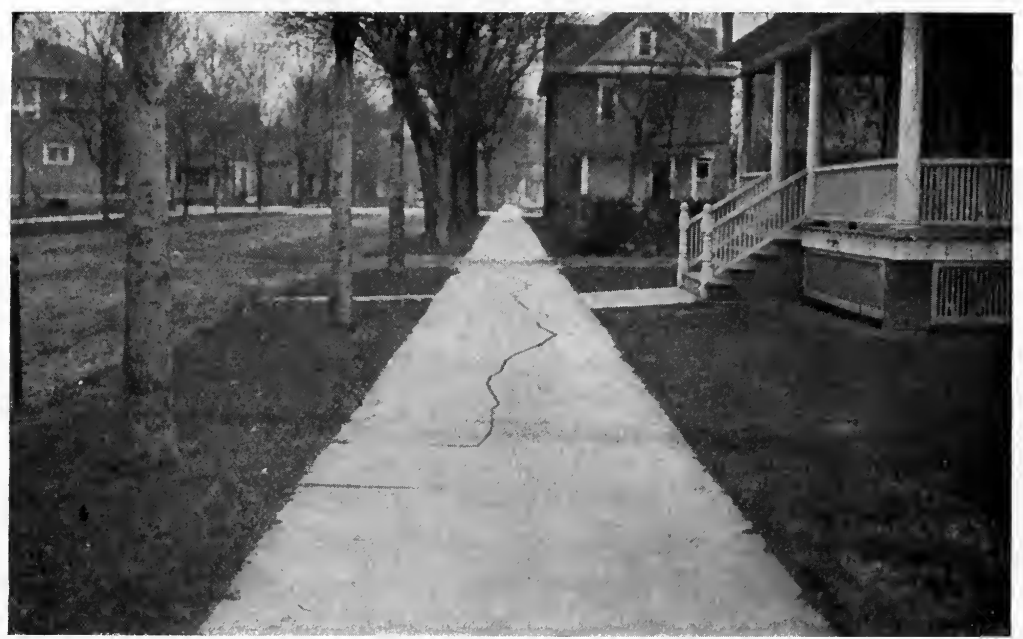

FIG. 178. Longitudinal Crack in Cement-Concrete Sidewalk, due to Frost Action.

it is constructed are available in many localities. It makes a durable surface if properly constructed, is not slippery under normal conditions, is easily cleaned, is more or less impervious to water, and its cost is not excessive. Concrete also possesses the advantage of being easily molded into any form desired. Moreover, it is possible to incorporate coloring matter in the concrete so as to obtain a variety of colors. When constructed in conjunction with a curb and gutter built of the same material, it gives the street a finished appearance which is difficult to obtain with other materials. 
Concrete pavements fail many times by the slabs bulging upward, caused frequently by the heaving action of the frost or because the slabs have been pushed up by the roots of trees, or it may be due to insufficient allowance for expansion. The photographs shown in Figs. 177 and 178 illustrate this type of failure. The slabs may be cracked through in this condition or the bulging may occur so that all the heaving takes place at a joint between two adjacent slabs without breaking them. Unequal settlement will also cause the slabs to be displaced.

Gravel. Gravel walks are laid 3 to 4 inches thick on a good subsoil. Where the soil is poor it is excavated and the space refilled with crushed stone, clinker, or screened gravel of large size. The total depth may be as much as 8 inches, the wearing course being $1 / 4$ to $1 / 2$ inch of fine gravel or torpedo sand.

Small Stone Setts. Small stone sett sidewalks are constructed. in many towns of Portugal. The stones are laid in arcs of circles or in figures of fancy design, different colored stones being used, thus giving a contrast in color very pleasing to the eye. In Germany, Kleinpflaster is used to a considerable extent for sidewalks.

Stone Flagging. Sidewalks in business districts are frequently constructed of stone flagging. Stone flagging also is used as a surfacing for sidewalks in residential districts in different parts of the United States where it is available. Granite and sandstone are the common materials from which the slabs or flagging are made. Granite slabs 6 inches thick are laid in Paris for sidewalks on some of the principal streets which carry a heavy foot traffic. Flagging of Yorkshire or Caithness stone is very popular throughout certain parts of England. Artificial flagging made of concrete under pressure has also been used to a slight extent. Fig. I79 shows a cross-section of the standard method of constructing flagstone walks in Pittsburg, Pa. In England both the natural and artificial flagging is bedded on a layer of lime mortar which rests on a 2 to 3 -inch course of clinkers. The joints are filled with a cement mortar. The granite slabs used in Paris are bedded generally on a concrete foundation.

The Stone. The rgra specifications of the Borough of the 
Bronx, New York City, require that new flagstones shall be of a good quality of sandstone (bluestone), with a fairly smooth surface, and shall measure not less than 4 feet in width, contain not less than ro square feet, except where necessary to fit around basin heads, and shall be uniformly not less than 3 inches in thickness. The Yorkshire flagging used in England is

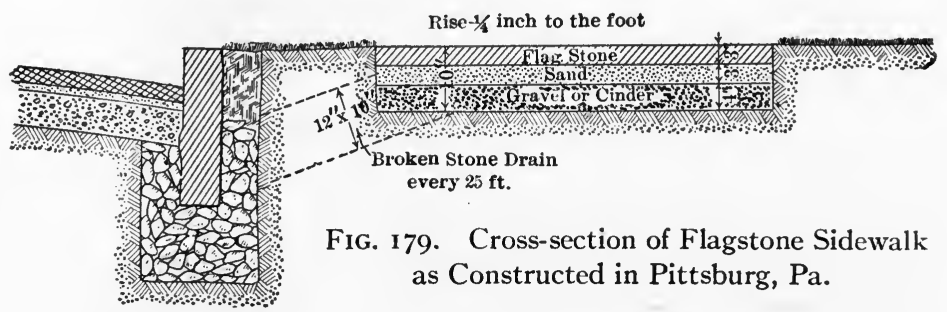

required to be $1 / 2$-inch thick for every square foot of surface and of such a size that there will not be more than I4 slabs to make roo square feet. Artificial flagging is made in slabs from 2 to 4 feet square.

Cost. In New York City the cost of bluestone sidewalk flags from the Hudson River, laid in place, varies from \$1.66 to $\$ 2.20$ per square yard. The cost of walks built with the same material in Boston varies from approximately $\$ 2.50$ to $\$ 3$ per square yard.

Characteristics. The life of granite slab sidewalks, if constructed on a proper foundation, is indefinite. The surface wears smooth in time, but it may be easily roughened by means of a tooth axe. There are many instances in England where flagstone sidewalks have lasted from twenty-five to thirty years. The sidewalks constructed with bluestone flagging in this country are generally quite satisfactory, except that in many instances the flags are displaced by frost action or other causes.

Tar-Concrete. Tar-concrete sidewalks are constructed in many places in the United States and England.

Laying the Concrete. This type of surface is usually constructed in two or more courses, the materials in the different 
courses varying in size. In Newton, Mass., a three-course method is used, the different courses being described as foundation course, binding course, and wearing course. The foundation course is composed of coarse gravel from 2 to 4 inches in greatest diameter, thoroughly coated with hot tar. The binding course is composed of clean screened gravel not exceeding I inch in greatest diameter, which is heated and mixed with a hot coaltar composition in an amount of about one gallon of the bituminous material to I cubic foot of gravel. The wearing course is composed of screened sharp sand, which is heated and mixed with a coal-tar composition, the mixture consisting of not more than 75 percent of sand and not less than 25 percent of the bituminous material, by weight. The surface is laid to a total depth of 3 inches. Each course as it is laid is thoroughly tamped and rolled. The binding course fills the voids in the foundation course to a large extent. The total thickness of these two courses, after compaction, is not less than $2 \frac{1}{4}$ inches. The wearing course, which is $3 / 4$ of an inch thick, is laid and rolled in a similar manner. The top surface, which is usually sprinkled with a fine sand or a Portland cement, is well rolled.

Cost. The cost of tar-concrete sidewalks in the United States is approximately \$o.6o per square yard.

Characteristics. Tar-concrete sidewalks usually are not slippery. If the bituminous material is of the proper consistency the surface is rather elastic and pleasant to walk upon. The use of a bituminous material not possessing the proper characteristics may result in cracks being formed in the surface in cold weather, with consequent disintegration of the pavement, or in warm weather the tar compound may soften to such an extent that the surface becomes objectionable to walk upon. The surface is easily cleaned when intact and is also one which may be easily repaired. Its low cost has led to its general use in many places, although at the present time it is being replaced to a considerable extent by cement-concrete. 


\section{Curbs}

Curbs are constructed of granite, limestone, sandstone, and cement-concrete.

Stone CuRbs. Stone curbs are made from 4 to $\mathrm{I} 2$ inches wide, 8 to 24 inches deep, and from 3 to 8 feet long. The top and front faces are dressed, the latter being given a slight batter, for a depth somewhat greater than the exposed part, to keep the wheels away from the top edge. The ends are square dressed and the curbs in first-class work are so laid that the ends are about $1 / 8$ inch apart.

Laying the Curb. Curbstones, although commonly laid on a well-compacted sand base, should be laid on a base of concrete, broken stone, or gravel. The broken stone or gravel is carried well up around the base of the curb, as shown in Fig. I79. The trench should be made wide enough to permit thorough ramming. In Baltimore, a bed of gravel, 4 inches deep, is laid on the bottom of the trench and well compacted. The curb is laid on this bed and set to the line and grade. The remainder of the trench is filled with layers of well compacted gravel.

Cost. The cost of a granite curb, including the cost of setting, is about \$I per linear foot.

Cement-Concrete Curbs. The curbs are generally built in situ, although it is possible to make them at some central point.

Construction. The curbs are made approximately 6 inches thick, 18 to 24 inches deep, and from 8 to ro feet in length. The proportions of the different materials used in the concrete are the same as those described for concrete sidewalks. The corner next to and above the gutter is always molded to a radius approximating $\mathrm{I} / 2$ inches in length. Sometimes this corner is formed by a metal strip, having the desired radius of the corner, which is built into the curb at the time the concrete is being laid. This strip is anchored to the body of the curo at three or four points in each length of 8 to ro feet by special forms of steel tie bars that are firmly attached to the metal strips. The protection afforded the edge of the curb by this metal strip is of a decided advantage. The concrete curb and a con- 
crete gutter are sometimes constructed as one piece, in which case the depth of the curb is somewhat less than in the case described above, as the base of the curb is flush with the base of

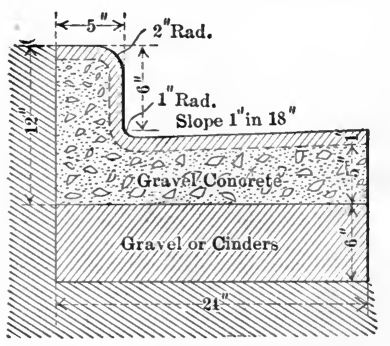

FIG. I80. Cement-Concrete Curb and Gutter. the gutter. (See Figs. I80 and I8I.)

A concrete curb should be constructed on a bed of well compacted sand, gravel, or cinders, in the same manner as described for stone curbs. The joints between adjacent curbs are made by placing metal plates in the forms at the end of each curb length. The concrete is filled in to the plates, and after it has obtained its initial set the plates are withdrawn, thus leaving a joint. When the curbs are built at the same time as the sidewalk surface, an expansion joint should be left between the sidewalk and the curb.

Cost. The cost of concrete curbing 8 inches wide by 24 inches deep varies from 30 to 40 cents per linear foot.

\section{GuTTERS}

As a general rule paved gutters are not constructed along the sides of roads except on grades where there is danger of wash-outs. Paved gutters are usually built on streets which are curbed and which have the roadways constructed with some kind of improved surfacing.

Materials. Gutters are constructed of brick, stone block, cobblestone, and cement-concrete. Cobblestone is extensively used in constructing gutters on roads. Cobblestone, cementconcrete, and brick gutters are frequently built adjacent to broken stone surfaces on streets. Brick gutters are also very popular in some cities where sheet asphalt and bituminous concrete pavements are built.

Construction. Although stone block, cobblestone, cementconcrete, and brick gutters are sometimes constructed with the same transverse slope as the adjoining surface of the carriageway, it is better to increase their water-carrying capacity 
either by building them on a sharper slope or by building the gutter with a concave curve section. The depth of the gutter at the center of the curve varies from 4 to 9 inches, depending upon the width and grade of the gutter. The gutters are built from 2 to 6 feet in width, depending upon the amount

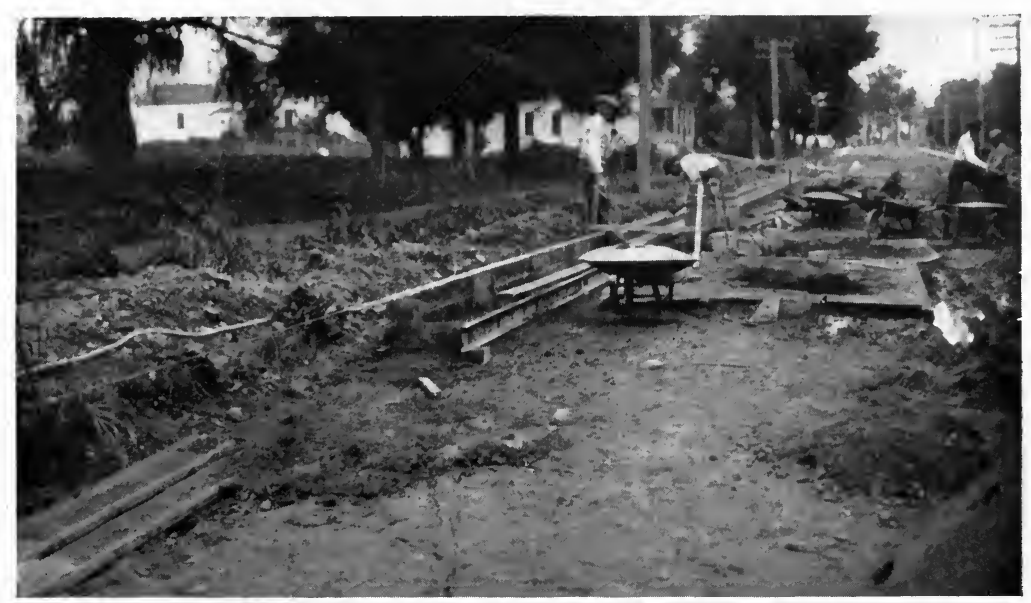

FIG. I8I. Metal Form Used in the Construction of a Cement-Concrete Curb and Gutter.

of water to be carried, 3 or 4 feet being widths used under ordinary conditions. Cobblestone, cement-concrete, and brick gutters are commonly constructed on a foundation of sand, gravel, or cinders, the joints being filled with sand or poured with a cement grout. On streets a concrete foundation is frequently built under a brick gutter. Since the cost data of gutters are the same as that of the different types of paving of which they are composed, information in regard to cost may be found in the chapters describing the construction of the various pavements.

\section{Cost Data}

Sidewalks, Curbs, and Gutters. In the following table are given, for several localities throughout the United States, the average I9I4 prices of sidewalks, curbs, and gutters constructed with various materials. 


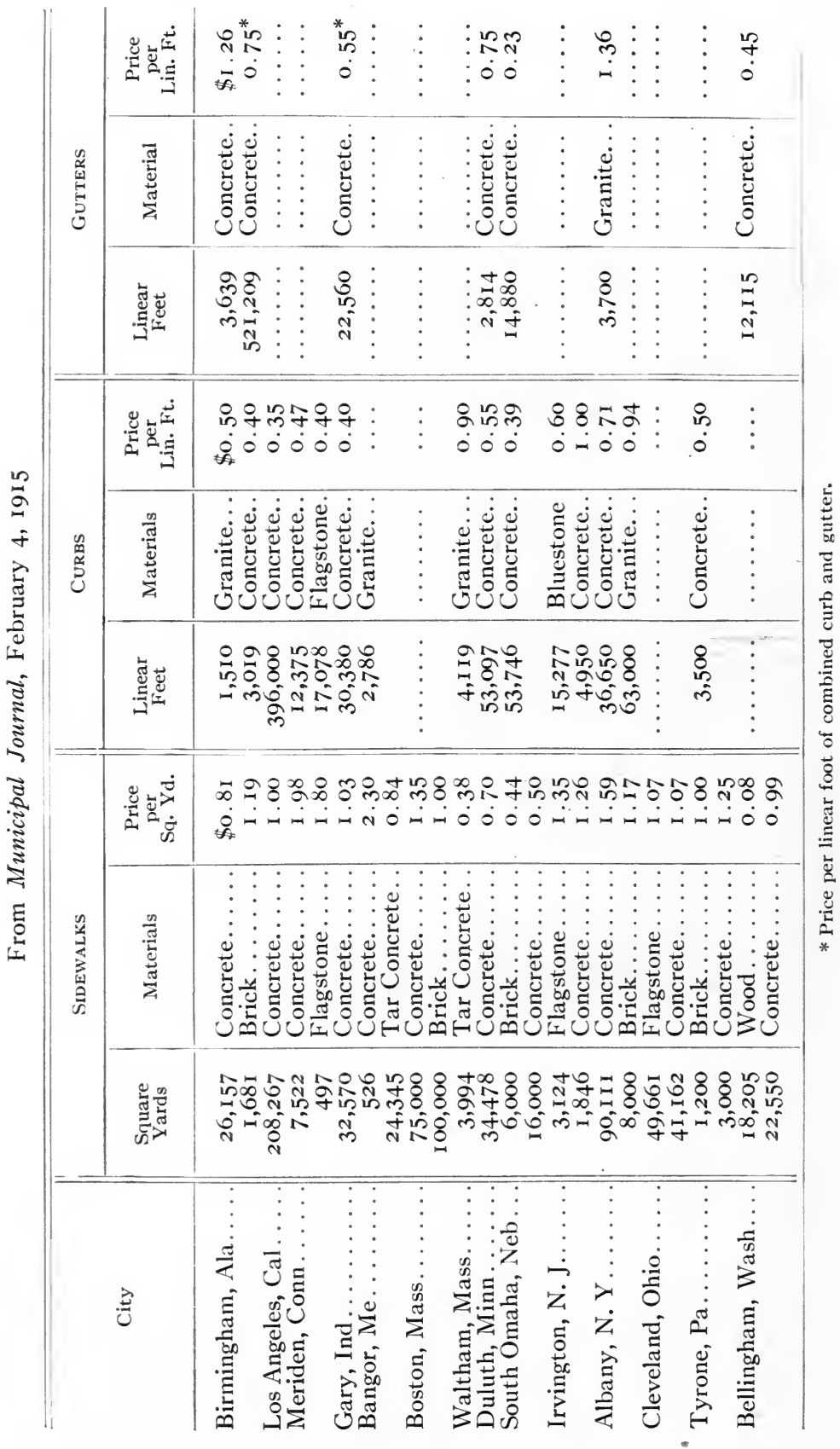




\section{CHAPTER XXI \\ HIGHWAY STRUCTURES}

\section{Bridges AND Culverts}

Determination of Waterway. The first step in designing a bridge or a culvert is to determine the size of opening necessary to take the water. The following methods are used in determining the size of opening or the amount of water for which provision must be made:

Empirical formulas, which give either the area of opening or amount of water.

Observation of high-water marks.

Measurement of the flow.

The factors which affect the amount of water that will come to any particular point are as follows: the size of the drainage area; its topography; the soil conditions throughout the area, whether sandy, rocky, grass land, or covered with forests; the amount of rainfall and its intensity; and climatic conditions.

Size of Drainage Area. Since the size of the drainage area enters into practically all of the calculations required, its determination will be considered before discussing the various methods of finding the size of opening. Every drainage area is separated from an adjacent drainage area by a divide or a line of high ground. The drainage area for a culvert or a bridge will, therefore, include all of the area above the structure bounded by the line of the divide. The drainage area may be determined by actual measurement in the field or from a map. The field survey may be made by running a traverse line around the boundary with a transit and stadia, or a pocket compass may be used to obtain the direction of the boundaries while the distances may be paced. If government topographical maps, made by the Geological Survey, or other contour maps are available, the drainage area can be marked off by tracing out the divides from the contours and the area be determined by planimeter or 
by scale. Besides the actual size of the area it is necessary to know the steepness of the slopes and the nature of the soil conditions, because these factors affect the run-off to a great extent. Such information can generally be determined only by examination.

Empirical Formulas. Empirical formulas are many in number and give results which are extremely variable. This may be accounted for, in some instances, by the fact that many formulas are based on local conditions. Some of these formulas contain only one variable, namely, the drainage area. It cannot be expected that results by such formulas will agree with those obtained by formulas which have coëfficients that are to be applied for different soil conditions, steepness of slope, etc.

Myers Formula. A formula which is used to a great extent by railroad engineers in the eastern part of the United States is the Myers formula or $A=C \sqrt{D}$, in which $A$ is the area of waterway in square feet; $D$ is the drainage area in acres; $C$ is a variable coëfficient, being I for comparatively flat ground, I.6 for hilly compact ground, and 4 for mountainous, rocky country. The Myers formula has been found to give satisfactory areas for small openings.

Talbot Formula. Another noted formula, derived by Professor A. N. Talbot, M. Am. Soc. C. E., from the Burki-Ziegler formula, is $A=C \sqrt[4]{D^{3}}$, in which the letters have the same significance as described above. The following is quoted from remarks by Professor Talbot relative to the value of the coefficient $C$ : "I conclude that for rolling agricultural country, subject to floods at time of melting snow, and with the length of valley three or four times the width, one-third is the proper value for $C$. In districts not affected by accumulated snow and where the length of the valley is several times the width, one-fifth or one-sixth or even less may be used. For steep and rocky ground $C$ varies from two-thirds to unity." This formula has been very generally adopted in the West and Southwest.

Observation of High Water Marks. High water marks are of the greatest assistance in determining the size of opening required, particularly if they are measured at a point where the 
stream is narrow and the bed conditions are the same as at the time of the occurrence of the high water. It should be remembered, however, in seeking evidences of high water that the investigation should cover a long period. It has been found, in studying the flow of streams, that a continuous record of five years will not usually include all of the varying conditions of stage to which streams are subjected. The measurement of the waterways of existing bridges along the same stream is an excellent guide if they have been built for some time.

Measurement of Flow. The amount of water may be determined from stream measurements. What has been said above in regard to long term records applies in this case as well. A record of stream discharge measurements for a year is practically worthless, when considered by itself, for the determination of the size of required opening. It is possible to approximate the run-off from a drainage area, even though the stream has not been measured, by comparing it with one of similar characteristics where the run-off has been determined. In such a case the same percentage of run-off would be applied to the amount of water falling on the area in question.

Culverts. Culverts are commonly classified as pipe, box, and arch. Pipe culverts are constructed of vitrified clay, castiron, corrugated metal, concrete, brick, and timber; box culverts are built of stone, concrete, and wood; arch culverts are constructed of stone, concrete, reinforced concrete, and brick. The selection of the type of culvert and the material to be used is largely a question of economy, particularly in the case of small waterways. The availability of materials, their first cost, freight charges, cost of hauling, and cost of construction all have to be considered. There may be cases where considerations other than cost would determine the selection of the type, such as, for example, the depth of fill over the culvert. Some kinds of pipe are, however, not manufactured in diameters of over 3 feet. When large areas of waterway are required, it will be necessary to use either a culvert of the box or arch type or two or more lines of pipe, the selection being based on the relative economy and durability of each method. 
Design. Culverts are required to support the weight of the material which covers them and the superimposed loads. They may also be subjected to severe expansive forces caused by water freezing within them. The amount of load carried to the culvert is indeterminate on account of the unknown action of earth pressure and of the distribution of superimposed loads. The load reaching the culvert will, therefore, have to be assumed. In using standard pipes of cast-iron, corrugated metal, or vitrified clay, it is ordinarily not necessary to investigate their strength, since they have been used under sufficiently varying conditions to demonstrate that they will resist successfully any load that they are likely to receive, provided the pipes are properly placed. The design of reinforced concrete and concrete pipes, box and arch culverts should be carefully prepared so that they will support the loads which they must carry. In order to save work necessitated by the design for the many varying conditions which are encountered, it is customary to prepare standard plans of these types of culverts which are designed to meet a series of average conditions.

Location. The proper location for a culvert can only be determined by an examination of conditions in the field. It is true that some idea as to the need of a culvert may be gained from looking over the profile of a highway on the drawing, since culverts are usually needed at all low points of the grade. When these places are examined in the field, however, it may be found that the ground slopes away from the road on both sides and hence, in some cases, no culvert will be needed to carry the water across the road. Other places, which are not apparent on the plans, may be found by a field examination where water will pond and cause property damages unless a culvert is constructed to remove it. In cuts with shallow side ditches, in localities where the highways are curbed, and in any place where it is not possible to obtain sufficient cover over the culvert and still have the inlet end of the culvert above the surface of the ground, some form of catch-basin or drop inlet will have to be built. Small culverts of the pipe or box type and small arch culverts are usually constructed at right angles to the axis of 
the road. If the culvert, when used on hills to carry the water from one side of the road to the other, is placed at an angle across the road it affords a somewhat easier access to the water. This scheme is also used in some cases to obtain sufficient cover over the culvert, or to bring the point of outlet to a more convenient place.

Construction. Culverts of all types should be built on a stable foundation. It is very important to examine the material of which the foundation is composed, since excessive settlement causes stresses in the structure that it is not designed to take. Pipe culverts should be firmly bedded on the foundation. If the soil furnishes a very poor support the pipes should be bedded in a layer of concrete or broken stone. Backfilling for pipe
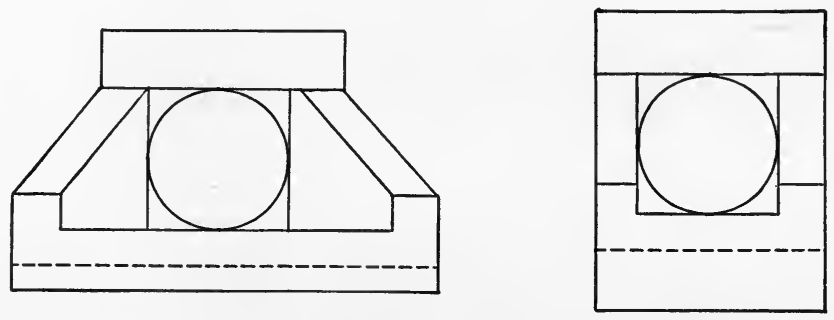

FIG. I82. Headwall with Wing Walls.

culverts should be composed of a selected fine material, free from large stones. Care should be taken to place the filling around and under the pipe, tamping the material in thin layers. Puddling may be necessary in some cases. A headwall should generally be constructed on both ends of a pipe culvert. The use of headwalls makes it possible to use a somewhat shorter culvert than would otherwise be necessary. Headwalls for small culverts are usually built parallel to the center line of the road. Sometimes, however, it may be found advisable or more economical in the case of culverts of large size to construct wing walls, either straight or flared, as shown in Fig. I82. Concrete and stone masonry are used in building headwalls. Cheapness, durability, and the fact that concrete can be molded into any form desired, renders it a very satisfactory material for this 
purpose. The bottom of the headwall should be carried is inches or more below the bottom of the pipe to prevent washing it out.

Vitrified Pipes. Vitrified pipes used for culverts should be the best quality salt-glazed sewer pipe of the double strength type, with socket joints. This pipe is made in 2-foot lengths with diameters from $\mathrm{I} 2$ to 36 inches. The pipes are so laid in the trench, with the socket end towards the inlet, that at least I 5 inches of material will be over the top of the pipe at its highest point. Under conditions ordinarily encountered in highway work

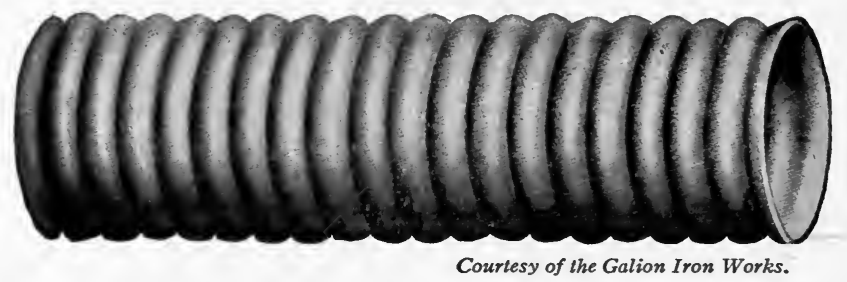

FIG. I83. Corrugated Metal Pipe.

vitrified pipe makes a very satisfactory as well as a cheap culvert.

Cast Iron Pipes. Cast iron water pipe with bell and spigot joints has been used in culvert construction for a long time. Standard cast iron water pipe is manufactured in $\mathrm{r} 2$-foot lengths and hence is not so easily adaptable for use. Until within a few years the standard water pipe was the only type of cast iron pipe available. At the present time special culvert pipe can be obtained which is made in 4 -foot lengths. A special type, similar in cross-section to a spherical triangle, has also been developed in which the three sides are shipped as separate pieces in $3^{-}$to 4-foot lengths and are fitted together in the culvert trench. Cast iron is very strong and will last for many years. This kind of pipe can be placed within 6 inches of the roadway surface without danger of breaking. The principal objection to standard cast iron water pipe, outside of its cost, is its weight, which makes it expensive to handle.

Corrugated Metal Pipes. Corrugated metal pipe, see Fig. I83, is made in any length desired, ranging by multiples of 2 feet 
up to 36 feet. Since it weighs about one-twentieth, as much as cast iron it is much more easily transported. Care should be taken to select pipes of the proper kind of metal. Wrought iron is superior to steel as far as its non-corrosive properties are concerned, and hence pipes made of iron generally have a longer life.

Concrete Pipes. When cast previous to laying, the pipes are made in lengths of from 4 to 8 feet, with thicknesses varying from 2 to 6 inches, depending upon the diameter. The joints are made tapering, with some form of socket or are simply square-faced. The last type has worked out very satisfactorily in practice.

Drop Inlets. Frequently the inlet end of a culvert will have to be placed some distance below the bottom of the ditches

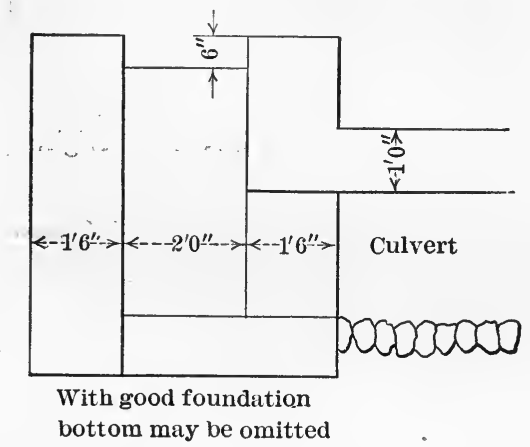

FIG. I84. Stone Box Inlet. Maine Highway Department.

leading to it. Where this distance is not great, it is possible to construct a drop inlet, which is an open box of concrete or stone masonry, as shown in Fig. I84. In case the inlet is far enough removed from the travelled way so as not to be dangerous to the traffic, no grating over the top is necessary.

Catch-Basins. In places where the wash carried along by the water is of large amount, a catch-basin is more serviceable than a drop inlet as there is not so much danger of the pipe becoming choked. (See Fig. 185.) The size of the catch-basin will depend on just how much material is liable to be washed into it and how 
often it is to be cleaned out. The inlet should offer as little obstruction as possible to the water, and the grating should be of such a form as not to be dangerous to traffic. The outlet

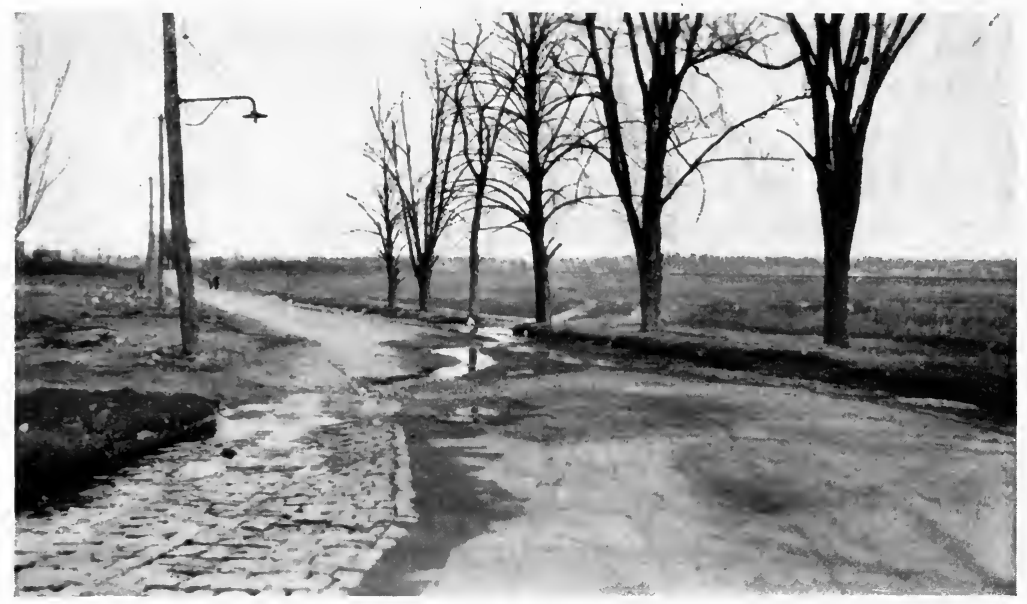

FIG. 185. Location Where Catch-Basin and Culvert Should Have Been Used to Take Storm Water Under the Highway.

pipes of catch-basins in cities frequently connect with sewers carrying house sewage, and it is essential in such cases that the
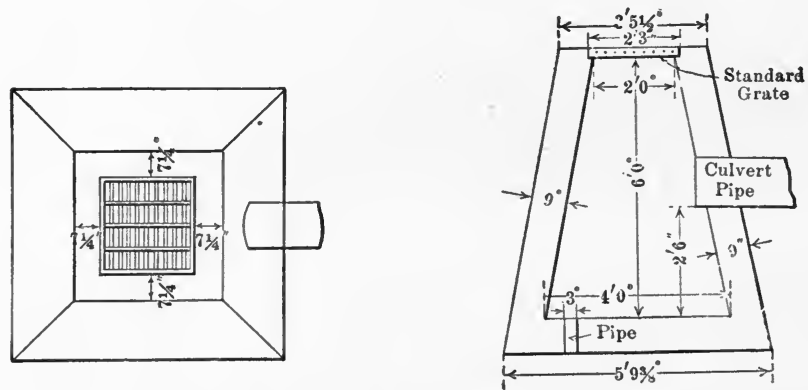

FIG. I86. Concrete Catch-Basin. New York State Highway Department.

pipes be trapped in order to prevent the emanation of objectionable gases from the sewers. A cement-concrete catch-basin used on roads is shown in Fig. I86, and a brick catch-basin designed for use in a municipality is shown in Fig. 187. 
Inlet Castings. There are many different types of castings used as catch-basin covers and inlets. If a casting is so placed
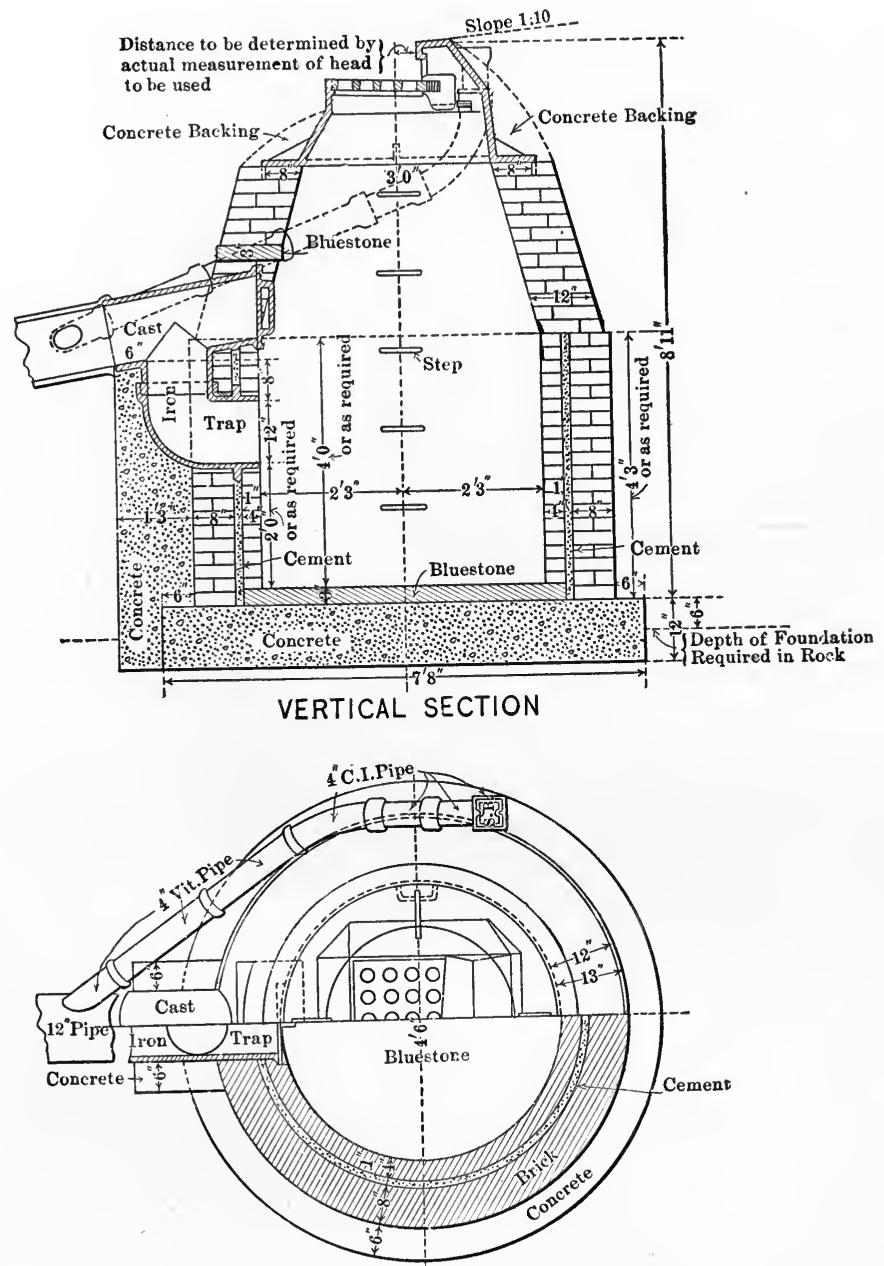

$\frac{1}{2}$ TOP VIEW AND $\frac{1}{2}$ HORIZONTAL SECTION

FIG. I87. Brick Catch-Basin. Borough of the Bronx, New York.

that traffic will pass over it, a very strong type will be required. Fig. I88 shows an inlet which is used to a considerable extent on park highways and on roads where there are no curbs. Fig. 
189 is a view of the iron castings used in the construction of catchbasins in the Borough of the Bronx, New York City.

Stone Box. Stone box culverts are made up of two side walls which are bridged over by capstones. If the stream running
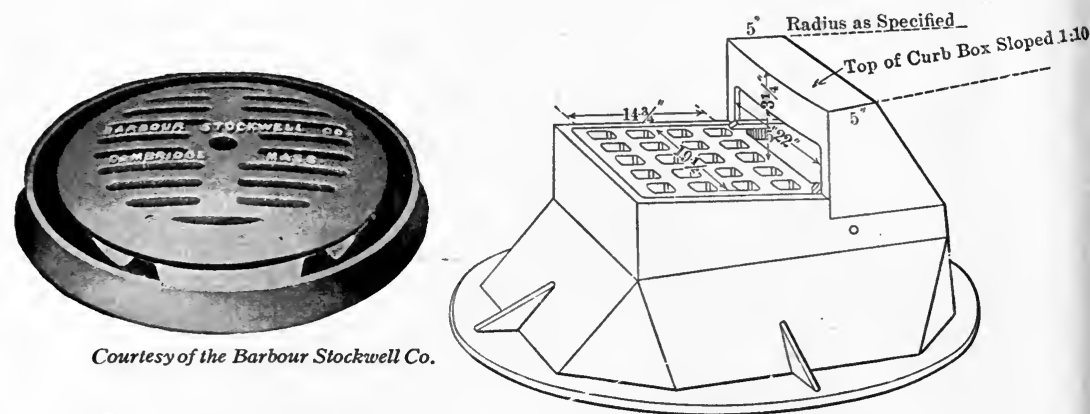

FIG. 188. Inlet Casting.
FIG. 189. Inlet Casting. Borough of the Bronx, New York.

through the culvert has enough force to cause scour, the bed should be paved with cobblestones or other suitable material. The side walls should be carried to a good depth below the bottom of the stream bed, i 8 to 30 inches generally being sufficient. The side walls are usually constructed of dry rubble masonry, and of varying thicknesses, depending upon the height of opening. It is good practice not to make the thickness of the wall at the top less than 2 feet even in the smallest size culverts. While the faces of the walls are generally straight, the backs of the walls are sometimes built with a batter. The wings of the culvert are formed by extending the side walls out straight and stepping them down. When the capstone is made of stone slabs, the specifications usually require that its thickness shall be at least I 2 inches for all sizes up to 4 feet. Such stones, however, are sometimes difficult to obtain and are expensive to handle, particularly for large culverts. Reinforced concrete slabs are used in place of the capstones for a cover in some cases. Fig. I90 shows a 3 by 3 stone box culvert as constructed by the Massachusetts Highway Commission.

Reinforced Concrete Box. Reinforced concrete box culverts 
are built in a manner similar to stone box culverts, except that concrete and steel are used throughout in their construction. The side walls are made quite thin in comparison with those of stone box culverts, ranging from 4 to 8 inches in thickness,
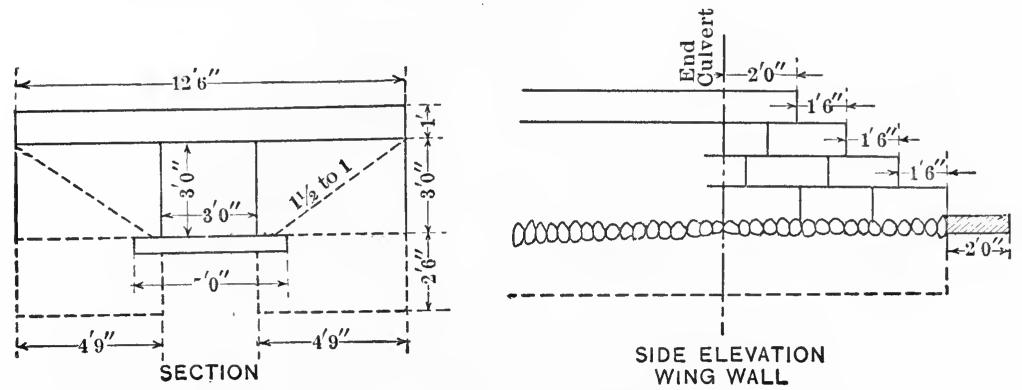

FIG. I90. Stone Box Culvert. Massachusetts Highway Commission

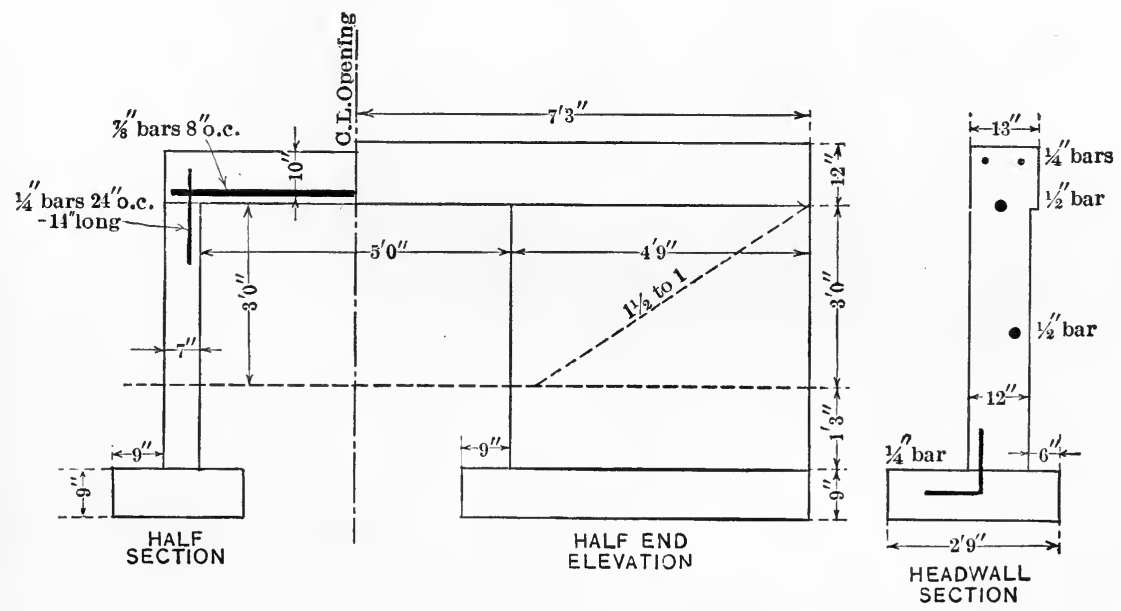

FIG. I9I. Reinforced Concrete Culvert. Massachusetts Highway Commission.

depending upon the height. In the larger size culverts, the side walls are reinforced. Where there is no danger of scour in the stream bed, the walls are carried 2 feet below the stream bed, and a footing is constructed under each wall which is from 9 to 12 inches in thickness and of a width sufficient to properly 
support the wall. In places where scour may occur, a concrete bottom is built in the culvert throughout its entire length. (See Fig. I9I.)

Timber Box. Where other materials are available there is no excuse for building a timber box culvert of the kind that is

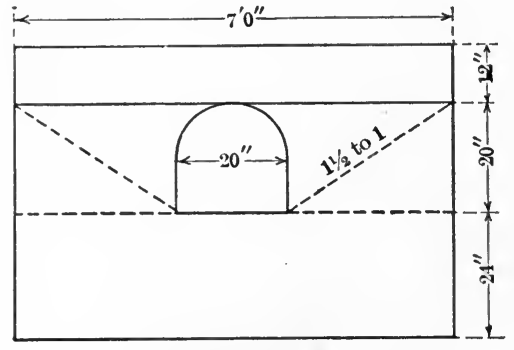

END ELEVATION
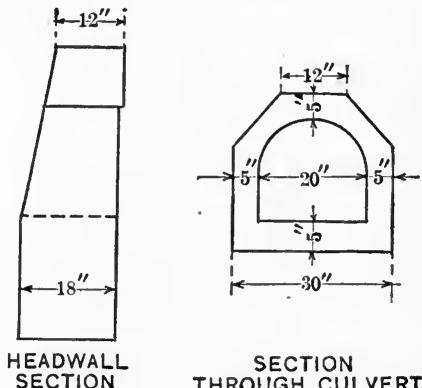

SECTION THROUGH CULVERT

FIG. 192. Concrete Arch Culvert. Massachusetts Highway Commission.

frequently encountered, consisting of two plank sides supporting a plank top. Such construction is not economical, as the planks soon rot out and the culvert becomes a source of danger to traffic.

Arch Type. A typical small arch culvert is shown in Fig. 192. No reinforcement is used in this design and the straight headwalls are placed parallel with the center line of the road.

BRIDGES. The types of bridges built on highways may be classified as follows:

Joist and plank floor

iWood trusses

Wood viaducts

I-beams

Plate girder, through and deck

Pony trusses

Trusses, through and deck

Viaducts

Cantilevers

Suspension types

Arch ribs

Draw bridges

Beams

Girders

Arches

Arches
Timber bridges

Steel bridges

Concrete and Reinforced Concrete

Stone 
The selection of the type of bridge best suited for any crossing is governed by the cost of the structure, its appearance and adaptability. Conditions at some crossings, such as headroom, requisite waterway, character of foundations, elimination of piers, or the maintenance of a navigable channel preclude the use of certain types which otherwise might be desirable. Generally too much importance is attached to the first cost. Many of the steel bridges in country towns are sold to the town representatives without the services of an engineer. The decision as to the type of structure, whether it is a girder, pony truss, or through truss, rests largely with the contracting bridge company, since the townspeople are dependent upon its advice. It is not surprising, therefore, that many of the existing steel bridges neither look well nor give good service. Very little attention is given in this country to æsthetics in bridge design, particularly in steel bridges of the small types. The use of reinforced concrete structures of both the arch and girder type, however, has made it possible to erect structures which harmonize with the environments.

Design. Bridges should not be designed to carry less than a 15 -ton road roller. The maximum live load to be used will depend upon local conditions. Care must be taken to obtain a firm foundation for all substructures and to make provision against all possibility of scour. The abutments and piers may be built of stone masonry or concrete, the latter material being used to a large extent for this purpose.

Location. The problem of location for a bridge requires more study than in the case of a culvert. The location will affect the selection of the type of structure to some extent. In certain cases it may be found that the required area of waterway will necessitate raising the grade on the approaches. If the alignment of the highway on either side of the stream is not good it may be advisable to shift the location of the bridge up or down stream from the original location, with a consequent improvement of the alignment. There may be occasions where lack of good foundations procurable at a reasonable cost would warrant placing the bridge at a point where good foundations will be 
readily accessible, the saving in cost of the substructure being more than enough to pay for the relocation of the approaches.

Bridge Floors. The floor systems on which the wearing surfaces rest are of two principal types, solid floor systems, generally composed of concrete, and the open framework system, formed by intersecting stringers and floorbeams. The first type is common to all concrete structures. It is possible, when this type is used, to build on it any type of roadway that may be desired, provided the structure is designed to take the load. Both types of floor systems are used on steel bridges. The solid floors are made up of concrete arches between longitudinal or transverse steel beams, of concrete on buckleplates supported on a steel framework, of concrete on a floor of riveted steel shapes, of reinforced concrete slabs supported on a steel framework, or of reinforced concrete slabs and beams in cases where the steel framework is omitted. The same remarks apply relative to the construction of the wearing course on these types of solid floors as were stated above relative to roadways on concrete structures. When some one of the above types of solid floors is not used in connection with steel bridges, the framework composed of the steel floorbeams and stringers is covered with a plank floor, which may act as the wearing course itself or may support a wearing course of some other kind of material. With the exception of bascule bridges the type or form of steel structure has no bearing on the type of floor system or wearing course to be used. The wearing course on a solid floor of either a concrete or steel structure may consist of earth, gravel, or broken stone, or cement-concrete, bituminous, brick, stone or wood block pavements. When the steel framework of the floor system is covered with planks, they may serve as the wearing course or may support a wearing surface of any one of the following types: another layer of planks, a wood block pavement, or a brick pavement. When a two-layer plank floor is built the planks in one layer are placed at right angles to the center line of bridge and the planks in the other layer are laid on lines at 45 degrees with the center line or vice versa.

Steel Bridges. The life of a steel bridge, if properly con- 
structed and maintained, is generally stated to be from forty to fifty years. The character and amount of the traffic usually changes materially during this time, hence a new structure may be required in a comparatively short period, although the bridge has not deteriorated to an extent which would require renewal. Many small bridges which are built by contract on the lump sum basis are so skimped in material that their life may not be over ten years. The floor systems of steel highway bridges generally deteriorate much more rapidly than the main members, due to the fact that there are many more places for the dirt to lodge. Water wets the dirt and soon rust begins to form, which rapidly eats away the steel. A steel bridge should be painted at least once every three or four years and perhaps more often, depending upon climatic and other conditions. Steel near salt water, where the spray can reach it, rusts rapidly and requires frequent painting. The floor systems of bridges over railroad tracks which are exposed to the gases from the smoke stacks of the engines will require painting with special kinds of paint in order to protect the metal. Bridge painting is unfortunately entirely neglected in many small towns, with the consequent rapid deterioration of the bridges.

I-Beam Bridges. I-beams with the ends resting on a beam supported by vertical supports or with the ends resting on abutments of either stone or concrete masonry are commonly used for short spans. The former is called a leg bridge and cannot be recommended. The maximum economical span is about 32 feet.

Pony Truss and Plate Girder Bridges. When the span is such that I-beams are no longer economical, either a riveted pony truss or a plate girder may be used. Low truss bridges are economical up to spans of about 80 feet, while the limiting span of plate girder bridges is about roo feet. It is doubtful, however, whether either of these types are economical when compared with a concrete structure. The construction of pony truss bridges, with light sections, cannot be recommended. If such a structure is to be used, it should be built with an excess of metal over and above what is required in order to provide 
requisite stiffness and rigidity to the structure. Pin-connected pony trusses should never be built.

Pin-Connected and Riveted Trusses. Both pin-connected and riveted trusses with parallel chords are used for spans from 80 to 170 feet in length. For spans over I 70 feet, trusses with inclined upper chords are usually employed.

Timber Bridges. Timber highway bridges are not generally constructed at the present time except as temporary structures. Considered from any other standpoint the construction of timber bridges is uneconomical and unwise, due to their rapid deterioration and the liability of their being destroyed by fire.

Concrete and Reinforced Concrete Bridges. Since 1905 the increase in the use of concrete for structures of all kinds

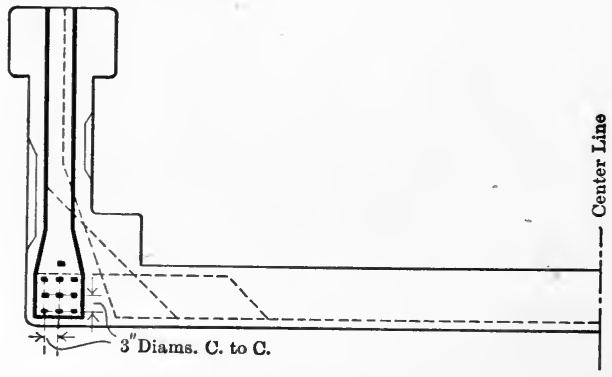

FIG. I93. Reinforced Concrete Girder Bridges. Illinois Highway Commission.

has been very rapid. The use of reinforced concrete has made it possible to construct bridges for many spans for which plain concrete bridges could not be economically built. If the structure lies under a heavy fill, any material increase in the live load will not increase the stress in the structure to any great extent, since the dead load is large in proportion to the live load. The ease with which concrete can be molded into different shapes makes it possible to add greatly to the appearance of the structure without materially increasing the cost.

Girder Bridges. The simplest types of reinforced concrete bridges are the deck girder and through girder. The Illinois Highway Commission has developed a reinforced concrete girder 
bridge of the through type which has been used to a considerable extent throughout that State for spans up to 60 feet in length. Fig. I93 shows a cross-section of this bridge and the general scheme of reinforcement.

Arch Bridges. Arch rings are built with the intrados line conforming to either a semi-circular, segmental, parabolic, elliptical, or some multiple centered curve. The semi-circular arch has been used to a great extent. Reinforced concrete arches with flat curves have frequently been constructed. The flatter the arch the greater the thrust on the abutment, hence care should be taken to see that the foundation provided under the abutment is capable of withstanding this pressure. The ratio of the span to rise will usually be determined by physical conditions, such as the waterway required, headroom, grade of roadbed, location of piers, cost of foundations, and appearances.

\section{GUARD RAILS}

Guard rails should be placed at the tops of all embankments and at culvert ends where there is the slightest element of danger. Wood, iron, and concrete are the materials used in the construction of guard rails. Guard rails are placed $\mathrm{I} 2$ inches from the edges of the embankment toward the center of the road; on concrete or masonry headwalls they are placed generally in the center of the masonry.

On concrete bridges of the deck type, side rails may be made of pipe railing or some form of concrete fencing. Bridges of the through girder type of steel or concrete do not need any railing unless the span is so short that the depth of the girders is not high enough to afford sufficient protection. The fencing on steel-truss bridges is made of pipe or railing composed of steel shapes riveted together.

Wood RAILs. Wooden guard rails, see Fig. I94, are usually built so that the top rail is about 3 feet 6 inches above the ground. The posts are spaced 8-feet center to center. The top rail is set cornerwise in V-shaped notches sawed in the tops of the posts or the tops of the posts are sawed off slanting towards the 
center of the road and the top rails nailed to the inclined faces. The top of the lower rail is placed about I foot 3 inches below the bottom of the top rail. All joints and exposed surfaces are well painted with a light-colored paint, white lead often being specified for this purpose. The first cost of wooden rails in

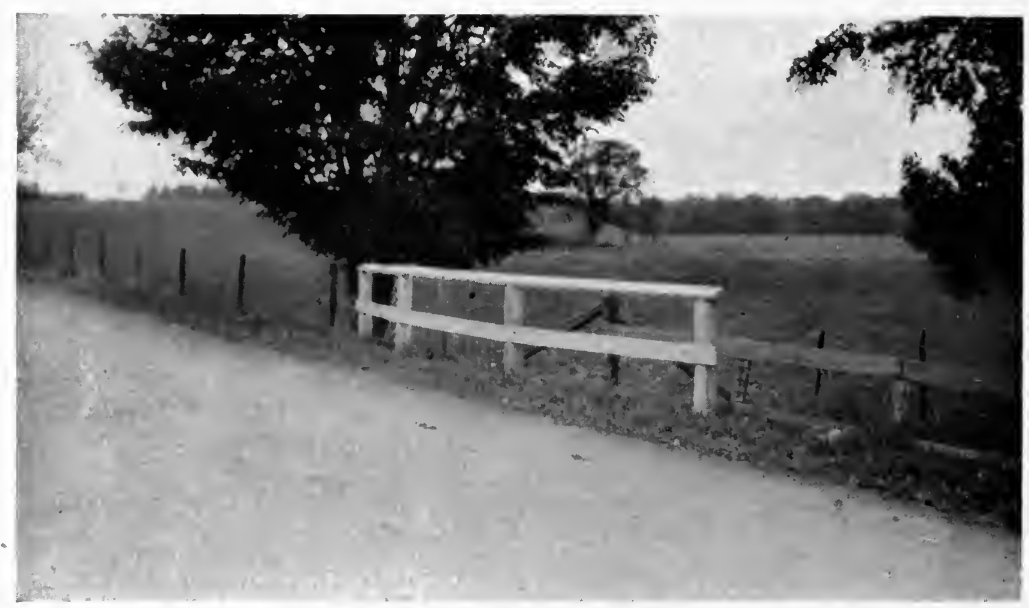

FIG. 194. Wooden Guard Rail.

place is ordinarily between 20 and 30 cents per linear foot and the cost of maintenance is from 5 to 6 cents per linear foot per year.

Iron rods are sometimes used in place of wooden posts where a guard rail is needed for a culvert headwall or for a ledge. The top of the rod is forked to receive a square wooden rail. The lower rail is frequently omitted.

PIPE RaILs. Gas pipe railing is also used on headwalls of culverts, or on ledges. (See Fig. I95.) The pipe used is $1 / 2$ or 2 inches in diameter. The railing is about 3 feet 6 inches high and is built with two or three lines of pipe. The iron posts are generally spaced 8 feet center to center. The pipes are fixed at the bottom by anchoring the bases in the ledge or concrete, or else the bottoms are set in a cast iron flange which is bolted to the ledge or masonry. The cost of gas pipe railing is about 75 cents per linear foot. 
Concrete RaILs. Concrete guard rails consist of concrete rails set on top of concrete posts. (See Fig I95.) The rails are built with a rectangular trough section fitted with cross diaphragms connecting the sides and top. The rails are generally reinforced and are set about 3 feet 2 inches above the ground.

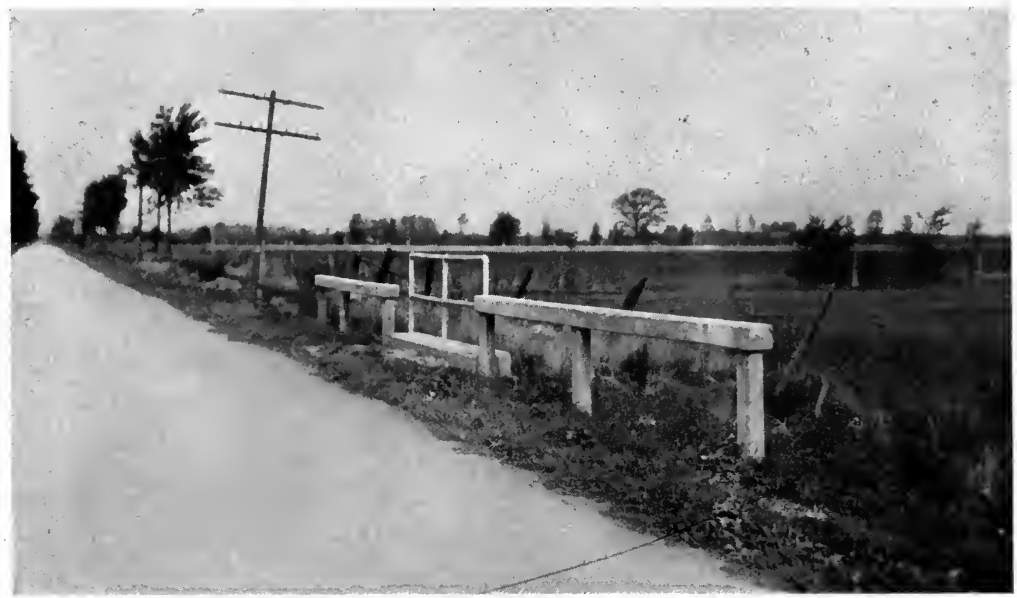

FIG. 195. Gas Pipe Railing and Concrete Guard Rails.

The cost of concrete guard rails is estimated to be about 50 cents per linear foot.

Parapet Walls. On masonry bridges and retaining walls, parapet walls that serve as guard rails are constructed above the level of the roadway. The walls are a part of the rest of the structure and are built of the same material. This type of construction generally gives the structure a better appearance than any of the types of guard rails heretofore described. It is also stronger and involves no maintenance costs. These advantages render the construction of parapet walls advisable where masonry. bridges and retaining walls are constructed.

\section{Highway Signs}

Road Signs. On highways outside of urban districts the signs usually employed consist of (I) direction and distance signs, (2) danger signs, and (3) highway department signs. 
Direction and Distance Signs. The fundamental principle of the design of direction and distance signs is that they should be so constructed and so located on the highway that the requisite information may easily be read by drivers of vehicles when at a reasonable distance from the signs. It is necessary in order to meet the above requirement to reduce the information on the sign to a minimum. The National Tourist Office of France has accomplished the most notable work in this field of highway engineering. Among the important conclusions reached by this Office are (I) that it is sufficient to erect plates at those crossings or intersections where confusion might arise; (2) that plates should be placed at right angles to the direction of the road; (3) that for each road at an intersection the sign should contain the names and distances of only two urban districts and that one name should be that of the next urban district on the given road; (4) that the empirical formula $L=\frac{10,000}{3} p$ indicates the distance which a word is legible

to a person with average eyesight when the letters are $p$ thick, $5 p$ high and $p$ apart.

Danger Signs. Four danger signs have been adopted by the Department of Roads and Bridges of France. These signs, which are placed on the highway from 500 to I,, 00 feet from the source of danger, indicate the following obstacles and dangers: (I) turnings; (2) obstacles along the road such as ditches, humps, bridges, etc.; (3) barriers, road crossings or railroad crossings when protected by barriers, except where such crossings should be classed as dangerous crossings; (4) dangerous crossings, road crossings or railroad crossings when not protected by barriers. One or more of these signs, which include a sign representative of the kind of danger and its name, have been adopted in many localities of Europe and in a few sections of the United States.

Highway Department Signs. Highway number and designation signs, milestones, and section monuments have not been standardized. Many countries of Europe and several States in America have adopted standards of their own. Fig. I96 shows 
the type of sign and post used in I9I4 by the New York State Highway Department.

Street Signs. In urban districts the signs which are in common use include street designation signs, general direction

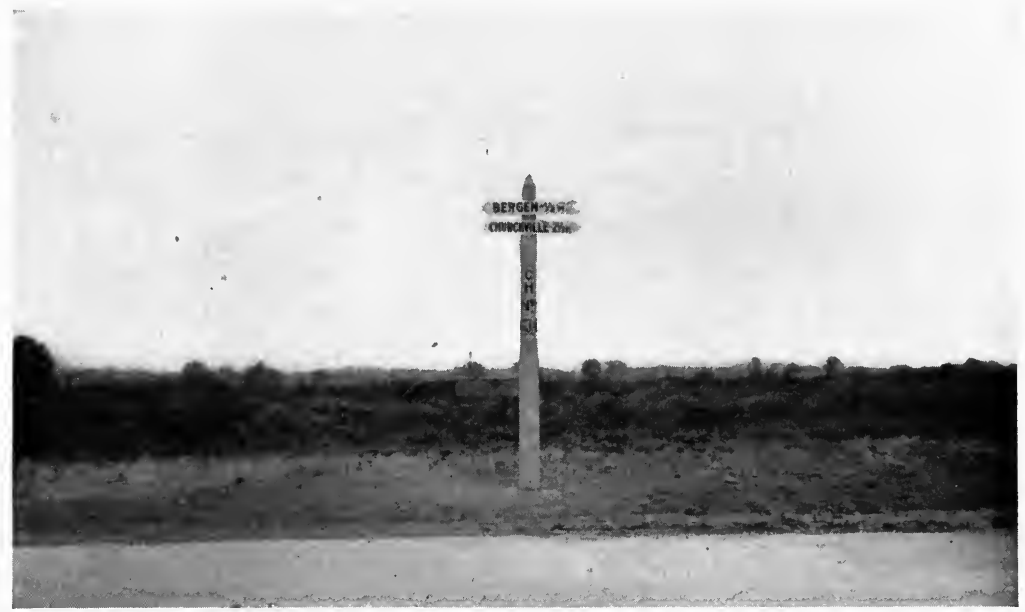

FIG. 196. Highway Department Sign Post, State of New York.

and speed signs for through traffic, and a large variety of signs used by police authorities for the proper regulation of traffic.

\section{CAR Tracks}

It was pointed out in Chapter IV, from the standpoint of the efficient design of the highway, the location of car tracks within the limits of the roadway is accompanied by several disadvantages. The progress and social development of communities, however, are dependent to a large extent upon transportation facilities. Street railways and motor-buses are the two systems which must be considered in designing the highways. Although it is reasonable to expect that motor-buses may replace surface railways in many instances, it is doubtful if their use will become so common that transportation by electric traction railways on roads and streets will be entirely eliminated. The problem is to construct the railways so that all of the 
advantages can be enjoyed and all of the disadvantages will be reduced to a minimum. This involves a consideration of the location of the tracks and details of track construction.

Location. There are several advantages in having the car tracks located on a part of the highway which is inaccessible to other traffic. This arrangement does not interfere with the convenience of those entering and leaving the cars and has the added advantage that the cars can be operated at higher speeds without danger to other traffic. The work incident to the maintenance of the tracks can be carried on without disturbing the surfacing of the roadway, and obviously, since the tracks are without the roadway, the wear of the latter is not affected by their presence. From the standpoint of the traction companies several advantages may be noted. The cost of the original construction is generally much less than when the tracks are located within the roadway, due to the fact that the special methods of construction are not required. The expenses of maintenance are less than where the tracks are so situated that they can be used by all kinds of traffic. The arrangement above described may be accomplished in cases of wide residential streets or boulevards, where the tracks may be located either at the sides or in the center of the highway. There are very few instances in cities of this country, however, where this arrangement is employed except in the case of boulevards.

The usual practice is to have the car tracks located within the roadway, either in the center or at the sides, the tracks being made flush with the adjoining pavement so as to offer as little obstruction as possible to other vehicular traffic. Whether the tracks should be located in the center or at the sides is dependent upon local conditions, but primarily depends upon the width of the roadway. In Chapter IV, the New York City ordinance was quoted as requiring a minimum width of roadway of 30 feet for streets in which there is a single track railroad and 40 feet for those in which there is a double track railroad.

The following physical data must be taken into consideration in the determination of location. The width, out to out, of cars varies from 8 to 9 feet. The clearance allowed between passing 
cars on a double track is variable, depending somewhat upon the speed. It is generally a minimum of 5 inches and may be as much as 2 feet on very wide streets, where there is ample room. The usual track gauge in this country is 4 feet $8 \mathrm{r} / 2$ inches. If a standard gauge is used and a minimum clearance, the distance center to center of tracks for the widest cars will be 9 feet 6 inches, and the total width, out to out, of cars on the tracks will be practically 14 feet.

Track Construction. Experience has shown that the maintenance of a roadway surface adjacent to a car track is usually more costly than other portions of the surface. Water, which seeps down by the rail, particularly at the joints, softens up the underlying soil with the result that the track pumps and the adjacent pavement is soon disintegrated. Sometimes the surface of the rail head as it comes from the rolls is more-or less uneven and wavy. The treads of car wheels may wear unevenly, and this, together with the unevenness of the rails, produces vibrations which are very injurious to the adjoining pavements. Sheet asphalt and other types of bituminous pavements are particularly susceptible to a very small movement of the rail, both laterally and vertically.

Rails. Among the earliest types of rails was a flat stepped head which was spiked to a wooden stringer, the stringers resting on wooden cross-ties. The traction companies in those times were not obliged to build their tracks so as to offer minimum obstruction to other traffic. In fact, one type of rail developed in New York City, was designed with the intent of being so objectionable that the vehicles would keep off of the car tracks. This, like the first rail described, was a rail head which was spiked to a wooden stringer. Instead of being a stepped head, however, with one side flush with the pavement, the rail head projected above the surface of the surrounding pavement in the form of an inverted $U$, the car wheels having a center groove. The railway companies soon appreciated that more permanent construction was necessary, and many types of rails were developed in which the head could be removed when worn and replaced with a new piece, the web and rail base remaining 
permanently in place. Stepped heads and those with a groove similar to the ones in use to-day were also tried.

The types of rails now used are the grooved rail, the stepped rail, and the T-rail, as shown in Figs. I97, I98, and 199, respec-

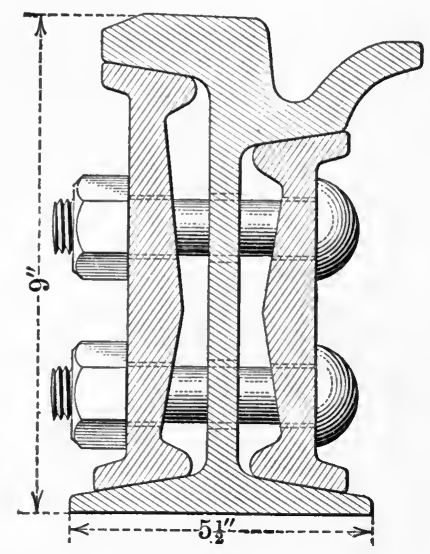

FIG. 197. Grooved Rail.

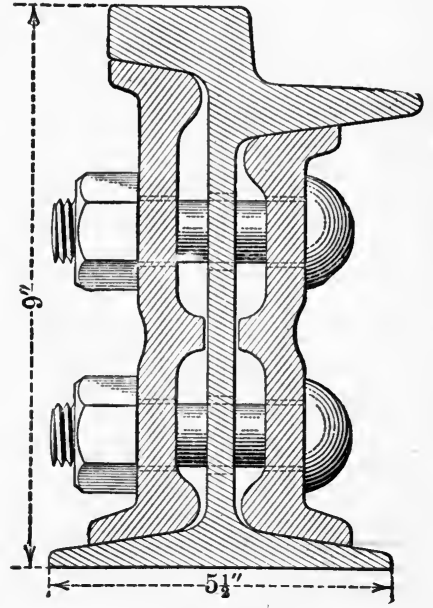

FIG. I98. Stepped Rail.

tively. When the car track occupies a space inaccessible to other traffic it is quite customary to use the T-rail. Although

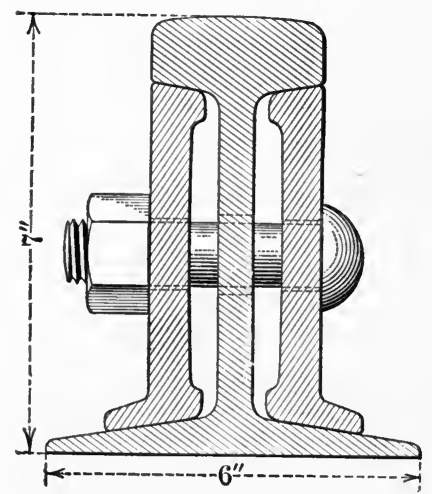

FIG. 199. T-Rail. this form of rail is also adopted sometimes for track construction within the roadway, special means are taken to form a groove so that the result, as far as the traffic is concerned, is practically the same as if a grooved rail had been used. A rail with a stepped head has been commonly used, but offers considerably more obstruction to traffic than a grooved rail. The smoothest track, from the standpoint of other traffic crossing over it, is without doubt constructed with grooved rails. This type is now being largely employed both in this country and in Europe. 
Rails are made of different depths, varying from about 4 to 9 inches. The 9 -inch rails are generally designated as girder rails. A rail of this depth is required, if a form of pavement such as wood block, stone block, or sheet asphalt, etc., is to be built next to the track, in order to give sufficient room for a proper thickness of concrete over the tie to support the pavement above.

Foundation. The simplest form of track foundation is that of imbedding wooden ties in gravel or broken stone. This method is ordinarily used in roadways for tracks constructed on roads
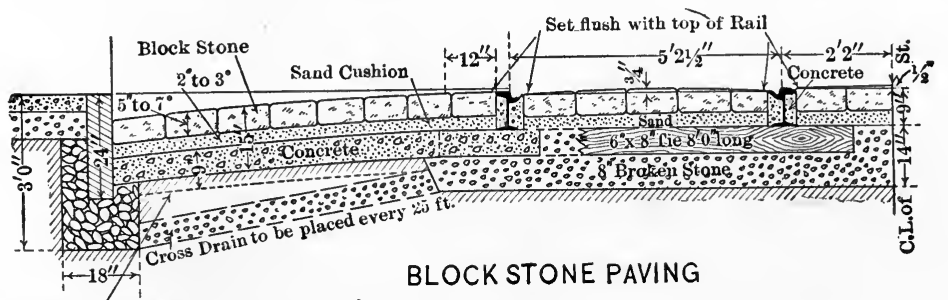

BLOCK STONE PAVING

Sub-grade for gravel

foundation

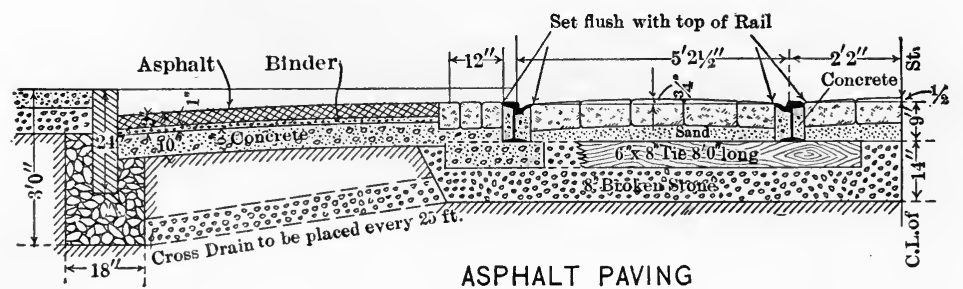

FIG. 200. Track Construction, City of Pittsburg.

surfaced with broken stone or similar material, and for tracks that are built on a right of way which is inaccessible to other traffic.

It is essential in track construction which is flush with the roadway and adjacent to pavements of wood block, granite block, brick, or any form of bituminous pavement to provide a foundation that will make the track as rigid as possible. The work should be done in such a manner as to reduce to a minimum the maintenance and renewal work. To provide a permanent foundation, concrete is used. The ties are laid on a bed of 
ballast or concrete which extends underneath the full width of track. Concrete is filled around and in some cases over the ties. Fig. 200 shows the foundation required for tracks laid adjacent to stone block and sheet asphalt pavements in the City of Pittsburg, Pa. In this construction a stone drain, leading from the foundation underneath the track to the gutter drain, is required every 25 feet. It is very important that the track should be thoroughly drained, as otherwise the water which seeps through will soften the foundation. In some cases the wooden cross-ties are omitted and a longitudinal support of concrete is built under each rail. (See Fig. 20I.) The rails are tied together at intervals with tie rods, which are

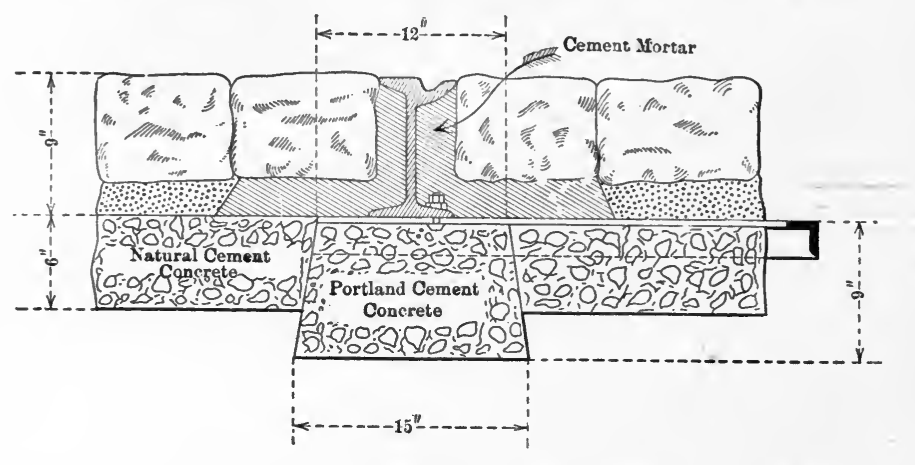

From Tillson's "Street Pavements and Paving Materials."

FIG. 20I. Longitudinal Support for Rail.

imbedded in the concrete between the rails. Special forms of support for the rails have to be used in some cases where the third rail or other device for delivering the current is below the ground. In Germany molded reinforced concrete blocks have been laid underneath the rails. The blocks are 5 inches thick, $3 \mathrm{I}$ inches long, and 20 inches wide, and are so molded that in the top surface a trough is provided which is wide and deep enough so that when the rail is set in it the head of the rail will be flush with the surface of the block.

Surfacing Adjacent to Rails. The franchises of streetrailway companies generally stipulate, both in this country and in Europe, that the company shall construct and maintain the 
pavement over the area covered by its tracks and for a distance from 18 inches to 2 feet outside of the rail adjacent to the roadway. The franchises also usually require the traction companies, to maintain the pavement next to the rails in as good condition as the adjoining pavement. The enforcement of these stipulations has been extremely difficult in certain localities.

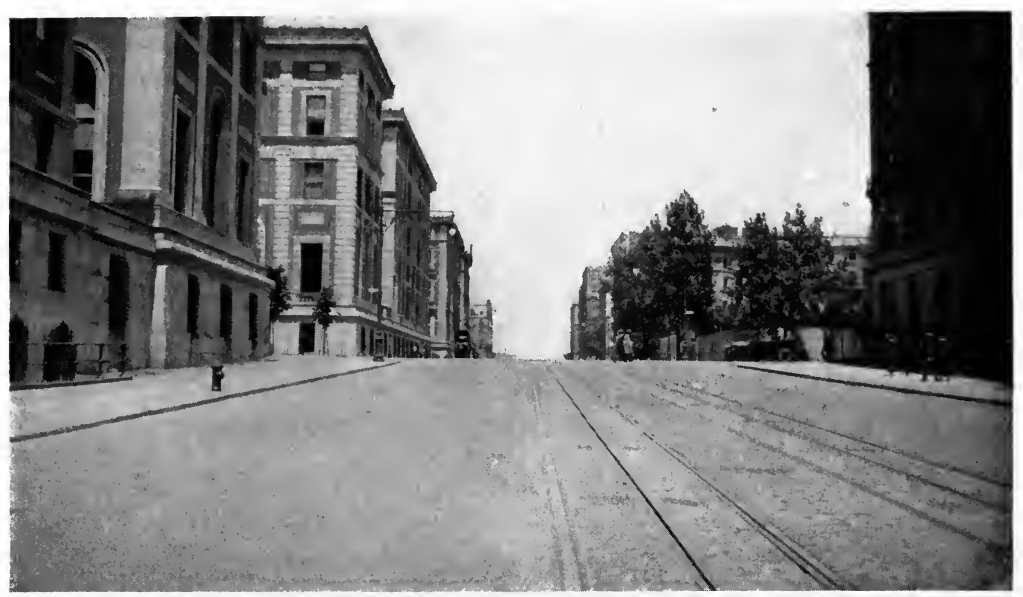

FIG. 202. Asphalt Blocks Adjacent to Outside Rails and Stone Blocks Between Rails.

It has been found necessary to use special methods of construction along and between the rails in order to procure the best results.

If the rails are of sufficient depth to provide room for the block and a firm foundation over the ties, brick, wood and stone block pavements can be constructed up to and between the rails. Although bituminous pavements are constructed up to and between the rails, better results have been obtained when some form of blocks has been placed between the edge of the pavement and the rail, as shown in Fig. 202. There are instances where a track is paved with granite or brick blocks for the full width between the rails and for 18 inches to 2 feet outside regardless of the type of surfacing in the remainder of the pavement. The space on either side of the rail web 
underneath the rail head is generally filled with cement mortar, as is shown in Figs. 200 and $20 \mathrm{I}$. Some engineers believe that the best results are obtained by using a low penetration bituminous material which is not objectionably susceptible to changes in temperature.

On roads where tracks are constructed with shallow rails resting on ties imbedded in gravel, bituminous concrete and bituminous macadam constructed adjacent to the rail will not wear satisfactorily. In cases where the rails are so shallow that blocks cannot be laid on edge between them and the pavement as previously described, an I8-inch strip of water-bound gravel or broken stone has been found to work satisfactorily. Paving blocks laid flat and cobblestones have also been used with good results.

\section{Pipe Systems}

Kinds of Systems. Pipe systems are to be found beneath streets in all cities. The business of some corporations controlling subsurface systems is so far-reaching in extent that their service pipes extend into the outlying districts beyond the city proper. As a general rule water supply pipes and pipes for the conveyance of sewage are the first systems installed in the development of a city. The universal use of gas as a means of light adds one more pipe service which must be so placed as to be available to the abutting property. Telegraph, telephone, and electric light wires, were formerly carried above the ground. Although this practice is still common, in the business districts of many large cities the wires are now being laid in conduits below the surface. Vaults underneath the sidewalks, subways underneath the streets, car tracks on the surface with their special construction sometimes for carrying current beneath the surface, pipes for carrying heat or refrigerating fluids from a central plant, pneumatic tubes, pipes for house connections, are all present in many cases to further complicate the problem. An engineer must assume, then, that pipes for sewage, water, and gas are an essential part of the development of any built-up district, and in designing the streets 
due allowance must be made for the accommodation of such systems.

These systems are not all built at the same time. The water supply and sewage systems are generally installed by the municipality, the custom being to build and extend these systems as the growth of the locality demands. The gas pipes, conduits for telephone, telegraph, or electric light wires may be laid by many different corporations and at various times. In a great many of our cities extremely poor records, showing the location of their services, have been kept by these private corporations. With all of these various systems underneath the surface of the street it is not surprising that the streets are continually torn up. This condition of affairs can only be alleviated by proper administration and legislation.

Pipe Subways. The use of subways, in which all pipe systems might be placed, would do away with a great deal of the trouble of street disturbances which are now so prevalent in those places where pipe systems exist. The construction of subways for this purpose, however, is very costly and for this reason would be financially impracticable except in the busiest and most important streets of large cities. Many European cities have pipe subways of varying lengths. In London there is a total of about seven miles. In Paris the sewers, which are of large dimension, are used for pipe subways. It is the belief of many engineers that the gas pipes should be excluded from subways in which electric cables are placed, because of the danger of explosion. The experience of Paris has been that this danger is largely eliminated if the subway is well ventilated.

Location. Many of the services enumerated above have connections running to the houses which face on the street, and therefore they must be placed somewhere between the property lines. This available space is generally divided into two sidewalks and one or more roadways. In some cases a narrow parking space is left between the curb of the walk and the paved sidewalk, which plan, however, will generally only be found in the residential parts of a city. Unless the sidewalks or parking spaces are very wide it is necessary to locate some of the pipe 
systems in the roadway. Where vaults, which extend to the surface, are constructed underneath the sidewalk, the use of the space underneath the sidewalk is no longer available for the services. As was mentioned in Chapter IV, ordinances in some cities now prevent the construction of such vaults within a distance nearer than four feet to the surface of the sidewalk, thus leaving this space for the location of subsurface pipes.

It is rarely feasible to have a roadway of a street without any pipe systems beneath it. The principle to be kept in mind is to place those systems beneath the roadway which will be disturbed the least. They should be located in such a manner that, if repair work is necessary, it may be accomplished with a minimum disturbance of traffic. If all of the different systems can be laid in a street before the roadway is surfaced, and if the house connections can be extended to the property lines at the same time the installation of the different systems is made, such a procedure will prevent, to a large extent, disturbances to the roadway at later periods.

RePaving TRenches. It is very difficult to properly repave a surface over a trench which has been made for the purpose of installing or repairing pipe systems. There is more or less settlement of the earth in the trench, which will cause a similar depression in the surface. The fact that the pavement replacements are not properly supervised and that frequently the work is done by people not familiar with the details of construction, gives results which are particularly unsatisfactory. It is essential that the earth in being filled back in the trench should be thoroughly compacted. This can be accomplished by tamping the earth in very thin layers. Puddling the earth with water will also aid compaction. When the pavement in which the trench has been cut is supported upon cement-concrete, the foundation may be replaced by either of the following methods in order to give it additional strength: first, the depth of the concrete may be increased; second, it may be reinforced and tied into the adjoining concrete; third, it may be cut away on strips adjacent to the trench and rebuilt by bridging the trench. 


\section{APPENDIX I}

\section{GLOSSARY OF TERMS APPLICABLE TO HIGHWAY ENGINEERING}

In the glossary will be found some terms and definitions adopted by the Special Committee on "Materials for Road Construction" of the American Society of Civil Engineers noted thus $\dagger$, others adopted by the American Society for Testing Materials designated thus *, and others proposed by the Com* mittee on "Standard Tests for Road Materials" (Committee D-4) of the American Society for Testing Materials, which have been indicated thus $\ddagger$.

Aggregate. The mineral material, such as filler, sand, gravel, shells, slag, or broken stone, or combinations thereof, with which the cement or bituminous material is mixed to form a mortar or concrete. Fine aggregate may be considered as the mineral material which will pass a $1 / 4$-inch screen and coarse aggregate the material which will not pass a $1 / 4$-inch screen.

Amorphous. A textural term used to describe a rock structure without definite form or crystalline composition.

Aqueous Rocks. Rocks which have been formed through the agency of water.

Arkose. A coarse feldspathic sandstone.

Asphalt. $\ddagger$ Solid or semi-solid native bitumens, solid or semi-solid bitumens obtained by refining petroleums, or solid or semi-solid bitumens which are combinations of the bitumens mentioned with petroleums or derivatives thereof, which melt on the application of heat, and which consist of a mixture of hydrocarbons and their derivatives of complex structure, largely cyclic and bridge compounds.

Asphalt Block Pavement. $\dagger$ One having a wearing course of previously prepared blocks of asphaltic concrete.

† Dec., I9I4 Proceedings, Am. Soc. C. E., r915 Report of Special Committee on "Materials for Road Construction," pages 30I I-30r9. 
Asphalt Cement. $\dagger$ A fluxed or unfluxed asphaltic material, especially prepared as to quality and consistency, suitable for direct use in the manufacture of asphaltic pavements, and having a penetration of between 5 and $25^{\circ}$.

Asphaltenes. $\dagger$ The components of the bitumen in petroleum, petroleum products, malthas, asphalt cements, and solid native bitumens, which are soluble in carbon disulphide, but insoluble in paraffin naphthas.

Asphaltic. $\dagger$ Similar to, or essentially composed of, asphalt.

Bank Gravel. Gravel found in natural deposits, usually more or less intermixed with sand, clay, etc.; gravelly clay, gravelly sand, clayey gravel, and sandy gravel indicate the various proportions of the admixture of the finer materials.

Basalt. A general name given to dark, basic, volcanic rocks of wide distribution, and in a restricted sense employed as a rock name for porphyritic and felsitic rocks consisting of augite, olivine, and plagioclase with varying amounts of a glassy base which may entirely disappear.

Base. $\dagger$ Artificial foundation.

Binder. $\uparrow$ (I) A foreign or fine material introduced into the mineral portion of the wearing surface for the purpose of assisting the road metal to retain its integrity under stress, as well as, perhaps, to aid in its first construction. (2) The course, in a sheet asphalt pavement, frequently used between the concrete foundation and the sheet asphalt mixture of graded sand and asphalt cement.

Bitumen. $\dagger^{*}$ A mixture of native or pyrogenous hydrocarbons and their non-metallic derivatives, which may be gases, liquids, viscous liquids, or solids, and which are soluble in carbon disulphide.

Bituminous Cement. $\dagger$ A bituminous material suitable for use as a binder having cementing qualities which are dependent mainly on its bituminous character.

Bituminous Concrete Pavement. $\uparrow$ One composed of stone, gravel, sand, shell, or slag, or combinations thereof, and bituminous materials incorporated together by mixing methods.

Bituminous Macadam Pavement. $\dagger$ One having a wearing 
course of macadam with the interstices filled by penetration methods with a bituminous binder.

Bituminous Material. $\dagger$ Material containing bitumen as an essential constituent.

Liquid Bituminous Material. $\dagger \ddagger$ Bituminous material showing a penetration at normal temperature under a load of $5^{\circ} \mathrm{grams}$ applied for I second of more than $35^{\circ}$.

Semi-Solid Bituminous Material. $\dagger$ Bituminous materıal showing a penetration at normal temperature under a load of Ioo grams applied for 5 seconds of more than ro, and under a load of 50 grams applied for I second of not more than $35^{\circ}$.

Solid Bituminous Material. $\dagger+$ Bituminous material showing a penetration at normal temperature under a load of Ioo gra.ns applied for 5 seconds of not more than Io.

Bituminous Pavement. $\dagger$ One composed of stone, gravel, sand, shell, or slag, or combinations thereof. and bituminous materials incorporated together.

Bituminous Surface. $\dagger$ A superficial coat of bituminous material with or without the addition of stone or slag chips, gravel, sand, or material of similar character.

Blanket. $\dagger$ See "Carpet."

Bleeding. $\dagger$ The exudation of bituminous material on the roadway surface after construction.

Blown Petroleums. $\ddagger$ Semi-solid or solid products produced primarily by the action of air upon liquid native bitumens which are heated during the blowing process.

Bond. $\dagger$ The combined action of inertia, friction, and of the forces of adhesion and cohesion which helps the separate particles composing a crust or pavement to resist separation under stress. Mechanical bond is the bond produced almost wholly, in a wellbuilt broken stone macadam road, by the interlocking of angular fragments of stone and the subsequent filling of the remaining interstices with the finer particles.

Bound. $\dagger$ Bonded.

Water-Bound. $\dagger$ Bonded with the aid of water.

Bituminous Bound. $\dagger$ Bonded with the aid of bituminous material. 
Breccia. A rock composed of angular fragments larger than sand grains, cemented together, and often presenting a variety of colors.

Brick Pavement. $\dagger$ One having a wearing course of paving bricks or blocks.

Bridge. $\dagger$ A structure for the purpose of carrying traffic over a gap in the road-bed measuring to feet or more in the clear span.

Camber of a Bridge $\dagger$ The rise of its center above a straight line through its ends.

Camber of a Road. $\dagger$ See "Crown."

Carbenes. $\dagger \ddagger$ The components of the bitumen in petroleums, petroleum products, malthas, asphalt cements, and solid native bitumens, which are soluble in carbon disulphide, but insoluble in carbon tetrachloride.

Carpet. $\dagger$ A bituminous surface of appreciable thickness, generally formed on top of a roadway by the application of one or more coats of bituminous material with gravel, sand, or stone chips added.

Cellular. A textural term used to describe a rock structure containing cells due to weathering out of some constituent

Cement. $\uparrow$ An adhesive substance used for uniting particles of other materials to each other. Ordinarily applied only to calcined "cement rock," or to artificially prepared, calcined, and ground mixtures of limestone and silicious materials. Sometimes used to designate bituminous binder used in bituminous pavements, when the expression "bituminous cement" (q. v.) is understood to be meant.

Cement-Concrete. $\uparrow$ An intimate mixture of gravel, shell, slag, or broken stone particles with certain proportions of sand or similar material, cement, and water, made previous to placing.

Cement-Concrete Pavement. $\dagger$ One having a wearing course of hydraulic cement-concrete.

Cemented. $\dagger$ Bonded. Referring to water-bound macadam, the term "cemented" is used to designate that condition existing when, after rolling the stone forming the crust, the remaining 
voids have been filled with the finer sizes, and the stone dust or "flour" has, under the action of water, taken a "set," as does cement itself.

Chert. $\ddagger$ Compact silicious rock formed of chalcedonic or opaline silica, or both.

Chips. $\dagger$ Small angular fragments of stone containing no dust.

Clay. $\dagger \ddagger$ Finely divided earth, generally silicious and aluminous, which will pass a 200-mesh sieve.

Coal-Tar. $\dagger \dagger$ The mixture of hydrocarbon distillates, mostly unsaturated ring compounds, produced in the destructive distillation of coal.

Coat. $\dagger$ See "Carpet." (I) The total result of one or more single surface applications. (2) To apply a coat.

Coke-Oven Tar. $\dagger \ddagger$ Coal-tar produced in by-product coke ovens in the manufacture of coke from bituminous coal.

Colloidal. A textural term used to describe a jelly or gluelike rock structure.

Consistency. $\dagger$ The degree of solidity or fluidity of bituminous materials.

Course. $\dagger$ One or more layers of road metal spread and compacted separately for the formation of the road or pavement. Courses are usually referred to in the order of their laying as first course, second course, third course, etc. Also a single row of blocks in a pavement.

Crown. $\dagger$ The rise in cross-section from the lowest to the highest part of the finished roadway. It may be expressed either as so many inches (or tenths of a foot), or as a rate per foot of distance from side to center, i. e., "the crown is 4 inches," or "the crown is $1 / 2$ inch to the foot."

Crusher Run. $\dagger \dagger$ The total unscreened product of a stone crusher.

Crusher-Run Stone. $\dagger$ The product of a stone crusher, unscreened except for the removal of the particles smaller than remaining on about a $1 / 4$-inch screen.

Crust. $\dagger$ That portion of a macadam or similar roadway above the foundation consisting of the road metal proper with its bonding agent or binder. 
Crystalline. A textural term used to describe a rock structure similar to that of granite.

Culvert. $\dagger$ A structure for the purpose of carrying traffic over a gap in the road-bed, measuring less than ro feet in clear span.

Cut-Back Products. $\dagger$ Petroleum, or tar residuums, which have been fluxed, each with its own or similar distillates.

Dead Oils. $\dagger^{*}$ Oils, with a density greater than water, which are distilled from tars.

Dehydrated Tars. $\ddagger \dagger$ Tars from which all water has been removed.

Diabase. Crystalline-granular igneous rocks, consisting essentially of plagioclase, augite, and magnetite, with or without olivine.

Diorite. Granitoid rock consisting essentially of plagioclase and hornblende, with usually more or less biotite.

Ditch. $\dagger$ The open-side drain of a roadway, usually deep in proportion to its width, and unpaved.

Dolerite. Coarsely crystalline basalts.

Dolomite. A native carbonate of calcium and magnesium, occurring as a crystallized mineral, and also on a large scale in granular crystalline rock-masses.

Drainage. $\dagger$ Provision for the disposition of water.

Side-Drainage. $\dagger$ That along the sides of the roadway.

Sub- or Under-Drainage $\dagger$ That below the surface.

Surface Drainage $\dagger$ That on the roadway or ground surface.

$V$-Drainage. $\dagger$ That provided by the construction of troughs in the subgrade of the roadway, which troughs are like a "V," with flat sloping sides, and are filled with stone.

Dust. $\dagger$ Earth or other matter in fine, dry particles, so attenuated that they can be raised and carried by air currents. The product of the crusher passing through a fine sieve.

Dust Layer. $\dagger$ Material applied to a roadway for temporarily preventing the formation or dispersion under traffic of distributable dust.

Earth Road. $\dagger$ A roadway composed of natural earthy material.

Emulsion. $\uparrow$ A combination of water and oily material made 
miscible with water through the action of a saponifying or other agent.

Epidiorite. Diabase whose augite is in part alterea to green hornblende.

Expansion Joint. $\dagger$ A separation of the mass of a structure, usually in the form of a joint filled with elastic material, which will provide opportunity for slight movement in the structure.

Fat. $\dagger$ Containing an excess. A fat asphalt mixture is one in which the asphalt cement is in excess and the excess is clearly apparent.

Felsite. Finely crystalline varıeties of quartz-porphyries, porphyries, or porphyrites that have few or no phenocrysts, and that, therefore, give but slight indications to the unaided eye of their actual mineralogical composition.

Filler. $\dagger+$ (I) Relatively fine material used to fill the voids in the aggregate. (2) Material used to fill the joints in a brick or block pavement.

Fixed Carbon. $\dagger^{*}$ The organic matter of the residual coke obtained upon burning hydrocarbon products in a covered vessel in the absence of free oxygen.

Flour. $\dagger$ Finely ground rocks or minerals pulverized to an impalpable product.

Flush Coat. $\dagger$ See "Seal Coat."

Flushing. $\dagger$ (I) Completely filling the voids. (2) Washing a pavement with an excess of water.

Flux. + Bitumens, generally liquid, used in combination with harder bitumens for the purpose of softening the latter.

Foliated. A textural term used to describe a rock structure which has a tendency to split along lines of stratification.

Footway. $\dagger$ The portion of the highway devoted especially to pedestrians. A sidewalk.

Foundation. $\dagger$ The portion of the roadway below and supporting the crust or pavement.

Artificial Foundation. $\dagger$ That layer of the foundation especially placed on the subgrade for the purpose of reinforcing the supporting power of the latter itself, and composed of material different from that of the subgrade proper. 
Natural Foundation. The natural earthy material below and supporting the artificial foundation or, if there is no artificial foundation, the crust or pavement.

Free Carbon. $\dagger^{*}$ In tars, organic matter which is insoluble in carbon disulphide.

Gabbro. Igneous rocks of granitoid texture, consisting of plagioclase and diallage, but as now employed, any monoclinic pyroxene may be present, with or without diallage.

Gas-House Coal-Tar. $\dagger \dagger$ Coal-tar produced in gas-house retorts in the manufacture of illuminating gas from bituminous coal.

Glass. A textural term used to describe an amorphous rock structure formed by the quick chilling of a fused lava.

Gneiss. Laminated or foliated granitoid rock that corresponds in mineralogical composition to some one of the plutonic rocks.

Grade. $\dagger$ (I) The profile of the center or the roadway, or its rate of rise or fall. (2) Elevation. (3) To establish a profile by cuts and fills or earthwork. (4) To arrange by sizes, broken stone, gravel, sand, or combinations of such materials.

Granite. A granitoid igneous rock consisting of quartz, orthoclase, more or less oligoclase, biotite, and muscovite.

Granitoid. A textural term to describe those igneous rocks which are entirely composed of recognizable minerals.

Granular. A textural term used to describe a rock structure made up of distinct grains.

Gravel. $+\dagger$ Small stones or pebbles which will not pass a Io-mesh sieve.

Greywacke. Metamorphosed, shaly sandstones that yield a tough, irregular breaking rock.

Grit. $\ddagger$ Stone chips, slag chips, or small gravel

Gutter. $\dagger$ The artificially surfaced and generally shallow waterway provided usually at the sides of the roadway for carrying surface drainage. Occasionally used synonymously with "ditch," but incorrectly so, as "gutters" are always paved or otherwise surfaced, and ditches are not.

Haunches. $\dagger$ The sides or flanks of a roadway. Sometimes also called "quarters." 
Highway. $\uparrow$ The entire right of way devoted to public travel, including the sidewalks and other public spaces, if such exist.

Holocrystalline. A textural term used to describe a rock structure that consists entirely of crystallized minerals.

Hornblende Schist. A schistose rock consisting chiefly of black or dark-green hornblende, but often interlaminated with feldspar, quartz, or mica.

Humus. Soil formed by the decomposition of vegetable matter on the surface of the ground.

Igneous Rocks. Rocks which have been formed by mineral matter flowing upward in a molten condition and cooling near the surface.

Laminated. A textural term used to describe a banded structure which is characteristic of many sedimentary rocks.

Layer. $\dagger$ A course made in one application.

Limestone. Rock composed essentially of calcium carbonate.

Loam. $\dagger \ddagger$ Finely divided earthy material containing a considerable proportion of organic matter.

Macadam. $\dagger$ A road crust composed of stone or similar material broken into irregular angular fragments compacted together so as to be interlocked and mechanically bound to the utmost possible extent.

Marble. Limestones which have sufficiently close texture to take a polish.

Marl. Calcareous clay containing a minimum of 15 percent of carbonate of lime and a maximum of 75 percent of clay.

Massive. A textural term used to describe igneous rocks that show no stratification.

Mastic. $\dagger$ A mixture of bituminous material and fine mineral matter suitably made for use in highway construction and for application in a heated condition.

Mat. $\dagger$ See "Carpet."

Matrix. $\neq$ The binding material or mixture of binding material and fine aggregate in which the large aggregate is embedded or held in place.

Mesh. $\dagger$ The square opening of a sieve.

Metal. $\dagger$ See "Road Metal." 
Metamorphic Rocks. Rocks which have been changed by dynamic or chemical agencies from their original condition.

Mortar. $\dagger$ A mixture of fine material such as sand, cement, and water or other liquid suitably proportioned and incorporated together for the purpose for which it is used.

Mush. $\dagger$ A greasy mud sometimes found on bituminous crusts.

Native Asphalt. $\ddagger$ Asphalt occurring as such in nature.

Norite. Rock of the gabbro family that consists of plagioclase and orthorhombic pyroxene, usually hyperosthene.

Normal Temperature. $\dagger \ddagger$ In laboratory investigations, $25^{\circ} \mathrm{C}$. $\left(77^{\circ} \mathrm{F}.\right)$.

Oil-Gas Tars. $\ddagger$ Tars produced by cracking oil vapors at high temperatures in the manufacture of oil-gas.

Palliative. $\dagger$ A short-lived dust layer.

Patching. $\dagger$ Repairing or restoring small isolated areas in the surface of the metaled or paved portion of the highway.

Pavement. $\dagger$ The wearing course of the roadway or footway, when constructed with a cement or bituminous binder, or composed of blocks or slabs, together with any cushion or "binder" course.

Peat. Soil formed by the decomposition of vegetable matter under water.

Pegmatite. Very coarse granites, such as have large quartz, feldspar, muscovite, biotite, tourmaline, beryl, and other characteristic minerals.

Penetration. $\dagger$ In laboratory investigations, the distance, expressed in tenths of a millimeter, entered a sample by a No. 2 cambric needle operated in a machine for the purpose and under known conditions of loading, time, and temperature. The degree of solidity of bituminous materials.

In construction, the entrance of bituminous material into the interstices of the metal of the roadway.

Penetration Method. + The method of constructing a bituminous macadam pavement by pouring or grouting the bituminous material into the upper course of the road metal before the binding of the latter has been completed. 
Petroleum. A natural rock oil composed of hydrocarbons. (The New International Encyclopædia.)

Pitch. $\dagger \ddagger$ Solid residue produced in the evaporation or distillation of bitumens, the term being usually applied to residue obtained from tar.

Hard Pitch. $\dagger$ Pitch showing a penetration of not more than ten.

Soft Pitih. $\dagger$ Pitch showing a penetration of more than ten.

Plutonic Rocks. Rocks which were formed by the cooling of molten mineral matter before it reached the surface.

Pocket. $\dagger$ A hole or depression in the wearing course.

Porphyritic. A textural term used to describe a compact structure throughout which there are large crystals.

Porphyry. Rock consisting of a very fine-grained or microcrystalline ground-mass through which are disseminated distinctly recognizable crystals of some mineral.

Pot-Hole. $\dagger$ A hole extending below the wearing course.

Profile. $\dagger$ A longitudinal section of a highway, generally taken along the center line.

Quarters. $\dagger$ The four sections of equal width which, side by side, make up the total width of a roadway.

Raveling. $\dagger$ The loosening of the metal composing the crust.

Refined Tar. $\dagger \ddagger$ A tar freed from water by evaporation or distillation which is continued until the residue is of desired consistency, or a product produced by fluxing tar residuum with tar distillate.

Renewals. $\dagger$ Extensive repairs over practically the whole surface of the metaled or paved portion of the highway.

Repairs. $\dagger$ The restoration or mending of a considerable amount of the metaled or paved portion of the highway, but not usually of a majority of the surface area. More extensive than "Patching" but less so than "Renewals."

Resurfacing. $\dagger$ The renewal of the surface of the crust or pavement.

Rhyolite. Volcanic rocks of porphyritic or felsitic texture, whose phenocrysts are prevailingly orthoclase and quartz, less 
abundantly biotite, hornblende, or pyroxene, and whose groundmass is crystalline, glassy, or both.

Road. $\dagger$ A highway outside of an urban district.

Road-Bed. $\dagger$ The natural foundation of a roadway.

Road Metal. $\dagger$ Broken stone, gravel, slag, or similar material used in road and pavement construction and maintenance.

Roadway. $\uparrow$ That portion of a highway particularly devoted to the use of vehicles.

Rock Asphalt. $\dagger$ Sandstone or limestone naturally impregnated with asphalt.

Rock Asphalt Pavement. $\dagger$ A wearing course composed of broken or pulverized rock asphalt with or without the addition of other bituminous materials.

Rubble. $\ddagger$ Rough stones of irregular shapes and sizes, broken from larger masses, either naturally or artifically, as by geological action, in quarrying, or in stone-cutting or blasting.

Sand. $\dagger \ddagger$ Finely divided rock detritus the particles of which will pass a ro-mesh and be retained on a 200-mesh screen.

Sand-Clay Road. $\dagger$ A roadway composed of an intimate mixture of sand and clay.

Sandstone. Rock formed by the consolidation of sand.

Scarify. $\dagger$ To loosen and disturb superficially.

Schist. Thinly laminated, metamorphic rocks which split more or less readily along certain planes approximately parallel and differing from the gneisses principally in the lack of feldspar.

Schistose. A textural term used to describe a rock structure which has a tendency to split along lines of stratification.

Screen. $\dagger \ddagger$ In laboratory work an apparatus, in which the apertures are circular, for separating sizes of material.

Screenings. $\ddagger$ Broken rock, including the dust, of a size that will pass through a $1 / 2$ - to $3 / 4$-inch screen, depending upon the character of the stone.

Seal Coat. $\dagger$ A final superficial application of bituminous material during construction to a bituminous pavement.

Setting Up. $\dagger$ The relatively quick change such as takes place in a bituminous material after its application to a roadway, indicated by its hardening after cooling and exposure to atmos- 
pheric and traffic conditions, as opposed to the slower changes later occurring gradually and almost imperceptibly.

Shaping. $\dagger$ Trimming up and preparing a subgrade preparatory to applying the first course of the road metal or artificial foundation.

Sheet Asphalt Pavement. $\dagger$ One having a wearing course composed of asphalt cement and sand of predetermined grading, with or without the addition of fine material, incorporated together by mixing methods.

Sheet Pavement. $\dagger$ A pavement free from frequent joints such as would accompany small slabs or blocks, and which has an appreciable thickness (say, in excess of I inch on the average) for its wearing course.

Shoulders. $\dagger$ The portion of the highway between the edges of the road metal or pavement and the gutters, slopes, or watercourses.

Side Drain. $\dagger$ See "Drainage."

Sidewalk. $\uparrow$ The portion of the highway reserved for pedestrians.

Sieve.f In laboratory work an apparatus in which the apertures are square, for separating sizes of material.

Silt. $\dagger \ddagger$ Naturally deposited fine earthy material, which will pass a 200-mesh sieve.

Slag. Fused compounds of silica in combination with lime or other bases, resulting as secondary products from the reduction of metallic ores. (New International Encyclopædia.)

Soil.t A mixture of fine earthy material, with more or less organic matter, resulting from the growth and decomposition of vegetable or animal matter.

Spalls. $\uparrow$ Fragments broken off by a blow, irregular in shape, and of sufficient size to be comparable to the original mass.

Squeegee. $\dagger$ A tool with a rubber or leather edge for scraping or cleaning hard surfaces, or for spreading and distributing liquid material over and into the superficial interstices of roadways.

Squeegee Coat. $\dagger$ An application by means of the squeegee.

Stone Block Pavement. $\dagger$ One having a wearing course composed of stone blocks quite or nearly rectangular in shape. 
Stone Chips. $\ddagger$ Small angular fragments of stone containing no dust.

Straight-Run Pitch. $\neq$ A pitch run to the consistency desired, in the initial process of distillation, without subsequent fluxing.

Stratified. A textural term used to describe a rock structure composed of parallel layers.

Street. $\dagger$ A highway in an urban district.

Subgrade. $\dagger$ The upper surface of the native foundation on which is placed the road metal or the artificial foundation, in case the latter is provided.

Superficial Coat. $\dagger$ A light surface coat.

Surface Coat. $\dagger$ See "Carpet."

Surface Treatment. $\dagger$ Treating the finished surface of a roadway with bituminous material.

Surfacing. $\dagger$ (I) The crust or pavement. (2) Constructing a crust or pavement. (3) Finally finishing the surface of a roadway. (4) Treating the surface of a finished roadway with a bituminous material.

Syenite. Granitoid rocks consisting of orthoclase, hornblende, biotite, and augite.

Tailings. $\dagger+$ Stones, which after going through the crusher, do not pass through the largest openings of the screen.

Tar. $\dagger$ Bitumen which yields pitch upon fractional distillation and which is produced as a distillate by the destructive distillation of bitumens, pyro-bitumens, or organic material.

Telford. $\dagger$ Properly, an artificial foundation advocated by Thomas Telford ( $1757-1820$ ), and consisting of a pavement of stone about 8 inches thick, laid by hand, and closely packed and wedged together. The individual stones were desired to be about I6 square inches in section, and about 8 inches in length. They were set close together on the prepared subgrade, their longest dimension vertical and on their larger ends, their interstices chinked with smaller stones, and the whole rammed (or rolled) until firm and unyielding.

Telford Macadam. $\dagger$ Macadam with an artificial foundation of Telford.

Trap Rock. A very general term, little employed in scien- 
tific language but commonly used to designate dense and generally fine-grained igneous rocks of black or dark-green color. The term is almost synonymous with basalt or diabase but might include as well, gabbro, norite, peridotite, pyroxenite, etc. When altered such rocks assume a green color from hornblende, chlorite, epidote, or other secondary minerals developed in them, and they are then known as greenstone. Both greenstone and trap would include a wide range of rock families which by reason of their fine texture and altered condition are difficult to determine without careful and generally microscopic study. (The New International Encyclopædia.)

Under-Drain. $\dagger$ See "Drainage."

Up-Keep. $\dagger$ Maintenance.

V-Drain. $\dagger$ See "Drainage."

Viscosity. $\dagger$ The degree of fluidity of bituminous materials.

Volatile. $\dagger$ Applied to those fractions of bituminous materials which will evaporate at climatic temperatures.

Volcanic Rocks. Rocks which have been formed by mineral matter erupted in a molten condition and cooled on the surface.

Water-Bound. $\dagger$ Bound or bonded with the aid of water.

Water-Gas Tars. $\ddagger$ Tars produced by cracking oil vapors at high temperatures in the manufacture of carburetted water-gas.

Wearing Coat. $\dagger$ The superficial layer of the crust or pavement exposed to traffic.

Wearing Course. $\dagger$ The ccurse of the crust or pavement exposed to traffic.

Wood Block Pavement. $\dagger$ One having a wearing course composed of wood paving blocks, generally rectangular in shape. 


\section{APPENDIX II}

\section{TESTS OF BITUMINOUS MATERIALS}

The following methods* for performing tests to determine the several chemical and physical properties of bituminous materials were recommended for adoption by the Special Committee on "Materials for Road Construction" at the r9I5 Annual Meeting of the American Society of Civil Engineers. It will be noted that some of these methods were originally proposed by Sub-Committees of Committee D-4 on "Standard Tests for Road Materials" of the American Society for Testing Materials.

\section{Specific Gravity}

For liquid and semi-solid materials, some standard form of pyknometer shall be used. For solid materials, the suspension method shall be used. Material and distilled water shall have a temperature of $25^{\circ}$ Cent. ( $77^{\circ}$ Fahr.).

The pyknometer to be used shall consist of a fairly heavy, straight-walled glass tube, $70 \mathrm{~mm}$. (2.75 inch) long and $22 \mathrm{~mm}$. ( $0.875 \mathrm{inch}$ ) in diameter, ground to receive a solid glass stopper with a hole of r.6-mm. (0.063-inch) bore, in place of the usual capillary opening. The lower part of this stopper shall be made concave in order to allow all air bubbles to escape through the bore. The depth of the cup-shaped depression is $4.8 \mathrm{~mm}$. (0.188 inch) at the center. The stoppered tube shall have a capacity of about $24 \mathrm{cu}$. cm. (0.8 I ounce) and when empty shall weigh about 28 grams. Its principal advantages are: (I) that any desired quantity of bituminous material may be poured in without touching the sides above the level desired; (2) it is easily cleaned; (3) on account of the I.6-mm. (0.063-inch) bore, the stopper can be more easily inserted when the tube is filled

*Dec., I914 Proceedings, American Society of Civil Engineers, pâges 3036-3050. 
with a very viscous oil than if it contained a capillary opening. When testing solid or semi-solid materials with the pyknometer, extreme care should be taken in melting, to avoid loss by evaporation, and, in filling the pyknometer, to avoid entrapping air.

When working with semi-solid bituminous materials which are too soft to be broken and handled in fragments, the following method of determining their specific gravity has been used with good results. The clean, dry pyknometer is first weighed empty and this weight is called $a$. It is then filled in the usual manner with freshly distilled water at $25^{\circ}$ Cent. ( $77^{\circ}$ Fahr.), and the weight is again taken and called $b$. A small quantity of the material is then placed in a spoon and brought to a fluid condition by the gentle application of heat, with care that no loss by evaporation occurs. When sufficiently fluid, enough is poured into the dry pyknometer, which may also be warmed, to fill it about half full, without allowing the material to touch the sides of the tube above the desired level. The tube and contents are then allowed to cool to room temperature, after which the tube is carefully weighed with the stopper. This weight is called $c$. Distilled water, at $25^{\circ} \mathrm{Cent}$. $\left(77^{\circ} \mathrm{Fahr}\right.$.), is then poured in until the pyknometer is full. After this the stopper is inserted and the whole is cooled to $25^{\circ}$ Cent. ( $77^{\circ}$ Fahr.) by a 30 -minute immersion in a beaker of distilled water maintained at this temperature. All surplus moisture is then removed with a soft cloth, and the pyknometer and contents are weighed. This weight is called $d$. From the weights obtained, the specific gravity of the material may be readily calculated by the following formula:

Specific gravity $25^{\circ}$ Cent. ( $77^{\circ}$ Fahr.) $/ 25^{\circ}$ Cent. ( $77^{\circ}$ Fahr.)

$$
=\frac{c-a}{(b-a)-(d-c)}
$$

Both $a$ and $b$ are constants, and need be determined only once. It is necessary, therefore, to make only two weighings for each determination after the first. Results obtained according to this method are accurate to within two units in the third decimal place, whereas the open-tube method commonly used is accurate to the second decimal place only. 
The specific gravity of fluid bituminous material may be determined in the ordinary manner with this pyknometer by completely filling it with the material and dividing the weight of the bituminous material thus obtained by that of the same volume of water.

\section{Flash PoINT}

The flash point shall be determined by the closed-cup test.

Although for ordinary purposes, the open-cup method of determining the flash and burning points of bituminous materials is reasonably accurate, the closed-cup method described below is to be preferred.

The oil tester shall consist of a copper oil cup having a capacity of about $300 \mathrm{cu} . \mathrm{cm}$. (IO.I ounce), and shall be heated in a water or oil bath by a small Bunsen flame. The cup shall be provided with a glass cover, carrying a thermometer, and a hole for inserting the testing flame. The testing flame shall be obtained from a jet of gas passed through the piece of glass tubing, and shall be about $5 \mathrm{~mm}$. (O.I97 inch) in length.

The flash test shall be made as follows: The oil cup shall first be removed and the bath filled with water or cottonseed oil. The oil may always be used, and is necessary for bituminous material flashing at a temperature of more than $100^{\circ}$ Cent. ( $212^{\circ}$ Fahr.). The oil cup shall be replaced and filled with the material to be tested to within $3 \mathrm{~mm}$. (O.I 8 inch) of the flange joining the cup and the vapor chamber above. The glass cover shall then be placed on the oil cup and the thermometer adjusted so that its bulk shall be just covered by the bituminous material. The Bunsen flame shall be applied in such a manner that the temperature of the material in the cup shall be raised at the rate of about $5^{\circ}$ Cent. ( $9^{\circ} \mathrm{Fahr}$.) per minute. From time to time the testing flame shall be inserted in the opening in the cover to about half way between the surface of the material and the cover. The appearance of a faint bluish flame over the entire surface of the bituminous material will show that the flash point has been reached and the temperature at this point is taken. 


\section{Solubility in Carbon Disulphide ( $\mathrm{CS}_{2}$ )}

This test shall consist in dissolving the bituminous material in carbon disulphide and recovering any insoluble matter by filtering the solution through an asbestos felt. The Gooch crucible used for the determination shall be $4.4 \mathrm{~cm}$. (I.722 inch) wide at the top, tapering to $3.6 \mathrm{~cm}$. ( $\mathrm{I} .4 \mathrm{I} 7 \mathrm{inch}$ ) at the bottom, and shall be $2.5 \mathrm{~cm}$. (0.984 inch) deep.

The asbestos shall be cut with scissors into pieces not exceeding I cm. ( 0.394 inch) in length, after which it shall be shaken up with just sufficient water to pour easily. The crucible shall be filled with the suspended asbestos and allowed to settle for a few moments. A light suction shall then be applied to draw off all the water and leave a firm mat of asbestos in the crucible. More of the suspended material shall be added, and the operation shall be repeated until the felt shall be so dense that it scarcely transmits light when held so that the bottom of the crucible is between the eye and the source of light. The felt shall then be washed several times with water, and drawn firmly against the bottom of the crucible by an increased suction. The crucible shall be removed to a drying oven for a few minutes, after which it shall be ignited at red heat over a Bunsen burner, cooled in a desiccator and weighed.

Two grams of bituminous material or to grams of an asphalt topping or rock asphalt shall then be placed in an Erlenmeyer flask, which shall have been weighed previously, and the accurate weight of the sample obtained. One hundred cubic centimeters (3.38r ounces) of chemically pure carbon disulphide shall be poured into the flask, in small portions, with continual agitation, until all lumps disappear and nothing adheres to the bottom. The flask shall then be corked and set aside for I5 minutes to allow settlement of the insoluble material.

The weighed Gooch crucible containing the felt shall be set up over the dry pressure flask, and the solution of bituminous material in carbon disulphide shall be decanted through the felt without suction by gradually tilting the flask, with care not to stir up any precipitate that may have settled out. At the first. 
sign of any sediment coming out, the decantation shall be stopped and the filter allowed to drain. A small quantity of carbon disulphide shall then be washed down the sides of the flask, after which the precipitate shall be brought upon the felt and the flask scrubbed, if necessary, with a feather or "policeman," to remove all adhering material. The contents of the crucible shall be washed with carbon disulphide until the washings run colorless. Suction shall then be applied until there is practically no odor of carbon disulphide in the crucible, after which the outside of the crucible shall be cleaned with a small quantity of the solvent. The crucible and contents shall be dried in the hot air oven at $100^{\circ}$ Cent. (2 $12^{\circ} \mathrm{Fahr}$.) for about 20 minutes, cooled in a desiccator, and weighed. If any appreciable quantity of insoluble matter adheres to the flask, it shall also be dried and weighed, and any increase over the original weight of the flask shall be added the weight of insoluble matter in the crucible. The total weight of insoluble material may include both organic and mineral matter. The former, if present, shall be burned off by ignition at a red heat until no incandescent particles remain, thus leaving the mineral matter or ash, which can be weighed on cooling. The difference between the total weight of material insoluble in carbon disulphide and the weight of substance taken equals the total bitumen, and the percentage weights are calculated and reported as total bitumen, and insoluble organic and inorganic matter, on the basis of the weight of material taken for analysis.

This method is quite satisfactory for straight oil and tar products, but, where native asphalts are present, it will be found practically impossible to retain all the finely divided mineral matter on an asbestos felt. It is generally more accurate, therefore, to obtain the result for total mineral matter by direct ignition of a I-gram sample in a platinum crucible, or to use the result for ash obtained in the fixed carbon test. The total bitumen is then determined by deducting from roo percent the sum of the percentages of total mineral matter and insoluble organic matter. If the presence of a carbonate mineral is suspected, the percentage of mineral matter may be most accurately obtained by treating the ash from the fixed carbon determination 
with a few drops of ammonium carbonate solution, drying at $100^{\circ}$ Cent. ( $212^{\circ}$ Fahr.), then heating for a few minutes at a dull red heat, cooling, and weighing again.

When difficulty in filtering is experienced-for instance, when Trinidad asphalt is present in any quantity-a longer period of subsidence than I5 minutes is necessary, and the following method, proposed by the Committee on Standard Tests for Road Materials (Committee D-4) of the American Society for Testing Materials, is recommended: (Note: English equivalents in brackets have been added by the Special Committee on Materials for Road Construction.)

From 2 to 15 grams (depending on the richness in bitumen of the substance) is weighed into a $150-\mathrm{cu} . \mathrm{cm}$. (5.072 ounces) Erlenmeyer flask, the tare of which has been previously ascertained, and treated with Ioo cu. cm. (3.38I ounces) of carbon disulphide. The flask is then loosely corked and shaken from time to time until practically all large particles of the material have been broken up, when it is set aside and not disturbed for 48 hours. The solution is then decanted off into a similar flask that has been previously weighed, as much of the solvent being poured off as possible without disturbing the residue. The first flask is again treated with fresh carbon disulphide and shaken as before, when it is put away with the second flask and not disturbed for 48 hours.

At the end of this time the contents of the two flasks are carefully decanted off upon a weighed Gooch crucible fitted with an asbestos filter, the contents of the second flask being passed through the filter first. The asbestos filter shall be made of ignited long-fibre amphibole, packed in the bottom of a Gooch crucible to the depth of not more than $1 / 8$ inch. After passing the contents of both flasks through the filter, the two residues are shaken with more fresh carbon disulphide and set aside for 24 hours without disturbing, or until it is seen that a good subsidation has taken place, when the solvent is again decanted off upon the filter. This washing is continued until the filtrate or washings are practically colorless.

The crucible and both flasks are then dried at $125^{\circ}$ Cent. 
$\left(257^{\circ} \mathrm{Fahr}\right.$.) and weighed. The filtrate containing the bitumen is evaporated, the bituminous residue burned, and the weight of the ash thus obtained added to that of the residue in the two flasks and the crucible. The sum of these weights deducted from the weight of substance taken gives the weight of bitumen extracted.

\section{Solubility of Bitumen in Carbon Tetrachloride $\left(\mathrm{CCl}_{4}\right)$}

The test shall be conducted in exactly the same manner as described for the test for "Solubility in Carbon Disulphide," except that Ioo cu. cm. (3.38I ounces) of chemically pure carbon tetrachloride shall be used in place of carbon disulphide, and the percentage of bitumen insoluble in carbon tetrachloride shall be reported on the basis of the bitumen taken as roo, the quantity of bitumen having been determined by the method described under the heading "Solubility in Carbon Disulphide."

\section{Consistency}

The "Engler Viscosimeter," the "New York Testing Laboratory Float," or the "Penetrometer," shall be used, as practicable, at $4^{\circ}$ Cent. ( $39^{\circ}$ Fahr.), $25^{\circ}$ Cent. ( $77^{\circ}$ Fahr.), $46^{\circ}$ Cent. (I I $5^{\circ}$ Fahr.), and $98^{\circ}$ Cent. (208 Fahr.).

\section{VIScosity Test}

The viscosity of liquid bituminous materials shall be determined at any desired temperature by using the "Engler Viscosimeter." This apparatus consists of a brass vessel for holding the material to be tested, and is closed by a cover. To the conical bottom is fitted a conical outflow tube exactly $20 \mathrm{~mm}$. (0.787 inch) long, with a diameter of $2.9 \mathrm{~mm}$. (O.I I4 inch) on top, and of $2.8 \mathrm{~mm}$. (0.IIo inch) on the bottom. This tube is closed and opened by a pointed hardwood stopper. Pointed metal projections are placed on the inside of the vessel at equal distances from the bottom, and serve for measuring the charge of material, 
which is $240 \mathrm{cu} . \mathrm{cm}$. (8.rir6 ounces). A thermometer is used to ascertain the temperature of the material to be tested. The vessel is surrounded by a brass jacket, which holds the material which may be used as a heating bath, either water or cottonseed oil, according to the temperature at which the test is to be made. A tripod serves as a support for the apparatus, and also carries a ring burner by which the bath is heated directly. The measuring cylinder, having a capacity of roo cu. cm. (3.38 I ounces), which is sufficiently accurate for work with road materials, is placed directly under the outflow tube.

As all viscosity determinations should be compared with that of water at $25^{\circ}$ Cent. ( $77^{\circ} \mathrm{Fahr}$.), the apparatus shall have been previously calibrated as follows: The cup and outlet tube shall first be scrupulously cleaned. A piece of soft tissue paper is convenient for cleaning the tube. The stopper shall then be inserted in the tube, and the cup shall be filled with water at $25^{\circ}$ Cent. ( $77^{\circ}$ Fahr.) to the top of the projections. The measuring cylinder shall be placed directly under the outflow tube so that the material, on flowing out, will not touch the sides. The stopper shall then be removed and the time required, both for 50 and Ioo cu. cm. (I.69I and 3.38I ounces) to run out, shall be ascertained by using a stop-watch. The results thus obtained shall be checked a number of times. The time required for $50 \mathrm{cu}$. $\mathrm{cm}$. (I.69I ounces) of water should be about II seconds and for Iо० cu. cm. (3.38I ounces) about 22.8 seconds.

Bituminous materials shall be tested in the same manner as water, and the temperature at which the test is made shall be controlled by the bath. The material shall be brought to the desired temperature and maintained there for at least 3 minutes before making the test. The results are expressed as specific viscosity compared with water at $25^{\circ} \mathrm{Cent}$. ( $77^{\circ} \mathrm{Fahr}$.), as follows:

Specific viscosity at - degrees centigrade for - $\mathrm{cu} . \mathrm{cm}$. equals

seconds for passage of given volume at - degrees centigrade seconds for passage of same volume of water. 


\section{FLOAT TEST}

The float apparatus consists of two parts, an aluminum float or saucer and a conical brass collar. The two parts are made separately, so that one float may be used with a number of brass collars.

In making the test, the brass collar shall be placed with the small end down on the brass plate, which shall have been previously amalgamated with mercury by rubbing it first with a dilute solution of mercuric chloride or nitrate and then with mercury. A small quantity of the material to be tested shall be heated in the metal spoon until quite fluid, with care that it shall suffer no appreciable loss by volatilization and that it shall be kept free from air bubbles. It shall then be poured into the collar in a thin stream until slightly more than level with the top. After the material has cooled to room temperature, the surplus may be removed with a spatula blade which has been slightly heated. The collar and plate shall then be placed in one of the tin cups containing ice water maintained at $5^{\circ}$ Cent. ( $4 \mathrm{I}^{\circ} \mathrm{Fahr}$.), and left in this bath for ${ }_{5} 5$ minutes. Meanwhile, the other cup shall be filled about three-fourths full of water and placed on the tripod, and the water shall be heated to any temperature desired for the test. This temperature shall be accurately maintained, and shall at no time throughout the entire test be allowed to vary more than $0.5^{\circ}$ Cent. $\left(0.9^{\circ} \mathrm{Fahr}\right.$.) from the temperature selected. After the material to be tested has been kept in the ice water for I 5 minutes, the collar and contents shall be removed from the plate and screwed into the aluminum float, which shall then be immediately floated in the warmed bath. As the plug of bituminous material becomes warm and fluid, it is gradually forced upward and out of the collar, until water gains entrance to the saucer and causes it to sink.

The time, in seconds, between placing the apparatus on the water and when the float sinks shall be taken as a measure of the consistency of the material under examination. 


\section{Penetration Test}

The penetration test for determining the consistency of a material shall be made by measuring the distance a weighted needle will penetrate into the material at a given temperature. A standard No. 2 cambric needle, weighted with roo grams, shall be used, except as noted below, and the depth of penetration shall be determined on the bituminous material maintained at $25^{\circ}$ Cent. $\left(77^{\circ} \mathrm{Fahr}\right.$.) while the load is applied for 5 seconds. When the penetration test, made as above described, will give a result of less than Io or more than 350 , the loading and time shall be changed to 200 grams for I minute, and 50 grams for 5 seconds, respectively. The penetration test shall also be made on the bituminous material under the following conditions whenever practicable: Penetration at $4^{\circ}$ Cent. $\left(39^{\circ}\right.$ Fahr.) with a weight of 200 grams for I minute; penetration at $46^{\circ}$ Cent. ( $115^{\circ}$ Fahr.) with a weight of 50 grams for 5 seconds. The loading time and temperature shall be reported with the resulting penetration in every case. The unit of penetration shall be reported as $0.1 \mathrm{~mm}$.

The penetration test is made as follows:

The sample of the material to be tested shall first be warmed just sufficiently to flow freely, stirred thoroughly, and poured into a flat-bottomed tin box, $5.715 \mathrm{~cm}$. (2.25 inches) in diameter, and with sides about $3.810 \mathrm{~cm}$. (I.5 inches) in height. The box and contents, after cooling in the air in the laboratory for ro minutes, shall be immersed in ice water for 20 minutes, and shall then be placed in water maintained at the temperature at which the material is to be tested, and allowed to remain immersed for 2 hours, during which period the water containing the sample shall be maintained at the prescribed temperature accurately and constantly. The sample, in a glass cup and covered with as much water at the temperature at which the material is to be tested as may be convenient without spilling, shall now be removed to the penetrometer. The needle shall have been firmly fixed in the machine and shall now be lowered with its holder until the point of the needle almost touches the surface of the sample. 
It shall then be cautiously brought down until the point of the needle just comes in contact with the surface of the sample, as will best be seen by having a light placed in such a way that on looking through the sides of the glass cup the needle will be reflected from the surface of the sample. After thus setting the needle, the rod connected with the recording dial shall be slowly lowered until the foot of the rod shall rest on the head of that part of the penetrometer carrying the needle, and a reading of the dial shall be taken, or the dial shall be adjusted to read at a convenient figure, such as o or Ioo.

Simultaneously noting the time and releasing the needle plunger, which shall have been previously weighted properly for the particular conditions above mentioned, the needle shall be allowed to act freely for exactly 5 seconds, as determined by a pendulum or by a chronometer, when it shall be stopped. The rod shall then be lowered until it rests on the head of the part of the instrument carrying the needle, and the difference between the first and second readings of the dial shall be taken as the distance penetrated by the needle, or the penetration.

Owing to the susceptibility of certain bituminous materials to slight changes in temperature, the water bath must be maintained accurately at the desired temperature both before and during the test, and, if the room temperature differs greatly from that of the bath, the water in the glass cup shall be renewed from the bath after each trial. An average of from three to five trials, which should not differ from one another more than three units, shall be taken as the penetration of the sample.

The needle shall be cleaned thoroughly by wiping with a dry cloth before and after each trial. The point of the needle should be examined with a magnifying glass from time to time to see if it has become injured in any way. If it is found to be defective, the needle shall be replaced with a perfect one. Care shall be taken that the needle, in place in the machine and released for action, shall be loaded as required.

\section{Melting Point}

The material under examination shall be first melted in a 
spoon by the gentle application of heat until sufficiently fluid to pour readily. Care shall be taken that it suffers no appreciable loss by volatilization. It shall then be poured into a $12.7-\mathrm{mm}$. (0.5-inch) brass cubical mold, which shall have been amalgamated with mercury and shall be placed on an amalgamated brass plate. The brass may be amalgamated by washing it first with a dilute solution of mercuric chloride or nitrate, after which the mercury is rubbed into the surface. By this means the bituminous material is, to a considerable extent, prevented from sticking to the sides of the mold. The hot material shall slightly more than fill the mold, and, when cooled, the excess shall be cut off with a hot spatula.

After cooling to room temperature, the cube shall be removed from the mold and fastened on the lower arm of a No. Io wire (B. \& S. gauge), bent at right angles at one end and suspended beside a thermometer in a covered Jena glass beaker having a capacity of $400 \mathrm{cu}$. cm. (I 3.526 ounces), which shall be placed in a water bath, or, for high temperatures, a cottonseed-oil bath. The wire shall be passed through the center of two opposite faces of the cube, which shall then be suspended with its base $25.4 \mathrm{~mm}$. ( $\mathrm{I}$ inch) above the bottom of the beaker. The water or oil bath shall consist of an 800-cu. cm. (27.051 ounces) low-form Jena glass beaker suitably mounted for the application of heat from below. The beaker in which the cube is suspended shall be of the tall-form Jena type, without lip. The metal cover shall have two openings. A cork, through which passes the long arm of the wire, shall be inserted in one hole and the thermometer in the other. The bulb of the thermometer shall be just level with the cube and at an equal distance from the side of the beaker. In order that a reading of the thermometer may be made, if necessary, at the point which passes through the cover, the hole shall be triangular and covered with an ordinary object glass through which the stem of the thermometer may be seen. Readings made through this glass shall be calibrated to the angle of observation, which may be made constant by sighting always from the front edge of the opening to any given point on the stem of the thermometer below the cover. 
After the test specimen shall have been placed in the apparatus, the liquid in the outer vessel shall be heated in such a manner that the thermometer registers an increase of $5^{\circ}$ Cent. ( $9^{\circ}$ Fahr.) per minute. The temperature at which the bituminous material touches a piece of paper placed in the bottom of the beaker shall be taken as the melting point. Determinations made in the manner described shall not vary more than $2^{\circ}$ Cent. $\left(3.6^{\circ} \mathrm{Fahr}\right.$.) for successive trials on the same material: At the beginning of this test the temperature of both bituminous material and bath shall be approximately at $25^{\circ}$ Cent. ( $77^{\circ}$ Fahr.).

\section{Loss ON Evaporation}

Fifty grams of the material shall be heated in a flat-bottomed dish, $5.715 \mathrm{~cm}$. (2.25 inches) in diameter and with sides about $3.810 \mathrm{~cm}$. (i. 5 inches) high for a total of 5 hours in three successive periods of $3, \mathrm{I}$, and $\mathrm{I}$ hours, respectively, in a wellventilated oven, the interior of which shall be maintained at a uniform and constant temperature of $163^{\circ}$ Cent. ( $325^{\circ}$ Fahr.). The oven temperature shall be controlled by any thermo-regulator effective within $2^{\circ}$ Cent. ( $3.6^{\circ}$ Fahr.), and shall be brought to its full temperature before the material is introduced. The dish shall be level, and its contents, without removal from the oven, shall be stirred thoroughly for I minute between the successive periods mentioned. In preparing the residue for the penetration test, it shall first be heated, and thoroughly stirred while cooling.

\section{Distillation}

(Method recommended by the Sub-Committee on Distillation of the American Society for Testing Materials. Note: Equivalents in English units have been added by the Special Committee on Materials for Road Construction.)

Sampling.-The sample as received shall be thoroughly stirred and agitated, warming, if necessary, to insure a complete mixture before the portion for analysis is removed.

Dehydration.--If the presence of water is suspected, or known, 
the material shall be dehydrated before distillation. About $500 \mathrm{cu} . \mathrm{cm}$. ( 16.907 ounces) of the material is placed in an 800-cu. $\mathrm{cm}$. (27.05I ounces) copper still provided with a distilling head connected with a water-cooled condenser. A ring burner is used, starting with a small flame at the top of the still, and gradually lowering it, if necessary, until all the water has been driven off. The distillate is collected in a $200-\mathrm{cu}$. cm. separatory funnel with the tube cut off close to the stop-cock. When all the water has been driven over and the distillate has settled out, the water is drawn off and the oils are returned to the residue in the still. The contents of the still shall have cooled to below $100^{\circ}$ Cent. (2 $12^{\circ} \mathrm{Fahr}$.) before the oils are returned, and they shall be well stirred and mixed with the residue.

Apparatus.-The apparatus shall consist of the following standard parts:

(a) Flask.-The distillation flask shall be a 250-cu. $\mathrm{cm}$. Engler distilling flask, having the following dimensions:

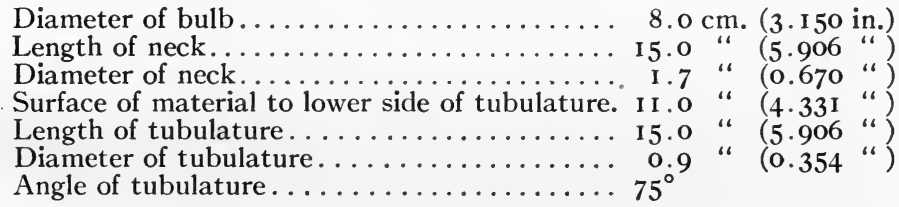

A variation of 3 percent from the foregoing measurements will be allowed.

(b) Thermometer.-The thermometer shall be of hardened glass, filled with carbon dioxide under pressure, and provided with an expansion chamber at the top; it shall read to $450^{\circ}$ Cent. $\left(842^{\circ} \mathrm{Fahr}\right.$.), shall be graduated in single degrees, centigrade, and shall have the following dimensions:

Diameter of stem......... 6.75 to $7.25 \mathrm{~mm}$. ( 0.266 to 0.286 in.) Length of thermometer...... " 335 " 350 " (13.189 "13.780") Length from $0^{\circ}$ to $450^{\circ}$ marks.. 285 " 300 " (II.22I " II.8II")

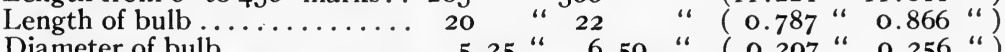
Diameter of bulb......... 5.25 “ 6.50 “ $(0.207$ “ 0.256 “)

It shall rise from $15^{\circ}$ to $95^{\circ} \mathrm{Cent}$. ( $59^{\circ}$ to $203^{\circ} \mathrm{Fahr}$.) in not less than 3 seconds nor more than 5 seconds when plunged into boiling water. 
The thermometer shall be set up as for the distillation test, using water, naphthalene, and dimethylamine as distilling liquids. The correctness of the thermometer shall be checked at $0^{\circ}$ Cent. $\left(32^{\circ}\right.$ Fahr. $)$ and $100^{\circ}$ Cent. (212 ${ }^{\circ}$ Fahr.) after each third distillation until seasoned.

(c) Condenser.-The condenser tube shall have the following dimensions:

Length

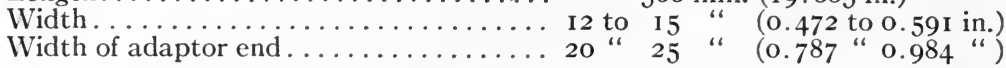
$500 \mathrm{~mm}$. (19.685 in.)

(d) Stands.-Two iron stands shall be provided, one with a universal clamp for holding the condenser, and one with a light grip arm with a cork-lined clamp for holding the flask.

(e) Burner and Shield.-A Bunsen burner shall be provided, with a tin shield, $20 \mathrm{~cm}$. (7.784 inches) long and $9 \mathrm{~cm} .(3.543$ inches) in diameter. The shield shall have a small hole through which to observe the flame.

( $f$ ) Cylinders. - The cylinders used in collecting the distillate shall have a capacity of $25 \mathrm{cu}$. cm. ( 0.845 ounces), and shall be graduated in tenths of a cubic centimeter.

Setting up the Apparatus.-The apparatus shall be set up, the thermometers being placed so that the top of the bulb is opposite the middle of the tubulature. All connections shall be tight.

Method.-One hundred cubic centimeters (3.38I ounces) of the dehydrated material to be tested shall be placed in a tared flask and weighed. After adjusting the thermometer, shield, condenser, etc., the distillation is commenced, the rate being regulated so that I $\mathrm{cu} . \mathrm{cm}$. (0.034 ounce) passes over every minute. The receiver is changed as the mercury column just passes the fractionating point.

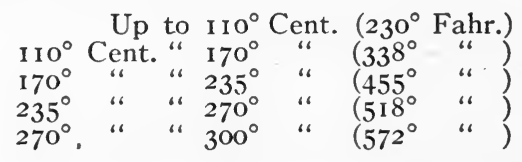

To determine the quantity of residue, the flask is weighed again when distillation is complete. During the distillation the 
condenser tube shall be warmed when necessary, in order to prevent the deposition of any sublimate. The percentages of fraction should be reported, both by weight and by volume.

\section{Ductility}

A briquette of the material to be tested shall be formed by pouring the molten material into a briquette mold. The dimensions of the briquette shall be: $\mathrm{I} \mathrm{cm}$. ( 0.394 inch) in thickness throughout its entire length; distance between the clips or end pieces, $3 \mathrm{~cm}$. ( $\mathrm{x} . \mathrm{I} 8 \mathrm{I}$ inch); width of asphalt cement section at mouth of clips, $2 \mathrm{~cm}$. ( 0.787 inch); width at minimum crosssection, half way between clips, I $\mathrm{cm}$. ( $0.394 \mathrm{inch})$. The center pieces are removable, the briquette mold being held together during molding with a clamp or wire.

The molding of the briquette shall be done as follows: The two center sections shall be well amalgamated to prevent the asphalt cement from adhering to them, and the briquette mold shall then be placed on a freshly amalgamated brass plate. The asphalt cement to be tested, while in a molten state, shall be poured into the mold, a slight excess being added to allow for shrinkage on cooling. When the asphalt cement in the mold is nearly cool, the briquette shall be cut off level, with a warm knife or spatula. When it is thoroughly cooled to the temperature at which it is desired to make the test, the clamp and the two side pieces are removed, leaving the briquette of asphalt cement held at each end by the ends of the mold, which now play the part of clips. The briquette shall be kept in water for 30 minutes at $4^{\circ}$ Cent. ( $39^{\circ}$ Fahr.) or $25^{\circ}$ Cent. ( $77^{\circ}$ Fahr.) before testing, dependent on the temperature at which the ductility is desired. The briquette with the clips attached shall then be placed in a "ductility test machine" filled with water at one of the above temperatures to a sufficient height to cover the briquette not less than $50 \mathrm{~mm}$. (1.969 inch). This machine consists of a rectangular water-tight box, having a movable block working on a worm-gear from left to right. The left clip is held rigid by placing its ring over a short metal peg provided for this pur- 
pose; the right clip is placed over a similar rigid peg on the movable block. The movable block is provided with a pointer which moves along a centimeter scale. Before starting the test, the centimeter scale is adjusted to the pointer at zero. Power is then applied by the worm-gear pulling from left to right at the uniform rate of $5 \mathrm{~cm}$. ( 1.969 inches) per minute. The distance, in centimeters, registered by the pointer on the scale at the time of rupture of the thread of asphalt cement shall be taken as the ductility of the asphalt cement.

\section{Solubility in Petroleum Naphtha, and Character of Residue on Glass}

Two grams of the material shall be placed in a 4-ounce oilsample bottle, made up to roo cu. cm. (3.38I ounces) with $88^{\circ}$ Baumé petroleum naphtha (boiling point between $40^{\circ}$ Cent. ( $104^{\circ}$ Fahr.) and $55^{\circ}$ Cent. ( $13 \mathrm{I}^{\circ}$ Fahr.), and the whole well shaken until the sample is digested. The bottle shall then be centrifugalized for ro minutes, $50 \mathrm{cu}$. cm. (I.69I ounces) withdrawn into a weighed flask, the naphtha distilled off by a water bath, and the residue weighed. From this weight the percentage of solubility shall be calculated.

Although there is no generally accepted method of determining the stickiness or oiliness of bituminous materials, except by the unsatisfactory method of handling, a test which has been used to a limited extent, and is based on the character of the residue on glass, appears to the Committee to give promise. This test is made as follows:

One-half gram of the residue obtained as just specified shall then be placed in the center of a circular glass disk, 32.258 sq. $\mathrm{cm}$. ( $5 \mathrm{sq}$. inches) in area, and a similar disk shall be imposed upon it. By warming and pressure of the fingers the material shall be as evenly distributed as practicable over the adjacent surfaces of the disks, and the disks with the material between them shall then be stored under a weight of $\mathrm{I} \mathrm{kg}$. and at a temperature of $25^{\circ}$ Cent. ( $77^{\circ} \mathrm{Fahr}$.) for at least 2 hours. The disks shall then be pulled apart horizontally and in a direction truly parallel to. 
their facial diameters at a regular rate of movement of $2.540 \mathrm{~cm}$. ( $\mathrm{r}$ inch) per minute, the maximum stress, in grams, required being recorded and reported.

\section{Fixed Carbon}

One gram of the bituminous material shall be placed in a platinum crucible weighing between 20 and 30 grams, between 28 and $38 \mathrm{~mm}$. (1.102 and r.496 inches) in height, and having a tightly fitting cover provided with a flange about $4 \mathrm{~mm}$. (o.157 inch) in depth. The crucible and its contents shall then be heated, first gently and then more severely, until no smoke or flame shall issue between the crucible and the lid. It shall then be placed in the full flame of a Bunsen burner for 7 minutes, holding the cover down with the end of a pair of tongs until the most volatile products shall have been burned off. The crucible shall be supported on a platinum triangle with the bottom 6 to $8 \mathrm{~cm}$. (2.362 to 3.150 inches) above the top of the burner. The flame shall be fully $20 \mathrm{~cm}$. ( 7.874 inches) high when burning free, and the determination shall be made in a place free from drafts. The upper surface of the cover shall burn clear, but the under surface may or may not be covered with carbon, dependent on the character of the bituminous material. The crucible shall be removed to the desiccator, and, when cool, shall be weighed, after which the cover shall be removed and the crucible placed in an inclined position over the Bunsen burner and ignited until nothing but ash remains. Any carbon deposited on the cover shall also be burned off. The weight of ash remaining shall be deducted from the weight of the residue after the first ignition of the sample. The resulting weight is that of the fixed carbon, which shall be calculated on the basis of the total weight of the sample, exclusive of mineral matter.

\section{PARAFFin}

One hundred grams of the material shall be distilled rapidly in a retort to a dry coke. Five grams of the distillate shall 
then be thoroughly mixed in a $60 \mathrm{cu} . \mathrm{cm}$. (2.029 ounce) flask with $25 \mathrm{cu}$. cm. ( 0.845 ounce) of Squibbs' absolute ether. Twentyfive cu. cm. ( 0.845 ounce) of Squibbs' absolute alcohol shall then be added, and the flask packed closely in a freezing mixture of finely crushed ice and salt for at least 30 minutes. The precipitate shall be filtered out quickly with a suction pump, using a No. 575 C. S. and S. $9 \mathrm{~cm}$. hardened filter paper. The flask and precipitate shall then be rinsed and washed with a mixture of equal parts of Squibbs' alcohol and ether cooled to $-\mathrm{I} 7^{\circ}$ Cent. ( ${ }^{\circ} \mathrm{Fahr}$.) until free from oil ( $5 \circ \mathrm{cu} . \mathrm{cm}$. ( 1.69 I ounces) of washing solution is usually sufficient). When sucked dry, the filter paper shall be removed and the waxy precipitate transferred to a small glass disk and evaporated on a steam bath. The residue (paraffin) remaining on the disk shall be weighed, and from this weight the percentage on the original 5 -gram sample shall be calculated.

(Note: Although the foregoing method is the one in general use, the following modification is believed by the Committee to promise accurate results and to merit thorough trial.)

One hundred grams of the material shall be distilled rapidly in a retort to dry coke. The distillate shall then be thoroughly mixed. A 5-gram sample of the distillate shall be placed in a tared $60 \mathrm{cu} . \mathrm{cm}$. (2.029 ounce) flask with $25 \mathrm{cu} . \mathrm{cm} .(0.845$ ounce) of Squibbs' ether. Twenty-five cubic centimeters ( 0.845 ounce) of Squibbs' alcohol shall be added, after which the mixture shall be shaken well and the flask packed closely in a freezing mixture of finely crushed ice and salt for at least 30 minutes. Without removing the flask from the freezing mixture, the solvent shall be sucked from the precipitated paraffin by using a tube connected with the filter pump, the end of the tube being covered with an accurately weighed tuft of absorbent cotton. When the solvent is all removed, the flask shall be taken from the freezing mixture and the cotton tuft pushed off the tube into the flask. The waxy precipitate shall be dissolved, with the tuft of cotton, in $25 \mathrm{cu}$. cm. ( 0.845 ounce) of Squibbs' absolute ether. Twenty-five cubic centimeters ( 0.845 ounce) of Squibbs' absolute alcohol shall then be added and the flask placed in the freezing mixture again for 30 minutes. The 
solvent shall then be removed with the pump and tube as described previously, keeping the flask in the freezing mixture. The second cotton tuft shall be pushed into the flask. The flask and contents shall then be placed in the drying oven at $100^{\circ}$ Cent. (21 $2^{\circ}$ Fahr.) until constant weight shall be reached. This weight, less the weight of the cotton used and less the weight of the tared flask, is the weight of the paraffin. Calculate the weight of the paraffin to a percentage of the original material. 


\section{APPENDIX III}

\section{TESTS OF NON-BITUMINOUS HIGHWAY MATERIALS}

Methods for performing tests to determine the physical properties of non-bituminous highway materials which have been adopted by the American Society for Testing Materials are designated thus, *; those proposed by the Committee on "Standard Tests for Road Materials" (Committee D-4) of the American Society for Testing Materials have been noted thus, $\dagger$; those proposed by the Committee on "Standard Specifications for Brick" (Committee C-3) of the American Society for Testing Materials have been indicated thus, $\ddagger$; and those recommended by the United States Office of Public Roads and Rural Engineering have been indicated thus, $\dagger \dagger$.

\section{Apparent Specific Gravity of Rock $\dagger$}

"The apparent specific gravity of rock shall be determined by the following method: First, a sample weighing between 29 and $3 \mathrm{I}$ grams, approximately cubical in shape, shall be dried in a closed oven for $\mathrm{I}$ hour at a temperature of $110^{\circ} \mathrm{C}$. $\left(230^{\circ} \mathrm{F}\right.$.) and then cooled in a desiccator for I hour; second, the sample shall be rapidly weighed in air; third, trial weighings in air and in water of another sample of approximately the same size shall be made in order to determine the approximate loss in weight on immersion; fourth, after the balances shall have been set at the calculated weight, the first sample shall be weighed as quickly as practicable in distilled water having a temperature of $25^{\circ} \mathrm{C}$. $\left(77^{\circ} \mathrm{F}\right.$.); fifth, the apparent specific gravity of the sample shall be calculated by the following formula:

$$
\text { Apparent specific gravity }=\frac{W}{W-W_{1}}
$$

in which $W=$ the weight in grams of the sample in air and $W_{1}=$ the weight in grams of the sample in water just after 
immersion. Finally, the apparent specific gravity of the rock shall be the average of three determinations, made on three different samples according to the method above described."

Apparent Specific Gravity of Sand, Stone Scrfenings, oR Other Fine Highway Material

Apparatus. The determination shall be made with a Jackson specific gravity apparatus, which shall consist of a burette, with graduations reading to 0.0 I in specific gravity, about $23 \mathrm{~cm}$. (9 inches) long and with an inside diameter of about $0.6 \mathrm{~cm}$. ( 0.25 inch), which shall be connected with a glass bulb approximately $13 \mathrm{~cm}$. ( 5.5 inches) long and $4.5 \mathrm{~cm}$. ( 1.75 inches) in diameter, the glass bulb being of such size that from a mark on the neck at the top to a mark on the burette just below the bulb the capacity is exactly r $80 \mathrm{cu} . \mathrm{cm}$.; and an Erlenmeyer flask which shall contain a hollow ground glass stopper having the neck of the same bore as the burette and a capacity of exactly $200 \mathrm{cu} . \mathrm{cm}$. up to the graduation on the neck of the stopper.

Method of Determination. The method shall consist of, first, drying at not over $110^{\circ} \mathrm{C}$. $\left(230^{\circ} \mathrm{F}\right.$.) to a constant weight a sample weighing about 55 grams; second, weigh out accurately to o.I gram, 50 grams of the dry sample and pour it into the unstoppered Erlenmeyer flask; third, fill the bulb and burette with kerosene, leaving just space enough to take the temperature by introducing a thermometer through the neck; fourth, remove the thermometer and add sufficient kerosene to fill exactly to the mark on the neck, drawing off any excess by means of the burette; fifth, run into the flask about one-half of the kerosene in the bulb to remove air bubbles and then run in more kerosene, removing any material adhering to the neck of the flask until the kerosene is just below the ground glass; sixth, place the hollow ground glass stopper in position and turn it to fit tightly and then run in kerosene exactly to the $200 \mathrm{cu}$. cm. graduation on the neck, care being taken to remove all air bubbles in the flask; seventh, read the specific 
gravity from the graduation on the burette and the temperature of the oil in the flask, noting the difference between the temperature of the oil in the bulb before the determination and the temperature of the oil in the flask after the determination; eighth, make a temperature correction to the reading of the specific gravity in accordance with the table furnished by the manufacturer of the apparatus, adding the correction if the temperature of the kerosene has increased and subtracting the correction if the temperature of the kerosene has decreased.

\section{Absorption of Water per Cubic Foot of Rock $\dagger$}

"The absorption of water per cubic foot of rock shall be determined by the following method: First, a sample weighing between 29 and $3^{\mathrm{I}}$ grams, and approximately cubical in shape, shall be dried in a closed oven for I hour at a temperature of $110^{\circ}$ C. $\left(230^{\circ}\right.$ F.) and then cooled in a desiccator for I hour; second, the sample shall be rapidly weighed in air; third, trial weighings in air and in water of another sample of approximately the same size shall be made in order to determine the approximate loss in weight on immersion; fourth, after the balances shall have been set at the calculated weight, the first sample shall be weighed as quickly as possible in distilled water having a temperature of $25^{\circ} \mathrm{C}$. $\left(77^{\circ} \mathrm{F}\right.$.); fifth, allow the sample to remain 48 hours in distilled water maintained as nearly as practicable at $25^{\circ} \mathrm{C}$. $\left(77^{\circ} \mathrm{F}\right.$.) at the termination of which time bring the water to exactly this temperature and weigh the sample while immersed in it; sixth, the number of pounds of water absorbed per cubic foot of the sample shall be calculated by the following formula:

Pounds of water absorbed per cubic foot $=\frac{W_{2}-\dot{W}_{1}}{W-W_{1}} \times 62.24$

in which $W=$ the weight in grams of sample in air, $W_{1}=$ the weight in grams of sample in water just after immersion, $W_{2}=$ the weight in grams of sample in water after 48 hours immersion, and $62.24=$ the weight in pounds of a cubic foot of dis- 
tilled water having a temperature of $25^{\circ} \mathrm{C} .\left(77^{\circ} \mathrm{F}\right.$. $)$. Finally, the absorption of water per cubic foot of the rock, in pounds, shall be the average of three determinations made on three different samples according to the method above described."

\section{Abrasion Test for Rock or SlaG*}

"The machine shall consist of one or more hollow iron cylinders closed at one end and furnished with a tightly fitting iron cover at the other; the cylinders to be $20 \mathrm{~cm}$. in diameter and $34 \mathrm{~cm}$. in depth, inside. These cylinders are to be mounted on a shaft at an angle of 30 degrees with the axis of rotation of the shaft, see Fig. 60 .

"At least 30 pounds of coarsely broken stone shall be available for a test. The rock to be tested shall be broken in pieces as nearly uniform in size as possible, and as nearly $5^{\circ}$ pieces as possible shall constitute a test sample. The total weight of rock in a test shall be within Io grams of 5 kilograms. All test pieces shall be washed and thoroughly dried before weighing. Ten thousand revolutions, at the rate of between 30 and 33 to the minute, shall constitute a test. Only the percentage of material worn off which will pass through a $0.16 \mathrm{~cm}$. $\left(\mathrm{I}_{10} / \mathrm{inch}\right)$ mesh sieve shall be considered in determining the amount of wear. This may be expressed either as the percentage of the 5 kilograms used in the test, or the French coefficient, which is in more general use, may be given, that is, coefficient of wear $=20 \times \frac{20}{w}=\frac{400}{w}$, where $w$ is the weight in grams of the detritus under $0.16 \mathrm{~cm}$. $(\mathrm{I} / \mathrm{I} 6 \mathrm{inch})$ in size per kilogram of rock used."

\section{Abrasion Test for Gravel}

The test for abrasion of gravel shall be made with a Deval abrasion machine, see Fig. 6o, which shall meet the following specifications: the machine shall consist of one or more hollow iron cylinders, the inside dimensions of each of which shall be $20 \mathrm{~cm}$. ( 7.87 inches) in diameter and $34 \mathrm{~cm}$. ( 13.39 inches) in 
depth; the cylinders shall be closed at one end and furnished with a tightly fitting iron cover at the other end, and be mounted on a shaft at an angle of 30 degrees with the axis of rotation of the shaft.

A charge of gravel shall consist of pieces which shall pass a screen having circular openings $5.08 \mathrm{~cm}$. (2 inches) in diameter and be retained on a screen having circular openings $1.27 \mathrm{~cm}$. ( 0.5 inches) in diameter. The total weight of gravel in a charge shall be within Io grams of 5 kilograms. The gravel to compose a charge shall be washed, and dried in a closed oven for I hour at a temperature within 5 degrees of $110^{\circ} \mathrm{C}$. $\left(230^{\circ} \mathrm{F}\right.$.). The charge of gravel shall be placed in one cylinder of the machine, which shall be rotated at a rate of not less than 30 nor more than 33 revolutions per minute. Ten thousand revolutions shall constitute a test. The percentage of material worn off which will pass through a sieve, having openings of $0.16 \mathrm{~cm}$. (I/r6 inch), shall be considered the amount of wear of the charge of gravel. The loss by abrasion, determined as stated, shall be expressed in terms of the percentage of the total weight of the charge of gravel.

\section{Toughness Test for Rock, Slag, or Similar Material*}

"I. Test pieces may be either cylinders or cubes, $25 \mathrm{~mm}$. in diameter, and $25 \mathrm{~mm}$. in height, cut perpendicular to the cleavage of the rock. Cylinders are recommended as they are cheaper and more easily made.

"2. The testing machine, see Fig. 62, shall consist of an anvil of 50 kilograms weight, and placed on a concrete foundation. The hammer shall be of 2 kilograms weight, and dropped upon an intervening plunger of I kilogram weight, which rests on the test piece. The lower or bearing surface of this plunger shall be of spherical shape having a radius of $\mathrm{I} \mathrm{cm}$. This plunger shall be made of hardened steel, and pressed firmly upon the test piece by suitable springs. The test piece shall be adjusted, so that the center of its upper surface is tangent to the spherical end of the plunger. 
"3. The test shall consist of a I $\mathrm{cm}$. fall of the hammer for the first blow, and an increased fall of $\mathrm{I} \mathrm{cm}$. for each succeeding blow until failure of the test piece occurs. The number of blows necessary to destroy the test piece is used to represent the toughness, or the centimeter-grams of energy applied may be used."

\section{Hardness Test fOR Rock or Slag $\dagger$}

"The test for the hardness of rock, i. e., the resistance of its surface particles to displacement by abrasion, as determined in the Dorry machine, was developed in the French School of Bridges and Roads and is used with slight modifications at the present day.

"The Dorry machine, see Fig. 63, consists of a circular steel disk, revolving in a horizontal plane about a vertical shaft, which is driven from the pulley by means of a bevel gear. The cylindrical rock core, $25 \mathrm{~mm}$. in diameter, is cut from a specimen of rock with a diamond core drill, and the test piece is held perpendicularly against a revolving cast-steel disk under a constant pressure of I,250 grams, while standard quartz sand, between 30 and 40 mesh, is fed on the disk to act as the abrasive agent. The machine used is arranged to hold two core pieces so that two tests can be run simultaneously. At the end of $\mathrm{I}, 000$ revolutions the loss in weight is determined and the test repeated with the specimen reversed. The average loss in weight computed from the two runs is used in determining the hardness of the rock. In the earlier work the loss in length was determined from measurements taken before and after each run, and the average loss expressed in millimeters per $\mathrm{I}, \infty 00$ revolutions subtracted from 20 was given as representing the hardness of the specimen. The arbitrary constant 20 was selected with a view to giving the results of this test about the same range of variation as the French coefficient of wear described under the abrasion test. It has been found, however, that the hardest rocks lose only about $2 \mathrm{~mm}$. per I, some of the softer varieties lose considerably more than $20 \mathrm{~mm}$., 
thus giving rise to negative values in the results of the test. In order to avoid this, the following method of expressing the hardness has been adopted:

$$
\text { Hardness, } H=20-\mathrm{I} / 3 W \text {, }
$$

where $W=$ loss in grams per $\mathrm{I}, \infty 00$ revolutions."

\section{Cementation Test for Rock Powders $\dagger \dagger$}

"The following method for testing the cementing value of rock powders was devised and perfected by Mr. Logan Waller Page. One-half kilogram of the rock to be tested is broken sufficiently small to pass a $1 / 2$-inch mesh screen. This material is placed in a ball mill with about $90 \mathrm{cu}$. $\mathrm{cm}$. of water, sufficient to make a stiff paste after grinding. The material is ground by the action of tow cast-steel shot, $2 \mathrm{r} / 2$ inches in diameter and weighing about 20 pounds. Grinding is continued for $2 \frac{1}{2}$ hours at the rate of 2,000 revolutions per hour, after which the 'dough' is removed and molded into cylindrical briquettes $25 \mathrm{~mm}$. in diameter and $25 \mathrm{~mm}$. high, in a special briquette-forming machine. Five briquettes are made from each test sample and allowed to dry 20 hours in air and 4 hours in a hot-air bath at $200^{\circ} \mathrm{F}$. After cooling 20 minutes in a desiccator, they are tested by impact in a machine especially designed for the purpose, see Fig. 6r. A motor drives a cam at the rate of 60 revolutions per minute, by means of a worm gear. The rise of the cam is such as to give an effective drop of one centimeter to the hammer. The reaction of the briquette after each blow of the hammer produces a vertical movement in the end of a lever. This motion is recorded on a sheet of silicated paper wrapped around the recording drum by means of a brass point at the end of the lever. Each revolution of the cam produces a slight motion of the drum, so that the drum makes a complete revolution in Ioo revolutions of the cam. The number of blows necessary to destroy the resilience of the briquette, so that no reaction is recorded on the drum, is taken to be the cementing value of the material." 
Mechanical Analysis of Broken Stone, Broken Slag, OR GRAVEL

The method shall consist of, first, drying at not over $110^{\circ} \mathrm{C}$. $\left(230^{\circ} \mathrm{F}\right.$.) to a constant weight a sample weighing in pounds six times the diameter in inches of the largest holes required; second, passing the sample through such of the following sized screens having circular openings as are required or called for by the specifications, screens to be used in the order named: $8.89 \mathrm{~cm}$. (3 $3 / 2$ inches), $7.62 \mathrm{~cm}$. (3 inches), $6.35 \mathrm{~cm}$. (21/2 inches), $5.08 \mathrm{~cm}$. (2 inches), $3.8 \mathrm{r} \mathrm{cm}$. ( $\mathrm{I} / 2$ inches), $3.18 \mathrm{~cm}$. (I $1 / 4$ inches), $2.54 \mathrm{~cm}$. (I inch), I.90 cm. ( $3 / 4$ inch), I. $27 \mathrm{~cm}$. $(\mathrm{r} / 2$ inch), and $0.64 \mathrm{~cm}$. ( $1 / 4$ inch); third, determining the percentage by weight retained on each screen; fourth, recording the mechanical analysis in the following manner:

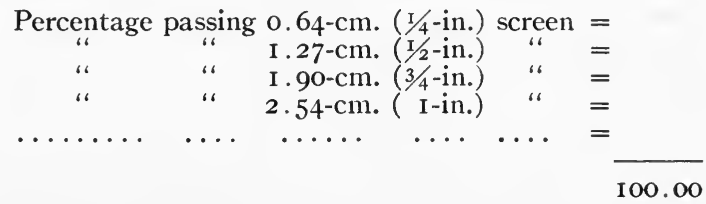

\section{Mechanical Analysis of Sand or Other Fine Highway Material}

The method shall consist of, first, drying at not over $110^{\circ} \mathrm{C}$. $\left(230^{\circ} \mathrm{F}\right.$.) to a constant weight a sample weighing roo grams; second, passing the sample through each of the following mesh sieves (American Society for Testing Materials standard sieves), the sieves to be used in the order named:

\begin{tabular}{|c|c|c|}
\hline Meshes per linear & \multicolumn{2}{|c|}{ Diameter of Wire } \\
\hline Inch $(2.54 \mathrm{~cm})$. & Ins. & $\mathrm{Mm}$. \\
\hline 1о $\ldots \ldots \ldots$ & 0.027 & $0.685^{8}$ \\
\hline $20 \ldots$ & 0.0165 & $0.419 \mathrm{I}$ \\
\hline 30. & o.1375 & 0.34925 \\
\hline -1, & 0.01025 & 0.26035 \\
\hline 50. & 0.009 & 0.22865 \\
\hline 80 . & 0.00575 & 0.1460 \\
\hline$\ldots \ldots \ldots \ldots \ldots$ & 0.0045 & O. I I 43 \\
\hline & 0.00235 & 0.05969 \\
\hline
\end{tabular}

third, determining the percentage by weight retained on each sieve, the sifting being continued on each sieve until less than 
I percent of the weight retained on each sieve shall pass through the sieve during the last minute of sifting; fourth, recording the mechanical analysis in the following manner:

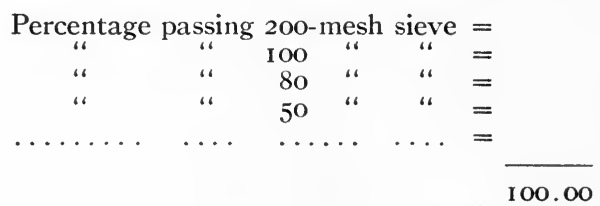

Mechanical Analysis of Mixtures of Sand or Other Fine Highway Material with Broken Stone, Broken Slag, OR GRAVEL

The method shall consist of, first, drying at not over $110^{\circ} \mathrm{C}$. $\left(230^{\circ} \mathrm{F}\right.$.) to a constant weight a sample weighing in pounds six times the diameter in inches of the largest holes required; second, separating the sample by the use of a ro-mesh sieve (American Society for Testing Materials standard sieve); third, examining the portion retained on the ro-mesh sieve in accordance with the method for making a "Mechanical Analysis of Broken Stone, Broken Slag, or Gravel"; fourth, examining the portion passing the Io-mesh sieve in accordance with the method for making a "Mechanical Analysis of Sand or Other Fine Highway Material"; fifth, recording the mechanical analysis in the following manner:

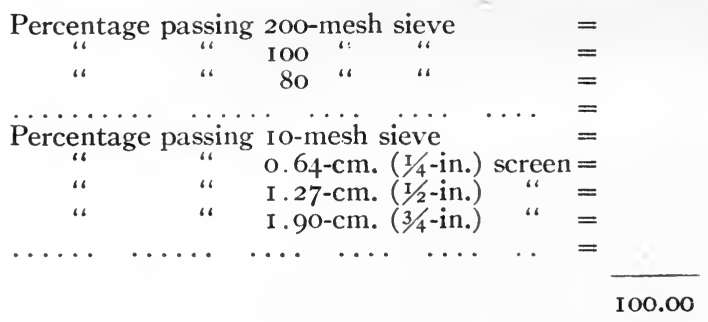

\section{Voids in Mineral Aggregates $\dagger$}

"The voids in mineral aggregates shall be determined by the Cone Specific Gravity method. In the method of making the 
determination of voids, as hereinafter described, there shall be used a truncated cone made of No. 8 B. \& S.-gauge galvanized steel with calked seams and having the following dimensions: overall diameter of bottom, $25.4 \mathrm{~cm}$. (Io inches); overall height, $25.4 \mathrm{~cm}$. (Io inches); inside diameter of opening, $7.6 \mathrm{~cm}$. (3 inches). The test shall be made in the following manner: First, thoroughly mix the aggregate by rolling on paper; second, fill the cone with aggregate, avoiding segregation; third, compact aggregate in cone by oscillation on edge of cone resting on wooden floor, wooden box, or block of wood and use cotton waste pressed against surface of aggregate to prevent segregation during oscillation; fourth, continue to add aggregate and compact until the cone is full of thoroughly compacted aggregate, which process will require from 300 to 500 oscillations; fifth, weigh cone with aggregate; sixth, weigh cone empty; seventh, weigh cone full of clean water; eighth, determine the specific gravity of aggregate; ninth, the percentage of voids in the aggregate shall be calculated by the following formula:

$$
\text { Percentage of Voids }=\left(\mathrm{I}-\frac{(C-A)}{(B-A) D}\right) \text { г०० }
$$

in which $A=$ the weight in grams of the cone; $B=$ the weight in grams of the cone filled with water; $C=$ the weight in grams of the cone filled with compacted aggregate; $D=$ the specific gravity of the aggregate."

\section{Rattler Test for Paving Brick $\ddagger$}

"Construction of the Rattler. General Design. The machine shall be of good mechanical construction, self-contained, and shall conform to the following details of material and dimensions, and shall consist of barrel, frame, and driving mechanism as herein described. (Note by Author. "The

$\ddagger$ Abstracts from "Proposed Standard Specifications for Paving Brick" recommended for adoption at the 1915 Annual Meeting of the American Society for Testing Materials by Committee C-3 on "Standard Specifications. for Brick." 
Standard Rattler for Testing Paving Brick" proposed by The National Paving Brick Manufacturers' Association on December I, I9I0, meets the requirements of the specifications of Committee C-3.)

"The Barrel. The barrel of the machine shall be made up of the heads, headliners, staves, and stave-liners."

"The Frame and Driving Mechanism. The barrel shall be mounted on a cast-iron frame of sufficient strength and rigidity to support it without undue vibration. It shall rest on a rigid foundation with or without the interposition of wooden plates, and shall be fastened thereto by bolts at not less than four points. It shall be driven by gearing whose ratio of driver to driven is not less than one to four."

"The Abrasive Charge. The abrasive charge shall consist of cast-iron spheres of two sizes. When new, the larger spheres shall be 3.75 inches in diameter and shall weigh approximately 7.5 pounds $(3.40 \mathrm{~kg}$.) each. Ten spheres of this size shall be used. These shall be weighed separately after each ten tests, and if the weight of any large sphere falls to 7 pounds (3.I $75 \mathrm{~kg}$.), it shall be discarded and a new one substituted; provided, however, that all of the large spheres shall not be discarded and substituted by new ones at any single time, and that so far as possible the large spheres shall compose a graduated series in various stages of wear. When new, the smaller spheres shall be 1.875 inches in diameter and shall weigh approximately 0.95 pound $(0.43 \mathrm{~kg}$.) each. In general, the number of small spheres in a charge shall not fall below 245 nor exceed 260 . The collective weight of the large and small spheres shall be as nearly 300 pounds as possible. No small sphere shall be retained in use after it has been worn down so that it will pass a circular hole $I .75$ inches in diameter, drilled in an iron plate $\mathrm{I} / 4$ inch in thickness, or weigh less than 0.75 pound ( $0.34 \mathrm{~kg}$.). Further, the small spheres shall be tested by passing them over the above plate or by weighing after every ten tests, and any which pass through or fall below the specified weight shall be replaced by new spheres; provided, further, that all of the small spheres shall not be rejected and replaced by new ones 
at any one time, and that so far as possible the small spheres shall compose a graduated series in various stages of wear. At any time that any sphere is found to be broken or defective it shall at once be replaced."

"Operation of the Test. The Brick Charge. The number of bricks per test shall be ten for all bricks of socalled 'block-size,' whose dimensions fall between 8 and 9 inches in length, 3 and $33 / 4$ inches in breadth, and $33 / 4$ and $4 \frac{1}{4}$ inches in thickness. No brick should be selected as part of a regular test that would be rejected by any other requirements of the specifications under which the purchase is made." (Note by Author. Each brick should be marked by small holes drilled in one of the faces of the brick. The initial weight of each brick composing the charge should be determined.)

"Speed and Duration of Revolution. The rattler shall be rotated at a uniform rate of not less than 29.5 nor more than 30.5 revolutions per minute, and I,800 revolutions shall constitute the test. A counting machine shall be attached to the rattler for counting the revolutions. A margin of not to exceed ten revolutions will be allowed for stopping. Only one start and stop per test is generally acceptable. If, from accidental causes, the rattler is stopped and started more than once during a test, and the loss exceeds the maximum permissible under the specifications, the test shall be disqualified and another made."

"The Scales. The scales must have a capacity of not less than 300 pounds, and must be sensitive to 0.5 ounce, and must be tested by a standard test weight at intervals of not less than every ten tests."

"The Results. The loss shall be calculated in percentage of the initial weight of the brick composing the charge. In weighing the rattled brick, any piece weighing less than I pound shall be rejected." (Note by Author. The loss should also be calculated in percentage of the initial weight of each brick composing the charge.) 



\section{N DE X *}

Abrasion test

Gravel, 489

Rock, I62, 489

Slag, 489

Absorption

Test for brick, 349

Test for rock, I64, 488

Test for wood block, 335

Administration

Alabama, 3 I

Boston, 37

California, 3 I

Connecticut, 3 I

Early Grecian highways, 2

Early Roman highways, 2

France, 25

Georgia, 32

Germany, 28

Great Britain, 28

Illinois, 32

Maryland, 32

Massachusetts, 33

Methods of financing, I 7

New Jersey, 34

New York, 34

Ohio, 35

Pennsylvania, 35

Providence, 38

Rhode Island, 36

St. Louis, $3^{8}$

Switzerland, 29

United States, 30

Esthetics, highways, 48

Alcatraz, 202

American highways, early

Cumberland Road, I5

Early highways, Boston, I3

Early legislation, New York, I3

Highways of Peru, I 3

Lancaster Turnpike, 14
American highways, early

Paving, I5

York Road, I 4

American Society of Civil Engineers, Special Committee on Materials for Road Construction

Bitumen and bituminous material, 195

Nomenclature, 192

Report forms, 402, 403

Tests of bituminous materials, 466-485

Traffic classification, 60

Type and blanket specifications for bituminous materials, 225

American Society of Municipal Improvements

Pressure distributors, 254

Sheet asphalt repairs, 3 IO

American Society for Testing Materials, Committee on Standard Tests for Road Materials

Abrasion test for rock, 489

Absorption of water test, 488

Distillation test, 478

Solubility in carbon disulphide test, 47 I

Specific gravity of rock, 486

Toughness test for rock, 490

Voids in mineral aggregates, 494

Ancient highways

America, I 3

Assyria, I

Britain, Io

Carthage, 2

France, 7

Greece, 2

Rome, 2

Spain, 8

* Prepared by Mr. W. C. Fry, Jr., C.E., A.M., Instructor in Highway Engineering, Polytechnic Institute of Brooklyn and Assistant Engineer with A. H. Blanchard. 
Asphalt

Alcatraz, 202

Bermudez, 199, 200

Cuban, 20I

Gilsonite, 202

Lists of tests, 2 I I, 212

Maracaibo, 20I

Mexican, 198

Oil asphalts, 204

Production of, 198-204

Rock, 196

Sources of, 196

Specification, 225

Trinidad, 199

See also Asphalt cement

Asphaltenes, $45^{2}$

Asphalt block pavement

Composition of blocks, 274,287

Cost of, 294

Manufacture of, 287

Maximum grade of, 85

Size of blocks, 274, 287

Tests of blocks, 287

See also Comparison of roads and pavements

Asphalt cement

Value of naphtha solubility test, 219

See also Sheet asphalt pavement

Asphaltic petroleums

Construction of bituminous surface with, 237

Fixed carbon in, 22 I

Methods of testing, 466- 485

Occurrence of, 204

Specific gravity of, 215

Use of, for dust prevention, 235, 236

Value of evaporation test, 220

Value of flash point test, 215

Value of naphtha solubility test, 219

See also Bituminous materials

“ " Dust prevention

Association for Standardizing Paring Specifications

Asphalt block specification, $27+$
Belgian block pavement, 363

See also Stone block pavement

Benefits of improved highways, 17

Bermudez asphalt

Analysis of, 200

Description of deposit, 199

Bins, stone, 173

Bitulithic pavement

Construction of, 274

Cost data, 293

Mineral aggregate, 275

See also Bituminous concrete pavement

Bitumen

Bitumen content, 278

Extraction of, 279

Gilsonite, 202

Test for, 218, 469

Bituminous concrete pavement

Abbott patent, 283, 284

Advantages of, 294

Asphalt block, 274, 287, 294

Bitulithic, 274, 293

Bitumen content, 278

Bituminous materials, 277

Causes of failure, 295

Classification of, 268

Cost, 277, 293

Covering, 284

Crown of, 91, 92

Development of, 267

Disadvantages of, 295

Drying aggregate, 275, 290

Excelsior pavement, 272

Extraction of bitumen, 279

Foundations, I 26, 280

Heating bituminous material, 275,28 I, 282

Limiting grades, $84^{-86}$

Mathews patent, 269

Mechanical appliances, 287-292

Mineral aggregates, 268

Mixing, 275, 282

Mixing machines, 287, 289-292

Proportions, 273-275, 282

Rolling, 270, 282

Seal coat, $283,286,287$ 
Bituminous concrete pavement

Size of aggregate, 269-27 I, 273, 274

Specifications, Rhode Island, 270

Spreading, 282

Subgrade, 280

Tarmac, 276

Thickness, 269, 270

Topeka, 273, 293

See also Comparison of roads and pavements

Bituminous gravel pavement, 260

See also Bituminous macadam pavement

“ " Comparison of roads and pavements

Bituminous macadam bavement

Advantages of, 262

Amount of bituminous material, 258-260

Applying bituminous material, 257-260

Bituminous materials used, 253

Causes of failure, 264

Cost data, 26I

Covering, 257-260

Crown of, 9I, 92, 257

Development of, 253

Disadvantages of, 263

Gladwell system, 259

Limiting grades, 84-86

Maintenance of, 26I

Modern pavement, 259

Pitchmac, 259, 260

Preparation of subgrade, 253

Repairing pot holes, 262

Rolling, 257-260

Seal coat, 257, 259

Size of stone, 254, 257-260

Thickness of courses, 254, 257260

See also Comparison of roads and pavements

Bituminous materials

Alcatraz, 202

Asphalts, I 93

Asphalt cement, 194

Bermudez asphalt, 199
Bituminous materials

California asphalt, 198, 202

Coke oven tar, 209

Creosote, 2 Io

Crude coal tar, 207

Cuban asphalt, 20I

Cut-back products, 193

Distillation test, $2 \mathrm{I} 8,478$

Ductility test, 2 I 4, 48 I

Evaporation test, 220, 478

Extraction of bitumen, 279

Fixed carbon test, 2 I 4, 22 I , 483

Flash point test, 2I3, 2I5, 468

Float test, 213, 21 7, 474

Flux, 193

Gilsonite, 202

Joint fillers, 339,358

Maracaibo asphalt, 20I

Melting point test, 2 I 3,2 I6, 476

Mexican asphalt, 198

Oil asphalts, 204

Paraffin test, 2I 4, 222, 483

Penetration test, 2I 4,475

Refined coal tar, 207

Rock asphalts, 194, 196

Solubility, carbon disulphide, 2 I 8,469

Solubility, carbon tetrachloride, 472

Solubility, 88 degree Baumé naphtha, 219,482

Specific gravity, 21 5, 466

Tars, 194, 206

Trinidad asphalt, 199

Types used, bituminous concrete, 277

Types used, bituminous macadam, 253

Types used, bituminous surfaces, 237

Viscosity test, 2I3, 472

Water gas tar, 209

Bituminous surfaces

Advantages of, 247

Amount of bituminous material, 237,239

Applying bituminous material, 239 
Bituminous surfaces

Cost of, 240

Crown of, 91, 92

Danger to fish life, 249

Development of, 227

Disadvantages of, 249

Failures, 250

Gravity vs. pressure distribution, 239

Injury to vegetation, 249

Maintenance of, 240

Materials used, 25 I

Mechanical appliances, see Distributors

On brick pavement, 360

On cement-concrete pavement, 324

Preparation of road surface, 237

Slipperiness, 249

Top dressing, 240

Use of, 237

See also Comparison of roads and pavements

Boiler, 173

Bond issues, 23

Brick

Absorption test, 349

Brick clay, 345

Brick shales, 345

Cross breaking test, 349

Manufacture, $3+5$

Rattler test, 349, 495

Repressed brick, 347

Size and character of, $34^{8}$

IVire-cut-lug, 345, 347

See also Brick pavement

Brick pavement

Asphalt filler, 354

Bituminous filler, $35^{8}$

Bituminous surface on, 360

Characteristics, 36I

Coal tar filler, 354

Cost data, $35^{8}$

Cross section of, 35I

Crown of, 91, 92, 353

Development of, 344

Expansion joints, $35+$

Foundation, 350
Brick pavement

Grout filler, 354, 359

Joint filler can, $35^{8}, 359$

Laying the brick, $35^{2}$

Maintenance of, 360

Maximum grade, $84-86$

Rolling, 353

Sand cushion, 352

Sand joint filler, 354

See also Brick

“ " Comparison of roads and pavements

Bridges

Bridge floors, 434

Concrete, 436

Concrete arches, 437 .

Concrete girders, 436

Design, 433

Formula for run-off, 422

Guard rails, 437

I-Beam, 435

Location, 433

Measurement of flow, 423

Myer's formula, 422

Observation high water, 422

Pin connected, 436

Plate girder, 435

Pony truss, 435

Reinforced concrete, 436

Riveted truss, 436

Selection of type, 433

Size drainage area, 42 I

Talbot formula, 422

Timber, 436

Types of, 432

Wearing surface, 434

British highways, ancient, Io

Broken stone

Mechanical analysis, 493

Size of, I78, 179

Tests of, see Rocks

Voids, 174, 494

Weights, I 74

See also Broken stone roads

Broken stone roads

Applying screenings, 183

Broken stone foundation, 122

Causes of wear, I 86 
Broken stone roads

Characteristics, I9I

Cost of, I 84

Cross section of, $\mathrm{I} 80$

Crown of, 9I, 92, I 80

Crushing the rock, I 68

Depth of stone, I 8 I, I 82

Effect of motor traffic on, 5I, $5^{2}$

Foundation, I 79

Hauling stone, I 8 I

History, I 75

McAdam's principles, 176

Preparation of subgrade, I 79

Quarrying the rock, I68

Ravelling, I 87

Regulating the thickness, 182

Repairing pot holes, $\mathrm{r} 88$

Resurfacing, I90

Rock classification, I 54

Rock testing, I6I, 486-492

Rollers, I 83

Rolling, I 82

Scarifiers, 190

Shoulders, I 89

Size of stone, 178

Spreading stone, I 8I

Telford foundation, I 2 I, I 79

Tresaguet's principles, I 75

V-drain foundation, I79

Voids in stone, I 74, 494

Weights of stone, 174

See also Comparison of roads and pavements

Brooms

Brass brooms, 238

Push brooms, 377

Sweeping machines, 378

Burnt clay roads, I 36

Calcium chloride, 232

California asphalt, 198, 202

Carpet

See Bituminous surfaces

\section{Car tracks}

Clearances, 442,443

Construction, 443,444

Drainage, 446

Location, 442

Rails, 443
Car tracks

Rail joints, 444

Surfacing adjacent to rails, 446448

Track foundation, 445

Width occupied by, 442, 443

Cart

See Wagon

Catch basin, 427

Cement

See Concrete

Cement-concrete pavement

Bituminous surface on, 324, 325

Blome pavement, 319

Characteristics, 327

Concrete cubes, 317

Cost data, 325

Crown of, 91, 92, 31 7

Development of, 3 I 5

Expansion joints, 320-322

Foundation, 316

Grouting method, 323

Hassam pavement, 322, 323

Ingredients, 3 I 5

Maintenance, 326

Mileage, 3 I 5

Mineral aggregates, 3 I5

Oil cement-concrete, 320

One course method, 319

Proportioning concrete, 3 I 5

Reinforced pavement, 320

Subgrade of, 316

Two course method, 319

See also Comparison of roads and pavements

Cementation test, I 62, 492

City planning

See Design

Clay

Adaptability, 129

Brick, 345

See also Soils

Clinker pavement, 373

Coal tar

Analysis of, 206

Blowing, 208

Danger to fish life, 249

Distillation, 208, 2 I 8,478 
Coal tar

Free carbon in, 206

Injury to vegetation, 249

Methods of testing, 466-485

Pitches, 208

Production of, 206

Refined tar, 207

Removing water, 207

Retorts, 207

Source of crude tar, 206, 207

Specific gravity, 21 5, 466

Tar stills, 207, 208

Cobblestone pavement, 372

Coke oven tar, 194

Manufacturr, 209

Comparison of roads and pavements

Annual cost, 396

Cost records, 400, $40 \mathrm{I}$

Effect of grade, 394

Haywood report, 393

Ideal, 390

Life of pavements, 390, 39I

Maximum grades, 393-396

Methods of comparison, 398

Noiselessness, 392

Report forms, 402, 403

Resistance to traffic, 393

Sanitary qualities, 392

Scientific comparison, 389

Slipperiness, 392

Suitability of types, 39I, 399

Concrete

Grouting method, I26, 323

In situ method, 125

Mixing, I23-I26, 3 I 7

Proportions of, 123, 315

See also Cement-concrete pavement

" " Foundation

“ " Sidewalk

Conduits

See Pipe systems

Convict labor, 18

Cost

See Material, road or pavement Crown, 91, 92

See also Road or pavement
Crushers

Bins, 173

Boiler, I 73

Elevator, 173

Engine, I73

Gyratory, 172

Jaw, 172

Screen, 173

Crushing

Crushers, I $7 \mathrm{I}$

Crushing plant, I 7 I

Cuban asphalt, 201

Culvert

Arch, 432

Cast iron pipe, 426

Concrete pipe, 427

Corrugated metal pipe, 426

Design, 424

Foundation, 425

Formula for run-off, 422

Headwalls, 425

High water mark, 422

Location of, 424

Measurement of flow, 423

Myer's formula, 422

Reinforced concrete, 430, 43 I

Selection of type, 423

Size of drainage area, $42 \mathrm{I}$

Stone box, 430

Talbot formula, 422

Timber box, 432

Vitrified pipe, 426

Cumberland Road, I5

Curbs

Concrete, 417

Cost, 4I 7, 41 8,420

Curb elevations, 87

Dimensions, 4I 7

Laying, 4I 7

Radii corners, 4I 7, 4I 8

Staking out, 74

Stone, 4I 7

Curves

Elimination of, 88

Radii of, 88, 89

Stationing, 65

Vertical, 87

Width of road on, 88 
Cut-back products, 193

Danger signs, 440

Design

City highway systems, 76

Crowns, 91, 92

Curb elevations, 87

Curves, 88

Determination of grade, 84

Determination of width, 80

Drainage, 45, I I I-I I 7

Effect, horse-drawn traffic, 50

" motor trucks, 52

“ motor vehicles, $5 \mathrm{I}$

“ traction engines, 54

Estimates, 93

Foundation, 44, I I 7

Influence of æsthetics, 48

“ of climate, 47

“ of locality, 48

" of maintenance methods, 47,48

“ of traffic, $49-63$

Loads and tire widths, 55

Location, 79

Park highway systems, 78

Scope of design, 78

State highway systems, 75

Street intersections, 87

Street systems, 75

Use of local materials, 47

Vertical curves, 87

Width, 80

Deval machine, I6I, 489

Direction signs, 440

Distance signs, 440

Distillation test, 218, 478

Distributors

Amount of pressure, 254

For spraying light oils, 234

Gravity, 24 I

Hand-drawn, 242, 243, 245

Pouring cans, 24I, 242

Pressure distributors, 244

Specifications, American Society of Municipal Improvements, 254

Ditch, I I 5, I 30

Dorry machine, I64, I66, 49 I
Drag scraper

Description, I I

Method of operation, IOI

Drainage

Blind drains, I 15

Catch-basins, 427

Concrete pipe subdrains, 427

Conditions encountered, I 12

Drop inlets, 427

Earth roads, I30, I3 I

Frost action, I 13

Gutters, I 5

Inlet castings, 429

Laying the pipe, I It

Object of, I I I

Preliminary examination, 45

Side ditches, I1 5 , I30

Size of pipe, I 3

V-drain, $12 \mathrm{I}$

Drilling, 168

Drop inlet, 427

Ductility test, 2 I 4, 48 I

Durax pavement

Foundation, 366, 370

Joint fillers, 370

Manufacture of blocks, 364

Size of blocks, 364

Dust palliatives

Calcium chloride, 232

Classification of, 23I

Definition of, 227

Emulsion, 234

Light oils and tars, 235

Use of, 230

Water, 23I

See also Dust prevention

Dust prevention

Calcium chloride, 232

Effects of dust, 228

Emulsions, 234

Formation of dust, 228

Light oils and tars, 235

Pathogenic effects of dust, 229

Preparation of road surface, 237

Use of palliatives, 230

Water, 23 I

Earthwork

Balancing cuts and fills, 85 
Earthwork

Earth shrinkage, 97

Estimating volume, 93

Grading classification, 96

Moving with drag scrapers, IOI

“ “ elevating grader,

“ “ $\quad \begin{aligned} & \mathrm{IO} 4 \\ & \text { road scrapers, } 102\end{aligned}$

“ “ wagons, 98

“ " wheel scrapers, 102

Earth road

Construction with elevating grader, 131

Cost of, 134

Cross-section of, 13 I

Crown of, 91, 130, 131

Directions for building, I 29

Drainage of, 129

Earth shrinkage, 97

Grading classification, 96

Maintenance, I37

Mileage in U. S., 128

Road drag law (Illinois), 139

Road dragging, 138

Slopes of banks, 95

Wearing course of, 132

See also Comparison of roads and pavements

Economics

Annual cost, 397

Bond issues, 23

Convict labor, i 8

Direct appropriation, 22

Direct taxation, 19

Labor tax system, i8

Private subscription, 24

See also Comparison of roads and pavements

Elevating grader

Description of, 104

Method of operation, 104

See also Earth road

Elevator, crushing plant, 173

Embankment

Construction of, 94

Shrinkage of, 97

See also Earthwork
Emulsion, 234

See also Dust prevention

Engine, crushing plant, I 73

Estimating

Balancing cuts and fills, 85

Cross-sections, 72

Earthwork, 93

See also Design

Evaporation test, 220, 478

Excelsior pavement, 272

Explosive, I 70

Fieldstone, I 60

Fixed carbon test, 2I 4, 22 I, 483

Flash point test, 2 I3, $21_{5}, 468$

Float test, 213, 217,474

Flushing

Flushing machines, 379

Hose flushing, 379

Squeegees, 379

See also Street cleaning

Flux, 193

Footway

See Sidewalk

Foundation

Bituminous concrete, 126

Broken stone, 122

Classification of, I 18

Concrete, 122

Examination, I 7

Importance of, 117

Methods of improving, 120

Over marshes, I26

Proposed by McAdam, 176

Rolling, 12 I

$$
\text { “Tresaguet, I } 75
$$

Safe loads on, 120

Soil classification, 1 1 8

Telford, 121

Use of old pavement, 126

V-drain, I 2 I

French highways, ancient

Condition of early highways, 7

Corvée system, 9

Tresaguet's method, 10

Frost, action of, II 3

See also Drainage

Gas pipes

See Pipe systems 
Joint filler

See Brick pavement

" Stone block pavement

“ Wood block pavement

Karri wood, 330

Kleinpflaster pavement

Foundation, 367

Manufacture of blocks, 364

Size of blocks, 366

Legislation, highway

Alabama, 3I

California, 31

Connecticut, 3 I

France, 25

Great Britain, 28

Illinois, 32

Loads and tire widths, 55, 56

Maryland, 32

Massachusetts, 33

New Jersey, 34

New York, 34

Ohio, 35

Pennsylvania, 35

Rhode Island, 36

Levelling

Bench marks, 68

Information desired, 68

Plotting profile, 72

Running levels, 68

See also Surveys

List of tests, 2 I I

Loads

Commerical motor trucks, 56

Heavy loads, New York City, 56

Loads on foundation, I 20

Motor car order of England limiting, 56

See also Design

Loam, I 9

Location,

Esthetics and location, 48

Bridges, 433

Culverts, 424

Pipes, see Pipe systems

Macadam road

See Broken stone road

Maintenance

See Road or pavement
Mapping

Cross-sections, 72

Drawing the grade, $8 \mathbf{5}$

Plan of road surveys, 70

Profile of road surveys, 72

Street surveys, 74

Topography, 74

Maracaibo, 201

Marl, I I 9

Marsh road, I 26

See also Earth road

McAdam

Principles of construction, I I, I 76

Mechanical analyses

Broken stone, broken slag or gravel, I 44, 493

Mixtures of sand with broken stone, broken slag or gravel, 494

Sand, 493

Medina sandstone

See Stone block pavement

Melting point tests, 213, 216, 476

Mexican asphalt, 198

Mineral aggregates

Bituminous concrete pavement, 268

Mechanical analyses, 493, 494

Voids, 494

Mixing machinery, I24, 125, 289

Mixing method

Hand mixing cement-concrete, 124

Machine mixing cement-concrete, I 24

See also Bituminous concrete pavement

“ " Sheet asphalt pavement

Motor trucks

Effect on highways, 51, $5^{2}$

Loads carried by, 56

See also Design

Muck, I I 9

National Paving Brick Manufacturers' Association

Fillers for brick pavement, 354

Foundation for brick pavement, 35 I 
Gilsonite, 202

Glossary, 45I-465

Grade

Curb, 74

Drawing, 85

Maximum, 85

Minimum, 85

Recording grade stake notes, 69 , 70

Relation grade to location, 45

Setting slope stakes, 70

Staking, 69

Vertical curves, 87

See also Design

Grader

See Elevating grader

Grading

Classification of materials, 96

Surveying for, 69

See also Earthwork

" " Earth roads

Granite

Composition of, I 57

Granite block pavement

See Stone block pavement

Gravel

Abrasion test, 489

Bank gravel, I4I

Binder in, 143

Definition of, I4I

Formation, 142

Mechanical analysis, 144, 145, 493,494

Quality of stone, I 45

Requisites, 142

Results of analysis, 145

Rolling, I 5 I

Sampling, 144

Screening, 150

Spreading, I5 I

Voids in, I 45, 494

Gravel road

Binder, 143

Cost of, 152, I 53

Cross-section of, 150

Crown, 91, 92, 146

Depth of, I46, I 48

Gravel, I4I-I 43
Gravel road

Maintenance of, 152

Mileage of, I4I

Patching, 153

Preparation of subgrade, I45

Resurfacing, I 53

Rolling, I 5 I

Spreading the gravel, I5I

Surface method, 146

Testing the gravel, 144,489

Thickness, I48, 149

Trench method, 147

See also Comparison of roads and pavements

Grecian highways, ancient, 2

Guard rail

Concrete, 439

Location, 437

Parapet wall, 439

Pipe, 438

Wood, 437

Gutter

Cost, 419, 420

Depth of, 419

Materials used, 418

Methods of construction, 4 I 8 .

Necessity for, 418

Widths, 419

Hand mixing, 124

Hardness test, 49I

Heater, surface, 3II, 312

Highway, 44.

Highway department signs, 440

History, pavement

Bituminous concrete, 246

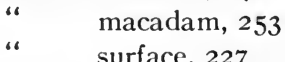

Brick, 344

Broken stone, I 2, I 75

Cement-concrete, 315

Dust palliatives, 227

Sheet asphalt, 298

Stone block, 363

Wood block, 328

Horse, pull exerted by, 84, 395 .

Horse-drawn traffic

Effect on highways, 50

Jarrah wood, 330 
Noiselessness, 392

Oiled road

See Dust prevention

Organization

State and county departments, 39

Urban district departments, 4 I

Paraffin test, 214, 222, 483

Park highways, 78

See also Design

Peat, 119

Penetration method

See Bituminous gravel pavement

"Bituminous macadam pavement

Penetration test, 214, 475

Petroleum, 204

Petrolithic road, 137

Pipe drain

Cost of, I I 5

Grade of, I 5

Laying, I 14

Size of, I I3, I I 4

Tile, 1 I 4

Pipe systems

Kinds of, 448

Location, 449

Pipe subways, 449

Repaving trenches, $45^{\circ}$

See also Design

Pitchmac, 259, 260

Plow

Grading plow, I I I

See also Earthwork

Pouring can, 24I

Preliminary investigation

Æsthetics, 48

Climatic conditions, 47

Drainage, 45

Foundation, 45

Local environment, 48

Local materials, 47

Location, 45

Maintenance, 47

Traffic, 49-53

Width, 46

Preserving timber

See Wood block
Quarrying

Blasting, I 70

Churn drills, 168

Cost of drilling, I 68

Hammer drills, I 68

Stripping quarry, I68

Railway

See Car tracks

Rattler test, 349, 495

Ravelling

See Broken stone road

Reinforced concrete

Sce Bridge

" Cement-concrete pavement

" Culvert

Road administration

See Administration

" Economics

" Legislation

Road drag

Drags vs. scrapers, 138

Lap plank drag, 99

Method of operation, 100

Plank drag, 99

Split log drag, 98

Steel drags, 100

Road machinery

See Machine or tool

Road scraper

Description, I03

Method of operation, 103

Road taxes, 20

Rocks

Abrasion test, 162, 489

Absorption test, I64, 488

Apparent specific gravity test, 486

Aqueous, I 54, 45 I

Ball mill, 492

Basalt, $45^{2}$

Breccia, 454

Cementation test, 492

Cementing value, 162

Definitions, I 54

Deval machine, I6I, 489

Diorite, 156

Dorry machine, I64, I66, 49 I

Fieldstone, I 60 
Rocks

French coefficient, I62

Gneiss, 159

Granite, 157, 160

Hardness test, I64, 49I

Igneous, I 54

Impact machines, I62, I63

Limestone, I59, I60

Mechanical analysis, 493

Metamorphic, I 54

Microstructure, 157

Mineral constituents, I 55, I 58

Properties rocks should possess, 160

Results of tests, i64, I67

Rock classification, 154

Rock testing, 16I, 486-492

Sandstone, I 59, I6o

Schist, I 59

Slate, I6o

Specific gravity test, I 64,486

Syenite, 159

Tests, I6I, 486-492

Toughness, I 64

Toughness test, 490

Trap, I 56, I 6o

See also Crushing

“" " Quarrying

Rock asphalt pavement

American practice, 305

Borough of Manhattan specifications, 305

Broken rock asphalt, 305

Crown of, 91, 92

European practice, 303

Powdered rock, 305

Rock asphalts of Europe, 196

Use of rock asphalt, 298, 303, 305

See also Comparison of roads and pavements

Roller

Horse roller, 106

Tandem roller, Io9

Three wheel, Io9

Roman highways, ancient, 2-7 Sand

Adaptability for road construction, 129
Sand

Apparent specific gravity test, 487

Definition of, I I 8, I4 I

Mechanical analysis of, I44, I45. 493,494

Sand cushion, 336, 352

Sand filler, 338,354

Wearing surface, sheet asphalt, 302

See also Soils

Sand-clay road

Clayey subsoil, 136

Construction, 129

Cost of, 134

Cross-section of, I 31

Drainage of, 129

Maintenance, 137

Mileage constructed, 128

Road dragging, 138

Sandy subsoil, I 35

Wearing course, 134

See also Comparison of roads and pavements

“ " Earth roads

Scarifier, I09

Schutté method, voids, 175

Screen

Rotary screen, I 73

Sizes, mechanical analysis, 144, I 78, 493

Sea water, 232

See also Dust prevention

Sewer

See Pipe systems

Shale, I 19

Sheet asphalt pavement

Action of gas leaks, 309

“ " water, 308

Asphalt cement, 2 I 8, 299

Asphalt plants, 303

Binder stone, 300

Causes of failure, 306

Construction, 302

Cost of, 306

Cross-section of, 298

Crown of, 9I, 92 
Sheet asphalt pavement

Defects in construction, 309

Development of, 298

Effect of ageing and exposure, 308

Filler, 30 I

Flux, 300

Foundation, 122, 1 26, 302, 309

Heating asphalt cement, 303

Laying binder, 302

Maximum grade of, 85

Patching, 312

Preparation binder course, 302

Preparation wearing surface, 302

Repairing, 310, 312

Sand, wearing surface, $30 \mathrm{I}$

Subgrade, 302

Surface heater, 3II, 3 I 2

Tandem roller, 303

Traffic deterioration, 307

See also Comparison of roads and pavements

Shell road,

Construction of, 185

Shoulder

Construction of, 189

Slopes of banks, I3I

Sidewalk

Asphalt mastic, 407

Brick and tile, 407

Cement-concrete, 409

Cinders, 409

Cost of, 407, 408, 413

Cross-section of, 408, 410

Essential qualities, 406

Foundation, 409, 4I6

Gravel, 4I 4

Slope of, 406

Small stone setts, 414

Stone flagging, 4I 4

Tar concrete, $4 \mathbf{I} 5$

Width of, 406

Signs

Danger signs, $44^{\circ}$

Direction and distance signs, 440

Highway department signs, 440

Street signs, 44I
Slag

Abrasion test, 489

Hardness test, 49 I

Mechanical analysis, 493, 494

Toughness test, 490

Slag block pavements, 373

Slag road, 184

Slipperiness, 392, 393

Snow removal

Flushing, 388

Machines, 385, 387

Organizing labor, 384

Use of plows, 386

“" "salt, 388

Soils

Bearing power of, 120

Classification of, I 18

Clay, I 19

Drainage of, 129

Loam, I 19

Marl, I 19

Muck, I I9

Peat, I 19

Sand, i 8

Shale, I 19

Solubility tests

Carbon disulphide, 2 1 8, 469

Carbon tetrachloride, 472

Naphtha, 219, 482

Specifications

See Material, road or pavement

Specific gravity test, $215,466,486$

Sprinklers

See Wateririg cart

Sprinkling

See Watering

Squeegees, 379

State highway

Design of system, 75

Width of, 82

Stone block pavement

Belgian block, 363

Characteristics, 375

Cost data, United States, 370, 37 I

Cross-section of, 368,369

Development of, 363

Durax, 364-367 
Stone block pavement

Foundation, 366

Grout filler, $37^{\circ}$

Kleinpflaster, 364-367

Laying the blocks, 367

Maintenance of, 374

Manufacture of blocks, 364

Maximum grade of, 84,85

Sand cushion, 367

Sand joint filler, 368, 369

Size of blocks, 366

Stone used, 364

Subgrade, 366

Tar and gravel filler, 369

Tests of blocks, 366

See also Comparison of roads and pavements

Stone screenings

Apparent specific gravity test, 487

Straw road, i 36

Street

Circumferential plan, 78

Cross-section of, 90

Crowns of, 9I, 92

Curves, 88

Design of street intersections, 87

Maximum grades, 85

Minimum grades, 85

Rectangular plan, 77

Widths, 80

See also Design

“ " "Surveys for city streets

Street cleaning

Bags and cans, 376, 378

Boston, 382

France, 383

Germany, 383

Great Britain, 382

Hand cleaning, 376

Heavy-traffic streets, 378

Hose flushing, 379

Light-traffic streets, 378

Machine sweeping, 378

Motor truck sweepers, 378

New York City, 380

Philadelphia, 38 I

Pick-up sweepers, 379
Street cleaning

Push brooms, 377

Rotary squeegees, 379

Squeegees, 379

Sweeping machines, 378,379

Washington, D. C., 382

Street intersection, 87

Street signs, 44I

Subdrain

See Drainage

Subgrade

See Road or pavement

Subsurface structures

See Pipe systems

Superficial tarring

See Bituminous surfaces

Surveys for city streets

Levels, 73

Mapping, 74

Monumenting, 73

Staking, 74

Survey for grading, 74

Traverse method, 73

Surveys for roads

Final survey, 70

General scope of work, 64

Levels, 68

Plotting the plan, 70 “ “ profile, 72

Staking grades, 69

Stationing and referencing, 65

Taking topography, 66

Transit line, 65

Use of maps, 64

Sweepers

Motor truck, 379

Pick-up, 379

Rotary, 379

See also Street cleaning

Sweeping

Motor truck sweepers, 379

Pick-up sweepers, 379

Push brooms, 377

Preparatory to applying bituminous surface, 237

Rotary sweeper, 379

Sweeping snow, 387

See also Street cleaning 
Tar, 194, 206, 2 I I

See also Coal tar

“ " Coke oven tar

“ “ Water gas tar

Tarmac pavement, 276

Telford

Construction, I 2 I

See also Broken stone road

" " Foundation

Tests

Bituminous materials, 466-485

Non-bituminous materials, 486497

Tile

See Pipe drain

Tires, 55

Topeka pavement, 273, 279

See also Bituminous concrete pavement

Topography

Cross-section levels, 68

Information desired, 66

Plotting, 74

Taking topography, 66

See also Surveys

Toughness test

Rocks, I64, 490

Trackway, 37 I

Traction, 393-395

Traffic

Diversion of, 62

Effect, horse-drawn vehicles, 50

" motor-car, 5 I

" motor truck, $5^{2}$

" traction engine, 54

Elements of classification, 49

Loads and tire widths, 55

Regulations, 62

Widths occupied by, 80,82

Traffic census

Classification of traffic, 57,60

France, $5^{8}$

Importance of, 49

Methods used prior to 1900,58

“ " since $1900,59,60$

United States, 59

Transit line

Running the line, 66
Transit line

Stationing, 65

Use of as center line, 65

“" " as reference line, 65

See also. Surveys

Trap rock

Composition of, ${ }^{5} 6$

Use of, as road metal, I6o

Traverse, 73

See also Surveys

Tresaguet, Io, I 75

Trinidad asphalt

Analysis of deposit, 200

Description of deposit, 199

$\mathrm{V}$-drain

Construction of, I 2 I

Viscosity test

Engler viscosimeter, 213, 472

Float test, 213, 21 7, 474

Penetration, 214, 475

Voids test

American Society for Testing Materials method, 494

Broken stone, I 74

New York State method, I 74

Pouring method, I 74

Schutté method, I 75

U. S. Office of Public Roads method, I 75

Volatilization test

See Evaporation test

Wagon

Patent bottom dump, 98

Tip cart, 98

Watering

As a dust layer, 23I

See also Dust prevention

" " Street cleaning

Watering cart

Description of, I I I

Water gas tar

Manufacture, crude, 209

Pitches, 2 ro

Water pipe

See Pipe systems 
Waterway

See Bridges

Wheel scraper

Description of, 102

Method of operation, I02

Width

See Design

" Sidewalk

Wood block

Amount of preservative, 334, 335

Causes of decay, 330

Creosote, 33I

Manufacture, 332

Open tank process, 334

Preservatives used, 33I

Pressure process, 334

Size, 332

Water absorption test, 335

Wood preservation, 33I

Woods used, 329

See also Wood block pavement
Wood block pavement

Bituminous filler, 339

Bleeding, 340

Characteristics of, 342

Cost data, 339, 340

Cost of maintenance, 342

Development of, 328

Expansion joint, 337

Foundation, 335

Grout filler, 339

Laying the blocks, 337

Maximum grade of, 85

Mortar cushion, 336

Relaying, 34I

Repairs, 34I

Rolling, 337

Sand cushion, 336

Sand filler, 338

Subgrade, 335

See also Comparison of roads and pavements

“ “ Woorl block 


ust we 
THIS BOOK IC TUE ON THE LAST DATE STAMPED BELOW

AN INITIAL FINE OF 25 CENTS WILL BE ASSESSED FOR FAILURE TO RETURN THIS BOOK ON THE DATE DUE. THE PENALTY WILL INCREASE TO 50 CENTS TE SEVENTH DAY DAY AND TO OVERDUE.

OCT \& 1932

(B) $\because 4$ 
4 化

1

\section{3}

UNIVERSITY OF CALIFORNIA LIBRARY 
